GRAHAM HAMILTON ROWE

\title{
APPLIED GEOLOGY OF WELLINGTON ROCKS FOR AGGREGATE AND CONCRETE
}

Submitted for the degree of Doctor of Philosophy in Geology at Victoria University of Wellington

November 1980

ISBN $\quad 0-473-00068-7$ 


\section{SODD'S FIRST LAW:}

When a person attempts a task, he or she will be thwarted in that task by the unconscious intervention of some other presence (animate or inanimate). Nevertheless, some tasks are completed, since the intervening presence is itself attempting a task and is, of course, subject to interference. 


\section{ABSTRACT}

This study was initiated to examine geological aspects of Wellington greywacke-suite rocks in relation to their end use as an engineering material aggregate, particularly for concrete.

An attempt has been made to map (at least in part), identify and categorise rocks for quarrying in the Wellington region, to evaluate and quantify their properties as aggregates and to appraise their qualities in concrete - in short to equate rock geology to aggregate and concrete performance as a tool for resource management.

Study of bedding led to a classification into three lithofacies and some 70 representative samples were examined petrographically. For engineering purposes, Wellington rocks may be divided into two categories, greywacke and argillite, each having separate and distinct mineralogies and chemistries which do not alter significantly between lithofacies. Greywacke is coarser and may be distinguished from argillite texturally at a mean grain size of 5 phi $(0.031 \mathrm{~mm})$.

Rock properties, in particular strength, modulus, density, hardness and degradation tendencies, are linked directly or indirectly with mean grain size. Argillites, though more dense, are generally weaker, softer, less elastic and degrade more readily than greywackes, the latter property being readily assessed from a newly devised test based on the destruction of chlorite by hydrochloric acid.

As aggregates, greywackes produce similar particle shapes irrespective of grading. Argillites, which are generally more angular, produce concretes which are more difficult to work. Physical properties of aggregate, inherently those of its parent rock, are reflected in concrete made from it. The possibility of laumontite promoting cement alkali-silicate reaction is obviated by the mode of occurrence of minerals within the rock.

Although argillite aggregates are unsuitable in certain environments and return lower strength in concrete than do greywacke aggregates, they still have a place in low strength concrete applications. 


\section{FORENCRD}

For too long a lack of detailed knowledge of the properties of rocks for concrete aggregates has precluded the use of anything but the 'best'. Recent consciousness of the need to conserve all natural resources has encouraged a re-think of past attitudes toward what is acceptable. Such re-appraisals are not wholly useful without the sort of information contained in this thesis.

Mr Rowe's long association with the concrete industry and his proposed topic made him the ideal first recipient of the New zealand Concrete Research Association's Research Fellowship. The industry has followed Mr Rowe's progress with interest and have been kept fully informed of his progress by regular reports, some of his findings are already in use.

Now that the thesis is completed it is to be hoped that it will encourage similar studies elsewhere.

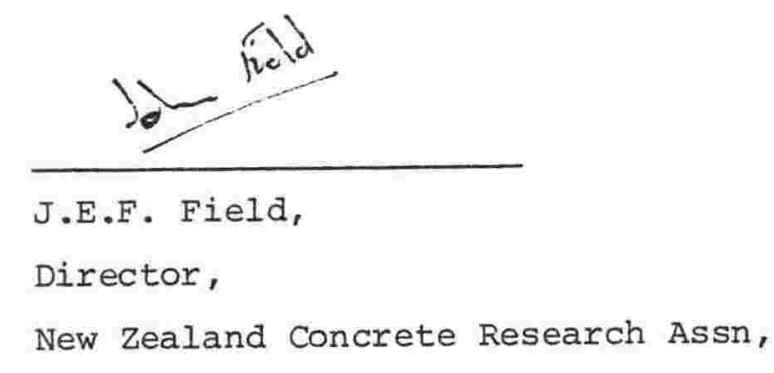

October, 1980. 


\section{ACKNOWLEDGEMENTS}

Initiation of the New Zealand Concrete Research Association Research Fellowship was promoted by Dr J.H. Garside (then Director, New Zealand Concrete Research Association) and Professor R. H. Clark (Head of Geology Department, Victoria University of Wellington).

Special thanks are due to Dr Peter Barrett (principal supervisor of the study) for his tactful, useful critisisms.

In every instance where help was sought it was provided without hesitation, in particular from:

(i) Members of the Departments of Geology, Geophysics and the Workshop, Victoria University of Wellington.

(ii) Managers at all quarries sampled, especially Mr B. Lucinsky and his staff.

(iii) Central and District laboratories, Ministry of Works and Development, Chemistry Division and Mr Tim Ball, Applied Maths Division, Department of Scientific and Industrial Research.

(iv) The staff of the New Zealand Concrete Research Association.

(v) My former flatmates, John Adams, Paul Morris, Paul Robinson, Julie Palmer and Dave and Elspeth Waghorn.

(vi) Cally Ward, who provided prompt, friendly, accurate and enthusiastic library services. I am greatly indebted to her for her efforts.

(vii) My family, who provided the greatest help. Their unflagging energy and patience could never be thanked enough.

Most chapter quotations are from Bloch, A. (1977) "Murphy's law and other reasons why things gobuoxM", Magnum books, London: $96 \mathrm{pp}$. 


\section{CONTENTS}

\section{Page}

Chapter 1

Introduction

1.1 The meaning of "greywacke" I

1.2 Known industry-related problems 3

1.2.1 The greywacke-argillite problem 3

1.2.2 The zeolite problem 4

1.2.3 The aggregate degradation problem 4

Geological properties of Wellington greywacke-suite rocks

2.1 The in situ nature of Wellington greywackesuite rock

2.1.1 The sandstone lithofacies

2.1.2 The thick-bedded lithofacies

2.1.3 The thin-bedded lithofacies

2.2 Mapping of lithofacies 14

2.3 Causal geology 16

2.4 Paleontology 17

2.5 Petrographic methods 17

2.6 Petrography 22

2.6.1 quartz 24

2.6.2 Feldspar 24

2.6.3 Rock fragments 26

2.6.4 Muscovite 28

2.6.5 Biotite 28

2.6.6 Chlorite 28

2.6.7 Metamorphic accessories and cements 30

2.6.8 Detrital accessories 30

2.6.9 Matrix 30

2.7 Petrographic comparisons of lithofacies 30

2.8 Argillite petrography 35

2.9 Comparison of greywackes and argillites 37

2.10 Provenance 37

2.11 Classification of greywackes by mineral
composition

2.12 Grain size 45

2.13 The relationship of mineralogy and texture 54

2.14 X-ray diffractometry 54

2.14.1 Whole rock quantitative analysis 57

2.14.2 Semi-quantitative analysis of the whole rock fraction finer than $0.015 \mathrm{~mm} \quad 58$

2.14.3 Degree of phyllosilicate crystallinity 64

2.15 Fissility 78

2.16 Weathering 79

2.16.1 Veining 81

2.16.2 Microcracking 82

2.16.3 Lamination, preferred orientation,
recemented shears 
2.17 Geochemistry

2.17.1 Major elements

2.17.2 Trace elements

Physical properties of Wellington Greywacke-suite rocks

3.1 Rock colour

3.2 Rock hardness

3.3 Rock integrity

3.3.1 Quantitative assessment of discontinuities 102

3.3.2 Ultrasonic velocity 107

3.4 Rock density and effective porosity 113
3.4.1 Density

3.4.2 Effective porosity

3.5 Uniaxial compressive strengths and static elastic modulus

3.5.1 Uniaxial compressive strength 119

3.5.2 Static elastic modulus 125

3.5.3 Rock strength and ultrasonic velocity

3.5.4 Static elastic modulus and rock texture relationships 130

3.6 Degradation 130

3.6.1 "A method of assessing degradation" 132

Chapter 4 Properties of Wellington greywacke-suite aggregates 133

4.1 Sampling methods and sample preparation 133

4.2 Aggregate characteristics 134

4.2.1 Gradings 135

4.2.2 Particle shape 135

4.2.3 Density and absorption 143

4.2.4 Bulk density and voids content 147

4.2.5 Crushing resistance 147

4.2.6 Los Angeles abrasion test 151

4.2.7 Fines from crushing and abrading 155

4.3 Alluvial versus quarried aggregate 155

4.4 Silicate reaction to cement alkalis 159

Chapter 5 Utilisation of Wellington greywacke-suite aggregates in concrete 167

5.1 Fresh concrete tests 168

5.1.1 "Workability" of fresh concrete 168

5.1.2 Density (unit mass) of fresh concrete 173

5.2 Hardened concrete tests 173

5.2.1 Uniaxial compressive strength 173

5.2.2 Static elastic modulus 175

5.2.3 Ultrasonic velocity 186

5.3 Strength - density relationships in concrete 191 
Chapter 6 Sumnary, conclusions and future work

Page

5.4 Aggregate strength as a factor of concrete strength

5.4.1 Effects of aggregate angularity

5.5 Aggregate performance in old concrete

201

6.1 Principle conclusions from this study 206

6.2 Future work 208

$\begin{array}{ll}\text { References } & 209\end{array}$

$\begin{array}{lr}\text { Appendices } & 222\end{array}$

1 Sample location sites 223

2 Staining of thin sections for identification of felsic minerals

3 Descriptive petrography of greywacke samples 231

4 Basu plot: raw data 250

5 Greywacke and argillite grain size data 251

6 Quantitative analysis by X-ray diffraction 252

7 Fabric measurement of Wellington greywackesuite rocks

8 Chlorite analysis by electron microprobe 263

9 Scratch hardness test to ASTM C235-68 270

10 Density, effective porosity and ultrasonic velocity of rock cores and handspecimens 271

11 Discontinuity spacing data 279

12 Preparation of rock cores for uniaxial compression testing

13 Uniaxial compressive strength of greywackesuite rocks: tables

14 Stress strain curves: methods and instrumentation

15 Static elastic moduli determination and failure mode analysis of rock cores

16 Classification of intact rock by deformation characteristics, applied to Wellington greywackesuite rocks

17 Angularity of rock particles: raw data 311

18 Comparison of Los Angeles abrasion test with uniaxial compression test, as a measure of rock strength

19 Effect of moisture content on ultrasonic velocity of rock

20 Measurement of unrestrained moisture movement in rock 
21 Measurement of cyclic moisture movement in rock

22 Measurement of rock permeability

23 Aggregate degradation assessment of greywackesuite rocks

24 Aggregate degradation: Washington degradation test and current research

25 Storage of greywacke-suite aggregates

26 Test results for sand (Walton Park) used in concrete mixes

27 Concrete mix designs

28 Concrete cylinders: materials preparation, mixing, moulding, curing and test

29 Concrete cylinders: tabulated test results

30 Measurement of rock specific heat 389

31 Measurement of rock durability by ultrasonic cavitation test

32 Quarry sludge properties

33 Sample number correlation with the petrology collection, Geology Department, VUW. 
2.1 Heezen - Hollister - Bouma criteria for the recognition of turbidites and contourites

2.2 Parameters used to differentiate lithofacies within the Wellington greywacke suite rocks

2.3 Composition of greywackes of the sandstone lithofacies 32

2.4 Composition of greywackes of the thick-bedded lithofacies 33

2.5 Composition of greywackes of the thin-bedded lithofacies 34

2.6 Composition of argillites 36

2.7 Detrital mineral suites characteristic of source rock types 40

2.8 Grain size parameters of Wellington greywacke-suite rocks 52

2.9 Quantitative XRD modes for whole rock powders 59

2.10 Quantitative XRD resolution for the clay fraction 61

2.11 Relative abundance of main minerals determined from diffractograms: $<0.015 \mathrm{~mm}$ fraction

2.12 Sharpness ratio data from $10 \AA$ diffractogram peaks, Weaver's method

2.13 Relative crystallinity data from $7 \AA$ diffractogram peaks, Kubler's method

2.14 Categories of weathering based on handspecimen colour change and strength loss

2.15 Chemical analyses of greywackes

2.16 XRF analyses of Wellington greywacke suite rocks: major elements

3.1 Density, ultrasonic velocity and apparent porosity data from rock core samples

3.2 Uniaxial compressive strengths of rock cores (with $\mathrm{h}: \mathrm{d}$ ratio of 2)

3.3 Reproducibility of commonly used strength tests

3.4 Summary of static elastic moduli from rock cores

4.1 Sieve analyses of $19 \mathrm{~mm}$ "all in" aggregates crushed from quarried blocks

4.2 Aggregate particle shape statistics

4.3 Summary of density and absorption data from sample aggregates 144

4.4 Summary of all test results from sample aggregates

4.5 Comparison of aggregate relative durability assessment from wet and dry crushing resistance

4.6 Comparison of test results from quarried and alluvial aggregates 160 
5.1 Summary of fresh concrete test results $\quad 169$

5.2 Sumary of hardened concrete test results: $\operatorname{mix} 1176$

5.3 Summary of hardened concrete test results: $\operatorname{mix} 2 \quad 177$

5.4 Concrete static elastic moduli: mixes 1 and $2 \quad 180$

5.5 Summary of survey on aggregate performance in old concrete 204

6.1 Summary of results of typical Wellington greywacke-suite rocks 207 
1.1 Statistics of building aggregate quarried in the Wellington region 1968-1978

2.1 Ideal sequence of structures in a turbidite bed 8

2.2 Location of quarry sites sampled for this study 20

2.3 Thin section estimate of quartz (500 counts) for each lithofacies 25

2.4 Thin section estimate of (A) plagioclase and (B) potassium feldspar (500 counts) (C) the ratio of the two for each lithofacies

2.5 Thin section estimate of rock fragments (500 counts) in each lithofacies (A) sedimentary (B) metamorphic and plutonic (C) acid volcanic (D) basic volcanic

2.6 Thin section estimate of muscovite (500 counts) for each lithofacies

2.7 Thin section estimate of chlorite (500 counts) for each lithofacies

2.8 Thin section estimate for metamorphic accessories and cements (500 counts) for each lithofacies

2.9 Thin section estimate of detrital accessory minerals (500 counts) for each lithofacies

2.10 Thin section estimate of matrix (500 counts) for each lithofacies 31

2.11 Basu plot of medium sand size quartz grains from greywacke of sandstone and thick-bedded lithofacies

2.12 Range and average concentrations of rock fragment types in greywackes of each lithofacies

2.13 Primary arenite triangle with plots representing the modal composition of greywacke from each lithofacies

2.14 Grain size histogram: greywackes of the sandstone lithofacies

2.15 Grain size histogram: greywackes of the thick-bedded lithofacies

2.16 Grain size histogram: greywackes of the thin-bedded lithofacies

2.17 Grain size histogram: argillites

2.18 Plot of greywacke bed thickness to rock mean grain size at mid-bed

2.19 Plot of mineral modes (optically determined) to rock mean grain size

2.20 Comparison of chlorite and white mica modes (optically determined) in relation to rock mean grain size

2.21 Relationship between mineral proportions (from XRD analysis) and rock mean grain size

2.22 Relationship of mineral abundance and rock mean grain size from rock powder fractions finer than $0.015 \mathrm{~mm}$

2.23 Part of an $\mathrm{X}$-ray diffractogram showing how relative sharpness of the $10 \AA$ illite peak is measured

2.24 Sharpness ratio of illite related to rock mean grain size

2.25 Relative crystallinity of chlorite related to rock mean grain size 
2.26 X-ray diffractograms of whole rock materials finer than $1.5 \mu \mathrm{m}$ from five lithologies

Page

2.27 ACF diagram comparison of Wellington greywacke suite rocks

2.28 Relationship of silica to alumina contents of greywacke suite rocks

2.29 Greywacke-argillite classification by alkali content

2.30 Major element chemistry related to rock mean grain size

2.31 Trace element chemistry related to rock mean grain size

3.1 Histograms showing discontinuity differences between the sandstone, thick-bedded and thin-bedded lithofacies

3.2 Histograms showing discontinuity differences between greywacke and argillite beds of the thick-bedded lithofacies, Horokiwi Quarry

3.3 Ripper performance related to ultrasonic velocities

3.4 Ultrasonic velocity related to rock mean grain size

3.5 Rock particle density related to rock mean grain size

3.6 Dry rock density related to rock mean grain size

3.7 Wet rock density related to rock mean grain size

3.8 Rock effective porosity related to rock mean size

3.9 Rock core uniaxial compressive strength related to rock mean grain size

3.10 Stress-strain curves of $O B-W$ argillite wet and dry

3.11 Rock core uniaxial compressive strength related to ultrasonic velocity

3.12 Rock static elastic modulus related to rock mean grain size, dry 131

3.13 Rock static elastic modulus related to rock mean grain size, wet

4.1 Grading histograms for $19 \mathrm{~mm}$ "all in" aggregate crushed from quarried blocks

4.2 Construction and formula for determining angularity $\left(A_{2 D}\right)$ of particles

4.3 Aggregate particle angularity related to grain size at two confidence, levels

4.4 Comparison of aggregate and core densities of identical rock

4.5 Aggregate 24 hour absorption related to core porosity

4.6 Aggregate $30 \mathrm{~min}$. absorption related to core porosity

4.7 Agregate crushing resistance related to particle shape

4.8 Effect of particle shape on abrasion resistance

4.9 Aggregate abrasion resistance related to crushing resistance 156

4.11 Division of innocuous and deleterious aggregates based on reduction in alkalinity 
5.1 Comparison of concrete workability by compaction factor and $\mathrm{V}-\mathrm{B}$ consistometer

Page

5.2 Effect of aggregate shape on concrete workability, determined from $\mathrm{V}-\mathrm{B}$ consistometer test

5.3 Effect of aggregate shape on concrete workability, determined from compaction factor

5.4 Dry aggregate density related to fresh concrete density 174

5.5 Dry rock core density related to fresh concrete density 174

5.6 Concrete strength related to time: mix $1 \quad 178$

5.7 Concrete strength related to time: $\operatorname{mix} 2 \quad 178$

5.828 day stress-strain curves: $\operatorname{mix} 11$

5.928 day stress-strain curves: mix $2 \quad 182$

5.1028 day static elastic modulus related to ultrasonic velocity: mixes 1 and 2

5.11 Static elastic modulus relationship of concrete to dry rock core

5.12 Ultrasonic velocity related to concrete strength: mix 1187

5.13 Ultrasonic velocity related to concrete strength: $\operatorname{mix} 2 \quad 188$

5.14 Ultrasonic relationship of concrete to wet rock core: $\operatorname{mix} 1 \quad 189$

5.15 Ultrasonic relationship of concrete to wet rock core: $\operatorname{mix} 2 \quad 190$

5.16 Concrete density related to concrete ultrasonic velocity: $\operatorname{mix} 1$

5.17 Concrete density related to concrete ultrasonic velocity: $\operatorname{mix} 2$

5.18 Density related to strength: $\operatorname{mix} 1 \quad 193$

5.19 Density related to strength: $\operatorname{mix} 2193$

5.20 Relationship of concrete ultrasonic velocity and strength to aggregate grain size: $\operatorname{mix} 1$

5.21 Relationship of concrete ultrasonic velocity and strength to aggregate grain size: $\operatorname{mix} 2$

5.22 Strength relationship between concrete and aggregate 196

5.23 Concrete strength related to rock core strength 198

5.24 Concrete strength relative to aggregate particle shape 202 


\title{
LIST OF PLATES
}

\author{
2.1 Sandstone lithofacies at Owhiro Bay Quarry (2 views) 12 \\ 2.2 Sedimentary rock fragment clasts (argillite) in "chipwacke" \\ (from Eve Bay) \\ 2.3 Lithofacies at Owhiro Bay Quarries (A) thick-bedded \\ (B) thin-bedded \\ 2.4 Floral debris in greywackes (2 views) 18 \\ 2.5 Floral debris in argillites (2 views) 19 \\ 2.6 Photomicrograph of bioturbation in argillite 84
}

3.1 A large bedding plane slickenside: Kiwi Point Quarry 103

4.1 Two sections of mix 1 design concrete, showing aggregate particle orientation, angularity and packing

5.1 Failure mode of BQ-IXA (mix 1) at three days: horizontal plane

5.2 Failure mode of BO-IXA (mix I) at three days: complimentary surfaces 


\section{CHAPTER ONE}

\section{INTRODUCTION}

For some 25 years, the aggregate industry of New zealand has been aware of many problems associated with rock products derived from Lower Mesozoic rocks, which form the country's main mountain ranges. With increasing use of quarried rock and as alluvial deposits are depleted or become less accessible, the problems assume greater significance.

Greater Wellington is increasingly dependent on quarried Lower Mesozoic rocks for use as aggregates of all types. The amount of material quarried for use as concrete aggregate is substantial (280,000 tonnes annually on average) even when compared with national production (Figure 1.1). Increase in population has been paralleled by increase in aggregate consumption and although low ( 4.5 tonnes/person a year) by national standards (6.3 tonnes/person in 1976) growth is expected to continue (Ward and Grant, 1978).

It seemed appropriate therefore, that an applied geological study be undertaken to provide fundamental data for some of the physico-mechanical properties of Lower Mesozoic rocks in the Wellington area, particularly as engineering difficulties associated with them are rarely found outside New Zealand. Impetus is added from a growing awareness world-wide that all natural resourses are finite to be husbanded if only, initially, for economic reasons.

\subsection{The meaning of "greywacke"}

The Lower Mesozoic rocks forming the axial ranges of New Zealand are often loosely described as "greywacke". The nomenclature and classification of greywacke-type rocks has been extensively discussed but no satisfactory agreement on a precise definition has been reached.

The term "greywacke" was first proposed by Lasius (1789), but by 1854 the term had fallen into disrepute and its abandonment was recommended. In New Zealand the term is in common usage but with indefinite meaning, such that it is likely to be applied to any hard, dark grey, metasedimentary rock. Indeed in the Wellington region all rocks of this type are often grouped together and referred to as "Wellington greywacke" - the term including the sandstones mostly referred to as "greywacke" and the mudstones referred to as "argillite", 


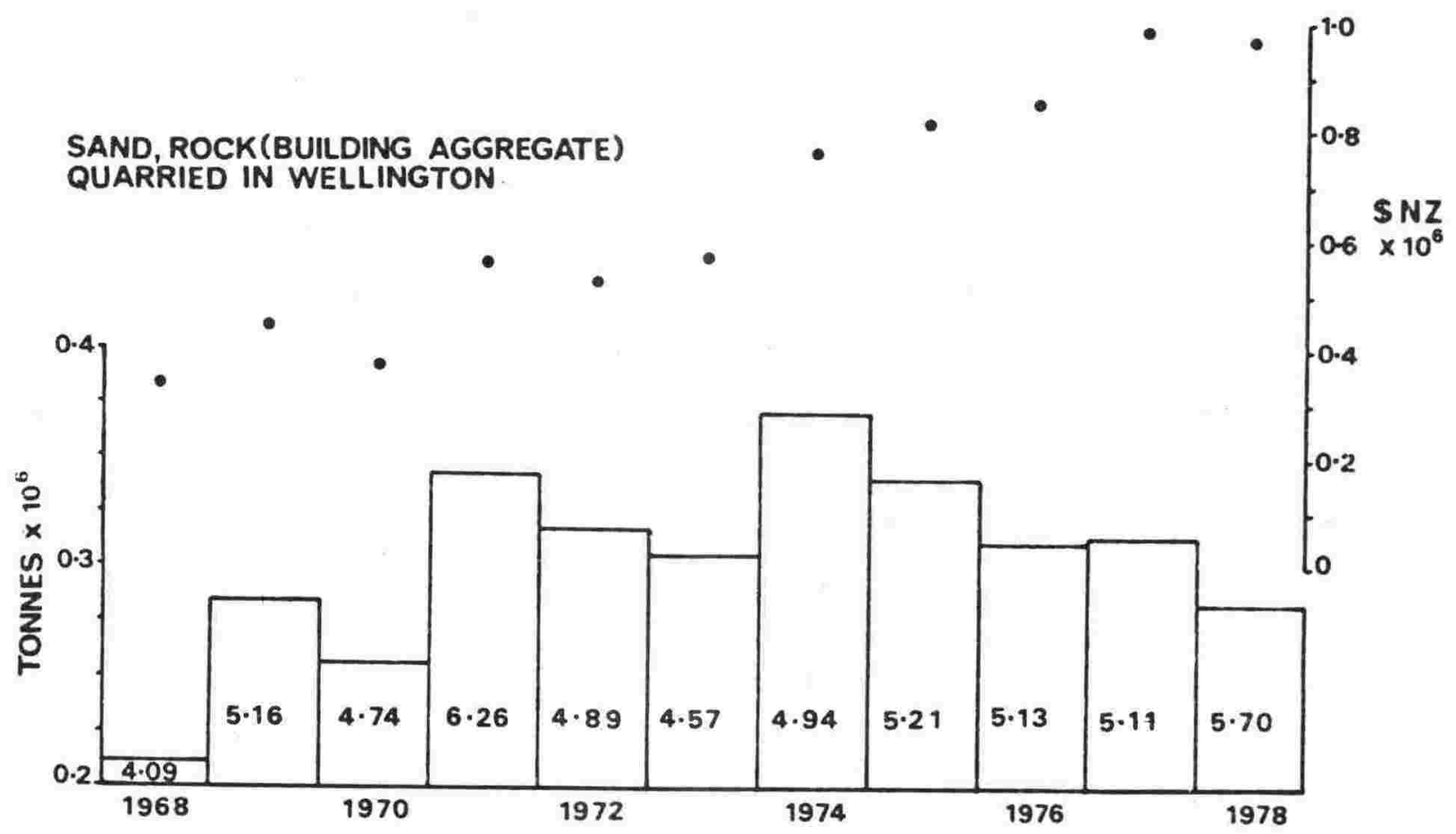

Figure 1.1 : Statistics of building aggregate quarried in the Wellington region 1968-1978.

Quantity and value of quarried rock for building (concrete) aggregate produced in Wellington by the following quarries: River Shingle and Sand (1935) Ltd., Wellington City Council (Kiwi Point), Carsons Quarry - formerly K.T. Wilkinson Ltd., (only since 1969), Horokiwi Quarry Ltd., (only since 1971), and Owhiro Bay quarries. Figures within histogram columns represent wellington production (percent) in terms of national production of building aggregates, the average for the period being 5.07 percent.

Source: Annual returns of production from quarries and mineral production statistics, Mines Division, Ministry of Energy 19681978. 
as defined by Flawn (1953) and Gamble (1971). To avoid the confusion associated with the grouping connotation implied by the term "greywackes", the rocks of the Wellington region could more appropriately be referred to as Wellington "greywacke-suite" rocks.

The basis of subdivision of Wellington greywacke-suite rocks into greywacke and argillite components will be discussed later but the terms are retained even though, in the case of greywackes, subtly different rock types may be identified within the limits of its definition. Such differences are even more subtle in the argillites, where there is not as broad a range in rock type.

Retention of the terms "greywacke" and "argillite" is felt justified because no one geological term has superseded greywacke as a term that has found acceptance to engineers, quarrymen, etc., in addition to geologists. If more precise classification or description is needed, then Folk et al. (1970) have provided a basis of classification which allows some resolution, of a geological nature, to be made within the greywackes.

For this study it is proposed that rocks of the greywacke-suite include greywacke and argillite.

\subsection{Known industry-related problems}

Greywacke-suite rocks provide many problems for the concrete and aggregate industries. Those discussed at the 1969 New Zealand Conference on Concrete Aggregates and the 1970 and 1979 New Zealand Roading Symposiums are detailed below.

\subsubsection{The greywacke-argillite problem}

Although greywacke and argillite occur together in Wellington and elsewhere (Reed, 1957, 1967) differentiating between them in the field and in the laboratory is not always easy. The recognition of these two rock types under varied conditions of weathering and/or tectonic shattering is important to the engineer. For this reason clear definitions and simply applied identifying test procedures need to be developed. 
The common consumer misconception (and in some cases an academic preconception) that "argillite is bad, greywacke is good" for engineering purposes, stems from practical experience and the literature on soft rocks. Arbitrary limits have been imposed by some authors on maximum argillite percentage allowed in concrete aggregates (e.g. Grant-Taylor, 1976). No research seems to have been undertaken to justify these limits, however.

\subsubsection{The zeolite problem}

Investigation of zeolite bearing rocks overseas has led to claims that local aggregates made from zeolite bearing greywacke, could be responsible for

destructive alkali-reaction if used with high alkall cement, and cause excessive shrinkage of concrete. Also they oblid caúse unadoeptable particle size reduction of graded aggregate whilst storea in stockpiles (Watters. 1969)

\subsubsection{The aggregate degradation problem}

This is related to the greywacke-argillite problem (section 1.2.1), confusion arising from apparent differences in the interpretation of the word degradation as well as from the recognition of the two rock types. Degradation may have different meanings to the quarryman, roading engineer, concrete technologist and geologist.

Degradation is a term used for different processes, not all being deleterious. Usually the roading engineer uses the term as Minor (1959) describes, and Buckland (1967) has clarified the term as used by New Zealand roading engineers. To the concrete industry, aggregate degradation is the non-mechanically induced breakdown of aggregate particles into smaller pieces by natural chemical and physical processes. Such a process is regarded as deleterious, with significant alteration imparted to grading. The release of deleterious minerals from vesicles, veins and/or joints is not regarded as degradation in itself although the presence of these features may contribute to degradation. The process seems to be a physical alteration of the aggregate and is a forerunner to more advanced states of degradation (weathering) but these are not found in concrete aggregate conforming to existing New Zealand Standards. Degradation by attrition produces fine mineral dusts, generally of more concern in roading than in concrete. 
Two additional problems (Craven, pers. comm.; Ward and Grant, 1978) now confront the aggregate industry:

(i) The production of ultra-fine materials in quarry washing operations quarry sludges and their disposal.

(ii) The depletion of good quality and easily won aggregates in areas of high demand. 


\section{FOURTH LAW OF REVISION}

After painstaking and careful analysis

of a sample, you are always told that

it is the wrong sample and doesn't apply

to the problem.

Geological properties of Wellington greywacke-suite rocks

A quarryman needs two pieces of information from a geological investigation:

Whether the rock investigated meets the specifications for the job.

Where it is located and how much is available.

Obviously the Wellington greywacke-suite rocks are useful; Mines Department returns (Figure 1.1) and discussions by other authors (Reed and Grant-Taylor, 1966; Grant-Taylor, 1976; Ward and Grant, 1978) indicate that they are extremely important. Quantitative data on resources have been provided by Ward and Grant (1978) but a compilation of localities for what may be deemed the "most useful" greywacke-suite materials for wellington is lacking.

The geology of the region has been presented by Stevens (1974) in an excellent book and specific aspects by Grant-Taylor (1976) and Ward and Grant (1978). Geological dating has been undertaken by Park (1975), McKean (1976) and Bird (in prep.). Smaller studies of relevance include those by Barnes (1979) and Cranney (1979). For a bibliography of Wellington geology, williams (1975) should be consulted.

2.1 The in situ nature of Wellington greywacke-suite rock

Rock masses are never homogenous, isotropic bodies. Their physico-mechanical properties alter according to interactions of mineral composition and fabric (including texture) and physical/chemical conditions throughout their geologic history, manifest on all scales from the individual grains, though the rock sample, to the rock mass or even the geologic region. In this section the properties of outcrops are considered. 
The greywacke-suite rocks are steeply dipping (generally more than $60^{\circ}$ ) and isoclinally folded about north-south trending axes (map in flap pocket). The sequence is dominated by alternations of "couplets" of sandstone (greywacke) and mudstone (argillite) that are evident even in the more metamorphosed areas. The alternations are, in some places, the result of deposition from a turbidity current and the essential features of the sequence of Bouma (1962) can be seen in many beds (Figure 2.1). However, some sand beds have different features (Table 2.1) and may have resulted from deposition by traction or contour currents.

The greywacke and corresponding argillite is referred to as a couplet as generally, despite diagenesis and metamorphism, a clear distinction can be made between the sandy lower portion (greywacke) and the upper portion (argillite) of each couplet regardless of the completeness of the Bouma sequence.

Conglomeritic deposits (Grant-Taylor, 1976) and volcanic rocks (Stevens, 1974) are small in volume, widely separated and not of importance to the aggregate industry and are therefore not part of this study.

The rocks of the region can be divided into three mappable lithofacies, sandstone, thick-bedded and thin-bedded, using as parameters average couplet thickness, average greywacke thickness, average argillite thickness and range of couplet thickness (Table 2.2).

Consistent with the nature of turbidite beds, the greywackes exhibit graded bedding, sometimes more than one sequence within a single greywacke bed. The grain orientation within greywacke and argillite is parallel to bedding (Onions and Middleton, 1968), and has been enhanced by metamorphism hence the rocks are anisotropic. Because of size grading, anomolies may arise from taking random samples from turbidite beds therefore a representative sample was taken from the mid-point of each bed to make petrographic comparisons.

As will be discussed, the many discontinuities within greywackes and argillites frustrate efforts to break handspecimens along planes which have not already experienced fracturing or veining. To examine sedimentary structures, fabrics and grain size, all rocks not sampled from stream beds or the coast require cutting in the laboratory. 


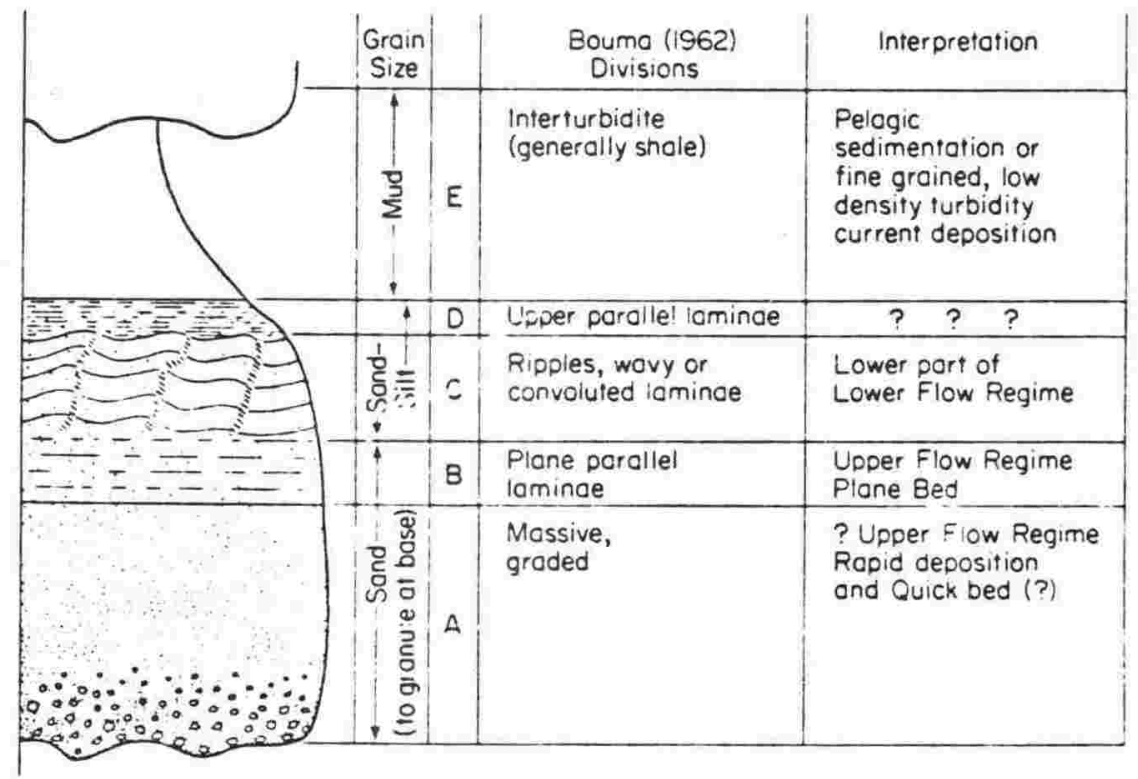

Figure 2.1 : Ideal sequence of structures in a turbidite bed. After Bouma (1962) with interpretation after Walker (1965), Walton (1967) and Middleton (1967). From Blatt et al. (1972). 
Table 2.1 : The Heezen-Hollister-Bouma criteria for the recognition of turbidites and contourites (from Stow and Lovell, 1979).

\begin{tabular}{|c|c|c|c|}
\hline & Turbidite & Contourite & Conclusions \\
\hline Size sorting & $\begin{array}{l}\text { moderate to poorly } \\
\text { sorted }>1.50 \text { (Folk) }\end{array}$ & $\begin{array}{l}\text { well to very well } \\
\text { sorted }<0.75 \text { (Folk) }\end{array}$ & $\begin{array}{l}\text { contourite is better } \\
\text { sorted }\end{array}$ \\
\hline $\begin{array}{l}\text { Bed thickness } \\
\text { and frequency }\end{array}$ & $\begin{array}{l}\text { usually } 10-100 \mathrm{~cm} \\
\text { infrequent }\end{array}$ & $\begin{array}{l}\text { usually }<5 \mathrm{~cm} \\
\text { abundant }\end{array}$ & $\begin{array}{l}\text { contourite has thinner } \\
\text { bedding, and many more } \\
\text { beds per core length }\end{array}$ \\
\hline $\begin{array}{l}\text { Primary sedimenta } \\
\text { grading and } \\
\text { be dding con- } \\
\text { tacts }\end{array}$ & $\begin{array}{l}\text { y structure } \\
\text { normal grading } \\
\text { ubiquitous, bottom } \\
\text { contacts sharp, upper } \\
\text { contacts poorly } \\
\text { defined }\end{array}$ & $\begin{array}{l}\text { normal and reverse } \\
\text { grading, bottom and } \\
\text { top contacts sharp }\end{array}$ & $\begin{array}{l}\text { contourite tends to be } \\
\text { less regularly graded } \\
\text { and has sharp upper } \\
\text { contacts }\end{array}$ \\
\hline $\begin{array}{l}\text { cross lamina- } \\
\text { tions }\end{array}$ & $\begin{array}{l}\text { common, accentuated } \\
\text { by concentrations } \\
\text { of lutite }\end{array}$ & $\begin{array}{l}\text { common, accentuated } \\
\text { by concentration of } \\
\text { heavy minerals }\end{array}$ & $\begin{array}{l}\text { contourite contrasts } \\
\text { sharply with turbidite } \\
\text { in that heavy mineral } \\
\text { placers are in the form }\end{array}$ \\
\hline $\begin{array}{l}\text { horizontal } \\
\text { laminations }\end{array}$ & $\begin{array}{l}\text { common in upper por- } \\
\text { tion only, accentuated } \\
\text { by concentration of } \\
\text { lutite }\end{array}$ & $\begin{array}{l}\text { common throughout, } \\
\text { accentuated by con- } \\
\text { centrations of } \\
\text { heavy minerals or } \\
\text { foraminifera shells }\end{array}$ & $\begin{array}{l}\text { of small-scale strati- } \\
\text { fiction }\end{array}$ \\
\hline $\begin{array}{l}\text { massive } \\
\text { bedding }\end{array}$ & $\begin{array}{l}\text { common, particularly } \\
\text { in lower portion }\end{array}$ & absent & $\begin{array}{l}\text { contourite is ubiqui- } \\
\text { tously laminated }\end{array}$ \\
\hline grain fabric & $\begin{array}{l}\text { little or no preferred } \\
\text { grain orientation in } \\
\text { massive graded por- } \\
\text { tions }\end{array}$ & $\begin{array}{l}\text { preferred grain orien- } \\
\text { tation paralell to the } \\
\text { beding plane is ubi- } \\
\text { quitous throughout } \\
\text { bed }\end{array}$ & $\begin{array}{l}\text { contourite has better } \\
\text { grain orientation }\end{array}$ \\
\hline
\end{tabular}

Principal constituents of sand and silt beds
matrix
$10-20$ percent
$0-5$ percent
contourite has less
$(<2 \mu \mathrm{m})$

microfossils

common and well preserved, sorted by size throughout bed

rare and usually worn or broken, often size sorted. in placers

plant and common and well preskeletal remains

rare and usually worn or broken

sub-greywacke, arkose and orthoguartz contourite shows more evidence of reworking

contourite shows more evidence of reworking

contourite is more

"mature" 


\subsubsection{The sandstone lithofacies}

This is composed of couplets having excess thickness of greywacke with respect to argillite thickness (Table 2.2). They are often poorly graded or ungraded, with no clear grain orientation. The beds have distinctly regular joint sets which are oriented obliquely to bedding. The lithofacies may be made up of successive greywacke beds about $2 \mathrm{~m}$ thick, separated by thin layers of highly comminuted and polished slabby argillaceous material which has accommodated relatively large amounts of slip. This may be the result of bedding plane slippage rather than argillite sedimentation. Many greywacke beds may accumulate (Walker, 1967) up to $30 \mathrm{~m}$ thick (Plate 2.1).

Possibly the most frequent assemblages of Bouma divisions are AE or AC (Figure 2.1), but in quarry outcrops the detection of Bouma divisions is difficult. Veining is common, both as linear infillings to tens of millimetres width vugs forming in larger examples or as infilled tension gashes. Principal vein minerals are prehnite, quartz and calcite.

\subsubsection{The thick-bedded lithofacies}

In the thick-bedded lithofacies, couplet thickness is generally about the same as in the sandstone lithofacies but the couplets contain a higher proportion of argillite.

Thicker greywackes are not as well graded as thinner greywackes. Bouma divisions include $A B C E, A E, A C E$.

The mean grain size variation is greatest in greywacke beds within the thickbedded lithofacies. Clasts from argillaceous beds which have been ripped up by a turbidity current may have become included, to appear in flaky or slablike form (colloquially known as "chipwackes"). Individual clasts may measure $0.4 \mathrm{~m}$ (Plate 2.2). Little if any grain orientation was noted in greywacke beds although in the coarser beds larger grains and argillite clasts did show some orientation.

Jointing is commonly at right angles to bedding in well developed sets in the greywackes and in thicker argillites. 
Table 2.2 : Parameters used to differentiate lithofacies within the Wellington greywacke-suite rocks.

\begin{tabular}{|c|c|c|c|c|c|}
\hline \multirow[t]{2}{*}{ Parameter } & \multicolumn{3}{|c|}{ Thin-bedded } & \multirow{2}{*}{$\begin{array}{c}\text { Thick- } \\
\text { bedded } \\
\text { HQ }\end{array}$} & \multirow{2}{*}{$\begin{array}{c}\text { Sandstone } \\
\text { KTW }\end{array}$} \\
\hline & RSS & $\mathrm{BQ}$ & DC & & \\
\hline \multicolumn{6}{|l|}{ Avge argillite bed } \\
\hline thickness & $5 \mathrm{~cm}$ & $12.5 \mathrm{~cm}$ & $8.9 \mathrm{~cm}$ & $68 \mathrm{~cm}$ & $16 \mathrm{~cm}$ \\
\hline \multicolumn{6}{|l|}{ Avge. greywacke bed } \\
\hline thickness & $13.9 \mathrm{~cm}$ & $14.4 \mathrm{~cm}$ & $18.8 \mathrm{~cm}$ & $164 \mathrm{~cm}$ & $100 \mathrm{~cm}$ \\
\hline \multicolumn{6}{|l|}{ Avge. argillite:greywacke } \\
\hline ratio & $1: 2.8$ & $1: 2.1$ & $1: 2.1$ & $1: 2.4$ & $1: 6.3$ \\
\hline Thickest couplet & $30 \mathrm{~cm}$ & $46 \mathrm{~cm}$ & $107 \mathrm{~cm}$ & $2.5 \mathrm{~m}$ & $4.6 \mathrm{~m}$ \\
\hline Thinnest couplet & $8 \mathrm{~cm}$ & $9 \mathrm{~cm}$ & $45 \mathrm{~cm}$ & $2.2 \mathrm{~m}$ & $0.15 \mathrm{~m}$ \\
\hline \multicolumn{6}{|l|}{ Avge thickness of } \\
\hline couplets & $19 \mathrm{~cm}$ & $36 \mathrm{~cm}$ & $28 \mathrm{~cm}$ & $2.35 \mathrm{~m}$ & $1.16 \mathrm{~m}$ \\
\hline Length of section & $2.48 \mathrm{~m}$ & $3.63 \mathrm{~m}$ & $5.26 \mathrm{~m}$ & $11.6 \mathrm{~m}$ & $30 \mathrm{~m}$ \\
\hline \multicolumn{6}{|l|}{ Normal range of couplet } \\
\hline thickness & 10 to 30 & $\mathrm{~cm}$ & & 50 to & $300 \mathrm{~cm}$ \\
\hline Percentage of argillite & 25 to 40 & & & & $<20$ \\
\hline
\end{tabular}



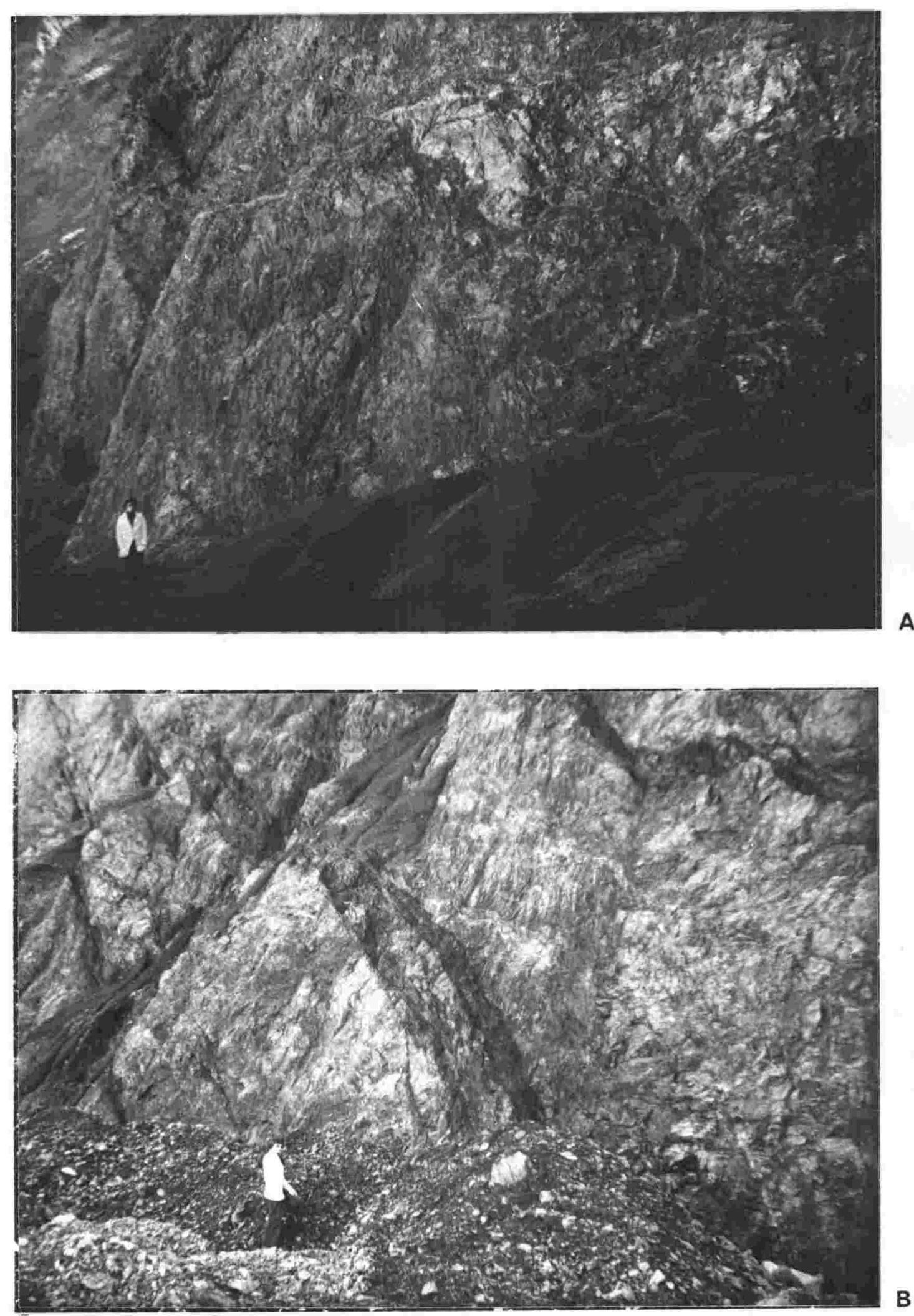

Plate 2.1 : Two views of the sandstone lithofacies at Owhiro Bay quarry; (A) shows a more extensively shattered outcrop than (B), which shows some obvious argillite bedding. 


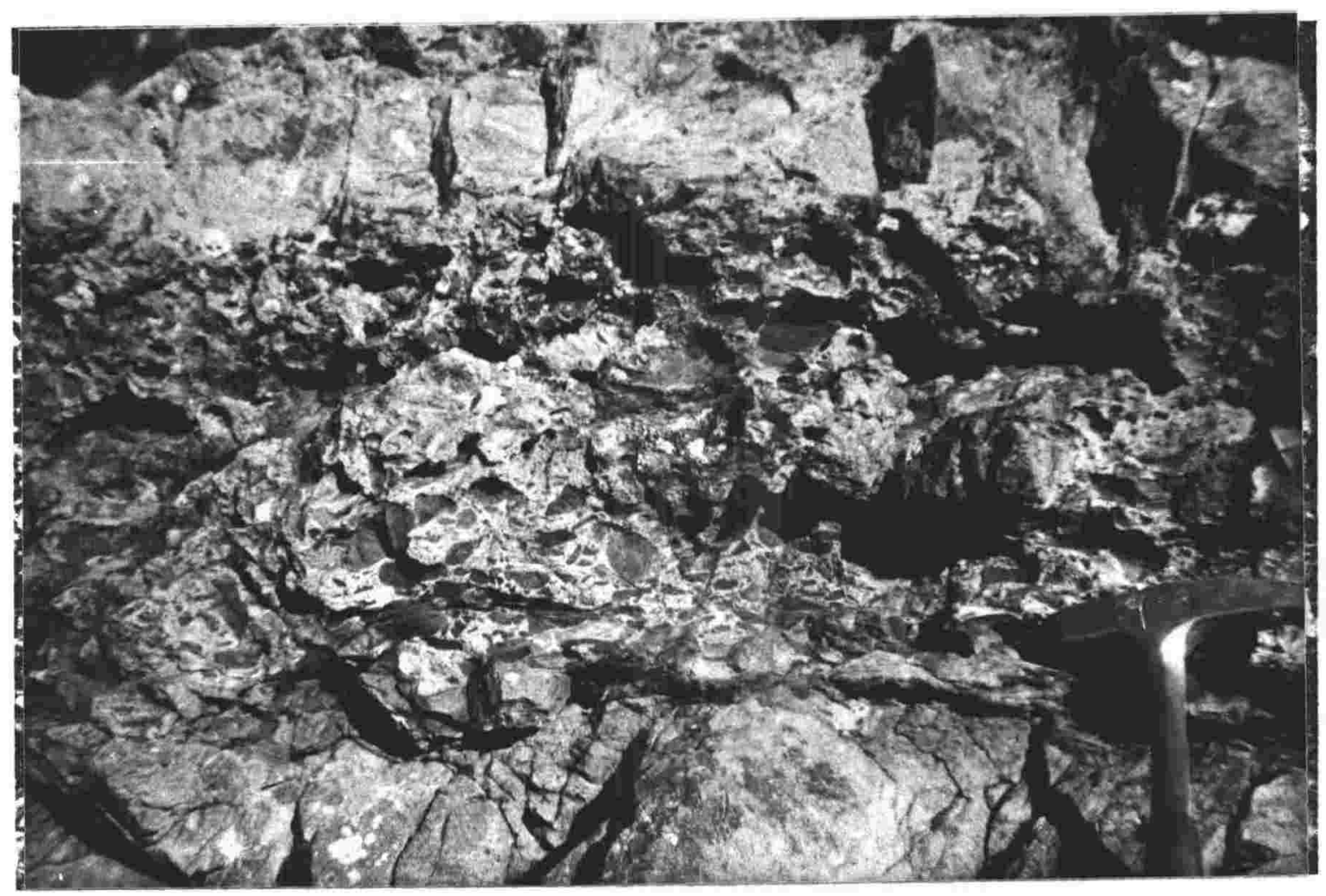

Plate 2.2 : Sedimentary rock fragment clasts (argillite) in "chipwacke" from Eve Bay (NZMS 1, N164/384163). At this locality clasts may reach $0.4 \mathrm{~m}$ in length displaying their original sedimentary structures. They were incorporated as turbidity currents dislodged large flakes and slabs of presedimented argillaceous material which achieved an initial coherence as a soft plastic sediment. 
Veining is frequent in the greywackes but rather less so in the argillites. Principal vein minerals include prehnite, cuartz, calcite and laumontite.

The thick-bedded lithofacies (Plate 2.3A) are commonly transitional between the sandstone and the thin-bedded lithofacies.

\subsubsection{The thin-bedded Iithofacies}

These include turbidities, contourites and inter-turbidite materials. Interturbidite materials include the $D$ and $E$ divisions of Bouma sequence; turbidites are represented by $A B C E, A C D E, A C E$ and $A C$ divisions. Evidence of contourites comes from large sequences of unknown total thickness, some with at least $10 \mathrm{~m}$ of thin, regular couplets, apparently devoid of an A division. Greywacke beds are more even grained than those of the other lithofacies, while laminations and rarer cross laminations are made more obvious by heavy mineral concentrations. Contacts between beds are sharp and grain orientation in the greywacke is well developed.

The lithofacies include contorted strata due to slumping (Plate 2.3B). Occasionally the lithofacies pinch out laterally to become massive argillite of reduced thickness.

Jointing is generally intense, with greywacke beds broken by large numbers of sets perpendicular to bedding. Argillites are often intensely shattered. Veining is again better developed in the greywacke beds though it does occur, often in ptygmatic style, in the argillites. Vein minerals are mainly prehnite, quartz, calcite or laumontite.

\subsection{Mapping of lithofacies}

Difficulty in mapping the region stems from a lack of outcrops suited to establishing lithofacies and structural relationships, in areas away from the coastline, new road cuts, quarries and the like. Even stream beds proved disappointing.

A map compiled from lithofacies is presented for part of the Wellington region east of Wellington Fault (map in flap pocket) and shows regional trends.

Strike of beds trends north-south; they are steeply dipping and young west. 

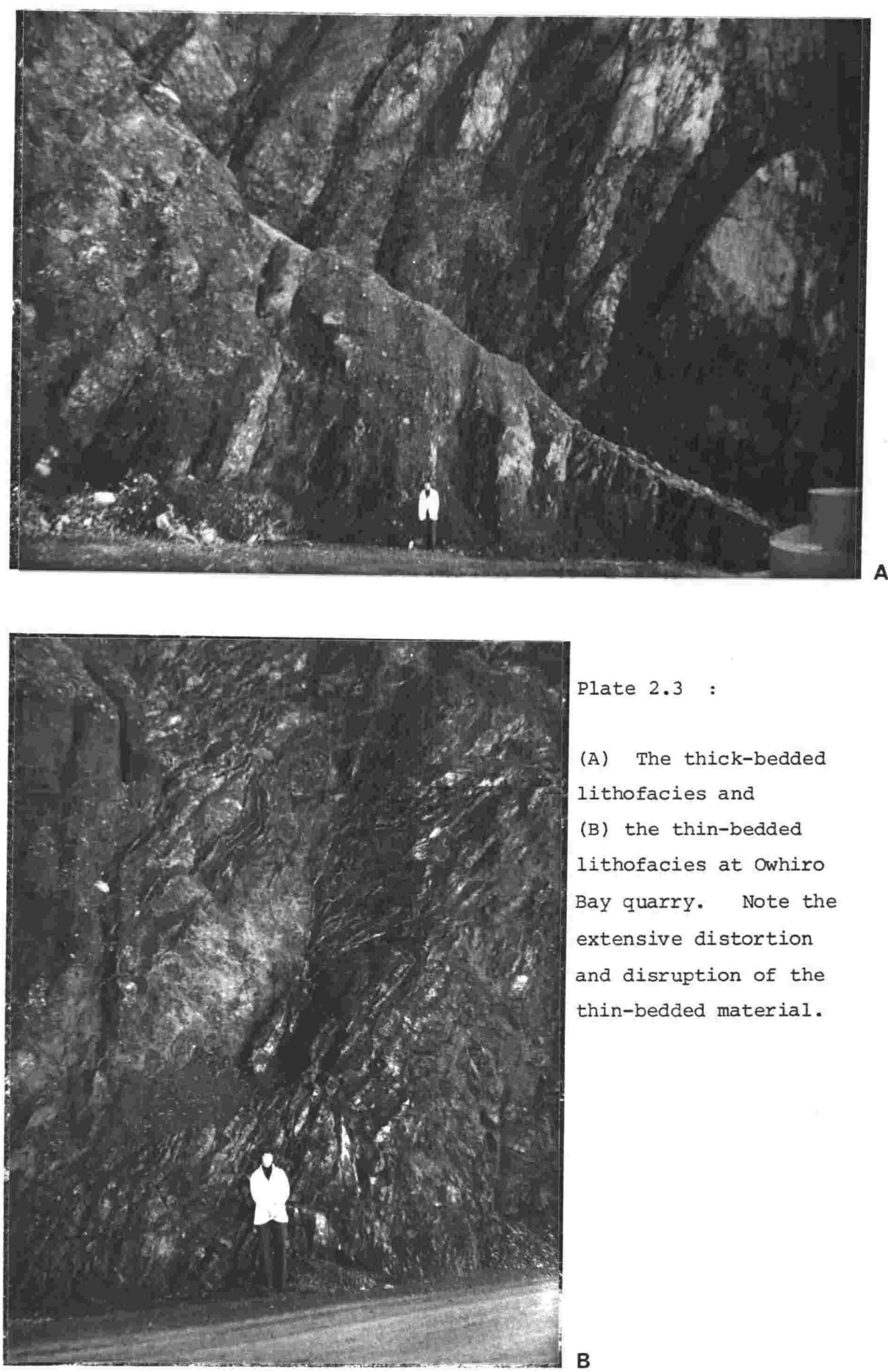

Plate 2.3 :

(A) The thick-bedded

lithofacies and

(B) the thin-bedded

lithofacies at owhiro

Bay quarry. Note the extensive distortion and disruption of the thin-bedded material. 
The magnitude of folding is difficult to establish accurately but appears to fall into two ranges - less than $5 \mathrm{~m}$ and in excess of $60 \mathrm{~m}$ - see also mapping by Brodie (1953) and Grant-Taylor et al. (1974).

\subsection{Causal geology}

Lithofacies control much of the topography and structural trends.

Examination of field relationships and structure revealed several interesting observations (map in flap pocket):

(i) Bays or inlets are associated with the thin-bedded lithofacies.

(ii) Major and minor headlands are coincident with the sandstone and thickbedded lithofacies respectively.

(iii) Most fault movement seems to have been accommodated in the thin-bedded lithofacies.

(iv) Slumping and contorted bedding (usually on a scale of $1 \mathrm{~m}$ to $30 \mathrm{~m}$ ) was observed only in the thin-bedded lithofacies.

More obscure information comes from observations by Stevens (1976), who plotted greywacke to argillite ratios enabling him to isolate what he termed the Waitangirua sandstone, which contains little argillite and corresponds well with the most resistant topographical features of the area.

Slumping, ptygmatic veining, drag folding, discontinuity spacing and boudinage structures all indicate that the thin-bedded lithofacies is incompetent just as argillite between greywacke beds is incompetent.

For engineering work these observations are significant. Slippage of fresh rock tunnel portals at Karori and at Northland (NZMS 1 grid refs. N164/317217 and N164/317220 respectively, both situated in crush zones of the wellington fault), is aggravated by their situation in thin-bedded lithofacies material.

Continuing road pavement damage in Lennel Road and Chaytor Street (N164/338247 and N164/317217 respectively) are pertinent examples of problems which can arise from subterranean drainage associated with the thin-bedded lithofacies. 


\section{4 Paleontology}

Webby (1967) provided an historical summary of paleontology from the Wellington region and recently Speden (1976) published fossil localities of Lower Mesozoic rocks of the North Island.

During this study two new fauna (Rowe, in prep.) and numerous unidentifiable floral debris were found (Plates $2.4,2.5)$ in greywacke (KS-2) and argillites (IB-13A)

\section{5 Petrographic methods}

Samples of both greywacke and argillite beds were obtained from quarries and outcrops for microscopic study to see how features seen in this section might relate to the physical properties of the rocks. Fieldwork was concentrated on existing main quarries (Figure 2.2) and about the southern coast of Wellington.

Appendix 1 lists the sample numbers for each sample location site and Appendix 33 correlates sample numbers with the Petrology collection, Geology Department, Victoria University of Wellington.

For the reasons outlined in section 2.1 samples were taken from the mid-point of each bed.

Thin sections were cut, usually perpendicular to bedding, to avoid biasing textural, modal and fabric determinations due to microlaminations and the natural sorting and anisotropic characteristics of preferred grain orientation. Portions of some greywacke thin sections were stained for K-feldspar or plagioclase feldspar, or both, using modified techniques (Appendix 2). It was found necessary to expose the thin sections to hydrofluoric acid fumes for relatively long periods to adequately etch the felsic grains but this destroyed other important minerals, notably zeolite and calcite, therefore only about 10 percent of any thin section area was stained (Appendix 2).

The preparation of thin sections for detailed petrographic work was of particular importance. For some samples, sections slightly thicker than the usual $0.03 \mathrm{~mm}$ were cut, especially in strongly oriented or coarser grained rocks to 


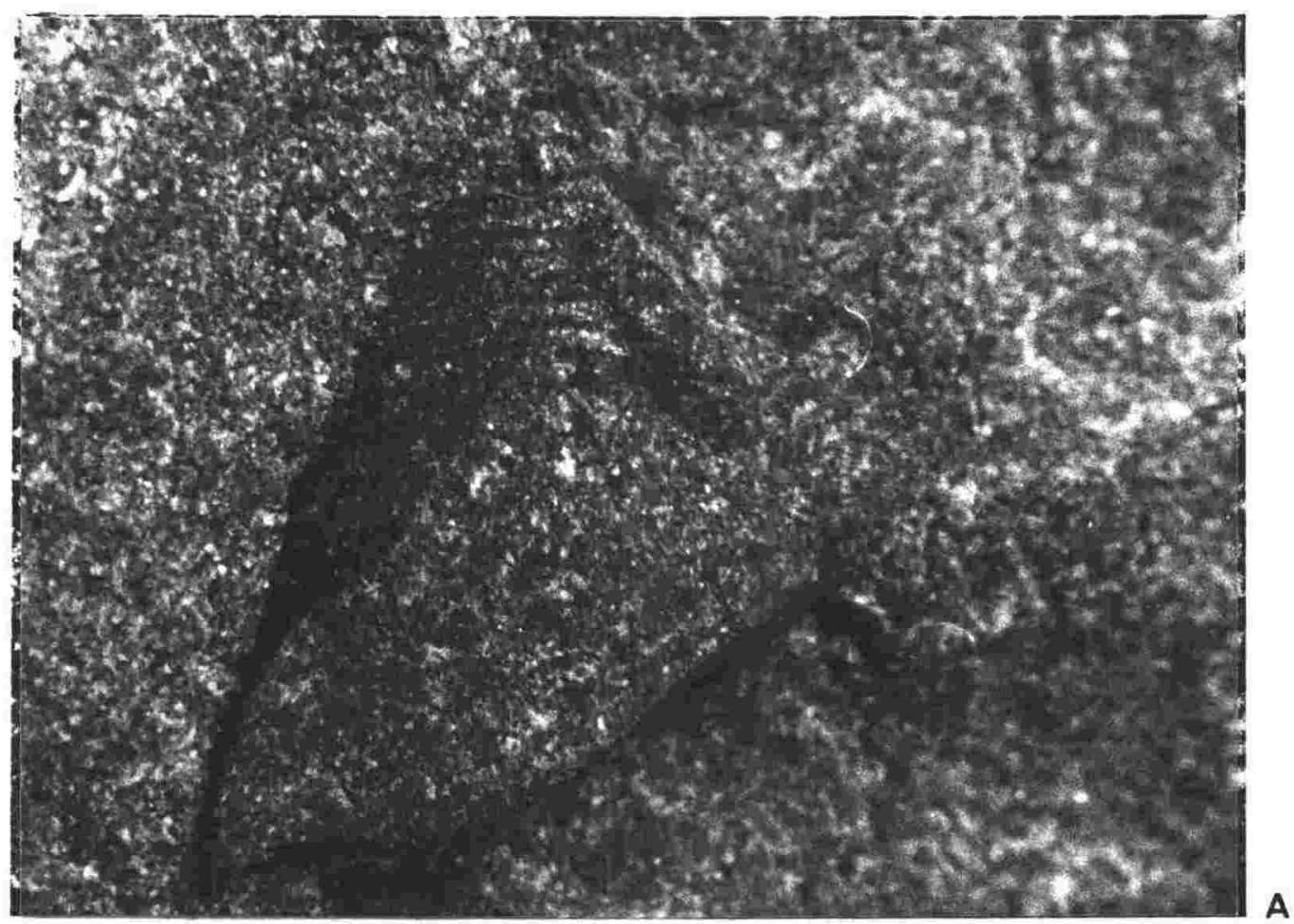

$5 \mathrm{~mm}$

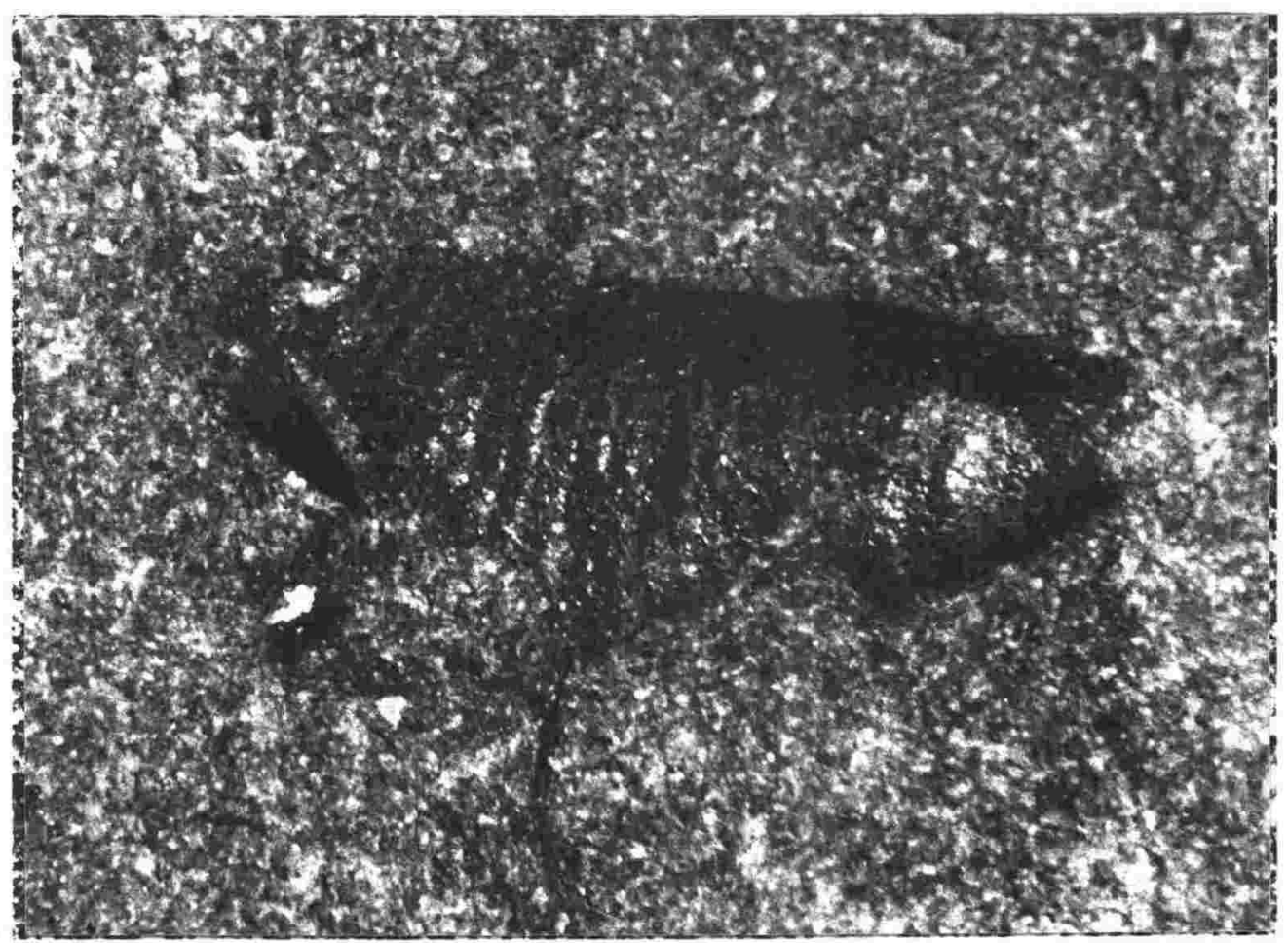

$7 \mathrm{~mm}$

Plate 2.4 : Floral debris in greywacke is rare:

(A) and (B) are corresponding portions of $\mathrm{KS}-2$,

clearly showing botanical detail in a carbonaceous film. 


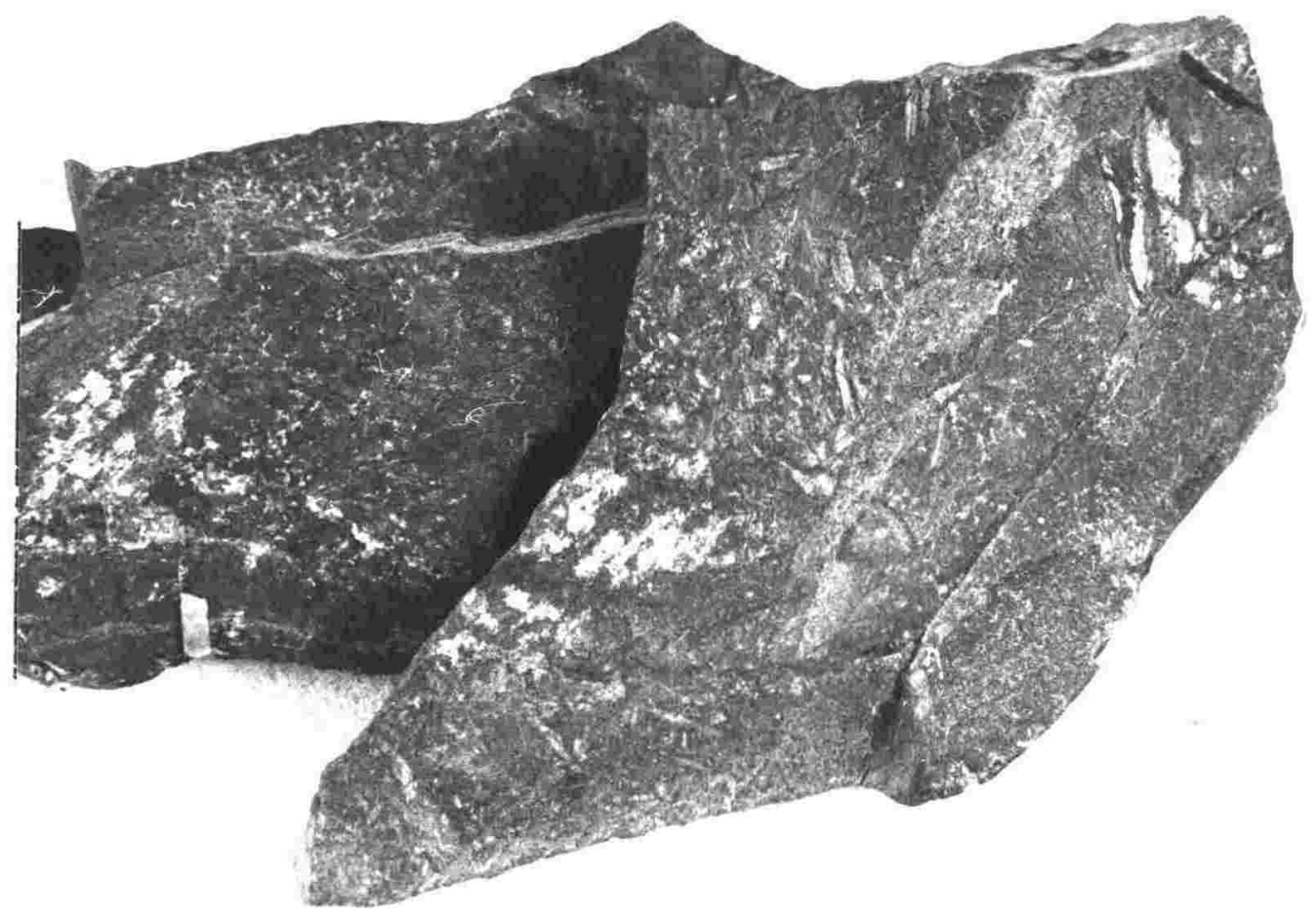

A

\section{$20 \mathrm{~mm}$}

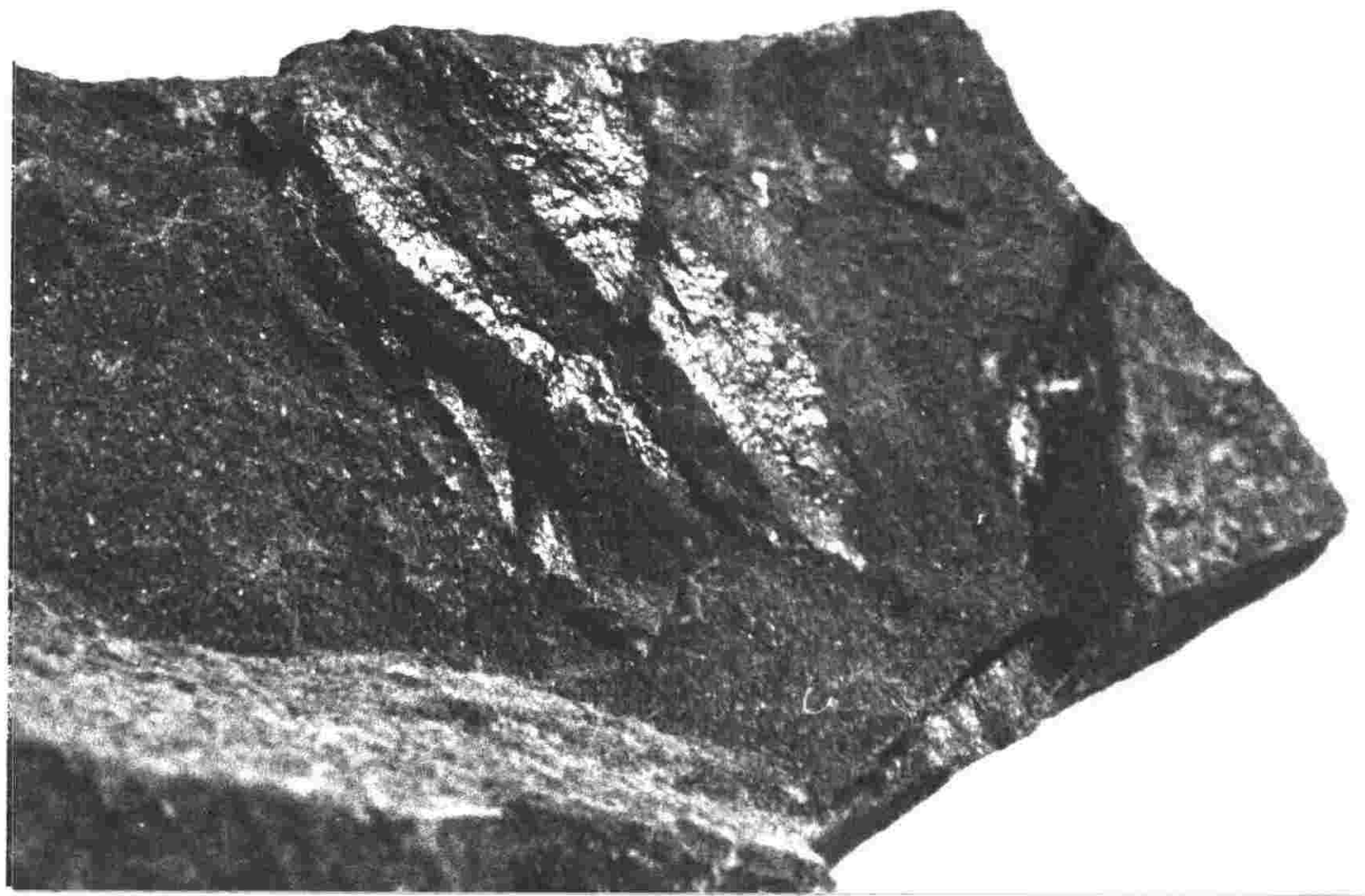

$12 \mathrm{~mm}$

Plate 2.5 : Floral debris in argillites (sample 1B-13A) show good continuity of some carbonaceous films.

(A) and (B) are corresponding pieces at different scales. 


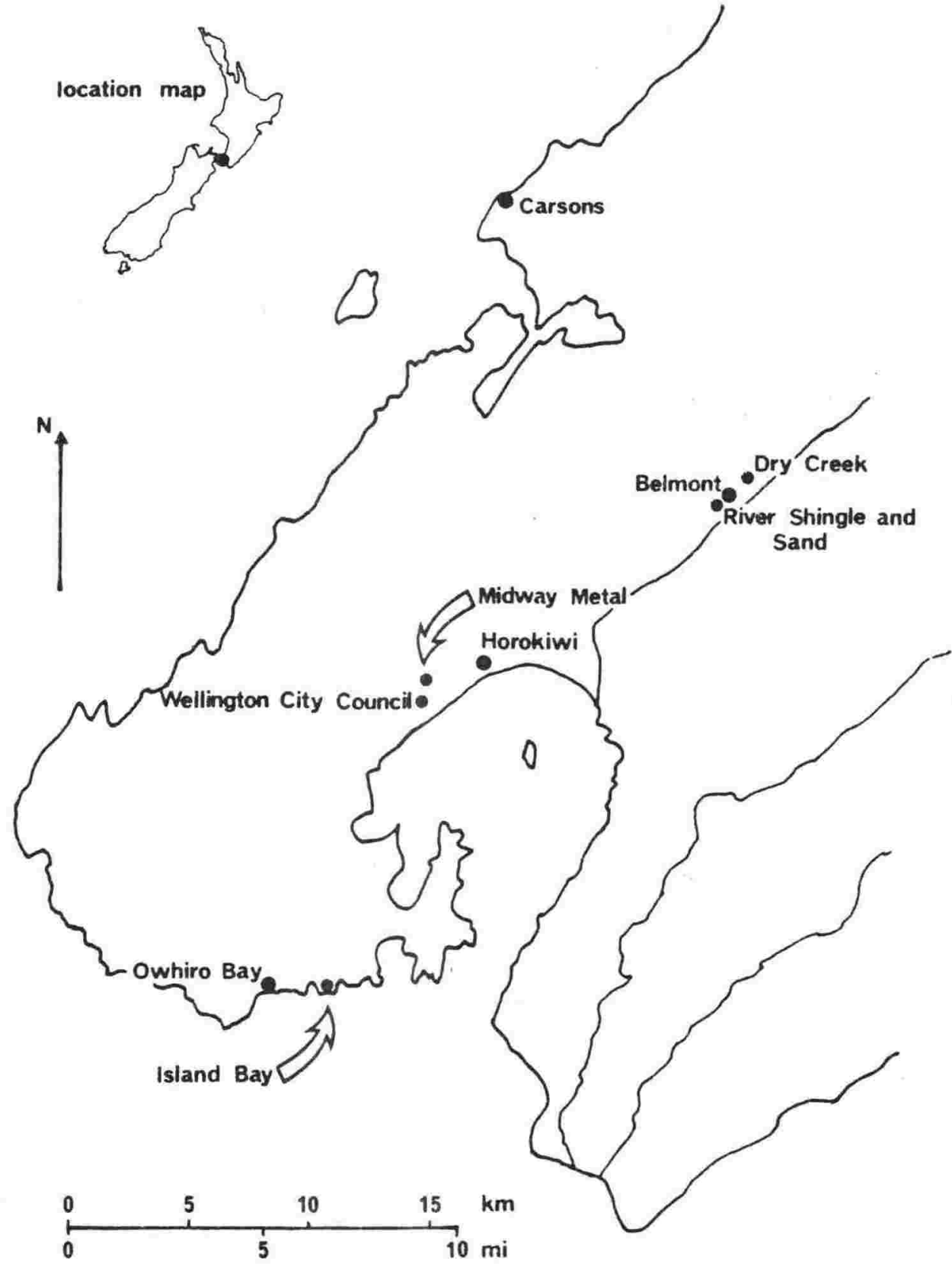

Figure 2.2 : Quarry sites sampled for this study. Quarries from which samples were taken but which are no longer operating are indicated by arrows. Shown by larger symbols are those quarries which will be most important in satisfying Wellington's future demands for aggregate (Ward and Grant, 1978). 
enable the habit of larger phyllosilicates to be better determined. Being cut perpendicular to bedding, thin sections adequately displayed preferred orientations of minerals,but true lengths of some mineral grains were indeterminate due to deviations of the mineral in and out of the plane of the thin section. Thicker sections were useful also in differentiating acid from basic volcanic rock fragments.

Ultra-thin rock sections were preferred in studying finer and more opaque rocks. Some were carefully polished to zero thickness at an edge to enable reliable grain size measurements in rocks with mean sizes finer than 5 phi $(0.03 \mathrm{~mm})$.

In argillite thin sections, overlapping grains were common so for optic modal analysis and size analysis, the thicker (= deeper) grain under the cross-hairs took precedence.

Modal and size analyses of rocks were made from thin sections by following the recommendations of Chayes (1956). As noted previously, thin sections were cut perpendicular to preferred orientation (= bedding) and thin sections having strong preferred orientations or laminations were positioned, where practicable, so that preferred orientation was at an angle to the long axis of the glass slide.

For point counting, the vertical interval between counted rows was chosen so that all the slide was covered in the examination. Horizontal intervals were ideally suited to most greywackes, being approximately the same as the mean maximum grain size, i.e. approximately $0.4 \mathrm{~mm}$. For finer rocks it was not practicable to change the gearing of the click stage and trials were carried out to determine whether more points should be counted by increasing the number of horizontal traverses or whether the slide should be reversed in its holder and re-examined in the usual way. It was found that both these alternatives were effective in duplicating analyses but results varied little from a single analysis. Reasons for this are:

(i) The fine grained rocks are relatively homogenous so that examination of a proportionally smaller area gives acceptable results, particularly for modes. 
(ii) Size analysis histograms of fine rocks showing the effects of mineral recrystallisation are leptokuritic. Therefore variations due to horizontal click interval are within an acceptable maximum.

Welsh (1967) has shown that acceptable reliability may be achieved between different operators examining optical mineral modes of greywackes even though the major source of error is operator error. There is a need for strict consistency. For this study much time and trouble was taken to become familiar with thin sections before modal or size analyses were attempted. Mineral staining helped in this regard and several modal analyses were duplicated months apart to maintain a record of consistency. Similar tests were done for grain size analysis (Appendix 5). With practice a very close approximation of mean grain size was achieved by observation alone (within 0.03 phi for rocks with a mean grain size between 5 and 6 phi, 0.031 and $0.0156 \mathrm{~mm}$ ). Point

counting of thin sections is the only practical means of acquiring grain isize data from greywacke-suit te rocks, though ifth s recogni sed that the present size distribution is how rather different from the oviginal size distribution. However, because we are now concerned mainly with a comparison of rocks in this size no attempt was made to convert the thin section size data to sieve equivalents (Adarns, 1974). Resufts from this study are, however, directly comparables as they are with other data similarly obtained.

An attempt was made to use rock slabs to determine mean grain size as described by Marshall (1974) but, compared with thin section analysis, mean grain size was over estimated due to the "blanketing" effect of matrix and smaller mineral grains. Induced shattering of grains by cutting and grinding preparation is never eliminated and confusion arises even after coating the surface with a clear lacquer or varnish. For rocks with mean grain sizes finer than about 3 to 3.5 phi $(0.125$ to $0.088 \mathrm{~mm})$ the technique is of no practical use.

\subsection{Petrography}

The purpose of this section is to outline the features and distribution of common minerals in Wellington greywacke-suite rocks, because mineral composition is likely to be an important factor in determining engineering properties of aggregare. Detailed petrographic descriptions are given in Appendix 3 . 
The composition of sand sized material was determined as if there had been no alteration after deposition. For example grains of volcanic rocks now containing much chlorite were counted as rock fragments and feldspar grains altered to white mica were counted as feldspar. Vein minerals were not included in the modal analysis but cements and authigenic minerals were. The greywackes were examined in terms of the following modal classes:

$\begin{array}{ll}\text { quartz } & \text { biotite } \\ \text { feldspar } & \text { chlorite } \\ \text { rock fragments } & \text { metamorphic accessories and cements } \\ \text { muscovite } & \text { detrital accessories } \\ & \text { matrix }\end{array}$

Argillite mineral components were classified twice:

(i) Using the following modal classes

$\begin{array}{ll}\text { quartz } & \text { chlorite } \\ \text { feldspar (all varieties) } & \text { non-opaque detrital heavy minerals } \\ \text { rock fragments (all varieties) } & \text { opaque minerals } \\ \text { white mica } & \text { metamorphic accessories and cements }\end{array}$

(ii) Without a matrix class so that every grain was counted in a mineral mode. Grains which were so fine as to be unidentifiable were placed in a class replacing matrix, called "unidentifiably fine material".

In this way operator consistency was checked and an estimate made on mineral composition of the matrix; such an estimate, taken for 10 argillites, may be considered similar to the matrix composition of the greywackes.

Modal analyses of greywackes were based on at least 500 counts and argillites on at least 300 counts. Although many modal analyses were undertaken, only 42 greywacke slides were examined in great detail; 20, 10 and 12 from the sandstone, thick-bedded and thin-bedded lithofacies respectively. 


\subsubsection{Quartz}

Varieties of quartz include monocrystalline, polycrystalline (excluding chert), wavy (quartz with undulose extinction) and non-wavy quartz (Figure 2.3).

Quartz plotted according to the method of Basu et al. (1975) gave inconclusive provenance although the scatter so determined indicated a low or middle rank metamorphic terrain for quartz origin (see section 2.10).

Significant differences between greywackes of different lithofacies were not detected by statistical analysis of quartz modes ( $P$ is greater than 0.1 ).

Recrystallised quartz associated with veining and shearing was not included in modal analyses.

\subsubsection{Feldspar}

Two classes of feldspar were recognised (Figure 2.4), though in the finer grained rocks they were difficult to differentiate. The first, k-feldspar (potassium feldspar) occurs as monocrystalline grains of orthoclase, microcline, perthitic or granophyric grains. In the case of orthoclase and microcline the grains have been altered mainly to white micas (sericitised). This class was included in a general feldspar mode for greywackes of the thinbedded lithofacies because of their relative paucity and finer grain size in those rocks.

The second class, plagioclase, occurs as monocrystalline grains both fresh and altered. Grains of authigenic albite and albitised plagioclase were included where they were distinct grains - authigenic albite was often very difficult to differentiate from detrital plagioclase. Authigenic plagioclase cements are rare and were included in the cement rather than the feldspar class.

The ratio of plagioclase to K-feldspar (Figure 2.4C) ranged from $3: 1$ to $23: 1$ for the sandstone lithofacies. The mean for the sandstone lithofacies and thick-bedded lithofacies was similar, i.e. 8:1. The ratio for the thinbedded lithofacies averaged $10.5: 1$ and showed $\mathrm{K}$-feldspar to be relatively scarce. 


\begin{tabular}{llllllll}
12 & 16 & 20 & 24 & 28 & 32 & 36 & 40 \\
\hline
\end{tabular}

sandstone

thick-bedded

thin-bedded

Figure 2.3 : Average and range in percentage of quartz estimated from thin sections (500 counts) for each litho-

facies in the Wellington region.

\begin{tabular}{llrrrrrr}
16 & 20 & 24 & 28 & 32 & 36 & 40 & 44 \\
\hline
\end{tabular}

sandstone

A thick-bedded thin-bedded

B

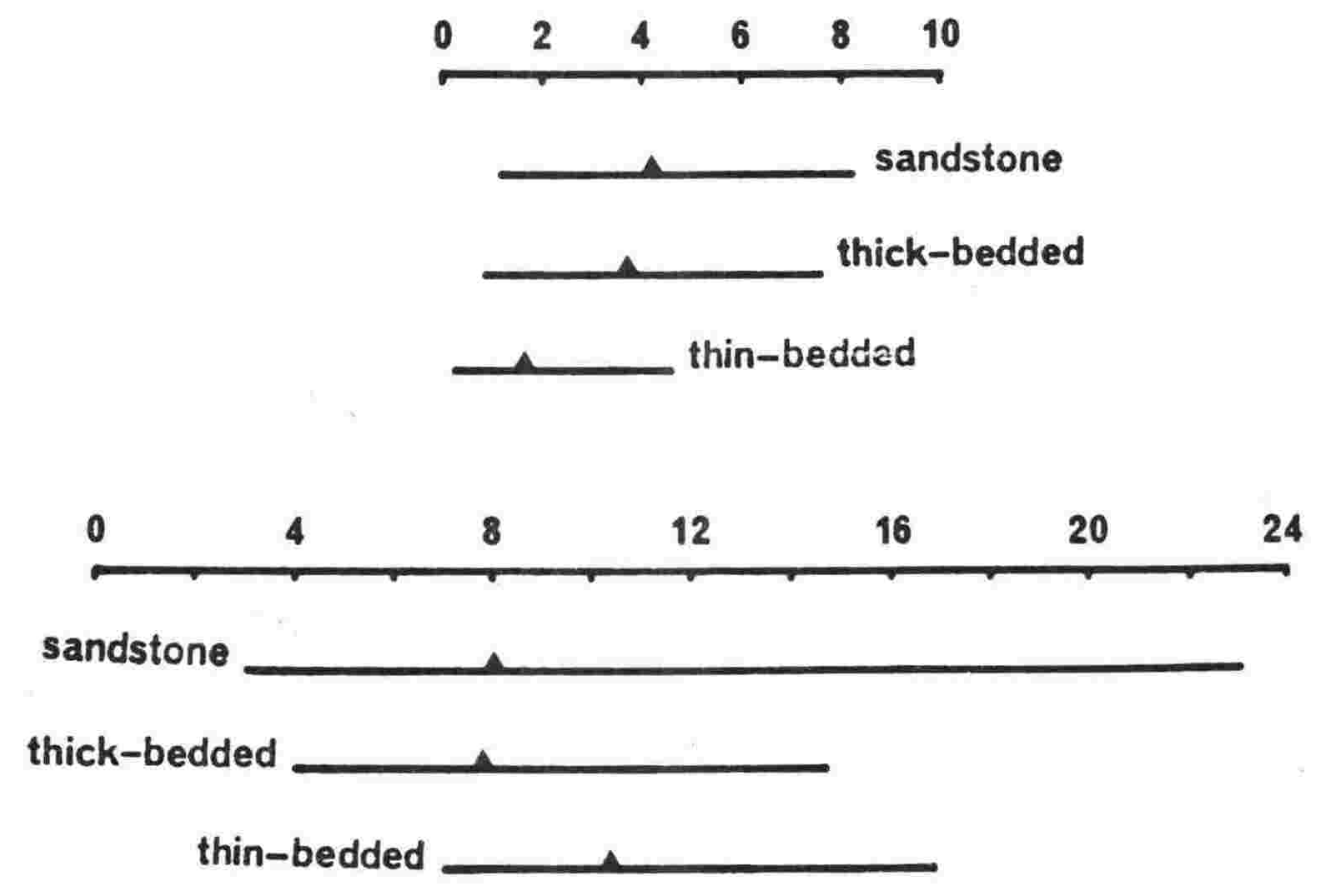

Figure 2.4 : Average and range in percentage of (A) plagioclase (B) potassium feldspar and (C) the ratio of plagioclase to potassium feldspar estimated from thin sections (500 counts) for each lithofacies in the wellington region. 
The mean ratio from all lithofacies was similar to that established by Reed (1957), 10:1.

\subsubsection{Rock fragments}

Rock fragments (Figure 2.5) were divided into four classes:

Sedimentary rock fragments include both intrabasinal and extrabasinal grains. Most are intrabasinal (derived from within the basin of sediment deposition), detrital chert being the only obvious extrabasinal sedimentary rock. They are mainly siltstones or mudstones but some have grain sizes of the same magnitude as the host rock and these were recognised from subtle differences in grain orientation, packing, roundness, sphericity, matrix content and contrast, sorting, boundary continuity, opacity and constituent mineralogy. Fine grained sedimentary rock fragments, in places, form "pseudomatrix" (Dickinson, 1970), where they have deformed around adjacent rigid grains. Such material was classified as a sedimentary rock fragment as it was obviously deposited as a rock fragment.

(ii) Metamorphic and plutonic rock fragments are mainly irregularly shaped aggregates of quartz, albite, perthite, orthoclase, microcline, muscovite, biotite, chlorite or epidote. The metamorphic fragments are schistose and the plutonic fragments, medium to coarse grained and holocrystalline. Both types lack ground mass. Metamorphic fragments are rounded and elongate or flaky in contrast to plutonic fragments which are generally larger in size. A few large euhedral feldspar grains had small pieces of quartz or other feldspar adhering to ends or edges of the grain (DC - 1); these were included in this class.

(iii) Acid volcanic rock fragments include glassy materials with or without aggregated sodic feldspar laths (where recognisable) whether altered or not. They are best identified under plane light with the substage diaphram stopped down to impart refractive index contrast between component minerals. Altered grains are often very difficult to differentiate from basic volcanic rock fragments, however the former tend to be more distorted.

(iv) Basic volcanic rock fragments are mainly identified by the presence of amphibole and pyroxene grains, plagioclase composition and micro-porphyritic 


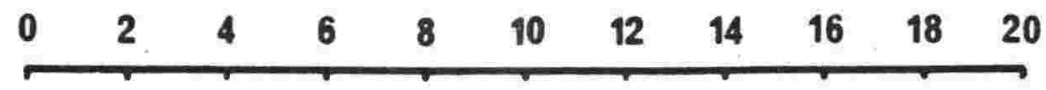

sandstone

A thick-bedded

thin-bedded

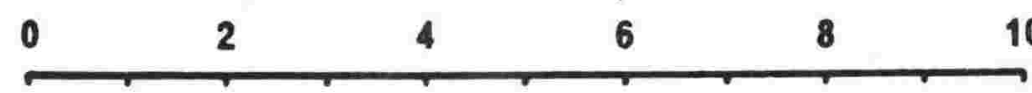
sandstone

B thick-bedded

thin-bedded

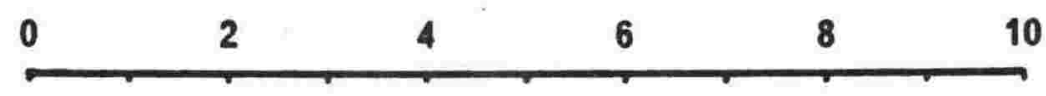

sandstone

C thick-bedded

$\sim$ thin-bedded

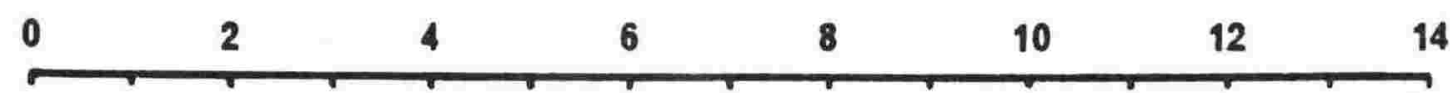

sandstone

D

thick-bedded thin-bedded

Figure 2.5 : Average and range in percentage of (A) sedimentary (B) metamorphic and plutonic (C) acid volcanic and (D) basic volcanic rock fragments estimated from thin sections (500 counts) for each lithofacies in the Wellington region. 
textures ranging from trachytic to pilotaxitic and hyalopilitic with increasing randomness of microlite orientation. Zeolitised,chloritised and basic volcanic rock fragment grains being replaced by iron oxides etc. were counted in this category. Fragments in greywackes of the thin-bedded lithofacies are so altered that grain size measurement is impossible, in which case the size of the largest included constituent grains were averaged to represent the size of the fragment.

\subsubsection{Muscovite}

This is not prolific in any but the coarsest greywackes (Figure 2.6). It is relatively easy to identify and, combined with other phyllosilicates, indicates preferred orientation and compaction. Fine grained material, less than 5.65 phi $(0.02 \mathrm{~mm})$, was arbitrarily termed sericite as were the products of feldspar decay unless grain size exceeded $5.65 \mathrm{phi}(0.02 \mathrm{~mm})$. Differences in structure between the two white micas is apparent, however, from x-ray diffractometry and infrared analyses.

Collectively termed "white mica" they are important constituents for considerations of rock end use.

\subsubsection{Biotite}

Most mineral matter termed biotite by Reed (1957) is in fact chlorite, a fact discovered independently by McKean (1976), Sameshima (1977), Bird (pers. comm.) and this study. The two minerals are difficult to differentiate, especially in greywackes with a mean grain size finer than 2 phi $(0.25 \mathrm{~mm})$. Most biotite is altering to chlorite or has zeolite extending along its cleavage planes. only in a few cases has biotite been counted separately - otherwise it has been counted with chlorite. For engineering assessment of the rocks, the chlorite mode includes biotite where biotite was not counted separately.

\subsubsection{Chlorite}

This is the most important mineral occurring in the greywacke-suite rocks from the viewpoint of engineering use (Figure 2.7). Several categories were recognised but all were included in one class. Recrystallised chloritic material in areas of matrix was counted as chlorite only if grain size exceeded 5.65 phi $(0.02 \mathrm{~mm})$. Detection of chlorite was often hampered by anomolous or low order interference colours. 


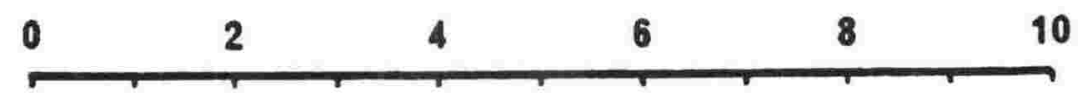

sandstone

thick-bedded

thin-bedded

Figure 2.6 : Average and range in percentage of muscovite estimated from thin sections (500 counts) for each

lithofacies in the Wellington region.

\begin{tabular}{rrrrrrr}
0 & 2 & 6 & 10 & 12 & 14 \\
\hline
\end{tabular}

sandstone

thick-bedded

thin-bedded

Figure 2.7 : Average and range in percentage of chlorite estimated from thin sections (500 counts) for each lithofacies

in the Wellington region. 


\subsubsection{Metamorphic accessories and cements}

This mode includes such minerals as calcite, laumontite, prehnite, pumpellyite and axinite (Bird, in prep.) provided their greatest grain dimension exceeded 5.65 phi $(0.02 \mathrm{~mm}$ ) (Figure 2.8). Veined materials were not included.

\subsubsection{Detrital accessories}

These include amphiboles, apatite, allanite, opaque iron oxides (mainly pyrite), carbonaceous material, sphene, garnet, zircon, zoisite, epidote and augite (Figure 2.9). Most occur in very small quantities and are of little importance to engineering properties with the exception of pyrite and carbonaceous material. For this and identification reasons, authigenic pyrite was also included in this portion of the mode. Mo sometimes carbonaceous material occurfed in long ribbons parallel to bedding (DC-IAM) and was counted as a detrital addessory. Where carbonacedis material was distinctly granular and dispersed, grains were usually of matrix size or smaller and were counted as such.

\subsubsection{Matrix}

This included all material, authigenic or detrital, less than 5.65 phi $(0.02 \mathrm{~mm})$ measured along the mean long axis of the mineral grain or aggregate (Figure 2.10).

\subsection{Petrographic comparison of lithofacies}

The results of 42 modal analyses of greywackes are shown in Tables $2.3,2.4$ and 2.5 .

Differences in petrography between greywackes. of different lithofacies are small, with a wide range in most mineral modes (Figure 2.3 to 2.10 ).

Most contrast is apparent when the thin-bedded lithofacies is compared with either the sandstone or the thick-bedded lithofacies. General increase in felsics (56 to 61 percent) and rock fragments ( 5 to 16 percent), are accompanied by decrease in matrix (22 to 17 percent), phyllosilicates ( 9 to 6 percent), detrital accessory minerals ( 3.5 to 1.5 percent) and in most samples, metamorphic accessories and cements. 


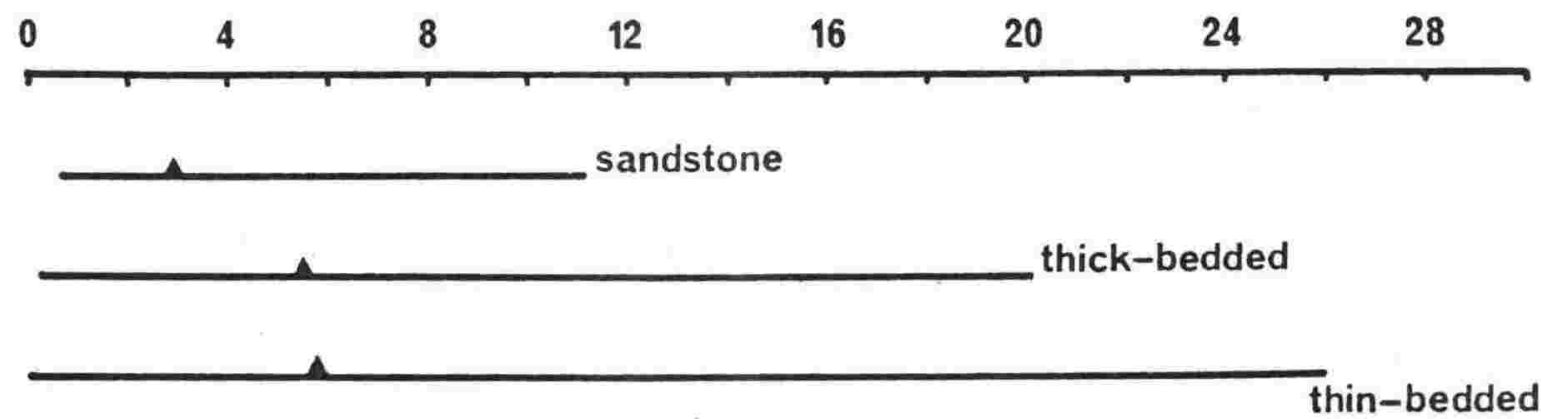

Figure 2.8 : Average and range in percentage of metamorphic accessories and cements estimated from thin sections (500 counts) for each lithofacies in the wellington region.

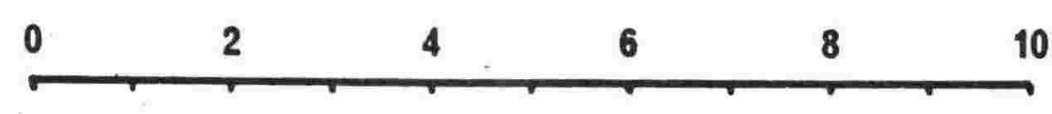

sandstone

thick-bedded

thin-bedded

Figure 2.9 : Average and range in percentage of detrital accessory minerals estimated from thin sections

(500 counts) for each lithofacies in the Wellington region.

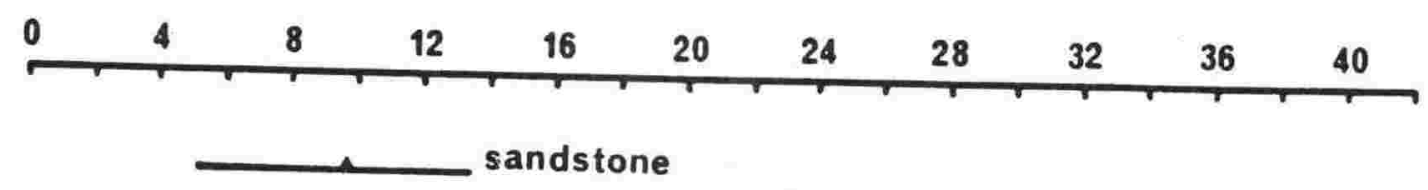
thick-bedded thin-bedded

Figure 2.10: Average and range in percentage of matrix estimated from thin sections (500 counts) for

each lithofacies in the Wellington region. 
Table 2.3 : Composition (in percent) for greywackes of the sandstone lithofacies (500 counts/thin section) arranged in order of decreasing mean grain size.

\begin{tabular}{|c|c|c|c|c|c|c|c|}
\hline Sample & $\mathrm{KTW}-13$ & KTW-14 & RSS -12 & BQ-xviii & $D C-1$ & $\mathrm{DC}-2$ & $B Q-V$ \\
\hline $\begin{array}{l}\text { Mean grain size, } \\
\text { phi (mm) }\end{array}$ & $2.4(0.19)$ & $633^{2.6(0.17)}$ & $2.6(0.17)$ & $\begin{array}{l}2.63(0.16) \\
(5)\end{array}$ & $\begin{array}{l}2.65(0,16) \\
590\end{array}$ & $64.82(0.15)$ & $53.3212^{2.73(0.15)}$ \\
\hline quartz & 27.2 & 28.3448 & 30.7 k. & 24.73 .44 & 27.045\}$, & 29.230 & 29.987 \\
\hline K-feldspar & 5.5 & 3.8 & 3.8 & 7.9 & 5.5 & 3.6 & 5.276 .1 \\
\hline $\begin{array}{l}\text { Plagioclase } \\
\text { Sedimentary rock }\end{array}$ & 36.752 .9 & 31.0491 & 27.6 & 27.9 & 27.185 .5 & 32.049 .3 & 34.2 \\
\hline $\begin{array}{l}\text { Sedimentary rock } \\
\text { fragments, } \\
\text { Metamorphic and plu- }\end{array}$ & 0.7 & 2.2 & 4.4 & 4.4 & 6.3 & 4.1 & 6.3 \\
\hline $\begin{array}{l}\text { Metamorphic and plu- } \\
\text { tonic rock fragments } \\
\text { Acid volcanic rock }\end{array}$ & 4.3 & 6.3 & 4.2 & 6.2 & 6.5 & 5.3 & 6.9 \\
\hline $\begin{array}{l}\text { Acla volcanic rock } \\
\text { fragments } \\
\text { Basic volcanic rock }\end{array}$ & 8.1 & 0.2 & - & 0.8 & 3.2 & 3.0 & 2.0 \\
\hline $\begin{array}{l}\text { Basic volcanic rock } \\
\text { fragments }\end{array}$ & & 3.2 & 6.3 & 6.0 & 9.7 & 6.7 & 13.3 \\
\hline Muscovite & 0.9 & 1.8 & 0.8 & 0.2 & 0.2 & 0.8 & 0.6 \\
\hline Biotite* & - & - & - & - & 2.2 & 3.2 & 3.2 \\
\hline $\begin{array}{l}\text { Chlorite } \\
\text { Metamorphic access- }\end{array}$ & 6.6 & 7.9 & 11.4 & 4.4 & 2.6 & 2.6 & 3.2 \\
\hline $\begin{array}{l}\text { Metamorphic access- } \\
\text { ories and cements }\end{array}$ & 0.6 & 3.4 & 1.9 & 11.2 & 2.0 & 2.8 & 1.8 \\
\hline $\begin{array}{l}\text { Detrital accessories } \\
\text { Matrix }\end{array}$ & 9.6 & $\begin{array}{l}2.4 \\
9.7\end{array}$ & $\begin{array}{l}1.0 \\
8.0\end{array}$ & $\begin{array}{l}1.2 \\
5.2\end{array}$ & $\begin{array}{l}1.2 \\
6.7\end{array}$ & $\begin{array}{l}0.4 \\
6.5\end{array}$ & $\begin{array}{l}0.4 \\
9.1\end{array}$ \\
\hline
\end{tabular}

Total: 100.

$100.2 \quad 100.1$

100.1

100.2

100.2

100.1

\begin{tabular}{|c|c|c|c|c|c|c|c|}
\hline Sample & WCC $-13 \AA$ & KTW-15 & KTW-17 & $\mathrm{SJ}-6$ & $\mathrm{KIW}-16$ & BQ-IXA & $O B-21$ \\
\hline $\begin{array}{l}\text { Mean grain size, } \\
\text { phi (mm) }\end{array}$ & $2.78(0.15)$ & $\begin{array}{l}.2 .78(0.15) \\
67)^{2}\end{array}$ & $2.79(0.15)$ & $\begin{array}{l}2.8(0.14) \\
70\end{array}$ & $2.83(0.14)$ & $\begin{array}{l}2.9(0.13) \\
585\end{array}$ & $\begin{array}{l}2.93(0.13) \\
642\end{array}$ \\
\hline $\begin{array}{l}\text { Quartz } \\
\text { K-feldspar } \\
\text { Plagioclase } \\
\text { Sedimentary rock }\end{array}$ & $\begin{array}{l}32.145: 4 \\
3.4 \\
35.0456\end{array}$ & $\begin{array}{r}27.643 .5 \\
1.5 \\
34.4\end{array}$ & $\begin{array}{r}37.5 \\
3.0 \\
30.2427\end{array}$ & $\begin{array}{r}29.341 ? \\
3.0 \\
37.755\end{array}$ & $\begin{array}{r}31.7 \\
8.2 \\
25.1\end{array}$ & $\begin{array}{r}27.9 \\
5.5 \\
25.1\end{array} 4^{92} 2.9$ & $\begin{array}{r}31.5 \text { \&97 } \\
3.2 \text { 66 } \\
30.0\end{array}$ \\
\hline $\begin{array}{l}\text { Sedimentary rock } \\
\text { fragments } \\
\text { Metamorphic and plu- }\end{array}$ & 3.4 & 1.7 & 0.8 & 2.4 & 0.4 & 2.6 & 1.3 \\
\hline $\begin{array}{l}\text { Metamorphic and plu- } \\
\text { tonic rock fragments } \\
\text { Acid volcanic rock } \\
\text { fragments } \\
\text { Basic volcanic rock }\end{array}$ & 3.2 & $\begin{array}{l}3.9 \\
-9\end{array}$ & $\begin{array}{l}4.5 \\
-\quad 8\end{array}$ & $\begin{array}{l}4.0 \\
0.6\end{array}$ & 5.4 & $\begin{array}{l}4.0 \\
5.9\end{array}$ & $\begin{array}{l}1.2 \\
2.6\end{array}$ \\
\hline $\begin{array}{l}\text { Basic volcanic rock } \\
\text { fragments }\end{array}$ & 5.5 & 3.7 & 2.5 & 2.0 & 5.0 & 9.6 & 7.4 \\
\hline $\begin{array}{l}\text { Muscovite } \\
\text { Biotite* } \\
\text { Chlorite }\end{array}$ & $\begin{array}{l}1.3 \\
- \\
2.5\end{array}$ & $\begin{array}{l}2.4 \\
- \\
6.8\end{array}$ & $\begin{array}{l}1.0 \\
3.0\end{array}$ & $\begin{array}{l}1.6 \\
-\overline{4}\end{array}$ & $\begin{array}{l}1.9 \\
4.8 \\
2.4\end{array}$ & $\begin{array}{l}0.9 \\
3.6 \\
1.9\end{array}$ & $\begin{array}{l}0.9 \\
0.2 \\
3.8\end{array}$ \\
\hline $\begin{array}{l}\text { Metamorphic access- } \\
\text { ories and cements }\end{array}$ & 1.7 & 4.4 & 6.6 & 0.8 & 1.9 & 2.8 & 5.6 \\
\hline $\begin{array}{l}\text { Detrital accessories } \\
\text { Matrix }\end{array}$ & $\begin{array}{l}2.1 \\
9.6\end{array}$ & $\begin{array}{r}3.2 \\
10.5\end{array}$ & $\begin{array}{r}0.5 \\
10.3\end{array}$ & $\begin{array}{r}1.4 \\
12.8\end{array}$ & $\begin{array}{r}0.6 \\
10.6\end{array}$ & $\begin{array}{l}0.8 \\
9.4\end{array}$ & $\begin{array}{r}1.3 \\
11.1\end{array}$ \\
\hline Total: & 99.8 & 100.1 & 99.9 & 100.2 & 100.2 & 100.0 & 100.1 \\
\hline
\end{tabular}

\begin{tabular}{|c|c|c|c|c|c|c|}
\hline Sample & $D C-3$ & HQ-27 & $\mathrm{sJ}-2$ & $\mathrm{KS}-2$ & $\mathrm{NC}-8$ & $\mathrm{KS}-10$ \\
\hline $\begin{array}{l}\text { Mean grain size, } \\
\text { phi (mm) }\end{array}$ & $3.08(0.12)$ & $\begin{array}{l}3.13(0.11) \\
70.2\end{array}$ & $\begin{array}{l}3.2(0.11) \\
30\end{array}$ & $\begin{array}{l}3.27(0.1) \\
61 .\end{array}$ & $3.37(0.1)$ & $\begin{array}{c}3.38(0.1) \\
6\} 3\end{array}$ \\
\hline Quartz & 27.347 .5 & 24.975 .5 & $36.65: 1$ & $29.968-1$ & $29.6 \mathrm{~kg} / \mathrm{f}$ & 30.2 घ 77 \\
\hline $\begin{array}{l}\text { K-feldspar } \\
\text { Plagioclase }\end{array}$ & $\begin{array}{r}3.3 \\
26.9\end{array}$ स6 8 & $\begin{array}{r}1.1 \\
44.2620\end{array}$ & $\begin{array}{r}2.0 \\
31.7\end{array}$ & $\frac{5.1}{26.6}+3.9$ & $\begin{array}{r}2.1 \\
27.7466\end{array}$ & $\begin{array}{r}3.3 \\
29.8 \text { प }>1\end{array}$ \\
\hline $\begin{array}{l}\text { Sedimentary rock } \\
\text { fragments }\end{array}$ & 1.7 & 3.4 & 2.4 & 5.1 & 7.0 & 1.4 \\
\hline $\begin{array}{l}\text { Metamorphic and plu- } \\
\text { tonic rock fragments } \\
\text { Acid volcanic rock }\end{array}$ & 2.5 & $3.0 \times$ & 2.5 & 3.5 & 3.3 & 5.2 \\
\hline $\begin{array}{l}\text { fragments } \\
\text { Basic volcanic rock }\end{array}$ & 4.8 & - & 0.2 & - & - & - \\
\hline $\begin{array}{l}\text { Basic volcanic rock } \\
\text { fragments }\end{array}$ & 6.1 & 5.3 & 2.7 & 9.3 & 7.5 & 6.5 \\
\hline $\begin{array}{l}\text { Muscovite } \\
\text { Biotite* }\end{array}$ & 2.7 & 2.0 & 1.0 & 0.8 & 2.3 & 1.9 \\
\hline $\begin{array}{l}\text { Biotite* } \\
\text { Chlorite }\end{array}$ & $\begin{array}{l}7.5 \\
3.5\end{array}$ & $\overline{4.2}$ & $\overline{7.4}$ & $\overline{4.3}$ & 5.0 & 7.5 \\
\hline $\begin{array}{l}\text { Metamorphic access- } \\
\text { ories and cements }\end{array}$ & 3.8 & 0.8 & 2.0 & 0.6 & 1.6 & 0.8 \\
\hline $\begin{array}{l}\text { Detrital accessories } \\
\text { Matrix }\end{array}$ & $\begin{array}{l}1.5 \\
8.5\end{array}$ & $\begin{array}{r}1.5 \\
10.6\end{array}$ & $\begin{array}{l}2.0 \\
9.6\end{array}$ & $\begin{array}{r}1.8 \\
13.4\end{array}$ & $\begin{array}{r}0.8 \\
13.2\end{array}$ & $\begin{array}{r}2.1 \\
11.4\end{array}$ \\
\hline Total: & 100.1 & 100.0 & 100.1 & 100.0 & 100.1 & 100.1 \\
\hline
\end{tabular}

* Dashes indicate biotite included in chlorite mode. 
Table 2.4 : Composition (in percent) for greywackes of the thick-bedded lithofacies (500 counts/thin section) arranged in order of decreasing mean grain size.

\begin{tabular}{|c|c|c|c|c|c|}
\hline Sample & $\mathrm{DC}-6$ & HQ-17 & $\mathrm{SJ}-3_{1}$ & $\mathrm{HQ}-2 \mathrm{I}$ & $\mathrm{HQ}-23$ \\
\hline $\begin{array}{l}\text { Mean grain size, } \\
\text { phi (mm) }\end{array}$ & $1.25(0.42)$ & $1.317(0.4)$ & $1.32(0.4)$ & $2.7(0.16)$ & $2.7(0.16)$ \\
\hline & 544 & 76 & 551 & 625 & $5 \&-2$. \\
\hline Quartz & 21.539 .9 & 24.2346 & 22.8413 & $34.2\} 64$ & 29.6 i9 \\
\hline & $2.1 \leqslant 16$ & 7.6 & 6.0 & $3.8,296$ & $3.4 \times 3\}$ \\
\hline $\begin{array}{l}\text { Plagioclase } \\
\text { Sedimentary rock }\end{array}$ & & & 26.3 เา? & & 17.2 \\
\hline fragments & 18.7 & 4.5 & 15.3 & 2.3 & 3.8 \\
\hline $\begin{array}{l}\text { Metamorphic and plu- } \\
\text { tonic rock fragments }\end{array}$ & 1.9 & 6.1 & 5.4 & 4.3 & 3.2 \\
\hline $\begin{array}{l}\text { Acid volcanic rock } \\
\text { fragments }\end{array}$ & 0.6 & 0.6 & 0.4 & 0.9 & 0.2 \\
\hline $\begin{array}{l}\text { Basic volcanic rock } \\
\text { fragments }\end{array}$ & 5.0 & 12.9 & 4.5 & 6.2 & 6.5 \\
\hline Muscovite & 0.2 & 0.2 & - & 1.3 & 1.0 \\
\hline Biotite* & - & - & - & - & - \\
\hline Chlorite & 3.0 & 1.3 & 6.2 & 7.2 & 5.1 \\
\hline $\begin{array}{l}\text { Metamorphic access- } \\
\text { ories and cements }\end{array}$ & 12.3 & 2.5 & 6.0 & 2.3 & 20.1 \\
\hline Detrital accessorites & s 0.8 & 0.6 & 5.0 & 1.3 & 1.6 \\
\hline Matrix & 3.4 & 1.1 & 2.1 & 11.3 & 8.5 \\
\hline Total: & 100.3 & 99.8 & 100.0 & 100.0 & 100.2 \\
\hline Sample & $\mathrm{HO}-16$ & $\mathrm{HQ}-25$ & HO-19 & $\mathrm{KTW}-\mathrm{G}$ & $\mathrm{BO}-21$ \\
\hline \multirow{2}{*}{$\begin{array}{l}\text { Mean grain size, } \\
\text { phi (mm) }\end{array}$} & $2.77(0.15)$ & $2.83(0.14)$ & $3.08(0.12)$ & \multirow[t]{2}{*}{$4.07(0.06)$} & ) $4.13(0.06)$ \\
\hline & 618 & 627 & 38 & & 456 \\
\hline Quartz & 28.0454 & 34.8555 & 27.1504 & 27.1 & $16.8 ; 6.8$ \\
\hline $\begin{array}{l}\text { K-feldspar } \\
\text { Plagioclase }\end{array}$ & $\begin{array}{l}2.6 \\
30.2489\end{array}$ & $\begin{array}{r}3.3 \\
24.6\end{array}$ & $\begin{array}{r}1.9 \\
24.8\end{array}$ & \} 21.0 & $\begin{array}{r}2.2 \\
16.6\end{array}$ \\
\hline Sedimentary rock & 36 & 24.0 & & & 16.6 \\
\hline fragments & 3.6 & 4.5 & 3.5 & 0.7 & 1.8 \\
\hline $\begin{array}{l}\text { Metamorphic and plu- } \\
\text { tonic rock fragments }\end{array}$ & 4.8 & 4.8 & 4.7 & 4.6 & 2.6 \\
\hline $\begin{array}{l}\text { Acid volcanic rock } \\
\text { fragments }\end{array}$ & 2.4 & 1.4 & 0.6 & \multirow{2}{*}{\} 1.8} & 0.6 \\
\hline $\begin{array}{l}\text { Basic volcanic rock } \\
\text { fragments }\end{array}$ & 6.4 & 8.3 & 7.8 & & 3.6 \\
\hline Muscovite & 0.8 & 0.6 & 1.2 & 8.3 & 1.6 \\
\hline Biotite* & 0.4 & 0.6 & - & - & - \\
\hline Chlorite & 5.8 & 4.1 & 9.7 & 22.5 & 11.0 \\
\hline $\begin{array}{l}\text { Metamorphic access- } \\
\text { ories and cements }\end{array}$ & 2.2 & 1.6 & 1.4 & 7.5 & 0.2 \\
\hline Detrital accessories & 1.4 & 0.6 & 0.8 & 0.6 & 1.6 \\
\hline Matrix & 11.7 & 11.0 & 16.7 & 6.1 & 41.5 \\
\hline Total: & 100.3 & 100.2 & 100.2 & 100.2 & 100.1 \\
\hline
\end{tabular}

* Dashes indicate biotite included in chlorite mode. 
Table 2.5 : Composition (in percent) for greywackes of the thin-bedded lithofacies counts/thin section) arranged in order of decreasing mean grain size.

\begin{tabular}{|c|c|c|c|c|c|c|}
\hline Sample & $B Q-i v$ & $D C-10$ & $B Q-i i i$ & RSS- $i$ & RSS-iii & KIW-i \\
\hline $\begin{array}{l}\text { Mean grain size, } \\
\text { phi (mm) }\end{array}$ & $3.3(0.1)$ & $\begin{array}{l}3.7(0.08) \\
675\end{array}$ & $3.78(0.07)$ & $3.82(0.07)$ & $4.08(0.06)$ & $\begin{array}{l}4.23(0.05) \\
22\end{array}$ \\
\hline $\begin{array}{l}\text { Quartz } \\
\text { K-feldspar } \\
\text { Plagioclase }\end{array}$ & $\begin{array}{r}18.1 \\
2.0 \\
24.0 \div 4\end{array}$ & $\begin{array}{l}26.8 / 9.2 \\
0.2 \\
40.5\end{array}$ & $\begin{array}{r}26.3 \\
2.9 \\
25.9\end{array}$ & $\begin{array}{r}31.9 \\
1.7 \\
28.6\end{array}$ & $\begin{array}{r}20.5 \\
1.0 \\
33.0\end{array}$ & $\begin{array}{r}32.9 \quad 850 \\
4.6 \\
34.9\end{array}$ \\
\hline $\begin{array}{l}\text { Sedimentary rock } \\
\text { fragments }\end{array}$ & 3.8 & 1.9 & 3.1 & 2.9 & 2.5 & 0.4 \\
\hline $\begin{array}{l}\text { Metamorphic and plu- } \\
\text { tonic rock fragments } \\
\text { Acid volcanic rock }\end{array}$ & 1.2 & 1.5 & 2.5 & 3.3 & 1.7 & 0.4 \\
\hline $\begin{array}{l}\text { fragments } \\
\text { Basic volcanic rock }\end{array}$ & 0.2 & - & 0.4 & - & - & - \\
\hline fragments & 2.4 & 1.9 & 3.1 & 1.9 & 2.6 & 0.4 \\
\hline $\begin{array}{l}\text { Muscovite } \\
\text { Biotite* }\end{array}$ & 0.8 & 1.0 & 0.4 & 1.0 & 1.3 & 3.6 \\
\hline Chlorite & 5.2 & 3.4 & 4.4 & 4.1 & 5.5 & 9.4 \\
\hline $\begin{array}{l}\text { Metamorphic access- } \\
\text { ories and cements }\end{array}$ & 21.8 & 5.2 & 13.7 & 2.9 & 0.2 & 0.4 \\
\hline $\begin{array}{l}\text { Detrital accessories } \\
\text { Matrix }\end{array}$ & $\begin{array}{r}1.2 \\
19.4\end{array}$ & $\begin{array}{r}5.4 \\
12.4\end{array}$ & $\begin{array}{r}0.8 \\
16.6\end{array}$ & $\begin{array}{r}1.7 \\
20.1\end{array}$ & $\begin{array}{r}1.3 \\
30.5\end{array}$ & $\begin{array}{l}6.6 \\
6.6\end{array}$ \\
\hline Total: & 100.1 & 99.8 & 100.1 & 100.1 & 100.1 & 100.2 \\
\hline
\end{tabular}

\begin{tabular}{|c|c|c|c|c|c|c|}
\hline Sample & $D C-8$ & $S J-I$ & DC-LAM & $\mathrm{BO}-\mathrm{i}$ & $\mathrm{KTW}-\mathrm{V}$ & RSS-ii \\
\hline $\begin{array}{l}\text { Mean grain size, } \\
\text { phi (man) }\end{array}$ & $4.5(0.04)$ & $4.72(0.04)$ & $4.8(0.04)$ & $4.87(0.03)$ & $5.0(0.03)$ & $5.18(0.03)$ \\
\hline Quartz & 27,6 & 33.4 & 31.5 & 18.2 & 31.3 & 24.3 \\
\hline $\begin{array}{l}\text { K-feldspar } \\
\text { Plagioclase }\end{array}$ & $\begin{array}{r}0.3 \\
28.4\end{array}$ & \} 30.1 & ] 16.1 & $\begin{array}{r}1.8 \\
16.6\end{array}$ & \} 28.1 & $\begin{array}{r}1.9 \\
23.3\end{array}$ \\
\hline $\begin{array}{l}\text { Sedimentary rock } \\
\text { fragments }\end{array}$ & 0.8 & 1.0 & 0.2 & $\begin{array}{r}10.0 \\
1.2\end{array}$ & - & $\begin{array}{c}23.3 \\
-\end{array}$ \\
\hline $\begin{array}{l}\text { Metamorphic and plu- } \\
\text { tonic rock fragments } \\
\text { Acid volcanic rock }\end{array}$ & 0.3 & 0.8 & 0.2 & - & - & 1.0 \\
\hline $\begin{array}{l}\text { Acid volcanic rock } \\
\text { fragments } \\
\text { Basic volcanic rock }\end{array}$ & - & - & - & 0.2 & - & - \\
\hline $\begin{array}{l}\text { Basic volcanic rock } \\
\text { fragments }\end{array}$ & 1.4 & - & 0.8 & 0.2 & 0.4 & - \\
\hline Muscovite & 2.8 & 2.7 & 6.0 & 1.4 & 4.2 & 1.0 \\
\hline $\begin{array}{l}\text { Biotite* } \\
\text { Chlorite }\end{array}$ & 3.3 & 8.8 & 11.2 & $\overline{9.4}$ & - & 13.3 \\
\hline $\begin{array}{l}\text { Metamorphic access- } \\
\text { ories and cement }\end{array}$ & 0.6 & 0.2 & - & $\begin{array}{r}9.4 \\
26.0\end{array}$ & $\begin{array}{c}13.4 \\
-\end{array}$ & $\begin{array}{c}13.3 \\
-\end{array}$ \\
\hline Detrital accessories & 4.5 & 2.5 & 6.8 & 3.2 & 2.6 & 3.9 \\
\hline Matrix & 30.1 & 20.5 & 27.3 & 22.0 & 20.0 & 32.3 \\
\hline Total: & 100.1 & 100.0 & 100.1 & 100.2 & 100.0 & 101.0 \\
\hline
\end{tabular}

* Dashes indicate biotite included in chlorite mode. 
The sandstone and thick-bedded lithofacies are not easily contrasted by petrography alone, due to the wide textural range displayed by the thickbedded lithofacies. The petrography of rocks within the same textural range for both lithofacies is similar, differences being limited to higher total feldspar modes in the sandstone lithofacies and large modes of metamorphic accessories and cements in the thick-bedded lithofacies. The magnitude of the difference is the same in both cases,i.e. approximately 4 percent.

There is no statistical evidence of any significant difference between the lithofacies based on the quartz mode ( $P$ is greater than 0.1 ) even though modes for a lithology may deviate by up to 1.5 percent from the mean i.e. 1.5 percent is the standard error for about 15 samples. Confidence interval for the standard error is 3 percent at the 95 percent confidence level.

\subsection{Argillite petrography}

Table 2.6 presents the data from modal analyses of argillites. Two analyses were undertaken, one counting matrix as material less than $0.02 \mathrm{~mm}$ in size, the other with no lower limit to grain size, every identifiable grain being allocated a mode class. Where identification was impossible a mode class "unidentifiably fine" was used. Comparison shows that an average of 85 percent of mineral components can be identified from thin section.

On average, matrix comprises some 60 percent, with chlorite and quartz occurring in subequal quantity and feldspar representing 30 percent of the fabric minerals. White mica contents vary from 1 to 7 percent, averaging 4 percent.

The proportions of quartz, feldspar, white mica and chlorite are similar regardless of how the modal analysis is done. Components not commonly occurring in sizes greater than $0.02 \mathrm{~mm}$ are opaque minerals and detrital heavy minerals.

Matrix therefore consists largely of chlorite and quartz, the former slightly dominant, with lesser amounts of white mica and feldspar - plagioclase is often twinned in grains $0.01 \mathrm{~mm}$ in size (WCC-8A). Small amounts of opaque minerals ( 3 percent average) and detrital heavies ( 2 percent average) constitute the remainder. 
Tahle 2.6 : Composition (in percent) for argillites (300 counts/thin section) arranged in order of decreasing mean grain size.

A Optic modal analyses of argillites

\begin{tabular}{|c|c|c|c|c|c|c|c|c|c|c|c|c|}
\hline Sample & $\mathrm{HQ}-26$ & $\mathrm{NC}-15$ & $\mathrm{HQ}-24$ & $\mathrm{OB}-\mathrm{W}$ & $\mathrm{HQ}-2 \mathrm{O}$ & $W C C-8 A$ & wCC- $5 A$ & $\mathrm{HQ}-18$ & $B Q-v i i$ & $\mathrm{HQ}-22$ & $\mathrm{OB}-13$ & AVERAGE \\
\hline $\begin{array}{l}\text { Mean grain size, } \\
\text { phi }\end{array}$ & 5.4 & 5.49 & 5.58 & 5.6 & 5.87 & 5.87 & 5.9 & 5.95 & 6.18 & 6.28 & 6.39 & $\mathrm{NA}$ \\
\hline guartz & 16.4 & 30.0 & 12.2 & 14.0 & 5.8 & 16.4 & 16.1 & 10.1 & 8.0 & 6.1 & 3.8 & 12.6 \\
\hline Feldspar & 14.8 & 10.4 & 8.0 & 15.3 & 7.8 & 14.1 & 11.4 & 5.1 & 6.0 & 6.5 & 3.8 & 9.4 \\
\hline White mica & 2.8 & 7.7 & 5.0 & 5.0 & 1.3 & 3.2 & 6.6 & 3.3 & 5.8 & 1.0 & 1.8 & 4.0 \\
\hline Chlorite & 13.4 & 7.7 & 15.9 & 13.1 & 13.3 & 13.4 & 9.8 & 9.6 & 12.8 & 4.9 & 8.5 & 11.1 \\
\hline Heavies & 2.2 & 2.7 & 0.5 & 0.6 & 2.0 & 1.6 & 1.6 & 0.8 & 0.3 & 0.4 & 0.3 & 1.2 \\
\hline Opaques & 0.8 & 1.1 & 2.0 & 0.9 & 3.3 & 0.6 & 1.9 & 3.5 & 3.5 & 0.6 & 0.6 & 1.7 \\
\hline Rock fragments & 0.5 & 0.3 & 0.2 & - & - & - & 0.3 & - & - & 0.2 & - & 0.1 \\
\hline $\begin{array}{l}\text { Metamorphic - } \\
\text { accessories }\end{array}$ & - & - & - & - & 0.7 & - & - & 0.3 & - & 0.2 & - & 0.1 \\
\hline Cements & - & - & - & - & - & - & - & - & 0.3 & - & - & tr \\
\hline Matrix $(0.02 \mathrm{~mm})$ & 49.0 & 40.1 & 56.2 & 51.1 & 65.9 & 50.7 & 52.5 & 67.4 & 63.3 & 80.2 & 81.3 & 59.8 \\
\hline Tota1: & 99.9 & 100.0 & 100.0 & 100.0 & 100.1 & 100.0 & $\$ 00.2$ & 100.1 & 100.0 & 100.1 & 100.1 & 100.0 \\
\hline
\end{tabular}

B Optic modal analyses of argillites disregarding matrix as a mode class

Quartz
Feldspar
White mica
Chlorite
Heavies
Opaques
Rock fragments
Metamorphic -
accessories
Cernents
Unidentifiably
fine
Total:

\begin{tabular}{|c|c|c|c|c|c|c|c|c|c|c|c|}
\hline 36.5 & 45.9 & 21.6 & 26.0 & 14.9 & 30.9 & 23.3 & 26.1 & 26.2 & 19.6 & Asses- 2 & 27.1 \\
\hline 18.9 & 10.3 & 12.0 & 20.8 & 10.8 & 18.0 & 18.6 & 13.2 & 6.9 & 10.1 & ment & 14.0 \\
\hline 7.0 & 9.5 & 10.6 & 8.3 & 6.8 & 8.5 & 8.5 & 10.2 & 10.7 & 9.4 & not & 9.0 \\
\hline 20.6 & 15.5 & 26.9 & 18.4 & 39.9 & 32.2 & 18.0 & 27.1 & 33.1 & 36.5 & practi- & 26.8 \\
\hline 4.3 & 3.8 & 0.8 & 3.4 & 1.9 & 1.9 & 5.3 & 4.0 & 0.9 & 4.6 & cable & 3.1 \\
\hline 0.9 & 0.8 & 5.0 & 4.0 & 7.4 & 1.6 & 3.2 & 7.3 & 8.3 & 9.6 & & 4.8 \\
\hline 2.2 & 0.3 & - & - & - & - & 0.3 & 0.7 & $0.2 ?$ & 0.2 & & 0.4 \\
\hline - & - & 0.3 & - & - & - & 0.5 & 0.3 & $0.2 ?$ & 0.5 & & 0.2 \\
\hline - & - & - & - & - & - & - & - & 0.2 & - & & tr \\
\hline 9.6 & 13.9 & 22.7 & 19.3 & 18.3 & 6.9 & 22.3 & 11.2 & 13.2 & 10.3 & & 14.8 \\
\hline 100.0 & 100.0 & 99.9 & 100.2 & 100.0 & 100.0 & 100.0 & 100.1 & 99.9 & 100.8 & & 100.2 \\
\hline
\end{tabular}

Quartz
Feldspar
White mica
Chlorite
Heavies
Opaques
Metamorphic -
accessories
Unidentifiably
fine
Total: cf. matrix
of A

\begin{tabular}{|c|c|c|c|c|c|c|c|c|c|c|c|}
\hline 20.1 & 15.9 & 9.4 & 12.0 & 9.1 & 14.5 & 7.2 & 16.0 & 18.2 & 13.5 & Asses- & 13.6 \\
\hline 4.1 & - & 4.0 & 5.5 & 3.0 & 3.9 & 7.2 & 8.1 & 0.9 & 3.6 & ment & 4.0 \\
\hline 4.2 & 1.8 & 5.6 & 3.3 & 5.5 & 5.3 & 1.9 & 6.9 & 4.9 & 8.4 & not & 4.8 \\
\hline 7.2 & 7.8 & 11.0 & 5.3 & 26.6 & 18.8 & 8.2 & 17.5 & 20.3 & 31.6 & practi- & 15.4 \\
\hline 2.1 & 1.1 & 0.3 & 2.8 & tr & 0.3 & 3.7 & 3.2 & 0.6 & 4.2 & cable & 1.8 \\
\hline 0.1 & 1.0 & 3.0 & 3.1 & 4.1 & 1.0 & 1.3 & 3.8 & 4.3 & 9.0 & & 3.1 \\
\hline - & - & 0.3 & - & - & - & 0.5 & - & - & 0.3 & & 0.1 \\
\hline 9.6 & 13.9 & 22.7 & 19.3 & 18.3 & 6.9 & 22.3 & 11.2 & 13.2 & 10.3 & & 14.8 \\
\hline 47.4 & 41.5 & 56.3 & 51.3 & 66.6 & 50.7 & 52.3 & 66.7 & 62.9 & 80.6 & & 57.6 \\
\hline
\end{tabular}


2.9 Comparison of greywacke and argillite

A direct comparison of argillite modes with greywacke modes is difficult because of different mode class requirements for the rock tynes but there is a striking difference in grain size.

As a generalisation, argillites have half as much quartz, two-thirds the total feldspar and no rock fragments, but four times the white mica and double the chlorite.

Non-opaque detrital accessories (heavies) are more abundant in argillites than greywackes, excepting some greywackes of the thin-bedded lithofacies. Metallic opaques are more abundant in argillite than greywacke as is carbonaceous material but they take different forms. Metallic opaques in argillites are sometimes apparent as large flakes of pyrite along planes of parting, having no relationship with bedding, or as nodules up to $10 \mathrm{~mm}$ long in bedding planes. Organic matter in argillites is more finely dispersed than in greywackes.

Metamorphic accessories, other than minerals included in modes, e.g. chlorite and metallic opaques, are absent in argillites.

Argillites possess six times as much matrix as greywackes of the sandstone and thick-bedded lithofacies and two to three times that of the thin-bedded lithofacies.

Generally, detrital grains in argillites are equant, angular to subrounded and most grains are fresh and monocrystalline.

\subsection{Provenance}

The provenance of sediments may be indicated by various physical and mineral characteristics of the rock concerned. In this study mineral characteristic methods were chosen using quartz, feldspar, rock fragments and heavy minerals.

The method used for quartz was suggested by Basu et al. (1975) based on a simple four category grouping, utilising undulosity and polycrystallinity of medium sand sized quartz to discriminate plutonic grains from those of low and high rank metamorphic affinity. Results for the Wellington greywacke-suite rocks 
are shown in Figure 2.11. Only greywackes from the sandstone and thickbedded lithofacies have sufficient medium sand sized quartz to provide plots based on 50 grains (Appendix 4).

The data suggest that most medium sand sized quartz is of low rank metamorphic origin. However, the interpretation is complicated by the possibility that the grains were strained after deposition.

Basu acknowledges the possibility of tectonic strain in folded sediments but maintains that careful sampling and examination of rocks containing softer matrix and rock fragments can minimise these effects. Packing proximities are high in Wellington greywackes (Appendix 7) therefore cushioning effects from matrix and rock fragments are minimal.

Blatt and Christie (1963) and Blatt (1967) have shown undulatory quartz to be less stable than non-undulatory quartz and that polycrystalline quartz breaks down relatively quickly to produce monocrystalline quartz. Older sediments, or those reworked should, on the Basu plot, trend towards a more plutonic affinity. Such a trend was not evident in this study.

Other detrital minerals,e.g. microcline and feldspar with perthitic and myrmekitic intergrowths, indicate an acid plutonic source but the provenance of most feldspar (plagioclase) is obscured by alteration of grains to sodic affinities (Appendix 3). Further indications of an acid igneous rock source, are minerals such as apatite, sphene, zircon and tourmaline (Pettijohn, 1957). Biotite, muscovite and tourmaline may be derived from metamorphic rocks or acid igneous rocks and epidote and zoisite indicate a high-rank metamorphic provenance (Table 2.7).

In coarser grained rock types, the mineral association most frequently encountered is that of an acid igneous rock source. Finer sediments (thin-bedded lithofacies), although having similar acid igneous rock affinities, also have assemblages indicative of basic igneous rock sources and characteristics of reworked sediments, not unexpectedly if some of these greywackes are contourites (section 2.1).

Fine grained sediments possess heavy mineral assemblages typical of basic igneous rock sources, e.g. ilmenite, magnetite, chromite, apatite, zircon 


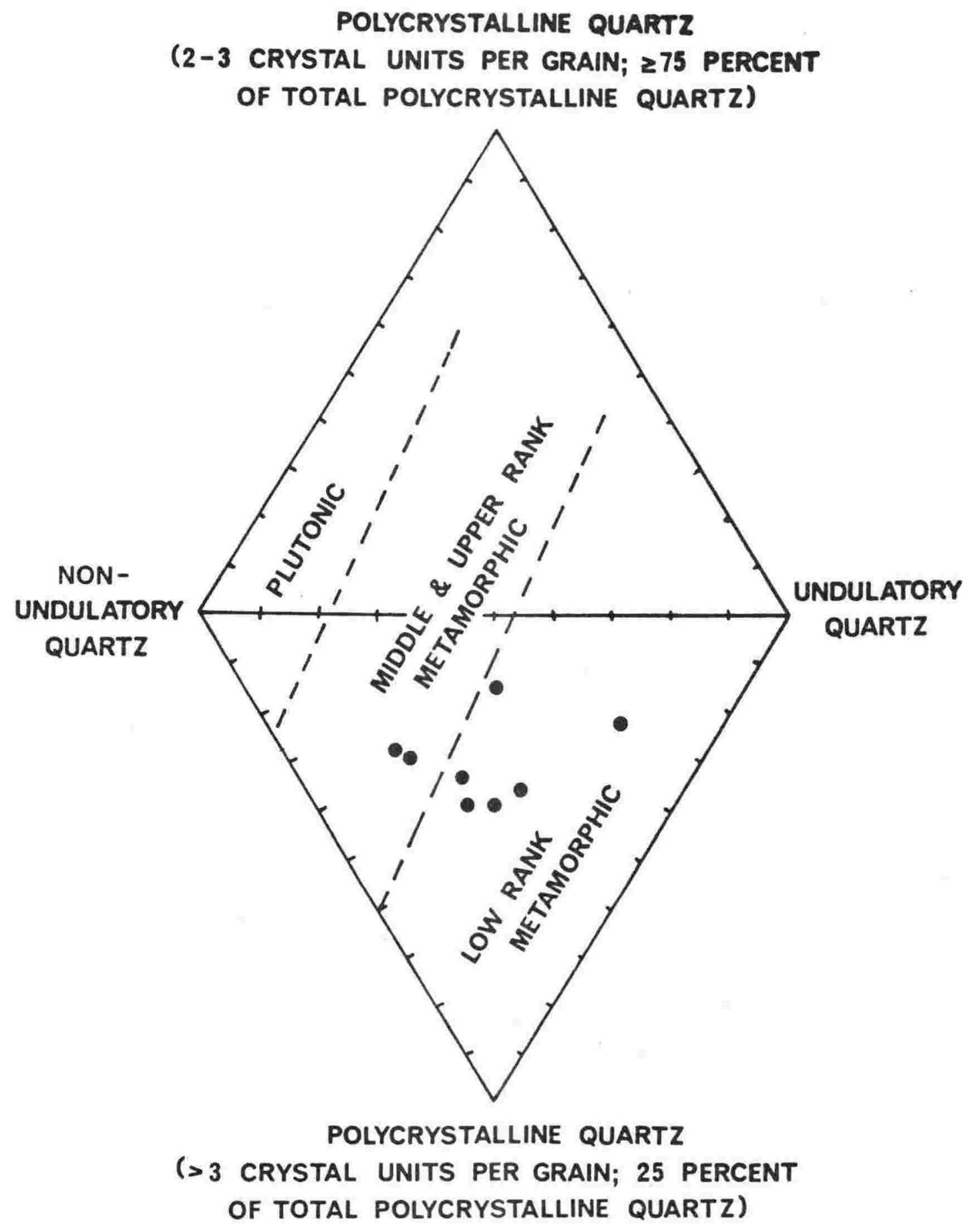

Figure 2.11 : Quartz grains of medium sand size from greywackes of the sandstone and thick-bedded lithofacies plotted on

the Basu plot. Fifty grains were counted for each plot. Raw data is given in Appendix 4. 
Table 2.7 : Detrital mineral suites characteristic of source rock types* (after Pettijohn, 1957).

Reworked sediments

Barite

Glauconite

Quartz (esp. with worn overgrowths)

Chert

quartzite fragments (orthoquartzite type)

Leucoxene
Rutile

Tourmaline, rounded

Zircon, rounded

Low-rank metamorphic

Slate and phyllite fragments

Biotite and muscovite

Chlorite (if clastic)

Feldspars generally absent
Quartz and quartzite fragments (metaquartzite type)

Tourmaline (small pale brown euhedra carbonaceous inclusions)

Leucoxene

High-rank metamorphic

\section{Gamet}

Homblende (blue-green variety)

Kyanite

Silzimanite

Andalusite

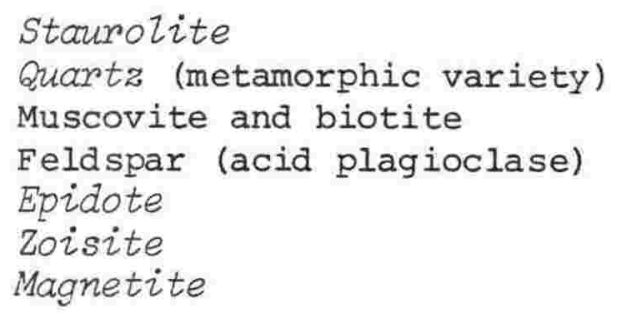

Staurolite

Quartz (metamorphic variety)

Muscovite and biotite

Feldspar (acid plagioclase)

Epidote

Zoisite

Magnetite

Acid igneous

\author{
Sphene \\ Zircon, euhedra \\ Quartz (igneous variety) \\ Microcline \\ Magnetite \\ Tourmaline, small pink euhedra
}

Basic igneous
Leucoxene

olivine

Rutile

Plagioclase, intermediate

Serpentine

Pegmatite

Fluorite

Tourmaline, Monazite

Garnet

Muscovite

Topaz

Albite

Microcline 
and rutile, as these minerals are all relatively stable. In coarser grained greywackes, basic igneous rock fragments as well as some of their heavy minerals occur together.

Rock fragment contents, particularly in the coarser grained greywackes, are of valuable assistance in determining source rock lithology. Lithologies identified have been described (Appendix 3). Sedimentary rock fragments probably come from penecontemporaneous erosion of the sea floor. This is substantiated by a positive relationship between sedimentary rock fragment size with mean grain size of host sediment and a positive relationship, by volume, of sedimentary rock fragments with increasing mean size of host sediment. They are most obvious in the greywackes of the thick-bedded lithofacies (chipwackes), where they occur as angular elongate flakes up to $0.4 \mathrm{~m}$ long, in which lamination and convolutions are still preserved. They deform to form pseudomatrix more readily than igneous rock fragments. In a plastic state, they must have been more susceptible to mechanical erosion than any other variety of rock fragment observed and therefore must have been added to the sediment immediately prior to its final emplacement. Reworked fine grained greywackes (thin-bedded lithofacies) have no significant sedimentary rock fragments.

Volcanic debris is mechanically weak and chemically unstable. Grains are rounded and the ratio of acid to basic volcanic debris is consistently small for all lithofacies (Figure 2.12). Only in greywackes of the thin-bedded lithofacies do the volcanic rock fragments diminish in volume - a response to reduced mean grain size and reworking. The volume in greywackes of the thick-bedded lithofacies is only slightly greater than that in the sandstone lithofacies indicating that, for the greywacke source sediments, volcanic debris was maintained at a consistent volume and is possibly intrabasinal (i.e. derived from a source within the basin of greywacke sedimentation) being relatively weak compared with metamorphic and plutonic rock fragments.

The latter rock fragments are probably extrabasinal in origin, schists, phyllites, quartzites and gneiss fragments being subordinate to granitic fragments, even in the size range 0.5 to $2 \mathrm{~mm}$ required for accurate identification of metamorphic rock fragments (Boggs, 1968). This indicates that, even though a wider range of metamorphic rock types is represented, granitic rocks are more likely to have produced the bulk of sediments forming the Wellington 


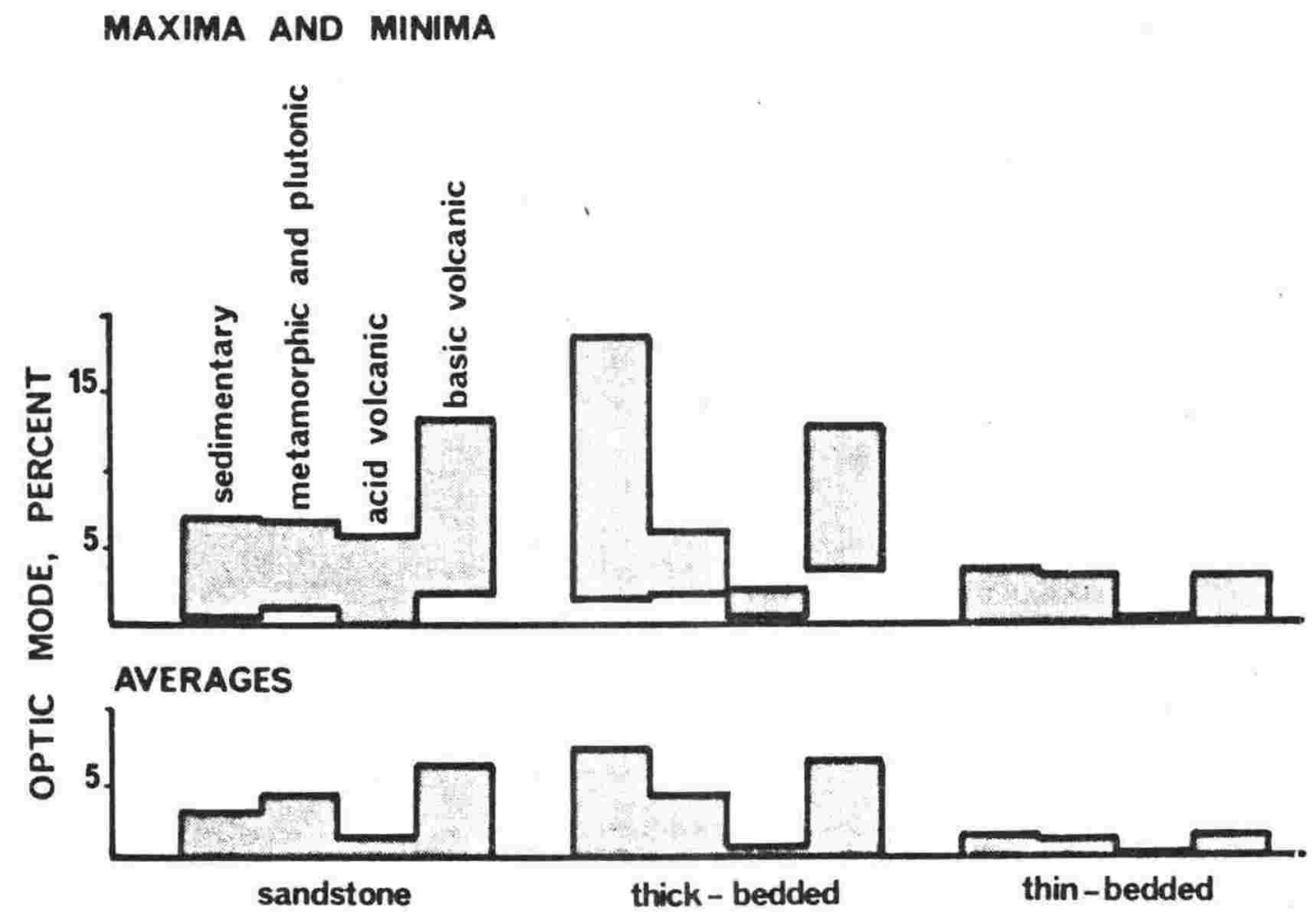

Figure 2.12 : Range and average concentrations of rock fragment types for greywackes by lithofacies. 
greywacke-suite greywackes. The presence of large myrmekitic and perthitic aggregates, with orthoclase crystals having euhedral grain boundaries with each other and quartz, indicate this.

The range in volumes of metamorphic and plutonic rock fragments in greywackes of each lithofacies is the same, within about 1 percent; gradual decrease both in range and maximum volume being evident from the sandstone lithofacies, through the thick-bedded to the thin-bedded lithofacies. This indicates that this chemically relatively stable debris forms the basis of greywacke sediments, a slight concession being made to volume with reduced mean grain size.

Approximate relative contributions of source rocks providing debris for the Wellington greywacke sediments is estimated to be:

Source

acid and basic plutonic

low rank metamorphic

basic igneous derived

acid igneous derived

redeposited sediments
Percentage contribution

50

20

10

5

15

\subsection{Classification of greywackes by mineral composition}

Folk et al. (1970) published a classification system for detrital sediments in New Zealand, based on relative abundances of quartz (excluding chert), feldspar and rock fragments (igneous, metamorphic and sedimentary, including chert). These three parameters recalculated to sum to 100 percent, are determined from optical modal analysis and are end members on a triangular (QFR) diagram. Figure 2.13 shows the QFR diagram (primary arenite triangle) with greywackes plotted by lithofacies association.

The conclusions drawn from the classification are that all the rocks examined are (lithic) feldsarenites, difference being due to grain size. All the rocks represent a single population i.e. all the greywackes in the study region had basically the same mineralogical starting point. 


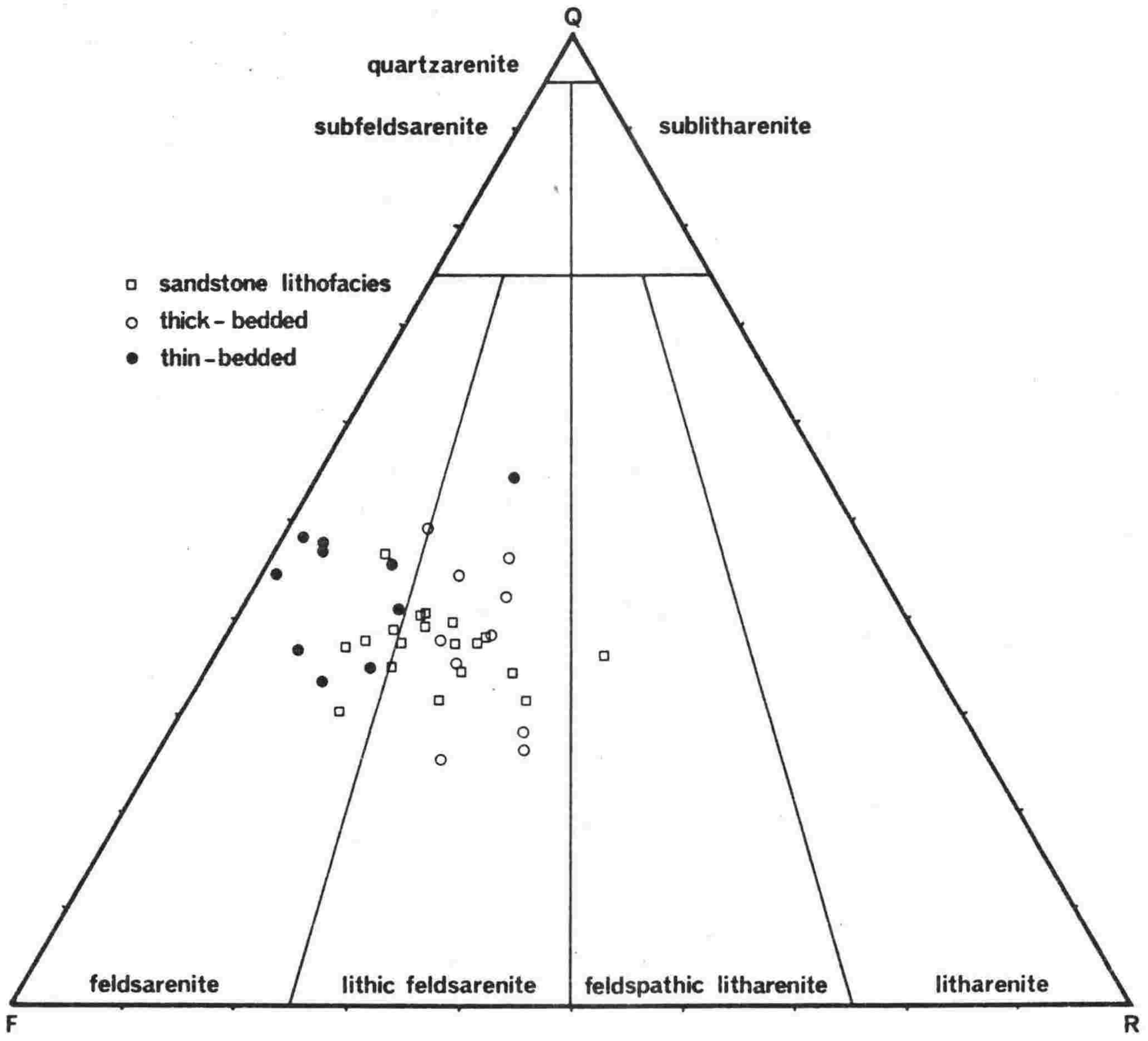

Figure 2.13 : Primary arenite triangle (after Folk et al., 1970) with plots representing the modal compositions of greywackes from each lithofacies. $Q=$ monocrystalline and polycrystalline quartz (excluding chert), $F=$ monocrystalline feldspar, $\mathrm{R}=$ rock fragments (igneous, metamorphic and sedimentary, including chert). 


\subsection{Grain size}

The grain size distribution of greywacke and argillite samples was determined from thin section measurement. The apparent long axes of at least 250 grains were measured using a graduated micrometer eyepiece and magnifications from x35 to $\times 250$. The spacing of the counting "grid" was adjusted to cover the whole section. Although Adams (1974) has shown a reliable relationship between thin section and sieve statistics, he recognised problems in converting the distributions. Therefore the data presented and discussed here have not been manipulated in any way, being the size distributions of apparent long axes in thin section.

Grain size distribution histograms (Figures 2.14 to 2.17 ) were plotted and graphic statistics were calculated (Folk, 1968) according to the formulae:

Graphic mean $\left(M_{z}\right)=\frac{\phi 16+\phi 50+\phi 84}{3}$ phi

Inclusive graphic standard deviation $\left(\sigma_{I}\right)$

$$
=\frac{\phi 84-\phi 16}{4}+\frac{\phi 95-\phi 5}{6.6} \text { phi }
$$

Graphic standard deviation $\left(\sigma_{G}\right)$

$$
=\frac{\phi 84-\phi 16}{2} \text { phi }
$$

used where the 5 and 95 percentiles were not obtainable.

Inclusive graphic skewness $\left(\mathrm{SK}_{\mathrm{I}}\right)$

$$
=\frac{\phi 16+\phi 84-2 \phi 50}{2(\phi 84-\phi 16)}+\frac{\phi 5+\phi 95-2 \phi 50}{2(\phi 95-\phi 5)}
$$

Graphic kurtosis $\left(\mathrm{K}_{\mathrm{G}}\right)$

$$
=\frac{\phi 95-\phi 5}{2.44(\phi 75-\phi 25)}
$$



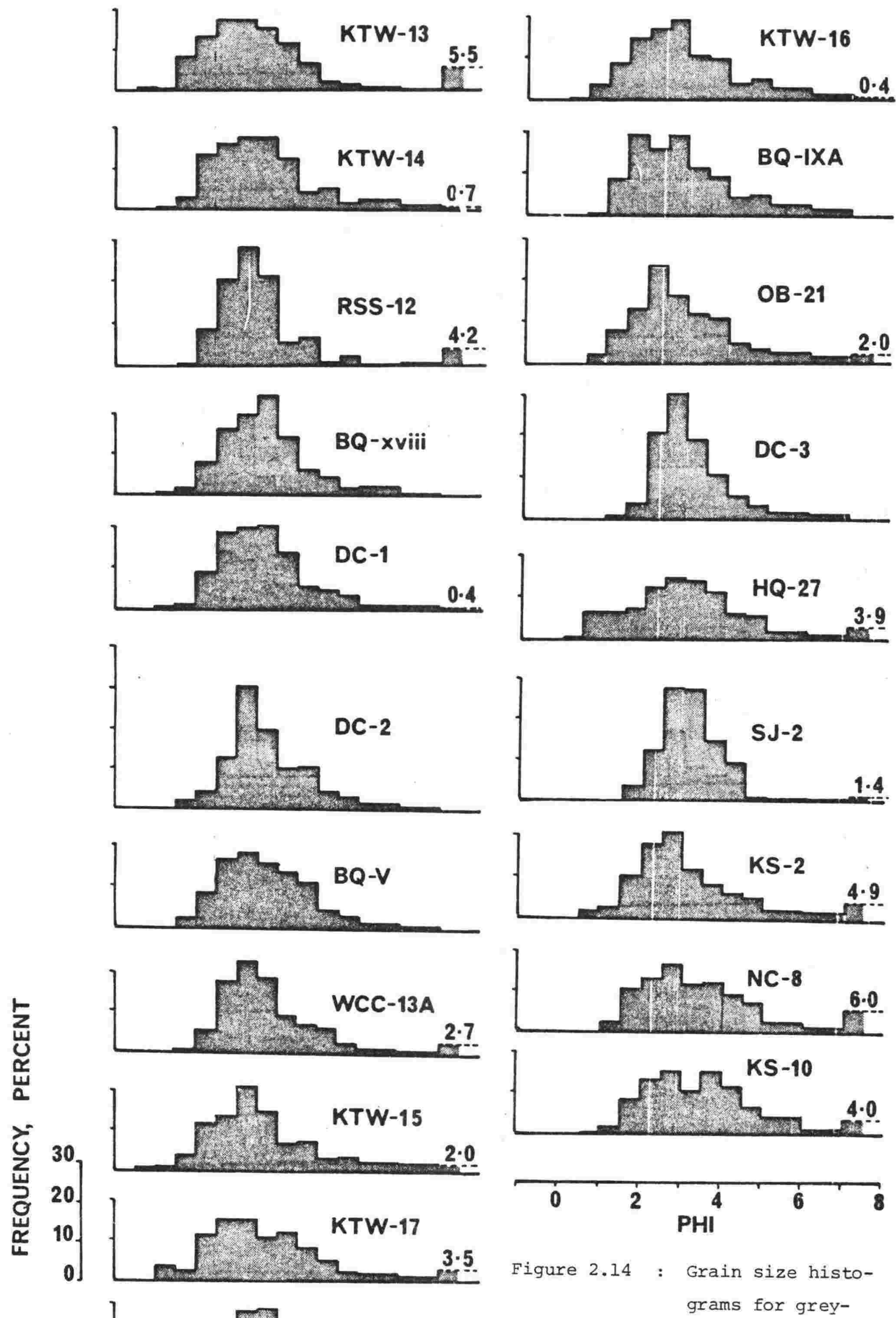

SJ-6

wackes of the sandstone litho-

1.2 facies arranged in order of diminishing mean grain size, see Table 2.8 . 

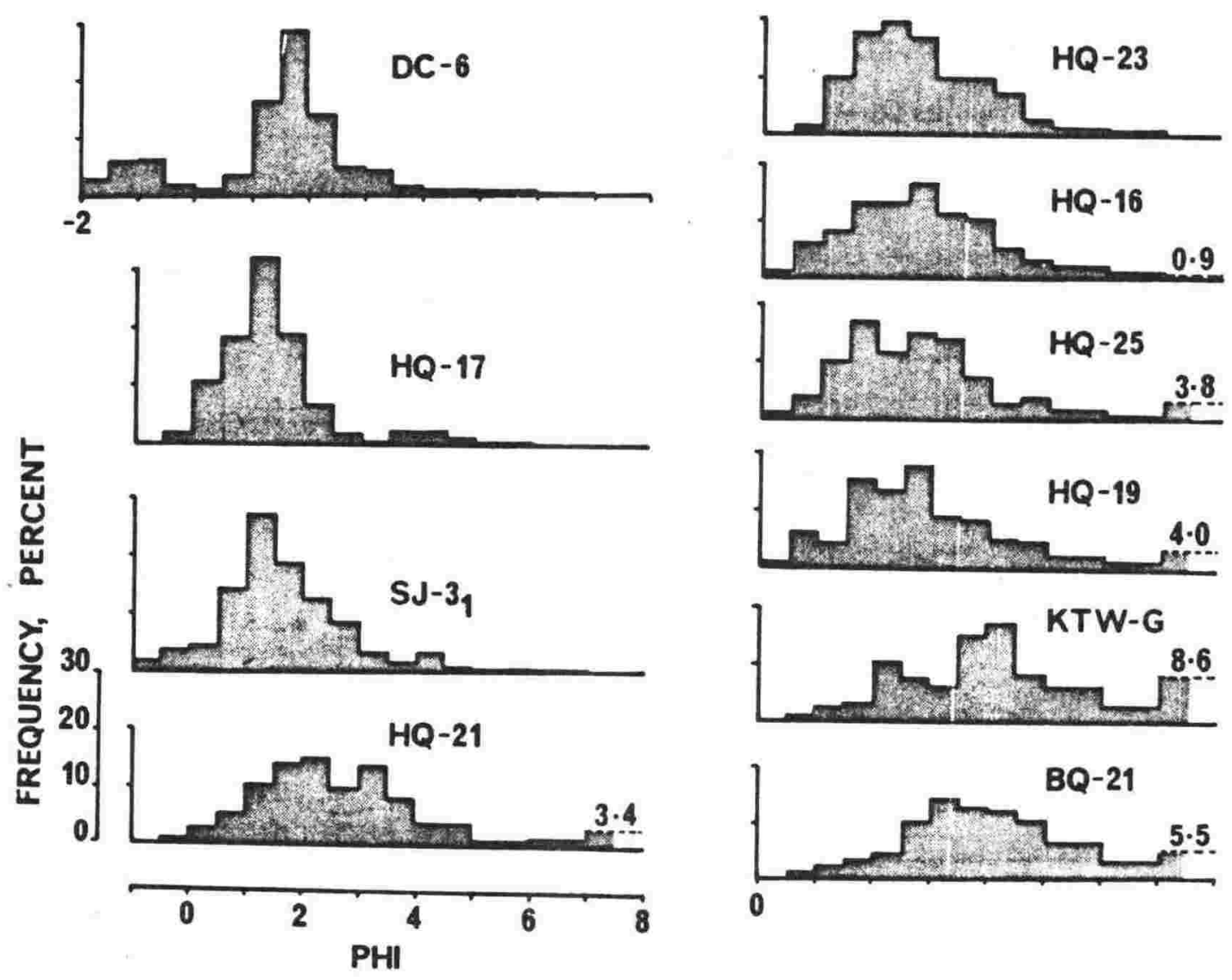

Figure 2.15 : Grain size histograms for greywackes of the thickbedded lithofacies arranged in order of diminishing mean grain size, see Table 2.8 . 

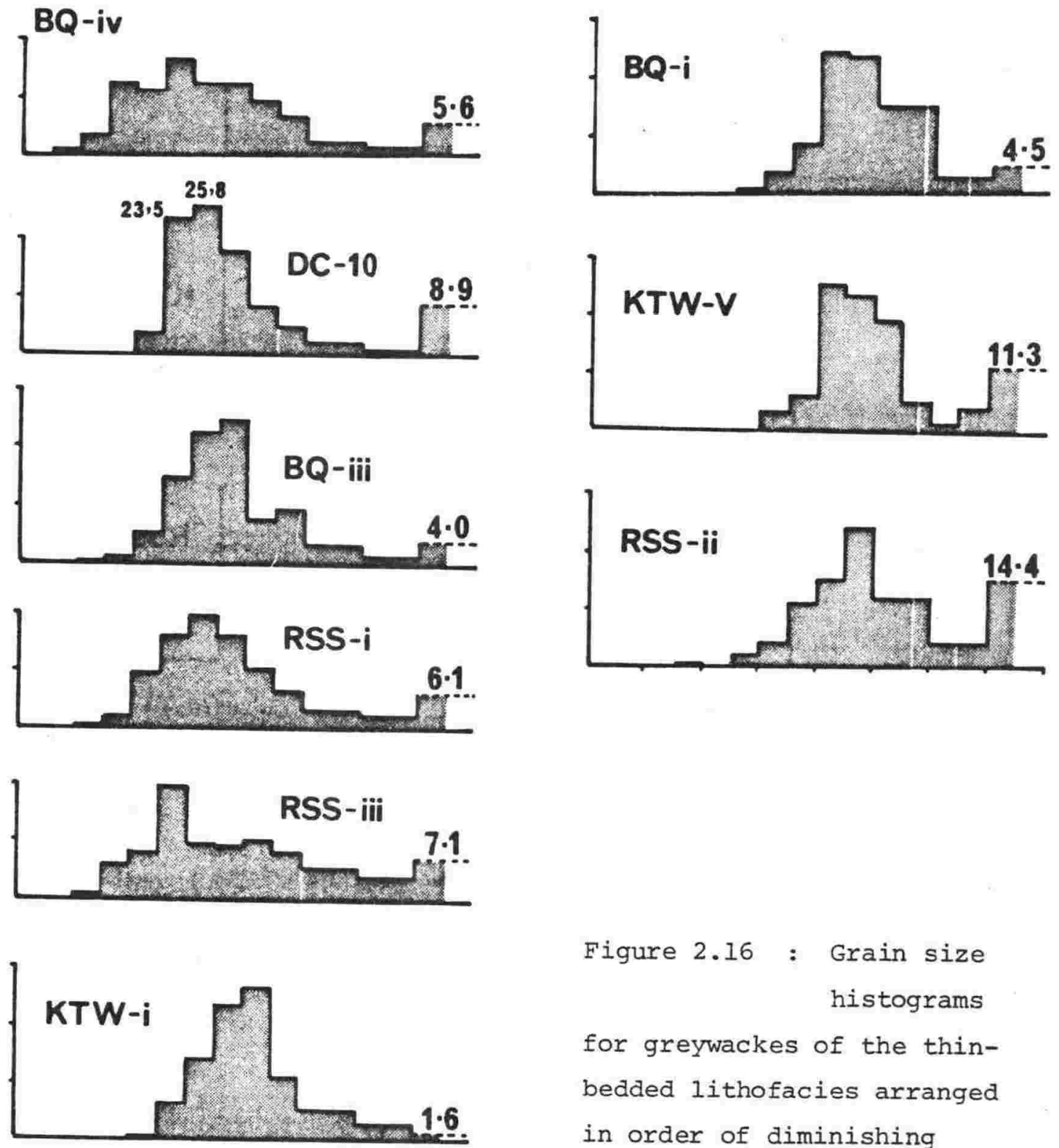
Figure 2.16 : Grain size histograms

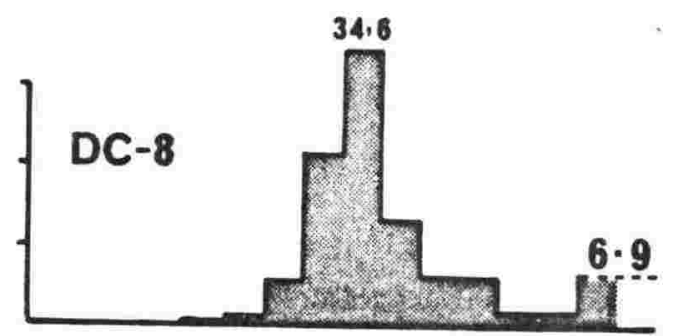

for greywackes of the thinbedded lithofacies arranged in order of diminishing mean grain size, see Table 2.8 .

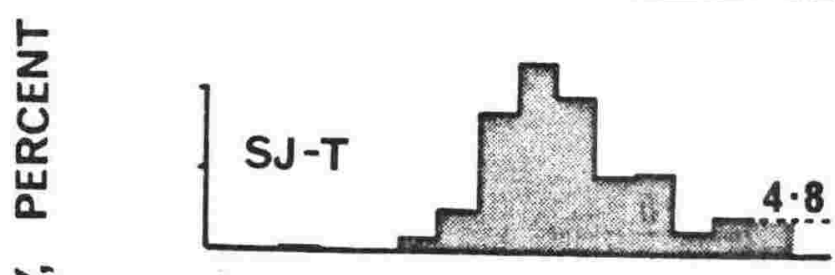

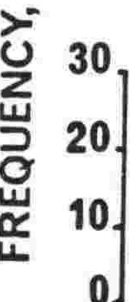
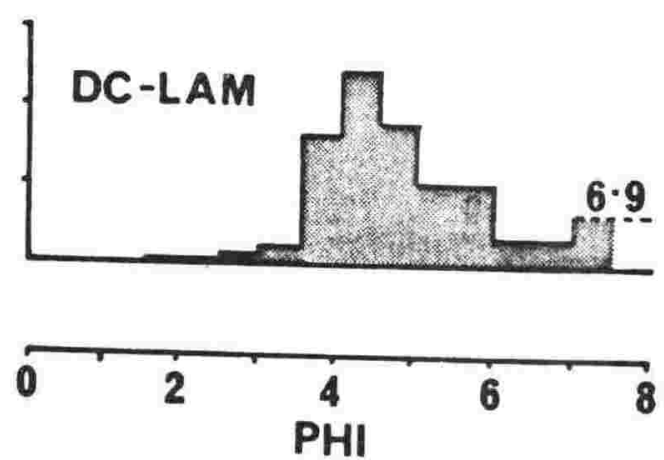

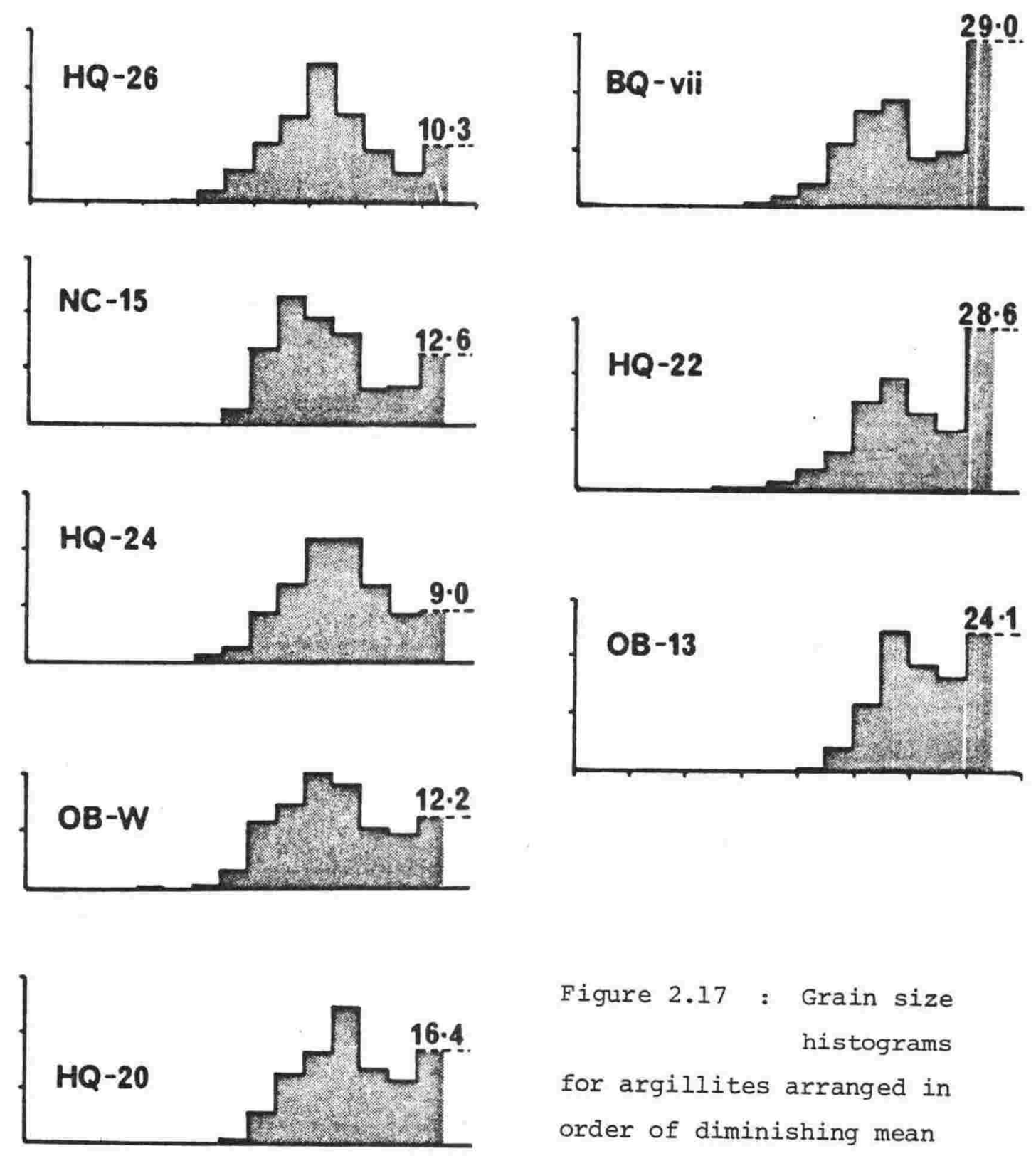

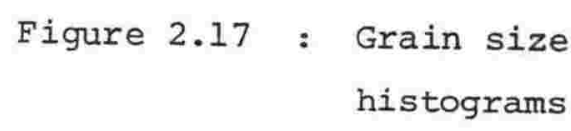
for argillites arranged in order of diminishing mean grain size, see Table 2.8 .
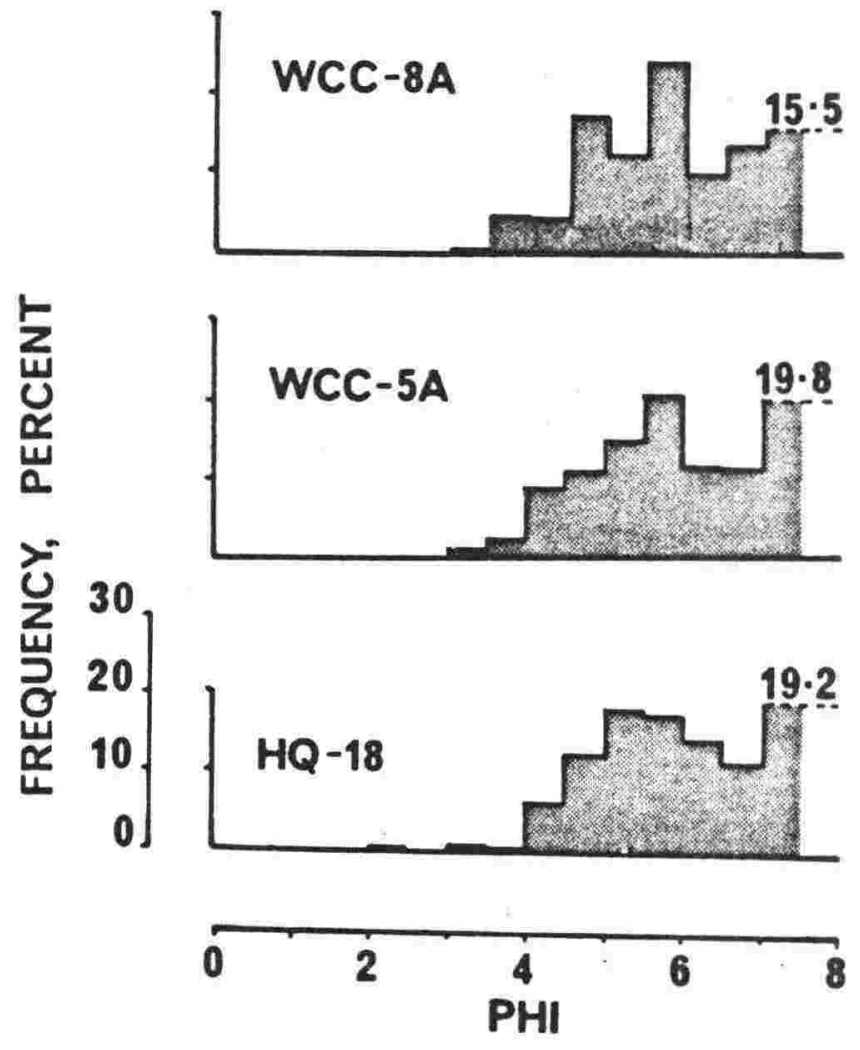
Grain size data provide a reliable basis for differentiating lithofacies in thin section. Figure 2.18 shows the relationship of rock mean grain size to bed thickness.

Greywackes of the sandstone lithofacies are restricted in mean grain size (2.4 to $3.38 \mathrm{phi}$ ) and are poorly sorted ( $\sigma=1.25$ average). Grain size distributions are more positively skewed and are less peaked than for greywackes of any other lithofacies.

Greywackes of the thick-bedded lithofacies have the greatest range in textural parameters: They overlap other greywackes in mean grain size (1.25 to $4.13 \mathrm{phi}$ ) but are generally finer than greywackes of the sandstone lithofacies and coarser than those of the thin-bedded lithofacies. They are more poorly sorted than those of the sandstone lithofacies. Grain size histograms may be skewed positive or negative, the negative skew being due to greywackes possessing large sedimentary rock fragments (chipwackes). Although they display the widest range in skewness values, these greywackes have grain size histograms most closely approximating a normal distribution.

Greywackes of the thick-bedded lithofacies have wider ranging Kurtosis values (Table 2.8) than those of the sandstone lithofacies and histograms are more leptokurtic. They include the most peaked grain size distributions.

Greywackes of the thin-bedded lithofacies have silt sized mean grain sizes. Sorting is better than in other greywackes and there is a smaller range of relatively high $(+0.21$ to +0.37$)$ skewness values. Kurtosis values are also limited ( 1.18 to 1.39 ).

Argillites are similar in size regardless of lithofacies affiliation. Modes vary between 5 and 6 phi $(0.03$ and $0.015 \mathrm{~mm})$ and mean grain sizes are finer than $5.4 \mathrm{phi}(0.023 \mathrm{~mm})$. Most argillites are poorly sorted.

Post-depositional effects (diagenesis) have reduced grains in size by erosion and alteration. Smaller grains have been reduced in size faster and more 


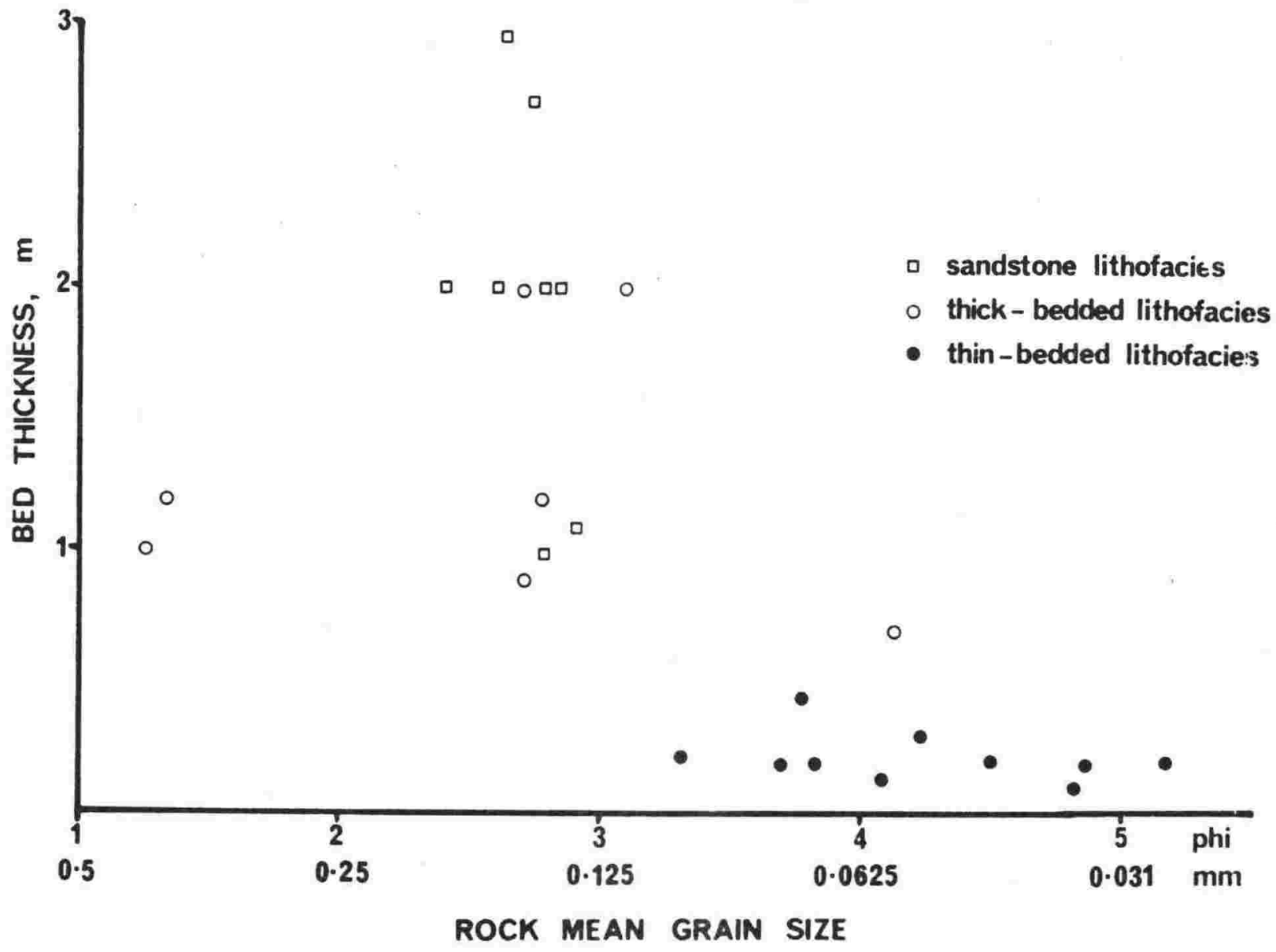

Figure 2.18 : Plot of greywacke bed thickness and rock mean grain size at mid-bed. 
Table 2.8 : Grain size parameters determined for wellington greywacke-suite rocks. Raw data is tabled in Appendix 5. Phi units used.

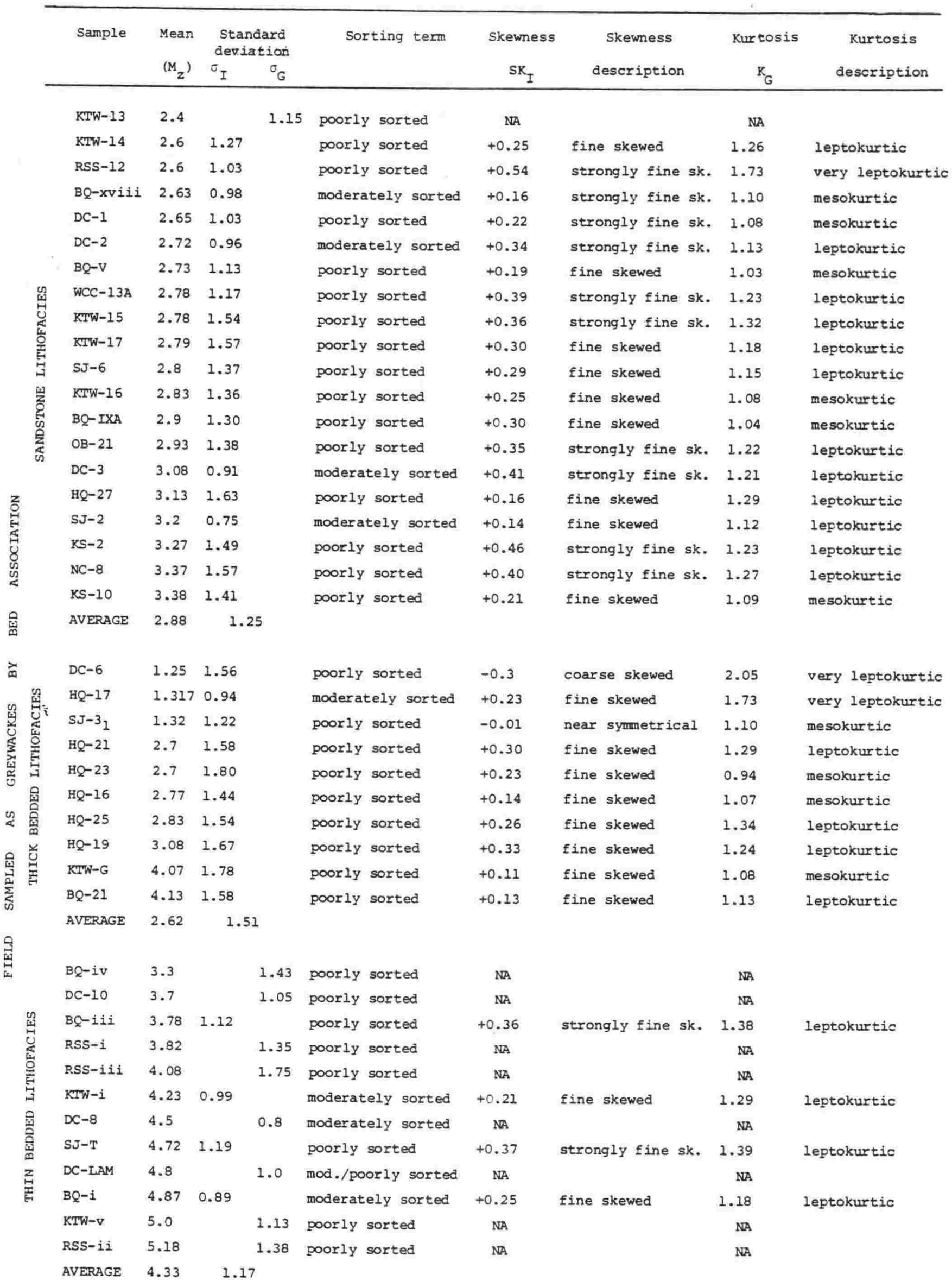


Table 2.8 : (continued)

\begin{tabular}{|c|c|c|c|c|c|c|c|c|c|}
\hline & \multirow[t]{2}{*}{ Sample } & \multirow{2}{*}{$\begin{array}{l}\text { Mean } \\
\left(M_{z}\right) \\
\end{array}$} & \multicolumn{2}{|c|}{$\begin{array}{r}\text { Standard } \\
\text { deviation }\end{array}$} & \multirow[t]{2}{*}{ Sorting term } & \multirow{2}{*}{$\begin{array}{l}\text { Skewress } \\
\mathrm{SK}_{\mathrm{I}}\end{array}$} & \multirow{2}{*}{$\begin{array}{c}\text { Skewness } \\
\text { description }\end{array}$} & \multirow{2}{*}{$\begin{array}{c}\text { Kurtosis } \\
\mathrm{K}_{G}\end{array}$} & \multirow{2}{*}{$\begin{array}{l}\text { Kurtosis } \\
\text { description }\end{array}$} \\
\hline & & & $\sigma_{I}$ & ${ }^{\sigma} G$ & & & & & \\
\hline \multirow{11}{*}{ 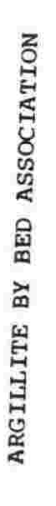 } & HQ -26 & 5.4 & & 1.03 & poorly sorted & & & & \\
\hline & NC-15 & 5.49 & & 1.13 & poorly sorted & & & & \\
\hline & HQ-24 & 5.58 & & 0.95 & moderately sorted & & & & \\
\hline & $O B-w$ & 5.6 & & 1.15 & poorly sorted & & & & \\
\hline & HO-2O & 5.87 & & 1.05 & poorly sorted & & & & \\
\hline & WCC-8A & 5.87 & & 1.05 & poorly sorted & & & & \\
\hline & WCC- $5 A$ & 5.9 & & 1.25 & poorly sorted & & & & \\
\hline & HQ-18 & 5.95 & & 1.18 & poorly sorted & & & & \\
\hline & BQ-vii & 6.18 & & 1.38 & poorly sorted & & & & \\
\hline & но-22 & 6.28 & & 1.23 & poorly sorted & & & & \\
\hline & $O B-13$ & 6.39 & & 0.99 & moderately sorted & & & & \\
\hline
\end{tabular}


significantly than larger grains, due to their larger surface area to volume ratios (section 2.14.3). In grain size populations less than, say, $0.02 \mathrm{~mm}$ recrystallisation due to diagenesis has probably meant that rocks have some mineral types enhanced in grain size (chlorite and white mica) relative to the grain population at deposition.

The effect of this is to increase positive skewness (reduce sorting) in greywackes and to perhaps enhance sorting and even mean grain size in argillites.

It is doubtful whether the most marked grain size changes in the population finer than $0.02 \mathrm{~mm}$ will have influenced textural distinctions - greywackes are still comparable one with another and argillites are of little help in discriminating lithofacies association.

\subsection{The relationship of mineralogy to texture}

In the course of the microscope work it became apparent that the mineralogy of the greywacke-suite rocks was related to texture and, in particular, mean grain size. This section examines that relationship, by plotting the main mineral modes against mean grain size (Figure 2.19).

The proportion of felsic grains remains more or less constant between 50 and 70 percent over the range 1 to $4 \mathrm{phi}(0.5$ to $0.063 \mathrm{~mm}$ ), but declines markedly from 5 to 6 phi $(0.03$ to $0.015 \mathrm{~mm})$ with a corresponding increase in phyllosilicates; rock fragments also decline dramatically at about 5 phi ( $0.03 \mathrm{~mm})$. While limitations of microscopic resolution can not be overlooked, there appears to be a mineralogical trend towards a higher proportion of phyllosilicates, which in these rocks are chlorite and white mica. These minerals appear, on average, to maintain similar proportion (Figure 2.20).

\section{$2.14 \quad x$-ray diffractometry}

$\mathrm{X}$-ray diffractometry (XRD) was used to establish the bulk mineralogy of the rocks as they occur in the field today and as a means of determining variations in metamorphic grade by assessing the crystallinity of white mica, particularly in the argillites. 


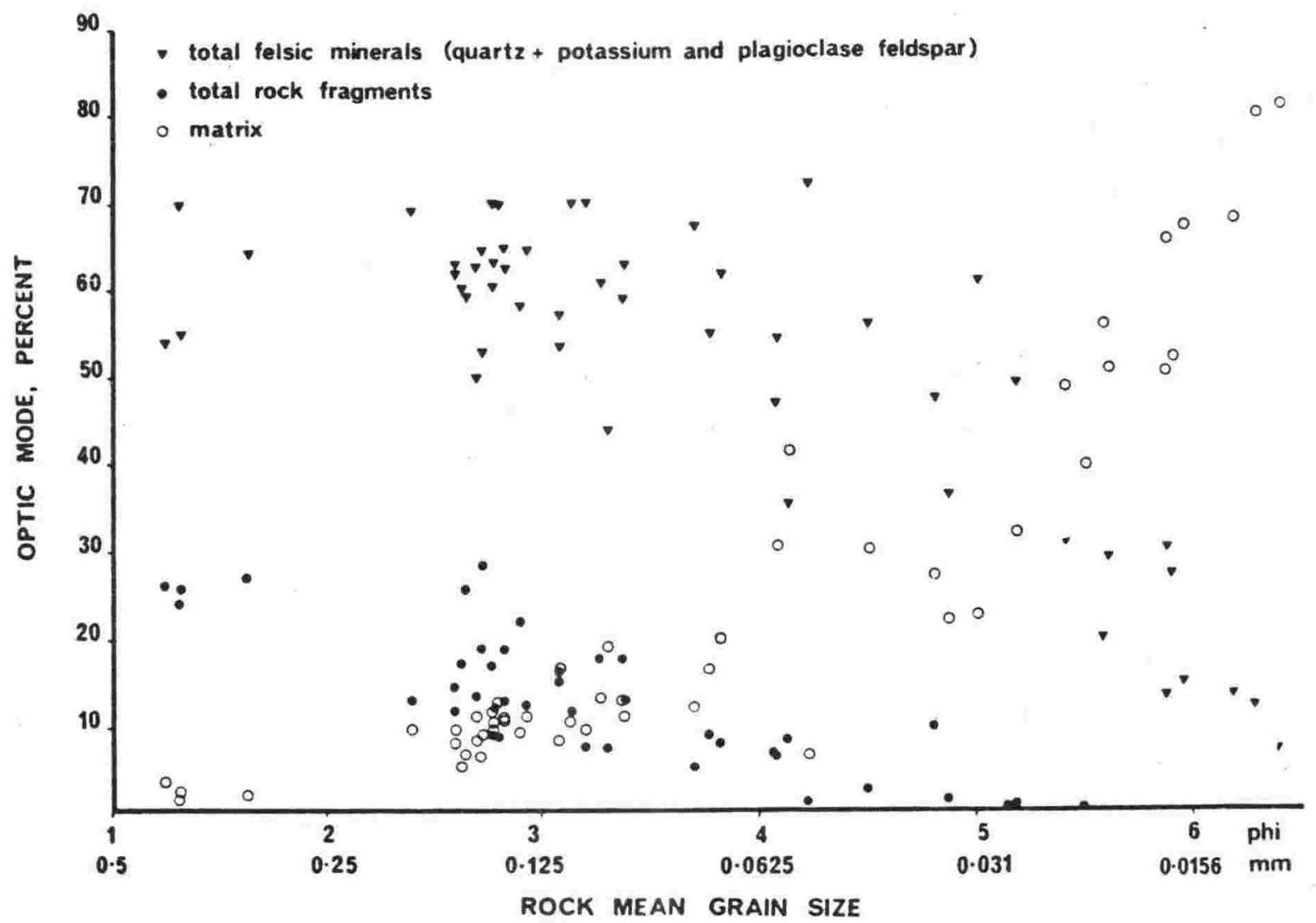

Figure 2.19 : Optically determined mineral modes show dramatic response to rock mean grain size. Note crossover at 5 phi, where matrix and felsic components are subequal and rock fragments assume negligible importance. cf. Figures 2.20 and 2.21 . 


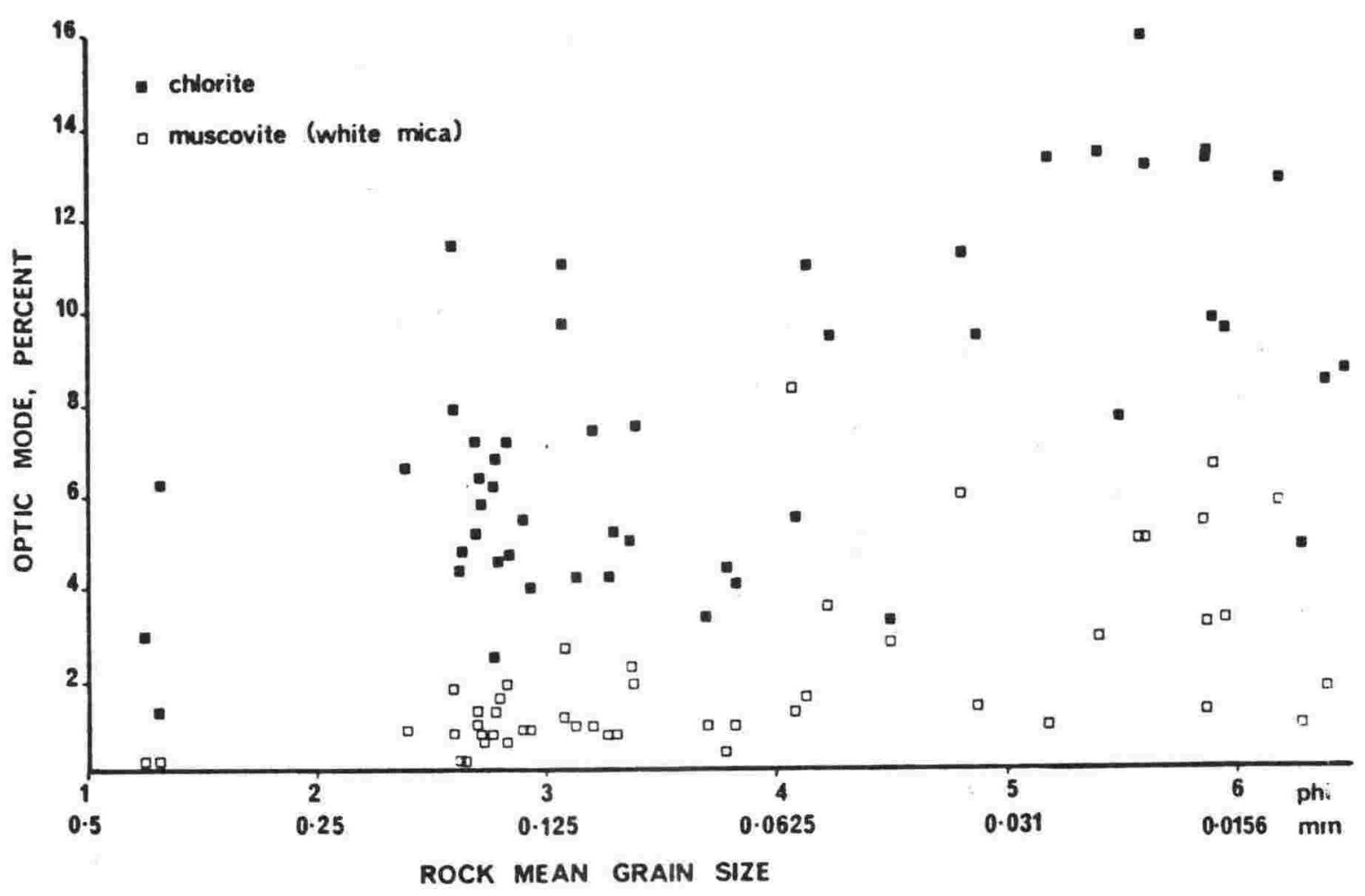

Figure 2.20 : Superior chlorite modes (optically determined), compared with white mica, exist throughout Wellington

greywacke-suite rocks. Chlorite increases in approximately constant ratio with muscovite with reduced rock mean grain size. cf. Figure 2.21 . 
This investigation was undertaken on an assumption that the physical properties of rock would be influenced by degrees of metamorphic change undetectable by any other means. Such properties as strength, hardness, and resistance to weathering, all important in engineering use, improve with higher degrees of metamorphism.

Whole rock samples were prepared, by crushing, in two ways:

(i) By using a hand operated agate pestle and mortar to powder the sample.

(ii) By using a tungsten carbide "Tema" swing mill.

A vibrating stylus was used to obtain material to establish the mineralogy of veins and surface coatings. For whole rock analyses, samples were selected free of veins, shears, slickensides and surface coatings to avoid enhancing certain mineral modes and to minimise effects of differing mineral crystallinity, strain, polytypism etc.

\subsubsection{Whole rock quantitative analysis}

An internal standard method of quantitative diffractometry was used (Klug and Alexander, 1974), see Appendix 6. Samples were prepared and run by Mr B. Yardley. After grinding sample powder and internal standard (LiF), a disoriented (back filled) powder mount was analysed using a Siemens (X-ray diffractometer, with nickel filtered CuK $\alpha$-radiation generated from $35 \mathrm{kV}$ at $20 \mathrm{~mA}$ and directed by a $1^{\circ}$ beam slit and a $0.2^{\circ}$ detection slit. Samples were scanned at $12 \theta /$ minute from $4^{\circ}$ to $40^{\circ} 2^{\theta}$. Chart speed and flow counter count rate settings were adjusted for optimum results. Time constant (seconds) was adjusted with scanning speed (degrees/minutes) so that the product of the settings was 1 or 2 (Schoen, 1962) at which values peak distortion is small (Parrish, 1960).

Diffractograms of known minerals and the ASTM Powder Data File were used to interpret results. Accurate d-spacings were obtained by reference to detrital quartz in the samples. Results should be accurate to \pm 3 percent (Appendix 6).

XRD indicated a higher white mica content than optical petrography had revealed. Presumably this resulted from altering feldspar and rock fragments 
or possibly the masking of white mica by chlorite during optical examination.

Results (Table 2.9) also show the content range of minerals to be greatest for plagioclase (15 percent) with white mica (11 percent) and chlorite least

(5 percent).

Composition determined by XRD indicates that felsics constitute at least 80 percent of any greywacke-suite rock, whereas composition determined optically Show a maximum of 70 percent. Quartz content is also inalcated to be higher by XRD than by optical means, almost doubled in greywackes and by at least 10 percent in argillites counted without a matrix category (Table 2,6B). Optical quantification of argillite matrix showed white mica not to exceed 10 percent and its ratio to chlorite to be less than 1 (Table 2.6C), but even this 1 S in doubt as XRO ald net conflinm the strong dominance of enlonite However trends of mineralogy with mean grain sizelto those established optically in section 2.13 are confimed (Figure 2.21 ).

\subsubsection{Semi-quantitative analysis of the whole rock fraction finer than $0.015 \mathrm{~mm}$.}

Diffractograms, similar whether sample powder was prepared by hand or "Tema" mill, indicated fresh greywacke and argillite to include only four main minerals; quartz, sodic plagioclase, white mica and chlorite. Of these minerals, white mica and chlorite are the most important from an engineering viewpoint since they may induce plasticity in rock fines, are soft, assume preferred orientation, are structurally weak, constitute most of the matrix material, and chlorite is chemically unstable.

Further investigation of these phyllosilicates was necessary because diagnostic peaks of both minerals at low $2 \theta$ angles mask peaks of clay minerals such as kaolinite, vermiculite, illite and chlorite mixed-layer minerals with expanding lattices, e.g. chlorite - montmorillonite, which are of importance for engineering purposes.

As phyllosilicates and clay minerals generally, have much finer natural size ranges than other detrital minerals, separation of finer materials from the powdered samples was necessary. A separation of clay minerals including phyllosilicates was required for XRD detection (Table 2.10). All methods of sample preparation were aimed at providing a well oriented, fine grained 
Table 2.9 : Quantitative XRD modes for whole rock powders, arranged in order of diminishing mean grain size. Results should be accurate \pm 3 percent (Appendix 6).

\begin{tabular}{lllllll}
\hline Sample & $\begin{array}{c}M_{z} \\
\text { phi }\end{array}$ & Run & Quartz & Plagioclase & $\begin{array}{c}\text { White } \\
\text { Mica }\end{array}$ & Chlorite Totals \\
\hline
\end{tabular}

\begin{tabular}{|c|c|c|c|c|c|c|c|}
\hline $\mathrm{HQ}-17$ & 1.317 & $\begin{array}{l}\text { avge. } 3 \\
\text { runs } \%\end{array}$ & 48 & 45 & 4 & 4 & 101 \\
\hline \multirow{4}{*}{ RSS-12 } & 2.6 & 1 & 41 & 52 & 1 & 5 & 99 \\
\hline & & 2 & 42 & 53 & 0 & 5 & 100 \\
\hline & & 3 & 44 & 51 & 0 & 5 & 100 \\
\hline & & avge. \% & 42 & 52 & $<1$ & 5 & 99 \\
\hline \multirow[t]{4}{*}{$\mathrm{NC}-8$} & 3.37 & 1 & 40 & 49 & 0 & 11 & 100 \\
\hline & & 2 & 41 & 52 & 0 & 7 & 100 \\
\hline & & 3 & 44 & 49 & 0 & 7 & 100 \\
\hline & & avge. \& & 42 & 50 & 0 & 8 & 100 \\
\hline \multirow[t]{4}{*}{$\mathrm{KS}-10$} & 3.38 & 1 & 44 & 50 & 0 & 6 & 100 \\
\hline & & 2 & 35 & 59 & 2 & 4 & 100 \\
\hline & & 3 & 42 & 50 & 2 & 5 & 99 \\
\hline & & avge. $\%$ & 40 & 53 & 2 & 5 & 100 \\
\hline \multirow[t]{4}{*}{ BQ -21} & 4.13 & 1 & 47 & 40 & 6 & 7 & 100 \\
\hline & & 2 & 42 & 45 & 7 & 6 & 100 \\
\hline & & 3 & 47 & 38 & 9 & 6 & 100 \\
\hline & & avge. $\%$ & 45 & 41 & 7 & 6 & 99 \\
\hline \multirow[t]{4}{*}{ KTW-V } & 5.0 & 1 & 45 & 42 & 6 & 7 & 100 \\
\hline & & 2 & 42 & 50 & 4 & 5 & 101 \\
\hline & & 3 & 38 & 52 & 3 & 7 & 100 \\
\hline & & avge. \% & 42 & 48 & 4 & 6 & 100 \\
\hline \multirow[t]{4}{*}{$\mathrm{NC}-15$} & 5.49 & 1 & 38 & 52 & 5 & 5 & 100 \\
\hline & & 2 & 44 & 47 & 5 & 5 & 101 \\
\hline & & 3 & 42 & 48 & 3 & 6 & 99 \\
\hline & & avge. $\frac{\circ}{8}$ & 41 & 49 & 4 & 5 & 99 \\
\hline \multirow[t]{4}{*}{$W C C-8 A$} & 5.87 & 1 & 38 & 44 & 7 & 11 & 100 \\
\hline & & 2 & 35 & 48 & 9 & 8 & 100 \\
\hline & & 3 & 39 & 47 & 8 & 7 & 101 \\
\hline & & avge. \% & 37 & 46 & 8 & 9 & 100 \\
\hline \multirow[t]{4}{*}{$\mathrm{HQ}-22$} & 6.28 & 1 & 49 & 37 & 8 & 6 & 100 \\
\hline & & 2 & 41. & 38 & 11 & 11 & 101 \\
\hline & & 3 & 38 & 40 & 13 & 8 & 99 \\
\hline & & avge. \% & 43 & 38 & 11 & 8 & 100 \\
\hline
\end{tabular}




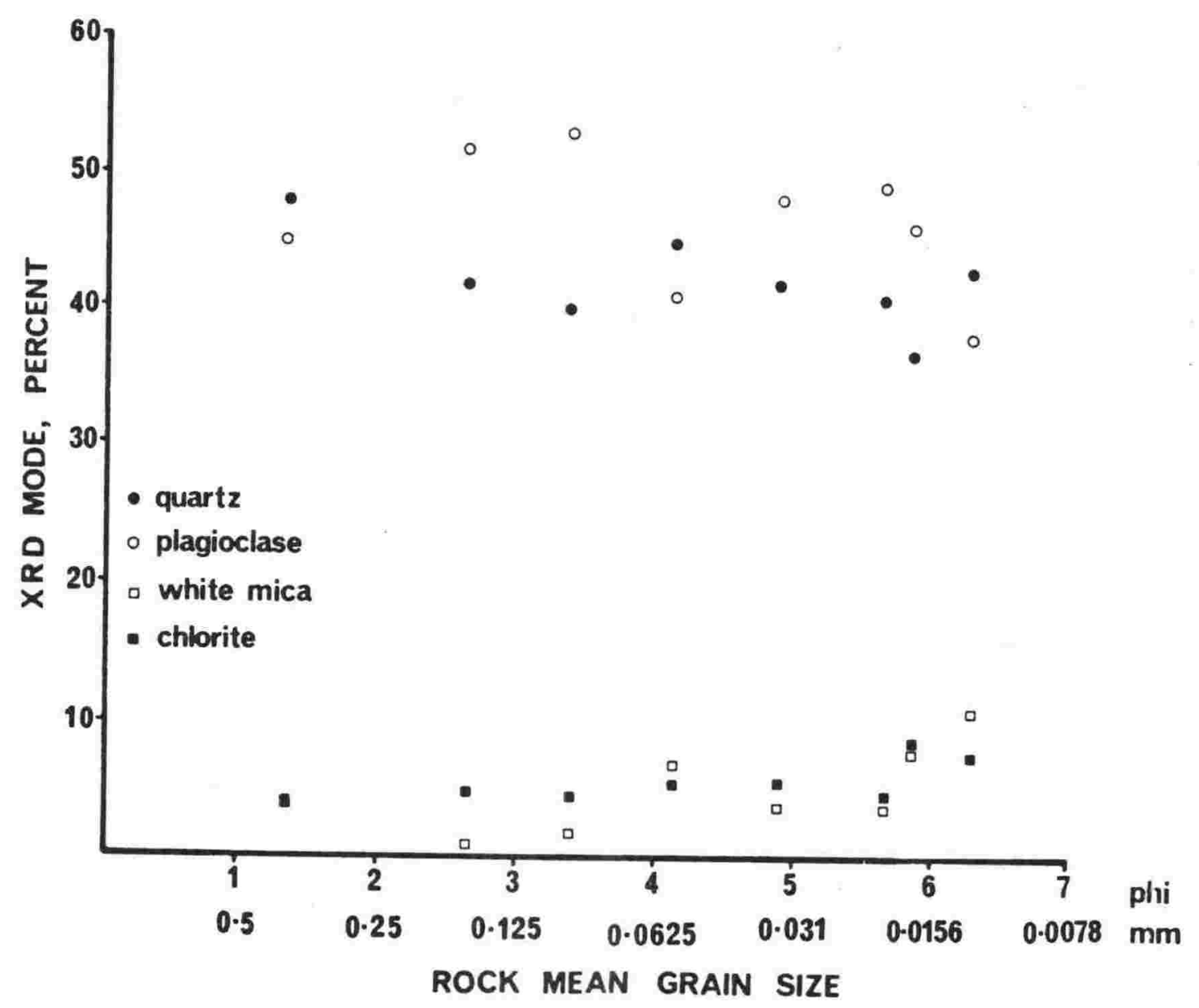

Figure 2.21 : Relationship between mineral proportions from XRD analysis and rock mean grain size for some

Wellington greywacke-suite rocks. The trends are similar to those found from optical petrography (Figure 2.19). 
Table 2.10 : Quantitative resolution by X-ray diffraction of clay minerals and certain others in the clay fraction ( $<2$ microns) of sedimentary materials (Cu $\mathrm{Ka}$; $50 \mathrm{kV}, 20 \mathrm{~mA}, 1^{\circ}$ scatter slit, $006 "$ receiving slit, $10^{3} \mathrm{cps} .$, multiplier 1 , ratemeter 4 ; oriented mount on tile). $I^{\circ} 2 \theta$ per minute; chart speed $0.5^{\prime \prime}$ per minute. (after Carroll, 1970).

\begin{tabular}{|c|c|c|c|}
\hline Mineral & $\begin{array}{l}\text { Lowest } \\
\text { percentage } \\
\text { identifiable }\end{array}$ & $\begin{array}{l}\text { Principal d } \\
\text { spacing used } \\
\text { for } \\
\text { identification }\end{array}$ & $\begin{array}{l}2 \theta^{\circ} \\
\text { (approx.) }\end{array}$ \\
\hline Kaolinite & 5 & $7.13-7.16$ & $12.36-12.4$ \\
\hline Kaolinite, disordered & $1-5$ & 7.15 & 12.38 \\
\hline Halloysite, $4 \mathrm{H}_{2} \mathrm{O}$ & 10 & 10.1 & 8.75 \\
\hline Halloysite, $2 \mathrm{H}_{2} \mathrm{O}$ & 10 & 7.21 & 12.26 \\
\hline Mica, $2 \mathrm{M}_{1}$ & 1 & $9.99-10.4$ & $8.85-8.80$ \\
\hline $\begin{array}{l}\text { Illite, mixed layer lb mica } \\
\text { polytype }\end{array}$ & 5 & 10.16 & 8.70 \\
\hline Biotite & 1 & 10.1 & 8.77 \\
\hline Vermiculite & 5 & 14.2 & 6.22 \\
\hline $\begin{array}{l}\text { Smectite group, } \\
\text { (montmorillonite) }\end{array}$ & 10 & 15.4 (variable) & 5.7 \\
\hline Chlorite, Mg & 1 & $14.1-14.2$ & $6.27-6.22$ \\
\hline Chlorite, $\mathrm{Fe}$ & 10 & $14.1-14.2$ & $6.27-6.22$ \\
\hline Quartz & 1 & 3.34 & 26.66 \\
\hline Orthoclase feldspar & 5 & $3.25-3.28$ & $27.4-27.16$ \\
\hline Plagioclase feldspar & 5 & $3.17-3.18$ & $28.14-28.0$ \\
\hline Calcite & 5 & 3.08 & 29.47 \\
\hline
\end{tabular}


sample over a large area of the glass slide, mounted so that basal d-spacings of minerals at low $2 \theta$ angles would give enhanced diffractogram peak heights i.e. maximum intensities. Best results were obtained from "Tema" ground whole rock samples separated by settling through water (Sameshima 1977). From nomographs of particle settling times through water (Tanner and Jackson, 1948) the resultant oriented material was less than $0.015 \mathrm{~mm}$ in size, entirely covering the slide (necessary for low angle diffractometry, soong, pers. comm.), with a uniform layer 0.015 to $0.03 \mathrm{~mm}$ thick (Schoen, 1962).

Diffractograms of these fine fractions were used to obtain semi-quantitative data, by utilising peak heights above background to establish relative peak intensities (Moore, 1968) at $28^{\circ} 2 \theta, 26.8^{\circ} 2 \theta, 12.5^{\circ} 2 \theta$ and $8.8^{\circ} 2 \theta$, representing quartz, K-feldspar, plagioclase, chlorite and sericite respectively. Adjustments were calculated directly from intensity values, some of the usual uncertainties of clay phyllosilicate semi-quantitative analysis from XRD, being reduced by the nature of chlorite and sericite - they are not as variable in behaviour as other clay minerals (Soong, pers. comm.).

Relative abundancies of all five minerals are shown (Table 2.11) though quartz and feldspar relative abundancies are important only for rocks finer than, say, 5 phi $(0.031 \mathrm{~mm})$. The results confirm the optic modal data on chlorite content over the range in rock mean grain size represented. Sericite, too, shows increase with reduced mean grain size, but in a more linear fashion and in direct antipathy with plagioclase. The reduction in K-feldspar parallels the trend for this mineral established by optical means. Quartz shows a scattered trend, averaging about 40 percent for any mean grain size. This may reflect a more perfect crystalline habit of what must be mostly detrital quartz, or more reasonably, indicates quartz to occupy larger size fractions in coarser rocks and to be more easily removed during sample preparation.

The fine mineral separates agree extremely well with the relative order of abundance of argillite matrix contents (determined optically) except the relative dominance of chlorite over quarta the two most abunaht matrix components in argillte. WRD data are probably mefledting absorption characteristics of mostly authigenic ch1orite and better crystallinity of detrital quartz. 
Table 2.11 : Relative abundancies of main minerals, determined from diffractogram peak height intensities of minus $0.015 \mathrm{~mm}$ whole rock oriented, sedimented samples.

\begin{tabular}{|c|c|c|c|c|c|c|c|c|c|c|c|c|c|c|}
\hline \multirow[b]{2}{*}{ 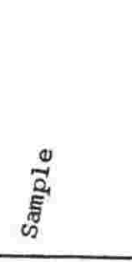 } & \multirow[b]{2}{*}{$\frac{7}{2}$} & \multicolumn{5}{|c|}{$\begin{array}{l}\text { Relative diffractogram } \\
\text { Peak heights }\end{array}$} & \multirow{2}{*}{$\begin{array}{c}\text { peak } \\
\text { height } \\
\text { क } \\
\text { क }\end{array}$} & \multicolumn{5}{|c|}{$\begin{array}{l}\text { Recalculated peak heights, } \\
\text { percent }\end{array}$} & \multirow[b]{2}{*}{ 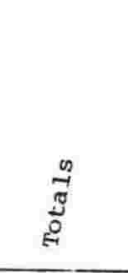 } & \multirow[b]{2}{*}{ 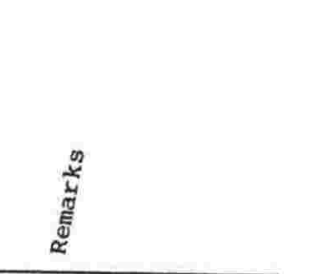 } \\
\hline & & 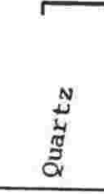 & $\begin{array}{c}0 \\
0 \\
0 \\
0 \\
0 \\
0 \\
0 \\
0 \\
-10 \\
-1 \\
\end{array}$ & 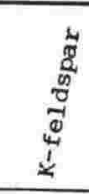 & 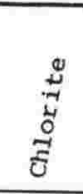 & 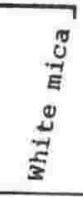 & & 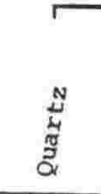 & 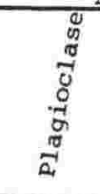 & 竞 & 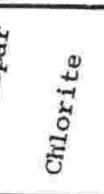 & 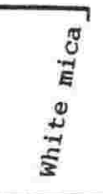 & & \\
\hline$D C-6$ & 1.25 & 10.8 & 4.1 & 2.1 & 4.2 & 2.9 & 24.1 & 44.8 & 17.0 & 8.7 & 17.4 & 12.0 & 99.9 & \\
\hline $\mathrm{HQ}-17$ & 1.317 & 14.6 & 12.0 & 4.2 & 4.3 & 3.2 & 38.3 & 38.1 & 31.3 & 11.0 & 11.2 & 8.4 & 100.0 & Laumontite also \\
\hline $\mathrm{sJ}-3_{1}$ & 1.32 & 6.0 & 3.2 & 1.5 & 8.2 & 3.3 & 22.2 & 27.0 & 14.4 & 6.8 & 36.9 & 14.9 & 100.0 & \\
\hline KIW-13 & 2.4 & 12.8 & 8.8 & 3.4 & 5.5 & 2.8 & 33.3 & 38.4 & 26.4 & 10.2 & 16.5 & 8.5 & 100.0 & \\
\hline $\mathrm{HQ}-21$ & 2.7 & 11.1 & 7.8 & 4.2 & 6.4 & 3.9 & 33.4 & 33.2 & 23.4 & 12.6 & 19.2 & 11.7 & 100.1 & expanding $14 \AA$ peak? \\
\hline$B Q-V$ & 2.73 & 10.1 & 4.7 & 2.0 & 6.2 & 3.1 & 26.1 & 38.7 & 18.0 & 7.7 & 23.8 & 11.9 & 100.1 & \\
\hline BQ-IXA & 2.9 & 10.9 & 4.8 & 2.5 & 5.5 & 3.4 & 27.1 & 40.2 & 17.7 & 9.2 & 20.3 & 12.6 & 100.0 & \\
\hline $\mathrm{OB}-21$ & 2.93 & 9.7 & 5.9 & 3.5 & 5.5 & 3.4 & 28.0 & 34.6 & 21.1 & 12.5 & 19.6 & 12.1 & 99.9 & \\
\hline $\mathrm{HQ}-19$ & 3.08 & 12.8 & 6.4 & 3.3 & 6.1 & 3.5 & 32.1 & 39.9 & 19.9 & 10.3 & 19.0 & 10.9 & 100.0 & \\
\hline KS-2 & 3.27 & 8.2 & 3.3 & 2.3 & 3.8 & 2.1 & 19.7 & 41.6 & 16.8 & 11.7 & 19.3 & 10.7 & 100.1 & expanding $14 \AA$ peak? \\
\hline BQ-iii & 3.78 & 11.8 & 6.2 & 2.2 & 4.4 & 4.0 & 28.6 & 41.3 & 21.7 & 7.7 & 15.4 & 14.0 & 100.1 & calcite also \\
\hline KTW-G & 4.07 & 7.4 & 3.7 & 2.0 & 4.5 & 5.2 & 22.8 & 32.5 & 16.2 & 8.8 & 19.7 & 22.8 & 100.0 & \\
\hline RSS-iii & 4.08 & 8.6 & 4.2 & 2.1 & 6.1 & 4.0 & 25.0 & 34.4 & 16.8 & 8.4 & 24.4 & 16.0 & 100.0 & \\
\hline$B Q-21$ & 4.13 & 9.2 & 3.0 & 1.5 & 4.0 & 3.0 & 20.7 & 44.4 & 14.5 & 7.3 & 19.3 & 14.5 & 100.0 & very ragged feldspar peak \\
\hline $\mathrm{KTW}-\mathrm{i}$ & 4.23 & 10.0 & 4.4 & 1.8 & 3.3 & 3.1 & 22.6 & 44.3 & 19.5 & 8.0 & 14.6 & 13.7 & 100.1 & ragged feldspar peak \\
\hline$K T W-i(R)$ & 4.23 & 9.7 & 4.3 & 2.1 & 3.1 & 2.3 & 21.5 & 45.1 & 20.0 & 9.8 & 14.4 & 10.7 & 100.0 & \\
\hline$D C-8$ & 4.5 & 13.1 & 4.4 & 2.4 & 5.2 & 2.8 & 27.9 & 47.0 & 15.8 & 8.6 & 18.6 & 10.0 & 100.0 & \\
\hline$B Q-i$ & 4.87 & 7.1 & 2.8 & 1.3 & 3.4 & 4.1 & 18.7 & 38.0 & 15.0 & 7.0 & 18.2 & 21.9 & 100.1 & calcite also \\
\hline RSS-ii & 5.18 & 5.0 & 2.7 & 1.4 & 6.5 & 4.7 & 20.3 & 24.6 & 13.3 & 6.9 & 32.0 & 23.2 & 100.0 & \\
\hline $\mathrm{HQ}-26$ & 5.4 & 7.0 & 3.0 & 1.8 & 2.6 & 2.1 & 16.5 & 42.4 & 18.2 & 10.9 & 15.8 & 12.7 & 100.0 & \\
\hline HO -24 & 5.58 & 8.8 & 1.8 & 1.2 & 4.5 & 3.3 & 19.6 & 44.9 & 9.2 & 6.1 & 23.0 & 16.8 & 100.0 & expancing $14 \AA$ peak? \\
\hline$O B-W$ & 5.6 & 11.7 & 1.9 & 1.0 & 5.4 & 5.3 & 25.3 & 46.3 & 7.5 & 4.0 & 21.3 & 21.0 & 100.1 & ragged feldspar peak \\
\hline $\mathrm{HO}-2 \mathrm{O}$ & 5.87 & 7.0 & 2.3 & tr. & 4.2 & 3.4 & 16.9 & 41.4 & 13.6 & tr. & 24.9 & 20.1 & 100.0 & ragged feldspar peak \\
\hline $\mathrm{HQ}-18$ & 5.95 & 9.0 & 1.8 & 1.0 & 4.0 & 3.4 & 19.2 & 46.9 & 9.4 & 5.2 & 20.8 & 17.7 & 100.0 & ragged feldspar peak \\
\hline BQ-vii & 6.18 & 9.5 & 2.2 & 1.3 & 6.5 & 6.0 & 25.5 & 37.3 & 8.6 & 5.1 & 25.5 & 23.5 & 100.0 & expanding $14 \AA$ peak? \\
\hline не- 22 & 6.28 & 19.4 & 4.6 & 3.2 & 9.5 & 7.9 & 44.6 & 43.5 & .10 .3 & 7.2 & 21.3 & 17.7 & 100.0 & expanding $14 \AA$ peak? \\
\hline OB-13 & 6.39 & 6.0 & 1.4 & tr. & 3.9 & 4.5 & 15.8 & 38.0 & 8.9 & $\operatorname{tr}$. & 24.7 & 28.5 & 100.1 & \\
\hline
\end{tabular}


From Figure 2.22 it may be concluded that orthoclase has a relatively smaller grain size population than plagioclase, in greywackes finer than about 4 phi $(0.0625 \mathrm{~mm})$ mean grain size. It is unlikely that the relatively low plagioclase to $\mathrm{K}$-feldspar ratios, seen in Figure 2.22 in rocks of finer mean grain size, have been induced by comminution of the larger K-feldspar grains (later discussed in section 2.34.3). The altered condition of finer plagioclase could enhance this trend.

A full discussion of mineral characteristics from XRD data has been provided by McKean (1976).

\subsubsection{Degree of phyllosilicate crystallinity}

Weaver (1960) showed that crystal ordering in phyllosilicate minerals increases with diagenesis and metamorphism. Burst (1959) studied the trend in chlorite in the Eocene of Texas and Flawn et al. (1961) incorporated Weavers work to quantify crystallinity of illite and relate it to metamorphism established by microscope study of slabs from the Ouachita Mountains, Texas, as follows

$\begin{array}{lc}\text { Degree of metamorphism } & \text { Sharpness ratio } \\ \text { Low-grade } & 12.1 \\ \text { Weak to very weak } & 6.3 \\ \text { Incipient to weak } & 4.5 \\ \text { Incipient } & 2.3 \\ \text { Unmetamorphosed Stanley } & 2.3 \\ \text { Unmetamorphosed Atoka } & 1.8\end{array}$

The most abundant references are for illite (Kubler, 1967). The crystallinity of illite or mica polymorphs increases almost universally with temperature and pressure. A "muscovite" with relatively small d-spacing is easier to study in this regard than chlorite as possible variations are less numerous and better known than in the chlorite group and white micas occur more frequently in sedimentary rocks than chlorite. Consequently, most studies of subtle diagenetic/metamorphic change in sediments have utilised the crystallinity of white mica polymorphs, usually illite, since it undergoes greater morphologic changes with temperature/pressure difference than other white mica types. 


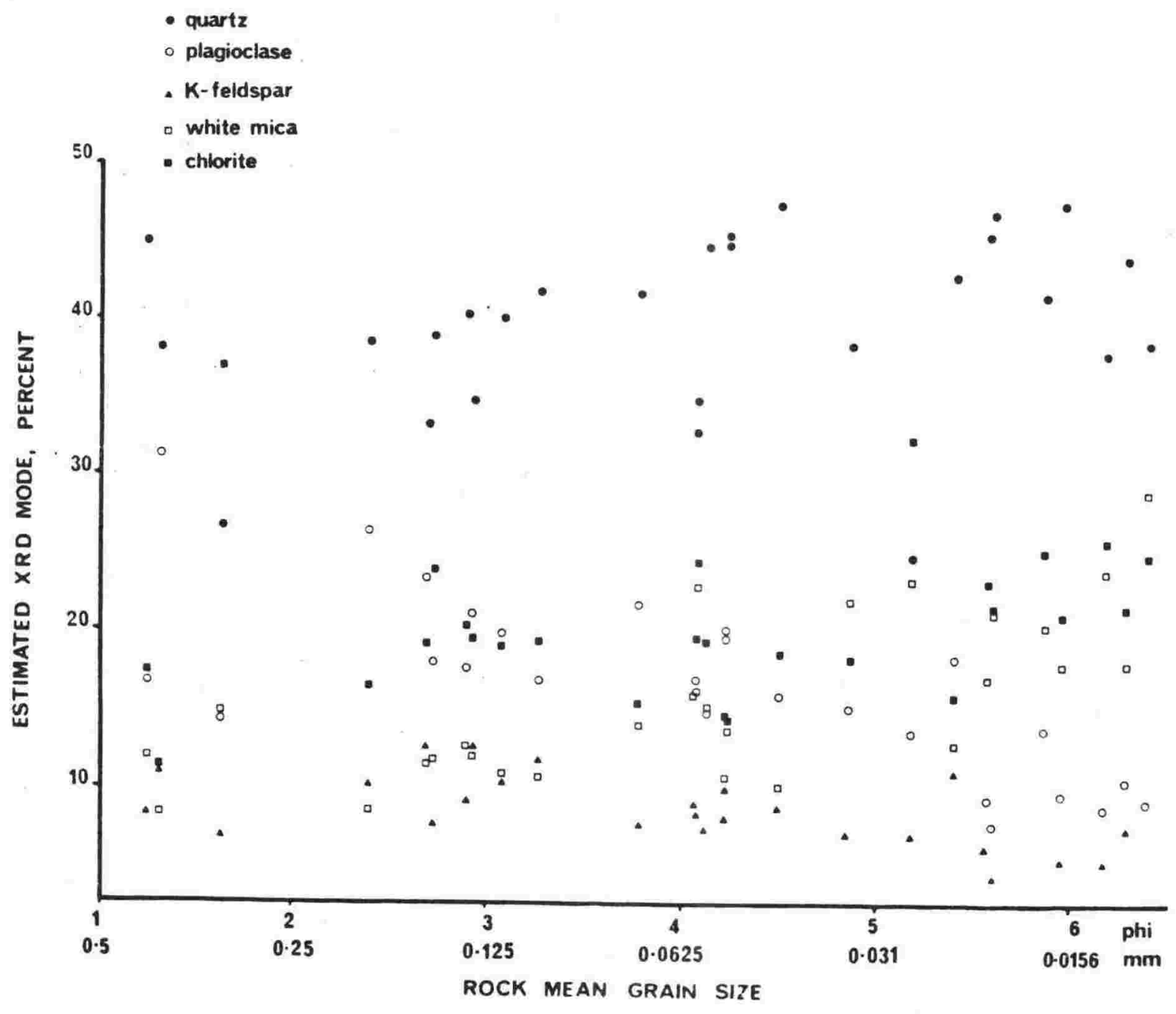

Figure 2.22 : Relationship of mineral abundance, from whole rock powder fractions finer than $0.015 \mathrm{~mm}$, with rock mean grain size. The trend reflects modal analyses obtained by quantitative XRD and optical determination. cf. Figures 2.19 and 2.21 . 
For this study the sharpness ratio method of Weaver (1960) was employed using the $10 \AA\left(8.8^{\circ} 2 \theta\right)$ diffractogram peak of oriented serictite in the less than $0.015 \mathrm{~mm}$ size whole rock fraction. Since peak intensities are related to both grain size (Carroll, 1970), and crystallite size (Rau, 1963) sampling rock mineral separates of very small grain size may cause a loss in resolution.

Generally, well developed (well crystallised) phyllosilicates afford stronger, more intense $\mathrm{X}$-ray reflections than poorly crystalline ones.

To determine the relative sharpness of the $10 \AA$ peak measurement was made from the baseline of the peak vertically to its tip and from the baseline of the peak to the point where a $10.5 \AA$ vertical line intersected the side of the peak. The ratio of these two measurements give a measure of the relative sharpness of the $10 \AA$ peak (Figure 2.23). As the shape of the $10 \AA$ peak is comparatively similar, it is not necessary to measure values for both sides of the peak and calculate a Kurtosis value.

Kubler (1967) recommended a change in the method of Weaver (1960) i.e. that a single measurement be made of peak width at a point half way up the $10 \AA$ peak. This is the method Rau (1963) adopts for measuring crystallite size. However, Weaver's method was used in this study as Kubler's method ignores peak asymetry which is a crystallinity indicator (Carroll, 1970).

As a check, Kubler's method was used to measure the $7 \AA\left(12.5^{\circ} 2 \theta\right)$ chlorite peak for the reasons below:

(i) This was the most intense peak in the low angle $2 \theta$ range making it easier to measure.

(ii) Chlorite crystallinity changes with diagenetic/metamorphic grade in the same manner as white mica.

(iii) The $7 \AA$ peak was more symmetrical than the $10 \AA$ peak.

(iv) For a restricted particle size range (effectively a maximum of about $0,025 \mathrm{~mm}$ ) width at half-peak height should be a reasonable indicator of crystallinity.

(v) The $7 \AA$ peak is purely a chlorite reflection. 


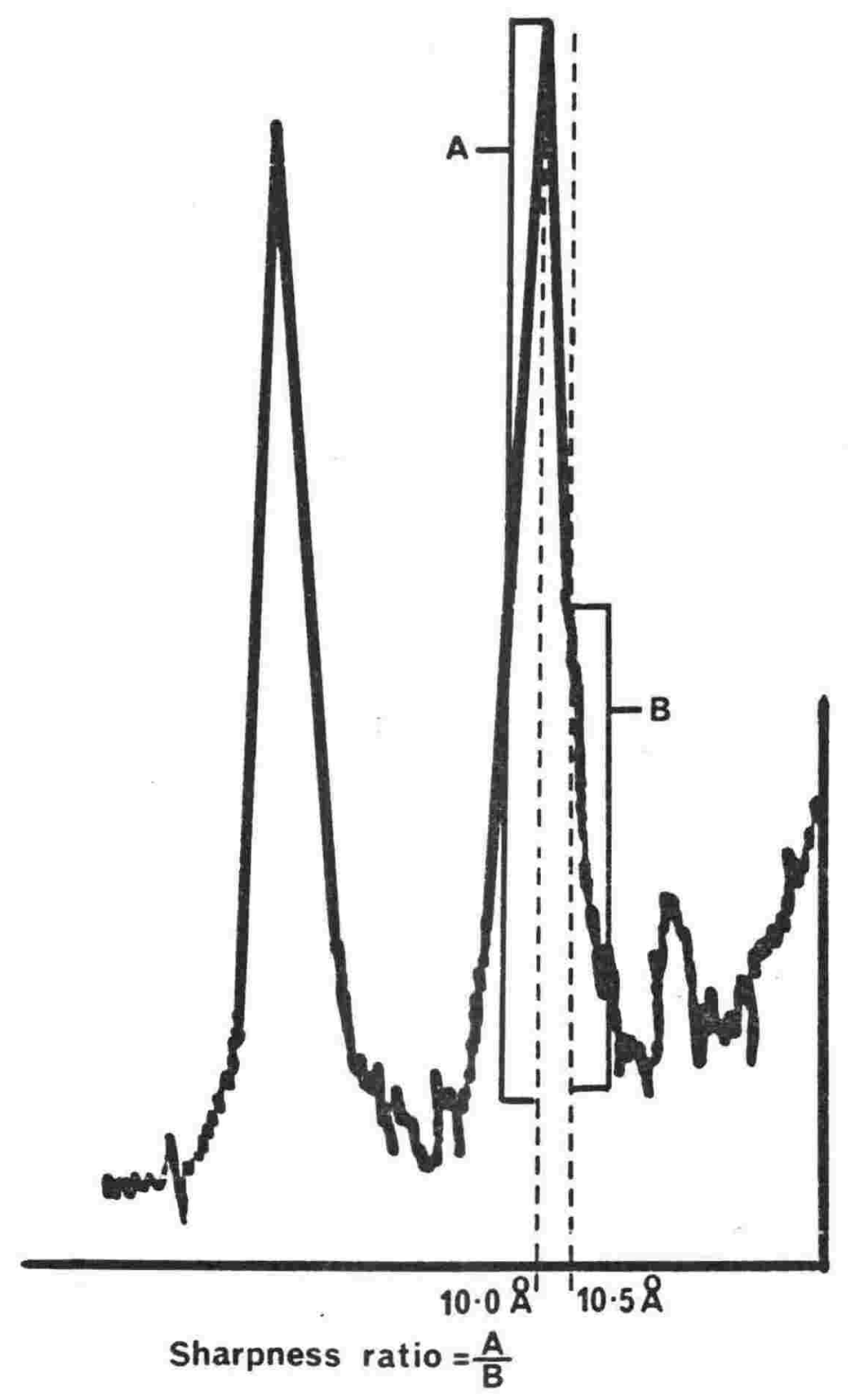

Figure 2.23 : Part of an X-ray diffractogram showing how relative sharpness of the $10 \AA$ illite peak is measured (after Weaver, 1960). 
The results (Tables $2.12,2.13$ Figures $2.24,2.25$ ) show the same trend for the two minerals measured by different means,i.e. the crystallinity of phyllosilicates in the finer than $0.015 \mathrm{~mm}$ (less than 7 phi) fraction is lower in rocks of smaller mean grain size.

To check both methods, five additional diffractograms were made from material settled to provide oriented slides of phyllosilicates with grain sizes of less than $1.5 \mu \mathrm{m}$ (less than $9.5 \mathrm{phi}$ ). The trend towards decreased crystallinity with reduced rock mean grain size is even more evident (Figure 2.24, 2.25).

The trend observed is not as might be expected nor is it apparent from a casual visual assessment of the diffractograms (Figure 2.26). It can be argued that rocks with reduced mean grain size have increased internal surface areas, of benefit to diagenetic/metamorphic reactions, bringing argillaceous rock to metamorphic equilibrium relatively quickly and more completely than coarser grained greywackes.

The trends shown could indicate a degradation of phyllosilicates within argillaceous rocks (e.g. from the strenuous action of the "Tema" mill) but several

1ikes of evidence suggest that differences between nocks ardireat and not due to sample preparations

(i) Mackenzie and Milne (1953) show considerable grinding (8 hours) is required to alter mica crystallinity significantly in an agate mill. Samples were ground in a "Tema" mill for only one minute.

(ii) The relative lack of introduced mineral materials in argillites may be due to reduced permeability (Bucke and Mankin, 1971) during diagenesis and metamorphism. This decrease in permeability does not allow percolation of fluids which aid the solution/deposition of minerals. These fluids are responsible for the recrystallisation of other minerals and if their passage is restricted, recrystallisation is also reduced. Then, in what were initially fine argillites, phyllosilicates may be expected to be relatively poorly developed in spite of large surface areas. 
Table 2.12 : Sharpness ratio, or peakedness, of the $10 \AA$ white mica peak measured from diffractograms by a method after Weaver (1960). Each measurement was an average of at least three sets of data from diffractograms of one slide. Those values marked (?) were not included in means. Five determinations, listed at the bottom of the table, were included as the method was not expected to operate where small peak intensities were encountered - a peak may occupy less physical space on a diffractogram than is provided between $10 \AA$ and $10.5 \AA$ points. To increase peak intensities a finer sediment (oriented) was used,i.e. $<1.5 \mathrm{~lm}$ - the five samples at base of the table.

\begin{tabular}{|c|c|c|c|c|c|}
\hline Sample & $\begin{array}{l}\mathrm{M}_{z} \\
\mathrm{phi}\end{array}$ & $\begin{array}{c}\text { Peak height } \\
\text { A }\end{array}$ & $\begin{array}{c}\text { mea surement } \\
\text { B }\end{array}$ & $\begin{array}{l}\mathrm{A}: \mathrm{B} \\
\text { ratio }\end{array}$ & $\begin{array}{c}\text { Mean } \\
A: B \text { ratio }\end{array}$ \\
\hline \multirow[t]{5}{*}{$D C-6$} & 1.25 & 40 & 6 & 6.67 & \multirow{5}{*}{4.42} \\
\hline & & 28 & 8.5 & 3.3 & \\
\hline & & 27 & 6.5 & 4.2 & \\
\hline & & 42 & 15 & 2.8 & \\
\hline & & 36 & 7 & 5.14 & \\
\hline \multirow[t]{3}{*}{$\mathrm{HQ}-17$} & 1.317 & 33 & 5 & $6.6 ?$ & \multirow{3}{*}{4.0} \\
\hline & & 72 & 16 & 4.5 & \\
\hline & & 67 & 19 & 3.5 & \\
\hline \multirow[t]{4}{*}{$\mathrm{SJ}-3_{1}$} & 1.32 & 33 & 5 & 6.6 & \multirow{4}{*}{7.38} \\
\hline & & 32 & 3 & 10.7 & \\
\hline & & 39 & 6.5 & 6.0 & \\
\hline & & 31 & 5 & 6.2 & \\
\hline \multirow[t]{4}{*}{ KTW-13 } & 2.4 & 27 & 4 & 6.8 & \multirow{4}{*}{7.4} \\
\hline & & 30 & 7 & $4.3 ?$ & \\
\hline & & 42 & 5 & 8.4 & \\
\hline & & 28 & 4 & 7.0 & \\
\hline \multirow[t]{4}{*}{$\mathrm{HQ}-21$} & 2.7 & 39 & 9.5 & 4.1 & \multirow{4}{*}{4.0} \\
\hline & & 33 & 9 & 3.7 & \\
\hline & & 36 & 9 & 4.0 & \\
\hline & & 40 & 10 & 4.0 & \\
\hline
\end{tabular}


Table 2.12 : (continued)

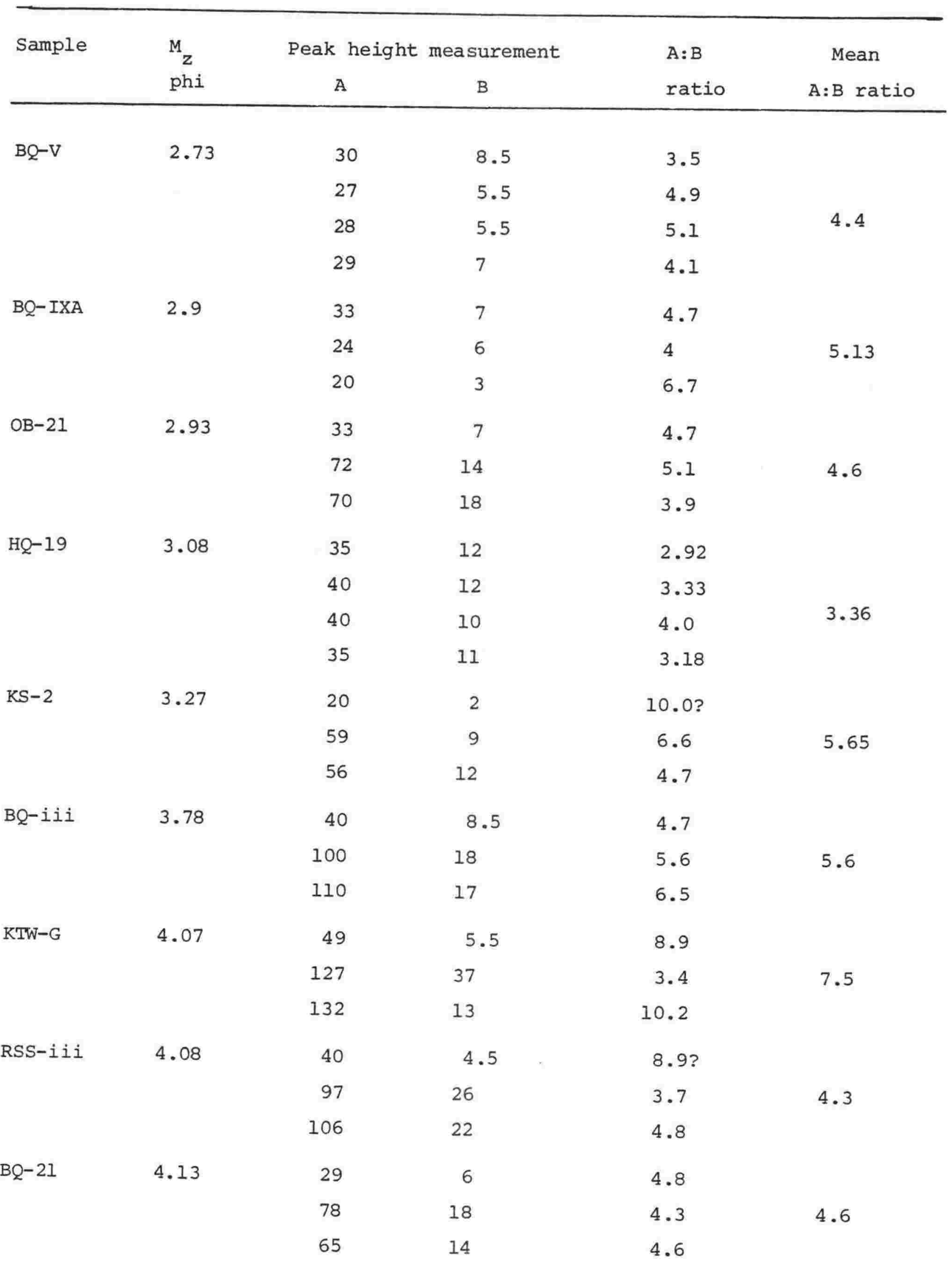


Table 2.12 : (continued)

\begin{tabular}{|c|c|c|c|c|c|}
\hline Sample & $\begin{array}{l}\mathrm{M}_{\mathrm{z}} \\
\mathrm{ph} i\end{array}$ & \multicolumn{2}{|c|}{ Peak height measurement } & $\begin{array}{l}A: B \\
\text { ratio }\end{array}$ & $\begin{array}{c}\text { Mean } \\
A: B \text { ratio }\end{array}$ \\
\hline \multirow[t]{3}{*}{ KTW-i } & 4.23 & 30 & 3 & $10.0 ?$ & \multirow{3}{*}{4.8} \\
\hline & & 73 & 15 & 4.9 & \\
\hline & & 63 & 13.5 & 4.7 & \\
\hline \multirow[t]{4}{*}{ KTW-i (R) } & 4.23 & 23 & 4 & 5.8 & \multirow{4}{*}{5.75} \\
\hline & & 22 & 3.5 & 6.3 & \\
\hline & & 27 & 4.5 & 6.0 & \\
\hline & & 22 & 4.5 & 4.9 & \\
\hline \multirow[t]{3}{*}{$D C-8$} & 4.5 & 28 & 8 & 3.5 & \multirow{3}{*}{3.6} \\
\hline & & 35 & 11 & 3.2 & \\
\hline & & 42 & 10 & 4.2 & \\
\hline \multirow[t]{3}{*}{$B Q-i$} & 4.87 & 41 & 12 & 3.4 & \multirow{3}{*}{3.2} \\
\hline & & 87 & 28 & 3.1 & \\
\hline & & 93 & 31 & 3.0 & \\
\hline \multirow[t]{3}{*}{ RSS-ii } & 5.18 & 47 & 9 & 5.2 & \multirow{3}{*}{4.6} \\
\hline & & 127 & 30 & 4.2 & \\
\hline & & 132 & 30 & 4.4 & \\
\hline \multirow[t]{3}{*}{$\mathrm{HQ}-26$} & 5.4 & 20 & 4 & 5.0 & \multirow{3}{*}{4.5} \\
\hline & & 41 & 12 & 3.4 & \\
\hline & & 67 & 13 & 5.2 & \\
\hline
\end{tabular}

$\begin{array}{lrrrrr}\text { HQ-24 } & 5.58 & 33 & 9.5 & 3.5 & \\ & 85 & 32 & 2.7 & 4.3 \\ \text { OB-W } & 86 & 26 & 3.3 & \\ & 5.6 & 52 & 14 & 3.7 & 3.0 \\ \text { HQ-20 } & 122 & 43 & 2.8 & \\ & & & 48 & 2.6 & 3.7\end{array}$


Table 2.12 : (continued)

\begin{tabular}{|c|c|c|c|c|c|}
\hline \multirow[t]{2}{*}{ Sample } & \multirow{2}{*}{$\begin{array}{l}M_{z} \\
\text { phi }\end{array}$} & \multicolumn{2}{|c|}{ Peak height measurement } & \multirow{2}{*}{$\begin{array}{l}\mathrm{A}: \mathrm{B} \\
\text { ratio }\end{array}$} & \multirow{2}{*}{$\begin{array}{c}\text { Mean } \\
\mathrm{A}: \mathrm{B} \text { ratio }\end{array}$} \\
\hline & & A & B & & \\
\hline \multirow[t]{4}{*}{ HQ-18 } & 5.95 & 34 & 12 & 2.8 & \multirow{4}{*}{3.1} \\
\hline & & 43 & 15 & 2.87 & \\
\hline & & 41 & 11 & 3.73 & \\
\hline & & 36 & 12 & 3.0 & \\
\hline \multirow[t]{3}{*}{ BQ-vii } & 6.18 & 60 & 16 & 3.75 & \multirow{3}{*}{3.9} \\
\hline & & 67 & 18 & 3.72 & \\
\hline & & 63 & 15 & 4.2 & \\
\hline \multirow[t]{3}{*}{$\mathrm{HQ}-22$} & 6.28 & 38 & 11 & 3.5 & \multirow{3}{*}{3.5} \\
\hline & & 82 & 23 & 3.6 & \\
\hline & & 79 & 24 & 3.3 & \\
\hline \multirow[t]{4}{*}{ OB-13 } & 6.39 & 44 & 9 & 4.9 & \multirow{4}{*}{4.3} \\
\hline & & 41 & 9.5 & 4.3 & \\
\hline & & 42 & 10 & 4.2 & \\
\hline & & 32 & 9 & 3.6 & \\
\hline $\mathrm{HQ}-17$ & 1.317 & 32 & 5 & 10.6 & 10.6 \\
\hline KTW-13 & 2.4 & 53 & 14 & 3.8 & 3.8 \\
\hline KS-2 & 3.27 & 40 & 6 & 6.7 & 6.7 \\
\hline DC-8 & 4.5 & 40 & 13 & 3.1 & 3.1 \\
\hline HO-22 & 6.28 & 105 & 43 & 2.4 & 2.4 \\
\hline
\end{tabular}


Table 2.13 : Relative crystallinity from peak widths at half peak height of the chlorite $7 \AA$ peak. The determinations are from the less than the $0.015 \mathrm{~mm}$ fraction of whole rock powders. The five results at the end of the table were determinations from the $<1.5 \mu \mathrm{m}$ fraction. (Kubler's method).

\begin{tabular}{|c|c|c|c|c|}
\hline Sample & 1 & $\begin{array}{l}\text { u n } \\
2\end{array}$ & 3 & $\begin{array}{l}\text { Mean } \\
\text { Value }\end{array}$ \\
\hline$D C-6$ & $3.0 *$ & 3 & $2.25^{*}$ & 2.9 \\
\hline $\mathrm{HQ}-17$ & 2.5 & 3 & 2.5 & 2.67 \\
\hline $\mathrm{SJ}-3_{1}$ & $2.5^{*}$ & 2.5 & 3 & 2.63 \\
\hline $\mathrm{KTW}-13$ & $3.5 *$ & 4.5 & 3 & 3.63 \\
\hline $\mathrm{HQ}-21$ & $3.0 *$ & 3.5 & 2 & 2.88 \\
\hline$B Q-V$ & $3.5^{\star}$ & 2.5 & 3 & 3.13 \\
\hline $\mathrm{BQ}-\mathrm{IXA}$ & $3.0 *$ & 3.5 & 3 & 3.13 \\
\hline$O B-21$ & 2.5 & 3 & 3 & 2.8 \\
\hline HQ-19 & $3.5 *$ & 3.5 & 3.5 & 3.5 \\
\hline $\mathrm{KS}-2$ & 3.5 & 4 & 3 & 3.5 \\
\hline BQ-iii & 2.5 & 2.5 & 3 & 2.67 \\
\hline$K T W-G$ & 3.5 & 4 & 4 & 3.8 \\
\hline RSS-iii & 2.5 & 3 & 2.5 & 2.67 \\
\hline $\mathrm{BQ}-2 \mathrm{I}$ & 3 & 4 & 4 & 3.67 \\
\hline KTW-i & 3.5 & 3 & 3.5 & 3.3 \\
\hline$K T W-i(R)$ & $2.25 *$ & 2.5 & 2.5 & 2.38 \\
\hline$D C-8$ & $3.0 *$ & 3 & - & 3.0 \\
\hline $\mathrm{BQ}-i$ & 2.5 & 2.5 & 2.5 & 2.5 \\
\hline RSS-ii & 3 & 3.5 & 3 & 3.17 \\
\hline HQ -26 & 3.5 & 4 & 3 & 3.5 \\
\hline $\mathrm{HQ}-24$ & 3 & 4 & 3.5 & 3.5 \\
\hline$O B-W$ & 3 & 3.5 & 4 & 3.5 \\
\hline $\mathrm{HQ}-2 \mathrm{O}$ & 4 & 4.5 & 3 & 3.8 \\
\hline HQ -18 & $2.75^{\star}$ & 3.5 & 4 & 3.25 \\
\hline BQ-vii & $3.0 *$ & - & 3.5 & 3.17 \\
\hline $\mathrm{HQ}-22$ & 3.5 & 4 & 3 & 3.5 \\
\hline$O B-13$ & $3.25 *$ & 3 & 3.5 & 3.25 \\
\hline
\end{tabular}

* Obtained by duplication of run. 
Table 2.13 : (continued)

$\begin{array}{lcccc}\text { Sample } & & \text { R u n } & & \text { Mean } \\ & 1 & 2 & - & 3 \\ \text { value }\end{array}$




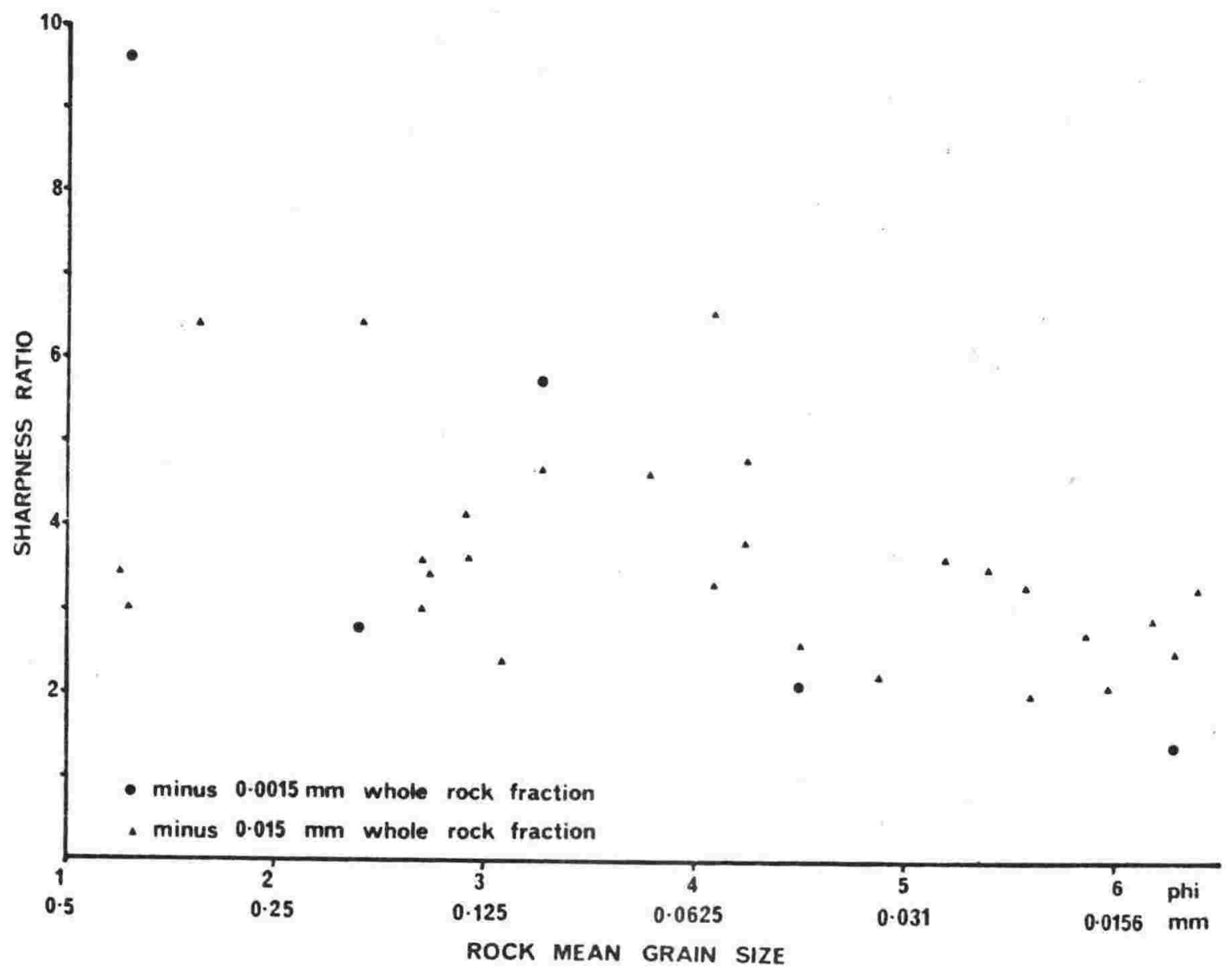

Figure 2.24 : Sharpness ratio of illite (Weaver, 1960) indicates that metamorphic change has taken place more completely in coarser grained greywacke-suite rocks. Circular points are values for whole rock powder fractions finer than $1.5 \mu \mathrm{m}$, triangles for whole rock powder fractions finer than $0.015 \mathrm{~mm}$. 


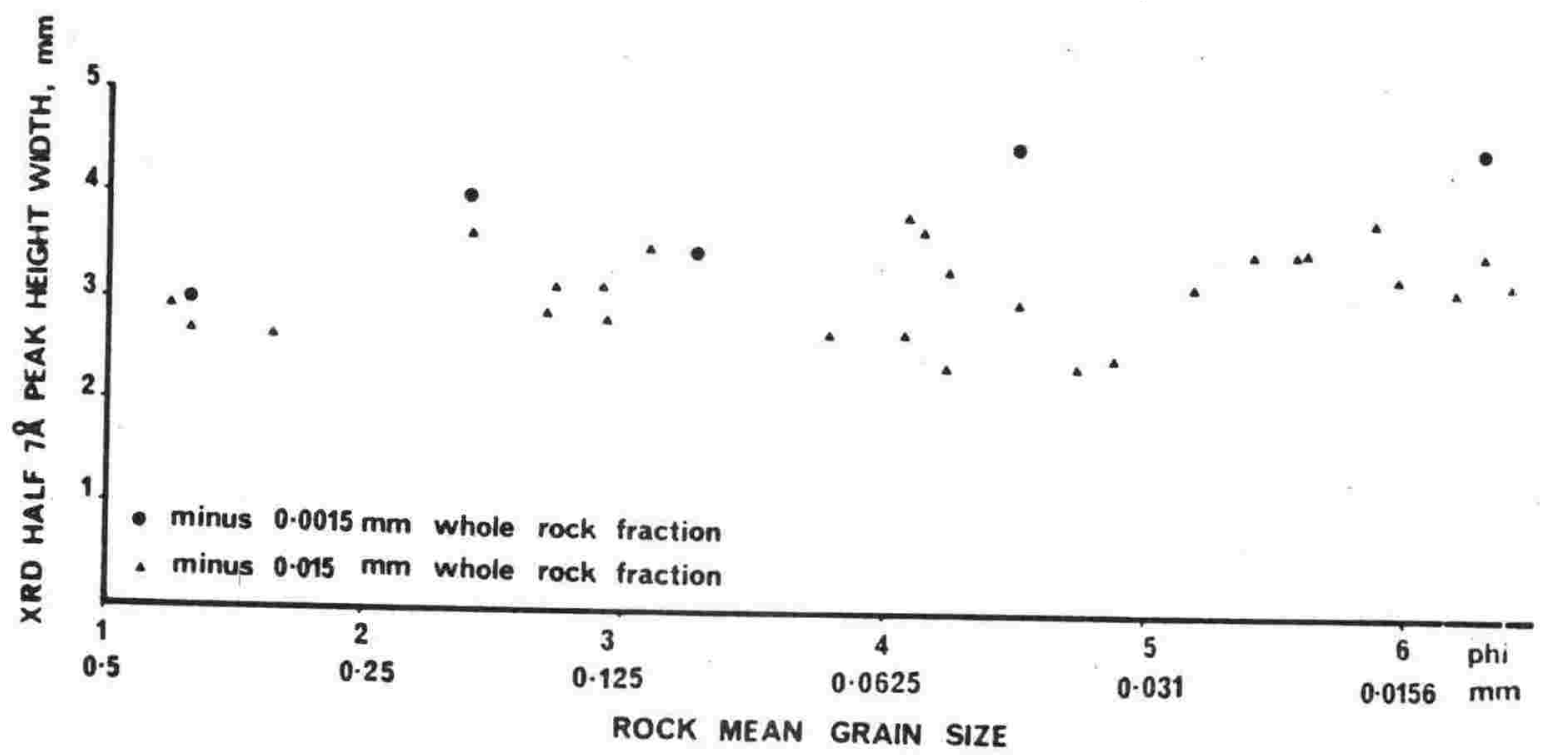

Figure 2.25 : Relative crystallinity (Kubler, 1967) of chlorite ( $7 \AA$ diffraction peak) assessed by measuring peak width at half peak heights. Circular points finer than $1.5 \mu \mathrm{m}$. , triangles for whole rock powder fractions finer than $0.015 \mathrm{~mm}$. Increasing values indicate reduced crystallinity. 


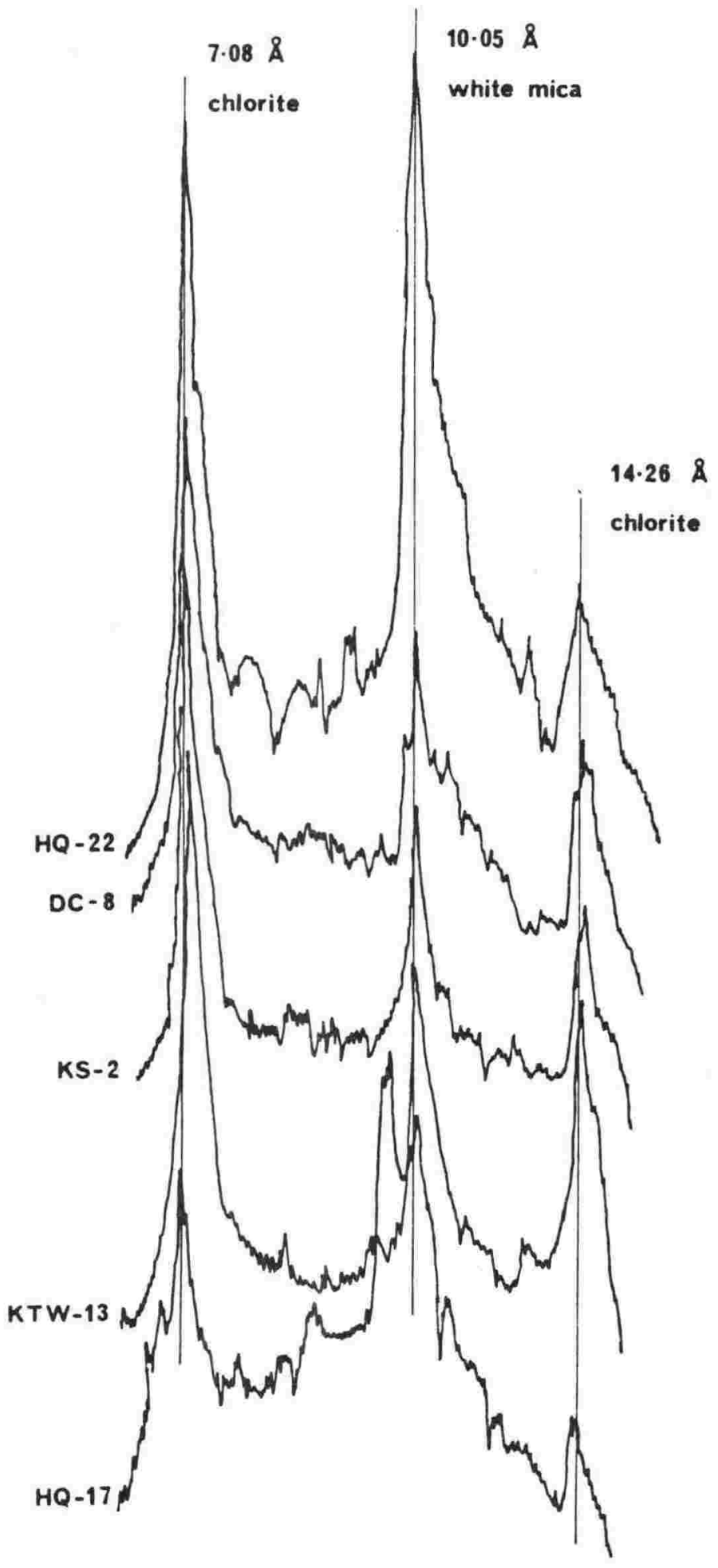

Figure 2.26 : X-ray diffractogram of whole rock materials finer than $1.5 \mu \mathrm{m}$ from five lithogies assembled to show contrast between peak intensity and sharpness ratio or half peak height widths,i.e. relative mineral abundance and crystallinity. 
(iii)

The fineness of material to emerge after "Tema" crushing is the same whether the crushed rock is a greywacke or argillite. Indeed, argillites sometimes emerged noticeably more "gritty" but they tend to smear the mill more than greywackes and smeared material was not included in the powder sample. Smeared material probably acted as a buffer minimising metal-tometal contact within the mill.

\subsection{Fissility}

Some argillites display fissility, the ability to split easily along closely spaced parallel planes. This influences the physical and chemical breakdown of the rock and so features of fissility in the Wellington greywacke-suite rocks are reviewed below.

Ingram (1953) classified mudrocks by fissility type i.e. massive, flaggy and flaky. The Wellington argillites fit the flaky category, described as rocks that "split along irregular surfaces parallel to bedding into uneven flakes, thin chips and wedge-like fragments whose length seldom exceeds 3 inches $(76 \mathrm{~mm})$ " and they are "predominantly grey or grey-black in colour".

From the literature, several reasons have been given for fissility in mud rocks: fabric, organic material, felsic grain content, mineral cement content, sand and silt size particle content (Ingram, 1953); overburden pressure applied to newly deposited clay material and the amount of liquid and rigid water in the clay at the time of application of pressure (O'Brien, 1963). The interface between zones of preferentially oriented grains and organic material, interfaces between zones of randomly oriented grains and organic material, and zones of preferentially oriented grains have been shown by Gipson (1965) to provide fissile planes. More recently Blatt et al. (1972) have claimed that type and crystallinity of clay minerals is important, fissility being favoured by higher proportions of well crystallised clays with bonding sites on surfaces rather than edges (Kaarsberg, 1959). Spears (1976) has shown how laminations within mudrocks can influence fissility and states the importance of preferred orientation of clay minerals may have been over estimated. Indeed, many inconsistencies arise, most "controls of fissility" not being universally applicable. 
The fissile argillites of Wellington do possess two features that distinquish them from the non-fissile argillites; stronger grain orientation and betterformed more coarsely crystalline phyllosilicates.

Fissility appears to be independant of rock mean grain size (Ingram, 1953), though some fissile argillites have larger phyllosilicate minerals. Fissility is enhanced by weathering (Ingram, 1953), splitting more easily and producing a flakier form in resultant particles ( section 2.12; Appendix 25).

The presence of carbonaceous (organic) material in a concentrated seemingly structureless layer (Gipson, 1965), was conducive to controlling fissile planes but a continuity of these materials was required (IB-13A, Plate 2.5).

Fissility can occur within a layer at the interface between oriented fine grained phyllosilicate materials and non-oriented or poorly oriented, felsic, coarser grained materials.

All of the above features of fissility are consistent with general descriptions by White (1961).

\subsection{Weathering}

Convenient classifications of weathering variation observed in greywackesuite rocks have been based on a simple grading system (Raisbeck, 1973; Marshall, 1974; Riddolls and Perrin, 1975), the nomenclature being shown in Table 2.14.

Although this study was based on fresh samples, some weathered samples were examined. Microscopic study was made of incipient chemical weathering, taken as that stage between categories 1 and 2 and often observable only by microscopic means in category 1 (Table 2.14). This is important for engineering considerations as it indicates the order of destruction of the various minerals, where it is concentrated and at what rate it proceeds.

While it is convenient to differentiate between physical and chemical weathering, it is improbable that either process acts alone (Sparks, 1960). Early experiments by Barton (1916), Blackwelder (1925) and Griggs (1936) showed the importance of chemical weathering in physical processes. Various physical 
Table 2.14 : Categories of greywacke-suite rock weathering (after Marshall, 1974), based on handspecimen colour changes and strength loss.

\section{Category 1 Fresh rock: Dark grey or dark blue-grey. Signs of weathering absent, apart from slight surface staining along open joints and fractures.}

Category 2 Slightly weathered: Discolouration along joints and fractures. Grey-brown colour penetrates less than $10 \mathrm{~mm}$.

Category 3 Moderately weathered: Rock decomposition will advanced. Weathering aureole around blocks, fresh material at centre of broken fragments. Clay materials form, especially along joint and shear planes. Rock appreciably weakened by weathering - is easily shattered by hammer blow.

Category 4 Heavily weathered: Equivalent to "rotten rock" of contractors and farmers. Colour varies from brown, through redbrown and lighter yellow-brown. No fresh material remains. Rock able to be broken by hand. An abundance of clay minerals. Rock retains original structures and is strong enough to maintain a steep cut face.

Category 5 Completely weathered: Material approaches soil in character (saprolite). Crushes between fingers. Original structure is lost and material will not maintain a steep face. 
and chemical processes and their sequential developments have been discussed elsewhere (Rowe, 1979; Appendix 25).

Factors influencing weathering of any rock were listed by Sparks (1960) as follows:

(i) Mineral composition. Of the four main component minerals of greywacke-suite rocks Marshall (1974) indicated chlorite to be most vulnerable, an observation made also by Goldich (1938).

(ii) Texture. Under certain conditions, coarse grained rocks should weather more rapidly than fine grained rocks of the same mineral composition.

(iii) Effects of minor structures. Minor structures in greywackes, and especially in argillites, dominate initial (and direct subsequent) weathering patterns once rocks are unconfined. Such effects as lamination (Spears, 1976), preferred orientation (Hedberg, 1936; Ingram, 1953), recemented shears, microcracking and veining are included in this category; any feature allowing ingress of chemical weathering agents or increasing surface area also increases rates of chemical weathering.

(iv) Climate. This is assumed to have been consistent for the Wellington greywacke-suite rocks over the period of development of a natural weathering profile $(10,000$ years $)$.

(v) Time.

Microscopic examination shows the association of the above factors clearly. Minor structures, notably veining and microcracking, play the most obvious role and are now discussed in some detail.

\subsubsection{Veining}

Some veins, notably those of prehnite (OB-21), allow access for weathering agents. Bright yellow and yellow-brown to black weathering products (semiopaque in polarised light) were observed adjacent to vein boundaries. The materials were fine grained (about $0.001 \mathrm{~mm}$ ) and massed at the vein boundary in a zone about $0.03 \mathrm{~mm}$ wide but extended up to $0.7 \mathrm{~mm}$ where colouration was patchy and consisted of red-brown, isotropic discontinuous blebs and 
aggregates, brown-red in reflected light. Within the veins some shapeless and ramifying material was observed as an extremely fine layer between grains (less than $0.006 \mathrm{~mm}$ ) but obliquity of grain contacts increased the apparent width observed - a problem solved only with the use of a universal stage (Glover, 1964).

\subsubsection{Microcracking}

Microcracks are here considered to be open cracks of such a size that on a smooth dry rock surface they are invisible to the naked eye (less than $0.004 \mathrm{~mm}$ wide). On wetting, such cracks become visible (in argillaceous rocks) as a relatively wetter, or darker linear feature, the width of which may vary visibly by application of hand pressures. Due to coarser texture, microcracks in greywackes may be wider than those in argillite and still be invisible to the naked eye. In any case they are much fewer and less persistent. They are more linear in greywackes than argillites, with local aberations due to textural considerations. Grains of quartz and feldspar are skirted rather than broken, the path of the crack often including the long axes of chlorite grains, with less than $0.001 \mathrm{~mm}$ displacement across the crack. Red-brown to black isotropic limonite may accumulate in cracks with the onset of weathering.

2.16.3 Lamination, preferred orientation, recemented shears Quartz veins in greywackes of the thin-bedded lithofacies and argillites may be relatively sinuous (ptygmatic). Associated with these are ubiquitous microcrush or shear zones, evident as linear concentrations of foliated matrix and highly comminuted fabric minerals to $0.12 \mathrm{~mm}$. Calcite, prehnite, zeolite or authigenic albite are not associated with these features. Shear zones are up to $0.35 \mathrm{~mm}$ wide but are often not obvious other than at low magnification, so subtle are the changes in matrix orientation and grain size reduction. Generally colour value is increased in these zones, often black, with grains about $0.005 \mathrm{~mm}$ in size. White mica is occasionally associated with both veins and shear zones.

The microcrush zones are here termed recemented shears, implying small size, physical continuity of the rock across them, and comminution. They are very common in argillites and, in these rocks, are almost undetectable with the naked eye $(\mathrm{OB}-12)$. They formulate conditions which may promote parting and/or weathering of the rocks (RSS-i). 
Laminations, preferred orientation and recemented shears are all minor structures, constituting a linear plane of weakness. Porous organic matter with associated chlorite and pyrite is concentrated along laminations. Preferred orientation arranges chlorite so that weathering may extend along cleavage planes which are oriented end-to-end. Laminations originate from successive differences in grain size of detrital grains in confined thin $(0.016$ to $2.2 \mathrm{~mm})$ layers, planar concentrations of carbonaceous material, detrital (and authigenic) pyrite and/or detrital heavies; they may be disrupted by bioturbation (Plate 2.6). Carbonaceous material may occupy large areas parallel to bedding.

The effects of texture are less than those of minor structures, but are still important. In coarse grained rocks the weathering of one constituent may have a proportionally larger effect than the weathering of the same constituent in a finer grained rock. This is true for in situ chemical weathering of Wellington greywacke-suite rocks but after guanying the effects of minor structures are more important. phys cal $i n$ situ weathering of greywacke-suite rocks shows argillite to be less resistant on the sea coast or where chemical weathering is advanced. Coarse grained greywackes (chipwackes) displayed the contrast well (see plate 2.2). In newly exposed fresh outcrops, however, chemical weathering is suppressed in argillites and enhanced in the greywackes,i.e. the coarser grained rocks. Vertical or steeply dipping beds and Induced secondary porosity (joints shears and faults) ficilitate chemical. weathering to deep letels for reasons discussed later, this induced perm-

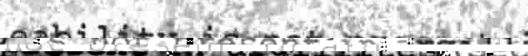

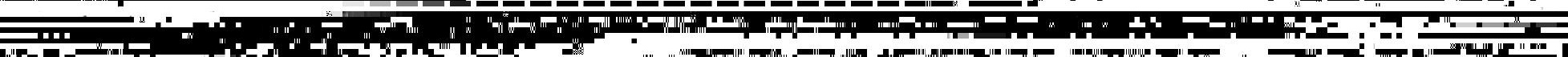

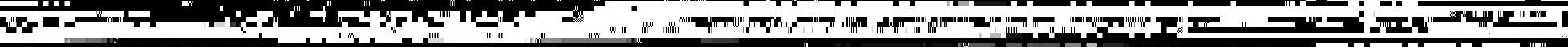

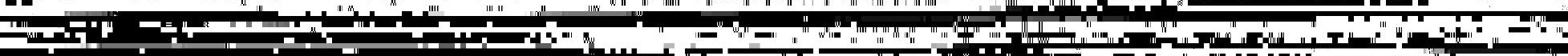

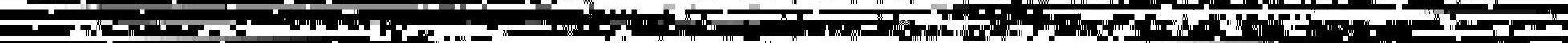

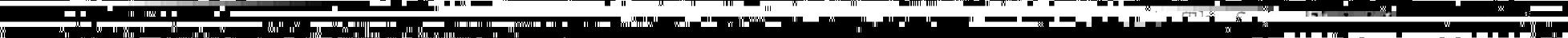

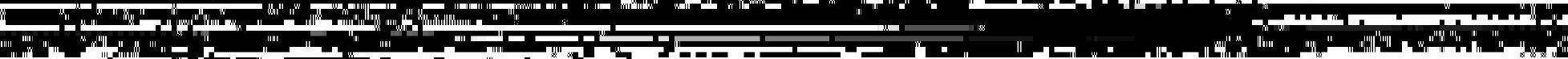

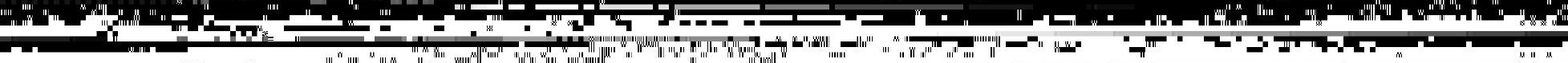

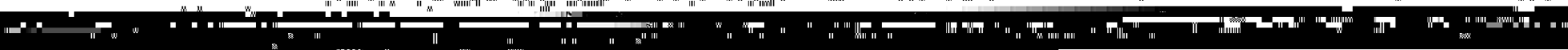

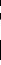

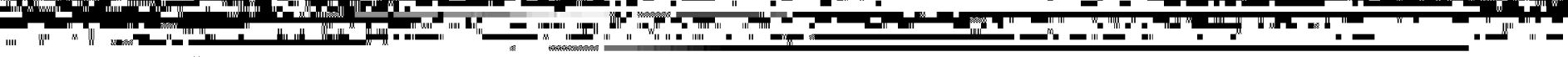




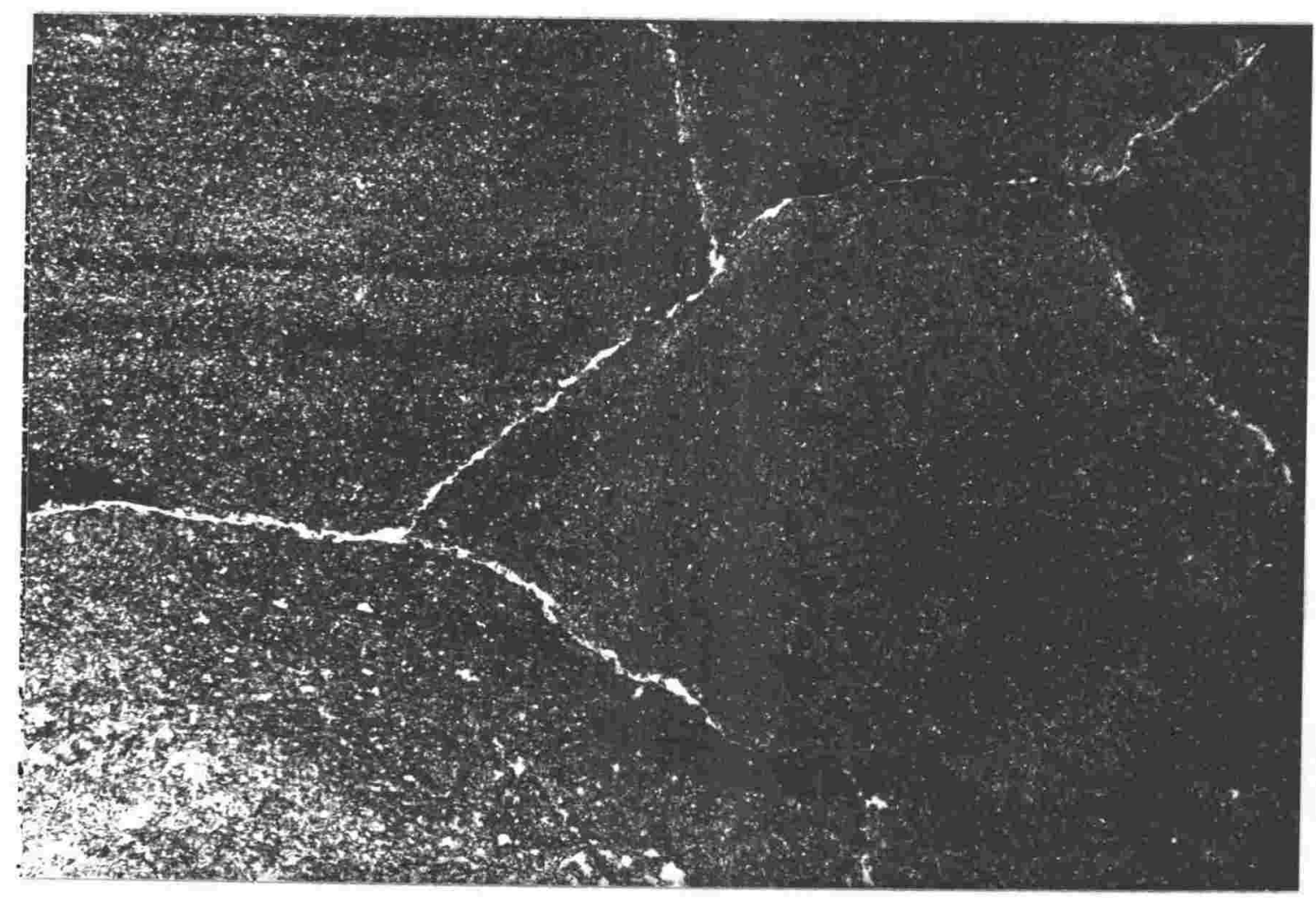

$5.5 \mathrm{~mm}$

Plate 2.6 : Bioturbation may disrupt fissility lamination in argillaceous rocks by attenuating sedimentary

laminations. Some benefit may result for engineering purposes. Shown is a sample (IB-6) of argillite (rock mean grain size $0.016 \mathrm{~mm}$ ) showing cracking in rock'circumnavigating'a bioturbation structure (centre right) which destroys laminations (upper left), in this case controlling fissility. The photomicrograph shown(in plane light) did not have the crack pattern "manufactured" during thin section production. 
that chlorite and white mica would behave similarly proved erroneous. Mica schist rock fragments adjacent to an alteration zone showed no sign of staining but chlorite, in any form, including that in sedimentary rock fragments, was affected.

\subsection{Geochemistry}

Greywackes as a rock type are very homogeneous chemically throughout the world despite large differences in age (Pettijohn et al. 1972), i.e. they are rich in $\mathrm{Al}_{2} \mathrm{O}_{3}, \mathrm{FeO}+\mathrm{Fe}_{2} \mathrm{O}_{3}, \mathrm{MgO}$ and $\mathrm{Na}_{2} \mathrm{O}$ - as may be seen in Table 2.15.

Most authors regard the alkali ratio $\mathrm{Na}_{2} \mathrm{O}: \mathrm{K}_{2} \mathrm{O}$ as being highly significant in the classification and interpretation of sedimentation of greywackes (Middleton, 1960; Pettijohn, 1963; Crook, 1974). The alkali content is of particular importance to this study as Reed (1957) and Sameshima (1977) both show rocks regarded as greywackes to have $\mathrm{Na}_{2} \mathrm{O}: \mathrm{K}_{2} \mathrm{O}$ ratios greater than unity and argillites less than unity. Reed (1966) used alkali contents to classify rock-types from aggregates that degraded on a motorway project. He showed (Reed, 1966, 1967) that alkali ratios for the failed aggregate were greater than unity and contended that this was due to secondary "albitisation". The failed aggregates were partially weathered and were in the mean grain size range 0.06 to $0.005 \mathrm{~mm}$. Most photomicrographs (Reed, 1966) indicate many of the rock types to be argillites on the textural parameters of this study and tests recently performed (Rowe, 1979).

The aim of this section is to present further chemical data on the wellington rocks and to relate this to the petrography (section 2.6). Thirty samples of various lithofacies, representing the textural range apparent in the Wellington greywacke-suite rocks, were analysed for major and trace elements. The major element analyses are listed in Table 2.16.

\subsubsection{Major elements}

Rocks were prepared by crushing for one minute in a "Tema" mill. X-ray fluorescence (XRF) analyses were performed on glass fusion discs following the preparation and correction procedures given by Norrish and Hutton (1969). Analyses were carried out on Siemens SRS-I Spectrometer at Victoria University by the late Mr F. Shafer. 
Representative chemical analyses of greywackes, after Pettijohn et al. (1972) compared with analyses of this study.

\begin{tabular}{|c|c|c|c|c|c|c|c|c|c|c|c|c|}
\hline & A & B & c & D & E & F & G & $\mathrm{H}$ & I & J & $\mathrm{x}$ & L \\
\hline $\mathrm{SiO}_{2}$ & 60.51 & 61.39 & 76.84 & 69.11 & 68.85 & 74.43 & 73.04 & 71.10 & 68.84 & 65.05 & 69.06 & 59.44 \\
\hline $\mathrm{TiO}_{2}$ & 0.87 & 0.62 & - & 0.60 & 0.74 & 0.83 & 0.15 & 0.50 & 0.25 & 0.46 & 0.52 & 0.81 \\
\hline $\mathrm{Al}_{2} \mathrm{O}_{3}$ & 15.36 & 16.97 & 11.76 & 11.38 & 12.05 & 11.32 & 10.17 & 13.90 & 14.54 & 13.89 & 14.74 & 18.29 \\
\hline $\mathrm{Fe}_{2} \mathrm{O}_{3}$ & 0.76 & 0.39 & 0.55 & 1.41 & 2.72 & 0.81 & 0.56 & trace & 0.62 & 0.74 & 0.59 & 0.75 \\
\hline Feo & 7.63 & 5.32 & 2.88 & 4.64 & 2.03 & 3.88 & 4.15 & 2.70 & 2.47 & 2.60 & 2.87 & 5.47 \\
\hline Mno & 0.16 & 0.12 & trace & 0.17 & 0.05 & 0.04 & 0.18 & 0.05 & nil & 0.11 & 0.05 & 0.07 \\
\hline MgO & 3.39 & 3.84 & 1.39 & 2.06 & 2.96 & 1.30 & 1.43 & 1.30 & 1.94 & 1.22 & 1.52 & 2.58 \\
\hline $\mathrm{CaO}$ & 2.14 & 3.21 & 0.70 & 1.15 & 0.50 & 1.17 & 1.49 & 1.80 & 2.23 & 5.62 & 2.05 & 1.58 \\
\hline $\mathrm{Na}_{2} \mathrm{O}$ & 2.50 & 2.78 & 2.57 & 3.20 & 4.87 & 1.62 & 3.56 & 3.70 & 3.88 & 3.13 & 3.45 & 1.80 \\
\hline $\mathrm{K}_{2} \mathrm{O}$ & 1.69 & 1.25 & 1.62 & 1.76 & 1.81 & 1.74 & 1.37 & 2.30 & 2.68 & 1.41 & 2.89 & 4.56 \\
\hline $\mathrm{H}_{2} \mathrm{O}+$ & 3.38 & 2.44 & \} & $\{4.13$ & 2.30 & $2.15\}$ & \multirow{2}{*}{$2.36^{1}$} & 1.90 & 1.60 & $2.30\}$ & \multirow{2}{*}{$2.03^{1}$} & \multirow{2}{*}{$4.08^{1}$} \\
\hline $\mathrm{H}_{2} \mathrm{O}-$ & 0.15 & 0.06 & 1.87 & $\{0.05$ & 0.77 & $0.20 \mathrm{~J}$ & & 0.26 & 0.35 & $0.28\}$ & & \\
\hline $\mathrm{P}_{2} \mathrm{O}_{5}$ & 0.27 & 0.19 & - & 0.03 & 0.06 & 0.18 & 0.23 & 0.10 & 0.15 & 0.08 & 0.17 & 0.19 \\
\hline $\mathrm{ZrO}_{2}$ & - & 0.07 & - & - & - & - & - & - & 0.05 & - & - & - \\
\hline $\mathrm{CO}_{2}$ & 1.01 & 0.88 & - & - & 0.08 & 0.48 & 0.84 & 0.12 & 0.14 & 2.83 & - & - \\
\hline $\mathrm{SO}_{3}$ & - & - & - & - & - & - & - & - & 0.15 & - & - & - \\
\hline s & 0.42 & 0.15 & - & - & 0.08 & 0.12 & 0.10 & trace & - & 0.05 & - & - \\
\hline $\mathrm{Cr}_{2} \mathrm{O}_{3}$ & - & 0.01 & - & - & - & - & - & - & - & - & - & - \\
\hline $\mathrm{BaO}$ & - & 0.06 & - & - & trace & - & - & - & 0.04 & - & - & - \\
\hline \multirow[t]{2}{*}{ c } & - & - & - & - & 0.07 & 0.17 & 0.17 & 0.09 & - & - & - & - \\
\hline & 100.24 & 99.75 & 100.18 & 99.69 & 99.94 & 100.45 & 99.80 & 99.80 & 99.93 & 99.77 & 99.94 & 99.62 \\
\hline
\end{tabular}

(1) Loss on ignition.

A. Greywacke (Archean), Manitou Lake, Ontario, Canada, B. Brunn, analyst (Pettijohn, 1957b. p. 306).

B. Greywacke (Archean), Knife Lake, Minnesota, U.S.A., F.F. Grout, analyst (Grourt, 1933, p. 997).

C. Greywacke TYler slate (Precambrian Animikian), Hurley, Wis., H.N. Stokes, analyst (Diller, 1898, p. 87).

D. Rensselaer Greywacke (Ordovician?), near Spencertown, N.Y., H.B. Wiik, analyst (Balk, 1953, p.824).

E. Tanner Greywacke (Upper Devonian - Lower Carboniferous), Scharzfeld, Germany, R. Helmbold, analyst (Helmbold, 1952, p. 256).

F. Greywacke from Stanley Shale (Carboniferous), near Mena, Arkansas, B. Brunn, analyst (Pettijohn, 1957b, p. 306).

G. Kulm (Carboniferous), Steinback, Frankenwalk, Germany (Eigenfeld, 1933, p. 58).

H. Composite sample (Lower Mesozoic), prepared by using equal parts of 20 greywackes exposed along shorline between Palmer Head and Hue-Te-Taka, Wellington, N.z., J.A. Richie, analyst (Reed, 1957, p. 16).

I. Franciscan Formation (Jurassic?), Quarry Oakland Paving Co., Piedmont, California, Jas. W. Howson, analyst (Davis, 1918, p.22).

J. Greywacke (Cretaceous?), Olympic Mountains, Washington, neaz Solduc, B. Brunn, analyst (Pettijohn, $1957 b$, p. 306).

K. Average of analyses for 19 wellington greywacke-suite rocks in mear grain size range 1.25 to 4.5 phi. L. Average of analyses for eight Wellington greywacke-suite rocks in mean grain size range 5.58 to 6.39 phi.
Compare $\mathrm{K}$ with $\mathrm{H}$. 
Table 2.16 : New major element analyses (percent) of the Wellington greywacke-suite rocks. LOI $=$ loss on ignition. * Analysed by B. Roser.

\begin{tabular}{|c|c|c|c|c|c|c|c|c|c|c|}
\hline Sample & $D C-6$ & но-17 & $\mathrm{sJ}^{-3}{ }_{1}$ & KIW-13 & KTW-14 * & RSS-12* & HQ-2I & $B Q-V$ & $B Q-I X A$ & $O B-21$ \\
\hline$M_{z}(p h i)$ & 1.25 & 1.317 & 1.32 & 2.4 & 2.6 & 2.62 & 2.7 & 2.73 & 2.9 & 2.93 \\
\hline $\mathrm{SiO}_{2}$ & 66.54 & 77.63 & 67.65 & 69.80 & 69.55 & 69.51 & 68.62 & 67.90 & 69.05 & 69.45 \\
\hline $\mathrm{Al}_{2} \mathrm{O}_{3}$ & 15.69 & 13.31 & 14.93 & 14.19 & 14.11 & 14.33 & 15.01 & 14.99 & 14.56 & 15.05 \\
\hline $\mathrm{TiO}_{2}$ & 0.59 & 0.27 & 0.55 & 0.49 & 0.50 & 0.46 & 0.51 & 0.54 & 0.53 & 0.42 \\
\hline $\mathrm{Fe}_{2} \mathrm{O}_{3}$ & 0.59 & 0.24 & 0.44 & 0.69 & 0.76 & 1.20 & 0.42 & 0.40 & 0.48 & 0.32 \\
\hline Feo & 3.20 & 1.32 & 3.32 & 2.51 & 2.36 & 2.32 & 2.80 & 3.68 & 3.02 & 2.36 \\
\hline Mno & 0.05 & 0.04 & 0.06 & 0.04 & 0.04 & 0.04 & 0.06 & 0.08 & 0.04 & 0.05 \\
\hline MgO & 1.61 & 0.57 & 1.71 & 1.54 & 1.47 & 1.66 & 1.45 & 1.66 & 1.74 & 1.34 \\
\hline $\mathrm{CaO}$ & 3.05 & 2.12 & 3.08 & 1.71 & 2.03 & 1.89 & 2.08 & 2.07 & 2.13 & 1.15 \\
\hline $\mathrm{Na}_{2} \mathrm{O}$ & 2.75 & 3.82 & 3.09 & 3.87 & 3.90 & 3.64 & 3.44 & 3.53 & 3.53 & 4.05 \\
\hline $\mathrm{K}_{2} \mathrm{O}$ & 3.29 & 2.31 & 2.74 & 2.66 & 2.61 & 2.91 & 3.17 & 2.52 & 2.51 & 3.54 \\
\hline${ }^{P_{2}} \mathrm{O}_{5}$ & 0.17 & 0.10 & 0.16 & 0.15 & 0.16 & 0.14 & 0.13 & 0.17 & 0.12 & 0.16 \\
\hline LOI & 2.16 & 2.20 & 2.02 & 1.77 & 1.89 & 1.70 & 1.94 & 1.99 & 1.90 & 1.52 \\
\hline Total: & 99.69 & 99.93 & 99.75 & 99.42 & 99.38 & 99.80 & 99.63 & 99.53 & $99.61 * * *$ & $99.41 * *$ \\
\hline Sample & HQ-19 & $\mathrm{KS}-2$ & KS-10* & $B Q-i i i$ & KIW-G & RSS-iii & $\mathrm{BQ}-2 \mathrm{I}$ & $K T W-i$ & $D C-8$ & $B Q-i$ \\
\hline$M_{z}(p h i)$ & 3.08 & 3.27 & 3.38 & 3.78 & 4.07 & 4.08 & 4.13 & 4.23 & 4.5 & 4.87 \\
\hline $\mathrm{SiO}_{2}$ & 68.28 & 67.77 & 70.23 & 68.54 & 65.77 & 68.10 & 66.57 & 70.70 & 70.45 & 61.52 \\
\hline $\mathrm{Al}_{2} \mathrm{O}_{3}$ & 15.07 & 15.12 & 15.16 & 13.50 & 15.64 & 15.12 & 15.93 & 14.18 & 14.11 & 14.56 \\
\hline $\mathrm{TiO}_{2}$ & 0.53 & 0.53 & 0.47 & 0.49 & 0.63 & 0.59 & 0.63 & 0.64 & 0.54 & 0.50 \\
\hline $\mathrm{Fe}_{2} \mathrm{O}_{3}$ & 0.54 & 0.50 & 1.49 & 0.33 & 0.56 & 0.59 & 0.57 & 0.64 & 0.46 & 0.06 \\
\hline Feo & 3.16 & 3.43 & 2.00 & 2.45 & 3.84 & 3.16 & 3.72 & 2.86 & 2.98 & 2.74 \\
\hline Mno & 0.04 & 0.06 & 0.03 & 0.06 & 0.06 & 0.06 & 0.05 & 0.04 & 0.08 & 0.13 \\
\hline MgO & 1.69 & 1.64 & 1.50 & 1.20 & 1.85 & 1.53 & 1.93 & 1.40 & 1.45 & 1.33 \\
\hline $\mathrm{CaO}$ & 1.64 & 2.00 & 2.00 & 4.00 & 1.41 & 1.59 & 1.97 & 1.73 & 1.35 & 7.06 \\
\hline $\mathrm{Na}_{2} \mathrm{O}$ & 3.58 & 3.32 & 3.59 & 3.40 & 3.08 & 3.15 & 3.98 & 3.61 & 3.26 & 2.85 \\
\hline $\mathrm{K}_{2} \mathrm{O}$ & 2.99 & 3.19 & 3.14 & 2.03 & 3.51 & 3.30 & 3.05 & 2.45 & 2.95 & 2.71 \\
\hline $\mathrm{P}_{2} \mathrm{O}_{5}$ & 0.13 & 0.16 & 0.16 & 0.20 & 0.19 & 0.19 & 0.21 & 0.23 & 0.20 & 0.19 \\
\hline LOI & 1.94 & 1.82 & 1.42 & 3.18 & 3.00 & 2.17 & 2.37 & 1.60 & 1.90 & 6.09 \\
\hline Total: & 99.59 & .99 .59 & 101.19 & 99.41 & 99.54 & 99.55 & 99.98 & $100.08 * * *$ & 99.73 & 99.74 \\
\hline Sample & RSS- $i$ i & HQ-26 & $\mathrm{HQ}-24$ & $\mathrm{OB}-\mathrm{W}$ & $\mathrm{HQ}-2 \mathrm{O}$ & $w C C-5 A *$ & $\mathrm{HQ}-18$ & BQ-vii & HQ- 22 & $\mathrm{OB}-13$ \\
\hline$M_{z}(p h i)$ & 5.18 & 5.4 & 5.58 & 5.6 & 5.87 & 5.9 & 5.95 & 6.13 & 6.28 & 6.39 \\
\hline $\mathrm{SiO}_{2}$ & 62.75 & 66.97 & 60.18 & 60.10 & 58.07 & 57.98 & 59.83 & 59.51 & 59.69 & 60.18 \\
\hline $\mathrm{Al}_{2} \mathrm{O}_{3}$ & 10.69 & 15.83 & 17.74 & 18.57 & 18.76 & 18.62 & 17.97 & 18.33 & 18.17 & 18.17 \\
\hline $\mathrm{TiO}_{2}$ & 0.70 & 0.68 & 0.81 & 0.84 & 0.83 & 0.83 & 0.80 & 0.77 & 0.82 & 0.81 \\
\hline $\mathrm{Fe}_{2} \mathrm{O}_{3}$ & 0.60 & 0.38 & 0.54 & 0.86 & 0.67 & 0.93 & 0.65 & 0.80 & 0.69 & 0.88 \\
\hline Feo & 4.66 & 3.52 & 5.64 & 5.14 & 6.22 & 5.52 & 5.56 & 5.12 & 5.58 & 4.96 \\
\hline Mno & 0.08 & 0.06 & 0.06 & 0.05 & 0.06 & 0.07 & 0.05 & 0.07 & 0.07 & 0.09 \\
\hline Mgo & 2.26 & 1.69 & 2.43 & 2.43 & 2.95 & 2.70 & 2.57 & 2.82 & 2.40 & 2.34 \\
\hline $\mathrm{CaO}$ & 1.65 & 1.66 & 1.56 & 1.36 & 1.63 & 1.44 & 1.71 & 1.41 & 1.60 & 1.94 \\
\hline $\mathrm{Na}_{2} \mathrm{O}$ & 2.74 & 3.02 & 2.04 & 1.44 & 1.88 & 1.70 & 1.94 & 1.81 & 1.83 & 1.78 \\
\hline $\mathrm{K}_{2} \mathrm{O}$ & 3.73 & 3.83 & 4.48 & 4.91 & 4.44 & 4.75 & 4.25 & 4.50 & 4.60 & 4.51 \\
\hline $\mathrm{P}_{2} \mathrm{O}_{5}$ & 0.22 & 0.23 & 0.17 & 0.13 & 0.15 & 0.19 & 0.16 & 0.19 & 0.24 & 0.25 \\
\hline LOI & 3.26 & 2.31 & 4.08 & 3.93 & 4. 39 & 4.21 & 4.07 & 3.93 & 4.16 & 3.88 \\
\hline Total: & 99.34 & 100.18 & 99.73 & 99.76 & 100.05 & 98.94 & 99.56 & 99.26 * & $99.55 * *$ & 99.79 \\
\hline
\end{tabular}


Initially, multiple analyses from each sample were averaged but the degree of correlation proved this unnecessary as did the comparison with check discs prepared by Mr B. Roser. Morris (1979) also found excellent agreement with major elements in subsequent analyses. Loss on ionition was determined by heating in excess of onegram of sample powder at $1,000^{\circ} \mathrm{C}$ for one hour. Feo was determined by, at least duplicate, wet chemical analyses (Shapiro and Brannock, 1956) and attempts made to establish $\mathrm{CO}_{2}$ by a quick chemical method also by these authors, but for small quantities of $\mathrm{CO}_{2}$ (less than 0.4 percent) the accuracy is unreliable and precision is very poor (Roser pers. comm.). Major element composition of the Wellington greywacke-suite (Table 2.16) shows strong affiliation to mineralogic modes. The greywackes range in $\mathrm{SiO}_{2}$ content from 66 to 71 percent, have a $\mathrm{Na}_{2} \mathrm{O}: \mathrm{K}_{2} \mathrm{O}$ ratio greater than unity, $\mathrm{Al}_{2} \mathrm{O}_{3}$ between 13 and 16 percent and less than 3 percent Cao. Argillites, by contrast, contain appreciably less $\mathrm{SiO}_{2}$, the $\mathrm{Na}_{2} \mathrm{O}: \mathrm{K}_{2} \mathrm{O}$ ratio is less than 1 and $\mathrm{Al}_{2} \mathrm{O}_{3}$ significantly greater ( 17.7 to 18.8 percent). Loss on ignition for argillites is appreciably higher.

Higher phyllosilicate content in the argillites is indicated by higher potassium and alumina content together with higher losses on ignition, the latter due to combined water, organic matter and pyrite contents. Rocks with lower felsic modes give lower sodium and silica values.

These trends were noted by McKean (1976) and Nathan (1976) and are consistent with other analyses of Wellington greywacke-suite rocks (Reed, 1957). The ACF diagram (Figure 2.27) compares analyses of this study with those of Reed (1957) and Pettijohn (1963). The diagram shows good agreement of data and indicates a clear distinction between greywackes and argillites. The trend toward the $\mathrm{C}$ (molar $\mathrm{CaO}$ ) portion of the diagram is protracted because of three samples, HQ-17, BO-i and BQ-iii; HQ-17 having significant modal laumontite, the others calcite.

Figure 2.28 shows an inverse relationship between silica and alumina contents in greywackes and argillites, governed by felsic and phyllosilicate modes respectively. From section 2.13, it is the gradual transition of these modes, in response to textural considerations, that determines whether a rock is "greywacke" or "argillite". The abundance of $\mathrm{SiO}_{2}$ in sandstones and $\mathrm{Al}_{2} \mathrm{O}_{3}$ in shales is an indication of mineralogic maturity of these rocks (Pettijohn, 1957) and when plotted, the inverse relationship is apparent (Figure 2.28). When compared with Kawachi (1974) and Nathan (1976), it appears that these 


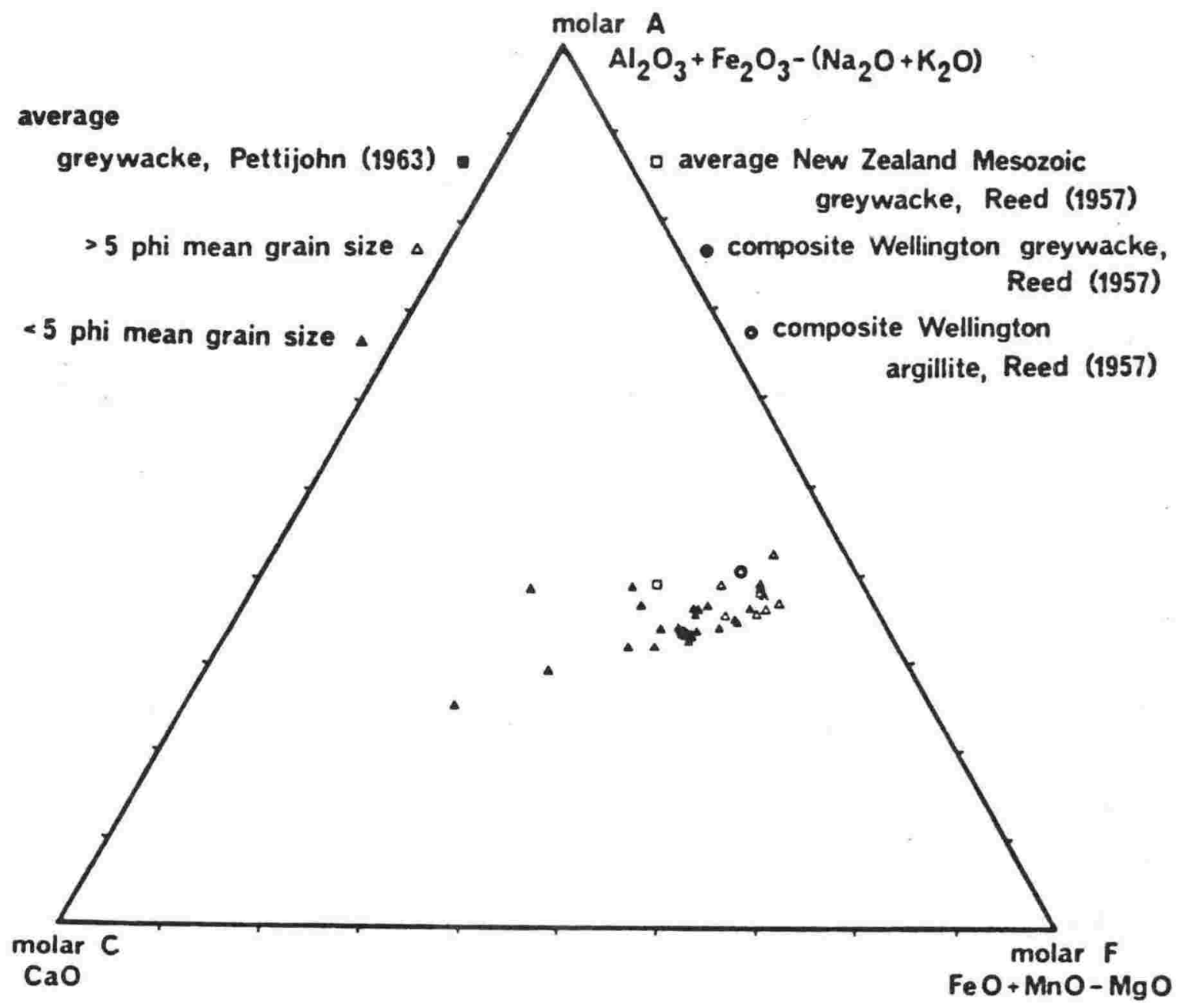

Figure 2.27 : ACF diagram for comparison of Wellington greywackesuite rocks of this study with Reed (1957) and

Pettijohn (1963). 


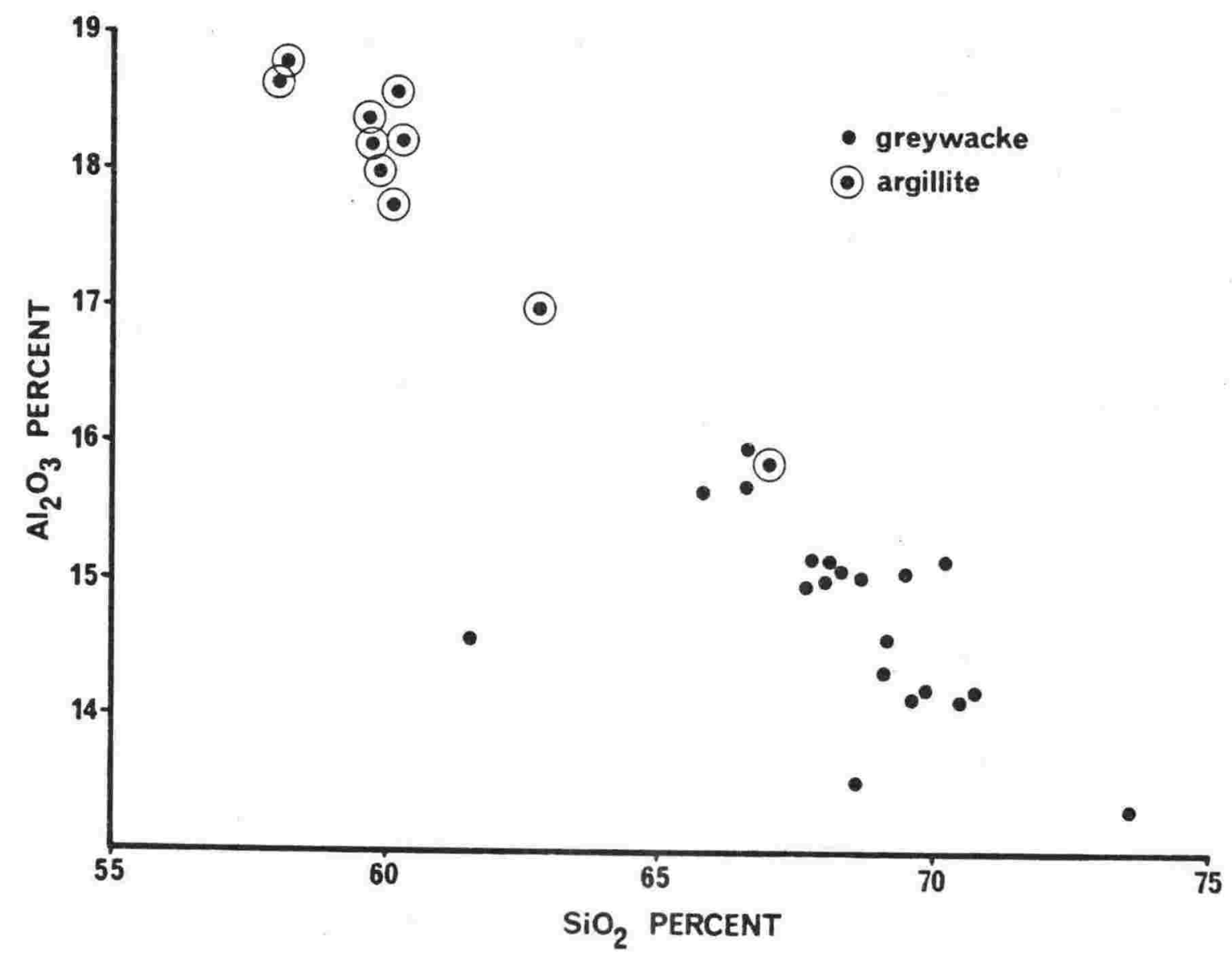

Figure 2.28 : Relationship of silica to alumina contents of greywacke-suite rocks. The inverse relationship shown is in response to relatively high felsic and phyllosilicate modes in greywackes and argillites respectively. 
trends are best displayed where mineralogical diversity is small. Further means of indicating the transition from greywackes to argillites may be seen by plotting a $\mathrm{Na}_{2} \mathrm{O}: \mathrm{K}_{2} \mathrm{O}$ diagram (Figure 2.29). The inverse relationship indicates that a 1:1 ratio may separate the rocks. This was a means by which Reed (1957) displayed the defective albitised argillite aggregates. It is noteworthy that most greywackes of the Wellington area plot in this field with "albitised" argillites.

Greywackes show relatively constant values of $\mathrm{K}_{2} \mathrm{O}$ (2 to 3.5 percent), the range of total alkalis $\left(\mathrm{Na}_{2} \mathrm{O}+\mathrm{K}_{2} \mathrm{O}\right)$ being due to the trend of $\mathrm{Na}_{2} \mathrm{O}$. From Figure 2.30, relating major element chemistry to rock mean grain size, the slight rise in $\mathrm{Na}_{2} \mathrm{O}$ content in greywackes with mean grain sizes between 2.4 and $3.8 \mathrm{phi}(0.19$ and $0.07 \mathrm{~mm})$, provides a larger scatter in the range of total alkalis of greywackes - 5.4 to 6.9 percent. Argillites have total alkali contents in the range 6.2 to 6.6 percent. The potassium content of greywackes reflects the stability of the matrix mode through their range. Sodium is enriched due to slightly higher feldspar and volcanic rock fragment modes in the fine and very fine sand size ranges of the greywackes (2.0 to $4.0 \mathrm{phi}$ ).

$\mathrm{FeO}: \mathrm{Fe}_{2} \mathrm{O}_{3}$ ratios of the Wellington greywacke-suite rocks confirmed a lack of weathering in any of the rocks analysed.

\subsubsection{Trace Elements}

All trace element work was undertaken by Mr B. Roser using pressed rock powder mounts analysed by XRF. Among elements analysed were $\mathrm{Cu}, \mathrm{Ni}, \mathrm{Zn}, \mathrm{Y}$, $\mathrm{Cr}, \mathrm{U}, \mathrm{Th}$ and $\mathrm{Nb}$. Trace element data are summarised in Figure 2.31. With a few exceptions trace elements show positive correlation with phi unit values and inverse relationship with $\mathrm{SiO}_{2}$. This is because $\mathrm{SiO}_{2}$ decreases with finer mean grain size of rocks and phyllosilicates (low in $\mathrm{SiO}_{2}$ and of small particle size) absorb alkali metals of increasing atomic number preferentially. Heier and Adams (1964) note that most marine clays are enriched in $\mathrm{K}$, $\mathrm{Rb}$ and Cs with respect to sea water. Strontium shows an inverse trend with phi units (positive with silica) due to the metamorphic rock fragments apparent in coarser grained greywackes. Zr occurs in greater concentrations in rocks of the coarse silt size range ( 4 to $5 \mathrm{phi}$ ). This is due to zircon having a preferred grain size range in natural sediments. These heavy minerals, together with opaque heavy minerals, help provide the laminations commonly seen in greywackes of this grain size range. 
- Pettijohn (1963) average greywacke

OReed (1957) composite Wellington greywacke

$\Delta$ Reed (1957) average New Zealand Lower Mesozoic greywacke

a Reed (1957) composite Wellington argillite

Wellington greywacke-suite rocks (Table 2.16)

- greywacke

- argillite

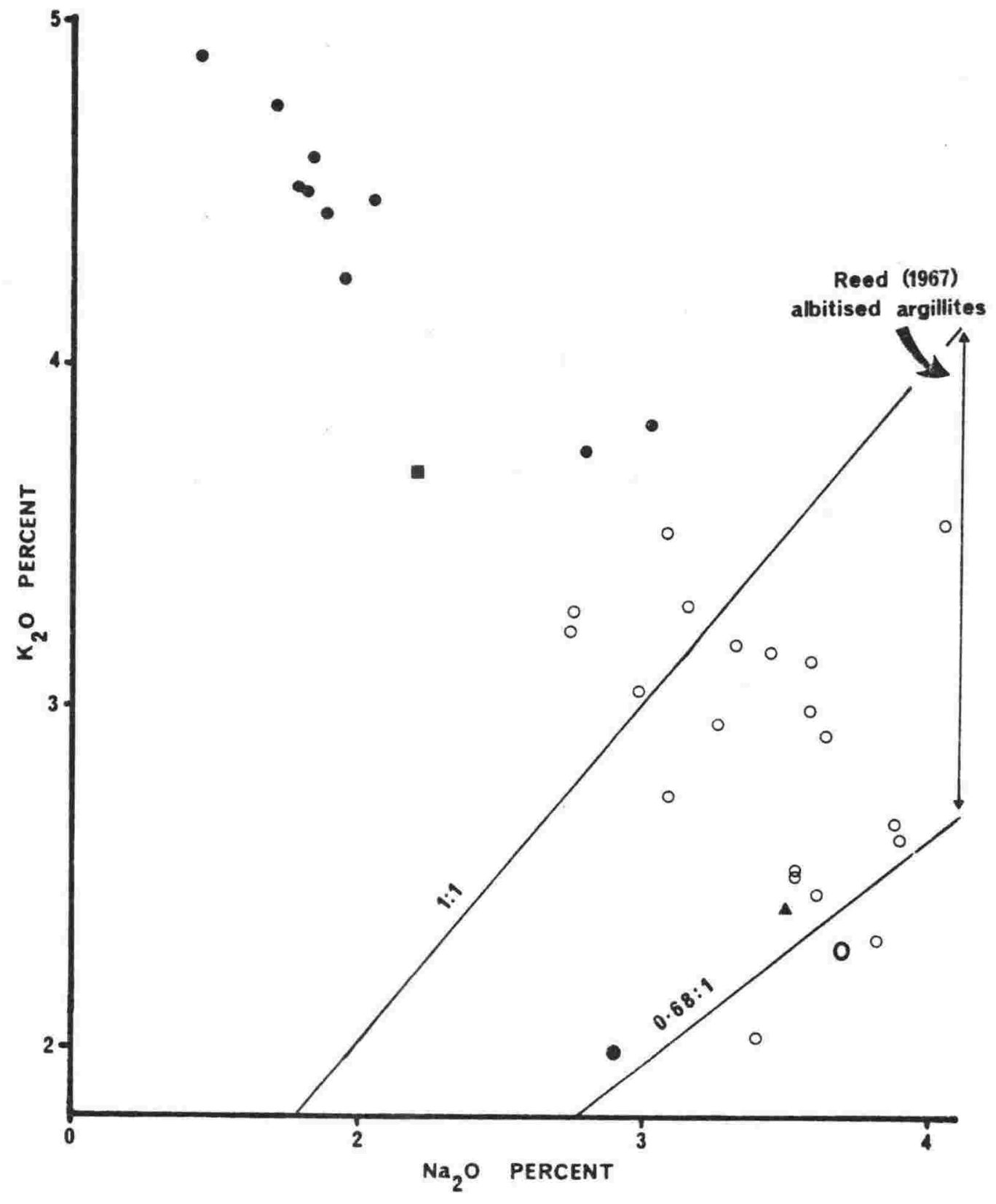

Figure 2.29 : Greywacke - argillite classification according to alkali content. Argillite is generally assumed to be rock material which plots above 1:1 line. 


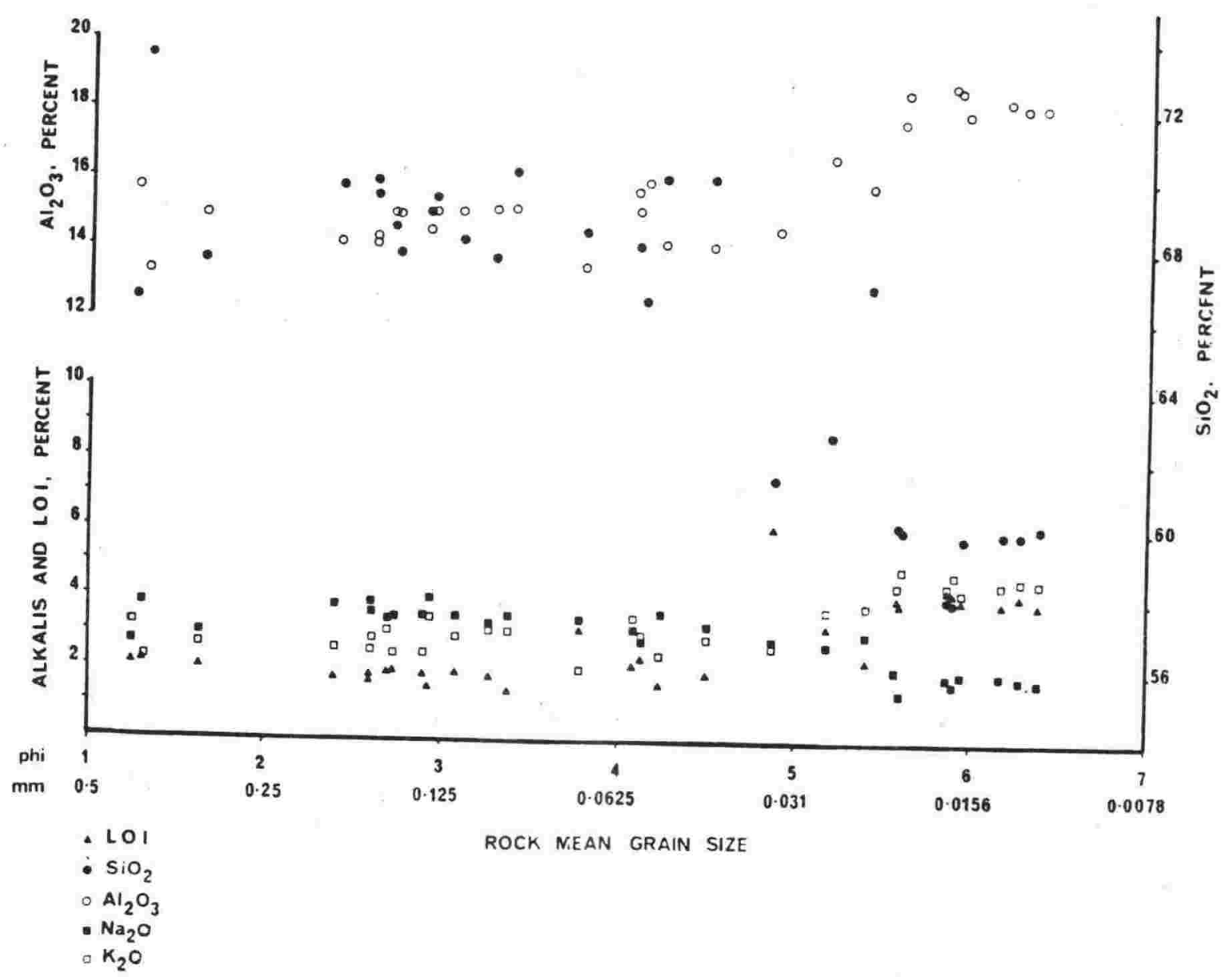

Figure 2.30 : Major element chemistry related to rock mean grain size. The transition of greywackes to argillite at the mean grain size of 5 phi $(0.03 \mathrm{~mm})$ is shown well by four major oxides and ignition loss. 

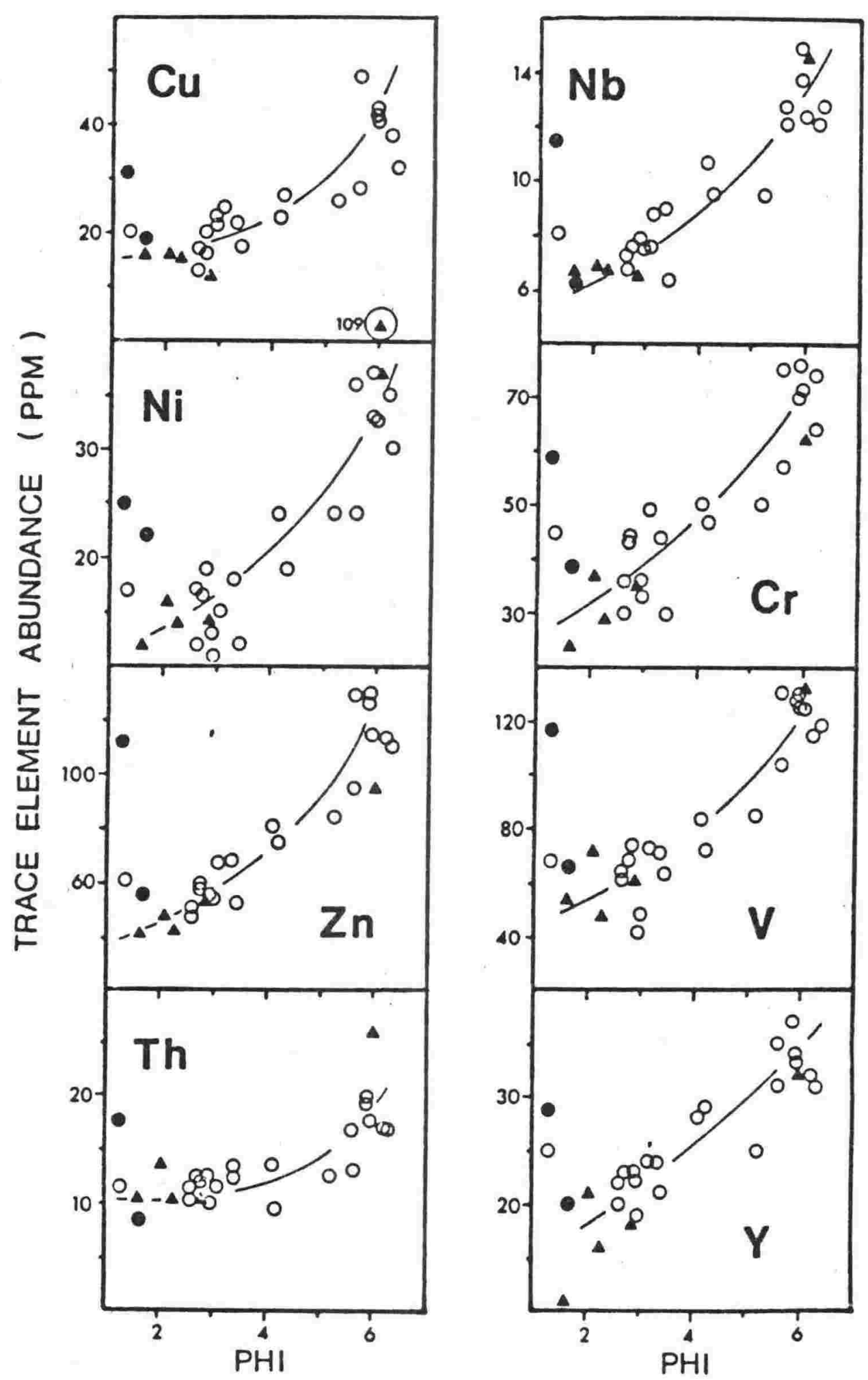

Figure 2.31 : Trace elements in Wellington greywacke-suite rocks; elements with positive correlation with phi unit

values. 
For more comprehensive discussions on trace element data see Roser (in prep.) or Rowe and Roser (in prep.).

Geochemistry of the greywacke-suite rocks is controlled by mineral modes which, for these rocks, depend on mean grain size. From the chemical data it appears that there are at least four main oxides, and loss on ignition (LOI), that may be useful for distinguishing greywacke from argillite (Figure 2.30). However, the distinction can be made only from fresh rock analyses as hydrothermal effects and weathering will alter parent rock chemistry.

The trend in silica is somewhat scattered but maintains a mean value (69.1 percent) with mean grain size to about $5 \mathrm{phi}(0.031 \mathrm{~mm})$ where, from a value of 70.5 percent, it drops to a mean of 59.4 percent in rocks finer than this size. The alumina trend is less scattered and maintains a very slight increase through the greywackes, again to approximately 5 phi where a jump of about 4 percent occurs. Sodium describes a trend, gently convex upwards, with mean grain size to a maximum in the fine and very fine sand sized greywackes, becoming more and more steeply decending after 5 phi. Potassium and LOI figures follow similar trends, remaining relatively constant to about 5 phi then rising gently some 2 percent.

Loss of ignition is lowest in the fine and very fine sand sizes.

In the very coarse greywackes (chipwackes) a drop in $\mathrm{SiO}_{2}$ and $\mathrm{Na}_{2} \mathrm{O}$ is due to the presence of argillaceous rock fragments but $\mathrm{Na}_{2} \mathrm{O}$ still exceeds $\mathrm{K}_{2} \mathrm{O}$ due to the relatively large grains of sodic feldspar and relative paucity of micaceous minerals elsewhere in these rocks.

From section 2.13, the conclusion of petrographic data, and the findings of Rowe (1979), argillite is defined as that rock material in the Wellington greywacke-suite rocks with a mean grain size finer than 5 phi $(0.031 \mathrm{~mm})$. The geochemical data strongly support this: the $\mathrm{Na}_{2} \mathrm{O}: \mathrm{K}_{2} \mathrm{O}$ ratio reversing at 5 phi, the drastic reduction of $\mathrm{SiO}_{2}$ and rise of $\mathrm{Al}_{2} \mathrm{O}_{3}$ at the same point and LOI indicating more combined water apparent in rocks finer than 5 phi.

Although there is good correlation between sedimentology, petrography, geochemistry and service records in the Wellington greywacke-suite rocks, this may not hold for other parts of New Zealand as alteration, which could change 
chemistry markedly, may have misleading effects. For example, the Auckland greywacke-suite rocks used to produce aggregate which failed in service (Reed, 1966, 1967) were described as albitised argillites and, "plotted" in terms of alkali ratios, might reasonably have been expected to behave as greywackes. In fact the rocks were often incipiently weathered and were of a mean grain size finer than the $5 \mathrm{phi}(0.031 \mathrm{~mm})$ criterion which this study suggests is more reliable. Clearly, a single chemical parameter is not sufficient to ascertain rock capabilities for engineering purposes.

Chemical composition of sedimentary rocks is a function not only of grain size, but also provenance, degree of induration/metamorphism and other post-depositional changes besides weathering (Pettijohn, 1963). The Wellington greywacke-suite greywackes show more chemical diversity than the argillites due to a greater range in texture, differing cements, and greater ranges of mineral alteration.

Probably the main reason for argillite homogenity is the lack of rock fragments and fresh feldspar.

Because of the observed chemical changes with texture, chemical differentiation may be expected within one greywacke bed due to vertical textural change. This and lithofacic differences make it extremely difficult to obtain a single reliable chemical analysis - an average - for Wellington greywacke-suite rocks. As vital as any other factor is the manner in which samples are collected.

The data expresses the range of chemical variability likely to be encountered within the suite but to use it in an attempt to average all, or even part, of the suite would be no more than speculation, without a weighting factor derived from textural considerations of constituent rocks and relative abundance within the suite.

Methods used in mapping Wellington greywacke-suite rocks (Brodie, 1953; GrantTaylor et al., 1974; Stevens, 1976) have been too rudimentary to provide such a factor but, should bulk chemical assessment be deemed necessary, current work by D. Williams (New Zealand Geological Survey) and relevant portions of this study may provide a suitable basis. 
It does appear, however, that there is relative consistency of major oxide values within each of two groups based on mean graingsze: greywackes 11.25 to $4.5 \mathrm{phi}, 0.42$ to $0.044 \mathrm{~mm})$, and argillites $(5.58$ to $6.39 \mathrm{ph}, \mathrm{t} 0.021 \mathrm{to} 0.012 \mathrm{~mm})$, (see Table 2.15 ). 


\section{Alz machines are amplifiers}

\section{Physical properties of Wellington greywacke-suite rocks}

Results from the previous chapter indicate that the Wellington greywacke-suite rocks have the following features:

(i) They comprise two dissimilar rock types; greywacke and argillite, with a rock mean grain size of 5 phi $(0.031 \mathrm{~mm})$ clearly differentiating the two. Argillites are those rocks with a mean grain size finer than 5 phi.

(ii) Greywackes and argillites have separate and distinctive mineralogies and chemistries which are directly related to the division based on size.

(iii) There is no significant difference in mineralogy or chemistry in either greywacke or argillite between lithofacies.

The most useful means hy which the Wellington greywacke-suite rocks may be characterised is their mean grain size. In this chapter, therefore, physical properties will be examined with respect to each other and to rock mean grain size.

Probably the most difficult task in assembling data was sampling, particularly where rock cores were required, made very time consuming by considerations of homogeneity, weathering, orientation and representation of in situ rock. Variation in handspecimen samples is readily observed from density and compressional wave velocity (ultrasonic velocity) data.

The physical parameters described and quantified in this chapter are those that may link fundamental geological properties with those of concrete made from derived aggregates. 
Tests and/or properties, e.g. plasticity, which may be important to other rock uses were not examined in this study which is confined to aggregate source rocks.

Unless specifically stated, no in situ information has been included and such tests as permeability, moisture movement and uniaxial compression strengths have been carried out on as homogeneous a piece of rock material as could be found (coherent rocks, Friedman, 1966).

\subsection{Rock colour}

The importance of colour in establishing both rock type and degree of weathering has long been acknowledged (Speden, 1971). In geological and quarrying pursuits the colour of fresh Wellington greywacke-suite rocks range from very light grey (N7) to black (N1), with modes, at medium grey (N5) and greyish black (N2), very crudely delineating greywacke from argillite. Colour is imparted to the rocks by their mineral components, most important of which are felsic minerals, rock fragments (especially sedimentary rock fragments), matrix and organic matter. The importance of phyllosilicates increases with diminishing mean grain size to overshadow the felsic content. Colour value (density) is enhanced by greater internal surface area so that even very felsic rocks may, if of small mean grain size, appear quite dark. Because mineralogy is related to grain size it follows, apart from the anomaly just outlined, that finer grained rocks are darker in colour. Veining tends to lighten the overall colour in the field, or in in situ rock as vein minerals such as zeolites, calcite and quartz are white.

When wetted, all rocks examined assumed higher colour values, but finer rocks have greater colour retention.

Classification by fresh rock colour is therefore possible but only where large colour contrasts exist and it is not quantitative. Rocks with similar colour values may vary geologically and/or in their physical properties.

A classification of weathering of greywacke-suite rocks has been established for Wellington (Raisebeck, 1973) and Auckland (Marshall, 1974). Both rely on colour differences for distinguishing lightly weathered rocks (Table 2.14). 


\subsection{Rock hardness}

This is a most complex property. In general, hardness implies resistance to deformation. Richards (1961) defines technological hardness as "the resistance of a material to permanent deformation of its surface". When metals are deformed or indented the deformation is predominantly outside the elastic range and often involves considerable plastic or permanent deformation. However, in dynamic hardness measurement, the elastic properties may be as important as the plastic properties. In all types of hardness, the properties of strength and elasticity are involved to some degree. The hardest rocks comprise those having hard minerals embedded in a tough* matrix or cement (Shepherd, 1951). Hardness depends on the type of binding forces between atoms and molecules and increases with the magnitude of these forces; it is closely related to the yield strength of the material.

Hardness was gauged in this study by the relative ability to withstand scratching by a specified stylus when applied to the rock surface under specified load conditions (Appendix 9). The test method adopted was that of ASTM C851-76 (1976, discontinued 1978) used to identify the quantity of soft particles in coarse aggregates, particularly those so poorly bonded that rock grains are easily detached. The test which is easy, quick, repeatable and provides comparative results was used on Wellington greywacke-suite rocks with a mean grain size range between 1.25 and $6.39 \mathrm{phi}(0.42$ and $0.012 \mathrm{~mm})$ and established those rocks with a mean grain size finer than $5.5 \mathrm{phi}(0.022 \mathrm{~mm})$ as being soft. Hence for engineering purposes, aggregate use particularly, argillites should be considered soft rocks.

The hardness of rock is due to a summation of many parameters, but mainly mineralogy, fabric and texture. From Chapter Two, both mineralogy and fabric are related to texture. The minerals mainly responsible for the relative degree of hardness in the greywacke-suite rocks are chlorite ( $\mathrm{H}=2.0$ to 2.5 Mohs scale) and white mica ( $\mathrm{H}=2.0$ to 2.5 ) and perhaps organic matter but to a lesser extent in greywackes. Chlorite and white mica increase with diminishing mean grain size and organic matter occurs in greater concentration in argillites.

* toughness: the resistance of aggregate to failure by impact (Neville, 1975). 


\subsection{Rock integrity}

The physical integrity of an outcrop is important to the study of rocks for use as engineering material, as it effects the major problems of quarrying, slope stability, winning methods, processing methods and economics.

The factors of rock integrity important to any extractive industry or engineering use include the following:

(i) Surface discontinuities - faults, bedding planes, shears, slickensides, foliation, joints, veins (their orientation, development, state of saturation and contribution to in situ permeability).

(ii) Contrasts in shear and tensile strength between the discontinuities and the rock material within which they occur.

The relationships between regional geological structural trends and folding, faulting and jointing are, as yet, unstudied (a basis for study could possibly come from guidelines set out by Harding, 1974). Certain effects of lithological control of faulting and jointing can be seen from a study of lithofacies. The lengths, widths and surface areas of discontinuities are difficult to interpret genetically but their abundance is probably the most important, and most easily quantified parameter.

The abundance of discontinuities, apart from bedding planes, veins and foliation,i.e. fractures generally:

(i) Increases in the vicinity of major faults and areas of high strain.

(ii) Increases with decreasing bedding thickness.

(iii) Is greater in brittle (competent) rocks rather than in ductile or less brittle (incompetent) rocks which tend to shear and squeeze.

(iv) Increases near the surface of the outcrop and in regions of high relief.

In Wellington rocks, faults, joints and the like far outweigh other discontinuities. Furthermore, the tensile strength between discontinuity faces is 
very low, since the surfaces are systematic, smooth, planar and continuous, without being "keyed" by large irregularities (Plate 3.1). The abundance of rock discontinuities is, therefore, of paramount important to the quarry industry and to engineering (tunnelling, base rock foundations for large structures etc.), as it directly influences slope stability, permeability, the ability of rock to be weathered, strength of the rock mass and the susceptibility of structures to earthquake damage. On a more specific scale it influences the number of discontinuities likely to be encountered in individual aggregate particles, which has been shown to be of significance (Cornwell, 1966; Marshall, 1974).

Relative abundance of rock mass discontinuities may be ascertained in several ways:

(i) By discontinuity spacing (Deere, 1964; Terzaghi, 1965; Watkins, 1970; a good summary is provided by Roberts, 1977).

(ii) By expressing a total length of discontinuities (veins) exposed in a measured area of prepared rock surface (Marshall, 1974).

(iii) By comparing the ultrasonic velocity of the rock mass with the ultrasonic velocity of a piece of intact rock material from the rock mass (Deere et al., 1969).

All three methods were used in this study but method (ii) was discontinued after correlation with method (i) was found to be poor and that it was time consuming for data yield. Problems associated with the method were outlined by the Geological Society Engineering Group Working Party (1977).

\subsubsection{Quantitative assessment of discontinuities}

A method for quantitative description of rock mass and its classification was developed by Deere (1964). The classification index, called rock quality designation (RQD), was based on analysis of recovered core; it has since been used on exposed rock faces. Pieces of core exceeding $100 \mathrm{~mm}$ in lengthare expressed as a total length and divided by the depth from which the total core was recoved. This fraction expressed as a percentage is the $R Q D$ for the rockmass. The selection of $100 \mathrm{~mm}$ as the unit for reckoning or discarding the core in the determination 


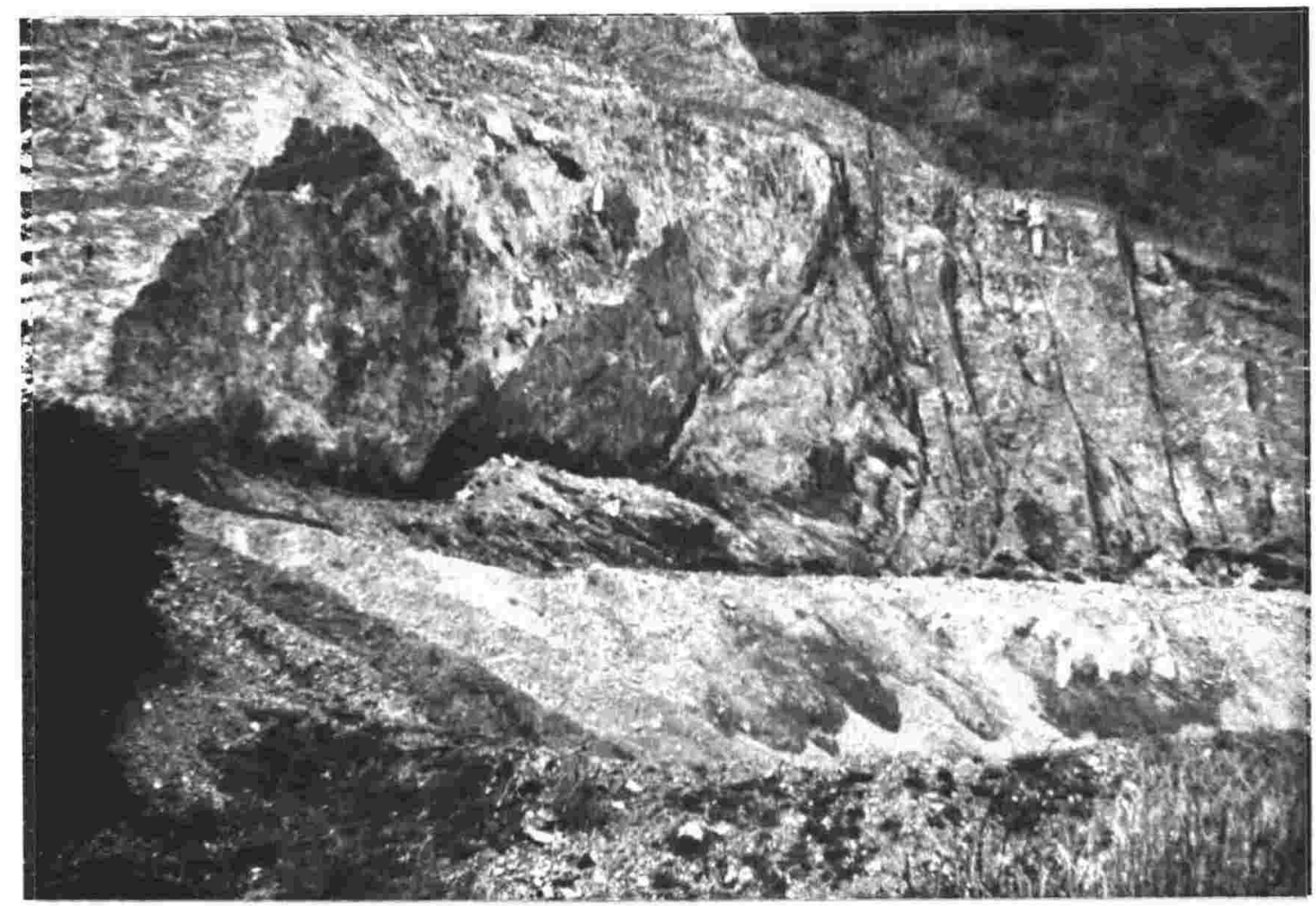

Plate 3.1 : A large bedding plane slickenside exposed in Kiwi Point quarry, Ngauranga Gorge. The quarry face is established parallel to strike. The surface shown is approximately $6 \mathrm{~m}$ high. 
of RQD has no justification except experience. Some modifications to the method have been made to obtain correlation between RQD and other parameters (Deere, et al., 1969).

Priest and Hudson (1976) found good correlation (within 5 percent) between RQD and joint frequency per metre.

Rock quality designation is a subjective observation because it is based on the number of discontinuities which are visible in in situ rock. Discontinuities include faults, shears, joints, veins, foliation, slickensides and bedding planes. These are not always discernable in the field as details are invariably lost due to dirt. The Geological Society Engineering Group Working Party (1977) affirmed RQD as a subjective technique and recommended a minimum of 200 readings per locality over continuous distances of $30 \mathrm{~m}$ or more. Where practicable these criteria were met for Figure 3.1. Raw data is presented in Appendix 11.

Spacings of discontinuities were taken along a traverse using a tape measure stretched across the outcrop perpendicular to bedding.

Individual beds within the traverse were assessed and additional data gained by shorter linear traverses within beds, measured parallel to bedding. Expressing discontinuity spacing by RQD provided little resolution, especially in the thick-bedded lithofacies, so frequency histograms were plotted for each bed (Figure 3.2).

Several trends, related to lithofacies, described in section 2.1 are apparent.

Results indicate a trend from the sandstone lithofacies through thick-bedded to the thin-bedded lithofacies of increasing numbers of closer spaced discontinuities,i.e. the sandstone lithofacies is more competent than the thickbedded lithofacies which is more competent than the thin-bedded lithofacies for any given locality. For a particular lithofacies the greywacke beds are more competent than their complementary argillite beds (Figure 3.2). Between localities, however, the same lithofacies may alter discontinuity characteristics, so that an argillite of the thick-bedded lithofacies at one locality (away from faulted areas) may have fewer discontinuities visible in situ than a greywacke of the sandstone lithofacies at another locality near faulting. 

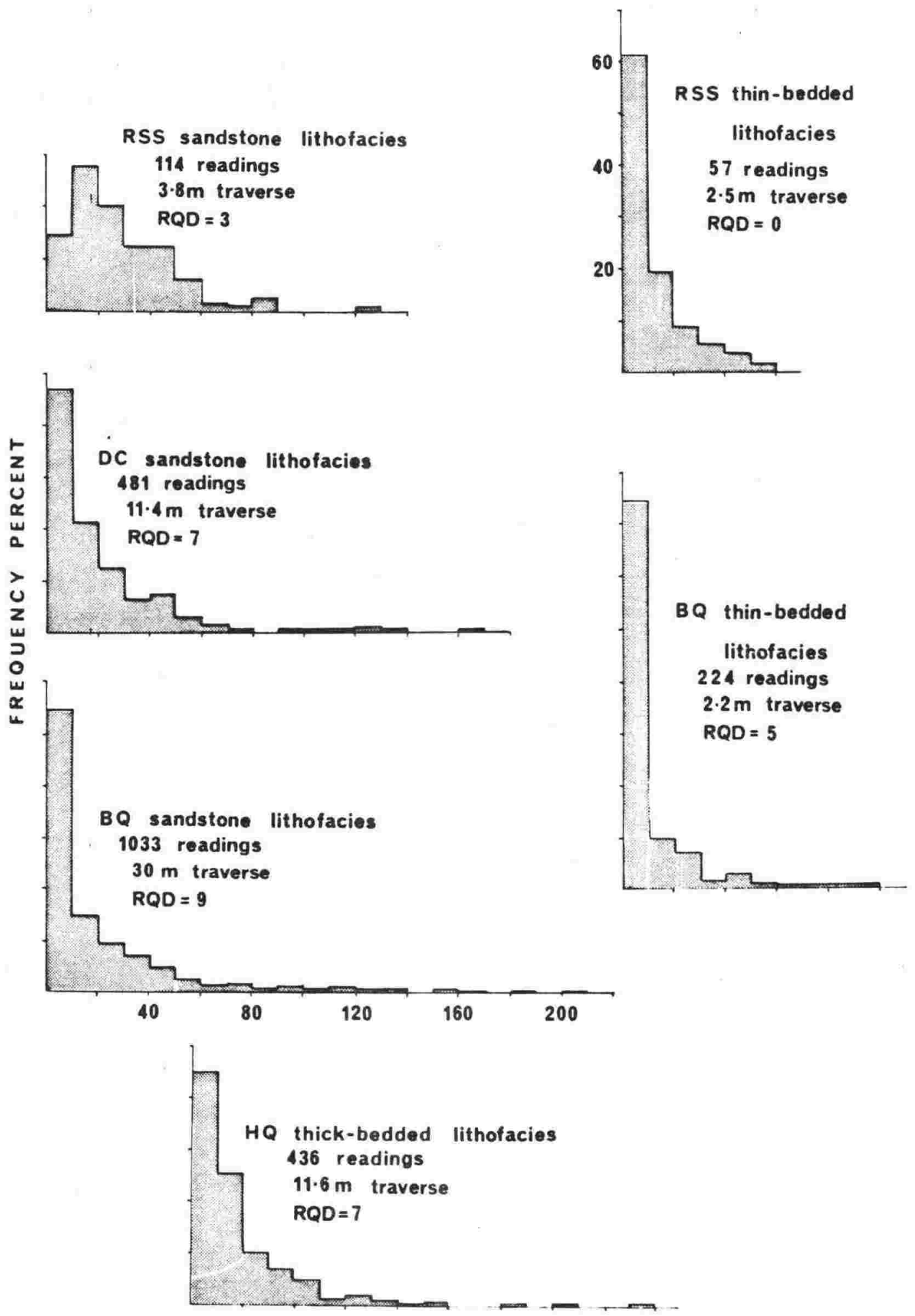

DISCONTINUITY SPACING, mm.

Figure 3.1 : Histograms showing discontinuity differences between the sandstone lithofacies (greywackes), thick-bedded and thin-bedded lithofacies of Wellington. 

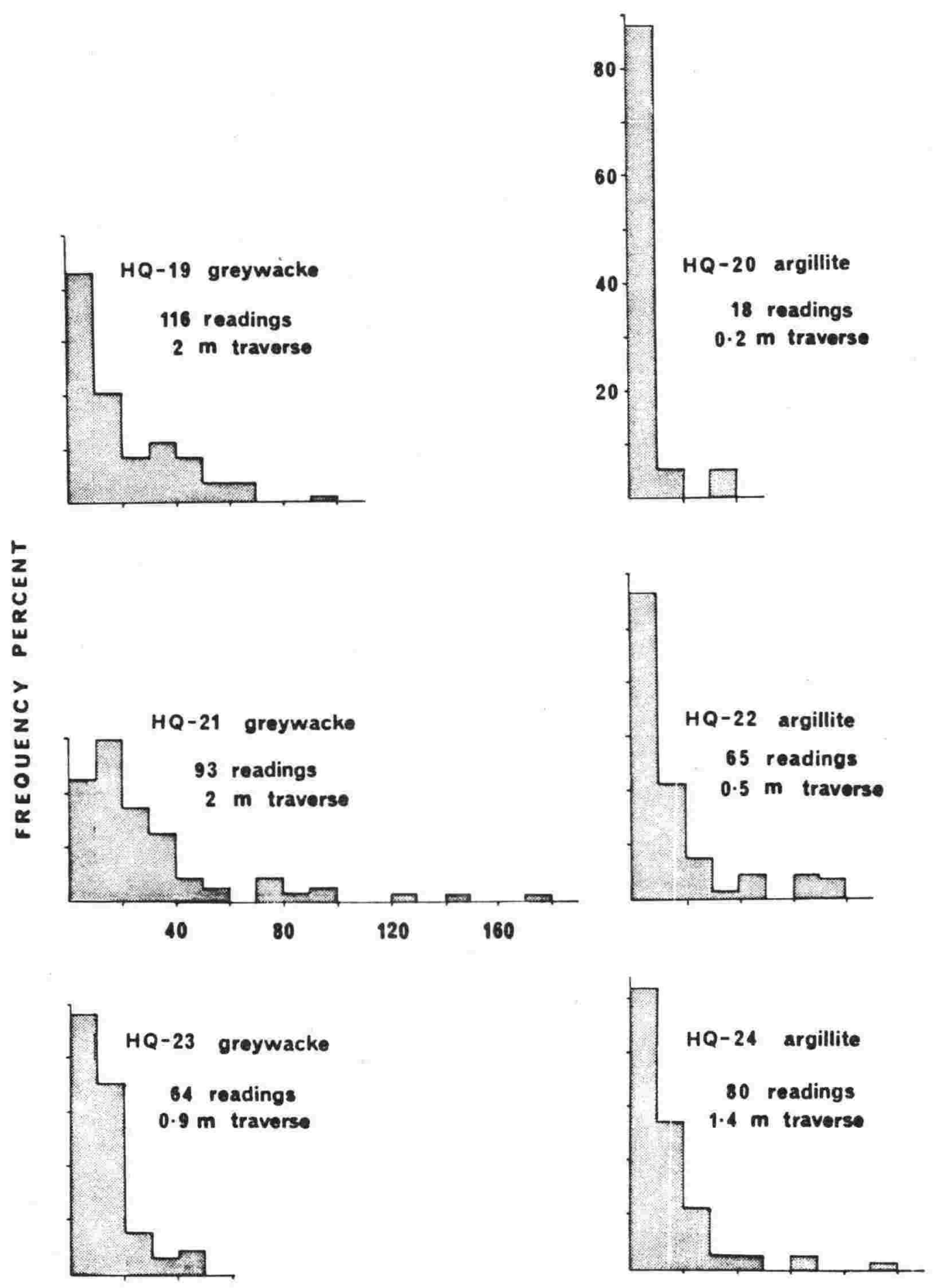

DISCONTINUITY SPACING, mm.

Figure 3.2 : Histograms showing discontinuity differences between greywacke and argillite beds of the thick-bedded lithofacies at Horokiwi quarry, Wellington. 


\subsubsection{Ultrasonic velocity}

The propagation of waves in rocks is dependent upon rock type, mineralogy, texture, density, porosity, stress, moisture content and temperature. It is related to the dynamic elastic modulus of the rock by the expression:

$$
v=\sqrt{\frac{E}{\rho} \cdot \frac{(1-v)}{(1+v)(1-2 v)}}
$$

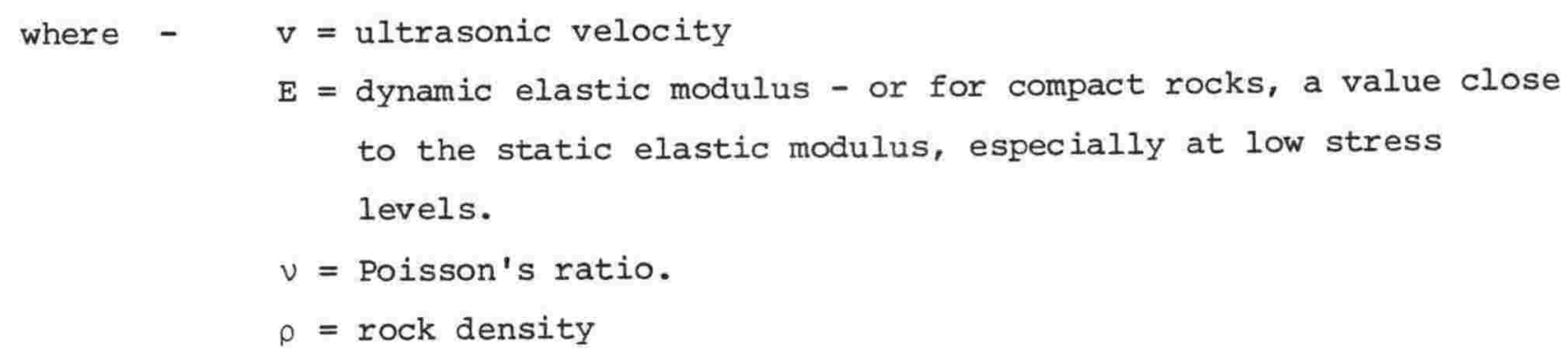

The measurement is precise, easy to undertake, may be performed on a wide range of sample sizes, and provides an assessment of rock integrity and static properties.

The ultrasonic (compressional wave) velocity of Wellington greywacke-suite rocks was measured in three different ways:

(i) Field measurements on in situ rocks of differing lithofacies to better understand the effects of discontinuities in the rock mass.

(ii) Handspecimens in the laboratory, to isolate differences in lithology.

(iii) Rock cores prepared in the laboratory.

(i) In situ testing:

Field ultrasonic velocity measurements were taken with a Geochrone manufactured by the Thiokol Chemical Corporation, Bristol, Pennsylvania, U.S.A. The instrument has been described and its performance discussed by Zachariadis (1966). 
Three traverses over $21.3 \mathrm{~m}, 15.2 \mathrm{~m}$ and $30.5 \mathrm{~m}(70,50$ and 100 feet) in the sandstone, thick and thin-bedded lithofacies respectively were examined (see Map 7, Appendix 1) .

In situ rock ultrasonic velocities are dependant on many parameters which may cause fluctuation at any given locality, water content and the degree of openness of joints both having very marked effects. To ensure stability of test conditions, measurement was carried out on a shore platform above high water mark, within a 4 hour period after a long dry spell with the following results:

$\begin{array}{lll}\begin{array}{c}\text { Sandstone } \\ \text { lithofacies }\end{array} & \begin{array}{c}\text { Thick-bedded } \\ \text { lithofacies }\end{array} & \begin{array}{l}\text { Thin-bedded } \\ \text { lithofacies }\end{array} \\ 2438 \mathrm{~m} \cdot \mathrm{s}^{-1} & 2514 \mathrm{~m} \cdot \mathrm{s}^{-1} & 2629 \mathrm{~m} \cdot \mathrm{s}^{-1} \\ \left(8000 \mathrm{ft} . \mathrm{s}^{-1}\right) & \left(8250 \mathrm{ft} . \mathrm{s}^{-1}\right) & \left(8625 \mathrm{ft} . \mathrm{s}^{-1}\right)\end{array}$

The least jointed sandstone lithofacies has a marginally lower ultrasonic velocity than the generally closely jointed thin-bedded lithofacies even though greywacke cores have consistently higher velocities than argillities cores (Appendix 10). This is probably due to the open nature of jointing in greywacke which generally allows free draining whereas, discontinuities induced by stress in the thin-bedded lithofacies, although more prolific, are closed, causing water retention.

The results indicate that even when compared to the liberal allowances made for bulldozer performance (Figure 3.3), greywacke-suite rocks generally will require blasting and at best will be difficult to rip.

As already mentioned, joints are probably the most prolific form of discontinuity existing in the Wellington greywacke-suite rocks and a transition to shears and faults is apparent. In most areas joints are planar and systematic in parallel sets. Several systems may be superposed. Their frequency and attitude to bedding, discussed by Stevens (1974), is related to the proximity of faulting.

Open joints minerally infilled, generally with calcite but sometimes zeolite, may be confused with veins, particularly near the joint. 


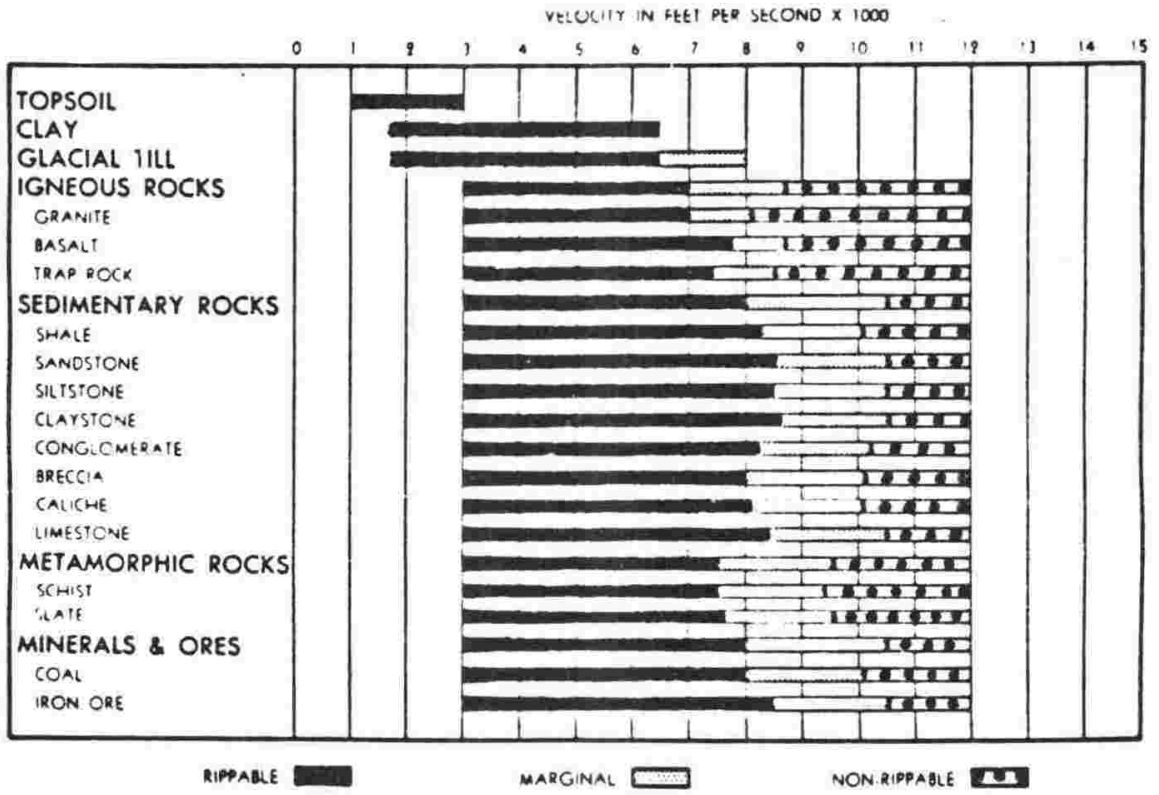

Figure 3.3 : Ripper performance as related to ultrasonic velocities (from Roberts, 1977). 
Laboratory measurements were made using the PUNDIT (portable ultrasonic nondestructive digital indicating tester). Laboratory measurements using the PUNDIT showed the same shortcomings experienced by New (1976) and a wide scatter of results from handspecimen samples is apparent (Figure 3.4, Appendix 10). Samples were prepared with 3 pairs of parallel faces for authogonal velocity studies to assess their degree of anisotropism both saturated and oven dried.

Cores used for uniaxial compression tests (section 3.5) were measured for ultrasonic velocity in two conditions; soaked in water (at $20 \pm 1^{\circ} \mathrm{C}$ ) for a minimum period of 30 days and at equilibrium with an environment of 50 percent R.H. at $20 \pm 1^{\circ} \mathrm{C}$. PUNDIT readings were taken using $15 \mathrm{~mm}$ diameter transducers and a frequency of $200 \mathrm{kH}_{\mathrm{z}}$ (least lateral dimension approximately $25 \mathrm{~mm}$ ). Results are summarised in Table 3.1 and shown in complete form in Appendix 10.

The results (rock core data) indicate that there is a reduction of elasticity in rocks of finer mean grain size when saturated but that ultrasonic velocity is constant for different moisture contents of rocks in the 4 to 5 phi mean grain size range. From handspecimen data (Appendix 10) anisotropism increases with decreasing grain size which is consistent with findings of preferred orientation (Appendix 7) and ultrasonic velocity is higher parallel to sheet layering in the phyllosilicates (Boguslavskiy, 1976).

Attempts have been made to use ultrasonic velocity as a guide to establishing rock suitability for various engineering purposes, e.g. De Puy (1965). He provides a general classification of "poor", "fair" and "good" quality rock as being rock with an ultrasonic velocity of less than $4572 \mathrm{~m} . \mathrm{s}^{-1}, 4572$ to $5182 \mathrm{~m} \cdot \mathrm{s}^{-1}$ and greater than $5182 \mathrm{~m} \cdot \mathrm{s}^{-1}$ respectively.

From Figure 3.4 the inconsistencies arising from handspecimen data are very marked and generally show reduced ultrasonic velocity values compared with rock core data. A trend of reduced ultrasonic velocity is apparent with reduced rock mean grain size. In the coarse grained greywackes (chipwackes) zeolitisation has a pronounced effect in reducing ultrasonic velocities, especially where the mineral occurs as a vein transecting the signal path. Homogenous, flawless samples (rock cores) show that the moisture content of the rock is relatively unimportant except in the case of argillites mentioned 


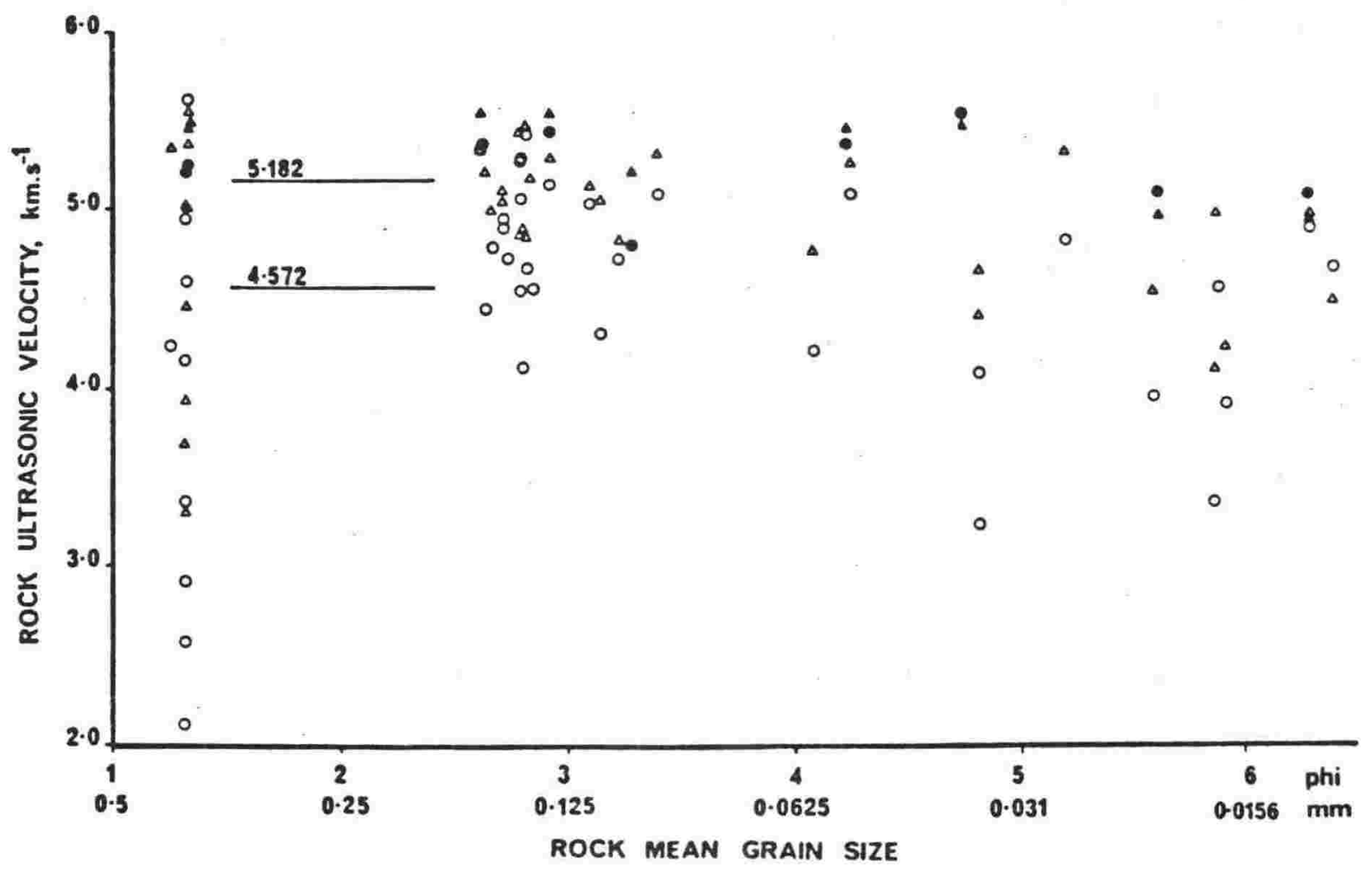

Figure 3.4 : Ultrasonic velocities diminish in value in finer greywacke-suite rocks. Handspecimen samples return scattered data compared to homogenous, flaw-free rock cores (solid points). Circular symbols denote rocks tested dry, triangles indicate saturated samples. The cored samples at 3.27 phi returned lower ultrasonic velocities due to relatively high porosities imparted by organic material. Ultrasonic velocity boundaries of De Puy (1965) are shown as horizontal lines. 
Table 3.1 : Sumarised density, ultrasonic velocity and apparent porosity data from rock core samples.

\begin{tabular}{|c|c|c|c|c|c|c|}
\hline \multirow[t]{2}{*}{ Sample } & \multirow{2}{*}{$\begin{array}{l}\text { Rock mean } \\
\text { grain size } \\
\text { phi }\end{array}$} & \multicolumn{2}{|c|}{$\begin{array}{c}\text { Ultrasonic } \\
\text { velocity } \\
\mathrm{m} \mathrm{s}^{-1}\end{array}$} & \multicolumn{2}{|c|}{$\begin{array}{l}\text { Density } \\
\mathrm{kg} \cdot \mathrm{m}^{-3}\end{array}$} & \multirow{2}{*}{$\begin{array}{l}\text { Effective } \\
\text { porosity } \\
\text { percent }\end{array}$} \\
\hline & & Dry & Wet & Dry & Wet & \\
\hline $\mathrm{DC}-6$ & 1.3 & - & - & 2643 & - & - \\
\hline $\mathrm{HQ}-17$ & 1.3 & 5230 & 5412 & 2653 & 2665 & 0.28 \\
\hline $\mathrm{SJ}-3_{1}$ & 1.3 & 5251 & 5484 & 2670 & 2692 & 0.27 \\
\hline KIW-14 & 2.6 & 5368 & 5528 & 2673 & 2679 & 0.29 \\
\hline$B Q-V$ & 2.7 & - & - & 2659 & - & - \\
\hline$B Q-1 X A$ & 2.9 & 5424 & 5526 & 2667 & 2678 & 0.34 \\
\hline $\mathrm{KS}-2$ & 3.3 & 4878 & 5220 & 2627 & 2636 & 0.48 \\
\hline$K T W-i$ & 4.2 & 5399 & 5438 & 2673 & 2679 & 0.29 \\
\hline$S J-T$ & 4.7 & 5524 & 5464 & 2696 & 2707 & 0.30 \\
\hline$O B-W$ & 5.6 & 5084 & 4945 & 2714 & 2723 & 0.38 \\
\hline$H Q-22$ & 6.3 & 5107 & 4969 & 2685 & 2702 & 0.51 \\
\hline
\end{tabular}


above. All values from greywacke rock cores indicate this rock type to be of "good" quality (de Puy, 1965), with one exception, KS-2, which is relatively porous because of the presence of organic material.

\subsection{Density and effective porosity}

Density and effective porosity values were determined in the laboratory, in conjunction with ultrasonic velocity measurements, on handspecimens and cored rock samples prepared for uniaxial compression testing (section 3.5). This was done as a potential for further classification of greywacke-suite rocks and to gain insight of their mechanical behaviour.

\subsubsection{Density}

Density determinations were undertaken using the method of Hatherton and Leopard (1964) although in some cases handspecimen sample weights did not conform to the $100-150 \mathrm{gm}$ guidelines of that paper.

To remove organic debris and loose material all samples were scrubbed thoroughly before testing. As constant temperature conditions were not available, measurements were confined to a fixed time on consecutive days during a period of stable weather. Temperature variation at the time of measurement was not great. Duplicate determinations were frequently made (Appendix 10). Rock core mean density values are shown in Table 3.1 .

Some density/porosity methods require a standard sample expressed by weight, by surface area to volume ratio, or by surface preparation (ASTM C97-47; Hatherton and Leopard, 1964). However, because of the relatively large handspecimens measured and the low values of effective porosity, the density measurements are considered accurate. The cored samples, though smaller, have a constant geometry and were measured under controlled conditions and results are again considered accurate $\pm 20 \mathrm{~kg} \cdot \mathrm{m}^{-3}$.

When plotted as histograms (Appendix 10) the results of handspecimens show a bimodal distribution for particle density. The scatter apparent in the dry and wet density histograms are attributable to micro-cracking, especially in the argillites and in greywackes which are fine grained and/or laminated or extensively veined by zeolite. Incipient weathering of some samples also gives anomolous values but bimodality may be seen in all density types. 
From Appendix 10, the particle densities reflect a change in mineralogy between modes, and this relationship is also evident from a plot of particle density against mean grain size (Figure 3.5). With smaller mean grain sizes there is an obvious increase in particle density due to a higher proportion of chlorite (s.g. $=2.6$ to 2.9$)$, white micas (s.g. $=2.76$ to 3.1 ) and heavy accessory minerals, e.g. pyrite, sphene, etc. ( $\mathrm{s.g} .=3.5$ to 5.0 ) with a reduction in the proportion of quartz and feldspar (s.g. 2.57 to 2.65). The densities corresponding to a mean particle size of 5 phi, however, cannot be used with confidence to differentiate greywackes from argillites (Figures 3.6, 3.7) because of the scatter in the data.

\subsubsection{Effective porosity}

Porosity is expressed as either total or effective porosity. Total porosity is a measure of the total pore volume including pores which may be sealed off, as well as those connected with the surface of the test specimen. It may be expressed:

$$
\text { Total porosity }=\mathrm{P}_{\mathrm{T}}=100\left(1-\frac{\mathrm{V}_{\mathrm{G}}}{\mathrm{V}_{\mathrm{B}}}\right)
$$

where $\mathrm{V}_{\mathrm{G}}$ is grain volume and $\mathrm{v}_{\mathrm{B}}$ is total or bulk volume of rock. More usually grain density $\left(D_{G}\right)$ is substituted for grain volume, and bulk density $\left(D_{B}\right)$ for bulk volume:

$$
P_{T}=100\left(1-\frac{D_{B}}{D_{G}}\right)
$$

Effective porosity $\left(\mathrm{P}_{E}\right)$, also known as apparent porosity or nett porosity, excludes sealed off or non-communicating pores. Pore volumes, $V_{P^{\prime}}$ which are interconnected and communicate with the surface of the test specimen are measured and expressed as a percentage of $\mathrm{V}_{\mathrm{B}}$ :

$$
\mathrm{P}_{\mathrm{E}}=100 \frac{\mathrm{V}_{\mathrm{P}}}{\mathrm{V}_{\mathrm{B}}}
$$

Clark (1966) discusses how the method of determining porosity may affect the values obtained. 


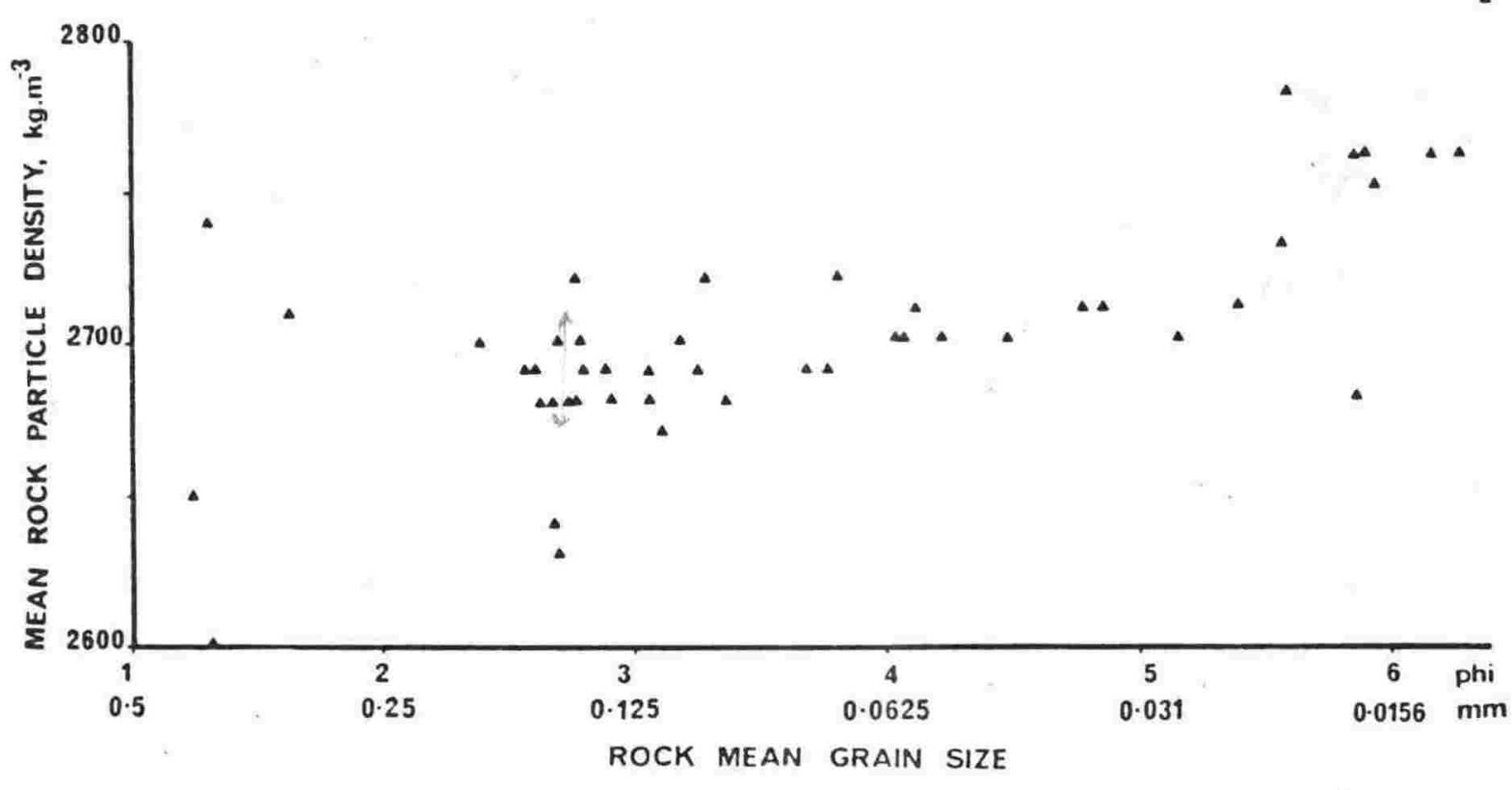

Figure 3.5 : A trend of increasing rock particle density is apparent in finer greywacke-suite rocks, particularly in those rocks finer than 5 phi. 


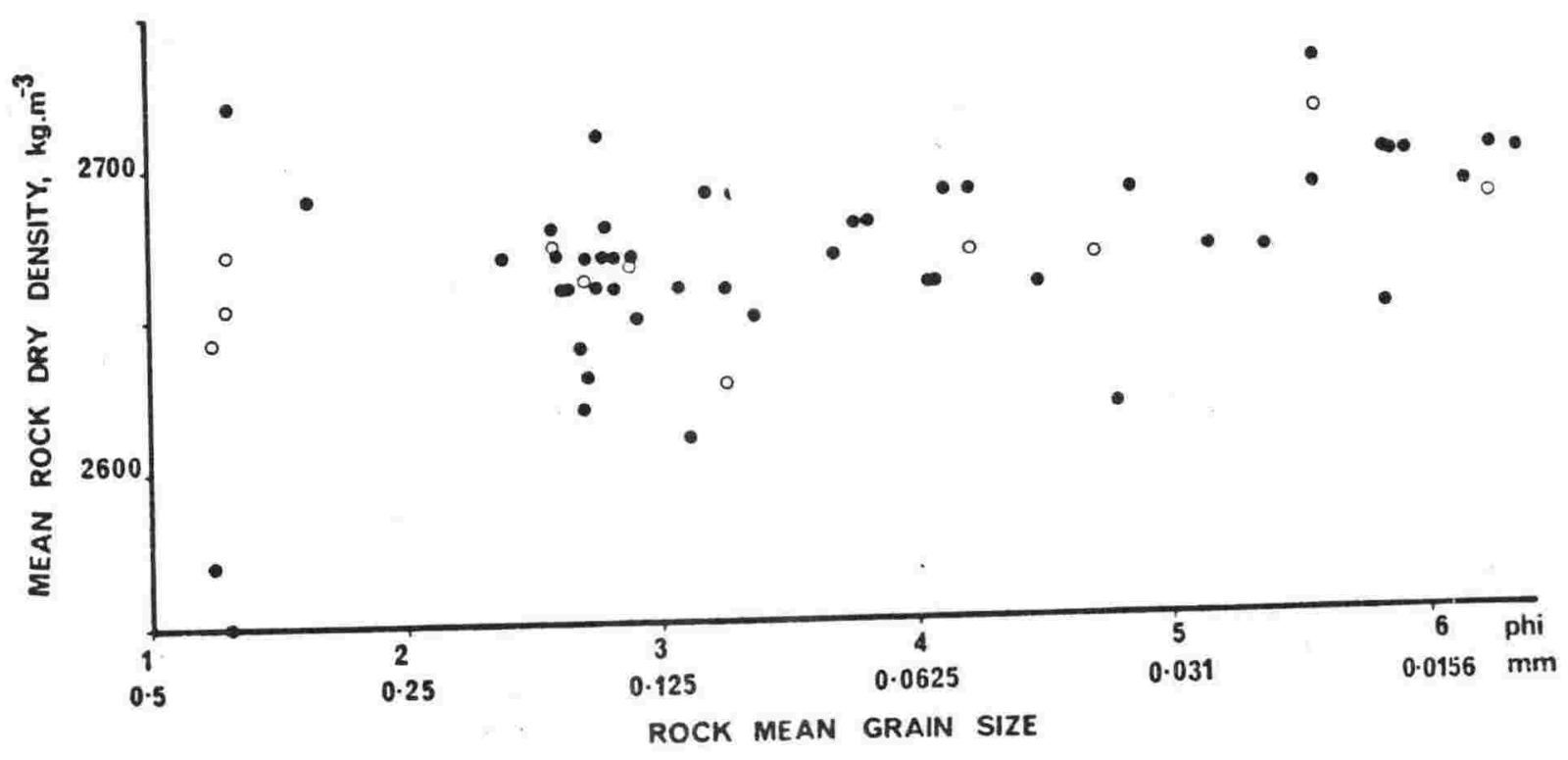

Figure 3.6 : Dry density appears to increase slightly with mean grain size. Circled points indicate core samples, which produce, for reasons of geometry and integrity, rather less scatter than handspecimens.

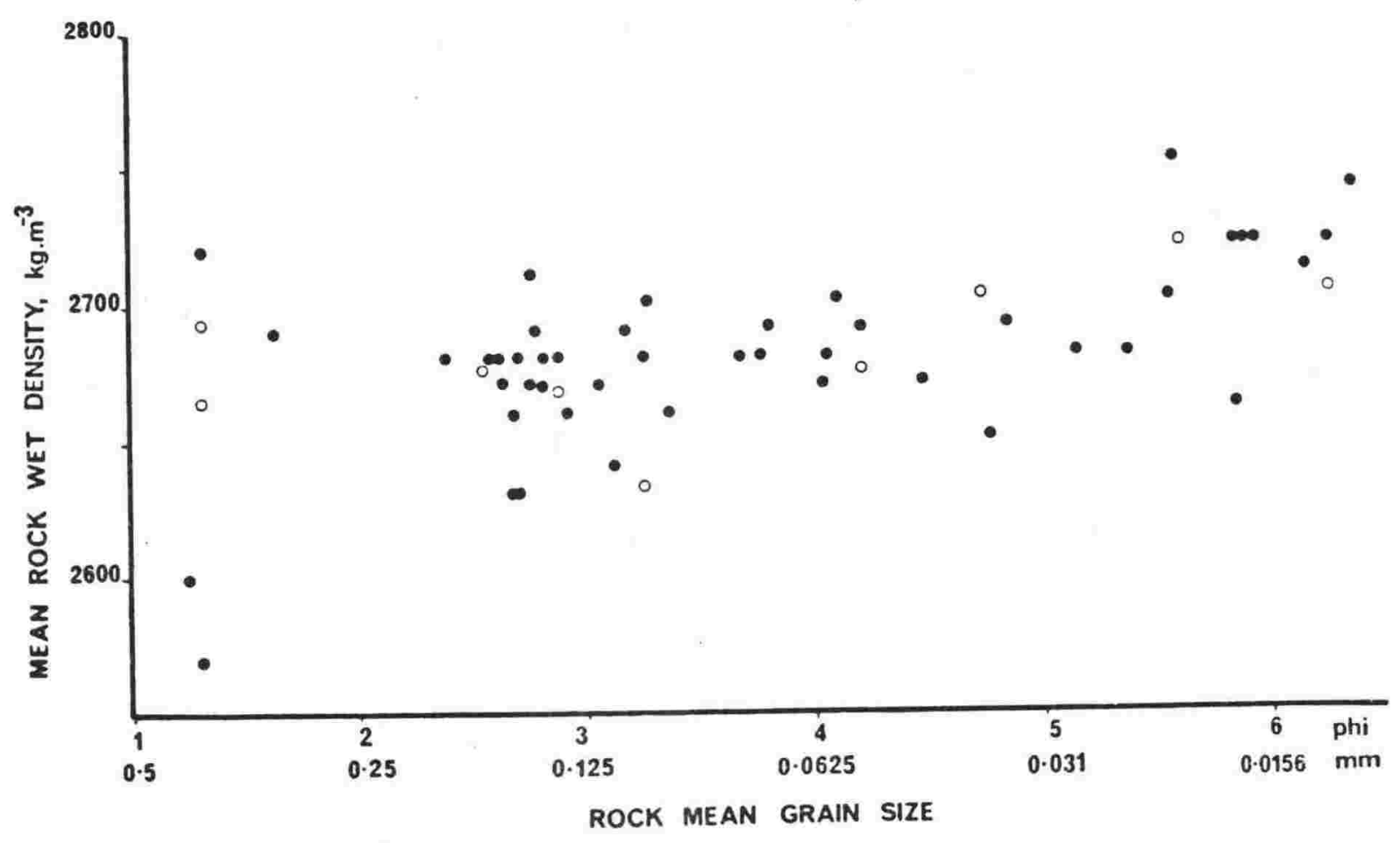

Figure 3.7 : Wet density also increases slightly with mean grain size, but the increase is much greater in rocks finer than 5 phi. Circled points are rock cores, the solid are handspecimens. 
In this study, oven dried (constant weight at $105 \pm 5^{\circ} \mathrm{C}$ ) samples were weighed, immersed in distilled water under vacuum ( $737 \mathrm{~mm}=29$ inches of mercury) for a minimum period of 18 hours then reweighed, firstly in water then in air, in a saturated surface dry (SSD) condition (NZS 3111:1974, Neville, 1975) to give both density and effective porosity data.

Vacuum was released 15 minutes before wet weighing so that air pressure could aid water penetration. Such an elaborate procedure was deemed necessary as low effective porosity was expected.

Core sample dry weight was measured at equilibrium after 5 weeks in an environment of 50 percent R.H. at $20 \pm 1^{\circ} \mathrm{C}$ and wet weight at equilibrium after 5 weeks in distilled water at $20 \pm 1^{\circ} \mathrm{C}$. Weighing was carried out in the former environment.

Results of handspecimen measurements may be found in Appendix 10. Results from rock cores are presented in Appendix 10 and are summarised in Table 3.1 .

The reduction of all strength properties of rocks with increasing porosity is well established; Lama and Vutukuri (1978) give a good modern sumary of reductions in rock compressive and tensile strengths, ultrasonic velocity and density.

Handspecimen porosity data and to a lesser degree core data, are very scattered. Figure 3.8 provides an indication of how porosity increases with reduced mean grain size - consistent with interpretation of ultrasonic velocity investigation.

In greywackes, porosity values are lower in handspecimen samples than in rock cores, in spite of vacuum assistance, probably as a direct result of the lower surface area to volume ratios of the former. For argillites the reverse is true, this being due to handspecimens having many fine fractures which open with wetting (Appendix 25) to hold relatively large volumes of water. Samples which contain organic matter, zeolite, large argillaceous rock fragments and/or are strongly laminated, generally show relatively high porosity values.

Increased porosity with reduced mean grain size does not reflect the usual 


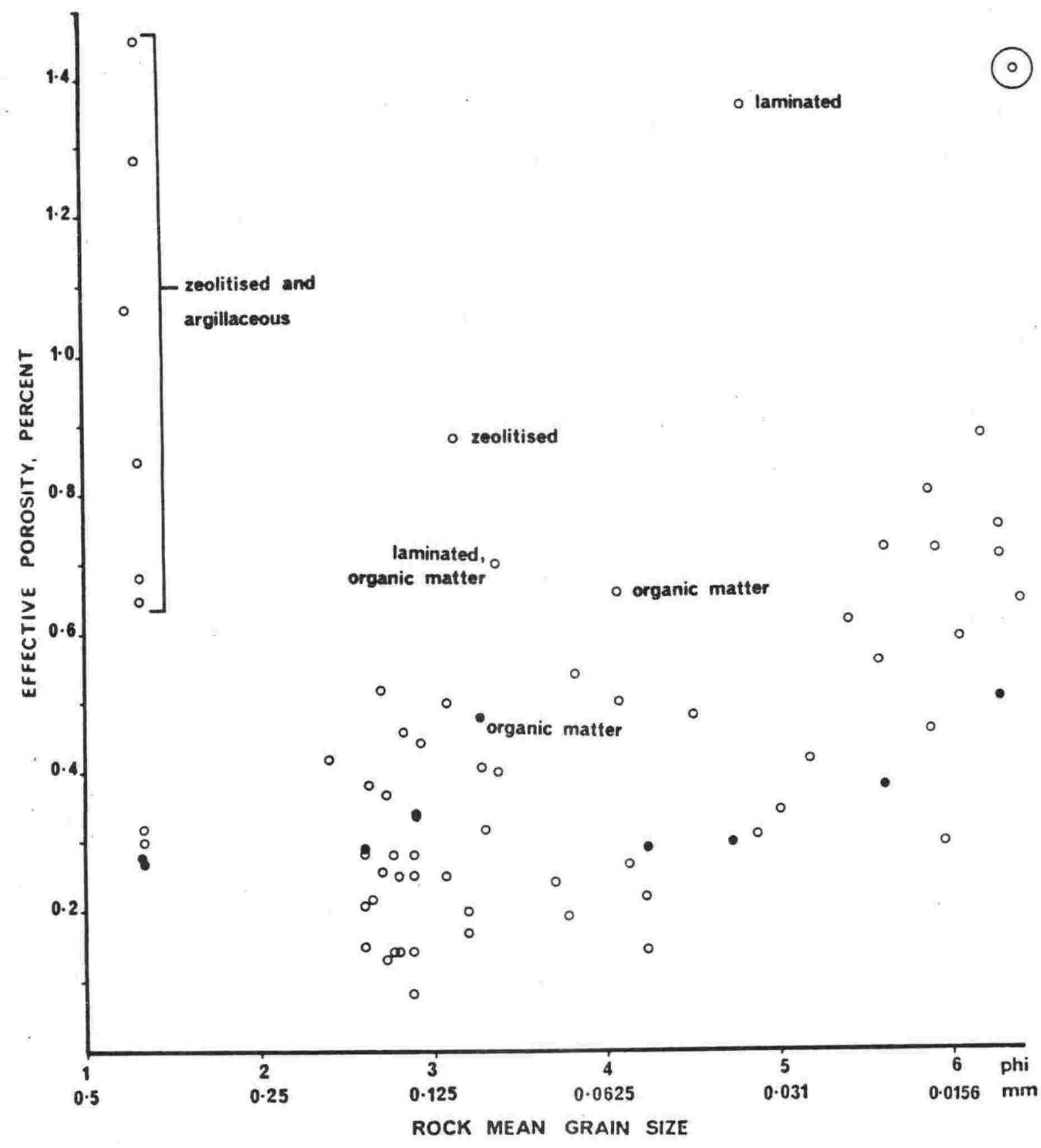

Figure 3.8 : Effective porosity values of greywacke-suite rocks increases in rocks of reduced mean grain size.

Rocks which are zeolitised, strongly laminated, contain organic matter and/or large argillaceous clasts show general increases in porosity. Rock core specimens are shown as solid symbols, handspecimens are circles. The single circled point is a very profusely microcracked argillite. 
reduction in density as with other rock types (Lama and Vutukuri, 1978) as density also increases with reduced mean grain size. The reason for this is that argillites are composed of relatively heavy minerals, mainly phyllosilicates, which possess large d-spacings. If mineral modes remained constant with reduced mean grain size and metamorphic effects remained constant throughout the range of mean grain size, then an inverse relationship between porosity and density could be expected.

\subsection{Uniaxial compressive strengths and static elastic modulus}

Uniaxial compressive strength and static elastic modulus are two of the most fundamental and informative parameters of rock materials. Both tests offer a means of engineering classification (Appendix 16).

The elastic modulus of a concrete aggregate particle influences many properties of the concrete of which it is part,i.e. flexural strength and the modulus of the concrete. Determination of strength aids in determining the types and applications of concrete, as inadequate strength of aggregate is a factor in limiting concrete strength even when the aggregate itself is strong enough to resist premature fracture.

\subsubsection{Uniaxial compressive strength}

The uniaxial compressive strength of rock is relatively easy to determine but requires meticulous preparation of many samples to give meaningful results. Sample preparation procedures are given in Appendix 12.

Compressive strength of concrete aggregate is an important consideration in concrete mix design because the strength of a concrete can never exceed that of the strongest predominant aggregate particles and the required strength of aggregate is generally considerably higher than the normal range of concrete strengths. This is because the actual stresses at the points of contact of individual particles within the concrete may be far in excess of the nominal compressive stress applied. Aggregate strengths are difficult to measure directly, and indirect test methods are usually used - point load tests, impact tests, crushing of bulk aggregate samples, crushing of geometrically prepared specimens and crushing of cast concrete specimens made with the aggregate in question. In this section results are presented from the 
crushing (uniaxial compression) of geometrically prepared greywacke-suite rock specimens.

The results (Table 3.2) show that mean dry compressive strengths are high (245 MPa, all rocks), even for argillaceous samples. Mean wet and dry argillite strengths (140 MPa and $196 \mathrm{MPa}$ respectively), are lower than those for greywacke (187 MPa and $258 \mathrm{MPa}$ ), although some argillites are as strong as greywackes for loads applied perpendicular to bedding. The scatter of mean values, for both wet and dry strengths of all rocks are about the same, the mean standard deviation being $58 \mathrm{MPa}$ and $53 \mathrm{MPa}$ respectively. The average difference between wet and dry mean strength is $45.7 \mathrm{MPa}$, with, in one case only (SJ-T), a wet strength higher than the corresponding dry strength. The ratio of the mean wet to dry strength of argillites and greywackes are comparable, 0.71 and 0.72 respectively.

The ratio of wet to dry strength is often stated to be an indication of rock softening (Michalopoulos and Triandafilidis, 1976); the higher the ratio, the lower the softening effect and the better the durability expectancy. But as argillites have been established as soft rocks (section 3.2) dynamic elastic modulus from ultrasonic velocity measurements (section 3.3.2) may provide a means of predicting durability quality.

The effect of water saturation, from a durability stand point, is more clearly seen from ultrasonic velocity measurements. Although wet and dry strength comparisons are useful, they are not important as a measurement of hardness for greywacke-suite rocks. Strength loss of a rock from water saturation is due to induced positive pore pressures (Young, 1974) and reduced bond strengths, especially in greywackes, as their behaviour is similar to that described in "undrained" tests (Paterson, 1978). For the argillites, reduced bond strength is probably the most important factor (Colback and Wiid, 1965).

Differences in mean compressive strength of cores (BQ-IXA and HQ-22) prepared and left at room temperature ( 18 to $23^{\circ} \mathrm{C}$ ) for approximately 18 months, compared with those prepared and tested after 2 months ( 1 month being at $20 \pm 1^{\circ} \mathrm{C}$, 50 percent R.H.), are interesting (Appendix 13).

In this example the strength gain over 18 months averaged $29 \mathrm{MPa}$ for BQ-IXA and $51 \mathrm{MPa}$ for HQ-22 but core height to diameter ratio (h:d) of HQ-22 was 1.5 rather than 2. Winkler (1973) suggests that higher strength of "older" 
Table 3.2 : Summary of uniaxial compressive strengths of rock cores with h:d ratios of 2, full data appear in Appendix 13.

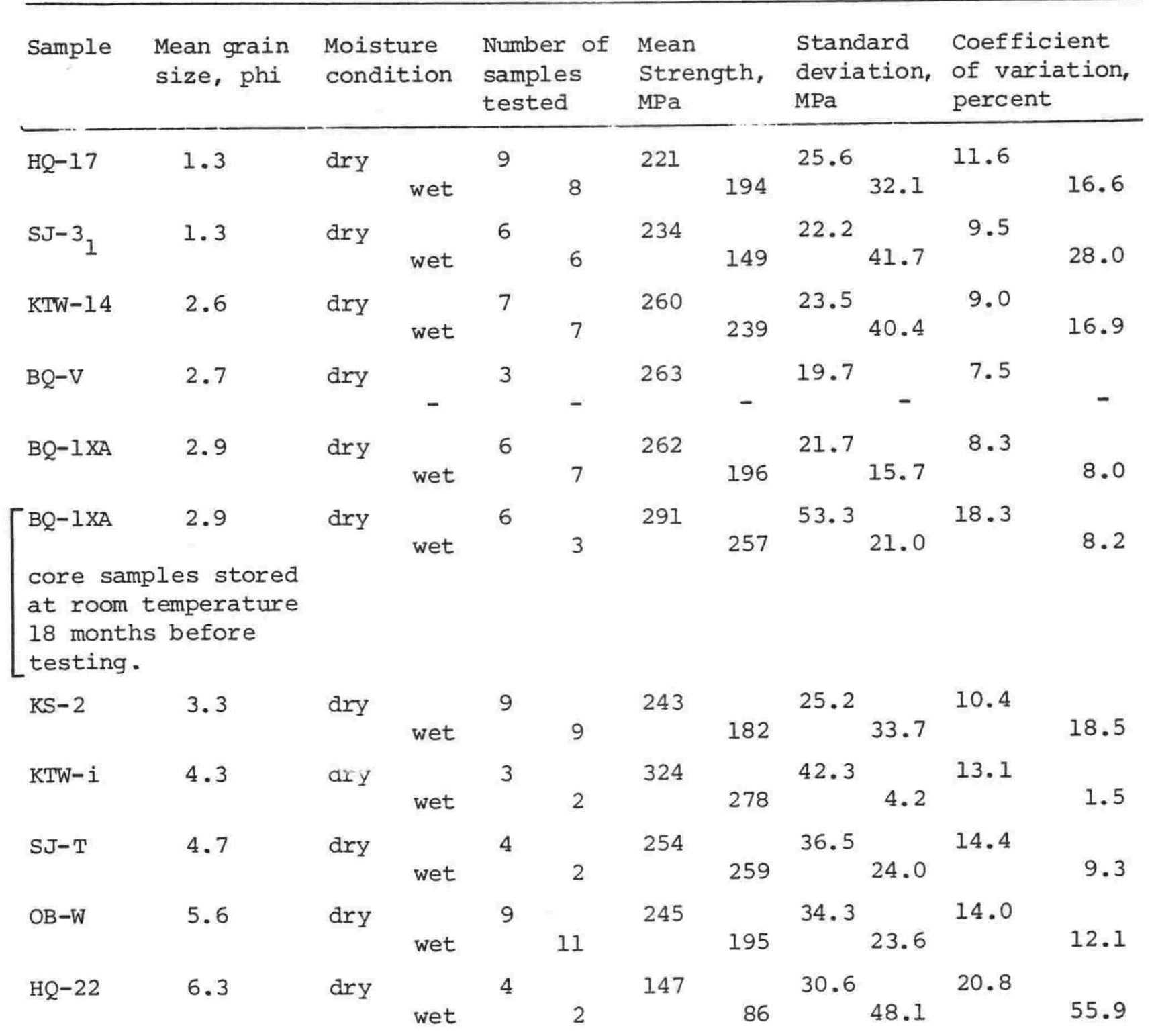


cores is due to water of various affinities gradully being lost with time. Stone masons often refer to this water as "quarry sap" (Hills, 1963); its loss increases durability but decreases workability (Appendix 25).

Results from uniaxial compressive strength tests suffer from high variability regardless of care in sample preparation and test execution. This is due to platen restraint and the presence of weakness planes in the rock which generally have less effect with decreased specimen size yielding a higher rock strength. This may be seen in Appendix 13 by comparing results from cores with h:d ratios of 1.5 and 2. Results of core uniaxial compression tests are difficult to relate to strength tests applied to the rock when crushed as an aggregate, mainly because of factors of geometry, but the test is still a means of comparing different parent lithologies.

A table from Neville (1975) is reproduced in part (Table 3.3A) to show the relative reproducibilities of different strength assessing tests commonly performed on aggregates.

The number of core sample tests required to establish means at various confidence levels has been calculated based on this study (Table 3.3B).

Results from uniaxial compressive strength testing show that mean rock strength of Wellington greywacke-suite rocks is related to mean grain size (Figure 3.9) with both ends of the textural range having relatively lower strength. Change of state from dry to wet displaces the strength curve to a lower value. Brace (1961) explained the lower compressive strength of quartzite, basalt, dolomite and limestone with increased maximum grain diameter, in terms of Griffith crack theory. This was confirmed by tests on a number of specimens of different textures but cut from a common block $\left(\mathrm{SJ}-3_{1}\right)$; the strength of the coarser specimens was lower without exception (Appendix 13). For the greywackes generally, an increase in dry and (particularly) wet strength with finer mean grain sizes is apparent to $5 \mathrm{phi}(0.031 \mathrm{~mm})$. A comprehensive discussion on brittle rock failure and Griffith theory is presented by Paterson (1978).

The lower strength of the argillaceous materials, in contrast to the generally observed trend that fine grained rocks withstand higher stresses (Paterson, 1978), may be attributed to the plastic nature of the bulk of their mineral grains - phyllosilicates. These are softer and weaker than the felsic minerals that predominate in coarser greywacke-suite rocks. 
Table 3.3(A) : Reproducibility of strength test results on aggregate. After Neville (1975).

Test

Number of samples to be tested to ensure 0.9 probability that

Coefficient mean will be -

of variation

percent

\begin{tabular}{ll}
\hline within & within \\
\pm 3 percent & \pm 10 percent \\
of true mean & of true mean
\end{tabular}

Impact of prepared specimen

17.1

90

8

Impact of bulk aggregate

3.0

-

Aggregate crushing strength

14.3

60

6

Aggregate crushing value

1.8

Los Angeles test

1.6

1

1

Table $3.3(\mathrm{~B})$ : Reproducibility of uniaxial compressive strength test results on rock cores from this study:

Number of greywacke-suite rock core samples required to estimate a mean uniaxial compressive strength (MPa) by a confidence level, within a prescribed confidence region.

\pm Difference

from mean

(MPa)

\begin{tabular}{c}
$\mathrm{D}-\mathrm{R}-\mathrm{Y}$ \\
\hline uniaxial comp. \\
\hline strength
\end{tabular}

\begin{tabular}{ccc}
$\mathrm{W}-\mathrm{E}-\mathrm{T}$ \\
\hline uniaxial & comp. & strength \\
\hline c.1. & $95 \%$ & $99 \%$ \\
& 5100 & 11800 \\
& 206 & 470 \\
51 & 120 \\
13 & 30 \\
2 & 5
\end{tabular}

Statistics by T. Aldridge, Applied Maths. Division, DSIR. 


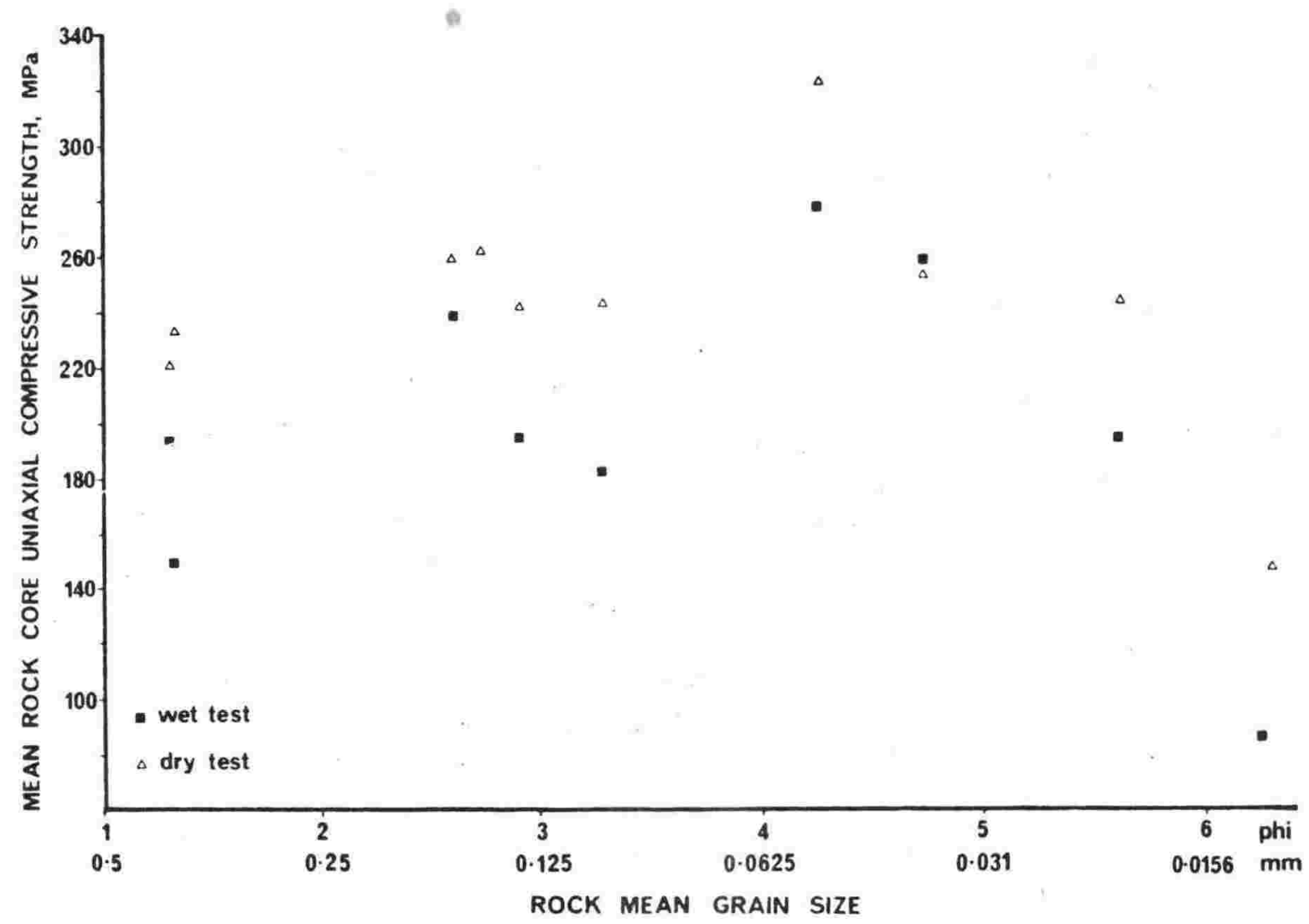

Figure 3.9 : Rock core uniaxial compressive strength related to rock mean grain size. Greywacke-suite rocks with mean grain sizes finer than 5 phi (argillites) display reduced strengths compared to greywackes which have increased strength with reduced mean grain size. Wet strengths are generally lower than dry strengths. 
There may even be a trend within the argillites of increasing strength with increasing mean grain size for reasons of crystallinity. This argument is supported by strength tests on two argillites (Table 3.2).

It is important to recognise that although the argillites have similar strengths to the greywackes tested, load was applied in a direction perpendicular to bedding. The strength of argillites where load is applied parallel to bedding would probably be reduced by approximately 10 percent due to fissility (section 2.15).

\subsubsection{Static elastic modulus}

The static elastic modulus (Young's modulus, compression modulus, modulus of elasticity or modulus of deformation) was established for each lithology tested in uniaxial compression.

This parameter is rarely determined for aggregate material but is important, as it is directly related to the elastic modulus of concrete although other factors are involved. The elastic modulus of aggregate also affects the magnitude of creep and shrinkage that can be realised by the concrete. Aggregate of low elastic modulus can be valuable in preserving the durability of concrete subject to volume changes. Lower stresses arise in concrete made with compressible aggregates when changes in temperature or moisture conditions may otherwise cause cracking of cement paste about rigid aggregate particles.

Stress-strain relationships were established, for each of three cores from each lithology both water saturated $\left(20 \pm 1^{\circ} \mathrm{C}\right)$ and $\operatorname{dry} 20 \pm 1^{\circ} \mathrm{C}, 50$ percent R.H.), by using wire resistance strain gauges (Appendix 14).

One cycle of load to failure, during which the rocks behaved as linear elastic solids, produced stress-strain curves (Figure 3.10) used to obtain the static elastic modulus of three stress levels (Table 3.4). These show interesting relationships with other physical parameters.

The initial tangent modulus $\left(E_{i}\right)$ - defined in Appendix 15 - of a saturated sample is influenced by predeformation stresses from a preliminary expulsion of water, e.g. from between platen and sample. The tangent elastic modulus 
Table 3.4 : Summary of static elastic moduli from rock cores. Full data appear in Appendix 15.

\begin{tabular}{lllccccc} 
Sample & $\begin{array}{l}\text { Rock } \\
\text { mean } \\
\text { grain } \\
\text { size, } \\
\text { phi }\end{array}$ & $\begin{array}{l}\text { Mean initial } \\
\text { tangent modulus } \\
\left(E_{i}\right), \text { GPa }\end{array}$ & $\begin{array}{l}\text { Mean tangent } \\
\text { modulus at } 50 \\
\text { percent ultimate } \\
\text { stress }\left(E_{t}\right), G P a\end{array}$ & $\begin{array}{l}\text { Mean secant } \\
\text { modulus to } \\
\text { ultimate stress } \\
\left(E_{S}\right), \text { GPa }\end{array}$ \\
\hline HQ-17 & 1.3 & 69.5 & 74.0 & 66.6 & 65.1 & 67.2 & 60.3 \\
SJ-3 & 1.3 & 73.5 & 85.8 & 73.7 & 67.5 & 73.4 & 47.7 \\
KTW-14 & 2.6 & 77.8 & 88.8 & 82.6 & 65.3 & 80.6 & 58.8 \\
BQ-V & 2.7 & 67.1 & - & 63.0 & - & 64.3 & - \\
BQ-1XA & 2.9 & 74.7 & 81.5 & 68.3 & 64.4 & 64.4 & 66.5 \\
KS-2 & 3.3 & 48.4 & 46.1 & 56.3 & 48.3 & 51.7 & 51.7 \\
KTW-i & 4.2 & 77.7 & 62.0 & 64.3 & 59.5 & 63.3 & 60.2 \\
SJ-T & 4.7 & 94.0 & 59.1 & 72.7 & 65.2 & 70.2 & 61.0 \\
OB-W & 5.6 & 63.9 & 55.5 & 51.6 & 37.1 & 48.1 & 38.3 \\
HQ-22 & 6.3 & 68.3 & 14.0 & 68.4 & 11.2 & 60.9 & 10.9
\end{tabular}


at 50 percent ultimate stress $\left(E_{t}\right)$ is reduced by saturation as is the secant modulus at ultimate stress $\left(\mathrm{E}_{\mathrm{S}}\right)$, though reduction is not uniform.

Deere and Miller (1966) compared static and dynamic properties of rocks and concluded that their magnitudes are equal for compact rocks at low stresses, although at high stress levels the dynamic properties are greater than static properties by about 10 to 20 percent. Similar findings were published by Ide (1936).

The PUNDIT tests on cores were undertaken at low stress levels (normal temperatures and pressures) and the ultrasonic velocity is related to the dynamic elastic modulus, $E$ (comparable with the static elastic modulus, $E_{i}$ ) by the relationship:

$$
E=\rho v^{2} \cdot \frac{(1+v)(1-2 v)}{(1-v)}
$$

where $\mathrm{v}=$ ultrasonic velocity

$E=$ dynamic elastic modulus - or for compact rocks, a value close to the static elastic modulus, especially at low stress levels.

$v=$ Poisson's ratio.

$\rho=$ rock density

The greatest influence on ultrasonic velocity will be E, since wet and dry densities of greywackes or argillites differ only slightly (Table 3.1). A reduction in value of $\mathrm{E}$ will lower the ultrasonic velocity as observed in the argillites (Appendix 10).

\subsubsection{Rock strength and ultrasonic velocity relationships}

It was hoped that ultrasonic velocity may provide means of evaluating rock strength. However, correlation between rock strengths and ultrasonic velocity is poor, mainly because of the inherent variability of strength test results (Table $3.3 \mathrm{~B}$ ).

It is interesting to note a tendency for dry rocks to be better resolved by ultrasonic velocity and wet rocks by compression testing (Figure 3.11). 


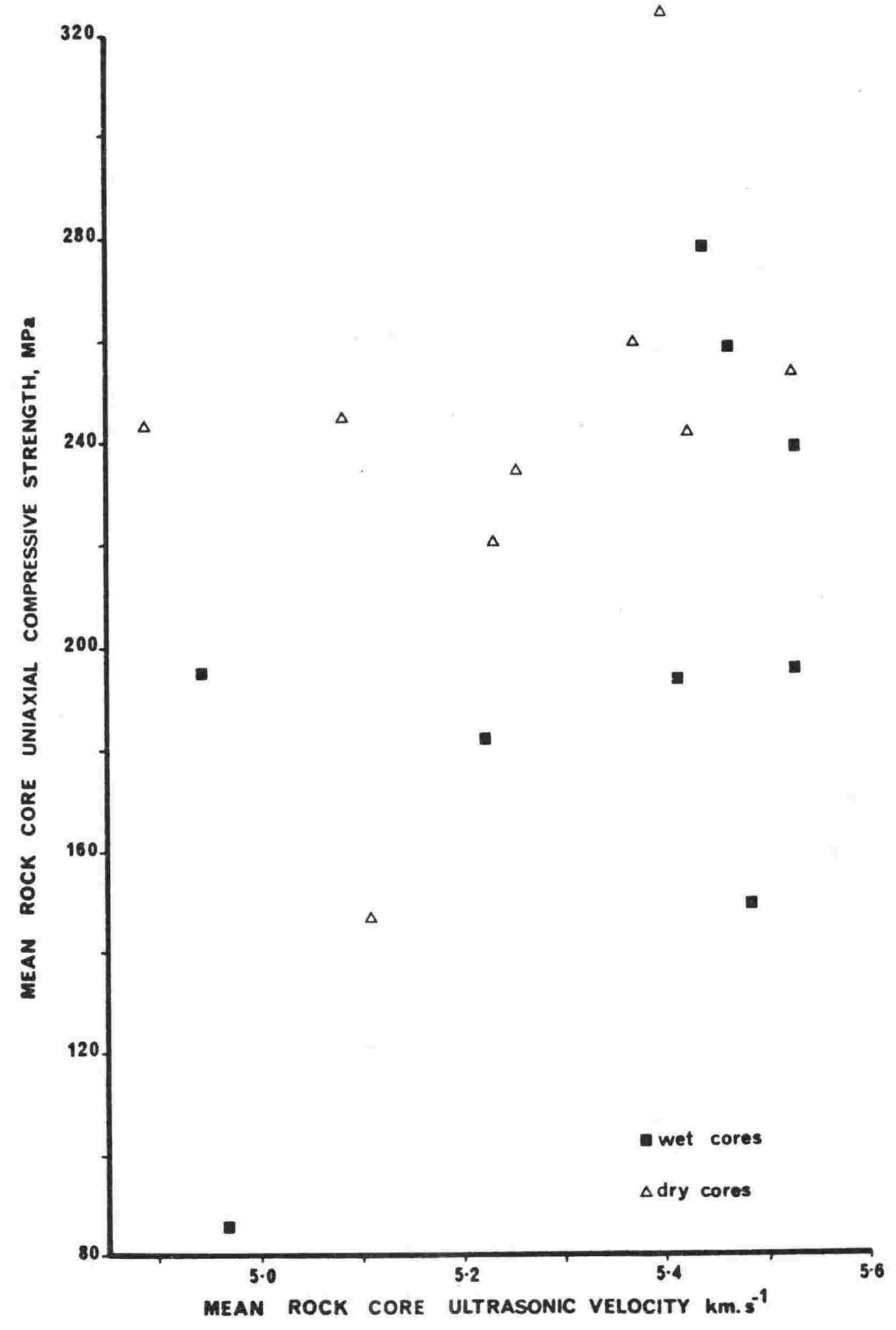

Figure 3.11 : Rock core uniaxial compression strength related to rock ultrasonic velocity. A poor correlation

exists between these two parameters. 


\subsubsection{Static elastic modulus and rock texture relationships}

The main contrast between Figures 3.12 and 3.13 is the tendency for dry rock static elastic moduli to remain linearly related to mean grain size whereas in wet rocks the relationship becomes rapidly more inverse with mean grain size finer than 5 phi. Moduli correlation improves from $E_{i}$ through $E_{t}$ to $\mathrm{E}_{\mathrm{S}}$ in dry rock but remains poor in wet rock. $\mathrm{E}_{t}$ provides the best correlation in greywackes. The moduli spread appears greater in coarser rocks.

Correlation disparity is explained by Belikov (1967) "the elastic parameters of rocks are a function of the elastic constants of the constituent minerals, but the former are generally lower than the latter because of the rock porosity which weakens the bonding between the mineral grains". He also determined elastic constants for some of the main rock forming minerals.

The felsic minerals, quartz and alkali feldspars, are more elastic than phyllosilicates and, if compared with the mineralogy of the rocks (section 2.7), the elastic modulus may be expected to be reduced in finer grained greywackesuite aggregates. Some coarse grained greywackes (chipwackes) contain large clasts of argillaceous material (sedimentary rock fragments, section 2.12) and it is these that produce the levelling effect in the curve in Figure 3.13.

\subsection{Degradation}

An important engineering characteristic of any aggregate material is stability when stockpiled, i.e. physical and chemical properties should not change to an extent where the material no longer meets specification.

These changes (collectively termed degradation when the process is deleterious) and the rate at which they take place, are especially important where an aggregate is to be exposed to weathering in service,e.g. as exposed aggregate in a concrete panel, railway ballast, road surfacing chip, rip-rap or filter blanket. 


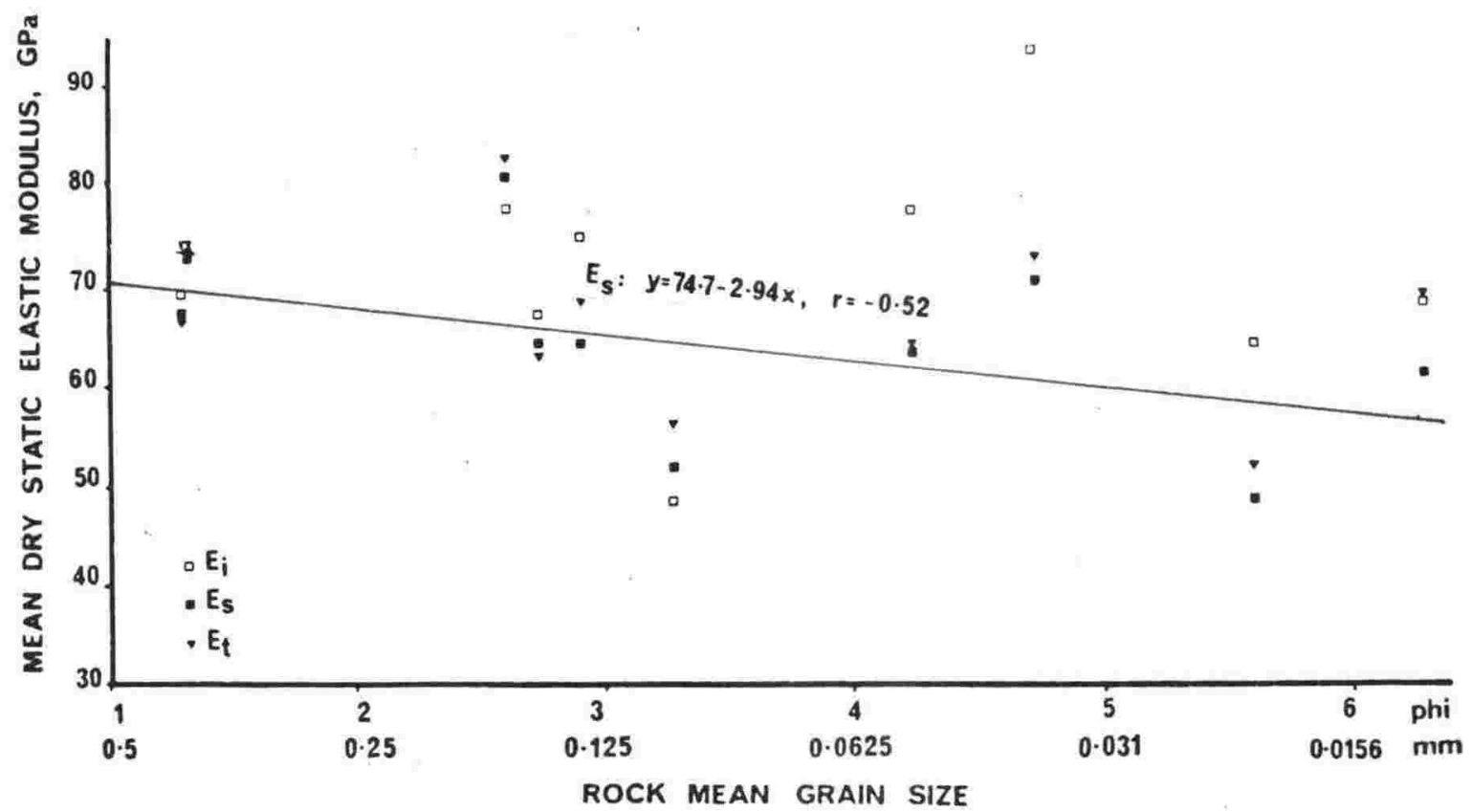

Figure 3.12 : Dry rock static elastic modulus related to rock mean grain size.

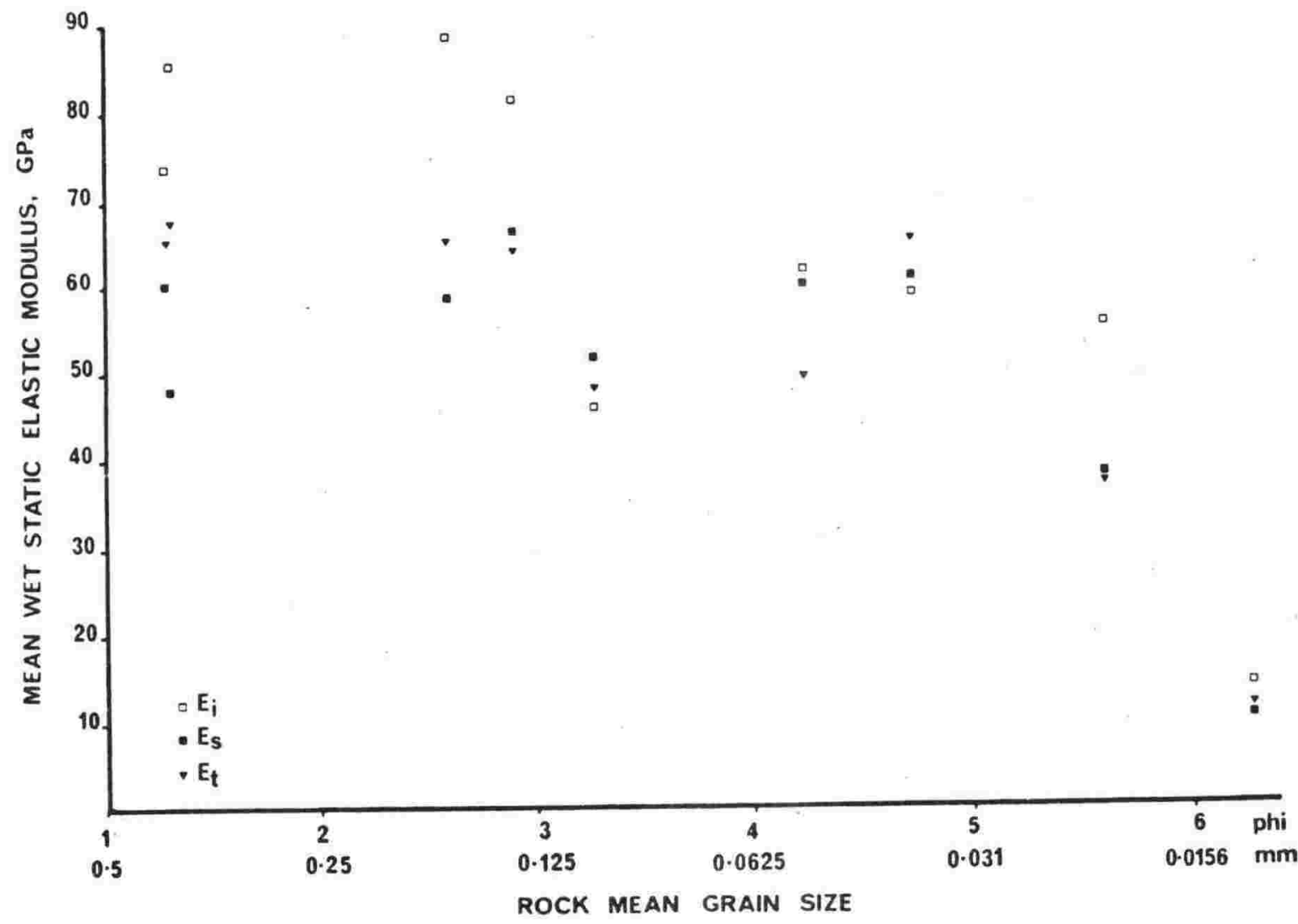

Figure 3.13 : Wet rock static elastic modulus related to rock mean grain size. Averaged wet rock static elastic moduli show an increasingly rapid decrease as mean grain size decreases. 
3.6.1 "A method for assessing degradation in New Zealand greywackes", a paper presented at the New zealand roading symposium, 1979.

Some greywacke-suite rocks do degrade and this paper and information elsewhere (Appendix 23, 24, 25) are included since relevant quantitative data is are scarce. 


\section{G.H. Rowe, First New Zealand Concrete Research Association Research Fellow}

\section{SYNOPSIS}

A laboratory method for determining the degradation potential of New Zealand greywacke-suite rocks has been developed to degrade rock aggregate in an accelerated and quantitative manner.

The test gives a Rock Stability value, here defined as the percent weight loss after 10 days treatment in 10 percent $\mathrm{HCl}$ at $80^{\circ} \mathrm{C}$ under standard conditions. The percent weight loss results from the solution of chlorite, and to lesser extents calcite and zeolite, and is a function not only of the proportions of these minerals but also of the degree of veining, fracturing and intergranular permeability.

The laboratory apparatus for performing the test is simple to construct and operate and requires minimal operator attention; it may be used to test aggregate chips or prepared rock samples.

\section{INTRODUCTION}

Over the last 15 years there has been much concern expressed over the "degradation" of aggregates (Buckland, 1967; Clelland, 1967; Cornwell, 1966; Dekker and Scott, 1969; Kear, 1965; Kear and Hunt, 1969; Reed, 1965, 1966, 1967; Skinner, 1970; Watters, 1969), particularly "wacke"-type aggregates (Kear, 1965; Reed, 1966), whilst stockpiled or otherwise exposed to weathering. This paper presents a new test developed to provide a means of better forecasting rock behaviour during storage and use as aggregate.

\section{THE DEGRADATION PROCESS}

Degradation is here regarded as the detrimental physico-chemical alteration (weathering) of rock. The two main factors influencing this alteration are mineral composition and texture (grain size). Throughout New Zealand the main mineral components of the greywackesuite rocks are quartz, sodic plagioclase, white micas and chlorite, with a texture range from gravel to silt size.

Marshall (1974) has shown that chlorite is the first of the four main minerals to be eliminated during weathering, the dominant processes being oxidation and hydration. Chloritic materials are common in greywacke-suite rocks, ranging from 7 percent to 90 percent (Rowe, in

Research Fellow Geology Department, Victoria University of Wellington. prep.). It was therefore concluded that the loss of chlorite was a critical factor in the degradation of aggregate. Degradation should also be influenced by the effects of inherent fabric structures, microcracks, preferred orientation etc. and the effects of elastic relief and desication rock experiences during quarrying before being subjected to heating/cooling and wetting/drying cycles of natural weathering.

\section{TEST PRINCIPLE AND ASSUMPTIONS}

It was assumed that chlorite is the first common mineral to be destroyed by weathering and that therefore an indication of rock performance could be gained by measuring the loss of chloritic components. The method adopted follows that of Carroll (1970), utilising a 10 percent concentration 8 Hydrochloric acid (by volume) at $80^{\circ} \mathrm{C}$, and relates percent weight loss to rock stability.

The weight loss, due largely to the solution of chlorite is a function not only of the proportion of chlorite in the sample but also to the degree of veining, fracturing and intergranular permeability.

Preliminary tests were on small chips of greywacke-suite rocks in open beakers. Dramatic changes occurred after only six days; the finer grained, more chlorite rich rocks were physically disrupted by crystallising iron compounds as the acid solution dried. Flaws, invisible prior to testing, were enhanced and disruption duplicated degradation effects observed in the field. Colour changes, too, were consistent with those seen in naturally degrading rock being leached to a lighter value* accompanied by concentrations of iron oxide giving yellow, yellow-brown and light red-brown surfaces and margins. Pieces able to be pulled apart in the fingers after testing often displayed a mineral coating on the parted planes which possessed a blue-grey metallic sheen. The coating is pyrolusite $\left(\mathrm{MnO}_{2}\right)$, chlorite having manganese occurring within its crystal lattice (B. Roser, pers. comm.; G. Bird, pers. comm.; Deer et al., 1971).

Degraded rock material from these tests was generally one to six millimetres in size, equidimensional with sharp, flaky form. A type of exfoliation process was seen in samples possessing strong preferred orientation, a phenomena more apparent with decreasing mean grain size. Samples all assumed a lighter colour after testing, with an increase in porosity and loss in weight. $\mathrm{X}$-ray

* Rock - colour chart; Geol. Soc. America 1970 . 
diffractometry confirmed chlorite has been removed from samples along with zeolite (laumontite) and calcite apparent in some samples.

\section{DEVELOPMENT OF TEST APPARATUS}

Following encouraging preliminary tests an apparatus was designed and built (Fig. I), essentially an insulated wooden box with a heat source to one side (a 60 watt light bulb serving as a pilot and illuminating light). A partition divided the box to give slight heat gradient both horizontally and vertically so that convection tubes (Fig. 1), which contained the sample were held perpendicular to the partition and allowed the acid solution placed within the tube to slowly circulate. After inclusion of the sample and the acid, the top was sealed with acid resisting plastic film, heat resisting plastic film and a rubber bung.

\section{DEVELOPMENT OF TEST PROCEDURE}

Time taken to reach the test temperature did not exceed one percent of the total testing time so that the temperature rise had little significant effect on samples. Numerous trials of using different sample loadings and heat source wattages were used to establish an optimum test situation in which the apparatus maintained a temperature of $84 \pm 3^{\circ} \mathrm{C}$ with ambient temperatures between $16^{\circ} \mathrm{C}$ and $22^{\circ} \mathrm{C}$.

A small sample of VUW standard chlorite, $196 / 1 / 1(b)$, was tested over 10 days to establish a maximum percent weight loss for chlorite and to ensure that the volume of acid used in the test was sufficient to prevent it being exhausted by the reaction. The percent weight loss of the chlorite standard was 60.7 percent. The sample after testing was a soft skeletal, porous mass with a pearly lustre: the "talc" layers of mainly Si and Al. Chemical analyses (Deer et al., 1971) of chlorites indicate that major oxides other than $\mathrm{SiO}_{2}$ and $\mathrm{Al}_{2} \mathrm{O}_{3}$ i.e. $\mathrm{MnO}, \mathrm{Fe}_{2} \mathrm{O}_{3}$, $\mathrm{FeO}, \mathrm{MgO}^{2}$ and $\mathrm{H}_{2} \mathrm{O}^{2}$, sum to an average of approximately 60 percent.

Samples were cut to give an approximate weight of 18 grams and dried to constant weight at $105^{2} 3^{\circ} \mathrm{C}$, cooled in a dessicator and weighed to four decimal places before being tested.

Relative performance between samples was quantified by establishing a percent weight loss.

Two trials, one using an argillite (mean grain size $6.28 \mathrm{phi}=0.013 \mathrm{~mm}$ ) and the other a greywacke (mean grain size $2.9 \mathrm{phi}=0.13 \mathrm{~mm}$ ) established that the precision of the test method at 10 days of testing to be $\{2.4$ percent weight loss and -0.8 percent weight loss respectively (fi.g 2 ). The trials also showed the trend of percent weight loss with time to be linear after four days of testing. Argillite lost more weight over any given interval of time than greywacke and its rate of weight loss is therefore higher at any time but especially the first four days of testing.

Plate 1. Showing the Rock Stability apparatus in operation. Note the wire strand, to hold convection tubes in an upright position. Insulation is provided by $12 \mathrm{~mm}$ polystyrene plastic covered with aluminium foil.

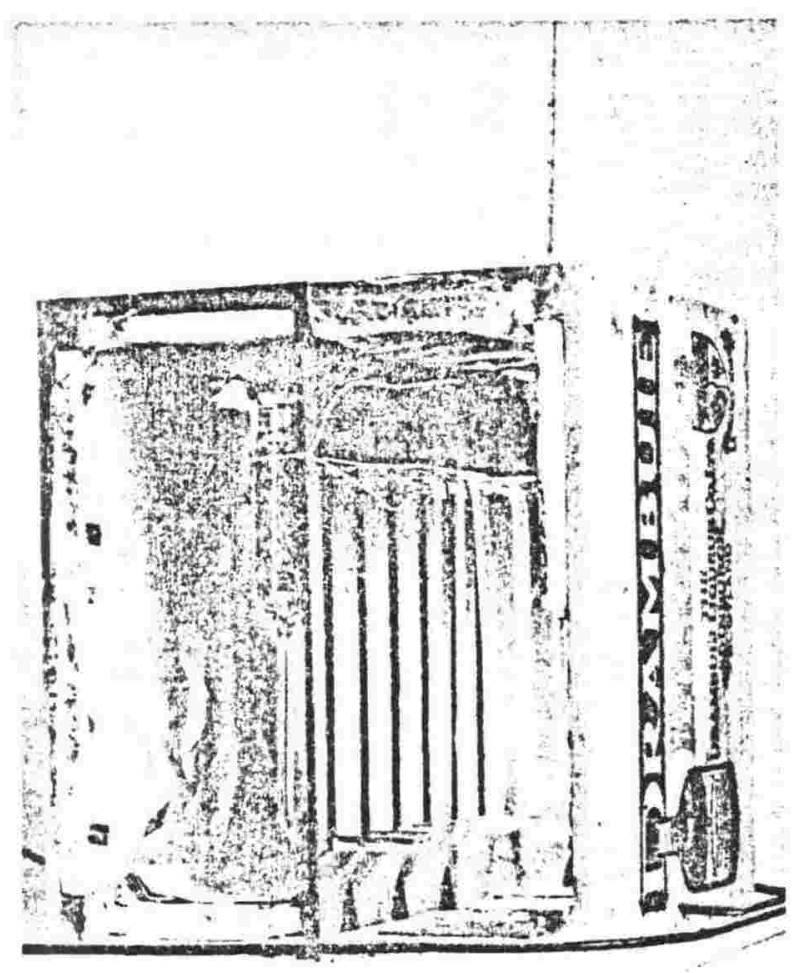

Surface area/volume ratios of samples were assumed to have a significant effect on test results, the larger this ratio the higher the expected percent weight loss. Trials were made with similar specimen shapes of differing dimensions so that weights differed. Weights and test results are shown in Table 1.

Samples cut after testing showed that leaching had occurred to a depth related to the manner in which the sample was prepared as well as rock type. There was a slight leaching to form a halo beneath a slickensided surface; the leaching halo being deeper beneath the surface for a naturally fractured surface than a sawn surface for any given rock type. The depth of leaching did not exceed four millimetres for most samples. Destruction of chlorite, i.e. halo penetration, did not proceed to the centre of the sample unless it was extremely flaky or small. Visible and invisible fractures (microcracks), iron oxides, the occurrences of calcite, laumontite and chlorite, especially along foliation planes, yielded higher percent weight losses.

It was apparent that though there may be changes in the Rock Stability value for different size aggregates due to differences in surface area/volume 
Figure 1.

Rock Stability apparatus shown in vertical and

horizontal section to give

basic dimensions and

illustrate relative

positions of internal

fittings. A maximum of six convection tubes were used.

c.f. Plate 1. Dimensions in millimetres.
Horizontal

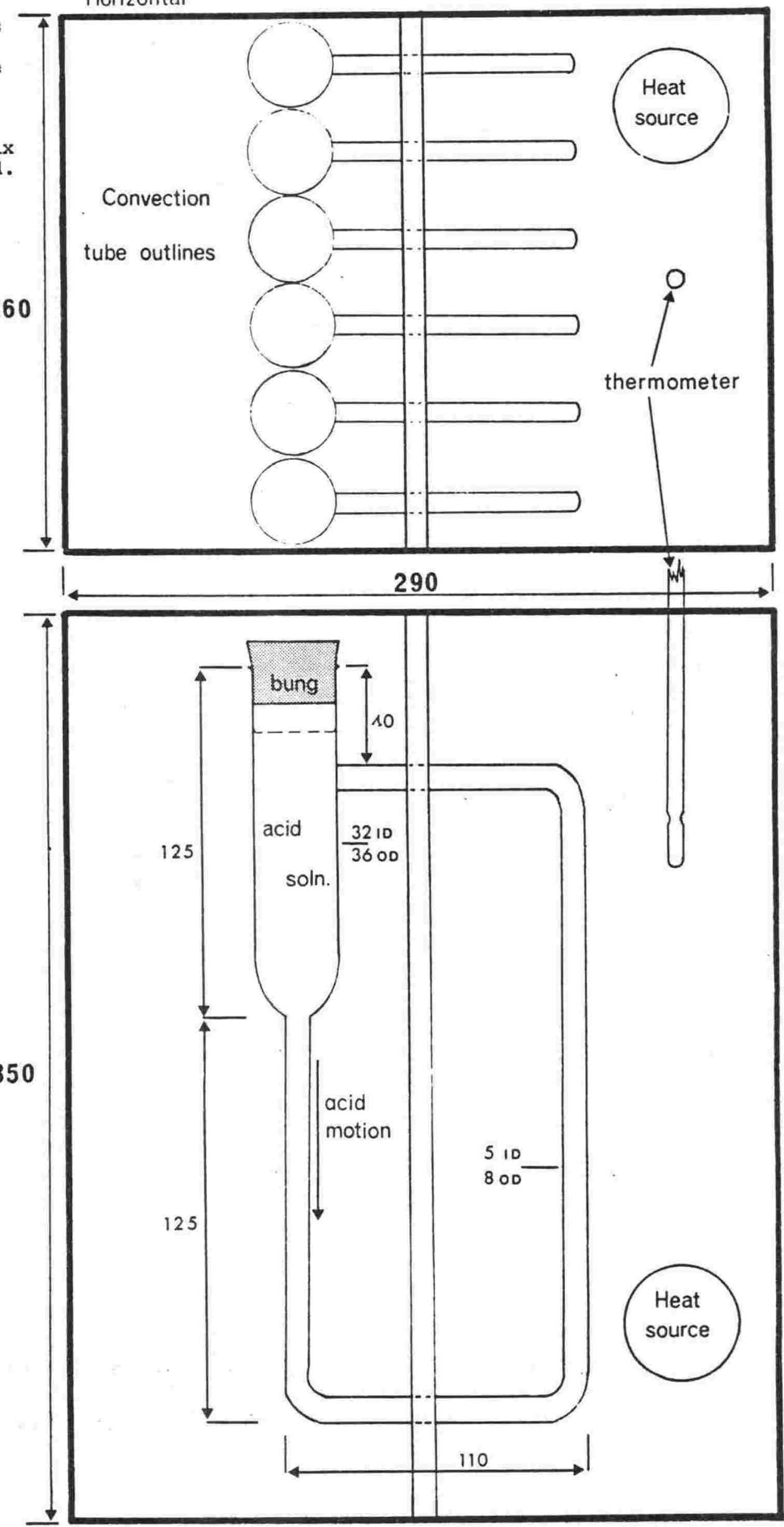




\section{Figure 2}

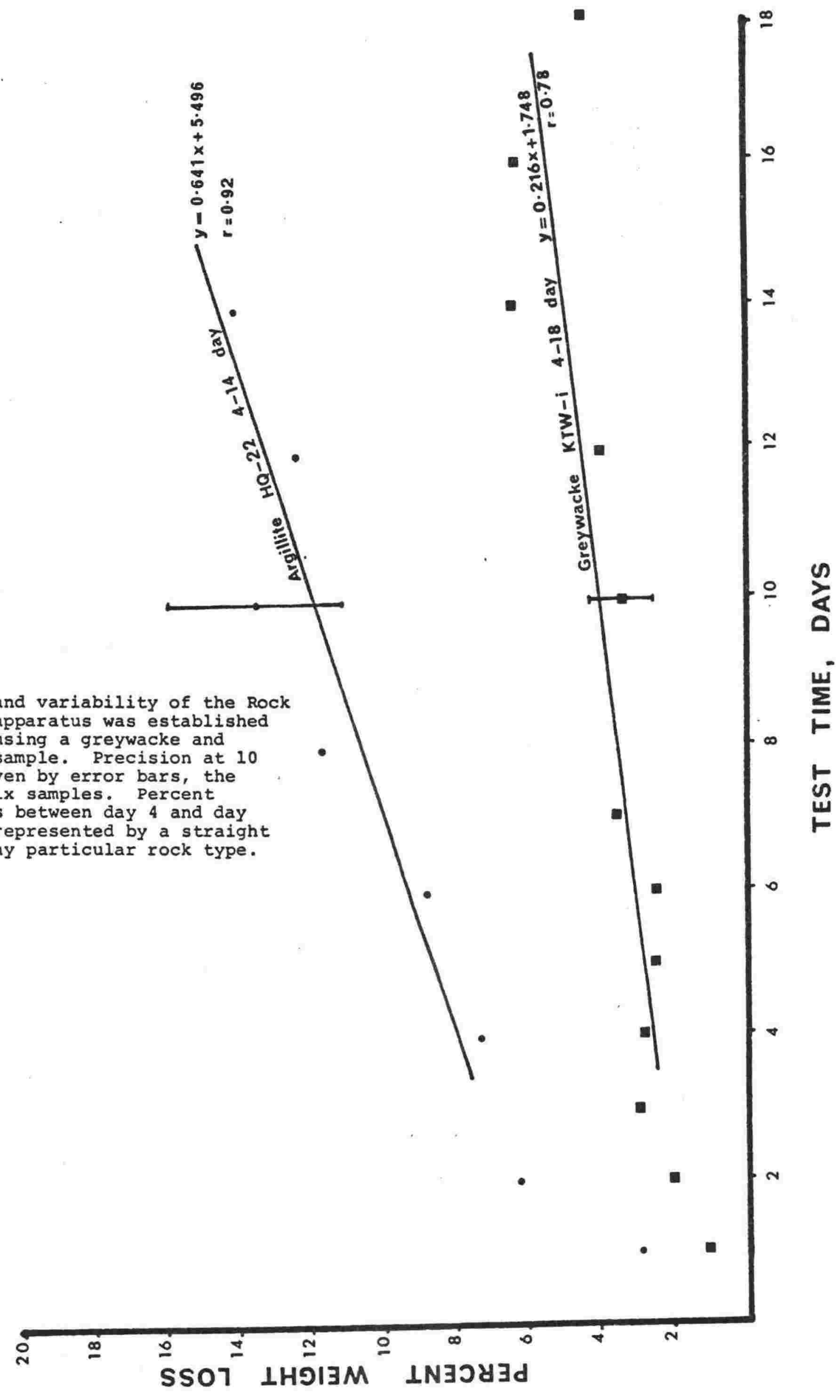

Precision and variability of the Rock Stability apparatus was established by trials using a greywacke and argillite sample. Precision at 10 days is given by error bars, the range of six samples. Percent weight loss between day 4 and day 12 may be represented by a straight line for any particular rock type. 


\section{Table 1}

The effects of surface area to volume ratio are indicated by using samples of different weight for a similar geometrical shape. Argillites show a tendency towards higher percent weight loss in heavier samples. Greywackes show highest percent weight loss with the lightest sample; scatter within the samples indicates surface area:volume ratio of samples of given weight relatively unimportant.

Oven dry sample weight before testing (gm)

Rock Stability Value

GREYWACKE BQ-IXa

$\begin{array}{ll}46.0954 & 4.2 \\ 41.9840 & 4.2 \\ 36.4027 & 5.1 \\ 34.6257 & 4.9 \\ 33.1153 & 5.5 \\ 29.6689 & 4.9 \\ 24.3285 & 5.6 \\ & \text { mean } 4.9 \\ & \end{array}$

ARGILLITE HQ-22

$\begin{array}{lr}50.8953 & 11.5 \\ 37.4426 & 11.4 \\ 31.4076 & 16.2 \\ 25.9724 & 15.0 \\ 22.9726 & 14.1 \\ 19.0884 & 13.7 \\ 18.9196 & 12.3 \\ & \text { mean } 13.5\end{array}$

ratios there was no significant effect for samples in the weight range $18-50 \mathrm{gm}$ (Table 1), which corresponds to the size range 19-25 $\mathrm{mm}$.

Samples are subjected to physico-chemical degradation in the same way as natural weathering agencies. The test therefore indicates the vulnerability of rock particles to degradation.

In quarried aggregates irregularities in gross surface texture and shape may increase percent weight losses.

\section{ROUTINE RESEARCH METHOD USED}

Approximately 120 greywacke-suite rock types, mostly from Wellington, have been tested in the following manner:

Representative samples were cut from large hand-specimens to measure approximately 25 - $30 \mathrm{~mm} \times 12 \mathrm{~mm} \times 12 \mathrm{~mm}$ with flat, coarse ground sides and weighing between 10 and $25 \mathrm{gm}$ but averaging 18 $19 \mathrm{gm}$. Commercialiy available aggregates were tested by selecting six pebbles typical of a $25-20 \mathrm{~mm}$ grading and meeting the overall criteria of dimensions and weight mentioned above.

Samples were dried in an oven $1105 \pm$ $\left.3^{\circ} \mathrm{C}\right)$ until they reached constant weight (six hours minimum), cooled in a vacuum desiccator and weighed (to four decimal places), before being sealed in the convection tubes with 10 percent HCl and subjected to a temperature of $83 \pm 3^{\circ} \mathrm{C}$ in the apparatus for four days. They were then removed from their acid solutions, rinsed overnight in slowly circulating tap water to leach all acid and soluble reaction products, dried, weighed, then returned to their respective tubes (and acid) and tested for a further eight days.

The percentage weight losses at four and 12 days was calculated for each sample:

$$
\frac{w_{0}^{-w_{x}}}{w_{0}} \times 1008
$$

\section{where $w_{0}=p r e t e s t$ oven} dry weight $w_{x}=$ oven dry weight at four and 12 days respectively

The average percent loss per day. for each sample was calculated over the period between day four and day 12 i.e. the gradient of a straight line joining the four and 12 day percent weight losses on a percent weight loss versus time graph:

$$
\frac{W_{12}-W_{4}}{8}=8 \text { weight loss per day. }
$$

The physical condition of the specimens before and after testing were recorded.

\section{RESULTS}

Figure 3 summarises the results obtained (based on approximately 120 samples), which are clearly separated into two groups by a well defined band (hachured in the figure) in which few samples plotted.

\subsection{Geological factors influencing results}

significantly weathered rock tended to have high percent weight loss rates, initially, due to higher porosity, permeability and concentrations of susceptible iron in readily mobile forms (samples 1 B 17 , 1B 22; fig 3). Other samples (DC-LAM, KTW-iii, WCC-23A) are laminated sand and silt sized rocks with increased effective porosities due to fissility developed parallel to bedding and high preferred orientation, encouraging permeability parallel to bedding. Concentrations of organic material in finer laminations also increases porosity and permeability.

Fresh samples with high weight percent losses (HQ-22) are susceptible to treatment due to microcracking giving increased surface area. The cracks (less than $0.004 \mathrm{~mm}$ wide) had not been detected with the naked eye before testing. 
Figure 3 The relative effects of microcracking, lamination, weathering, zeolites and organic matter content of rocks subjected to the Rock stability test.

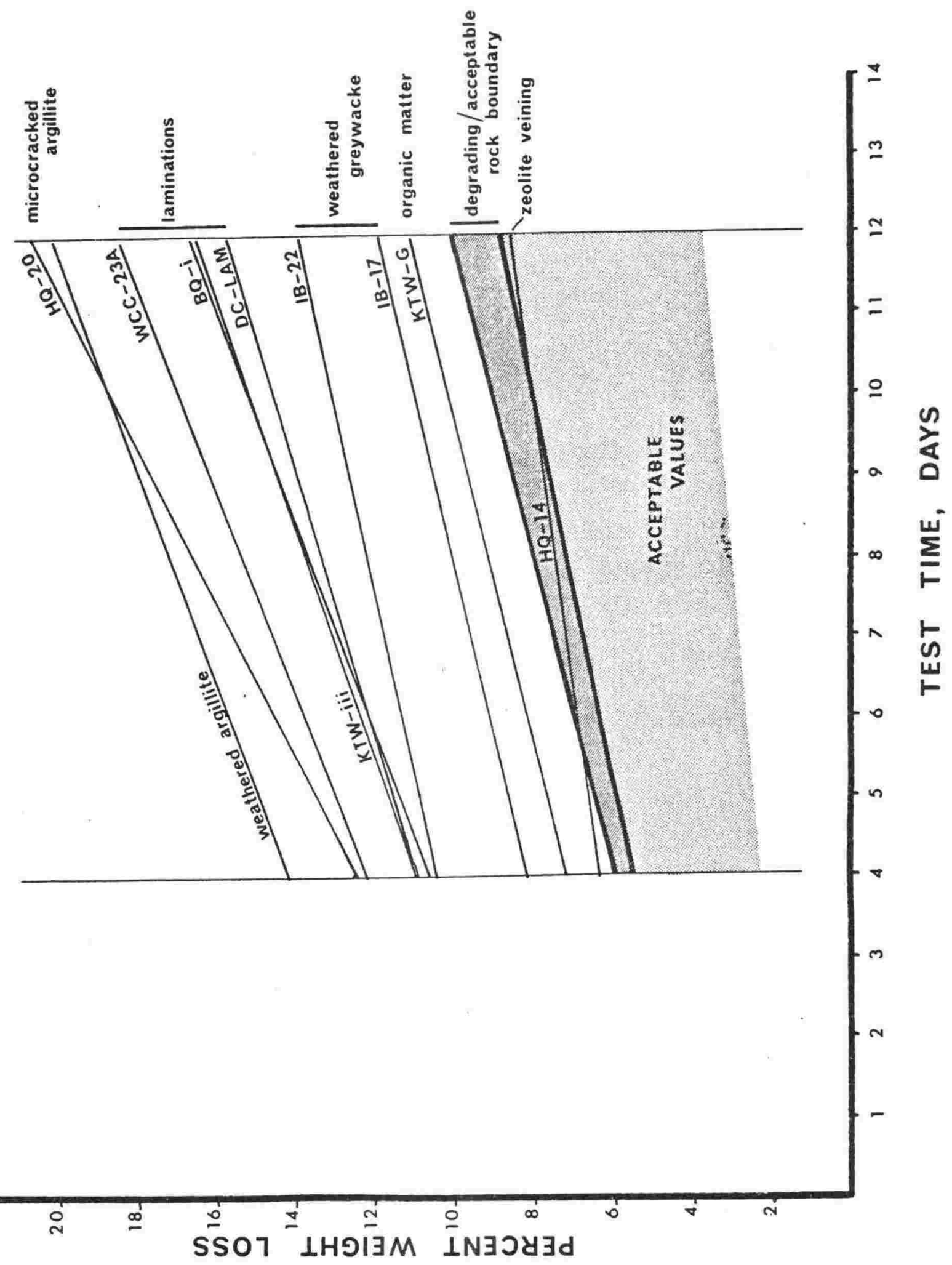




\subsection{Rock Stability}

From figure 3 the range of percent weight loss values separating rocks with low and high weight losses increases with time. For a laboratory test to be used routinely in assessing aggregates only one determination of weight percent loss, rather than two, undertaken at four and 12 days, is desirable. A 10 day test was considered definitive, resolution of results being consistent with acceptable testing time - the Accelerated Weathering test (Clelland, 1967) takes a similar length of time.

Weight percent loss of a rock sample at 10 days is therefore defined as the Rock Stability value (RSV).

As may be expected there is a positive, scattered correlation between RSV and the percentage sum of chlorite components of rocks (Fig. 4) established by modal analysis of the sample rocks in thin section. Percentage sum of chloritic components (chlorite) was taken as the sum of the percentage of sedimentary rock fragments, basic volcanic rock fragments and detrital and authigenic chlorite with grain sizes larger than 5.65 phi $(0.02 \mathrm{~mm})$ and matrix - material with a grain size less than 5.65 phi $(0.02 \mathrm{~mm})$. $\mathrm{X}-\mathrm{ray}$ diffractometry estimates of chlorite percentage reveals a similar trend with RSV.

There is also a positive non-linear scattered correlation between diminishing mean grain size of samples and RSV, due to an increase in chloritic material, preferred orientation, organic matter, and microcracking which accompanies reduced mean grain size. A similar trend is seen for chlorite and mean grain size (Figs 5 and 6 ).

Results from tests of four commercially available greywacke aggregates, where RSV is an average from six aggregate particles, are shown in Table 2 with corresponding Los Angeles abrasion, 10 percent fines and Accelerated Weathering test results.

\section{DISCUSSION}

Results indicate that a sample with a RSV exceeding 8 percent can be expected to degrade. This delineation is supported by field evidence, physical testing and petrography. Exceptions arise in weathered materials which have a high RSV for particular mean grain sizes and reduced percent weight loss rates per day; these materials are usually yellowbrown in colour, have lower densities and give poor performances in normal aggregate tests.

Coarser grained greywacke-suite rocks often have argillite fragments included in their clastic components i.e. sedimentary rock fragments. These fragments may range in size from $2 \mathrm{~mm}$ to
$400 \mathrm{~mm}$ or more but are commonly in the range $5 \mathrm{~mm}$ to $60 \mathrm{~mm}$. These rocks have a rather higher RSV than may be expected from their mean grain size but it is the large fragments of included argillite which reverse the trend of $\mathrm{fig} .6$. If these rocks are crushed to yield aggregate then portions of the rock with clasts exceeding, say, $15 \mathrm{~mm}$ may well have excessive argillite particles and therefore a higher chance of degradation.

Crushed aggregates give a higher RSV than aggregates from river sources, generally, because of increased surface area induced by irregular surfaces, crushing, etc. Natural degradation is also somewhat enhanced by such effects of manufacture and the test may be considered as having a "built-in" mechanism to assess incipient mechanical weakness induced by manufacture.

The results of most existing test methods are valid only at the time of test and give little indication of performance expectancy over the working iife of the aggregate. Some tests have their results "improved" by parameters such as particle morphology e.g. the Los Angeles test gives "poorer" results if aggregates are angular rather than rounded, finer graded rather than coarser (Orchard, 1964). The 10 percent fines test tends to have an "improved" result if the aggregate particles are equidimensional rather than flakey, rounded rather than irregular. Not surprisingly, these two tests show good correlation (Shipway, 1964). A comparison may be seen in Table 2 of two very different rock types juxtaposed in a Wellington quarry.

From Table 2 the fresh argillite gives the impression of being as "good" as the greywacke, and at the time of testing it may well have been, the Rock Stability value however gives a better idea of what may be expected from the argillite. The other tests would have to be repeated with time on the same sample to yield similar information.

The wetting and drying, heating and cooling of the Accelerated Weathering tests (Clelland, 1967) is given a secondary role in the Rock Stability test. The importance of chemical effects in rock decay was indicated well by Griggs (1936) and unpublished research by the author suggests chemical effects may be more important than physical changes in degradation of aggregates below a certain maximum screen size. 
ROWE

Figure 4 A scattered, positive correlation between Rock Stability value and $\Sigma$ chlorite percent exists. Samples labelled depart from the trend due to influences of organic matter, lamination, calcite or zeolite in greater than normal concentrations.

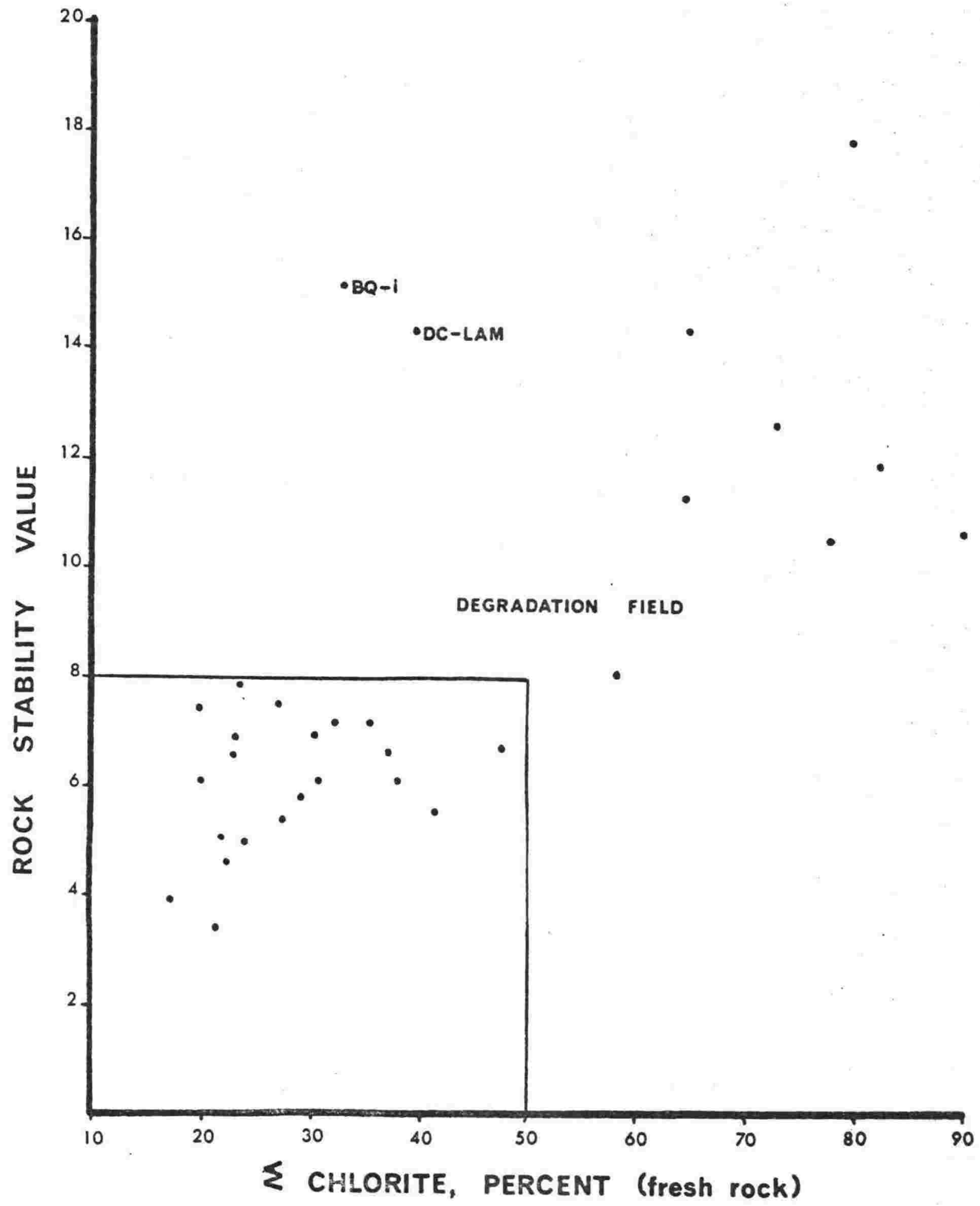


Figure 5 Rock Stability value is enhanced with smaller mean grain sizes in greywacke-suite rocks due to the increase in chlorite components in these rocks. The coarsest greywacke-suite rocks also show increasing Rock Stability values due to a relative increase in size and number of chlorite bearing rock fragments.

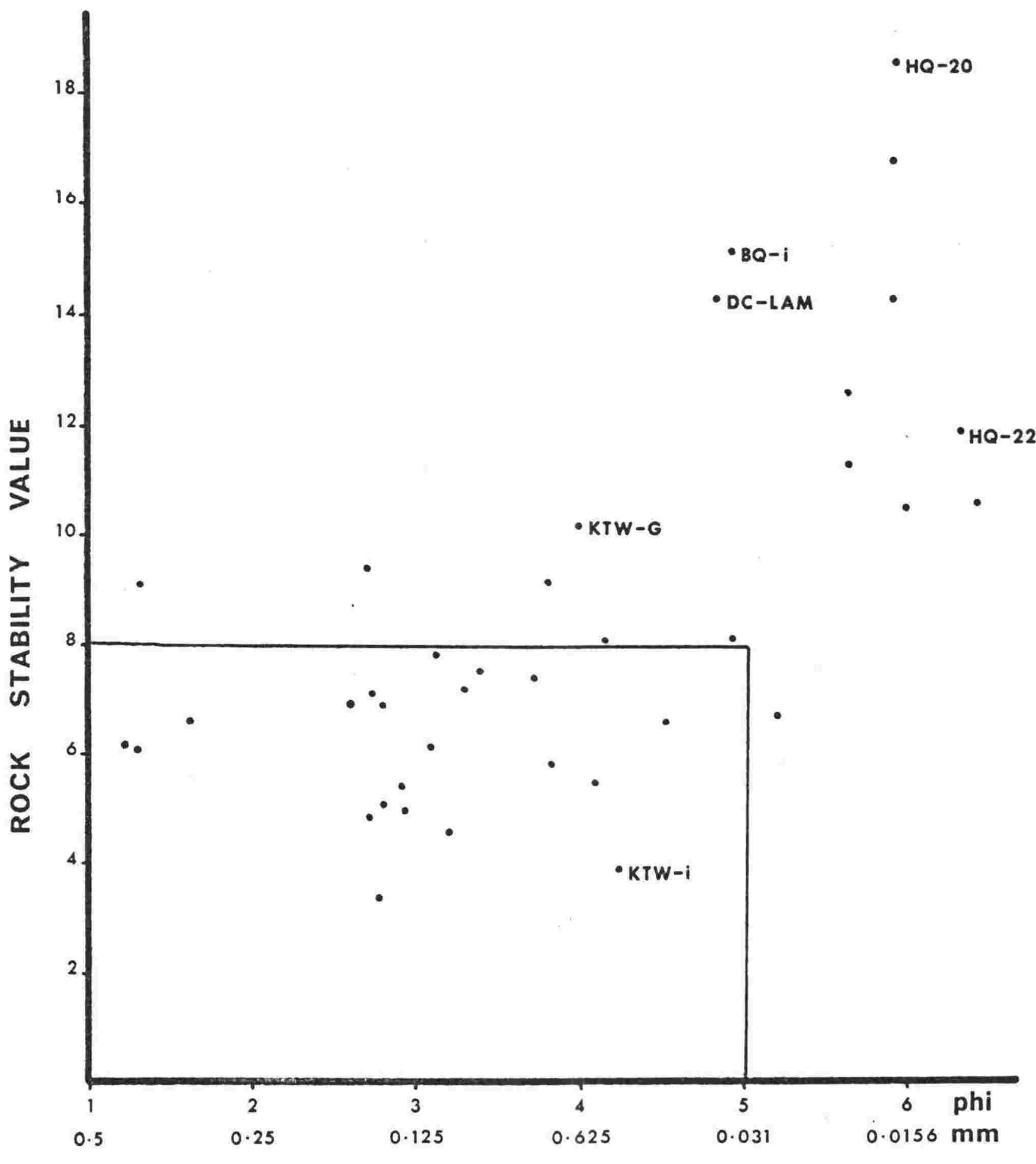

ROCK MEAN GRAIN SIZE 
Figure 6 Greywacke-suite rocks rapidly increase in chlorite content with reduced mean grain size. The fine grained rocks (Argillites) are susceptible to degradation.

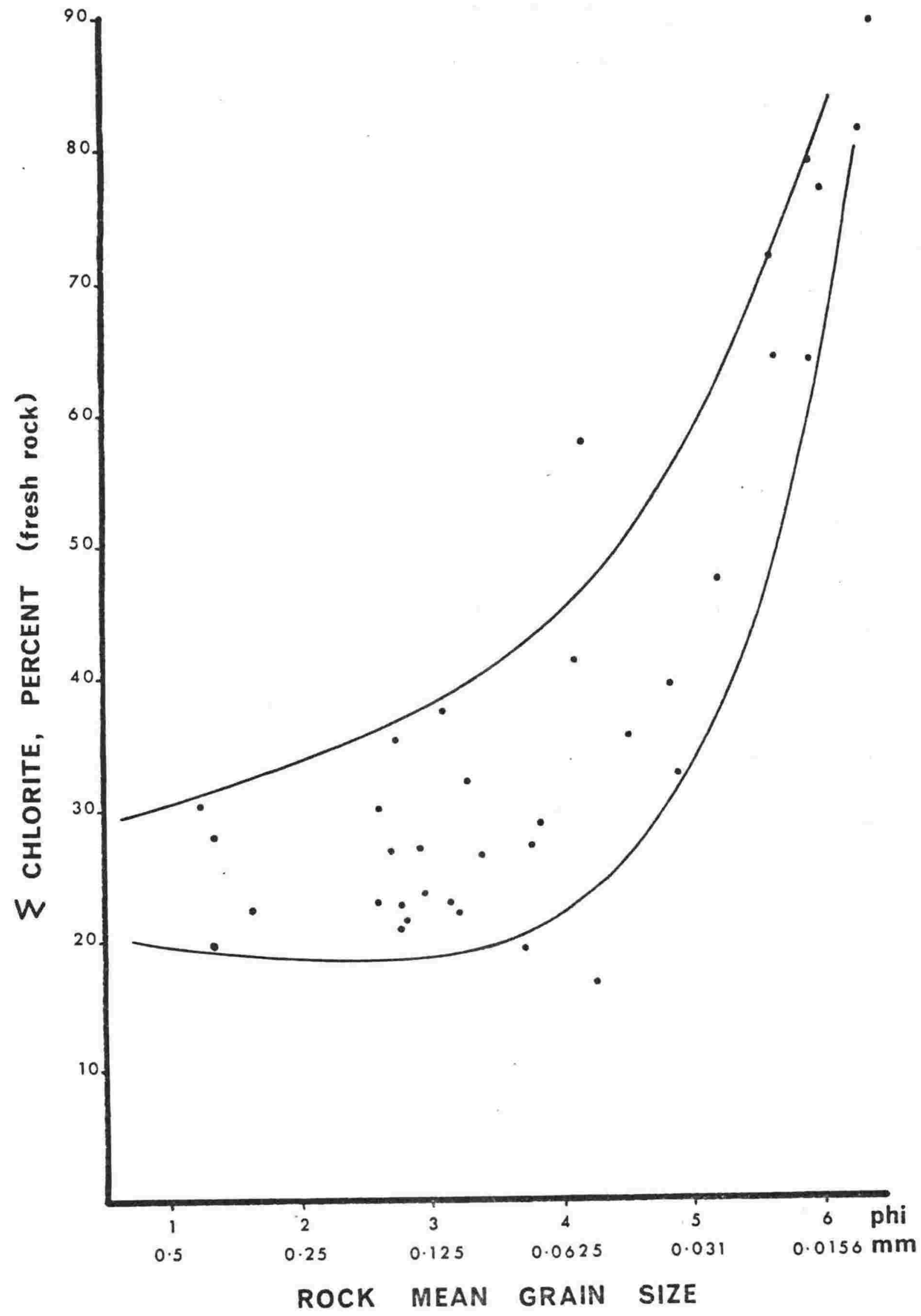


Table 2. A comparison between different aggregate performances for various established tests and the Rock Stability test. (Based on data supplied by the N.Z. Concrete Research Association Laboratories).

\begin{tabular}{|c|c|c|c|c|}
\hline Aggregate type & $\begin{array}{l}\text { Los } \\
\text { Angeles } \\
\text { test }\end{array}$ & $\begin{array}{l}10 \text { percent } \\
\text { fines } \\
\text { test }\end{array}$ & $\begin{array}{l}\text { Accelerated } \\
\text { Weathering } \\
\text { test }\end{array}$ & $\begin{array}{l}\text { Rock } \\
\text { Stability } \\
\text { value }\end{array}$ \\
\hline $\begin{array}{l}\text { Fresh argillite } \\
\text { (degrades within } \\
\text { three months of } \\
\text { initial exposure) } \\
\text { wellington }\end{array}$ & 138 & 29 tons & $A B$ & 11.98 \\
\hline $\begin{array}{l}\text { Fresh greywacke } \\
\text { (adjacent to } \\
\text { argillite tested } \\
\text { above) } \\
\text { Wellington }\end{array}$ & 198 & 29 tons & BB & 6.18 \\
\hline $\begin{array}{l}\text { Commercially } \\
\text { available } \\
\text { rounded greywacke, } \\
\text { Christchurch }\end{array}$ & 128 & 43 tons & $A A$ & 5.48 \\
\hline $\begin{array}{l}\text { Commercially } \\
\text { available } \\
\text { crushed } \\
\text { rounded greywacke, } \\
\text { Christchurch }\end{array}$ & 128 & 36 tons & $A A$ & 5.68 \\
\hline $\begin{array}{l}\text { Commercially } \\
\text { available } \\
\text { crushed greywacke, } \\
\text { Whangarei; } \\
\text { contains plastic } \\
\text { clays. }\end{array}$ & 148 & 23 tons & $A B$ & 9.88 \\
\hline $\begin{array}{l}\text { Commercially } \\
\text { available } \\
\text { rounded greywacke, } \\
\text { Christchurch }\end{array}$ & - & 61 tons & - & 7.28 \\
\hline
\end{tabular}

\section{COST OF THE TEST}

The main items of equipment necessary for performing the Rock Stability test are normally found in well equipped laboratories i.e. drying oven, dessicator, and balance (weight to two decimal places would be adequate for routine work). Construction of the Rock Stability apparatus is well within the capability of technician staff at a cost of the order of $\$ N 2200$.

Time involved for a routine work is 10 days of testing with perhaps an extra working day required for drying, leaching, weighing, etc. Two litres of acid solution is adequate for 20 samples. Technical personnel need only attend the apparatus for a half hour at the commencement and conclusion of a test. operator error is at a minimum.

\section{CONCLUSIONS}

A rock stability test that involves treatment of the sample with 10 percent
$\mathrm{HCl}$ at $80^{\circ} \mathrm{C}$ is presented. The test indicates the degradation susceptability of greywacke-suite rocks and should fill a need for means of predicting the performance of greywacke-suite aggregates.

\section{ACKNOWLEDGEMENTS}

This work was carried out as part of the author's doctoral research on the Wellington greywacke-suite rocks. Some unpublished data was provided by the New Zealand Concrete Research Association.

Dr W. A. Watters provided access to the New Zealand Geological survey petrology collection.

Dr P. J. Barrett (Victoria University), Dr J. H. Garside and Mr J. B. Tait (New Zealand Portland Cement Association) and $M r$ D. H. Rowe provided valuable criticism of the manuscript.

Mr J. Casey photographed the apparatus. 


\section{REFERENCES}

BUCKLAND, A.H. (1967) The Degradation of Roading Aggregate. Proc. Roading Symp., Road Res. Unit, N.Z. Nat. Roads Board, V.2: 692-715.

CARROLI, D. (1970) Clay Minerals: A Guide to their X-ray Identification. Geol. Soc. Am. Spec. Paper 126: 80 p.

CLELLAND, J. (1967) An Artificial Weathering Test for Roading Aggregates. Proc. Roading Symp., Road Res. Unit, N.Z. Nat. Roads Board, V.2: 743-758.

CORNWELL, W.L. (1966) Assessment of Basecourse Aggregate Quality, AucklandHamilton Motorway. M.O.W. Internal Report: $9 \mathrm{p}$.

DEER, W.A., HOWIE, R.A. and ZUSSMAN, J. (1971) An Introduction to the Rockforming Minerals. Longman, London: $528 \mathrm{p}$.

DEKKER, B. and SCOTT, K.O. (1969) Some Aspects of Aggregate Supply for North Island Power Stations. Proc. Nat. Conf. Concrete Aggregates, Hamiltón, New Zealand: 26-34.

GRIGGS, D.T. (1936) The Factor of Fatigue in Rock Exfoliation. Jl. Geol. V. $44(7)$ : 783-796.

KEAR, D. (1965) South Auckland Road Metal Quarries "Wacke"-type Rocks. N.Z. Geol. Survey Report 2: $24 \mathrm{p}$.

KEAR, D. and HUNT, J.L. (1969) Aggregate Resources of New Zealand. Proc. Nat. Conf. Concrete Aggregates, Hamilton, New Zealand: 17-25.

\section{MARSHALL, T.W. (1974) A Petrographic} Investigation of Greywacke-type Aggregate from the Auckland Region. Unpub. M.Sc. (Hons) Thesis: $125 \mathrm{p}$.

ORCHARD, D.F. (1964) Factors

Influencing the Wear of Coarse Aggregate in the Los Angeles Test. Proc. Second Conf. Australian Road Res. Board, V.2. part 2: 963-980.

REED, J.J. (1965) Mineralogy and Petrology in the New Zealand Geological Survey 1865-1965. N.Z. J1. Geol. Geophys. V.8 (6): 999-1087.

REED, J.J. (1966) Geological and Petrological Investigations of Wacke Aggregates used in Auckland - Hamilton Motorway, Redoubt and Takanini Sections. N.Z. Geol. Survey Report 20: $47 \mathrm{p}$.

REED, J.J. (1967) Application of Recent Petrological Advances to Selection of Road Aggregates. Proc. Roading Symp., Road Res. Unit, N.Z. Nat. Roads Board, V.2: 716-742.
SHIPWAY, C.H. (1964) A Study of the Aggregate Crushing Test. Proc. Second Conf. Australian Road Res. Board, V.2 part 2: 981-996.

SKINNER, D.N.B. (1970) Mineralogical changes in some New Zealand Sedimentary and Igneous rocks and their effect on Aggregate Quality. First International Congress of the International Association of Engineering Geology, Paris, France, 8-11 September. Section 1: Natural and Industrial Materials of Construction: 534-547.

WATTERS, W.A. (1969) Petrological Examination of Concrete Aggregates. Proc. Nat. Conf. Concrete Aggregates, Hamilton, New Zealand: 48-54.

\section{APPENDIX 1}

Method of test to determine the Rock Stability value of aggregates from greywacke-suite rocks.

\section{Scope}

An accelerated laboratory test designed to assess whether greywackesuite aggregates will degrade by physico-chemical alteration.

\section{Procedure}

A. Apparatus

1. An insulated box and fittings of approximate dimensions given in $\mathrm{fig}$. 1 , fitted with a heat source such that the box when closed will equilibrate at a temperature of $83^{ \pm} 3^{\circ} \mathrm{C}$ within three hours. A 60 watt electric lamp will suffice.

2. Six convecting tubes with dimensions as in $f i g .1$.

3. Six rubber bungs to fit 2 , above each with an acid resistant (polythene) and a heat resistant ("glad" oven bag) plastic film barrier (a $60 \mathrm{~mm}$ square of each material per bung is adequate).

4. One mercury in glass thermometer, capable of being read to $1^{\circ} \mathrm{C}$ in the range $70^{\circ} \mathrm{C}$ to $90^{\circ} \mathrm{C}$.

5. A balance capable of weighing up to $50 \mathrm{gm}$ to $\pm 0.01 \mathrm{gm}$.

6. A ventilated oven controllable between $100^{\circ} \mathrm{C}$ and $110^{\circ} \mathrm{C}$

7. A dessicator ( $150 \mathrm{~mm}$ ) with active silica gel, or other suitable dessicant, in its base.

B. Reagents

1. Concentrated Hydrochloric acid (laboratory reagent grade or better) diluted with distilled water to give a 10 percent solution by volume. May be made up and kept, sealed. indefinitely. Approximately $100 \mathrm{ml}$ of the 10 percent solution is required for each test.

WARNING

Hydrochloric acid and its fumes are highly corrosive, protective clothing, gloves and face visor should be worn when mixing this chemical with water. Mixing should be carried out in a fume 
cupboard. Always mix by pouring acid into water, NEVER water into acid; mixing should be done slowly as the reaction is exothermic (heat generating). ALWAYS use good quality pyrex or polypropylene mixing vessels. Storage of 10 percent $\mathrm{HCl}$ may be in glass or plastic vessels with a screw type plastic cap.

\section{Sample Preparation}

1. Samples must be selected as being those most representative of a representative sample, with regard to rock type, size, shape and surface texture of the aggregate concerned.

2. A minimum of six samples must be tested for each aggregate type.

3. Samples must be selected from the $25 \mathrm{~mm}$ - $20 \mathrm{~mm}$ size range and weigh between $15 \mathrm{gm}$ and $25 \mathrm{gm}$. Should aggregate in question be too large then pieces may be sawn or broken to assume approximate shape of a square right prism and fulfilling the weight requirements above consistent with size to fit the convection tubes.

4. Samples must be scrubbed to remove loose adhering matter, dried to constant weight (about $6-8$ hours) in an oven at $105 \pm 3 \% \mathrm{C}$. Allow to cool in the dessicator for 1 hour.

5. Identify and weigh each ample (to two decimal places).

D. Testing Procedure

1. Place samples into convection tubes (one sample per tube) and fill the tube to within $20 \mathrm{~mm}$ of the top. Remove air bubbles by tilting the tube.

2. Firmly insert a rubber bung into each tube. The base of the bung should be covered with a piece of heat resisting then acid resisting plastic film before being fitted.

3. Position all tubes in the apparatus in the manner shown in plate 1.

4. Shut the box and monitor the temperature on the light bulb side of the partition; it should remain

5. Continue for 10 days \pm 4 hours.

6. Remove tubes from the apparatus, remove samples from the tubes by pouring the hot acid from the tubes in a fume cupboard.

7. Place samples in a shallow $140 \mathrm{~mm}$ deep) plastic or glass vessel large enough so samples are well separated.

8. Apply a slow flow of tap water over the samples by way of a tube so as not to disturb the samples. Continue for 18 hours.

9. Dry the samples to constant weight, cool in a dessioator for 1 hour and weigh to two decimal places.
Results

The percent weight loss for each sample is calculated from

$$
\begin{aligned}
& \frac{w_{0}-w_{10}}{w_{0}} 1008 \text { where } w_{0}=\begin{array}{l}
\text { initial oven } \\
\text { dry weight of } \\
\text { the sample }
\end{array} \\
& w_{10}=\text { oven dry weight } \\
& \text { of sample } \\
& \text { after } 10 \text { days } \\
& \text { testing }
\end{aligned}
$$

The mean percent weight loss for the aggregate rock-type is reported as the Rock Stability value reported to the nearest 0.1 percent.

The majority of individual results should not depart from the mean by more than 2 percent, in most cases wide variations can usually be explained, and this alone is an indication of Rock Stability.

If the Rock Stability value exceeds 8 percent the aggregate rock-type may be regarded as having a high degradation potential.

\section{APPENDIX 2}

Assessment of Rock Stability value with Rocks of Known Performance

To establish the test's ability to identify degrading greywacke-suite rock types, aggregates used in the Auckland-Hamilton motorway, Redoubt and Takanini Sections and described by Reed (1966) were tested in the Rock Stability apparatus. The results are listed below with partial reproduction of Table 2; 'Stages of Albitisation of Silt and Clay Wackes (Argillites) of the Auckland District' from Reed (1966).

From the thin sections studied, the reconstitution of argillites, termed "albitisation" by Reed (1966), is also the geologic process that concentrates and enhances chloritic components, at the same time causing a mean reduction in grain size. All rocks tested have an unsatisfactory Rock Stability value. Significant and intense "albitisation" may have a hardening effect (though P30647 was soft according to ASTM test C235 68 "Scratch Hardness of Coarse Aggregate Particles") but does not significantly increase the ability of argillacous rocks to withstand degradation when used as aggregate. Albite and prehnite are minerals possessing relatively good mechanical properties. It is unlikely therefore that they are reliable indicators of rocks susceptable to degradation. The minerals of paramount importance are those that form the matrix, which commonly encloses, cements and prevents continuity of the more durable mineral components in greywacke-suite rocks. In greywacke-suite rocks these are chloritic in composition. 


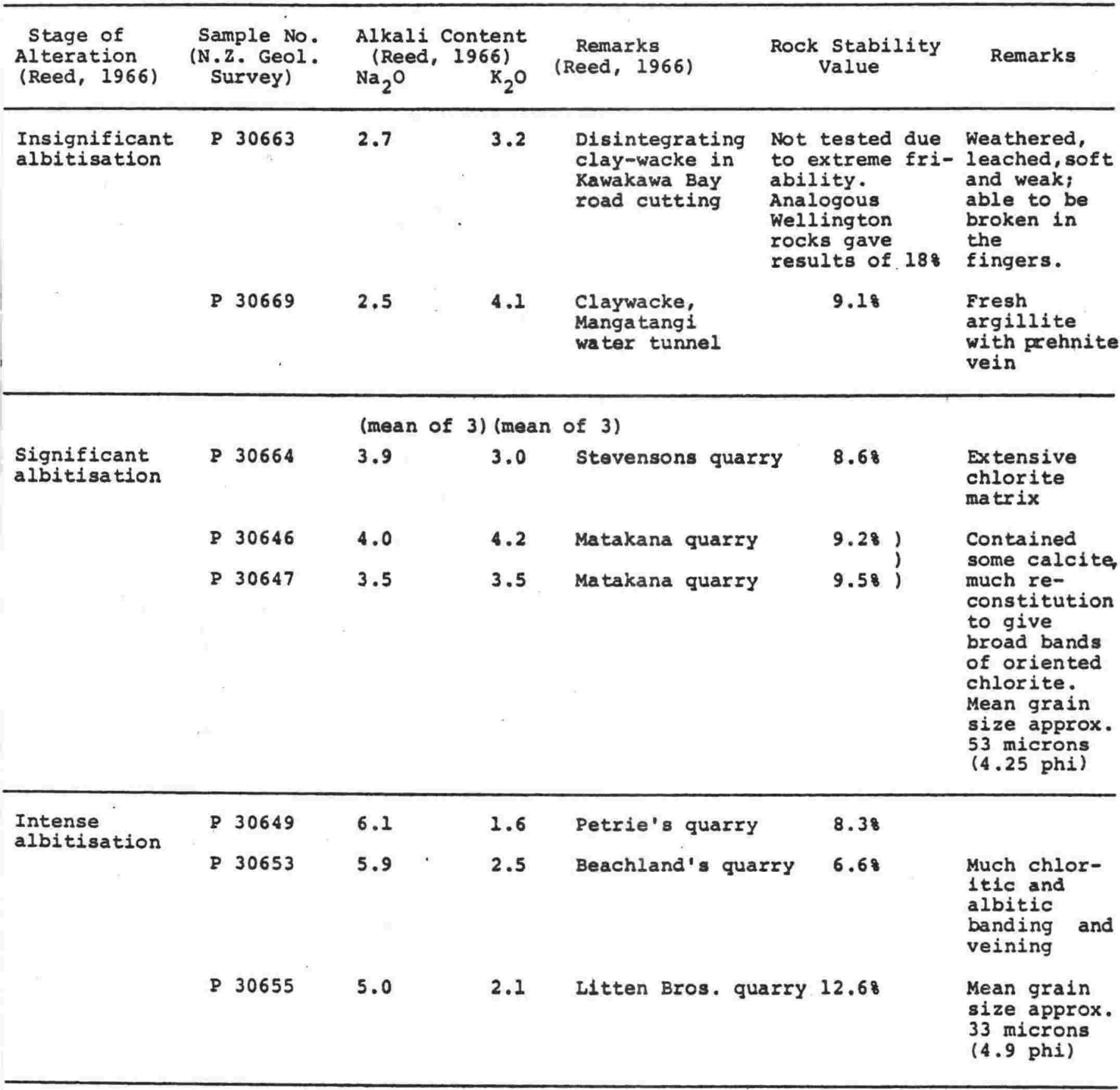




\title{
CHAPTER FOUR
}

\author{
BOOKERS LAW: \\ An ounce of application is \\ worth a ton of abstraction.
}

Physical properties of Wellington greywacke-suite aggregates

This chapter relates geological and physical properties of the Wellington greywacke-suite rocks to those of their derived aggregates and to the properties of concrete made with these aggregates.

To obtain aggregates for testing and concrete making, samples were selected on the following criteria:

(i) Samples had to be representative of rock from localities with the greatest future potential for quarrying purposes.

(ii) Samples had to reflect a representative range of textural features apparent in Wellington greywacke-suite rocks.

(iii) Samples had to be as free as possible from contamination by close veining, weathering and close jointing.

4.1 Sampling methods and sample preparation

Samples were quarried from a $3 \mathrm{~m}$ length of a single bed, in each of four quarries as follows:

Sample Quarry Rock mean Rock types Lithofacies grain size

phi

$\begin{array}{lllll}\text { HQ-17 } & \text { Horokiwi } & 1.3 & \text { greywacke } & \text { thick-bedded } \\ \text { KTW-14 } & \text { Carsons } & 2.6 & \text { greywacke } & \text { sandstone } \\ \text { BQ-IXA } & \text { Belmont } & 2.9 & \text { greywacke } & \text { sandstone } \\ \text { SJ-T } & \text { Owhiro Bay } & 4.7 & \text { greywacke } & \text { thin-bedded } \\ \text { OB-W } & \text { Owhiro Bay } & 5.6 & \text { argillite } & \text { thin-bedded } \\ \text { HQ-22 } & \text { Horokiwi } & 6.3 & \text { argillite } & \text { thick-bedded }\end{array}$


These quarries were chosen because they have the largest inferred "reserves" (Ward and Grant, 1978). For economic and logistic reasons, too, these quarries will be the most important to the Wellington region for the next 20 years at least.

Each sample was quarried by hand, using bars and hammers, to obtain approximately $700 \mathrm{~kg}$ of cobble and boulder size rock. The material was crushed in a jaw primary crusher and swing hammer mill, then screened to pass $19 \mathrm{~mm}$ before being placed in reconditioned, rust free 200 litre (44 gallon) drums as $19 \mathrm{~mm}$ "all-in", unscrubbed, unwashed aggregate. All hoppers, crushers, conveyor belts and handling equipment were cleaned before crushing successive samples. All handling, crushing and screening was undertaken by Ryans Quarries, Ngauranga.

To aid the detection of contamination between successive crushing runs the order of crushing was as follows:

KTW-14, НQ-22, НQ-17, ОВ-W, BQ-IXA, SJ-T

The marked difference in colour and texture between lithogies in this sequence enabled small amounts of contaminating material to be removed by hand later, when the aggregates were coned, quartered and split to obtain representative samples. These were finally screened to $19-9.5 \mathrm{~mm}, 9.5-4.8 \mathrm{~mm}$ and minus $4.8 \mathrm{~mm}$ size fractions. Material coarser than $4.8 \mathrm{~mm}$ was thoroughly hand washed.

\subsection{Aggregate characteristics}

A number of aggregate characteristics were measured to aid concrete mix design and help establish the connection between the rock and concrete produced from it. They included grading, aggregate density, water absorption, bulk density, voids content, and crushing resistance (NZS 3111:1974). In addition, abrasion resistance was assessed by the Los Angeles test and particle angularity was measured by the method of Lees (1964).

Tests for whole rock alkali reactivity were not undertaken as much work of this type had already been carried out by the Inorganic Materials section, Chemistry Division, DSIR, with the indication that, for Wellington greywacke- 
suite rocks, alkali reactivity is not a problem (St John, pers. comm.; see also section 4.4), apart from a few isolated cases observed in the laboratory. The Accelerated Weathering test (Clelland, 1967, NZS 3111:1974 part 202.4) was omitted for reasons outlined elsewhere (Rowe, 1979).

Tests for cleanness, and lightweight particles (NZS 3111:1974 parts 202.2; 201.5) were not necessary because the aggregate had been washed and because of the nature of the rock.

\subsubsection{Gradings}

All samples were crushed under identical conditions. They were then screened to passing $19 \mathrm{~mm}$ retained $9.5 \mathrm{~mm}$; passing $9.5 \mathrm{~mm}$ retained $4.8 \mathrm{~mm}$; and passing $4.8 \mathrm{~mm}$ fractions. (Figure 4.1 ).

Coarse aggregate grading was carried out mainly to see if there was a relationship between grading and rock type, though it was also necessary to separate, physically, the size fractions for later recombination according to concrete mix designs.

No clear relationship emerged between grading and rock mean grain size (Figure 4.1), although there are substantial differences in the gradings (Table 4.1). No explanation can be offered and this is an area that deserves further study.

\subsubsection{Particle shape}

Particle shape is important in assessing concrete aggregates as it is a key factor in determining the workability of fresh concrete.

Problems associated with quantifying particle shape have been discussed by many authors (see Barrett, 1980, for a review). Opinions are split between quantifying particle shape by individual grain measurement and averaging particle shape on a single parameter, e.g. permeability or specific surface area.

The first approach is usually pursued by geologists, the second by those associated with engineering or industry. 

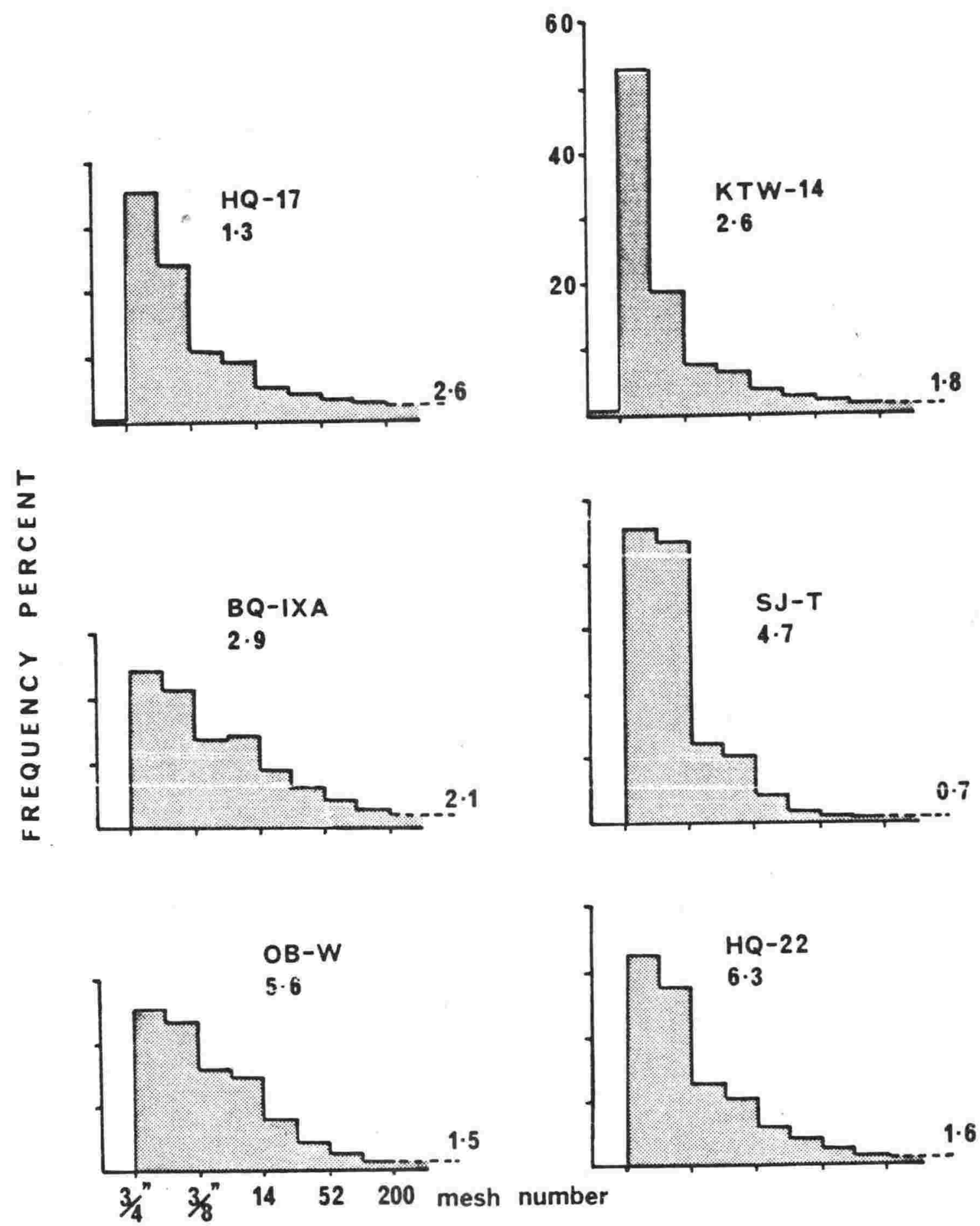

$\begin{array}{llllll}19.0 & 9.5 & 1.18 & 0.3 & 0.075 & \mathrm{~mm} .\end{array}$

\section{SIEVE SIZE}

Figure 4.1 : Grading histograms of aggregate samples produced by crushing from quarried blocks,i.e. $19 \mathrm{~mm}$ "all in"

aggregate. Percentage of material finer than $0.075 \mathrm{~mm}$ is shown numerically to the right of each histogram. Rock mean grain size in phi units is shown for each sample beneath sample numbers. 
Table 4.1 : Sieve analyses of $19 \mathrm{~mm}$ "all-in" aggregates crushed from quarried blocks. (minus $4.8 \mathrm{~mm}$ sand sieve analyses by F. Williams).

\begin{tabular}{|c|c|c|c|c|c|c|}
\hline & $\mathrm{HQ}-17$ & $4571 \mathrm{gm}$. & KTW-14 & $3504 \mathrm{gm}$. & $B Q-I X A$ & $3465 \mathrm{gm}$. \\
\hline Sieve sizes & $\%$ on & $\begin{array}{l}\text { Cumulative } \\
\text { \% retained }\end{array}$ & 8 on & $\begin{array}{l}\text { Cumulative } \\
\text { \& retained }\end{array}$ & $\%$ on & $\begin{array}{l}\text { Cululative } \\
\% \text { retained }\end{array}$ \\
\hline $19 \mathrm{~mm}\left(3 / 4^{\prime \prime}\right)$ & 0.24 & 0.24 & 0.9 & 0.9 & - & - \\
\hline $12.7 \mathrm{~mm}(1 / 2 ")$ & 18.24 & 18.5 & 34.9 & 35.8 & 9.2 & 9.2 \\
\hline $9.5 \mathrm{~mm}(3 / 8 ")$ & 17.7 & 36.2 & 18.2 & 54.0 & 15.5 & 24.7 \\
\hline $4.75 \mathrm{~mm}\left(3 / 16^{\prime \prime}\right)$ & 24.3 & 60.5 & 18.9 & 72.9 & 21.8 & 46.5 \\
\hline $2.36 \mathrm{~mm}$ (№. 7) & 11.0 & 71.5 & 7.8 & 80.7 & 14.0 & 60.5 \\
\hline $1.18 \mathrm{~mm}$ (№. 14) & 9.5 & 81.0 & 6.5 & 87.2 & 14.5 & 75.0 \\
\hline $600 \mu($ No. 25) & 5.4 & 86.4 & 3.9 & 91.1 & 9.3 & 84.3 \\
\hline $300 \mu($ No. 52$)$ & 4.4 & 90.8 & 2.9 & 94.0 & 6.6 & 90.9 \\
\hline $150 \mu($ No. 100$)$ & 3.6 & 94.4 & 2.3 & 96.3 & 4.5 & 95.4 \\
\hline $75 \mu$ (No. 200) & 3.0 & 97.4 & 1.9 & 98.2 & 3.0 & 98.4 \\
\hline \multirow[t]{3}{*}{ PAN } & 2.6 & 100.0 & 1.8 & 100.0 & 2.1 & 100.5 \\
\hline & 100.0 & & 100.0 & & 100.5 & \\
\hline & $S J-T$ & $3970 \mathrm{gm}$. & $\mathrm{OB}-\mathrm{W}$ & $5554 \mathrm{gm}$. & HQ -22 & $4316 \mathrm{gm}$. \\
\hline $19 \mathrm{~mm}(3 / 4 ")$ & - & - & - & - & - & - \\
\hline $12.7 \mathrm{rmm}(1 / 2 ")$ & 21.7 & 21.7 & 8.7 & 8.7 & 11.1 & 11.1 \\
\hline $9.5 \mathrm{~mm}(3 / 8 ")$ & 24.1 & 45.8 & 16.8 & 25.5 & 21.6 & 32.7 \\
\hline $4.76 \mathrm{~mm}\left(3 / 16^{\prime \prime}\right)$ & 23.5 & 69.3 & 23.9 & 49.4 & 27.8 & 60.5 \\
\hline $2.36 \mathrm{~mm}$ (No. 7) & 12.2 & 81.5 & 16.0 & 65.4 & 12.9 & 73.4 \\
\hline $1.18 \mathrm{~mm}$ (No. 14) & 10.2 & 91.7 & 14.9 & 80.3 & 10.6 & 84.0 \\
\hline $600 \mu$ (No. 25) & 4.3 & 96.0 & 8.3 & 88.6 & 6.0 & 90.0 \\
\hline $300 \mu$ (No. 52 & 2.1 & 98.0 & 4.9 & 93.5 & 4.2 & 94.2 \\
\hline $150 \mu($ No. 100$)$ & 1.0 & 99.0 & 2.9 & 96.4 & 2.8 & 97.0 \\
\hline $75 \mu$ (No. 200) & 0.7 & 99.7 & 1.7 & 98.1 & 1.8 & 98.8 \\
\hline \multirow[t]{2}{*}{ PAN } & 0.7 & 100.4 & 1.5 & 99.6 & 1.6 & 100.4 \\
\hline & 100.4 & & 99.6 & & 100.4 & \\
\hline
\end{tabular}


A major problem in this study was one of resolution,i.e. all the aggregates were of similar provenance, metamorphic rank and geologic character. All were crushed using the same plant and subject to the same screening. Quantification of particle shape required a method that would be sensitive to subtle differences in the shapes of crushed rock. Lees (1964) devised a method specifically for this purpose, although his interest was in road aggregate. The method takes cognizance of the number of corners, their sharpness and their degree of projection from the main body of the particle measured. Lees' procedure involves taking measurements from photographs taken in the three planes $a / b, b / c, a / c$, where $a, b$ and $c$ are the long, intermediate and short axes of particles. Results from the planes were averaged. Such is the tedium of measuring particles in this way that Lees produced a chart for visually determining the degree of angularity of particles. Although not used in this study, the validity of angularity assessment by measurement from a single particle projection plane, was accepted. Measurement was therefore undertaken using two dimensions of the particle, quantified as a dimensionless number (degree of angularity, $\left.A_{2 D}, F i g u r e ~ 4.2\right)$ which increases with angularity.

Measurements were made from a photocopy (Appendix 17) of a section of concrete cast in $200 \times 100 \mathrm{~mm}$ cylinder moulds (conforming to NZS 3112:1974, 201 method B1), cut longitudinally through a diameter (Plate 4.1; Appendix 17). Particles to be measured, from each photocopied face, were selected by using a 12 × $25 \mathrm{~mm}$ grid - generally this meant more particles were counted from $\operatorname{mix} I$ cylinder photocopies than $\operatorname{mix} 2$. Measurement of angles was done with a protractor and the radii of inscribed circles determined by circular templates of known diameter. Projection of corners was measured with a millimetre scale.

The results (Table 4.2) show that, although standard deviation is large, Lees' angularity is a consistent measure - there is close agreement between means of different mixes of the same aggregate. Also, angularity increases with decreasing rock grain size (Plate 4.1; Figure 4.3; Appendix 17).

It is known that particle shape and hence angularity is strongly influenced in two ways:

(i) The nature of the crushing process, (McIntosh, 1957), the same for each sample in this study (section 4.2.2). 
(A)

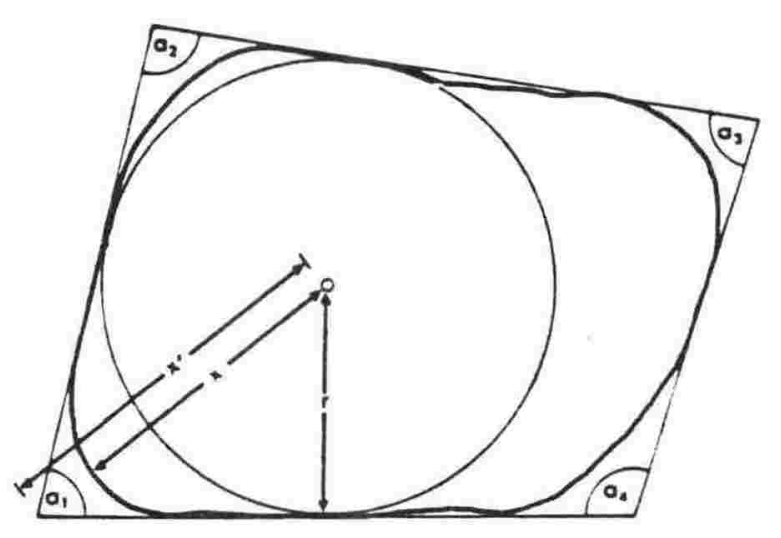
$A_{20}=\sum(180-a) \frac{X}{r} \quad \begin{aligned} & A_{20}-529 \text { using } x \\ & A_{20}=029 \text { using } x\end{aligned}$

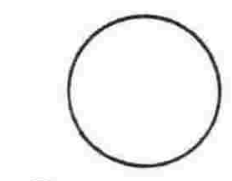

(B)

$A_{20}=0$

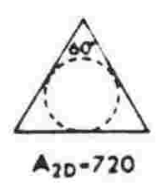

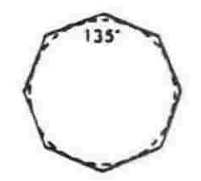

$A_{20}=390$

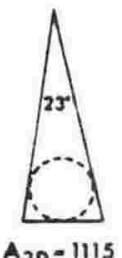

$A_{20}=1115$

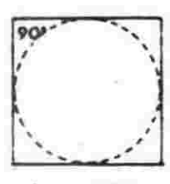

$A_{20}=508$

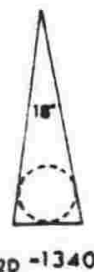

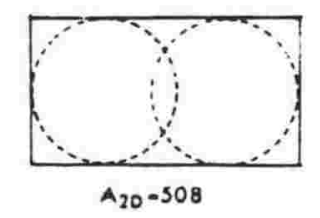

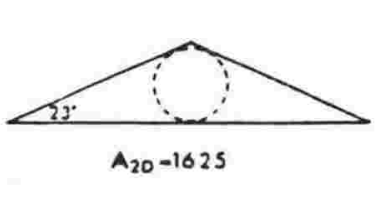

Figure 4.2 : (A) Construction and formula for determining angularity $\left(A_{2 D}\right)$ of a particle by the method of Lees (1964). (B) Values for degree of angularity $\left(A_{2 D}\right)$ for various regular figures (mainly from Lees, 1964, with a corrected value for the octagon from Barrett, 1980). 


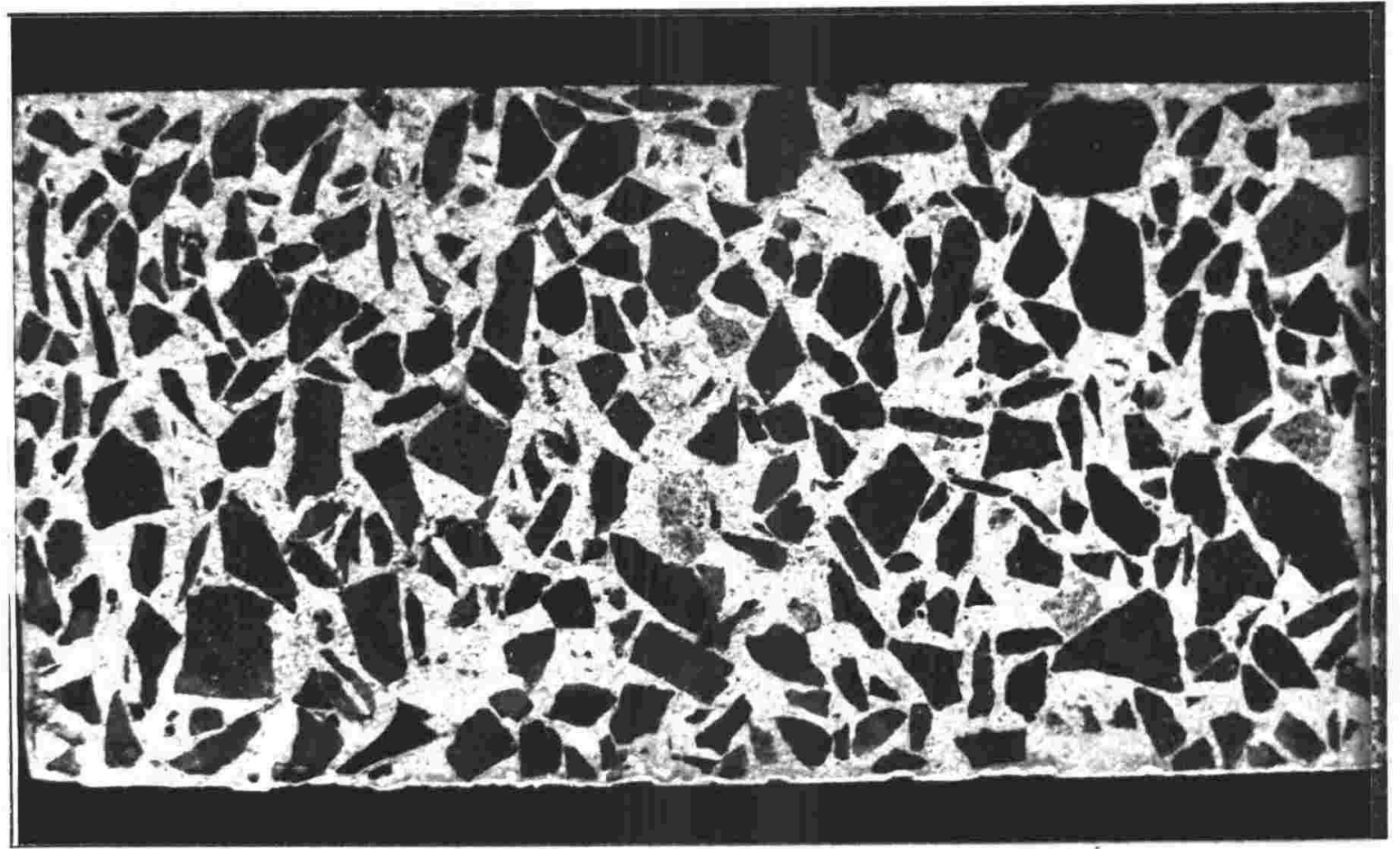

HQ-17

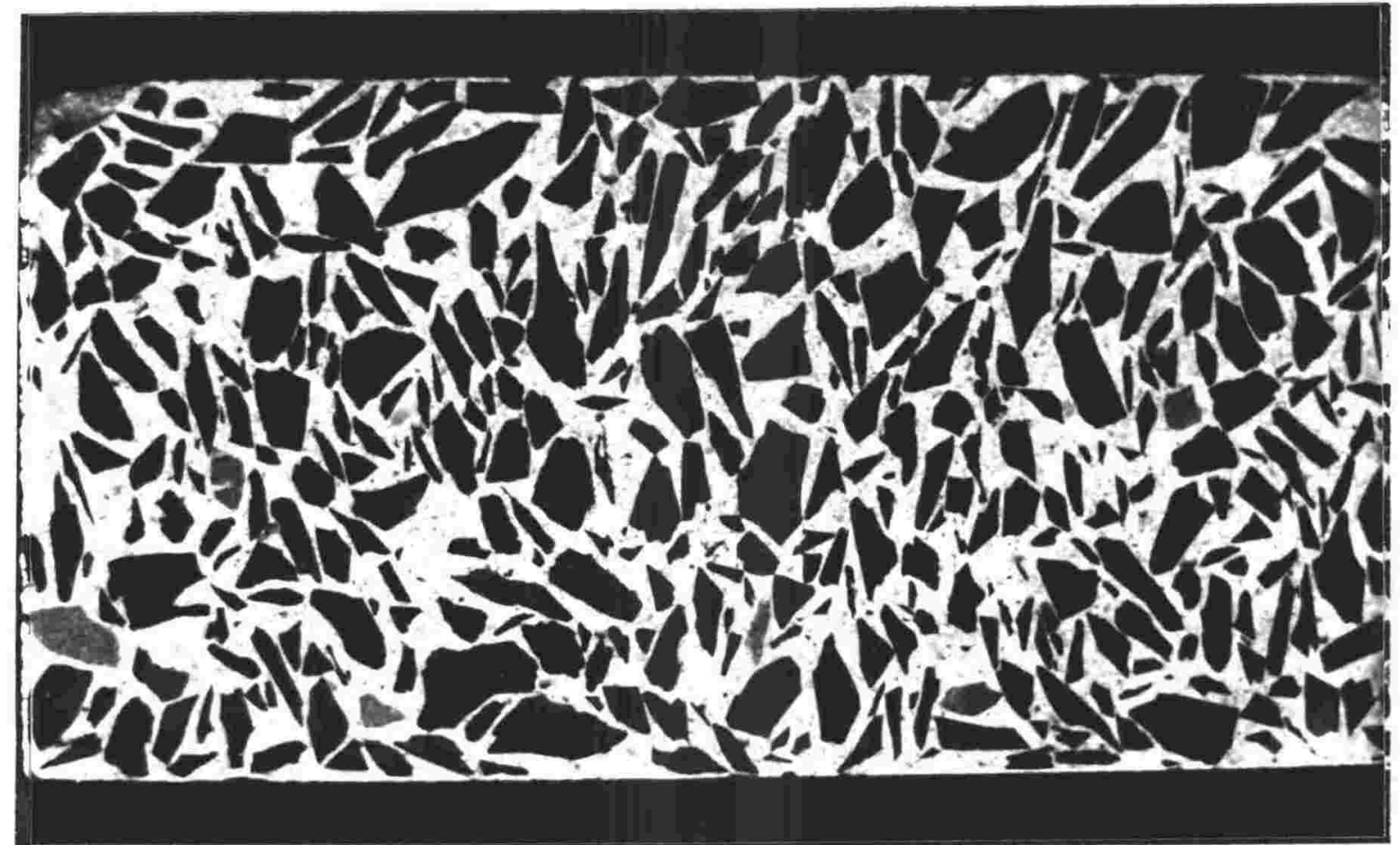

OB-W

Plate 4.1 : Sections of mix 1 design concrete are shown for two aggregate types to display aggregate particle orientations, angularities $\left(\mathrm{A}_{2 \mathrm{D}}\right)$ and packing. The photographs have been taken from $200 \times 100 \mathrm{~mm}$ concrete cylinders after they have been cut in half longitudinally. Both sections are shown with the uppermost surface (as cast) to the left. Angularities $\left(A_{2 D}\right)$ were measured from photocopies of these surfaces directly for both mix designs. Particles for angularity measurements were selected by grid overlay (Appendix 17). 
Table 4.2 : Aggregate particle shape statistics derived using the method of Lees (1964).

\begin{tabular}{|c|c|c|c|c|c|c|c|c|c|}
\hline Sample & $\begin{array}{l}\text { Rock } \\
\text { Mean } \\
\text { grain } \\
\text { size, } \\
\text { phi }\end{array}$ & $\begin{array}{l}\text { Mix } \\
\text { design }\end{array}$ & $\begin{array}{l}\text { Total } \\
\text { angula- } \\
\text { rity }\left(A_{2 D}\right) \\
\text { for mix } \\
\text { design }\end{array}$ & $\begin{array}{l}\text { Mean } \\
\text { parti- } \\
\text { cle } \\
\text { angula- } \\
\text { rity }\end{array}$ & S.D. & $\begin{array}{l}\text { Coefficient } \\
\text { of varia- } \\
\text { tion, per- } \\
\text { cent }\end{array}$ & $\begin{array}{l}\text { Minimum } \\
\text { particle } \\
\text { angula- } \\
\text { rity }\end{array}$ & $\begin{array}{l}\text { Maximum } \\
\text { particle } \\
\text { angula- } \\
\text { rity }\end{array}$ & n. \\
\hline \multirow[t]{2}{*}{$\mathrm{HQ}-17$} & 1.3 & 1 & 30640 & 747 & 314 & 42.1 & 350 & 1800 & 41 \\
\hline & & 2 & 32347 & $\frac{789}{768}$ & 330 & 41.9 & 305 & 1765 & 41 \\
\hline \multirow[t]{2}{*}{ KTW-14 } & 2.6 & 1 & 32338 & 874 & 406 & 46.4 & 460 & 2320 & 37 \\
\hline & & 2 & 31394 & $\frac{826}{850}$ & 398 & 48.0 & 415 & 2740 & 38 \\
\hline \multirow[t]{2}{*}{$\mathrm{BQ}-\mathrm{IXA}$} & 2.9 & 1 & 28432 & 768 & 238 & 31.0 & 400 & 1315 & 37 \\
\hline & & 2 & 32010 & $\frac{889}{829}$ & 325 & 36.6 & 385 & 1965 & 36 \\
\hline \multirow[t]{2}{*}{$S J-T$} & 4.7 & 1 & 31453 & 850 & 359 & 42.3 & 380 & 1895 & 37 \\
\hline & & 2 & 23990 & $\frac{727}{789}$ & 247 & 33.9 & 340 & 1350 & 33 \\
\hline \multirow[t]{2}{*}{$\mathrm{OB}-\mathrm{W}$} & 5.6 & 1 & 46883 & 1.019 & 474 & 46.6 & 350 & 2325 & 46 \\
\hline & & 2 & $43882 \bar{x}$ & $\frac{1070}{1045}$ & 469 & 43.8 & 295 & 2495 & 41 \\
\hline \multirow[t]{2}{*}{$\mathrm{HQ}-22$} & 6.3 & 1 & 33624 & 934 & 359 & 38.4 & 290 & 1880 & 36 \\
\hline & & 2 & 36325 & $\frac{931}{933}$ & 299 & 32.1 & 535 & 1880 & 39 \\
\hline
\end{tabular}




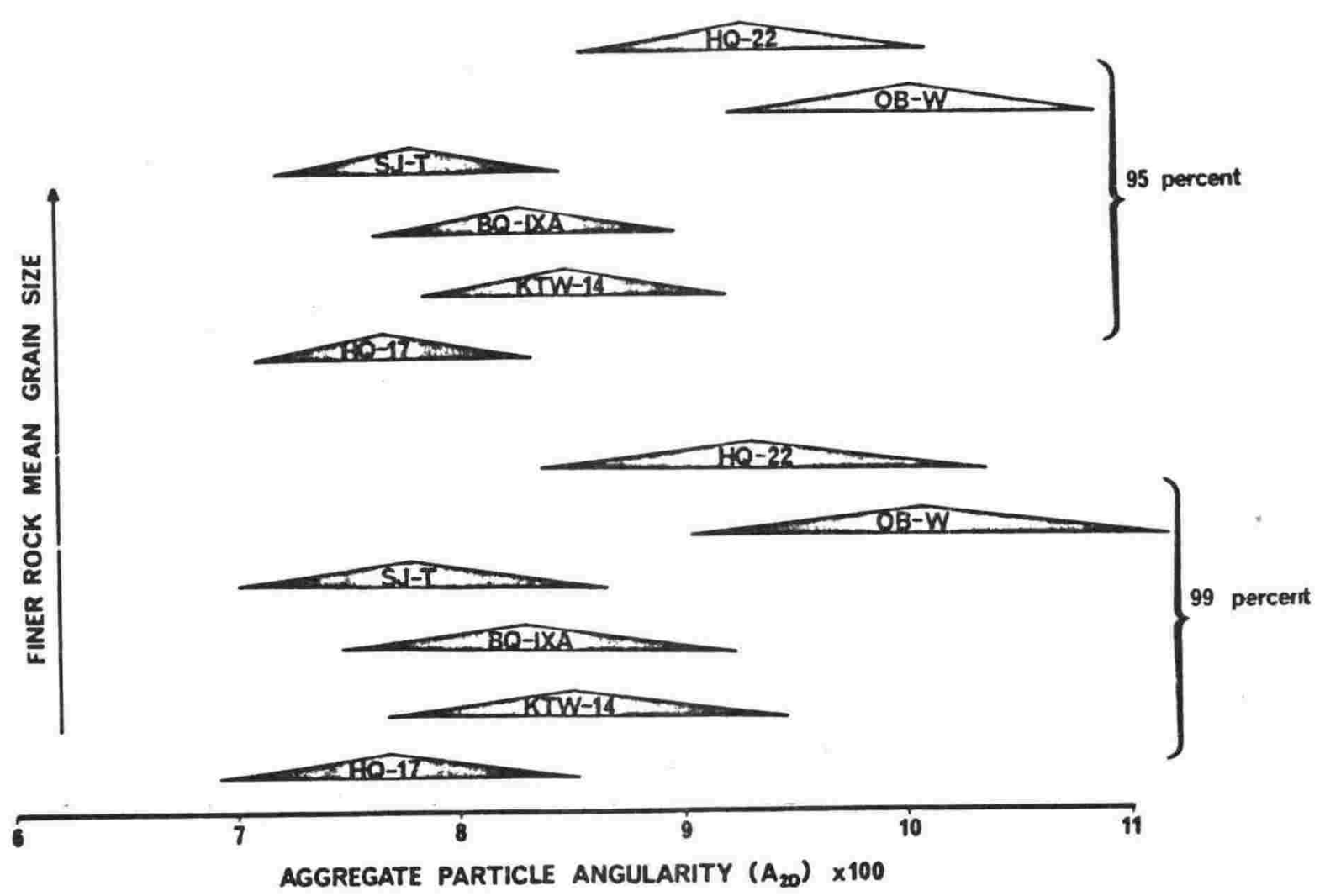

Figure 4.3 : Aggregate particle angularity errors, at two levels of confidence, in order of grain size. The apex of triangles denote mean angularity $\left(\mathrm{A}_{2 \mathrm{D}}\right)$; bases span error at confidence levels indicated. 
(ii) The crushing ratio, i.e. the ratio of the size of material introduced to the crusher, to that which the crusher produces. Large ratios tend to produce flakier particles, which give high values of angularity.

Crushing ratio was large in most cases, certainly for aggregates KIW-14, BQ-IXA (boulder size), less so for HQ-17, OB-W and HQ-22 (boulder and cobble sized material) and very much less, by orders of magnitude, for SJ-T (cobble and pebble size). However, there is no clear relationship between angularity and crushing ratio, whereas that between angularity and rock mean size is quite well established $(y=38.28 x+719.6 ; r=0.71)$.

\subsubsection{Density and absorption}

Tests for density and absorption (NZS 3111:1974, parts 202.1 and 202.3) were undertaken, the results being listed in Table 4.3. In addition, a 30 minute water absorption was determined for use in concrete mix design (Appendix 27).

Density increases slightly with decreasing rock mean grain size (Table 4.3). Water absorption data reflect surface area to volume ratio differences between different aggregate gradings, i.e. the ratio between the 30 minute water absorption of 19 and $9.5 \mathrm{~mm}$ aggregate average 0.55. Higher values are apparent for greywacke HQ-17, due to the presence of zeolite (Appendix 3) and for argillaceous samples SJ-T, OB-W and HQ-22.

For absorptions obtained to NZS 3111:1974 method 202.1, the ratio between absorption of 19 and $9.5 \mathrm{~mm}$ aggregates is higher, average 0.82 , because $19 \mathrm{~mm}$ aggregate takes a longer time to equilibrate. Samples $\mathrm{OB}-\mathrm{W}$ and HQ-22 had the highest values and HO-17 the lowest.

To better understand the influences of rock crushing on the densities of aggregate produced, aggregate densities were correlated with corresponding rock core densities for both dry and SSD conditions (Figure 4.4). Correlation was good for both conditions but was not linear in either case, crushing apparently tending toreduce the density of aggregate for all but the most argillaceous samples. Although dry densities were less than SSD densities in all cases, the density values of $19 \mathrm{~mm}$ aggregates correlate well with those of cores. A single trend was apparent in the more argillaceous rock types, i.e. those 
Table 4.3 : Density and absorption results for greywacke-suite aggregates used for concrete making, arranged in order of rock mean grain size.

\begin{tabular}{|c|c|c|c|c|c|c|}
\hline Sample & $\begin{array}{l}\text { Rock } \\
\text { mean } \\
\text { grain } \\
\text { size, } \\
\text { phi }\end{array}$ & $\begin{array}{l}\text { Coarse } \\
\text { aggre- } \\
\text { gate } \\
\text { grading, } \\
\text { mm. }\end{array}$ & $\begin{array}{l}\text { SSD } \\
\text { density, } \\
\mathrm{kg} \cdot \mathrm{m}^{-3}\end{array}$ & $\begin{array}{l}\text { Oven } \\
\text { dry } \\
\text { density, } \\
\mathrm{kg} \cdot \mathrm{m}^{-3}\end{array}$ & $\begin{array}{l}\text { Water- } \\
\text { absorp- } \\
\text { tion, } \\
\text { percent }\end{array}$ & $\begin{array}{l}30 \text { minute } \\
\text { water } \\
\text { absorp- } \\
\text { tion, } \\
\text { percent }\end{array}$ \\
\hline \multirow[t]{2}{*}{$\mathrm{HQ}-17$} & 1.3 & 19.0 & 2662 & 2647 & 0.56 & 0.22 \\
\hline & & 9.5 & 2653 & 2632 & 0.77 & 0.33 \\
\hline \multirow[t]{2}{*}{ KTW-14 } & 2.6 & 19.0 & 2673 & 2660 & 0.47 & 0.15 \\
\hline & & 9.5 & 2660 & 2644 & 0.61 & 0.32 \\
\hline \multirow[t]{2}{*}{$\mathrm{BQ}-I X \mathrm{X}$} & 2.9 & 19.0 & 2670 & 2658 & 0.48 & 0.17 \\
\hline & & 9.5 & 2666 & 2651 & 0.59 & 0.37 \\
\hline \multirow[t]{2}{*}{$S J-T$} & 4.7 & 19.0 & 2706 & 2691 & 0.56 & 0.21 \\
\hline & & 9.5 & 2696 & 2676 & 0.76 & 0.36 \\
\hline \multirow[t]{2}{*}{ OB-W } & 5.6 & 19.0 & 2740 & 2713 & 0.96 & 0.26 \\
\hline & & 9.5 & 2730 & 2699 & 1.14 & 0.57 \\
\hline \multirow[t]{2}{*}{$\mathrm{HQ}-22$} & 6.3 & 19.0 & 2694 & 2671 & 0.87 & 0.33 \\
\hline & & 9.5 & 2700 & 2676 & 0.88 & 0.52 \\
\hline
\end{tabular}




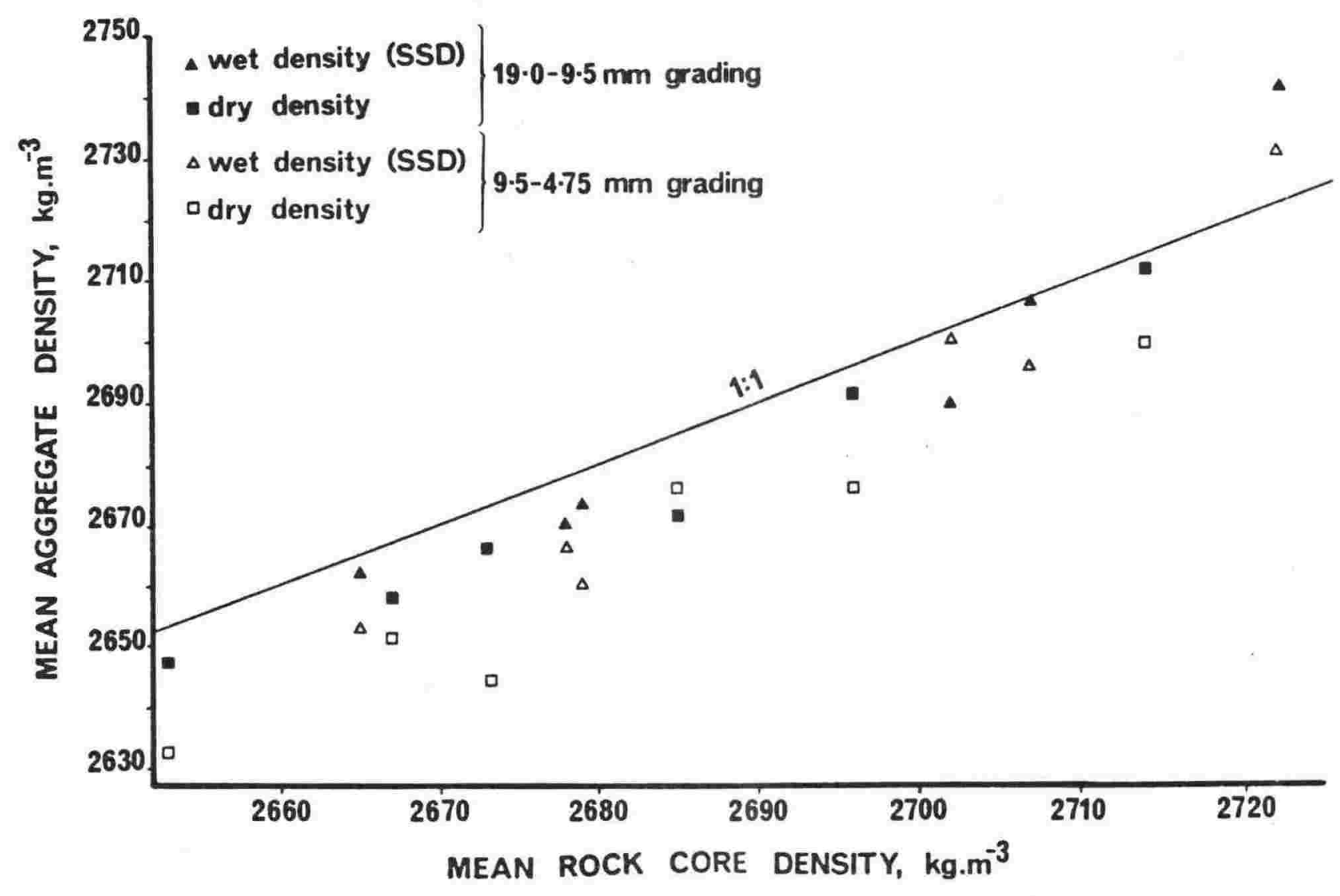

Figure 4.4 : A comparison of densities of identical rock types in two forms, aggregate and cores. 
with dry densities in excess of $2690 \mathrm{~kg} \cdot \mathrm{m}^{-3}$. Below this value the difference between SSD and dry densities was less for core material than for aggregate material (Figure 4.4). These effects are brought about by the crushing process; a larger surface area to volume ratio tends to increase a lower dry density and raise the SSD density of aggregates. Both density values are lower than those of equivalent cores. In the greywackes this is due to surface texture features, microcracking and a resultant increase in capillary space.

The effect was greatest in the rocks of larger mean grain size. Disruption of rock adjacent to a new formed outer surface seems to be greatest in fine to medium grained greywackes compared with argillites (Appendix 15). On close examination surface flaking of small regions of aggregate particles can be seen. The flakes may be still attached but translucent due to their separation from the aggregate particle over their entire area. Such flakes are larger than the mean grain size of the rock but are very strongly attached (Appendix 15). Further, argillites do not have the well developed surface texture or small scale surface flaking of greywackes. The surface may be very hackly but does not appear to retain the same proportion of trapped water, except in larger size gradings where irregularites may be well indented - a possible reason for the trend going above the $1: 1$ density ratio in Figure 4.4 .

The relationship shown by Figure 4.4 for $9.5 \mathrm{~mm}$ aggregate is more scattered but has the same features as the $19 \mathrm{~mm}$ aggregate discussed above.

The behaviour of $9.5 \mathrm{~mm}$ HQ-22 aggregate seens anomalous in that both its SSD and dry densities are greater than those of $19 \mathrm{~mm}$ HQ-22. However, differences between the aggregate densities for both gradings are almost identical ( 5 and $6 \mathrm{~kg} \cdot \mathrm{m}^{-3}$ ) and are not significant, as absorption figures for this particular rock type in both aggregates are almost identical ( $19 \mathrm{~mm}, 0.87$ percent; $9.5 \mathrm{~mm}, 0.88$ percent).

Comparison of effective porosity of cores with absorption characteristics of aggregates show no relationship, except that $9.5 \mathrm{~mm}$ aggregates have greater absorptions than $19 \mathrm{~mm}$ aggregates for any particular rock type - reflecting increasing surface area to volume ratios in finer aggregate sizes. This is superposed on a tendency for the more argillaceous rocks to absorb more water. Over 24 hours, $19 \mathrm{~mm}$ aggregates absorb between 1.7 and 2.5 times as much as 
their cored counterparts and $9.5 \mathrm{~mm}$ aggregates between 1.7 and 2.8 times; again, greater scatter is apparent in the finer grading (Figure 4.5).

There is better correlation between effective porosity of cores and 30 minute water absorptions (Figure 4.6) determined for concrete mix designs. In addition, it seems that there is an aggregate surface area to volume ratio which enables a rapid water absorption, equalling the natural effective porosity of the parent rock. The surface area to volume ratio which allows this to take place in, say, 4 to 8 hours and the corresponding particle size may provide valuable information regarding aggregate degradation (Appendix 25).

\subsubsection{Bulk density and voids content}

The bulk density and voids content of aggregates were measured using NZS 3111:1974 method 201.6 (Table 4.4). The measurement is of direct use in concrete mix design (NZS 3111:1974 method 201.4 "Method for determining aggregate performance in concrete").

Results represent the efficiency with which aggregate can be packed into a container. For aggregate of a particular specific gravity, bulk density depends on size grading and particle shape; the more well sorted the aggregate,i.e. the more uniform particles are in size, the greater the space left unfilled. Aggregates with greater variation in particle size may be packed more closely giving higher bulk densities. More equant and less angular particles also pack closer. In fact some tests for measuring the angularity of coarse aggregate particles have been based on theoretical and loose poured bulk densities (Shergold, 1953; Hughes, 1966). It is interesting to note that argillites, in spite of higher rock densities, have lower bulk densities and higher voids contents in both 19 and $9.5 \mathrm{~mm}$ gradings. This is directly attributable to their flaky particle shapes.

\subsubsection{Crushing resistance}

The strength of aggregate as a particulate mass is a difficult property to measure. Approaches to strength assessment for aggregates include uniaxial compression strengths of prepared samples (section 3.5), strengths of concrete made with the aggregate, the 10 percent fines test (forerunner to the crushing resistance test), aggregate impact value (BS 812: part 3:1978), point load tests on prepared rock specimens or aggregate particles (Bieniawski, 


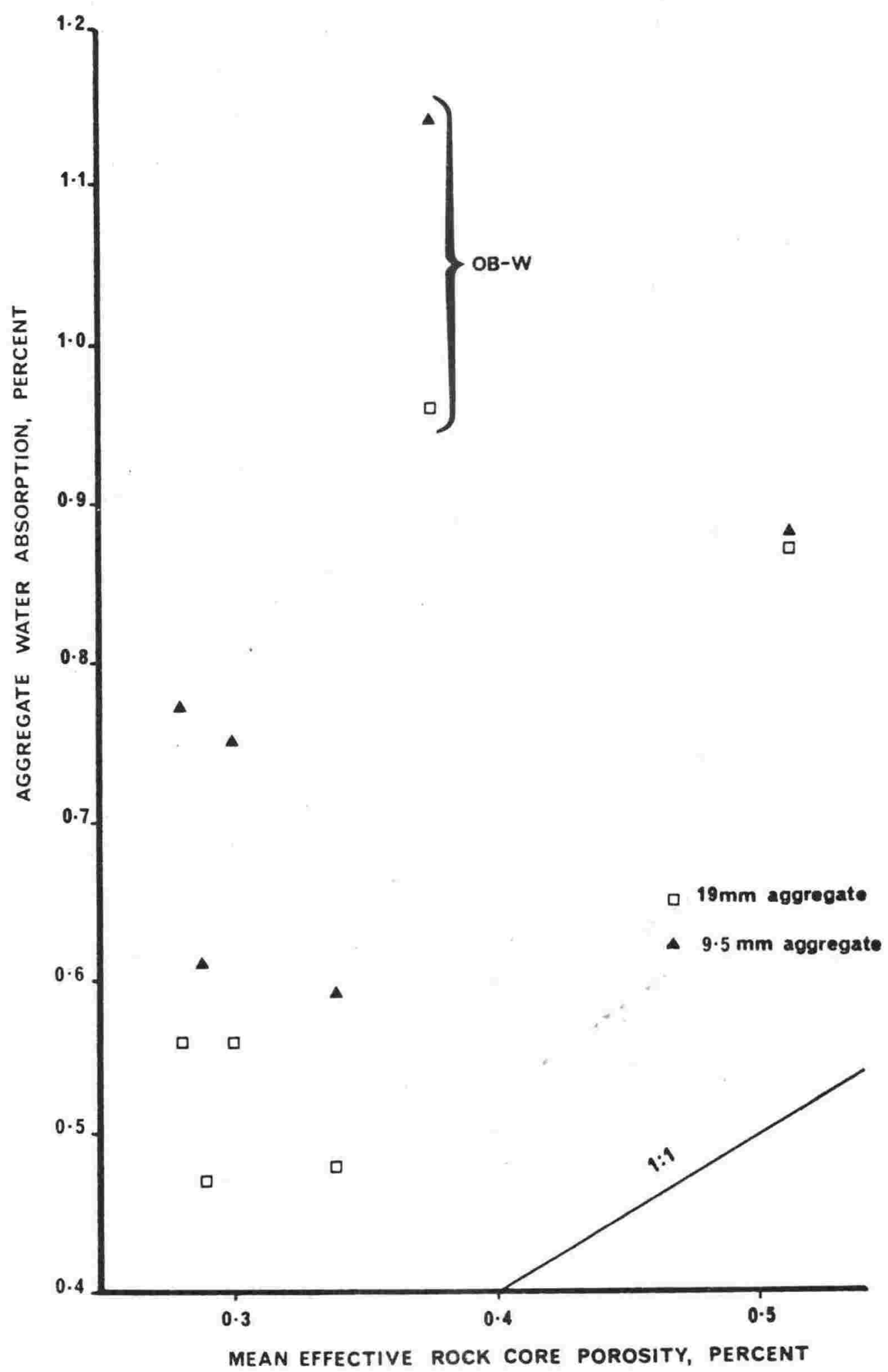

Figure 4.5 : Little correlation exists between 24 hour aggregate absorption and rock core effective porosity. Note

that scatter is greater for finer aggregate fractions. A large surface area to volume ratio for $O B-W$ is apparent from its absorption. 


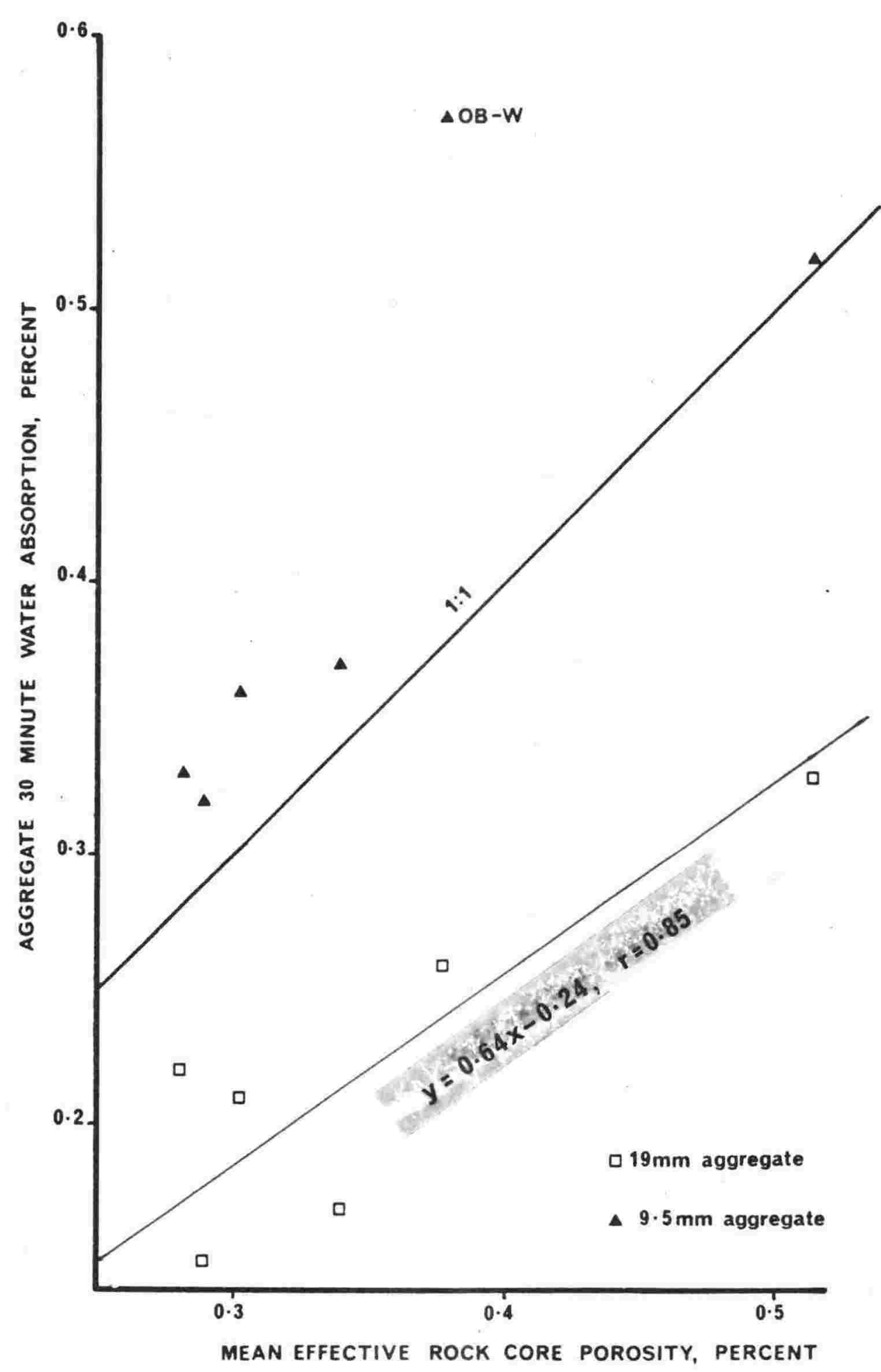

Figure 4.6 : Rock core effective porosities show good correlation with aggregate 30 minute water absorptions. Again the relatively high surface area to volume ratio of $9.5 \mathrm{~mm}$ $\mathrm{OB}-\mathrm{W}$ aggregate is readily satisfied even within 30 minutes of soaking. 
Table 4.4 : Aggregate test results for all rock types.

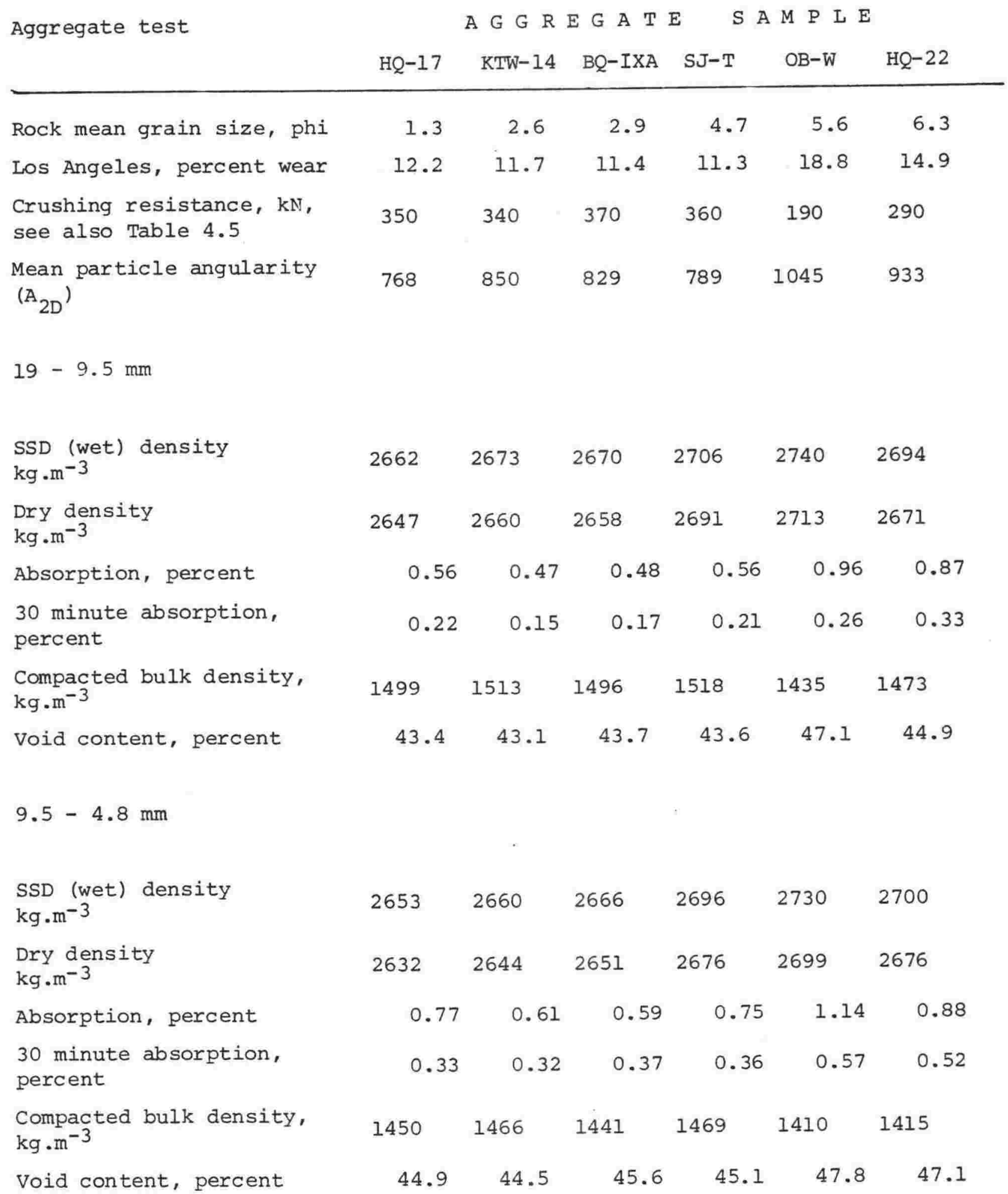


1975), testing large (cobbles) and small (pebbles) irregular rock specimens (Hobbs, 1963; Ramsay et al., 1974; Vutukuri et al.,1974), and the crushing resistance test (NZS 3111:1974, method 202.3). The latter method was used in this study.

All tests mentioned above have different applications. When bulk aggregate particles are tested for crushing resistance, results are influenced by the effects of packing, particle shape (Figure 4.7), point loading, and abrasion resistance, which provide better resolution of performance in strong aggregates.

The crushing resistance of the samples tested appears to be more related to angularity of the particles (Figure 4.7), than mean grain size (Table 4.4) or strength of the rock (Table 3.2), though effects of packing will have had some influence. Particle shape is a.lready known to affect aggregate impact values (Ramsay et al., 1974), which measures a similar aggregate property. Crushing resistance results from aggregate tested wet and dry also allow some assessment of rock durability (Table 4.5).

Table 3.3A, in part reproduced from Neville (1975), gives an indication of the relative precision of several commonly used methods of assessing aggregate strength.

\section{2.6 Los Angeles abrasion test}

This test measures the combined effects of attrition and abrasion and consists of grinding the aggregate with steel balls in a rotating drum for a set time. The Los Angeles value is the percentage of ground material passing a $1.7 \mathrm{~mm}$ sieve; details of the test are given by ASTM C131-76. It has been found to correlate well with the compressive strength and wearing characteristics of concrete (Neville, 1975). As with the crushing resistance test, the results depend very much on toughness, hardness, elasticity, strength and especially particle shape (Figure 4.8) - most of these properties being better assessed by other means. Use of the Los Angeles test is declining in New Zealand as in most cases results are difficult to apply, by direct means, to aggregate use. Results presented (Table 4.4) are included for completeness.

The Los Angeles values for the aggregates tested also show a close relationship to crushing resistance (Figure 4.9), indicating that both tests yield the same sort of information. 


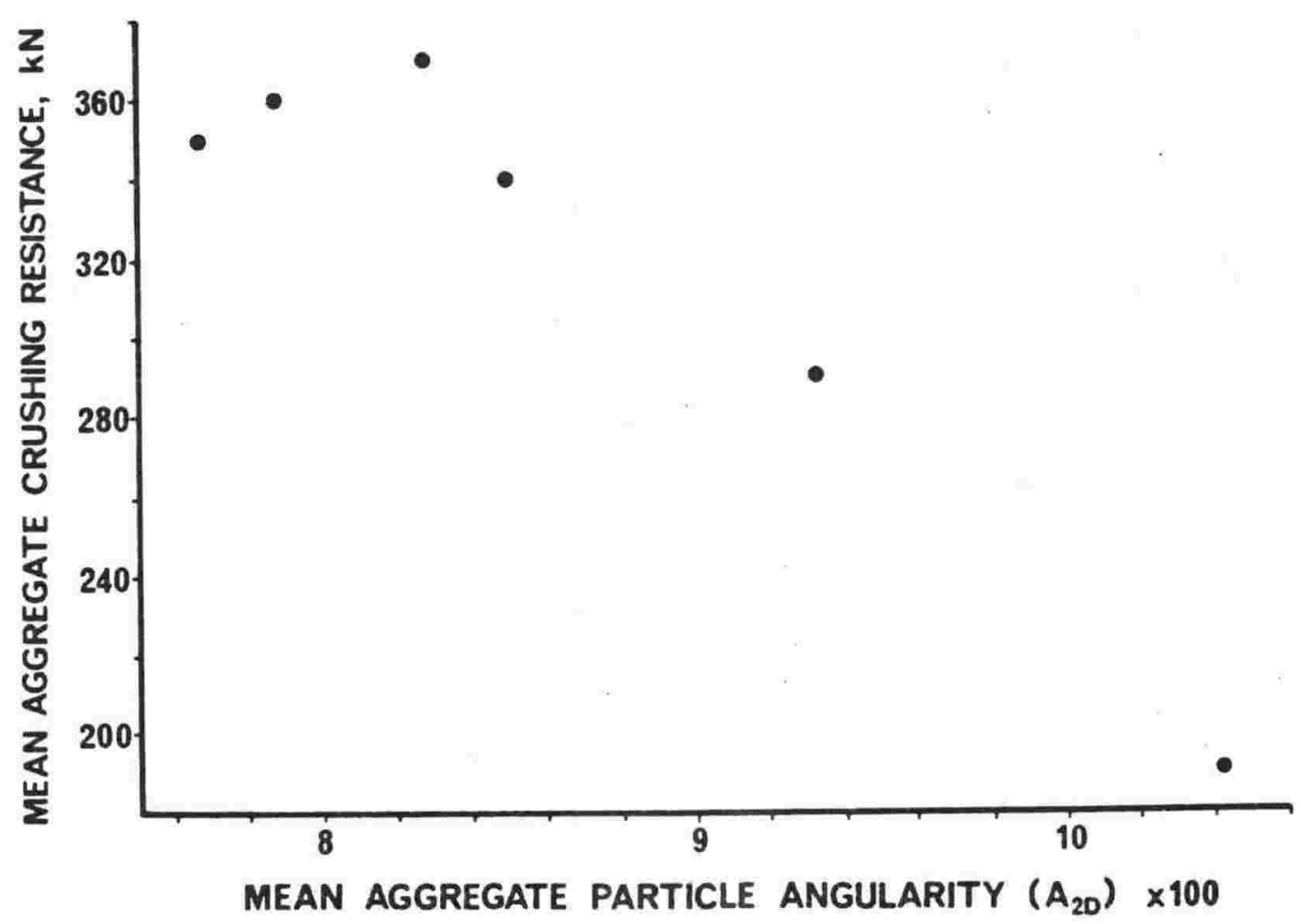

Figure 4.7 : Aggregate particle shapes affect aggregate crushing resistance results. More angular materials return a lower crushing resistance. 
Table 4.5 : Comparison of aggregate relative durability, as measured by wet and dry crushing resistance. Samples tested wet were soaked seven days beneath a $100 \mathrm{~mm}$ head of water before being otherwise tested" according to test method T215, Department of Main Roads, N.S.W., Australia: durability of coarse aggregate by the ten percent fines (wet/dry variation) procedure; April 1979.

\begin{tabular}{|c|c|c|c|c|}
\hline \multirow[t]{2}{*}{ Sample } & \multirow{2}{*}{$\begin{array}{l}\text { Rock mean } \\
\text { grain size, } \\
\text { phi }\end{array}$} & \multicolumn{2}{|c|}{$\begin{array}{c}\text { Crushing resistance, } \\
\mathrm{kN}\end{array}$} & \multirow[t]{2}{*}{$\begin{array}{l}\text { Wet crushing resistance } \\
\text { as percentage of dry* }\end{array}$} \\
\hline & & dry & wet & \\
\hline $\mathrm{HQ}-17$ & 1.3 & 350 & 320 & 91 \\
\hline$K T W-14$ & 2.6 & 340 & 330 & 97 \\
\hline $\mathrm{BQ}-I X A$ & 2.9 & 370 & 360 & 97 \\
\hline $\mathrm{SJ}-\mathrm{T}$ & 4.7 & 360 & 320 & 89 \\
\hline$O B-W$ & 5.6 & 190 & 140 & 74 \\
\hline $\mathrm{HO}-22$ & 6.3 & 290 & 220 & 76 \\
\hline
\end{tabular}

* A minimum value of 65 percent is required by the DMR for their aggregates. 


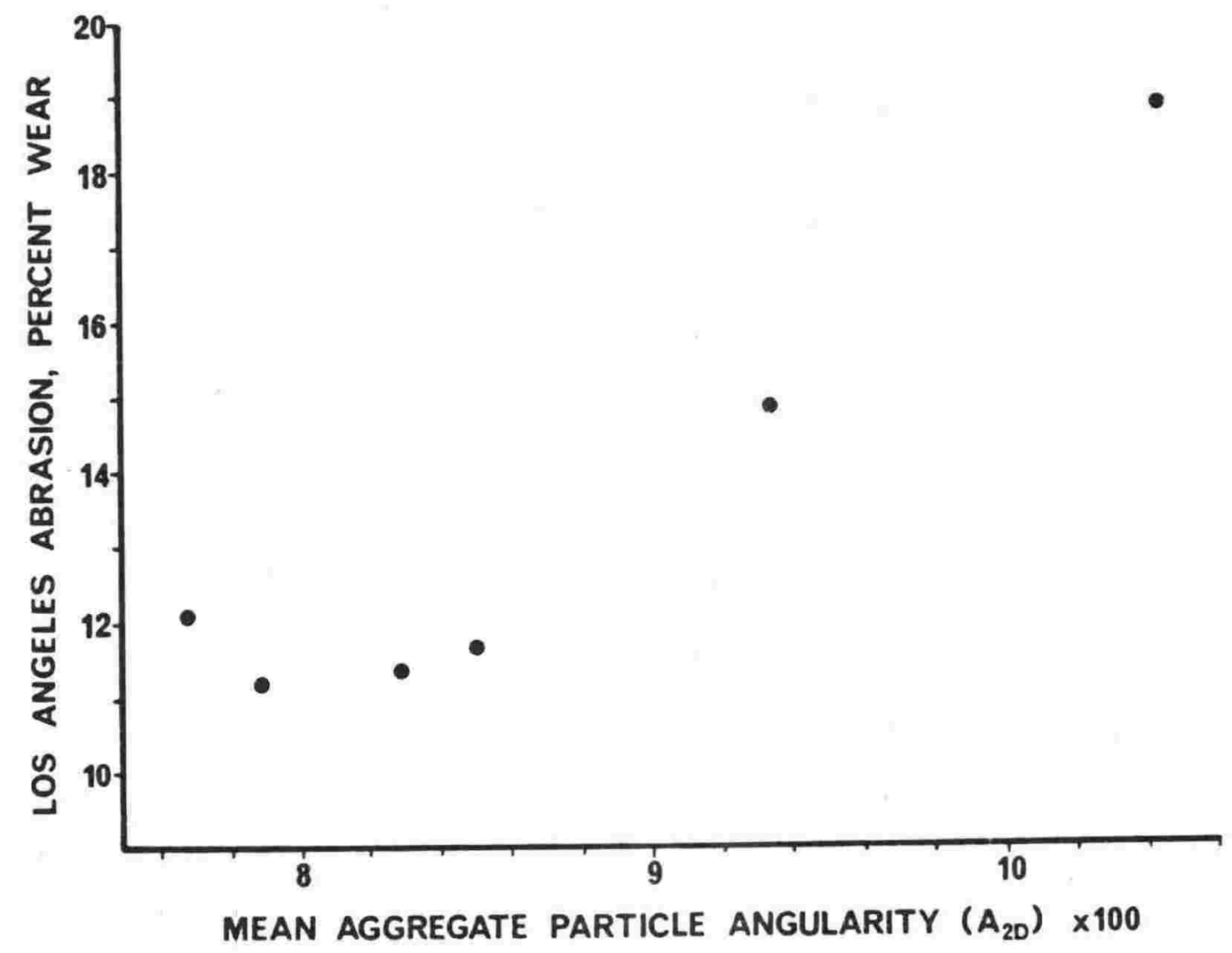

Figure 4.8 : Aggregate particle shape affect the abrasion resistance of aggregate. More angular materials return a greater loss due to abrasion. 


\subsection{6a Results of bulk testing}

The uniformity in the results of bulk testing shown by greywackes is in marked contrast to the difference between the two argillites tested (Table 4.4). Some parameters, Los Angeles abrasion test and crushing resistance, show direct relationships with particle angularity and therefore are only indirectly related to rock mean grain size. Generally, the argillites show an increase in Los Angeles abrasion percentage wear over greywackes ( 3 to 7 percent), lower crushing resistance (approximately $100 \mathrm{kN}$ less), increased wet density $\left(20 \mathrm{~kg} \cdot \mathrm{m}^{-3}\right)$, higher absorption ( 0.4 percent), compacted bulk density reduced by $40-50 \mathrm{~kg} \cdot \mathrm{m}^{-3}$ and higher (1-4 percent) voids content.

\subsubsection{Fines from crushing and abrading}

Fines produced during crushing can influence significantly the quality of the aggregate, which acquires a fine dust coating that is only partly removed by washing. This coating is probably formed initially by electrostatic charge generated by friction during crushing but the fineness of the dust is responsible for adhesion which makes separation by washing difficult.

Different crushing methods produce different proportions of fines, but whatever the method used, argillite yields more and finer material than greywacke (Figure 4.10).

\subsection{Alluvial versus quarried aggregate}

Traditionally the use of greywacke-suite aggregates from alluvial and quarried sources has been dependent upon place value and ease of production. Prior to law amendments from the early 1950's, alluvial and beach gravels and sands were the most important source of aggregate in Wellington. These sources were accessible, easily extracted, were clean and without soft or weathered particles, due to sorting by moving water. Even today Owhiro Bay Quarries use the sea as a "scrubber" and crude sieve by deliberately placing freshly won material on a small beach, adjacent to the quarry, for a period of time (Rowe, in prep.).

Pressures from increased population have had the effect of increasing demand for aggregates whilst also requiring maintenance of alluvial aquifers, beaches and river channels. For these reasons most aggregate in the Wellington region (Grant-Taylor, 1976; Ward and Grant, 1978) is now quarried. One major advantage inherent to alluvial aggregates, is that the particles are rounded in contrast to the sharp corners of crushed aggregate. The rounded particles improve the workability of concrete (section 5.1.1), which is especially important for pumped concretes, where strict size gradings must be adhered to, to allow minimum cement, sand and water contents for economy and strength. Other advantages of alluvial material are cleanness and a general freedom from deleterious matter. 


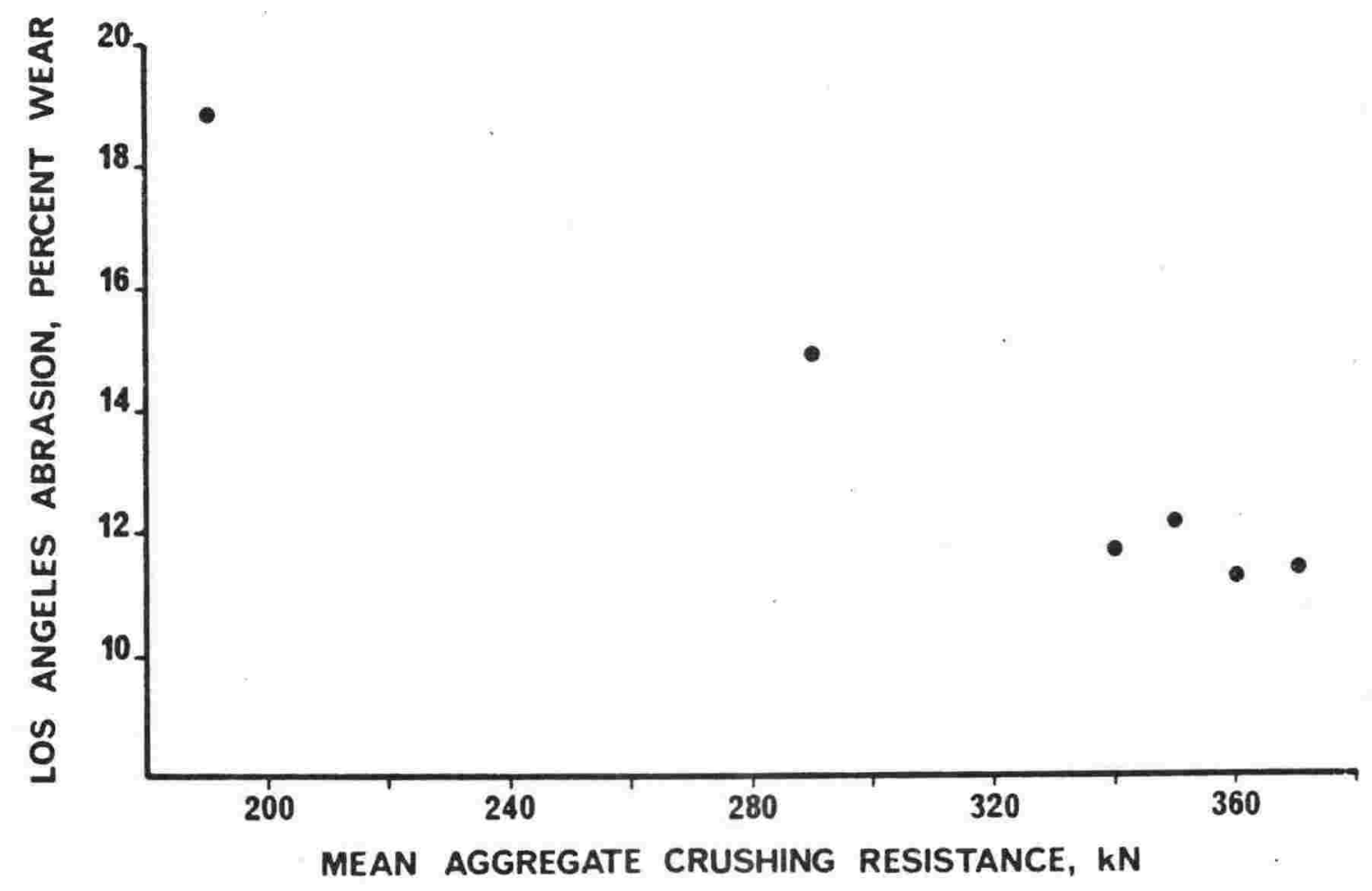

Figure 4.9 : Los Angeles results relate well with the crushing strength of bulk aggregate. A similartrend is apparent for uniaxial compression strength of rock cores (Appendix 18). 


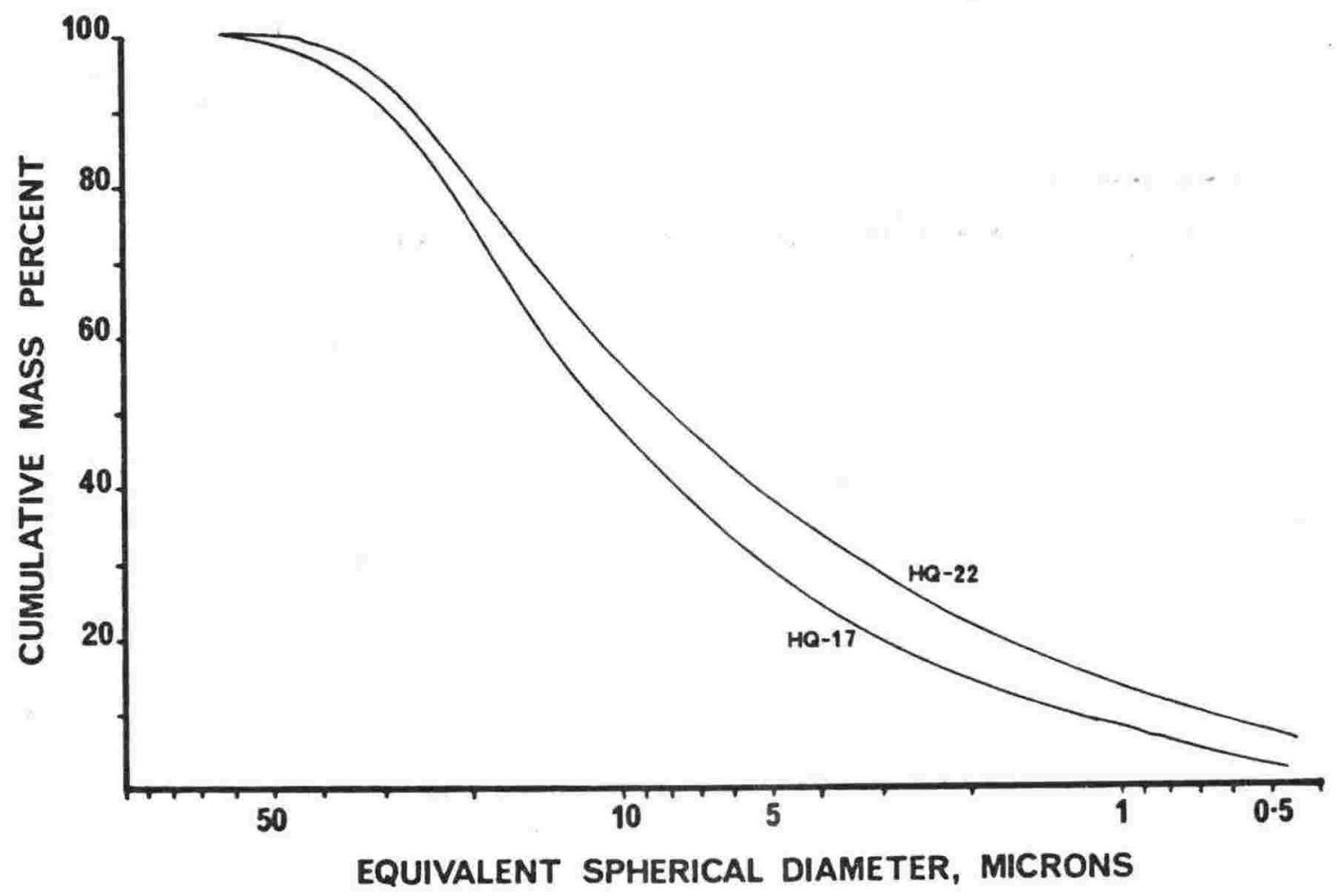

Figure 4.10:A comparison between the coarsest greywacke and finest argillite aggregate fines (minus $0.065 \mathrm{~mm}$ ) produced by the Los Angeles test indicates that finer material is produced from argillites. The other four aggregates tested in the study have curves that plot between those shown and are arranged from the HO-17 curve to the HO-22 curve in order of decreasing rock mean grain size. 
Grant-Taylor (1976), comparing several different quarried road basecourse aggregates with river-won aggregates, concluded that for river gravel "Los Angeles abrasion test results appear to be consistantly 3 to 5 percent lower (better) than for similar rock from a quarry. This difference will be due to the presence of rounded faces". However, it is also worth noting that quarried basecourse aggregate, although angular, invariably contains more weathered and therefore softer rock, (see Grant-Taylor, 1976, Table 1), which also yields high Los Angeles values.

Grant-Taylor (1976) also points out that rock jointed "to include the product grade range, would be expected to give a better Los Angeles test than rock which is all artifically crushed" and has greater angularity. Rocks crushed for aggregate used in this study were selected for their lack of geological discontinuity - veining etc., and included large boulders. Their Los Angeles values are even lower than those of the best (large river) gravel deposits (minimum Los Angeles test values), and rocks from "best" quarries (minimum Los Angeles test values) of Grant-Taylor (1976):

$\begin{array}{ll}\text { Average Los Angeles } & \text { Averaged Los Angeles } \\ \text { test minimums for } & \text { test minimums for } \\ \text { eight best quarries } & \text { gravel from nine } \\ \text { in Wellington } & \text { large river sites, } \\ \text { region, (Grant- } & \text { (Grant-Taylor, 1976, } \\ \text { Taylor, 1976, } & \text { Table 6). } \\ \text { Table 5) } & \end{array}$

13.3 percent highest minimum 14.7 percent lowest minimum 11.6 percent $\mathrm{n}=376$
13.7 percent highest minimum 16.5 percent 12.2 percent $\mathrm{n}=241$ lowest minimum

\section{Average of four} greywackes, this study.

$$
\begin{aligned}
& 11.7 \text { percent } \\
& \text { maximum } \\
& 12.2 \text { percent } \\
& \text { minimum } \\
& 11.3 \text { percent } \\
& \mathrm{n}=4
\end{aligned}
$$


Differences are not significant between Grant-Taylors' minimum values for either aggregate source and this work.* This may imply that veining and other discontinuities do not affect Los Angeles values as much as, say, the type of crushing machinery, which influences particle shape, and hence Los Angeles results (Orchard, 1964).

A comparison of some commercially available quarried and alluvial greywackesuite concrete aggregate is presented in Table 4.6. Generally this shows agreement with Grant-Taylors' (1976) data indicating that alluvial greywackes are more consistent in the Los Angeles test than quarried greywackes. This is probably because the quarried aggregate normally includes some argillite which is more easily comminuted, more absorbent and contains more incipient flaws than greywacke. The aggregate may also include some weathered material.

\subsection{Alkali reactivity}

Zeolites have been placed, as a mineral group, into the category of reactive components when aggregate particles, containing it, are used in cont junction with high alkali cements to make concrete (Rhoades and Mielenz, 1946; Swenson and Chaly, 1956; Hansen, 1966; Neville, 1975).

Gillott (1975) has described three subdivisions of alkali-aggregate reactions and has given a good summary of the problem. The type of reaction discussed here is an alkali-silicate reaction.

* "For nominal $19.0 \mathrm{~mm}$ maximum size coarse aggregate with percentages of wear in the range of 10 to 45 percent, the multilaboratory coefficient of variation has been found to he 4.5 percent. Therefore, results of two properly conducted tests from two different laboratories on samples of the same coarse aggregates should not differ from each other by more than 12.7 percent of their average. The single-operator coefficient of variation has been found to be 2.0 percent. Therefore, results of two properly conducted tests by the same operator on the same coarse aggregate should not differ from each other by more than 5.7 percent of their average." Extracted from ASTM C131-76, 'Resistance to abrasion of small size coarse aggregate by use of the Los Angeles Machine'. 
Table 4.6 : A comparison of test results of New Zealand greywacke-suite aggregates from quarried and alluvial sources.

QUARRIED GREYWACKES

\begin{tabular}{|c|c|c|c|c|c|c|c|c|c|c|c|c|}
\hline \multirow[b]{2}{*}{ AGGREGATE TEST } & \multicolumn{3}{|c|}{ Same Aggregate* } & \multicolumn{2}{|c|}{ Same aggregate } & \multirow{2}{*}{ SP2-69B } & \multirow[b]{2}{*}{$1 / 019 B$} & \multirow[b]{2}{*}{$1 / 061$} & \multicolumn{4}{|c|}{ This study } \\
\hline & $1 / 002$ & $1 / 003$ & $1 / 044$ & $1 / 011$ & $S P 7-75$ & & & & $\mathrm{HQ}-17$ & KIW-14 & $B Q-1 X A$ & $S J-T$ \\
\hline $\begin{array}{l}\text { Crushing resistance, } \\
\mathrm{kN}\end{array}$ & 260 & 220 & 450 & 230 & 230 & 290 & 320 & 320 & 350 & 340 & 370 & 360 \\
\hline Cleanness value & 81 & 86 & 91 & 73 & 79 & 84 & 81 & 85 & - & - & - & - \\
\hline Bulk density, $\mathrm{kg} \cdot \mathrm{m}^{-3}$ & 1446 & 1455 & 1540 & 1528 & 1528 & 1546 & 1562 & 1600 & 1499 & 1513 & 1496 & 1518 \\
\hline Voids contact, percent & 42.2 & 41.1 & 42.0 & 42.5 & 42.5 & 41.0 & 40.5 & 40.0 & 43.4 & 43.1 & 43.7 & 43.6 \\
\hline $\begin{array}{l}\text { S.S.D. (wet) density, } \\
\mathrm{kg} \cdot \mathrm{m}^{-3}\end{array}$ & 2630 & 2650 & 2680 & 2670 & 2650 & 2640 & 2660 & 2690 & 2662 & 2673 & 2670 & 2706 \\
\hline Dry density, $\mathrm{kg} \cdot \mathrm{m}^{-3}$ & 2590 & 2640 & 2670 & 2660 & 2610 & 2600 & 2640 & 2660 & 2647 & 2660 & 2658 & 2691 \\
\hline $\begin{array}{l}\text { Absorption, S.S.D. (wet) } \\
\text { basis, percent }\end{array}$ & 1.20 & 0.44 & 0.5 & 0.78 & 1.44 & 0.95 & 0.95 & 0.89 & - & - & - & - \\
\hline $\begin{array}{l}\text { Absorption, oven dry } \\
\text { basis, percent }\end{array}$ & 1.22 & 0.44 & 0.5 & 0.79 & 1.46 & 0.96 & 0.96 & 0.90 & 0.56 & 0.47 & 0.48 & 0.56 \\
\hline $\begin{array}{l}\text { Accelerated weathering } \\
\text { test }\end{array}$ & $\mathrm{AA}$ & BA & - & $A B$ & - & BB & $\mathrm{AA}$ & - & - & - & - & - \\
\hline $\begin{array}{l}\text { Los Angeles abrasion } \\
\text { test percent wear }\end{array}$ & 17.2 & 15.5 & - & 14.2 & - & 18.8 & 13.4 & - & 12.2 & 11.7 & 11.4 & 11.3 \\
\hline $\begin{array}{l}\text { Sodium sulphate sound- } \\
\text { ness test, percent loss }\end{array}$ & 1.6 & 2.5 & - & 13.8 & - & 5.4 & 7.4 & - & - & - & - & - \\
\hline
\end{tabular}

QUARRIED ARGIILIES

Same aggregate* This study

AGGREGATE TEST

1/019A SP2/69A

Crushing resistance,

$\mathrm{kN}$

Cleanness value

Bulk density $\mathrm{kg} \cdot \mathrm{m}^{-3}$

Voids contact, percent

S.S.D. (wet) density,

$\mathrm{kg} \cdot \mathrm{m}^{-3}$

Dry density, $\mathrm{kg} \cdot \mathrm{m}^{-3}$

Absorption, S.S.D(wet)

basis, percent

Absorption, oven dry

basis, percent

Accelerated weathering

test

Los Angeles abrasion test percent wear

Sodium sulphate soundness test, percent loss

$\begin{array}{rrrr}250 & 290 & 290 & 190 \\ 45 & 69 & - & - \\ 1573 & 1532 & 1473 & 1435 \\ 39.8 & 42.5 & 44.9 & 47.1 \\ 2650 & 2650 & 2694 & 2740 \\ 2610 & 2620 & 2671 & 2731 \\ 1.39 & 1.48 & - & - \\ 1.41 & 1.50 & 0.87 & 0.96 \\ \text { BB } & \text { AB } & - & - \\ 17.0 & 13.1 & 14.1 & 18.8 \\ 12.8 & 12.5 & - & -\end{array}$

* Same aggregate tested twice in last 10 years. Data applies only to $20 \mathrm{~mm}$ aggregate.

All data other than of this study supplied by New Zealand Concrete Research Association. Sample numbers from aggregate testing programme. 
A cement is considered to have a high alkali content where $\mathrm{Na}_{2} \mathrm{O}$ percent + $\left(0.658 \times \mathrm{K}_{2} \mathrm{O}\right.$ percent $)=0.6$ percent minimum (Lerch, 1962). All New Zealand cements produced at present have low alkali contents,i.e. less than 0.6 percent as calculated above. Exceptional cases of low alkali cements reacting with aggregates have been recorded (Neville, 1975).

Hutton (1945) tested various New Zealand aggregates for alkali reactivity including 18 greywackes; he concluded greywackes were non-reactive with cement and could perhaps be used with high alkali cements. One greywacke tested, however, had "a large number of intermediate to basic volcanic fragments, some with a residuum of dusty isotropic material, probably glass, although due to general neomineralization, one could not be too definite about this. In one case this glassy material gave $\mathrm{n}=1.525$ by the immersion method". This greywacke reacted slightly, suggesting to Hutton that it should be used with low alkali cements. It may be that the material observed was laumontite, which though not isotropic, has a changing refractive index depending on hydration state:

$$
\begin{array}{rr}
\text { laumontite (hydrated form) } & \mathrm{n}_{\mathrm{x}}=1.509, \mathrm{n}_{z}=1.525 \\
\text { leonhardite (dehydrated form) } & \mathrm{n}_{\mathrm{x}}=1.502, \mathrm{n}_{z}=1.518 \\
\text { Coombs (1952). }
\end{array}
$$

The petrographic associations of laumontite are discussed in Appendix 3. Laumontite is often a replacement product of calcic plagioclase, volcanic glass, or nepheline in basic volcanic rocks due to late-stage hydrothermal alterations or as an authigenic cement or feplacement product in sediments due to incipient metamorphism.

To test mineral aggregates for their potential alkali reactivity there are at least three orthodox approaches:

(i) The mortar-bar test, NZS 3111:1974, part 201.7 and ASTM C227-71.

(ii) The quick chemical test, ASTM C289-71.

(iii) The rock cylinder test, ASTM C586-69: for carbonate rocks. 
Although not normally used for pure mineral samples, as the results are difficult to interpret, the quick chemical test was used by Dr N. Milestone, Chemistry Division, DSIR, - because of its simplicity and speed - to assess potential reactivity of leonhardite. Five grams of sample taken from $1 \mathrm{~mm}$ wide veins in Horokiwi quarry produced the following measurements:

$$
\begin{aligned}
& \text { Quantity } S_{C}-\text { dissolved silica (millimoles per litre) }=28 \\
& \text { Quantity } R_{C}-\text { reduction in alkalinity (millimoles per litre) }=45.5
\end{aligned}
$$

Rationalising these figures for a pure mineral test gave a plot shown in Figure 4.11. Within Wellington greywacke-suite rocks, laumontite is most commonly found in veins and because of its weakness, generally coats exterior surfaces of aggregate particles when crushed. Surface material surviving the production processes is then in a locality best suited to reaction with cement paste. Aggregate stockpiling allows desiccation of the mineral and it becomes a fluffy, friable, anhydrous powder of crystalline mineral coating (leonhardite) which is weaker and more easily removed than laumontite. Relatively small amounts of zeolite, as surface coatings, may therefore remain on aggregate particles.

From permeability studies (Appendix 22) access by solutions containing calcium ions (e.g. the liquid phase of concrete) to replace sodium and potassium ions in the lattices of zeolite, within the rook, would takelplacenonly if hydrostatic: head exceeded about 20 metres

The mechanism of alkali reactivity by base exchange suggested by Swenson and Chaly (1956) is: "zeolite minerals .... are subject to base exchange in which the calcium ions from the cement paste solutions are absorbed, replacing Na or $\mathrm{K}$ ions originally present in these materials. The change in composi-

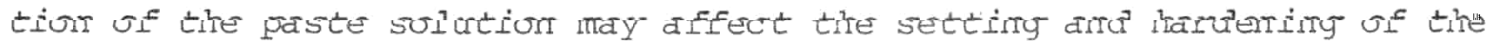
concrete. The resulting increase in the alkali content in the paste solution appears to be one of excessive efflorescence, and may also promote reaction with alkali-reactive aggregates". From this argument, the 


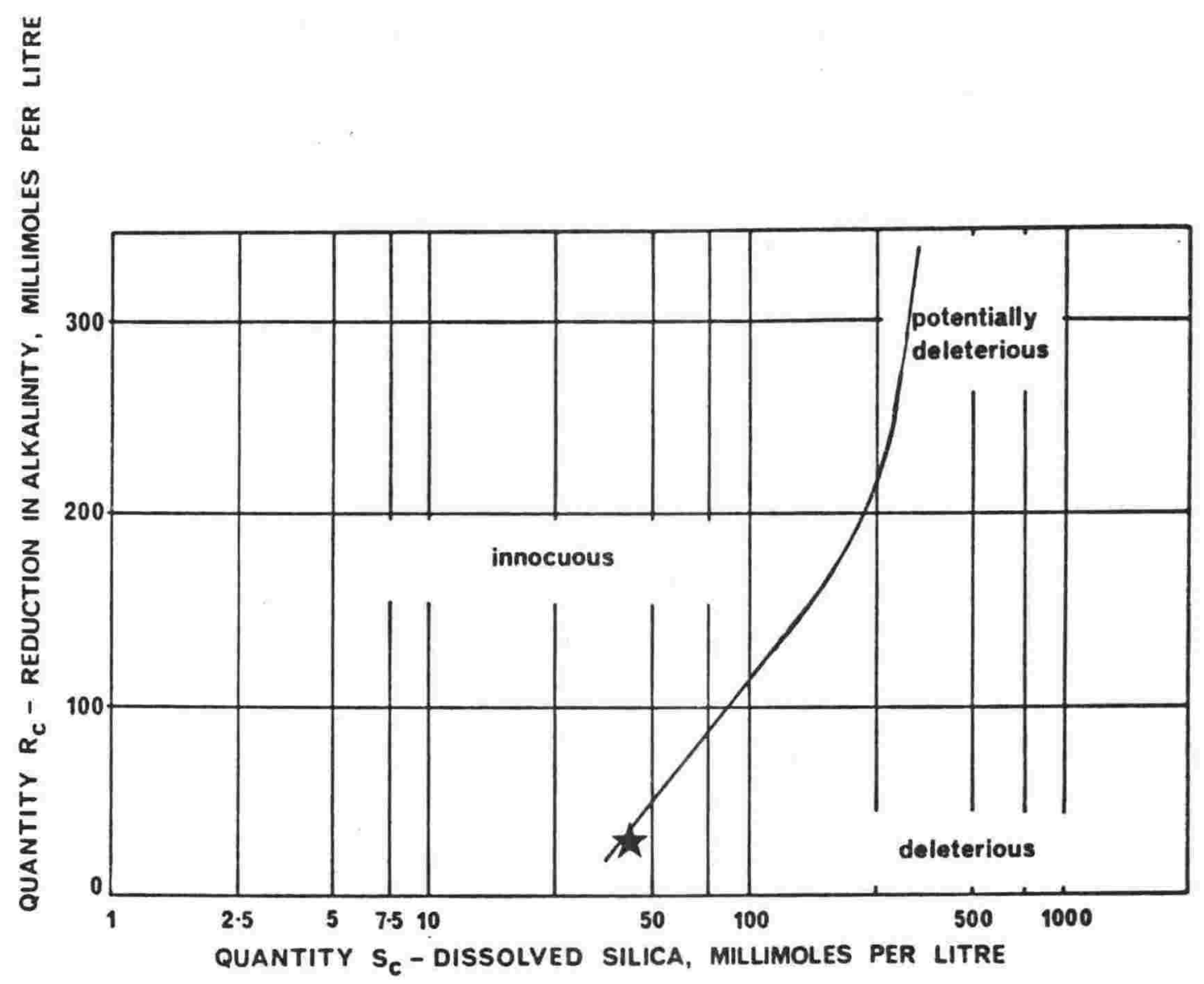

Figure 4.11 : Illustration of the division between innocuous and deleterious aggregates on the basis of reduction in alkalinity test (from ASTM C289-71). 
orthorhombic zeolites such as natrolite*, ferrierite* and mordenite*, rather than laumontite* would be better able to provide enrichment of the cement paste in $\mathrm{Na}$ and $\mathrm{K}$. Also, alkali reactivity is then broughtabout only if an alkali reactive aggregate is present, the zeolite acting merely as a catalyst for enhanced alkali content of cement paste.

A further concern with aggregate containing laumontite in particular, is that the mineral may be responsible for the disruption of concrete by volume change with varying degrees of hydration. Disruption of laumontite bearing rock has been established as being deleterious to aggregate production elsewhere (Appendix 25).

Hansen (1963) states "the zeolite laumontite on exposure to air or to gentle heat loses about 0.125 of its water to form leonhardite. This occurs with a change in the volume of the unit cell of about 1.5 percent. Sometimes this occurs with the crystal changing to a powder. The reaction is reversible and fairly rapid. According to Coombs (1952) the rehydration may be as brief as one or two hours. It appears from this that this rehydration process might be sufficiently slow to produce a volume change in concrete that would result in harmful expansion if leonhardite were a component of an aggregate".

Physical disruption of concrete due to volume change of leonhardite bearing aggregate is unlikely, however, because:

(i) The presence of hydration expansion is not likely to be great enough to exert pressures exceeding the tensile strength of the fresh greywackesuite rocks. Coombs (1952) gives measurements of expansion of leonhardite, "after soaking in water to convert to laumontite form, the (100) lattice spacing of the (same) crystal increased from 13.68 to $13.86 \AA$ and the (010) from 13.10 to $13.17 \AA$, all \pm 0.01 to $0.02 \AA "$. Lattice spacings of this order

Natrolite $\quad \mathrm{Na}_{2} \quad\left(\mathrm{Al}_{2} \mathrm{Si}_{3} \mathrm{O}_{10}\right) \quad .2 \mathrm{H}_{2} \mathrm{O}$

Ferrierite

$(\mathrm{Na}, \mathrm{K}) \quad 4 \mathrm{Mg}_{2}$

$\left(\mathrm{Al}_{6} \mathrm{Si}_{30} \mathrm{O}_{72}\right)$

(OH) $2 \quad \cdot 18 \mathrm{H}_{2} \mathrm{O}$

Mordenite

$$
\left(\mathrm{Na}_{2}, \mathrm{~K}_{2}, \mathrm{Ca}\right) \quad\left(\mathrm{Al}_{2} \mathrm{Si}_{10} \mathrm{O}_{24}\right) \quad \cdot 7 \mathrm{H}_{2} \mathrm{O}
$$


and an open alumino-silicate framework of channels and cavities which give laumontite a specific gravity of 2.2 to 2.3 combined with its hardness of between 3.5 to 5.5 (Mohs scale) suggests that distortion of the mineral lattice would accompany any increase in stress due to hydration expansion.

(ii) Zeolite minerals are all permeable (Hurlbut, 1971) and excess water beyond that required for hydration of leonhardite is not "stored" or "kontained" to produce excess pressures if confined.

(iii) "The amount of laumontite (three samples of nine examined) is so small that it can probably be neglected, particularly in unveined rocks" (Watters in Grant-Taylor, 1976). See Appendix 3.

Recent work by Duncan et al. (1973) and Gillott (1975) showed that alkali treatment - $2 \mathrm{M} \mathrm{NaOH}$ at $38^{\circ} \mathrm{C}\left(100^{\circ} \mathrm{F}\right)$ for one month - of greywackes, phyllites and argillites from Nova Scotia, containing a vermiculite-type mica (after biotite and chlorite) resulted in expansive reactions as the vermiculite mineral "exfoliated". An expansive reaction reported by oberholster and Brandt (1974) in illite rich shales and summarised by the formula:

$$
\text { K-illite }(10 \AA)+0.5 \mathrm{Ca}^{++} \rightarrow \mathrm{Ca}-\text { vermiculite }(14 \AA)+\mathrm{K}^{+}
$$

may be disruptive in its own right or may promote alkali-reaction in concrete bearing alkali reactive aggregates, by the release of $\mathrm{K}$ to the cement paste, even where low alkali cements have been used.

A note by watters (in Grant-Taylor, 1976), briefly describing mineralogy of some greywackes from Wellington, mentioned the findings of Gillott (1975) and predicted a potential for expansion cracking in concrete made with greywackes, should they be shown to contain vermiculite or montmorillonite. Neither of these minerals have been found in the present study (section 2.14.2).

With weathering, however, both vermiculite (Barnes, 1979) and montmorillonite (Appendix 24) may form.

Recent experiments have shown the expansion of a greywacke from a sheared greywacke-argillite interface, when subjected to alkali treatment (St John, pers. comm.). It may be that an illite-vermiculite type reaction 
(Oberholster and Brandt, 1974) could occur in such materials due to the presence of illite in fault zones (Barnes, 1979).

Alkali aggregate reactions are becoming increasingly significant to New Zealand, with approximately 25,000 square kilometres of rock-types considered potentially reactive with high alkali cements. Although Neville (1975) claims alkali-aggregate reactions in concrete are widespread in New Zealand, no real problem presently exists (all New Zealand made cements are currently low alkali) although potentially, difficulties could be acute. If high alkali cement were used with these aggregates without proper mix design consideration exposure reactions would create massive damage, often over a long (20 or 30 year) time interval.

High alkali cement production is attractive for a very impelling reason - production cost reduction.

Rising energy charges, an appreciable contribution of production cost, can be offset by increasing the alkali content of the raw mix or recycling kiln stack dust in raw mix of relatively low alkali content to induce clinkering at lower temperature. The end product in both cases is cement of higher alkali content (Gillott, 1975; Gratten-Bellew et al., 1978).

Aggregate related durability problems may then compound since:

(i) High alkali cementsare often used with relatively inferior aggregates.

(ii) Premium material is increasingly remote from urban areas.

(iii) New technologies and legislation aimed at environmental protection may also increase costs of aggregate production.

New Zealand will probably manufacture high alkali cements in the near future (Kennerly, pers. comm.; Field, pers. comm.) for reasons outlined above. Increasingly, therefore, there is a need for aggregates to be carefully examined and zoned geologically for their potential use in concrete as aggregates and/or use as engineering materials. 


\title{
CHAPTER FIVE
}

\author{
"So, Nat'ralists observe, a Flea \\ Hath smazler Fleas that on him prey. \\ And these have smaller Fleas to bite 'em, \\ And so proceed ad infinitum."
}

Dean Swift (1733) On Poetry: a rhapsody: $20 p p$.

\section{Utilisation of greywacke-suite aggregate in concrete}

This chapter investigates the properties of concrete made of aggregate from Wellington greywacke-suite rocks, and attempts to relate these properties to those of the aggregate and rock.

In chapter 4, links were established between quarried aggregate and the parent rock, in particular with angularity, density, bulk density, crushing resistance and Los Angeles test values. Of these properties, all of which are related to rock mean grain size, angularity, density and crushing resistance were selected as being those most likely to influence concrete properties.

Because the results of chapter 3 and 4 indicate greywacke-suite rocks ( and especially the greywackes) to be very strong, elastic materials with close ranging physical properties, it was decided to design the concrete mix so that the sometimes subtle differences in the physical properties of the aggregate were more readily discernable and comparable. To gauge the importance of aggregate strength, a very high strength concrete was necessary. Although the strength of the cement paste would invariably be much lower than that of the rock materials used as aggregate, a reasonable matching of static elastic properties was considered desirable and attainable

High strength concrete calls for low water to cement ratios, as concrete strength is inversely related to the water to cement ratio in fully compacted concrete (Neville, 1975). Initial testing of mixes with water to cement ratios of 0.4 and 0.5 did not provide concretes of sufficient strength and showed that such a difference in ratios masked subtle workability effects imparted by the aggregates thus precluding confident comparison of aggregate performance. 
The two mixes finally chosen (Appendix 27) used water to cement ratios of 0.375 $(\operatorname{mix} 1)$ and $0.4(\operatorname{mix} 2)$. They were designed to achieve very high strengths with high aggregate to cement ratios without the use of additives or admixtures. This provided a good basis for comparing performance of different aggregates from Wellington greywacke-suite rocks. A special interest was shown in concrete from argillite, because this rock type has been traditionally unacceptable to the building industry.

Although concrete strengths from the chosen designs are well in excess of those normally required of concrete in commercial use, the mix designs would not be commercially viable as workability and cohesion are too low due to the low sand content.

The sand chosen for the study was monomineralic, well graded, and consisted of rounded grains. The latter properties are well suited to impart plasticity to concrete ar moderate water requirements (Appendices 26, 28).

Each concrete mix design was used with each aggregate in $0.03 \mathrm{~m}^{3}$ batches which provided twelve 100mm diameter x 200mm long cylinders to NZS 3112:1974 clause 201. Mix designs and calculations may be found in Appendix 27 while ingredients, moulding, curing and testing is detailed in Appendix 28.

At age $3,7,28$ and 90 days, three cylinders, randomly selected from each batch, were removed singly from the curing chamber and immediately weighed in air, then in water, their long axis ultrasonic velocity determined with the PUNDIT, and measured longitudinally and across two diameters, $22.5^{\circ}$ each side of the cylinder mould seam at mid-height. They were then tested in uniaxial compression

(Appendix 28). All tests were carried out in accordance with NZS 3112:1974

"Methods of test for concrete".

At 28 days, the static elastic modulus was determined using temperature compensated half-bridge strain instrumentation, a single PL-60 strain gauge (60mm gauge length) being attached parallel to the longitudinal axis of the cylinder centred on mid-height (Appendix 14). 


\subsection{Fresh concrete tests}

Results are presented in Table 5.1.

\subsection{1 "Workability" of fresh concrete}

"Workability" of fresh concrete is measured in different ways and tests have been specifically designed to simulate certain types of "workability", e.g. its ability to be pumped - pumpability, its deformation under the influence of gravity - slump, the rate at which it can be transformed from one shape to another - remoulding effort (Tattersall, 1976).

Two workability tests were used in this study (both mix designs gave concrete of essentially zero slump):

(i) Compacting factor: Not often used in New Zealand, this test to BS 1881:1970; part 2, measures the degree of compaction after a set amount of work has been imparted to the concrete, and was used for comparative purposes.

Concrete is allowed to drop through two inverted truncated cones (frustrums) to fill a standard sized cylinder and its mass is expressed as a ratio to the mass at optimum compaction required to fill the cylinder. Compacting factor is therefore a density ratio, with a range from 0 to 1 , which is sensitive to concrete of low workability provided the mix does not stick or hesitate in the apparatus during test. The test mixes performed well in this regard.

(ii) Vebe consistometer: The vebe ( $\mathrm{V}-\mathrm{B}$ ) apparatus measures the time (seconds) taken to remould a cone of fresh concrete to a cylinder, under vibration at a predetermined frequency. The energy required to compact the concrete is deemed a measure of workability, simulating compaction into moulds or formwork.

The V-B test provided better resolution of mix workability than the compacting factor test (Figure 5.1) especially for mix 1 .

Test results (Table 5.1, Figures 5.2 and 5.3) showed that workability decreases with degree of angularity $\left(A_{2 D}\right)$. The effect is more marked as workability increases and in design 2 mixes generally. 
Table 5.1 : Fresh concrete test results. Within each mix design the arder of concrete made was randomised. Results are listed here in order of diminishing rock mean grain size.

\begin{tabular}{|c|c|c|c|c|c|c|c|c|c|c|}
\hline & $\begin{array}{l}\text { Aggregate } \\
\text { Sample }\end{array}$ & $\begin{array}{l}\text { Order in } \\
\text { which } \\
\text { concrete } \\
\text { was made }\end{array}$ & $\begin{array}{l}\text { Rock } \\
\text { mean } \\
\text { grain } \\
\text { size, } \\
\text { phi }\end{array}$ & $\begin{array}{l}\mathrm{V}-\mathrm{B} \\
\text { Consisto- } \\
\text { meter } \\
\text { seconds }\end{array}$ & $\begin{array}{l}\text { Compac- } \\
\text { ting } \\
\text { factor }\end{array}$ & \multicolumn{2}{|c|}{$\begin{array}{l}\text { Fresh } \\
\text { concrete } \\
\text { density, } \\
\mathrm{kg} \cdot \mathrm{m}^{-3}\end{array}$} & \multicolumn{2}{|c|}{$\begin{array}{l}\text { Concrete } \\
\text { yield }\end{array}$} & $\begin{array}{l}\text { Calcu- } \\
\text { lated } \\
\text { cement } \\
\text { content } \\
\mathrm{kg} \cdot \mathrm{m}^{-3}\end{array}$ \\
\hline & HQ- 17 & 3 & 1.3 & 23.9 & 0.77 & 2502 & \} & & \} & \\
\hline & KTW-14 & 5 & 2.6 & 26.6 & 0.71 & 2494 & \} & & \} & \\
\hline$\dashv$ & $\mathrm{B} Q-1 \mathrm{XA}$ & 1 & 2.9 & 29.7 & 0.69 & 2509 & \} & & \} & \\
\hline $\begin{array}{l}\rtimes \\
1 \\
\Sigma\end{array}$ & SJ-T & 2 & 4.7 & 22.1 & 0.75 & 2501 & \} & 0.97 & \} & 360.8 \\
\hline & $O B-W$ & 4 & 5.6 & 50.9 & 0.66 & 2543 & \} & & \} & \\
\hline & $\mathrm{HQ}-22$ & 6 & 6.3 & 34.1 & 0.69 & 2504 & \} & & \} & \\
\hline & $\mathrm{HQ}-17$ & 8 & 1.3 & 12.0 & 0.77 & 2471 & \} & & \} & \\
\hline N & KTW-14 & 9 & 2.6 & 12.8 & 0.78 & 2473 & \} & & \} & \\
\hline$x$ & $B Q-1 X A$ & 7 & 2.9 & 12.9 & 0.76 & 2476 & \} & & \} & \\
\hline $\begin{array}{l}H \\
\Sigma\end{array}$ & $S J-T$ & 12 & 4.7 & 10.1 & 0.76 & 2505 & \} & 0.97 & \} & 360.8 \\
\hline & $O B-W$ & 10 & 5.6 & 15.8 & 0.72 & 2520 & \} & & \} & \\
\hline & $\mathrm{HQ}-22$ & 11 & 6.3 & 17.4 & 0.74 & 2503 & \} & & \} & \\
\hline
\end{tabular}




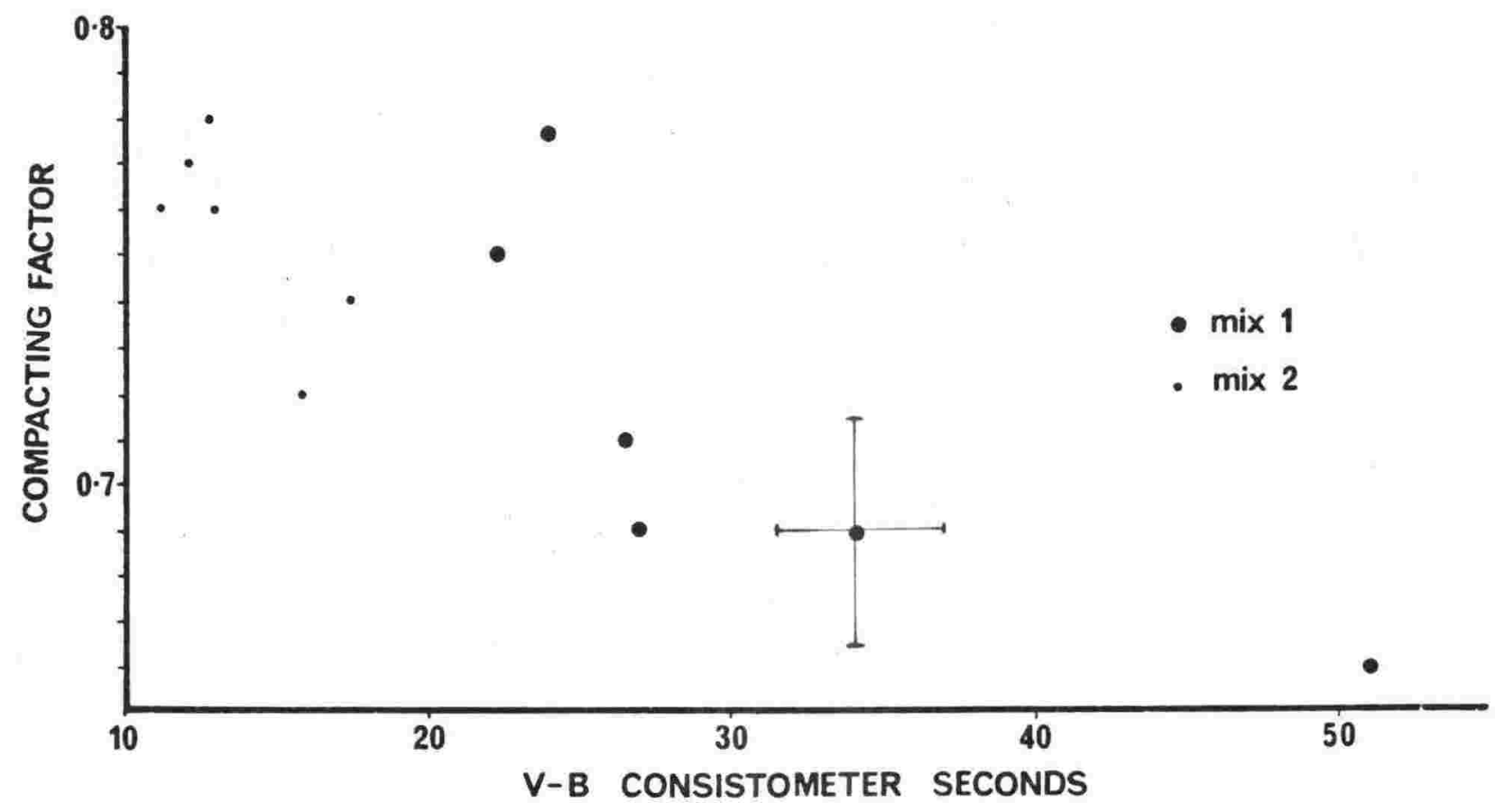

Eigure 5.1 - A comparison of workability by compacting factor and $V-B$ consistometer. Although related and able to be used with concrete of low workability, the $\nabla-B$ consistometer provides better resolution. Error bars based on the standard deviation from 5 runs. Standard deviation for V-B, 2.7 seconds; for compacting factor 0.024 . These data are consistent with the findings of clelland (pers.comm.) who indicated respective repeatibilities of 3 seconds and 0.03 for mixes in the workability range of this study. 


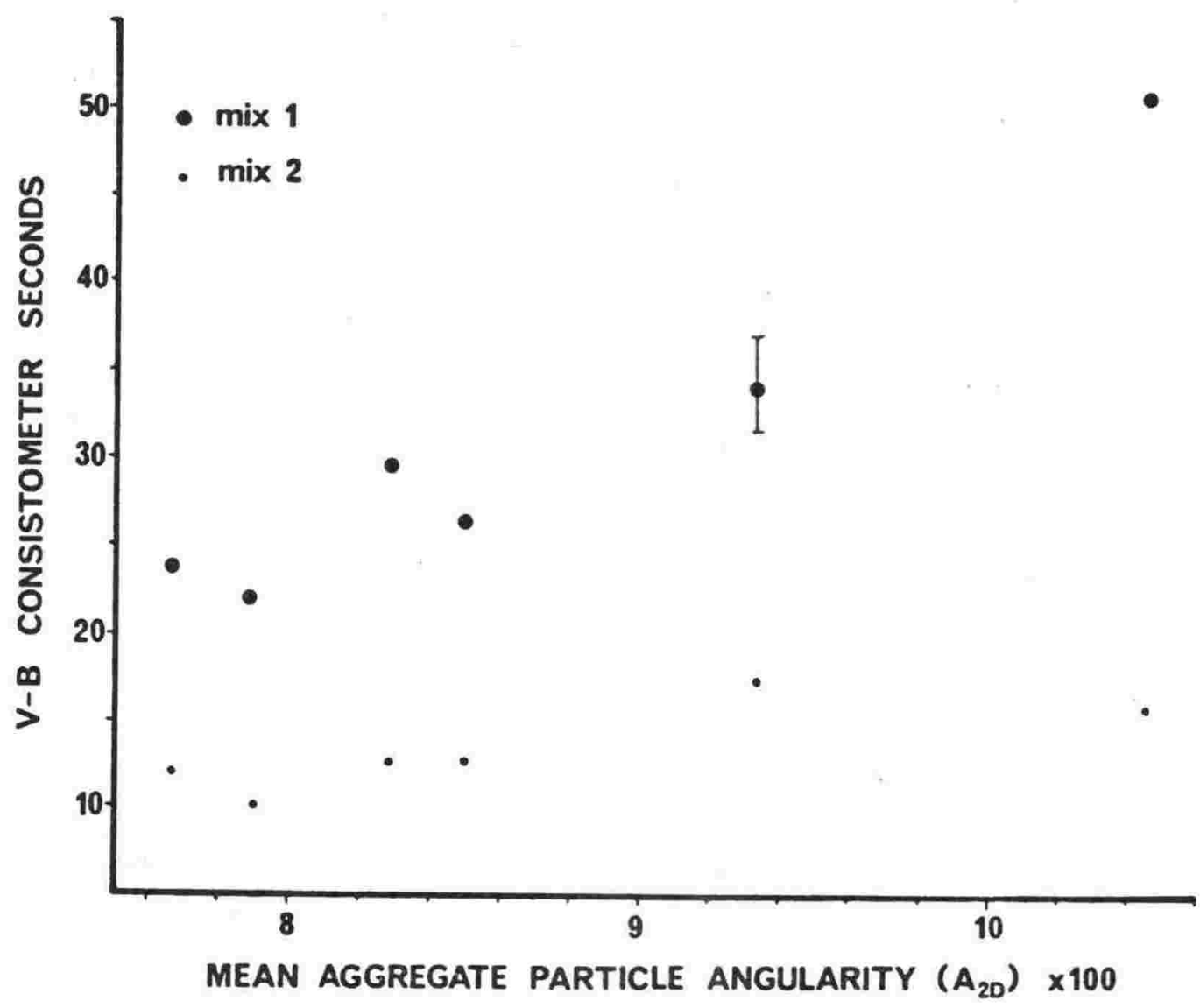

Figure 5.2 : Aggregate particle shape has a profound effect on $\mathrm{V}-\mathrm{B}$ seconds workability especially in mixes of increased aggregate to cement ratio. Compare with Figure 5.3. 
- $\operatorname{mix} 1$

- $\operatorname{mix} 2$

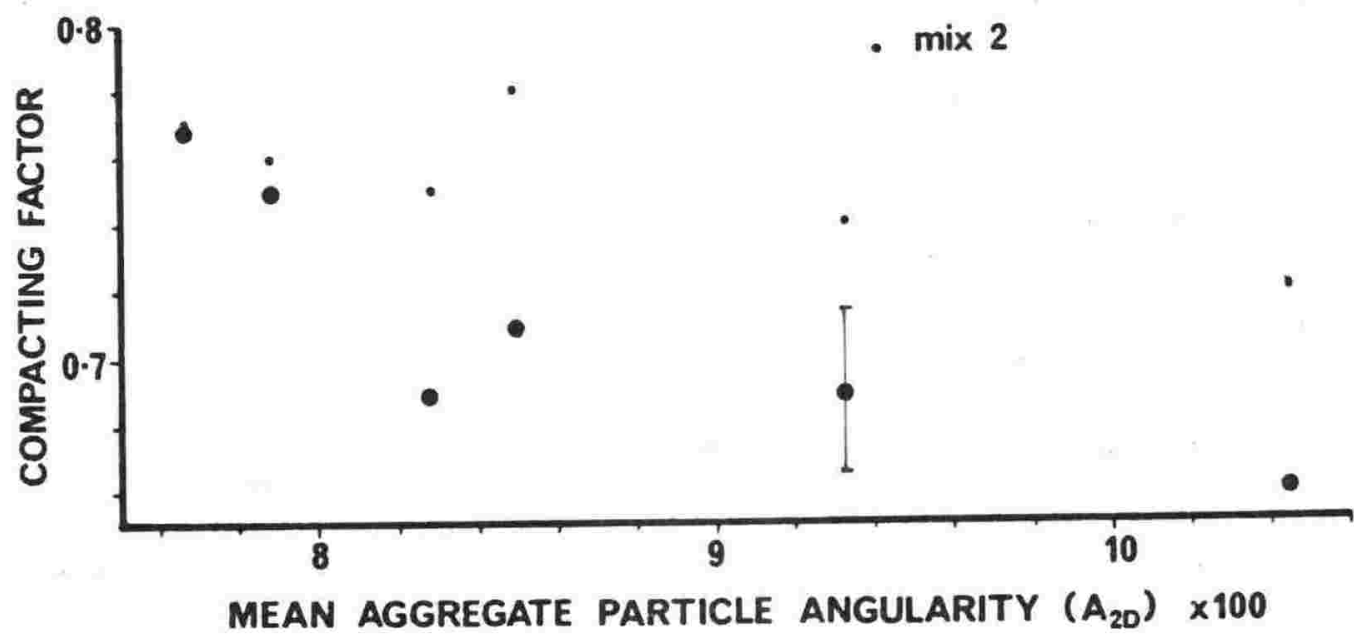

Figure 5.3 : Aggregate particle angularity influence over workability as measured by compacting factor, but does not identify differences in mix design as well as V-B seconds (Figure 5.2). 
Convergence of the two trends shown in Figures 5.2 and 5.3 with decreasing particle angularity values suggests that workability is determined entirely by angularity below $600 \mathrm{~A}_{2 \mathrm{D}}$ for mixes with high aggregate to cement ratios $(>5)$. This trend is best shown by the $V-B$ test, though generally for mixes with a lower aggregate to cement ratio, and slumps greater than $15 \mathrm{~mm}$, the test is less sensitive.

\subsubsection{Density (unit mass) of fresh concrete}

Densities of mix 1 concrete were higher than those of mix 2 , for the same aggregate, due to a lower water to cement ratio and corresponding increase in aggregate to cement ratio in the mix design.

Mix 1 results show no clear relationship between fresh concrete density and that of rock core and aggregate (Figures 5.4 and 5.5), though one sample, OB-W, had a significantly greater core, aggregate and fresh concrete density.

Mix 2 concretes show clear linear relationships (very high correlation coefficients for rock and aggregate densities, Figures 5.4 and 5.5), presumably because the concrete density scatter was much greater than in mix 1 . Rock density influences are probably better assessed from mix 2 concrete because the higher water to cement ratio produces a sand/cement paste mortar of lower density.

\subsection{Hardened concrete tests}

Though many tests may be performed on hardened concrete to assess its properties, only those most likely to illustrate the role of aggregate were carried out. Therefore tensile strength and more time consuming investigations of concrete shrinkage, thermal conductivity and coefficient of linear thermal expansion were not determined. Instead uniaxial compressive strength, ultrasonic velocity, static elastic modulus and density were measured. Complete results are presented in Appendix 29 except those for static elastic modulus which are in section 5.2.2.

The quality of bond in concretes of this study followed the normal pattern (Table 5.1A). However, bond strength was not measured because:

(a) the greatest interest for this study was aggregate performance which is well recorded from measurements of ultrasonic velocity, compression strength and elastic modulus.

(b) no widely accepted method of measuring bond strength exists. 
A recent review of the cement-aggregate bond (Struble et al., 1980*) concluded that the nature of the bond is far better understood than is the influence of the bond on concrete performance, although most workers apparently agree that the bond is an important factor in the strength of concrete, especially the flexural strength (Neville, 1975). "Generally, when bond is good, a crushed concrete specimen should contain some aggregate particles broken right through, in addition to the more numerous ones pulled out from their sockets. An excess of fractured particles, however, might suggest that the aggregate is too weak. Because it depends on the paste strength as well as on the properties of aggregate surface, bond strength increases with the age of concrete; it seems that the ratio of bond strength to the strength of the paste increases with age. Thus, providing it is adequate, the bond strength per se may not be a controlling factor in the strength of concrete. However, in high strength concrete there is probably a tendency for the bond strength to be lower than the tensile strength of the cement paste so that preferential failure in bond takes place". (Neville, 1975).

The effect of the bond on concrete performance is a subject of controversy but a positive relationship between concrete strength and bond strength seems to exist. (Struble et al., 1980).

Further study in this field would have required very considerable research effort beyond that which would seem reasonable within the context and scope of this study.

\subsubsection{Uniaxial compressive strength}

The compressive strength of concrete is one of its most useful and important properties. It is one of the most easily determined and the most directly

*Struble, L., Skalny, J. and Mindess, S. (1980). A review of the cementaggregate bond. Cement and Concrete Res., Vol.10:277-286. 


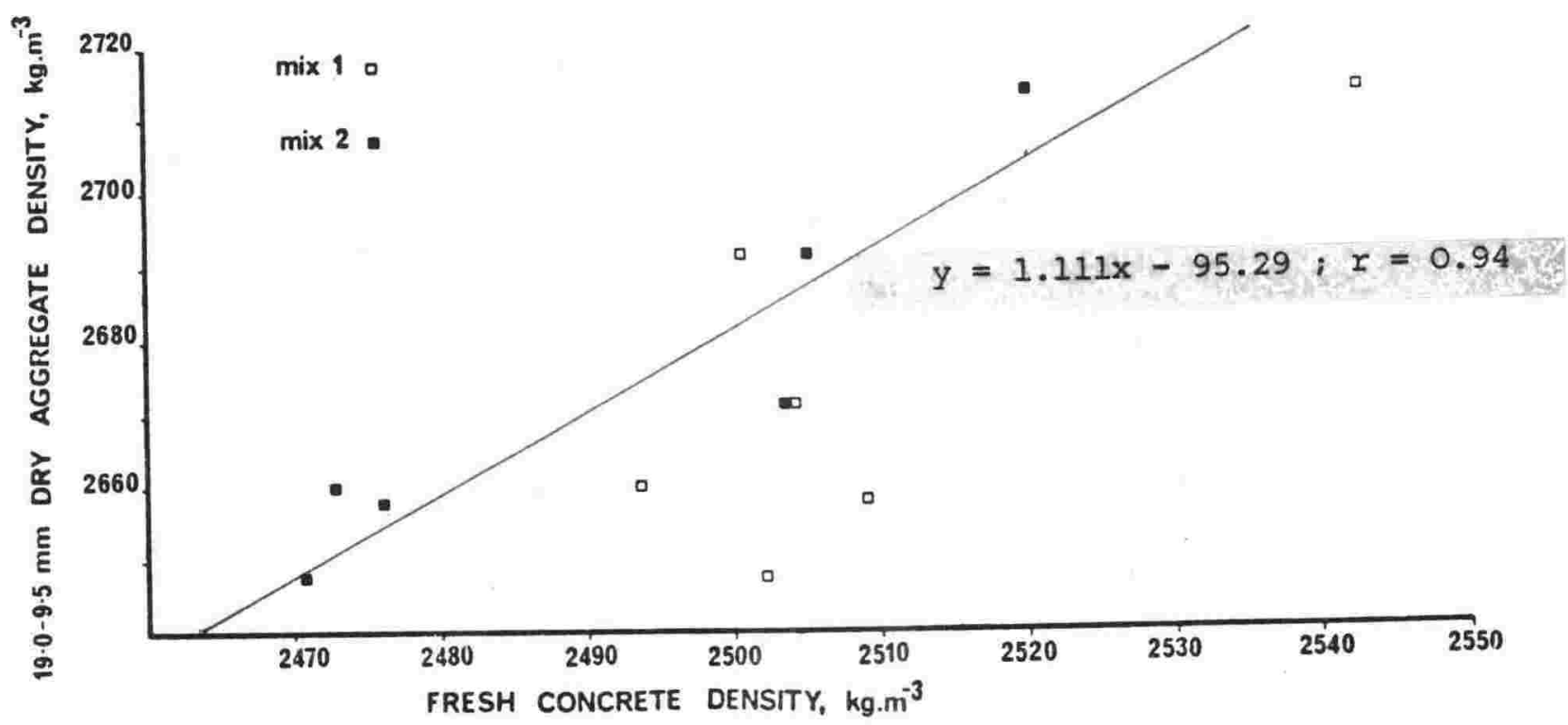

Figure 5.4 : Dry $19 \mathrm{~mm}$ aggregate density related to fresh th concreteldensityt A clearer relationship is bt ide

apparent in concretes of mix 2 design.

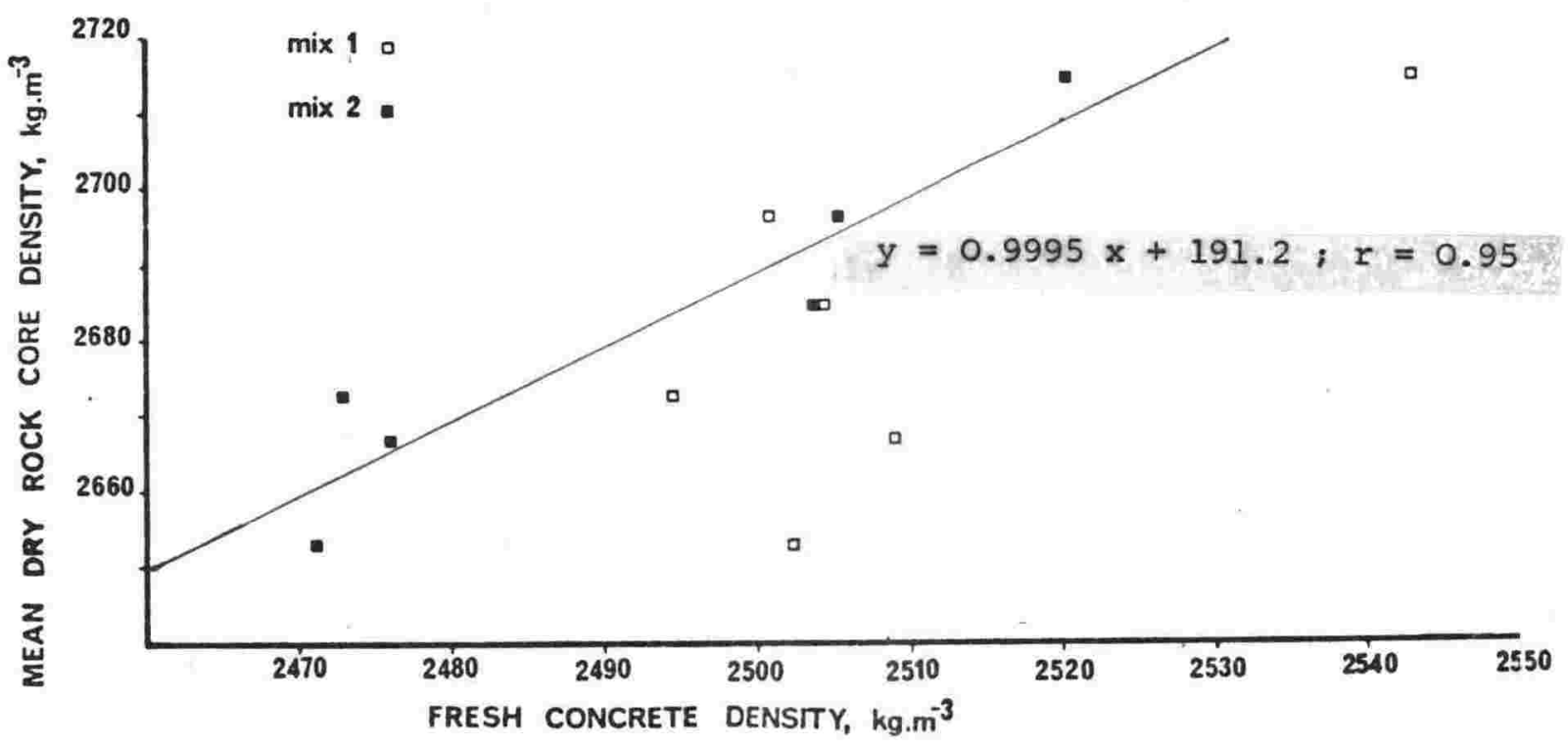

Figure 5.5 : Dry rock core density related to fresh concrete density. As in Figure 5.4, better correlation is apparent in concretes of $\operatorname{mix} 2$ design. 
Table 5.1a: Bond qualities from all mixes of this study. A subjective assessment from failure surfaces. $\mathrm{B}=$ aggregate not broken $\mathrm{A}=$ aggregate broken

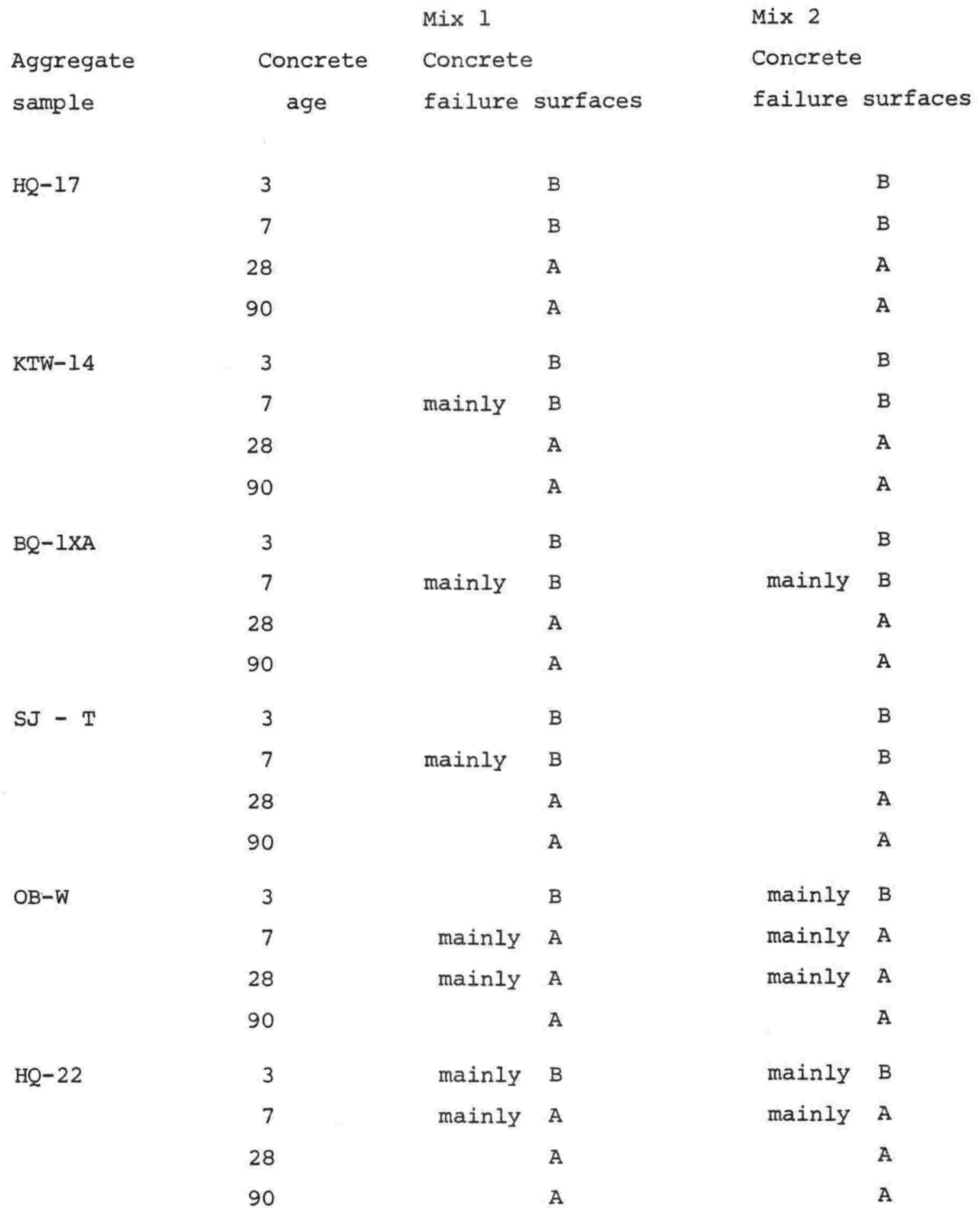


applicable, so compressive strength is the parameter generally used to assess quality.

Test results relating compressive strength to age, aggregate type and mix design are shown in Tables 5.2, 5.3 and Figures 5.6, 5.7.

Concrete of both mix designs behaved in a manner consistent with concrete of more orthodox designs. Several observations may be made from Figures 5.6, 5.7: The rate of strength development, initially rapid, decreased exponentially.

(11) There is little significant strength difference in concrete younger than seven days, but from 28 days, differences in aggregate become apparent e.g. OB-W, a low strength aggregate, yields a lower strength concrete.

(iii) From 28 days, the strength of $O B-W$ concrete is significantly weaker than the rest in each of the mix designs.

(iv) At days 3 and 90 respectively, the strength of mix 2 concrete was 80 and 90 percent that of $\mathrm{mix} 1$ except for OB-W, (75 and 95 percent).

\subsubsection{Static elastic modulus}

The range in rock strengths and the greater degrees of angularity of aggregates from the (generally) weakest rocks (sections 3.5.1, 4.2.2) prompted the investigation of concrete static elastic modulus. Weak rocks are generally considered to have low elastic moduli. High values of aggregate angularity give lower concrete workabilities and lead to preferred orientation of aggregate particles.

The difference between static and dynamic elastic moduli data is greatly influenced by the presence of fractures, cracks or cavities, static data generally providing lower values (see Boult, 1979).

The static elastic modulus was measured in preference to the dynamic elastic modulus because the latter can be readily determined only at low stress levels 
Table 5.2 : Summary of hardened concrete test results for concrete of Mix 1 design. Full data appear in Appendix 29.

Aggregate, Concrete age, Mean density, Mean strength, Mean ultrasonic velocity,

\begin{tabular}{ccccc} 
& days & $\mathrm{kg} \cdot \mathrm{m}^{-3}$ & $\mathrm{MPa}$ & $\mathrm{m} \cdot \mathrm{s}^{-1}$ \\
\hline HQ-17 & 3 & 2475 & 30.1 & 4570 \\
7 & 2478 & 49.3 & 4727 \\
& 28 & 2482 & 74.4 & 4896 \\
& 2481 & 88.0 & 4956
\end{tabular}

\begin{tabular}{|c|c|c|c|c|}
\hline \multirow[t]{4}{*}{ KTW-14 } & 3 & 2482 & 30.3 & 4685 \\
\hline & 7 & 2480 & 49.8 & 4786 \\
\hline & 28 & 2484 & 73.9 & 4979 \\
\hline & 90 & 2483 & 85.5 & 4963 \\
\hline \multirow[t]{4}{*}{ BO-IXA } & 3 & 2482 & 29.8 & 4604 \\
\hline & 7 & 2480 & 48.0 & 4734 \\
\hline & 28 & 2491 & 74.0 & 4946 \\
\hline & 90 & 2485 & 87.2 & 5011 \\
\hline \multirow[t]{4}{*}{$S J-T$} & 3 & 2500 & 28.4 & 4553 \\
\hline & 7 & 2496 & 49.9 & 4708 \\
\hline & 28 & 2502 & 73.8 & 4883 \\
\hline & 90 & 2505 & 83.4 & 4955 \\
\hline \multirow[t]{4}{*}{$\mathrm{OB}-\mathrm{W}$} & 3 & 2515 & 31.4 & 4360 \\
\hline & 7 & 2520 & 48.6 & 4499 \\
\hline & 28 & 2518 & 62.7 & 4641 \\
\hline & 90 & 2523 & 67.9 & 4702 \\
\hline \multirow[t]{4}{*}{$\mathrm{HQ}-22$} & 3 & 2489 & 29.9 & 4446 \\
\hline & 7 & 2494 & 48.5 & 4591 \\
\hline & 28 & 2498 & 71.3 & 4771 \\
\hline & 90 & 3497 & 82.4 & 4789 \\
\hline
\end{tabular}


Table 5.3 : Summary of hardened concrete test results for concrete of Mix 2 design. Full data appear in Appendix 29.

Aggregate, Concrete age, Mean density, Mean strength, Mean ultrasonic velocity,

\begin{tabular}{llllr} 
& days & $\mathrm{kg} \cdot \mathrm{m}^{-3}$ & $\mathrm{MPa}$ & $\mathrm{m}^{-1}$ \\
\hline $\mathrm{HQ}-17$ & 2463 & 22.1 & 4504 \\
7 & 2464 & 41.4 & 4715 \\
28 & 2467 & 66.9 & 4872 \\
& 2471 & 79.6 & 4937
\end{tabular}

\begin{abstract}
KTW-14
\end{abstract}

$\begin{array}{rr}3 & 2473 \\ 7 & 2475 \\ 28 & 2479 \\ 90 & 2479\end{array}$

BO- IXA

$\begin{array}{rr}3 & 2469 \\ 7 & 2468 \\ 28 & 2471 \\ 90 & 2477\end{array}$

SJ-T

$\begin{array}{rr}3 & 2489 \\ 7 & 2493 \\ 28 & 2489 \\ 90 & 2497\end{array}$

$O B-W$

$\begin{array}{rr}3 & 2505 \\ 7 & 2512 \\ 28 & 2513 \\ 90 & 2513\end{array}$

HQ- 22

$\begin{array}{rr}3 & 2483 \\ 7 & 2480 \\ 28 & 2486 \\ 90 & 2486\end{array}$

25.4

42.1

68.8

80.0

21.7

38.2

65.9

75.6

22.8

38.2

64.0

72.5

23.6

42.4

60.5

65.4

4528

4741

4912

4967

4503

4671

4841

4909

4511

4648

4807

4864

4242

4464

4629

4684

23.6

4339

41.1

4507

68.0

4704

72.8

4746 


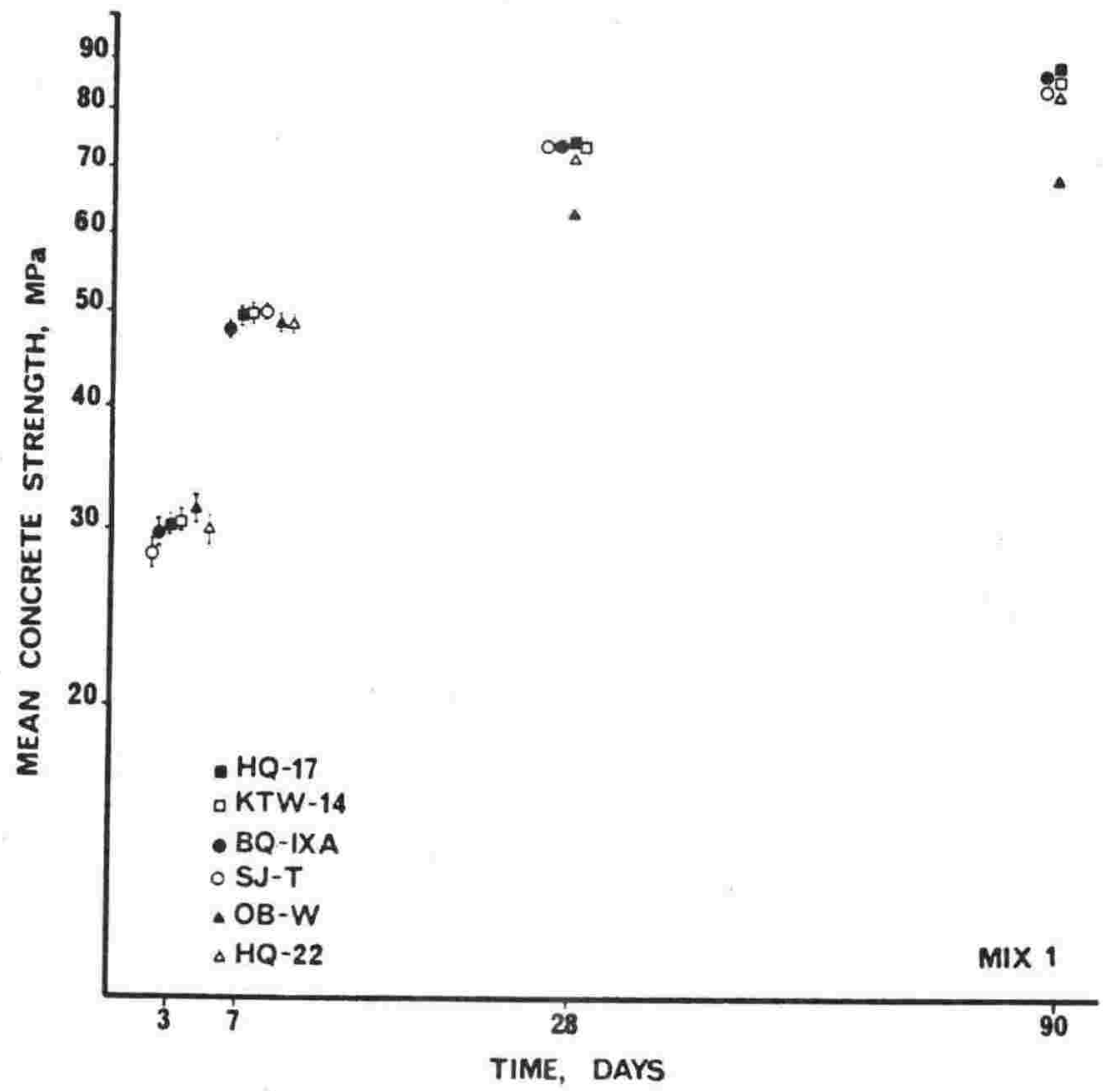

Figure 5.6 : Concrete strength related to time: $\operatorname{mix} 1$.

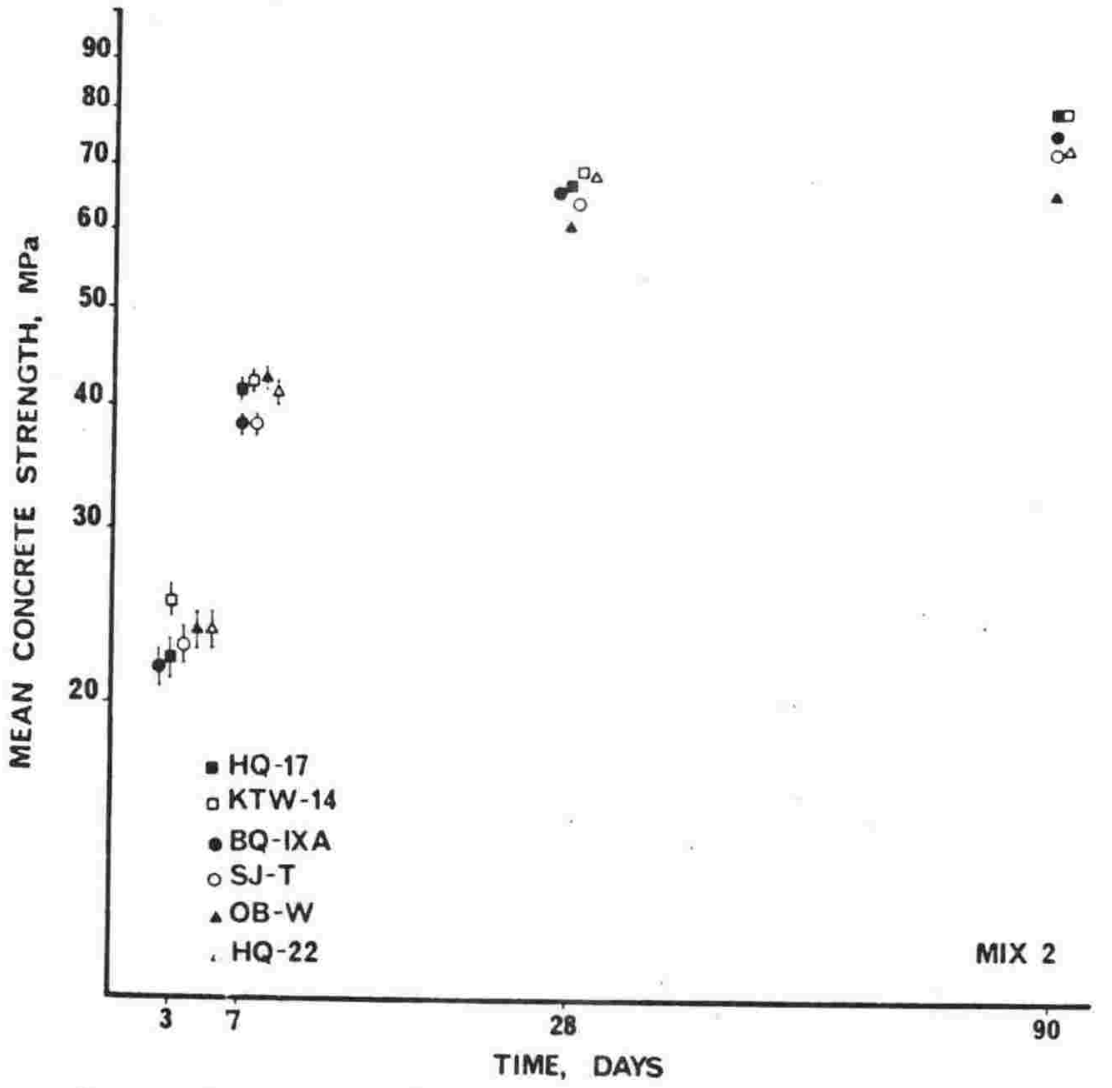

Figure 5.7 : Concrete strength related to time: $\operatorname{mix} 2$

Comprehensive strength of concrete of two mix designs with different greywacke-suite aggregates at ages of $3,7,28$ and 90 days. Both axes are logarithmic scales. Standard error about the mean is $\pm 1.02 \mathrm{MPa}$, shown as bars at 3 and 7 days. Symbol size precludes error bars at 28 and 90 days. Symbols are slightly offset from test ages for clarity. 
and there it is comparible with the initial tangent static elastic modulus $\left(E_{i}\right)$.

Elastic moduli are of interest in the design of concrete structures and although not normally used routinely*, may be required in:

(i) Reinforced concrete design theory. Concrete has negligible strength in tension thus reinforcing steel is used to accommodate tensile strain imposed by loads. Deflection calculations for beams and pillars and the positioning of lever arms, two-way spanning slabs and the like also require its use.

(ii) Calculation of the slenderness effects of columns in high-rise structures.

The method of determining the static modulus of concrete specimens at 28 days is discussed in Appendix 14: results are shown in Table 5.4.

Stress-strain curves are shown in Figures 5.8, 5.9. The elastic modulus is valid only from the more linear part of the curve as the strain increase at the top of the curve is considered to be due to creep (Neville, 1975).

As no universally accepted method of determining the elastic modulus of concrete appears to exist, the secant elastic modulus $\left(E_{C}\right)$ at 50 percent ultimate stress was chosen as the most appropriate for the comparison of data and representation of concrete (Neville, 1975).

* For practical purposes the elastic modulus of any normal weight concrete may be found from:

$$
E_{C}=4700 \sqrt{f^{\prime} C}
$$

where $\mathrm{E}_{\mathrm{C}}=$ concrete elastic modulus, $\mathrm{MPa}$

$\mathrm{f}^{\prime} \mathrm{c}=$ concrete compressive strength, $\mathrm{MPa}$

see the "New Zealand reinforced concrete design handbook". Preferred concrete strengths ( $f^{\prime} C$ ) are listed in DZ 3109 "Concrete construction" as $17.5,20,25,30,35,40$ and $45 \mathrm{MPa}$. 
Table 5.4 : Static elastic moduli for concrete of all aggregate samples of Mix 1 and 2 design, obtained as the secant elastic modulus at 50 percent ultimate stress.

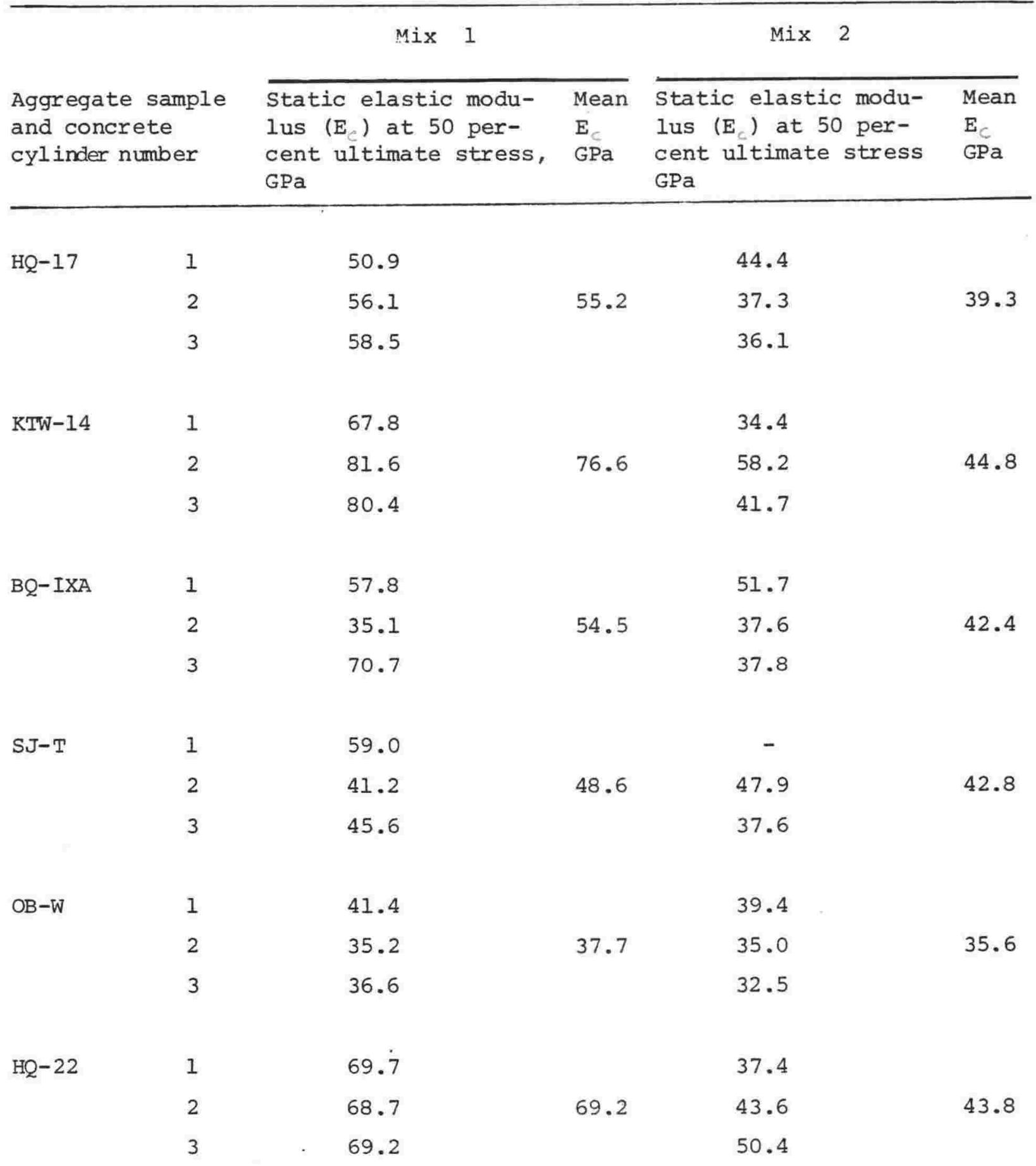




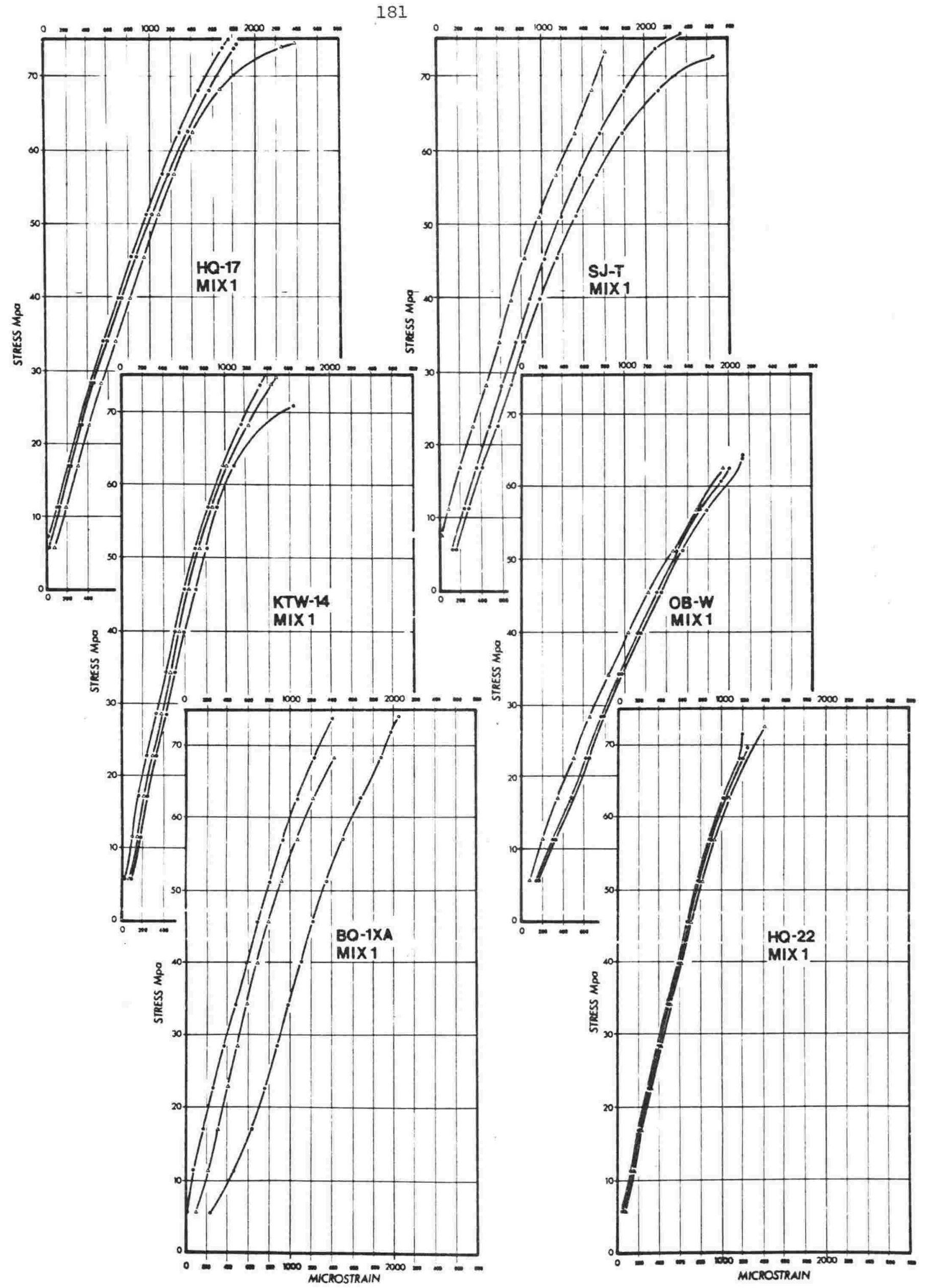

Figure 5.8 : Mix 1 concrete 28 days stress-strain curves.

N.B. Mpa should read MPa. 

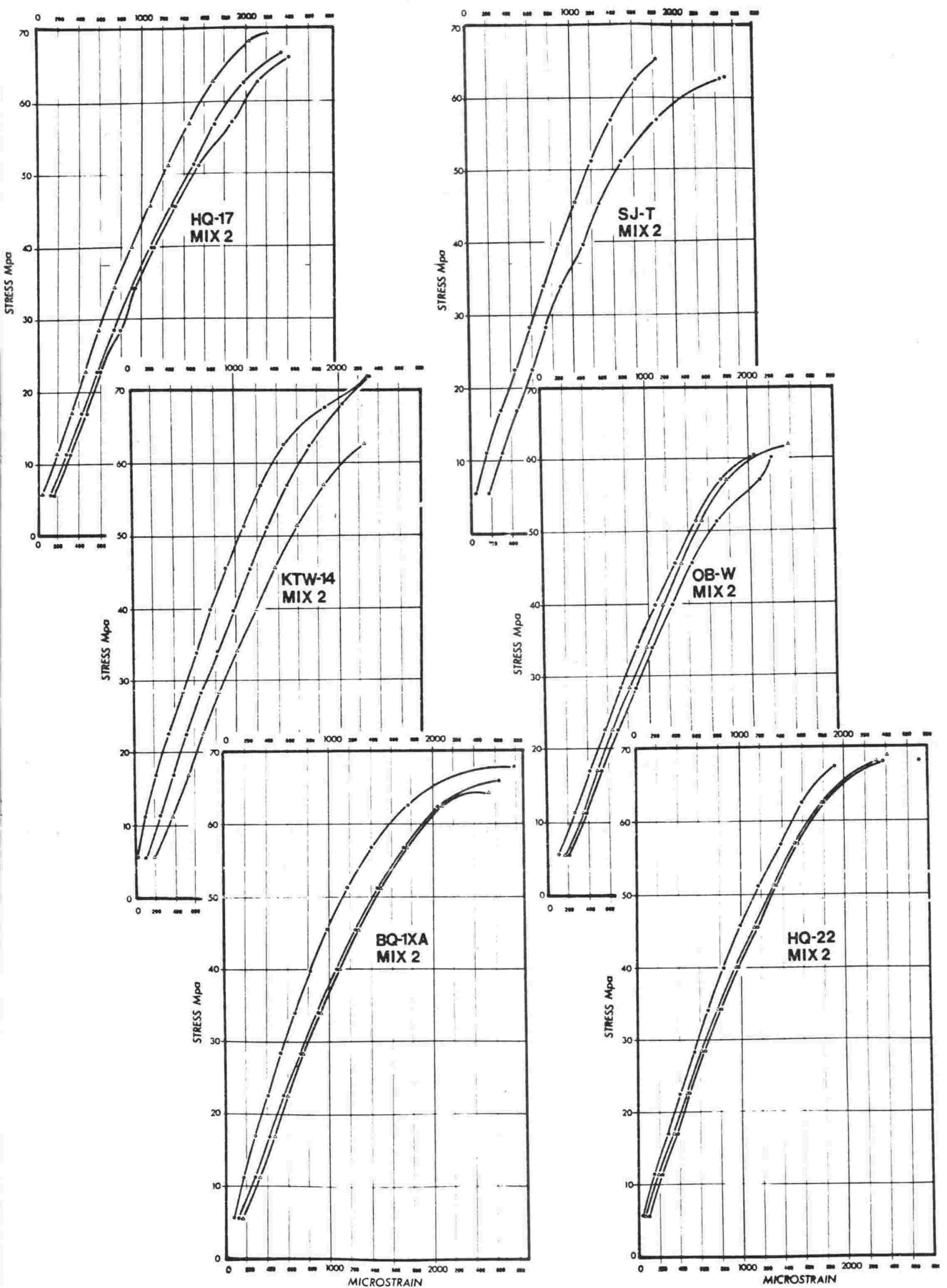

Figure 5.9 : Mix 2 concrete 28 day stress-strain curves.

N.B. Mpa should read MPa. 
Table 5.4 shows that $\operatorname{mix} 1$ concretes have higher $E_{c}$ values than mix 2 conccretes, within each aggregate type,i.e. the elastic modulus is higher in stronger concretes for any aggregate type. This is due to the higher strength cement paste and the higher proportions of aggregate in the mix 1 design.

\section{It is also interesting to note that results from the stronger concrete from} mix 1 are more scattered than those from $m i x ~ 2$ concrete.

Neville (1975) has shown the relationship between static elastic modulus and ultrasonic pulse velocity, and his graph is extended by this study (Figure 5.10) although in practice generalisations can not be made regarding the relationship.

Generally, it is contended that the static elastic modulus of concrete is related to the static elastic modulus of the rock from which the included aggregate is made. Woolf (1966) declares such a relationship to be no more than "fair" having regard for the difficulties in determining moduli, the non-uniformity of rock specimens and of derived aggregates, in bulk and as they occur in concrete, together with the problems inherent in instrumentation. However, results from this study (Figure 5.11) indicate that a linear relationship does exist.

\section{The two main components of concrete, aggregate and sand/cement paste, each have} more or less linear stress-strain curves but combined as concrete the resultant curve shows strain rate acceleration as ultimate stress is approached due to the development of microcracking at the interfaces between the components. It is not surprising, then, that relationships exist between aggregate particle shape, static modulus and the shape of stress-strain curves (Woolf, 1966; Neville, 1975).

La Rue (1946) working with four limestone aggregates found the relationship between aggregate and concrete modulus to be exponential; given by the expression:

$$
E_{C}=5.875\left(1-0.08^{e}-0.3 \cdot E_{S}\right)
$$

where $E_{C}=$ concrete modulus

and $\quad \mathrm{E}_{\mathrm{S}}=$ coarse aggregate modulus 


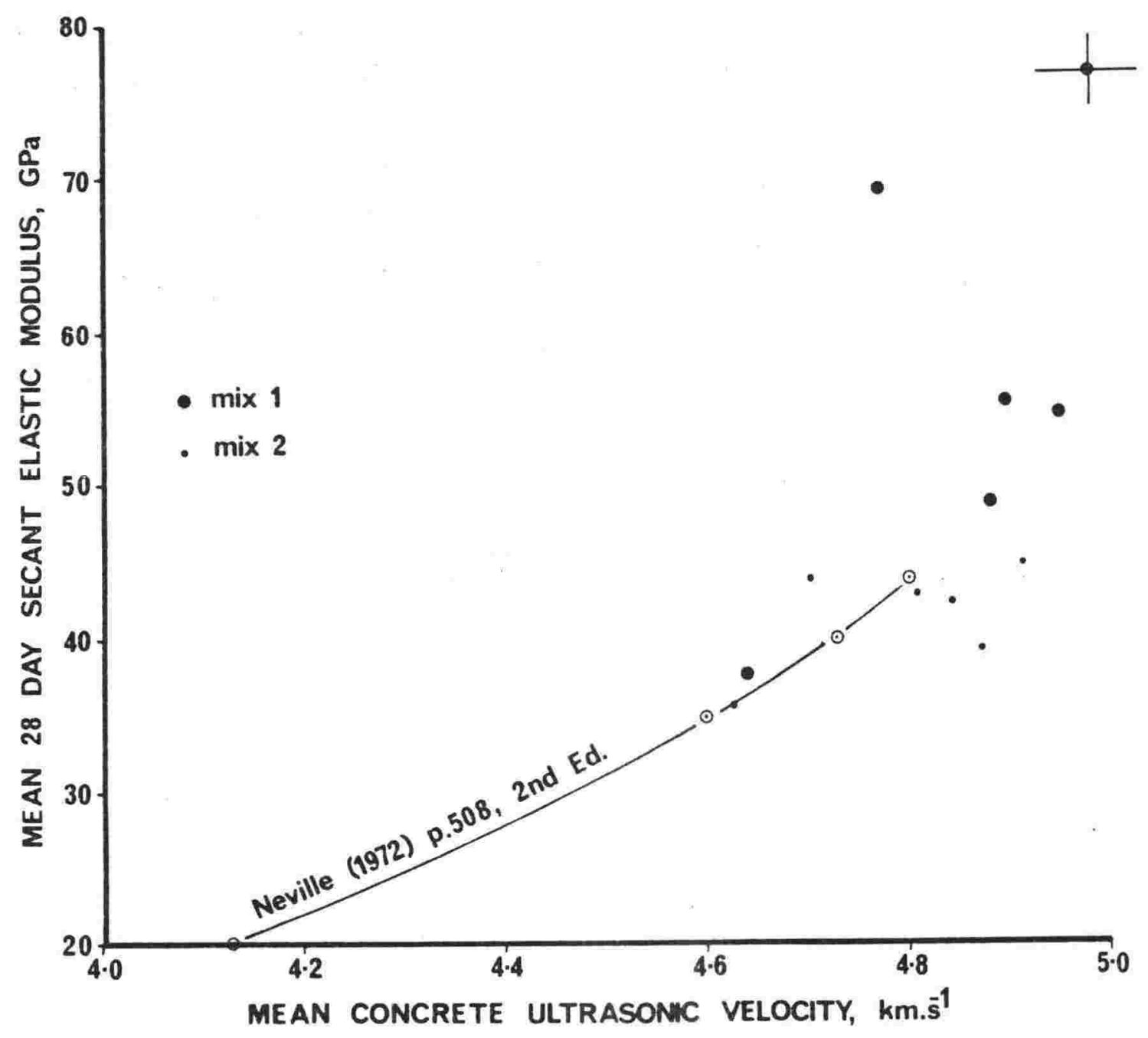

Figure 5.10 : The static elastic modulus of concrete may be used as an indicator of dynamic properties when related to ultrasonic velocity. Error bars are shown on one sample. 


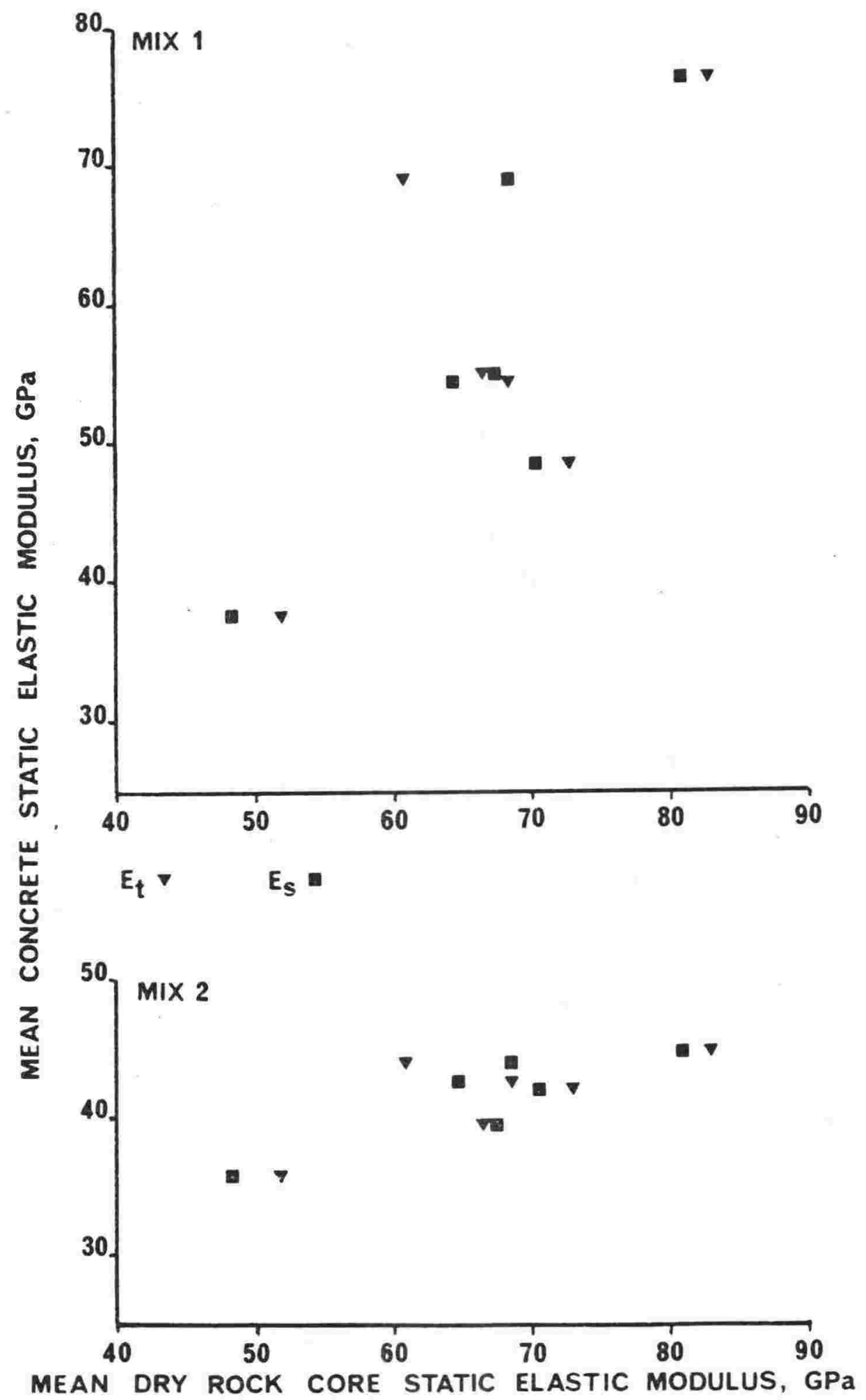

Figure 5.11 : Static elastic modulus relationship of concrete and dry rock core. A linear relation appears to exist. For mix 1 , rock core $F_{t}$ correlation coefficient $=0.81$ and for $E_{S}=0.71$

For mix 2, rock core $E_{t}$ correlation coefficient $=0.91$ and for $E_{s}=0.78$. 


\subsubsection{Ultrasonic velocity}

The PUNDIT apparatus mentioned earlier (section 3.3.2) was originally produced in response to a demand for non-destructive assessment of relative strengths of in situ concrete, as laboratory strength testing does not accurately represent the strength of the same concrete in a structure. Ultrasonic velocity has been found to be directly related to strength under certain conditions, although there is no universally applicable relationship between them (Jones and Gatfield, 1955).

The axial ultrasonic velocity of each cylinder was determined using $50 \mathrm{~mm}$ transducers with a frequency of $50 \mathrm{kH}_{\mathrm{z}}$. Templates were used to locate the transducers centrally on the cylinder ends with glycerine and talcum powder paste to ensure acoustic contact.

There is a direct relationship between ultrasonic velocity and strength for each concrete made, with a numerical displacement between corresponding samples from each mix design (Figures 5.12, 5.13). Ultrasonic resolution is good until aggregate strength exceeds concrete strength, generally at about 28 days and except for 3 day samples in $\mathrm{mix} 2$, incorporating greywacke aggregates.

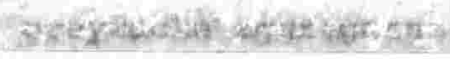

Comparison of Figures 5.12 and 5.13 shows differences in young concrete strengths are not influenced by aggregate parameters where sand/cement paste is strong (mix 1). Indeed, they are only marginally capable of resolution in conoretes of mix 2 design and this is probably due to increased workabilities allowing argularity dependent particle packing to be better established.

Although, generally, there is no miversally applicable correlation between strength and ultrasonic velocity in concrete (Neville, 1975), there is a strong relationship between the ultrasonic velocity of parent rock and concrete made with derived aggregate, which becomes apparent when wet rock core velocities are compared with those of corresponding hardened concrete (Figures 5.14, 5.15). The relationship is similar at all ages and both mixes.

As parent rock density is reflected through its derived aggregate to become a determinant in the density of concrete in which it is included, and as density is related directly to elastic modulus and inversely to ultrasonic velocity, any assessment of concrete by ultrasonic velocity must have due regard for 


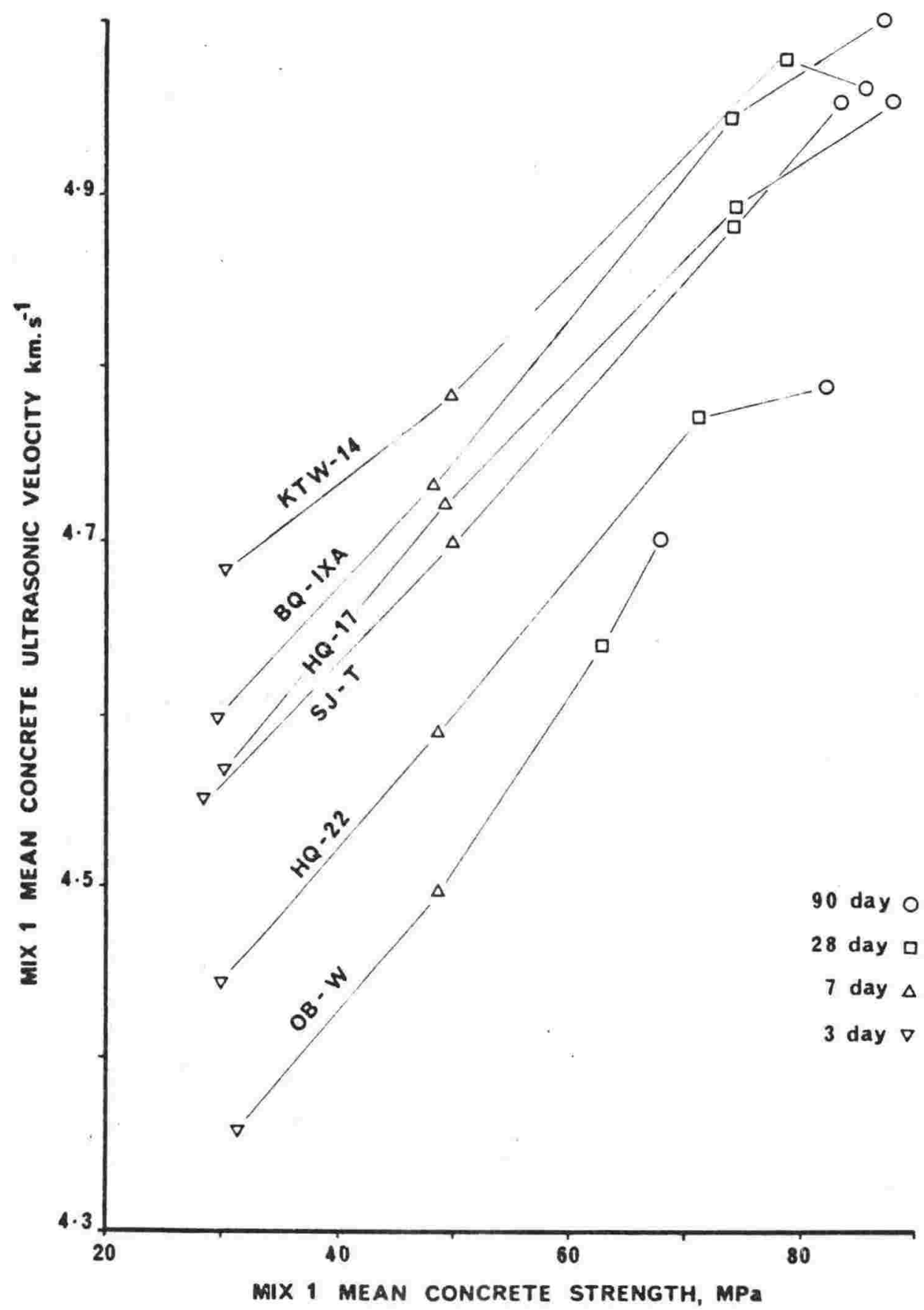

Figure 5.12 : Mix 1 concrete strength related to ultrasonic velocity showing influence of aggregate strength with hardening sand/cement paste. 


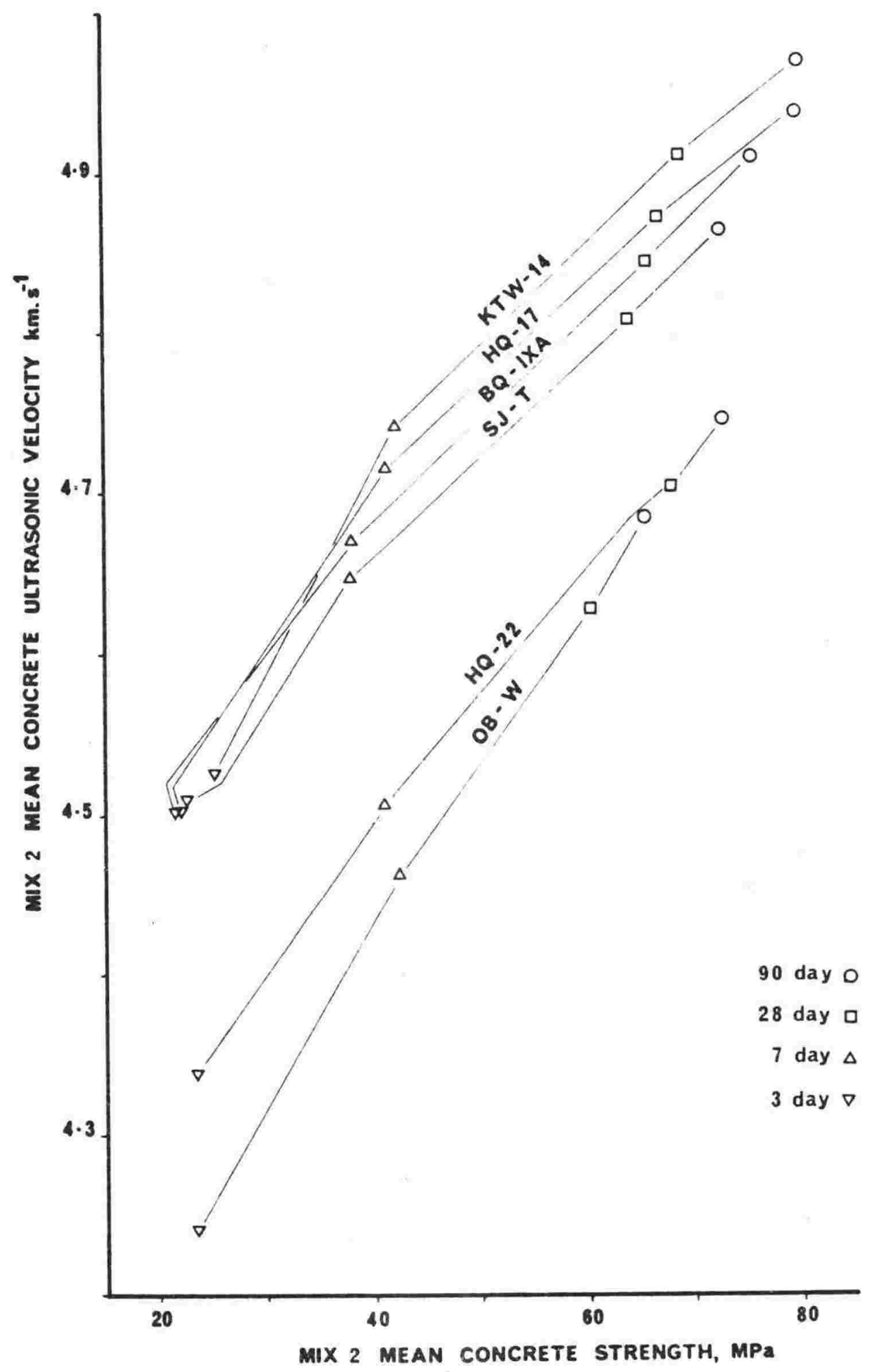

Figure 5.13 : Mix 2 concrete strength related to ultrasonic velocity showing influence of aggregate strength with hardening sand/cement paste. 


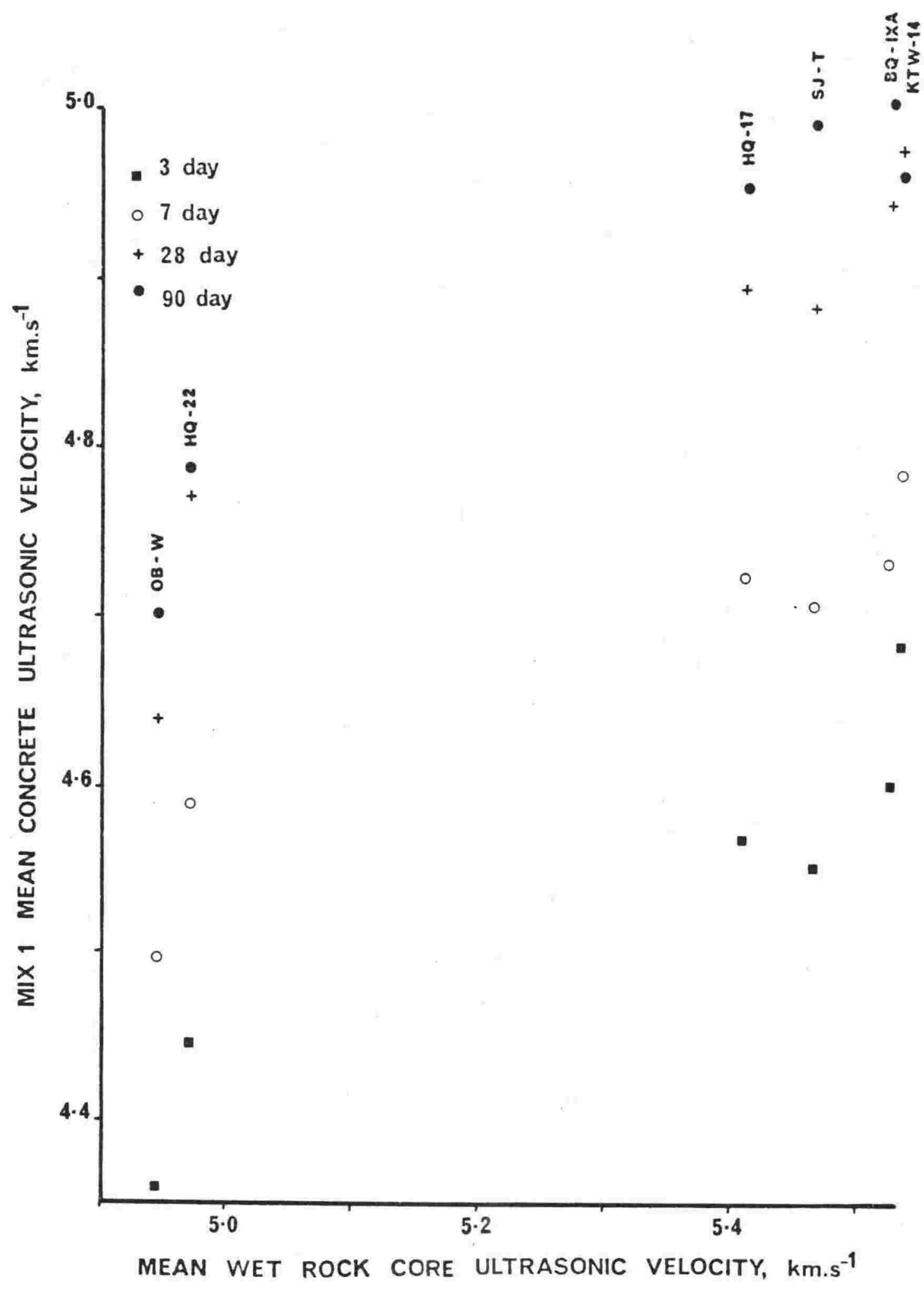

Figure 5.14 : Ultrasonic velocities of wet rock cores are reflected in concrete ultrasonic velocities up to 90 day concrete ages, when sand/cement paste alters the trend as it gains. strength. 


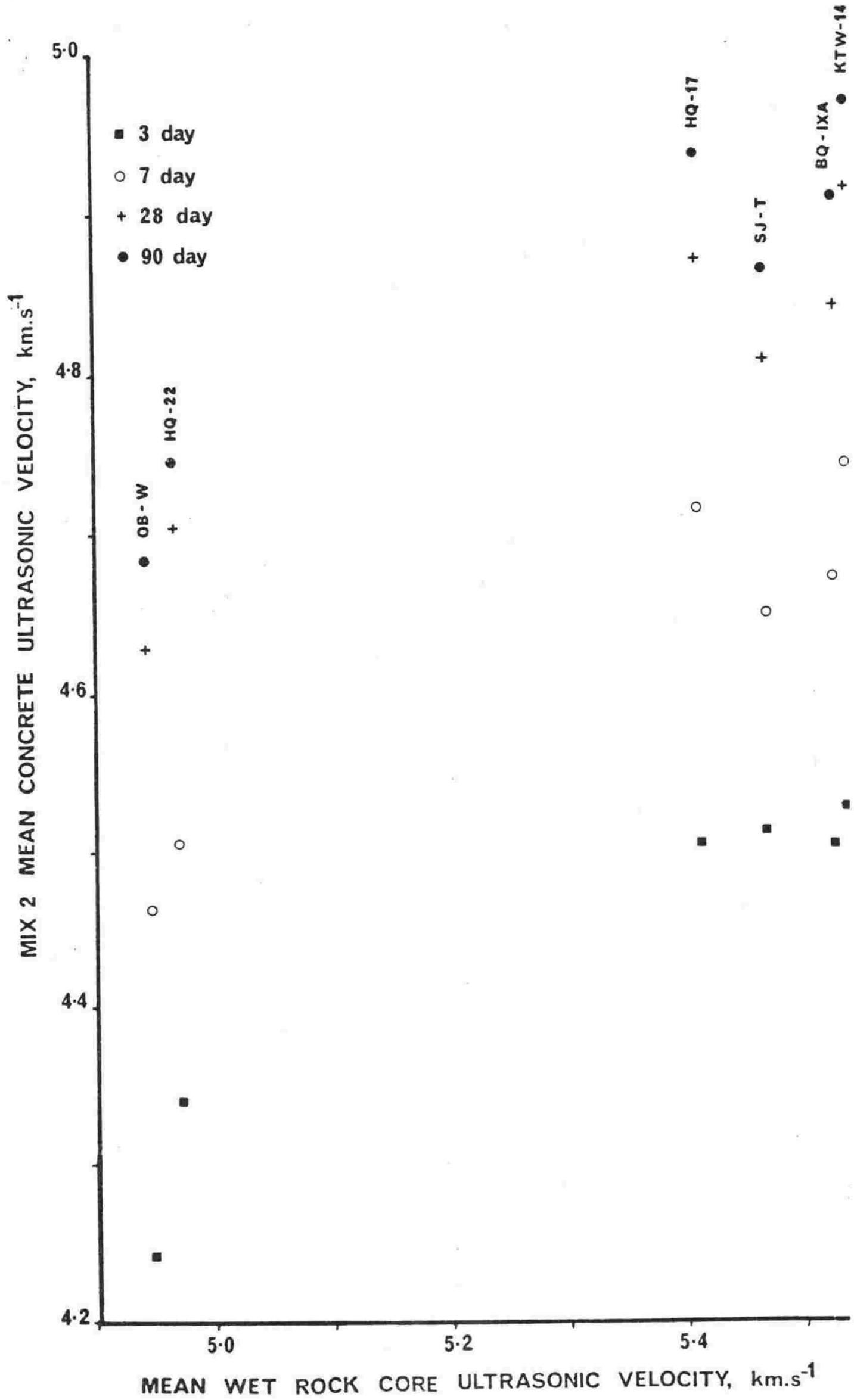

Figure 5.15 : Ultrasonic velocities of wet rock cores are reflected in concrete ultrasonic velocities, but with less resolution than in concretes of mix 1 design concretes (Figure 5.14). Mix I contains more aggregate per unit volume. 
elastic modulus (Figure 5.10). This is well demonstrated in this study, where concretes made to the same design from aggregates derived from a range of rocks of varying density, showed an inverse relationship between concrete density and ultrasonic velocity at a given concrete age (Figure 5.16, 5.17).

\subsection{Strength - density relationships in concrete}

For any concrete, the ratio of compacted density achieved to density attainable is related to the resulting strength of that concrete (Neville, 1975).

Nevilte's statement is no less applicable to this study where each concrete had i as far as practicable, achleved maximum compaction and therefore maximum congrete density, However mo st of the concreto density differences, within each mix series were related to aggregate density differences (with differences of mix design and time of secondary and tertiary importance respectively), and aggregates of greater density (argillites), with lower crushing resistances, lower elastic moduli and more angular particle shapes, produced relatively dense doncxete of reduced relative strength (Figures $5.18,5.19$ ):

Compressive strengths and ultrasonic velocities of concrete were lower for aggregate types from rocks of finer mean grain size (Figure 5.20, 5.21) although the effect is more marked in mix 1, which had slightly higher aggregate to cement ratios.

\subsection{Aggregate strength as a factor of concrete strength}

Ingredients of concrete are nearly always assessed in terms of concrete strengths they produce in predetermined conditions. If aggregate imparts a strength to concrete lower than proven aggregates in the same mix design, then its strength is generally lower than the nominal compressive strength of the concrete. Clearly, such aggregate is better used in concrete of lower strength.

McIntosh (1957) stated that every aggregate has a compressive strength ceiling which should become evident as concrete strength is increased. Therefore aggregate crushing resistance, a measure of the ceiling, was plotted against concrete compressive strength (Figure 5.22). Aggregate crushing resistance 
- 3 day 07 day $\times 28$ day 90 day

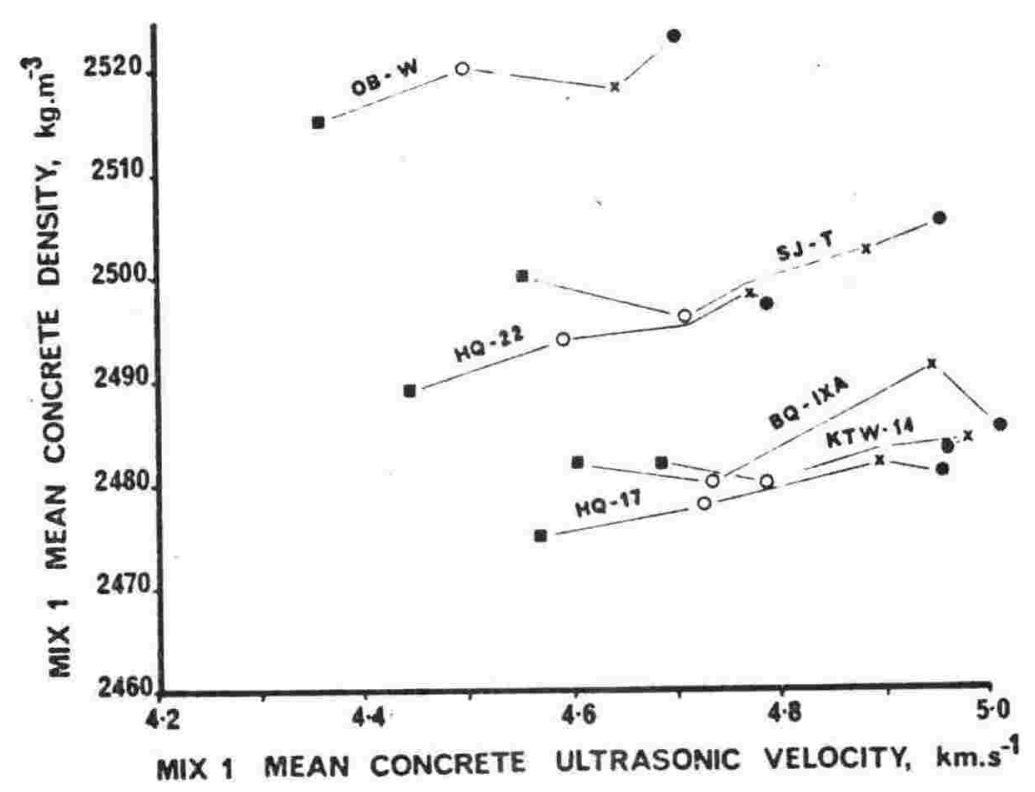

Figure 5.16 : See caption below.

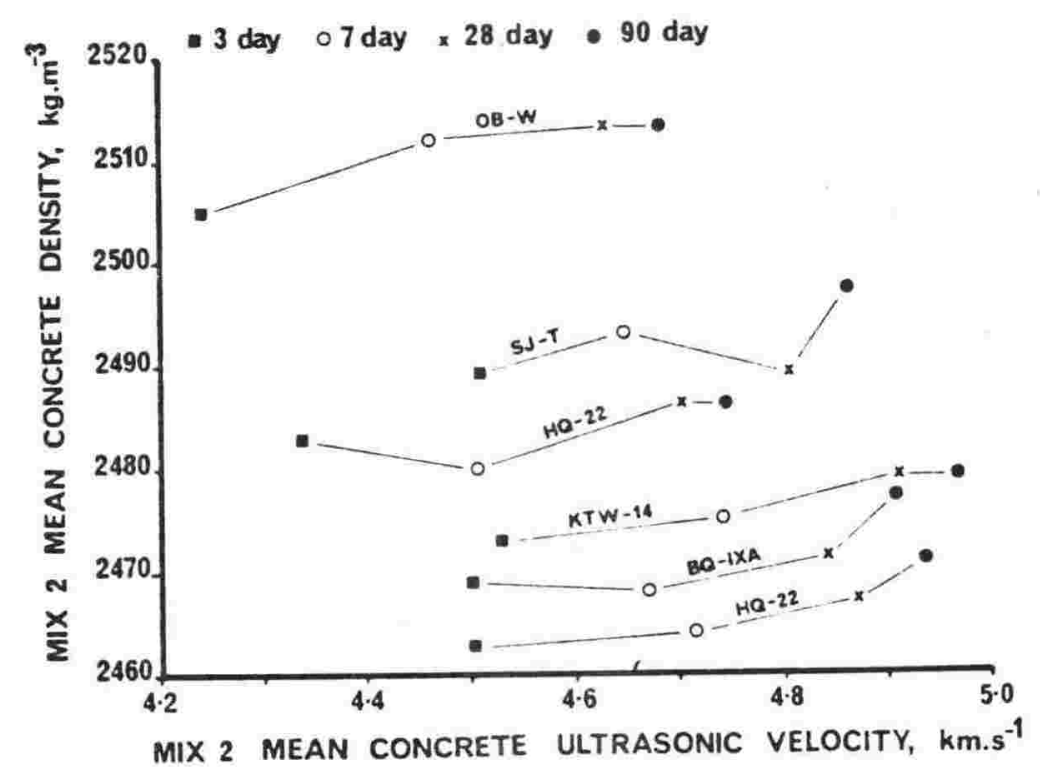

Figure 5.17 : Concrete density shows a positive relationship with ultrasonic velocity of concrete for any particular aggregate. Denser concretes produce lower ultrasonic velocities at any given concrete age, however. 


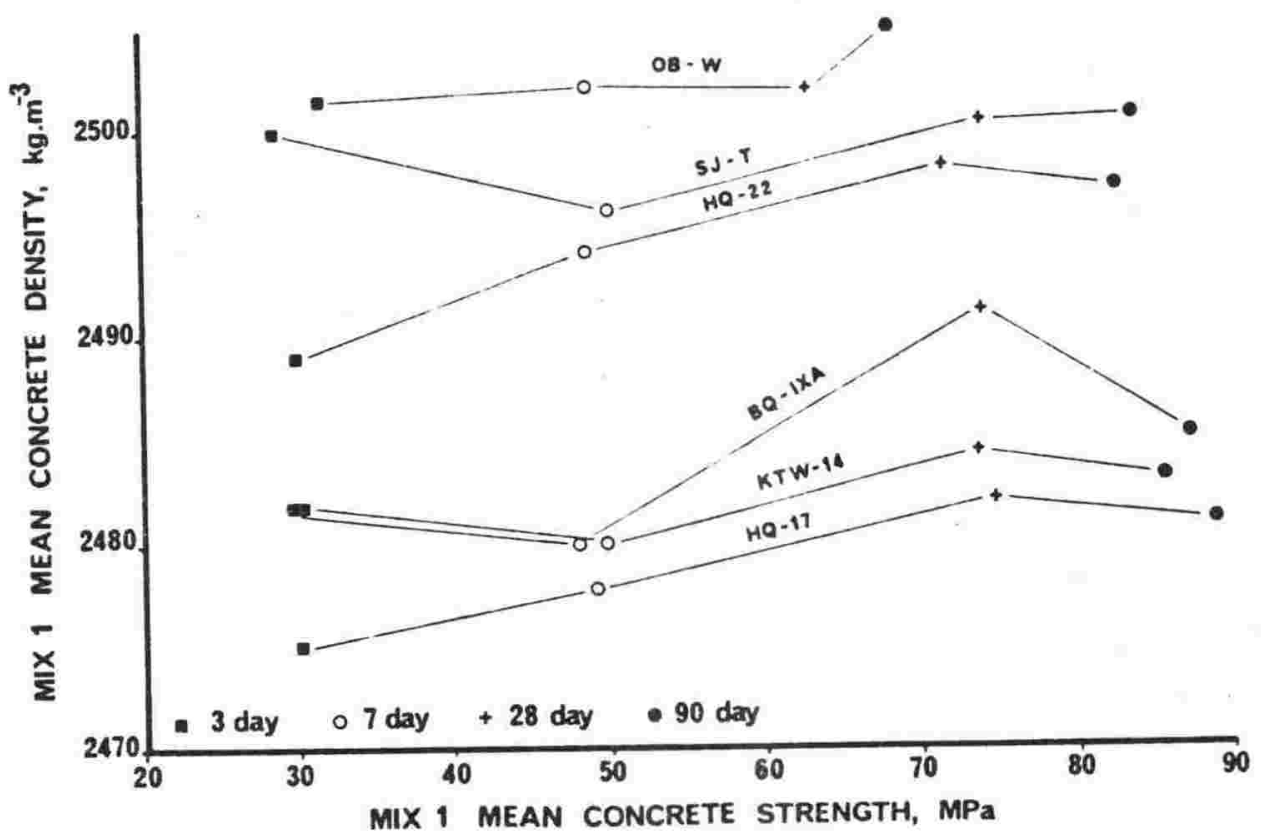

Figure 5.18 : See caption below.

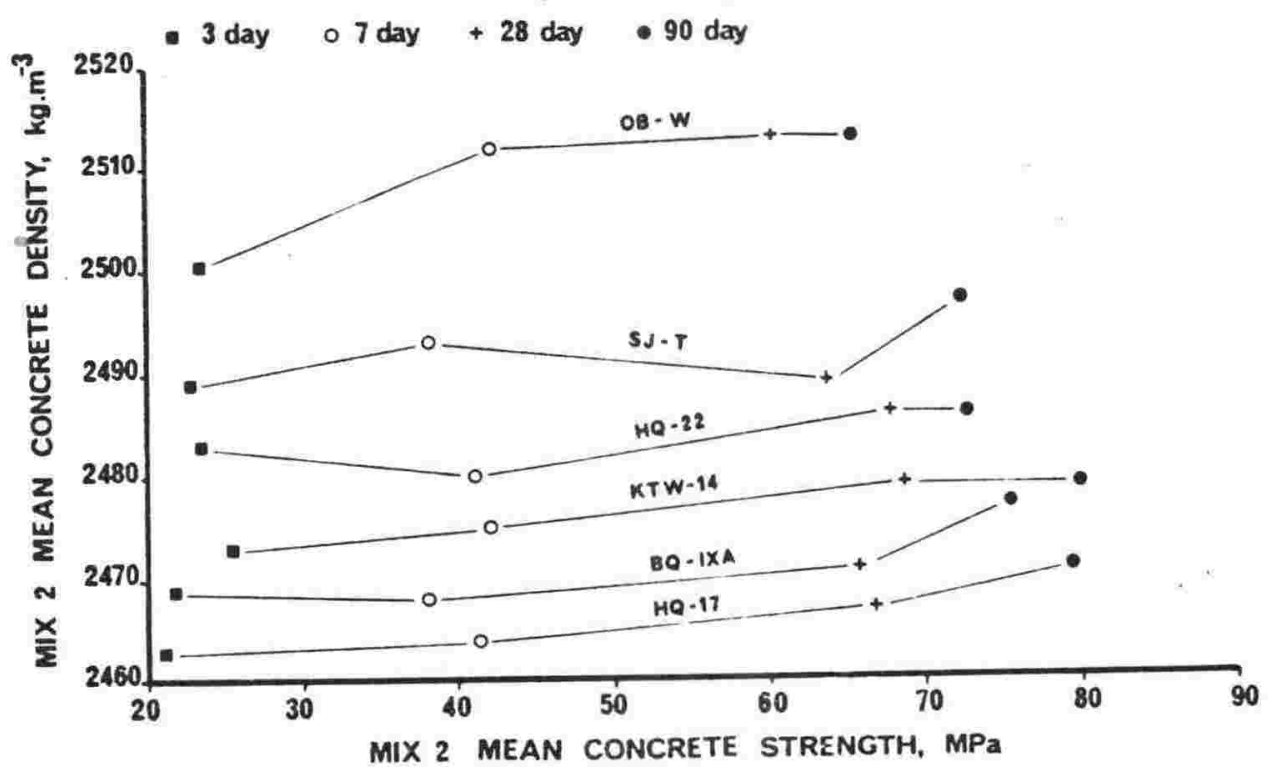

Figure 5.19 : For each aggregate type, density and strength of concrete increases with age. At each test age, however, denser concretes tend to produce lower strengths due to aggregate type. 


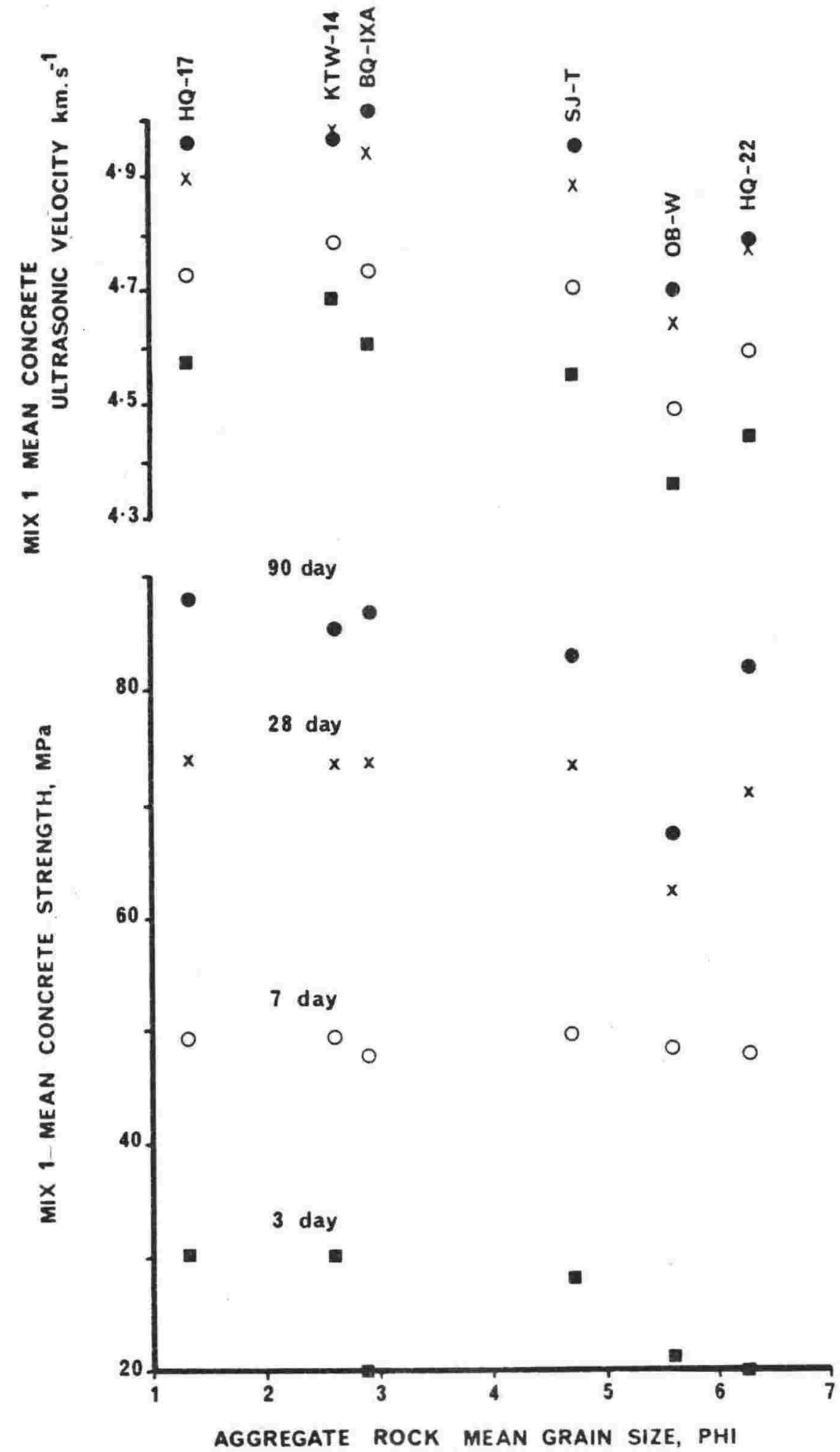

Figure 5.20 : Concrete strength and ultrasonic velocity are reduced at all ages, in concrete of mix 1 design, when aggregates of finer mean grain size are used. 


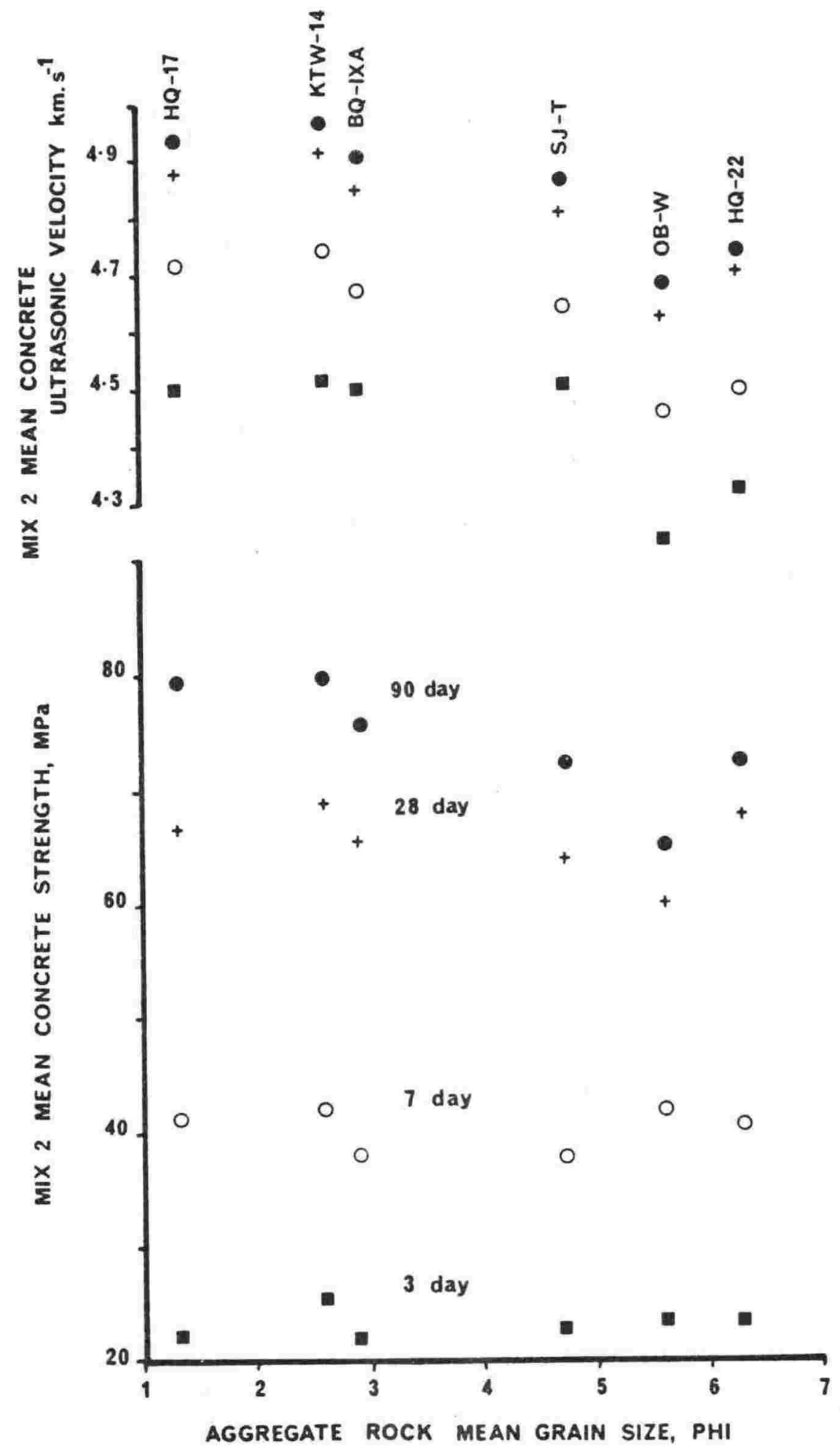

Figure 5.2I : Concrete strength and ultrasonic velocity are reduced especially at older concrete ages, in concrete of mix 2 design, when aggregates of finer mean grain size are used. Compare with Figure 20. 


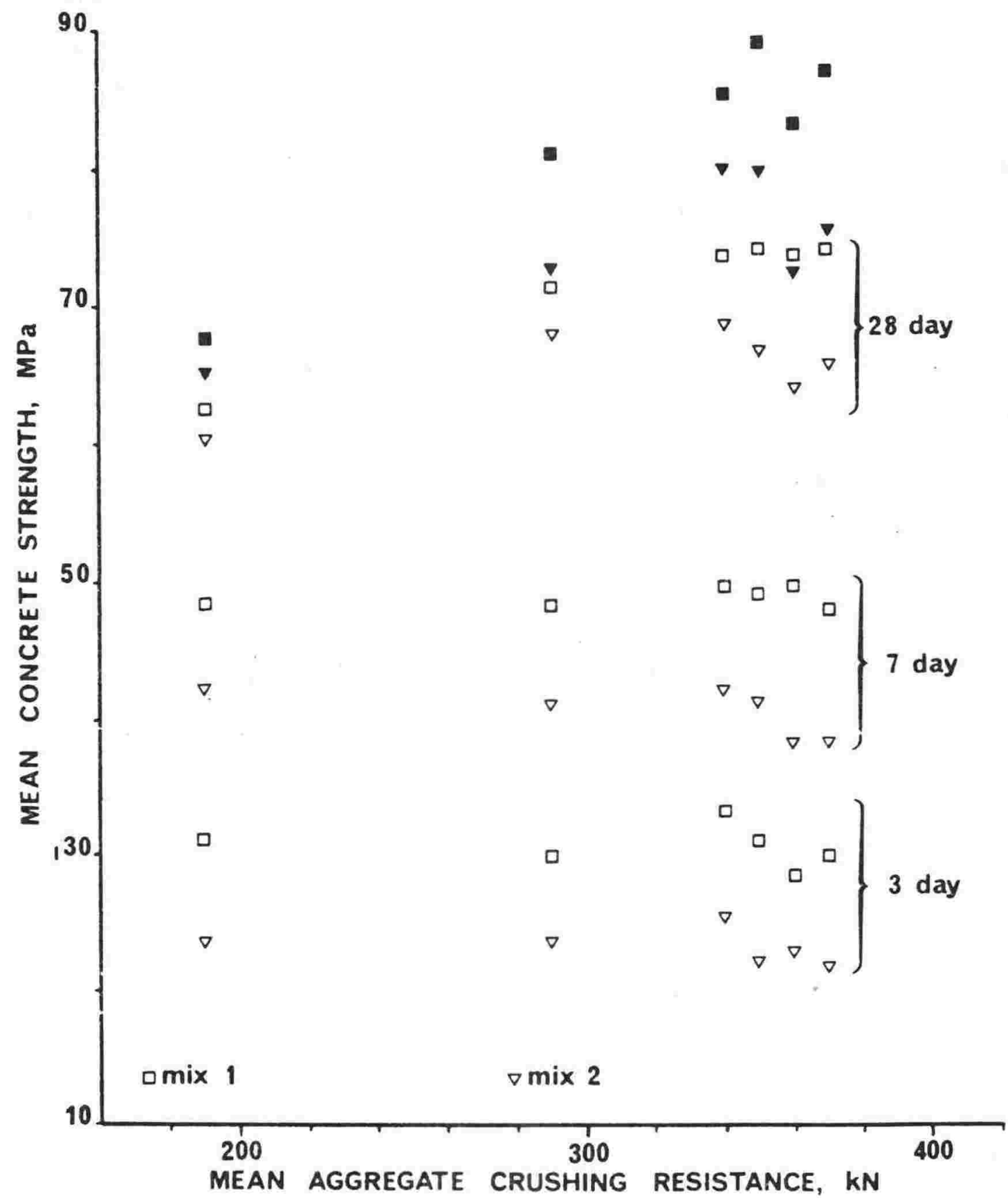

Figure 5.22 : Strength relationship between concrete and aggregate. Increase in concrete strength with increased aggregate crushing resistance is more apparent in high strength concrete (mix 1). Black symbols denote 90 day old concrete. 
At 90 days, trends indicate that aggregates of low crushing resistance, could possibly make even higher strength concrete. Mix 1 concretes certainly indicate that potentially higher concrete strengths are available from aggregates of high crushing resistance.

A similar conclusion is reached by relating rock core strengths to the compressive strengths of concrete made with corresponding aggregates (Figure 5.23), although the influence of particle shape is also evident.

Results suggest that there are real advantages, at least in material usage efficiency, in matching the physical characteristics of aggregates to those of the hardened sand/cement paste in the mix, which in turn is designed to meet the in-service conditions. Certainly strong concrete cannot be made with weak aggregate,nor hard (abrasion resistant) with soft aggregate, but a strong aggregate in a weak sand/cement paste may induce lower compression strength in concrete than one more closely matched to the mortar characteristics.

Practical considerations (handling, transport) dictate a minimum strength for precast concrete products but where this is not a requirement, lower preferred strengths, e.g. DZ 3109 "Concrete construction", could well be met with so called marginal aggregates provided they conform to the grading and organic impurity requirements of NZS 3111:1974. For concrete not exposed to the weather, weathering resistance of the aggregate is not important nor is cleanness if the nature of the "dirt" is known and can be accommodated by mix design.

\subsubsection{Effects of aggregate angularity}

Bache and Nepper Christensen (1965) noted that concrete tested in compression often disolays bond failures along the underside of aggregate particles (with respect to how they have been cast), at early ages. This feature was noted during 3 day testing, particularly in concretes with highly angular aggregates. The effect has been attributed to a relative increase in the water to cement ratio localised beneath elongated or flaky particles as a result of laitance and/or entrapment of air (Plates 5.1, $5.2)$. 


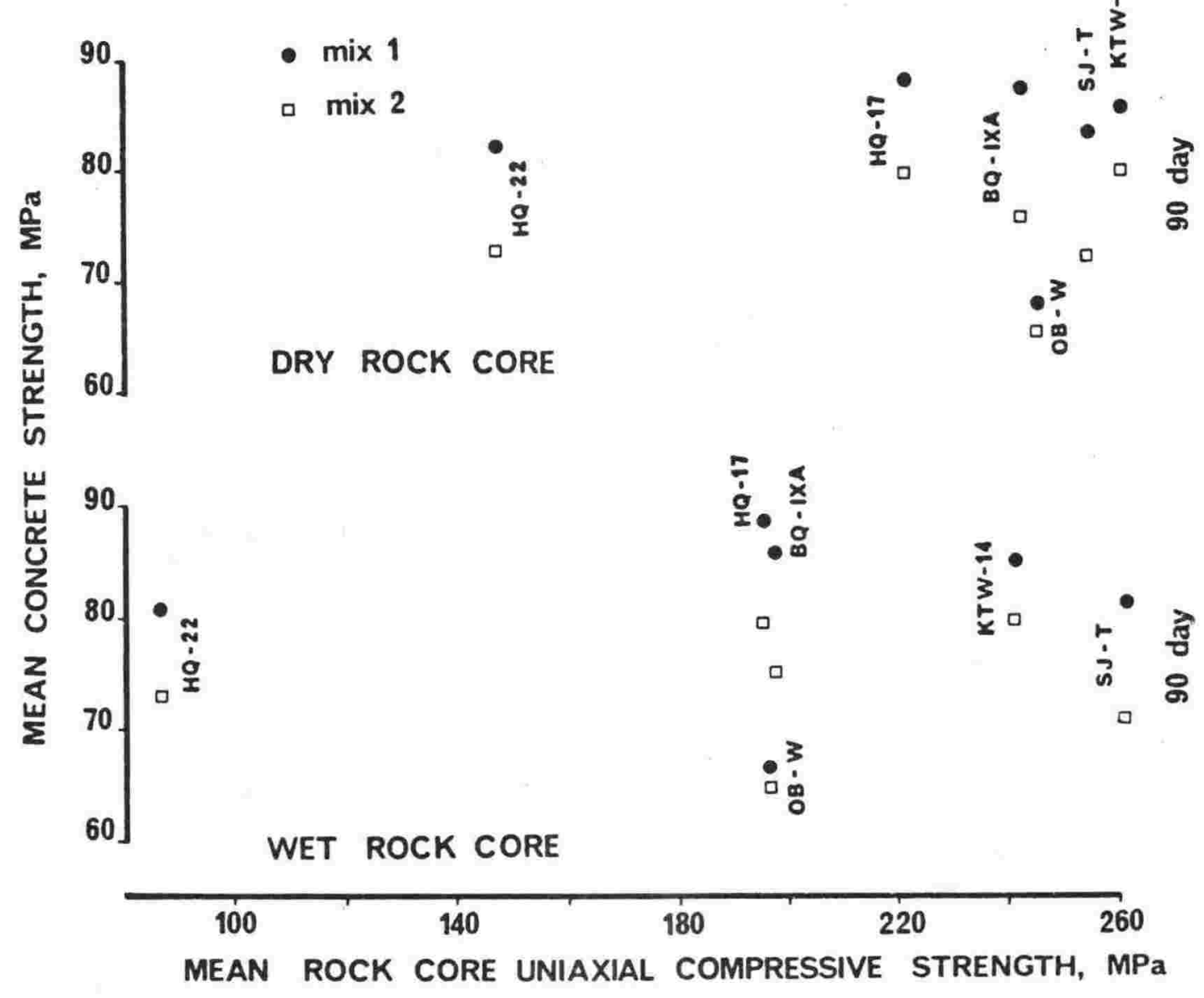

Figure 5.23 : A correlation, especially at later concrete ages, between dry rock core compressive strength and concrete strength is probably influenced by aggregate particle shape. 


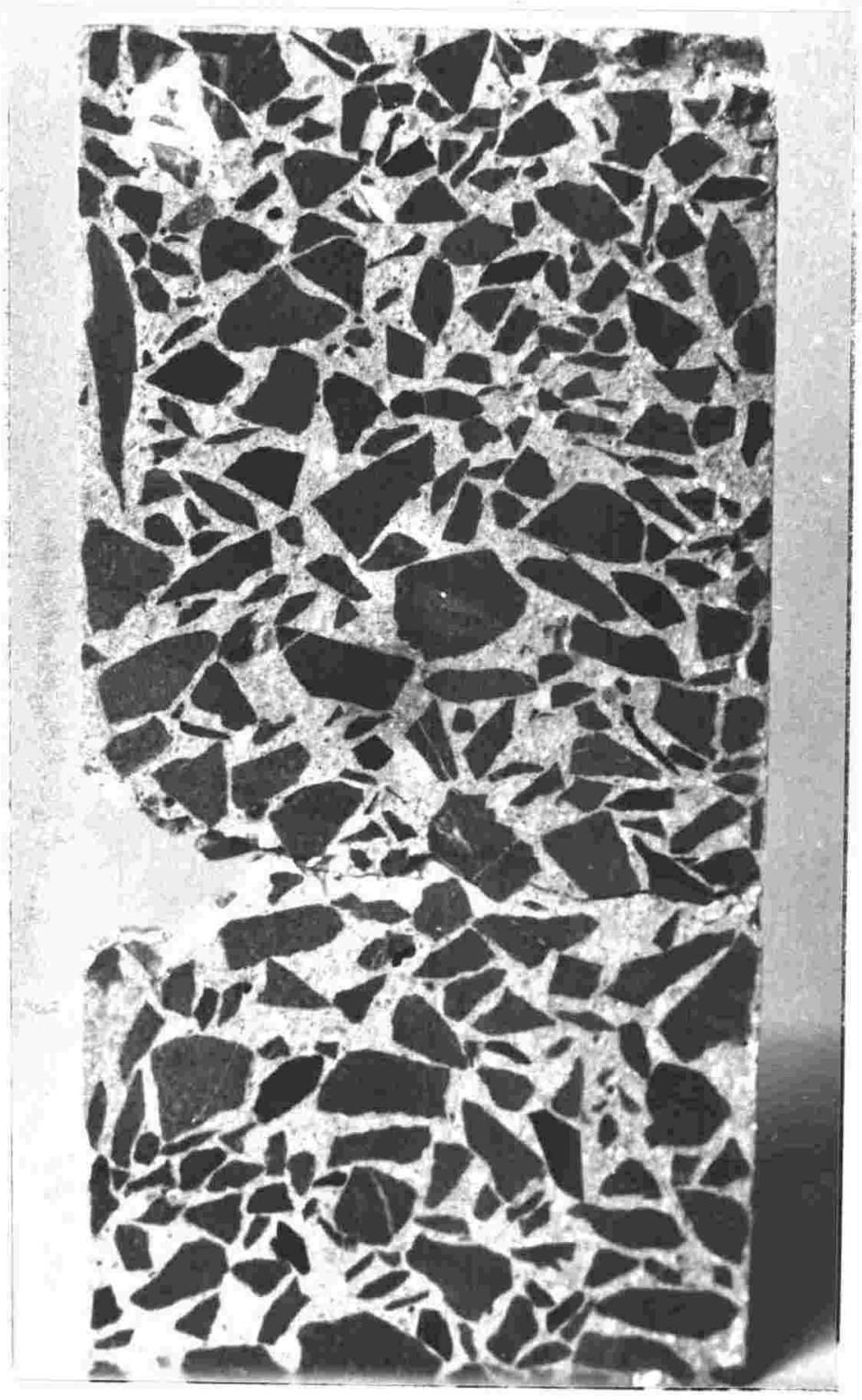

Plate 5.1 : The failure mode of $B Q-1 X A$ ( $\operatorname{mix} 1$ ) at 3 days is a horizontal plane, which has traversed the cylinder about $67 \mathrm{~mm}$ above its base, as cast. The plane shows integrated bond failures at the bottom surfaces of aggregate particles. The cylinder measures $200 \times 100 \mathrm{~mm}$. 


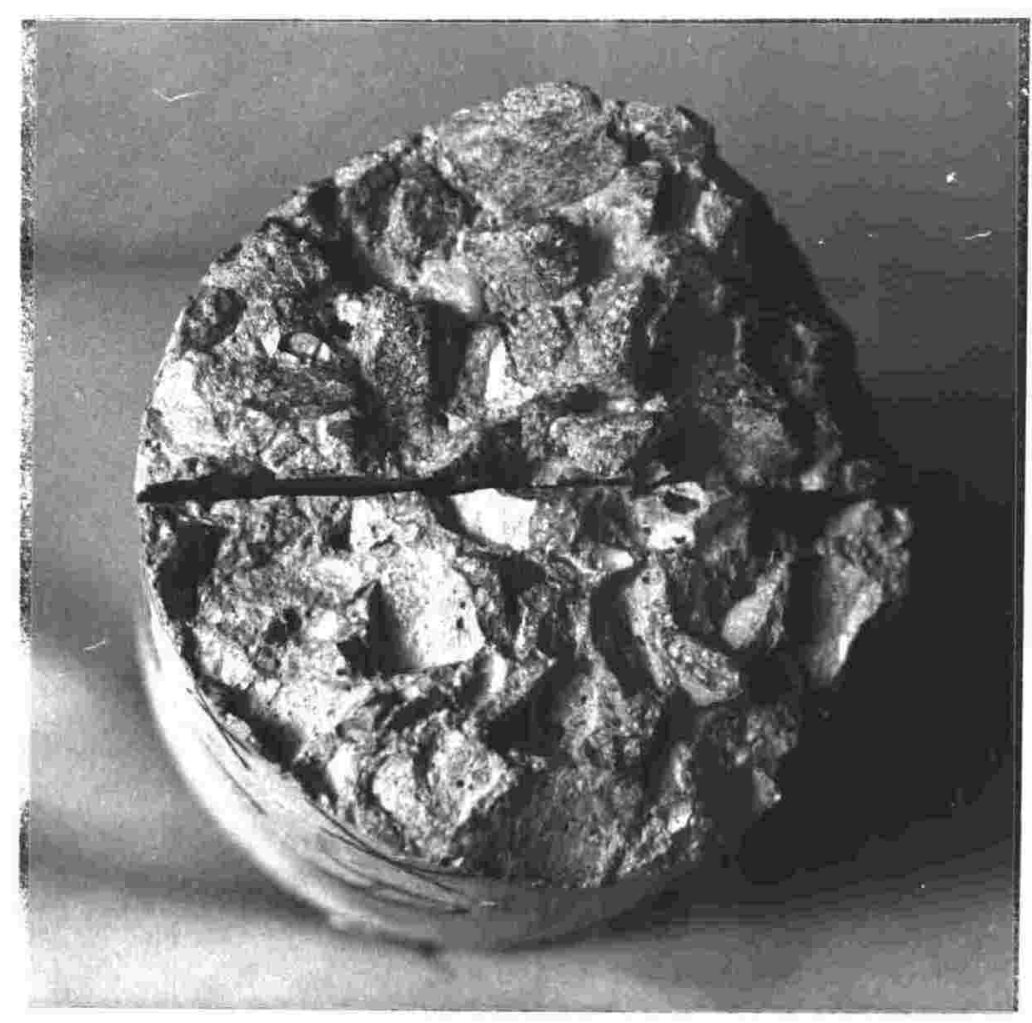

Plate 5.2 : The upper and lower portions of concrete shown in Plate 5.1 are photographed here as complimentary surfaces. Almost all the coarse aggregate particles adhere in the upper portion of the cylinder (top section in photograph), the portion that was uppermost during compaction of the fresh concrete.

The lower portion of the cylinder (bottom section shown) has its fracture plane displaying numerous air voids, indicating that segregation and local increase in water to cement ratio has resulted in a preferred bond failure. See also Bache and Nepper-Christensen (1965). The cylinder is $100 \mathrm{~mm}$ in diameter. 
Figure 5.24 shows concrete strengths plotted with angularity. The very

slight increase In 3 day strength with angularity value (mix I) suggests that aggregate flakiness may actually increase early strength, possibly due to a mechanically stable paoking of panticies, normal to the applied load, during compaction (Rlate 4.1 , Appendis 17 ).

In high strength concrete (mix 1 ) at increased age, more equant grains (which are also the mechanically stronger rock types) appear to enhance strengths. The trend is more scattered for mix 2. More equant particles may be expected to promote higher strengths as, for a given particle size, greatest strengths will be provided by those with the greatest volumes displaying the mean angularity for the aggregate as a whole.

\subsection{Aggregate performance in old concrete}

A search of literature has provided only one reference supporting a suggestion "that aggregates could continue to degrade even after (the) concrete has hardened" Corlett and De Gast (1963*) in West and Aughenbaugh (1964), and there appear to be no reports opposing this view with the possible exception of Kear and Hunt (1969).

Corlett and De Gast (1963) base their contention on "stress relaxation within rock pieces" and this type of phenomenon is relevant to greywacke-suite rocks (Appendix 25) in that desiccation and subsequent wet and dry cycling is seen as a probable cause of microcracking in argillite. Clasts (flakes and chips) of argillite included in greywacke (chipwackes) exposed in outcrops, display microcracking parallel to preferred orientation within the clasts. This is analogous to argillite particles in concrete.

A long term assessment of aggregate degradation within concrete was not possible in this study but to ascertain whether argillaccous particles known to degrade on exposure and in roading situations did degrade in concrete, samples of known age and from varicus localities, were assessed in thin sections and slabs

The original work of these authors was unobtainable. 
- $\operatorname{mix} 1$

- $\operatorname{mix} 2$

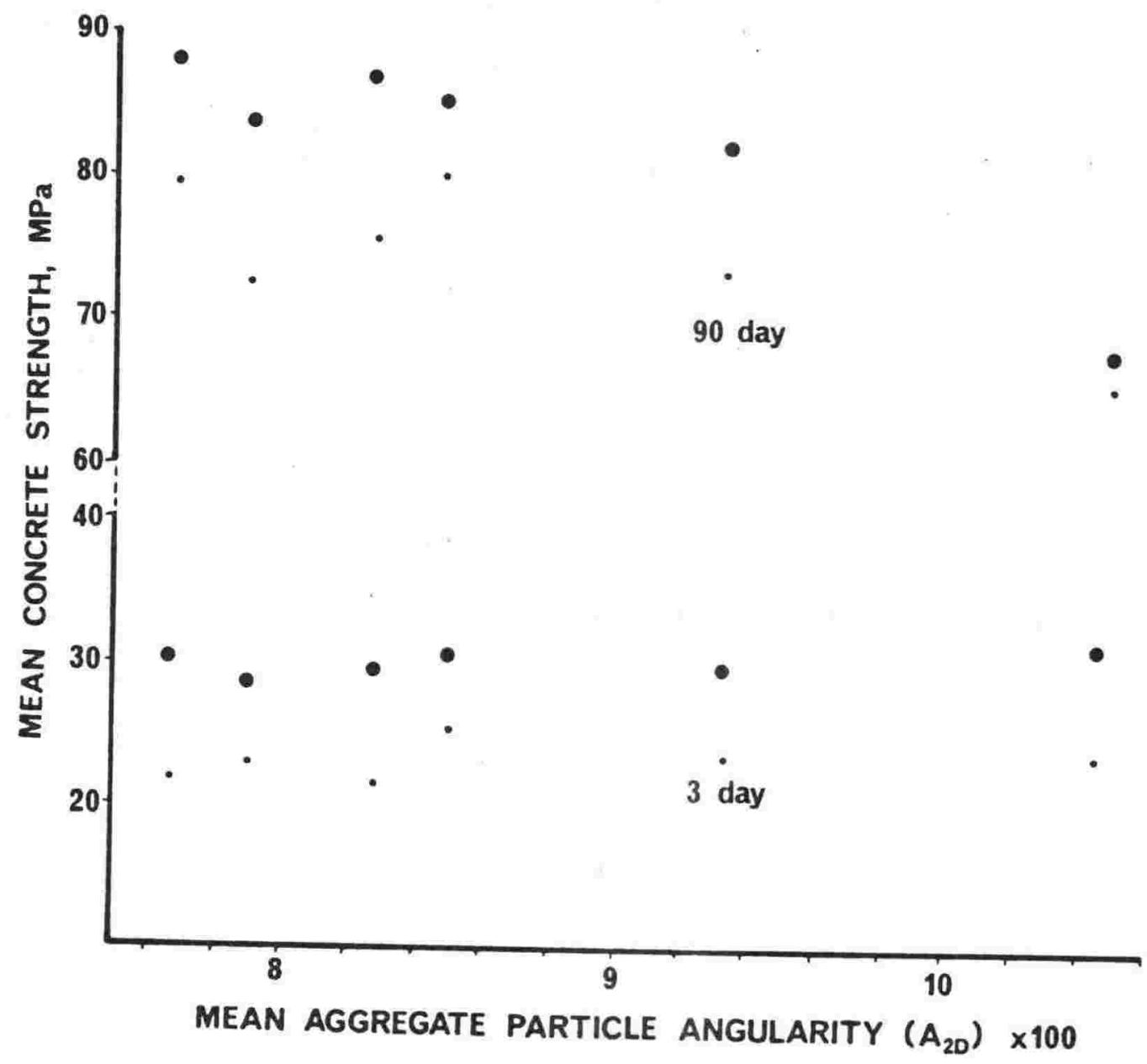

Figuxe 5.24 : Angularity of aggregate particles is reflected in H concrete strength. The more angular particles have produced concrete of lower strength (other factors equal) for two reasons: (i) Rock which produces angular particles tends to be argillaceous and is strongly anisotropic.

(ii) Flaky particles have high surface area to volume ratios and are therefore weaker for any given size.

The effect is not apparent at early concrete ages as failure then is almost entirely within sand/cement mortar. 
Prior to 1950 most aggregate for Wellington was alluvial or beach derived, mostly free from argillite but not from weathered greywacke particles and it often contained significant amounts of shell material. Weathered particles had well rounded surfaces facilitating examination for particle/cement bond.

From the late 1950's quarried material, including argillite, was used so that argillite-bearing concrete is still relatively young in the area.

Results of the survey are shown in Table 5.5. One sample taken from a demolition site showed some argillite microcracking which may have been caused by degradation in the concrete but possibly by desiccation and weathering after exposure resulting from demolition or even induced by the demolition process. The latter cause would seem unlikely when compared with cracking induced by uniaxial compression testing. Here the cracks in argillite particles could generally be traced through the cement paste as well, and were generally wider than microcracks induced by desiccation.

Shrinking aggregates in concrete have been shown (Roper et al., 1964) to have a crack pattern mainly concentric about, and at the particle/cement paste interface,i.e. a bond failure, but degradation is unlikely if the particle is wholly within the concrete because:

(i) Potential argillite volume change is significant $(0.2$ percent, Appendix 20) but if desiccation occurred it would be very slow because of low permeability.

(ii) Argillite clasts in chipwackes are as fresh as the surrounding greywacke until they are exposed at the surface, at which time microcracks within argillite do not extend into the greywacke fabric.

This survey is inconclusive but desiccation of argillite in concrete, if it occurs at all, must be slow, otherwise bond strength would exceed the lowest tensile strength of the argillite particle since argillite is grossly anisotropic (Appendix 7) and any strain consequent to volume reduction is relieved by microcracking within that particle.

Microcracking could be minimised by confining argillite particles to a maximum nominal particle size of less than, say, $10 \mathrm{~mm}$ or accepting a relatively large surface area to volume ratio, say, 6:1 for argillite particles in concrete aggregate (Appendix 25). The latter choice would cause low workabilities in in fresh concretes. 
Table 5.5 : Sumary of survey on aggregate performance in old concrete.

\section{Concrete source Age of concrete Brief description of concrete Remarks}

\begin{tabular}{|c|c|c|}
\hline $\begin{array}{l}\text { Tinakori Gun } \\
\text { Emplacements, } \\
\text { Tinakori Hill, } \\
255 \text { m ( } 837 \mathrm{ft.})\end{array}$ & 37 years & $\begin{array}{l}\text { Most coarse and fine aggregate } \\
\text { weathered. Aggregate rounded. } \\
\text { Argillite in finer aggregate } \\
\text { population. Concrete appeared } \\
\text { of good quality. }\end{array}$ \\
\hline
\end{tabular}

Karori Cemetery,

60 years

Karori Road.

Very lean, highly porous and permeable concrete. Rounded aggregate. Most particles fresh, very little argillite. Concrete surface weathered at least $1 \mathrm{~mm}$.

Inland Revenue Building,

Cnr. Manners St. and Taranaki st.

No date, con-

Approximately 40 percent of firmed at least coarse aggregate weathered. 44 years coarse aggregate is rounded to angular. Limited argillite.

No construction Rounded aggregate, approximately

old house foundation,

18A St Michael's cres., Kelburn.

Old Pearse House, Cnr. Sturdee St. and Dixon St.

Cnr. Farish St. and Manners st. Building had no particular name.

Concrete retaining wall,

21 Wilton Rd., wilton. date available, 10 percent of coarse aggregate

30 years

weathered. Negligible argillite.
35 years

73 years

(1)


The occurrence of dark rim material in some weathered greywacke particles (Table 5.5) is unusual and difficult to interpret (Mather, 1973). Thin sections of concrete from the Inland Revenue Building, 18A St Michael's Crescent, and 21 Wilton Road all showed little resolution of the dark rim surrounding weathered aggregate particles. Because the rim appears to be merely a colour contrast and is seen in rocks with relatively large mean grain sizes, it is probably due to an absorption of cement paste material (perhaps the lime diffusion front of Stocker, 1972), changing the colour of intergranular materials of aggregate particles to a depth of up to $0.6 \mathrm{~mm}$ from their interface with cement paste and extending along recemented shears locally to $1.2 \mathrm{~mm}$. Penetration may depend on relative water contents of cement paste and aggregate particles.

Several thin sections showed microcracks about the interface of weathered aggregate and cement paste, some, the result of thin section preparation but others, clearly a feature of the concrete. The cracking around particles is consistent with shrinking aggregates and probably resulted from the high moisture content of weathered greywacke-suite particles.

- Reaction-products observed in the concretes examined, all appeared innocuous and it is probable that if argillite does microcrack in concrete the process may be reduced or eliminated by careful aggregate production to a finer maximum nominal size grading, which, due to the nature of the material, should be a relatively easy and low cost undertaking. 
CHAPTER SIX

Summary, conclusions and future work

A wide range of properties of Wellington greywacke-suite rocks, unprocessed, as aggregate, and in concrete ( $2 \mathrm{mix}$ designs), were measured to find out how closely concrete properties could be related to rock properties. A summary of properties of typical samples, along with those of aggregates and concrete from them, is presented in Table 6.1. In addition, other specific problems, e.g. aggregate degradation and alkali-silicate reactivity, were investigated.

6.1 Principle conclusions from this study.

(i) The Wellington greywacke-suite rocks comprise two rock types, greywacke and argillite, which have separate and distinctive mineralogies and chemistries. The fundamental basis for distinction is grain size, argillites having a mean grain size finer than 5 phi $(0.031 \mathrm{~mm})$. There is no significant difference in mineralogy or chemistry in greywacke in each of the three lithofacies. Argillite also shows no difference.

(ii) The crushing strength of aggregate from Wellington greywacke-suite rocks is related to the uniaxial compression strength of its parent rock, and determines to some degree the resulting strength of concrete in which it is used.

(iii) Greywacke-suite aggregates produce concrete which are, for the most part, unaffected by alkali-silicate reactions. Laumontite is present locally but does not react because of its habit.

(iv) Discontinuity spacing indicates that the thin-bedded lithofacies may be easier to win and process than other lithofacies but would create more waste.

(v) A test for degradation potential of greywacke-suite rocks, based on destruction of chlorite by hydrochloric acid, has been successfully devised. 
TABLE 6.1 : A sumary of results for typical greywacke-suite rocks from the Wellington region. Values listed are averages for samples tested dry.

* denotes parameters measured from cores.

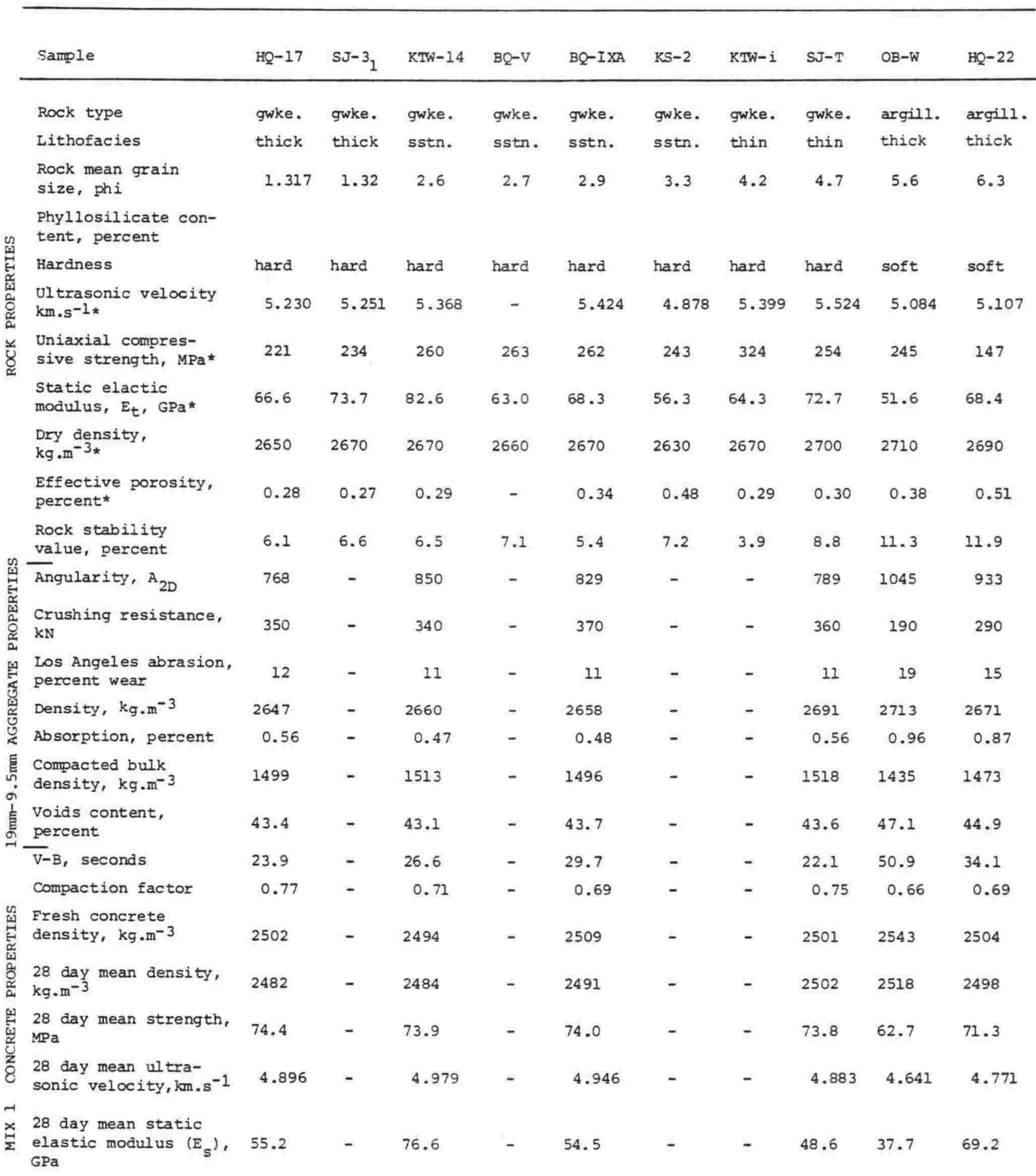


(vi) Greywacke aggregates will, with confidence, produce concrete to meet not only the strength requirements of common commercially viable mixes, but also the special requirements of very high strength concrete.

Argillite aggregates, which on average are more angular, produce concretes that are harder to work and, when compacted, particles tend to align. Use of argillites also results in lower maximum strength concrete and it should not be used where low strength concretes will be subjected to great ranges in moisture content, temperature, or where abrasion resistance is necessary. In particular, argillite aggregates should not be used as exposed aggregate unless protected against wetting and drying. Nevertheless, there are still many concretes in which argillite can be safely used.

\subsection{Future work}

The following are pure and applied geological research topics which require further work to allow proper understanding of the processes involved.

(i) A study of greywacke weathering rates and changes. The study would involve researching techniques for better studies of internal surface areas of fresh and weathering rocks. An application of this work to the aggregate industry could show whether rocks, now considered waste materials or over-burden, could be safely utilised in concrete, or in bound granular form.

(ii) Argillite tends to degrade after being won because of its geological and physical properties. Optimum gradings for argillaceous rock types should be measured and uses for the argillaceous fines, even considering quarry sludges, whould be found to minimise wastage in the aggregate industry. 
PARKINSONS SIXTH LAW:

The progress of science varies inversely

with the number of journals published.

ADAMS, J.E. (1974) Empirical determination of sieve size statistics from grain measurement. Unpub. M.Sc. thesis, Geology Dept., Victoria University of Wellington: $155 \mathrm{pp}$.

ALEXANDER, K.M. (1963) A study of concrete strength and mode of fracture in terms of ratrix, bond and aggregate strengths. Tewksbury symp. on Fracture, University of Melbourne: $25 \mathrm{pp}$.

ARCHIE, G.E. (1950) Introduction to petrophysics of reservoir rocks. Buzl. Am. Assoc. Petrol. Geologists, V. 34: 943-61.

ATTEWELL, P.B. and FARMER, I.W. (1976) "Principles of engineering geology". Chapman and Hall, London: $1045 \mathrm{pp}$.

BACHE, H.H. and NEPPER-CHRISTENSEN, P. (1965) Observations on strength and fracture in lightweight and ordinary concrete. In "The Structure of concrete and its behaviour under load". Conf. Proc., Session B; (Eds.) Brooks, A.E. and Newman, K; C. and C.A.: 93-108.

BADGER, C.W., CUMMINGS, A.D. and WHITMORE, R.L. (1956) The disintegration of shales in water. Jt. Instit. Fuet. V. 29: 417-23.

BAILEY, E.H. and STEVENS, R.E. (1960) Selective staining of K-feldspar and plagioclase on rock slabs and thin sections. Am. Min., V. 45: 1020-5.

BARNES, C.J. (1979) Structure and petrography of Rimutaka greywackes and associated rocks. Unpub. B.Sc. (Hons.) thesis, Geology Dept., Victoria university of Wellington: $59 \mathrm{pp}$.

BAROID DRILIING MUD DATA BOOK (1954) Estimation of cation exchange capacity of clays. Section 900: 44-5.

BARRETT, P.J. (1980) The shape of rock particles, a critical review. Sed., V. 27: 291-303.

BARTON, D.C. (1916) Notes on the disintegration of granite in Egypt. J2. Geol., V. 24: $382-93$.

BASU, A., YOUNG, S.W., SUTTNER, L.J., JAMES, W.C. and MACK, G.H. (1975) Re-evaluation of the use of undulatory extinction and polycrystallinity in detrital quartz for provenance interpretation. JT. Sed. Pet., V. 45(4): 873-82.

BELIKOV, B.P. (1967) Plastic constants of rock forming minerals and their effect on the elasticity of rocks. In Zalesskii, B.V. (Ed.) "Physical and Mechanical Properties of Rocks". The Israel Prog. for Scientific Trans: 124-40. 
BENCE, A.E. and ALBEE, A.L. (1968) Empirical correction factors for the electron microanalysis of silicates and oxides. Jl. Geol. V. 76: 382-403.

BIENIAWSKI, Z.T. (1975b) The point-load test in geotechnical practice. Eng. Geol. V. 9: $1-11$.

BLACKWELDER, E. (1925) Exfoliation as a phase of rock weathering. J. Geol. V. 33: 793806 .

BLATT, H. (1967) Original characters of clastic quartz. Jl. Sed. Pet. V. 37: 401-24. and CHRISTIE, J.M. (1963) Undulatory extinction in quartz of igneous and metamorphic rocks and its significance in provenance studies of sedimentary rocks. J2. Sed. Pet. V. 33: 559-79.

, MIDDLETON, G. and MURRY, R. (1972) "Origin of sedimentary rocks". PrenticeHall. $634 \mathrm{pp}$.

BOGUSLAVSKIY, M. Ye. (1976) Effects of crystal structure characteristics of mineral formations on anistropy of the speed of ultrasonic waves. Internat. Geot. Rev. V. 18(6): $729-33$.

BOGGS, S. (1968) Experimental study of rock fragments. Jl. Sed. Pet. V. 38(4): $1326-39$.

BOULT, B.F. (1979) Thermal properties of concrete. New zealand Concrete Research Association, GLR 15: $27 \mathrm{pp}$.

BOUMA, A.H. (1962) "Sedimentology of some flysch deposits". Elsevier Publishing Co., Amsterdam: $168 \mathrm{pp}$.

BRACE, W.F. (1961) Dependence of fracture strength of rocks on grain size. In 4 th Symp. on Rock Mechanies; Pennsylvania State University: 99-103.

- (1965) Some new measurements of linear compressibility of rocks. Jl. Geophys. Res., V. 70(2): $391-8$.

BREWER, R. (1964) "Fabric and mineral analysis of soils". John Wiley and Sons, New York: $470 \mathrm{pp}$.

BRODIE, J.W. (1953) Stratigraphy and structure of the greywackes and argillites on the South Coast of Wellington Peninsula. N.Z. Jl. of Sei. and Tech., B. 34(4): 205-26.

BRYANT, J.M. (1977) Some properties of Kaimanawa greywacke. M.W.D. N.Z. C. Lab. Report No. $2-77 / 1$ : $20 \mathrm{pp}$.

BUCKE, D.P. and MANKIN, C.J. (1971) Clay-mineral diagenesis within interlaminated shales and sandstones. J. Sed. Pet., V. 41 (4): 971-81.

BUCKLAND, A.H. (1967) The degradation of roading aggregate. Proc. Roading Symp., Road Res. Unit, N.Z. Nat. Roads Board, V. 2: 692-715.

BURST, J.F. (1959) Postdiagenetic clay mineral environmental relationships in the Gulf Coast Eocene. In "Clays and Clay Minerals" Proc. 6th. Nat. Conf. on Clays and Minerals: 327-41; A. Swineford (Ed.): $411 \mathrm{pp}$. 
CARROLL, D. (1970) Clay minerals: A guide to their X-ray identification. Geol Soe. Am. Special Paper 126:80 pp.

CHAYES, F. (1956) "Petrographic modal analysis". Wiley, New York: 113 pp.

CLARK, B.R. (1970) Mechanical formation of preferred orientation in clays. Am. Jl. Sei., V. 269: $250-66$.

CLARK, S.P. (Ed.) (1966) Handbook of physical constants. Geol. Soc. Am. Memoir 97 : 587 pp.

CLELLAND, J. (1967) An artificial weathering test for roading aggregates. Proc. Foading Symp. 1967. Road Res. Unit, N.2. Nat. Roads Board, V. 2: 743-58.

- (1971) Russell Road quarry material. Gyratory compactor tests. M.W.D., Central Laboratories, Gracefield, Report No. 400: $20 \mathrm{pp}$.

COLBACK, P.S.B. and WIID, B.L. (1965) The influence of moisture content on the compressive strength of rocks. Proc. 3rd Can. Rock. Mech. Symp., Toronto: 65-83.

COOMBS, D.S. (1952) Cell size, optical properties and chemical composition of Laumontite and Leonhardite. With a note on regional occurrences in New zealand. Am. Min., V. 37: 812-30.

CORLETT A.V. and DegAST, A.A. (1963) A study of properties of Kingston limestone deleterious in concrete. Paper presented at the 1963 Annual General Meeting of the Engineering Institute of Canada.

CORNWELL, W.L. (1966) Assessment of basecourse aggregate quality, Auckland-Hamilton motorway. M.W.D. Internal Report: $9 \mathrm{pp}$.

CRANNEY, P. (1979) Structure and sedimentology of Lower Mesozoic rocks at Titahi Bay. unpub. B.Sc. (Hons.) thesis, Geology Dept., Victoria University of Wellington: $41 \mathrm{pp}$.

CROOK, K.A.W. (1974) Lithogenesis and geotectonics: the significance of compositional variation in flych arenites (greywackes). Soc. Econ. Pal. Min. Special Pub. No. 19: $304 \cdots 10$.

CURTIS, B.F. (1371) Measurement of porosity and permeability. In Carver, R.E. (Ed.) "Procedures in sedimentary petrology". Wiley and Sons, New York: 335-65.

DEER, W.A., HOWIE, R.A. and zUSSMAN, J. (1971) "An introduction to the rock-forming minerals". Longmàn, London: $528 \mathrm{pp}$.

DEERE, D.U. (1964) Technical Jescription of rock cores for engineering purposes. Rock Mech. and Engng. Geol., V. 1: 17-22.

and MILLER, R.P. (1966) El-ineering classification and index properties for intact rock. Air Force Weapons Laboratory Research and Technology Div; Tech. Report No. AWFL-TR-65-116, Kirtland Air Force Base, New Mexico: 300 pp.

, MERRITT, A.H. and COON, R.F. (1969) Engineering classification of in-situ rock. Air Force Weapons Laboratory Research and Technology Division; Tech. Report No. AFWL-TR-67-144, Kirtland Air Force Base, New Mexico: 272 pp. 
DEKKER, B. and SCOTT, K.O. (1969) Some aspects of aggregate supply for North Island Power Stations. Proc. Nat. Conf. Concrete Aggregates, Hamilton, N.Z.: 26-34.

De PUY, G.W. (1965) Petrographic investigations of rock durability and comparisons of various test procedures. Bull. Ass. Engng, Geologists, v. 2(2): 31-46.

DICKINSON, W.R. (1970) Interpreting detrital modes of greywacke and arkose. Jl. Sed. Pet., V. 39: 1243-55.

DUNCAN, M.A.G., SWENSON, E.G., GILLOTT, J.E. and FORAN, M.R. (1973) Alkali-aggregate reation in Nova Scotia. Cement and Concret Res. V. 3(1,2,3,5) Parts 1,2,3 and 4: 55-69, $119-28,233-45,521-35$.

DUNCAN, N. (1969) "Engineering geology and rock mechanics". Vol. I. Leonard Hill, London: $252 \mathrm{pp}$.

EKSE, M. and MORRIS, M.C. (1959) A test for production of plastic fines in the process of degradation of mineral aggregates. ASTM Spec. Tech. Puib. No. 277: 122-6.

FAIRBURN, P.E. and ROBERTSON, R.H.S. (1957) Liquid limit and dye absorption. Clay Minerals Bulz., V. 3(17): 129-36.

FLAWN, P.T. (1953) Petrographic classification of argillaceous sedimentary and lowgrade metamorphic rocks in subsurface. Bulz. Ass. Am. Petrol. Geol., V. 37: 560-5.

' GOLDSTEIN, A., KING, P.B, and WEAVER, C.E. (1961) The Ouichita system. Pub. Texas Bur. Econ. Geol., University of Texas Pub. 6120: 401 pp.

FOLK, R.L. (1968) "Petrology of sedimentary Rocks". Hemphill's, Texas: 170 pp.

, ANDREWS, P.B. and LEWIS, D.W. (1970) Detrital sedimentary rock calssification and nomenclature for use in New Zealand. N.z. J2. Geoz. Geophys. V. 13(4): 937-68.

FRIEDMAN, M. (1966) Description of rocks and rock masses with a view to their physical and mechanical behaviour. Theme 2; Proc. Int. Cong. Rock Mech., 1st., V. 3, Iisbon.

GAMBLE, J.C. (1971) Durability-plasticity classification of shales and other argillaceous rocks. Unpub. PhD. thesis, University of Illinois at Urbana-Champaign: $161 \mathrm{pp}$.

GEOLOGICAI SOC. ENGINEERING GROUP WORKING PARTY (1977) The description of rock masses for engineering purposes. Quat. Jl. Engng. Geol., V. 10: 355-88.

GILIOTT, J.E. (1975) Alkali-aggregate reactions in concrete. Eng. Geol. V. 9: $303-26$.

GIPSON, M. (1965) Application of the electron microscope to the study of particle orientation and fissility in shale. Jl. Sed. Pet., V. 35(2): 408-14.

GLOVER, J.E. (1964) The universal stage in studies of diagenetic textures. Jl. Sed. Pet., V. 34(4): 851-4.

GOLDICH, S.S. (1938) A study in rock-weathering. Jl. Geol., V. 46: 17-58.

GOONEWARDANE, K. (1977) Behaviour of aggregate in the washington degradation test. Ji. Testing and Evaluation, V. 5(1): 16-25. 
GRAMBERG, J. (1962) Rock mechanics. The axial cleavage fracture in brittle materials at compressive loading. Technological University Delft, The Netherlands; Report No. 1.07: $36 \mathrm{pp}$.

(1965) Axial cleavage fracturing, a significant process in mining and geology. Eng. Geol., V. 1(1): 31-72.

GRANT-TAYLOR, T.L. (1976) Aggregates from quarries in the Wellington region. N.z. Geological Survey unpublished report, M 52: 75 pp.

, ADAMS, R.D., HATHERTON, T., MILNE, J.D.G., NORTHEY, R.D. and STEPHENSON, W.R. (1974) Microzoning for earthquake effects in wellington, New Zealand. N.Z. DSIR, BuZZ. 213: $62 \mathrm{pp}$.

GRATTAN-BELLEW, P.E., SEREDA, P.J. and DOLAR-MANTUANI, L.M.M. (1978) The aggregate shortage and high alkalai cement in a changing energy situation. Can. Jl. Eng., V. 5(2): $250-61$.

GRIGGS, D.T. and HANDIN, J. (1960) Observations on fracture and hypothesis of earthquakes. In Rock Deformation, Geol. Soc. Am. Mem. 79: 347-64.

GRIGGS, P.T. (1936) The factor of fatigue in rock exfoliation. Jl. Geol., V. 44(7): 783-96.

HANDIN, J. (1966) Strength and ductility. In Clark, S.P. (Ed.). Handbook of physical constants; Geol. Soc. Am. Mem. 97: 224-89.

HANSEN, W.C. (1963) Anhydrous and organic materials as sources of distress in concrete. Properties of concrete, Highway Research Record No. 43, Highway Research Board: $1-7$.

(1966) Chemical Reactions of concrete aggregates. Concrete and concretemaking materials, ASTM. STP 169A: 487-96.

HARDING, T.P. (1974) Petroleum traps associated with wrench faults. Am. Ass. Pet. Geot. BuzZ., V. 58(7): 1290-304.

HATHERTON, T. and LEOPARD, A.E. (1964). The densities of New Zealand rocks. N.Z. JZ. Geoz. Geophys., V. ?(3): 605-25.

HAWKES, I. and MELLOR, M. (1970) Uniaxial testing in rock mechanics laboratories. Eng. Geol., V. 4(3): 177-285.

HAYES, J.R. and KLUGMAN, M.A. (1959) Feldspar staining methods. Jl. Sed. Fet., V. 29: $227-32$. HEDBERG, H.D. (1936) Gravitational compaction of clays and shales. Am. Th. Sci., V. 31: 241-87.

HEIDECKER, E. (1968) Rock Pressures induced by weathering and physiocochemical processes. Proc. Aust. Instit. Mining and Metalturgy, V. 226(1): 43-5.

HEIER, K.S. and ADAMS, J.A.S. (1964) The geochemistry of the alkali metals: 253-382. In Ahrens, L.H., Press, F, and Runcorn, S.K. (Eds.): "Physics and Chemistry of the Earth" V. 5. McMillan, New York.

HEY, M.H. (1954) A new review of the chlorites. Min. Mag., V. 30: 277-92. 
HIIIS, E.S. (1963) "Elements of structural geology". Methuen, London: 483 pp.

HOBBS, D.W. (1963) A simple method for assessing the uniaxial compressive strength of rock. Int. Jl. Rock Mech. Min. Sei., V. 1: 5-15.

HOGAN, J.A. (1979) Stratigraphy and sedimentology of the Kapuni formation Taranaki, New Zealand. Unpub. MSc. thesis, Geology Dept., Victoria University of Wellington: $189 \mathrm{pp}$.

HOWIE, J.A. (1910) "The geology of building stones". Edward Arnold, London: 455 pp.

HUGHES, B.P. (1966) A laboratory test for determining the angularity of aggregate. Magazine of Concrete Res., V. 18(56): 147-52.

HURLBUT, C.S. (1971) "Dana's manual of mineralogy". 18th Ed., J. Wiley and Sons, New York : $579 \mathrm{pp}$.

HUTTON, C.A. (1945) The problem of reaction between aggregate materials and high alkali cements. N.Z. Jl. Sci. Tech., V. 266(4): 191-200.

IDE, J.M. (1936) Comparison of statically and dynamically determined Young's modulus of rocks. Proc. Nat. Acad. Sci., V. 22(2): 81-92.

INGRAM, R.I. (1953) Fissility of mudrocks. Bulz. Geol. Soc. Am., V. 64: 869-78.

INOMATA, M. and TATEYAMA, H. (1974) Titano-penninite from the phlogopite-bearing ultramafic rocks in the Ufu-san ultramafic body, the Mikabu zone, Central Japan. ת. Japan Assoe. Min. Pet. Econ. Geol., V. 69(9): 332-7.

JAEGER, C. (1972) "Rock Mechanics and Engineering".Cambridge University Press: 417 pp.

JAEGER, J.C. and COOK, N.G.W. (1976) "Fundamentals of Rock Mechanics", 2nd Ed. Chapman and Hall, London: $585 \mathrm{pp}$.

JETTER, L.K. and BORIE, B.S. (1953) A method for the quantitative determination of preferred orientation. JT. Applied Physics, V. 24(5): 532-5.

JONES, F.O. (1964) New fast, accurate test measurement of bentonite in drilling mud. oir and Gas Ji., V. 1: 76-8.

JONES, R. and GATFIELD, E.N. (1955) Testing concrete by an ultrasonic pulse technique. DSIR, Road Research Tech. Paper No. 34. , H.M.S.O., London: 48 pp.

KAARSBERG, E.A. (1959) Introductory studies of natural and artificial argillaceous aggregates by sound propagation and X-ray diffraction methods. Jl. Geol., V. 67: $447-72$.

KAHN, J.S. (1956) Analysis and distribution of packing properties in sand-sized sediments. 2. The distribution of the packing measurements and an example of packing analysis. Jl. Geol., V. 64: 578-606.

KAWACHI, Y. (1974) Geology and petrochemistry of weakly metermorphosed rocks in the upper Wakatipu District, southern New Zealand. N.Z. M. Geot. Geophys., V. 17(1): 169-208. 
KAZI, A. (1975) Quantitative fabric analysis of Dramen clay using X-ray diffraction technique. Jl. Sed. Pet., V. 45(4): 883-90.

and AL-MANSOUR, Z.R. (1980) Empirical relationship between Los Angeles abrasion and Schmidt hammer strength tests with application to aggregates around Jeddah. Quat. Jl. Engng. Geol., London, V. 13(1): 45-52.

KEAR, D. and HUNT, J.L. (1969) Aggregate resources of New Zealand. Proc. Nat. Conf. on Conerete Aggregates, Homilton, New Zealand; N.Z. Portland Cement Assoe.: 17-25.

KLUG, H.P. and ALEXANDER, L.E. (1974) "X-ray diffraction procedures for polycrystalline and amorphous materials". 2nd Ed. J. Wiley and Sons, New York: 966 pp.

KRYNINE, P.D. and JUDD, W.R. (1957) "Principles of Engineering Geology and Geotechnics". McGraw-Hill Book Co., New York: 730 pp.

KUBLER, B. (1967) La Cristallinite de L'illité et les zones tout à fait supérieures du metamorphisme. Etages Tectoniques, Colz. Neuchâtel: 105-22.

KUSHIRO, I. and NAKAMURA, Y. (1970) Petrology of some lunar crystalline rocks. Proc. Apolzo 11 Lunar Sei. Conf. 1: 607-26.

LAMA, R.D. and VUTUKURI V.S. (1978)"Handbook on Mechanical properties of rocks". Vol 2, Trans Tech. Publications, Germany: 481 p.

LANIZ, R.V., STEVENS, R.E. and NORMAN, M.B. (1964) Staining of plagioclase feldspar and other minerals with F.D. and C. red No. 2. U.S. Geo2. Survey. Prof. Paper 501-13: B152-3.

LA RUE, H.A. (1946) Modulus of elasticity of aggregates and its effects on concrete. Proc., ASTM, V. 46: 1298-310.

LASIUS, G.S.O. (1789) Beobachtungen über das Harzgebirge mit Karte. Hanover.

LEES, G. (1964) A new method for determining the angularity of particles. Sedimentology V. $3(1): \quad 2-21$.

and KENNEDY, C.K. (1975) Quality, shape and degradation of aggregates. Quat. JI. Engng. Geology, V. 8(3): 193-209.

LERCH, W. (1962) Chemical reactions of aggregates in concrete. Modern Concrete, V. 25(11): $41-44$.

LOUGHNAN, F.C. (1969) "Chemical weathering of the silicate minerals". Elsevier, Amsterdam: $154 \mathrm{pp}$.

MacKENZIE, R.C. and MILNE, A.A. (1953) The effect of grinding on micas. I. Muscovite. Min. Mag., V. 30: 178-85.

MARSHALL, T.R. (1967) Washington test - A status report. Washington State Highway Commission, Dept. of Highways Materials, Spokane, Report 103: 15 pp.

MARSHALL, T.W. (1974) A petrographic investigation of greywacke type aggregates from the Auckland region. Unpub. M.Sc. (Hons.) thesis. Geology Dept., University of Auckland: $125 \mathrm{pp}$. 
MARTINEZ, J.D. (1958) Photometer method for studying quartz grain orientation. Am. Ass. Petrol. Geol. Buiz., V. 42(3): 588-608.

MATHER, K. (1973) Examination of cores from four highway bridges in Georgia. U.S. Army Eng. Waterways Exp. Stn., Corps. Engng., Vicksburg, Mississippi. Misc. Paper., C 73-11: $20 \mathrm{pp}$.

MAYER, A. (1963) Recent work in rock mechanics. 3rd. Rankine Lecture, Geotechnique, V. 13: 97-120.

MCINTOSH, J.D. (1957) The selection of natural aggregates for various types of concrete work. Reinf. Conerete Rev., V. 4(5): 281-305.

(1966) "Concrete mix design" Cement and Concrete Assoc., London: 123 pp.

MCKEAN, T.A.M. (1976) The petrology and $\mathrm{K} / \mathrm{Ar}$ geochronology of the Wellington argillites North Island, New Zealand. Unpub. B.Sc. (Hons.) project, Victoria University of Wellington: $60 \mathrm{pp}$.

MELVILLE, P.L. (1948) Weathering study of some aggregates. Proe. Highway Res. Board, V. $28: 238-48$,

MICHALOPOULOS, A.P. and TRIANDAFILIDIS, G.E. (1976) Influence of water on hardness, strength and compressibility of rock. Bull. Ass. Engng. Geologists, V. 13(1): 1-22.

MIDDLETON, G.V. (1960) Chemical composition of sandstones. Geol. Soe. Am. Bul2., V. 71: $1011-26$.

MINOR, C.E. (1959) Degradation of mineral aggregates. ASTM Special Tech. Pub. No. 277: 109-21.

MOORE, C.A. (1968) Quantitative analysis of naturally occurring multi-component mineral systems by X-ray diffraction. Clays and Clay Min., V. 16: 325-36.

MORGENSTERN, N.R. and TCHALENKO, J.S. (1967) The optical determination of preferred orientation in clays and its application to the study of microstructure in consolidated Kaolin (parts 1 and 11). Proc. Roy. Soc. London, Series A, V. 300: 218-34 and 235-50.

MORRIS, P. (1979) Major and trace element chemistry of volcanic rocks from the chatham Islands. Analytical Facility Contribution No. I; Dept. of Geology Publ. No. 11, Victoria University of Wellington. $32 \mathrm{pp}$.

MÜLLER, G. (1967) "Methods in sedimentary petrology". Translated by Hans-Ilrich Schmincke. Stuttgart Hafner Pub. Co., New York: 283 pp.

MURRAY, H.H. and LYONS, S.C. (1960) Further correlations of Kaolinite crystallinity with chemical and physical properties. In Proc. 8th Nat. Conf. on Clays and Clay Min.: $11-7$.

NATHAN, S. (1976) Geochemistry of the Greenland Group (Early Ordovician), New Zealand. N.Z. JI. Geol. Geophys., V. 19(5): 683-706.

NEUBERT, H.K.P. (1967) "Strain gauges; kinds and uses". MCMillan: 164 pp. 
NELVILLE, A.M. (1975) "Properties of concrete". 2nd Ed., Pitman Pub., England: 686 pp.

NEW, B.M. (1976) Ultrasonic wave propogation in discontinuous rock. Transport and Road Research Laboratory Report 720: 9 pp.

NORRISH, K. and HUTTON, J.T. (1969) An accurate X-ray spectrographic method for the analysis of a wide range of geologic samples. Geochim. et Cosmochim. Acta, V. 33: $431-54$.

OBERHOLSTER, R.E. and BRANDT, M.P. (1974) An example of cement-aggregate reaction in South Africa. Proc. Electron Microscopy Soc. South Africa, V. 4: 59-60.

O'BRIEN, N.R. (1963) A study of fissility in argillaceous rocks. Unpub. Ph.D. thesis, University of Illinois, Urbana, Illinois, U.S.A.

OLLIER, C. (1969) "Weathering" Oliver and Boyd, Edinburgh: 304 pp.

ONIONS, D. and MIDDLETON, G.V. (1968) Dimensional grain orientation of ordovician turbidite greywackes. J2. Sed. Pet., V. 38(1): 164-74.

ORCHARD, D.F. (1964) Factors influencing the wear of coarse aggregate in the Los Angeles test. Proc. of 2nd Conf., Australian Road Res. Board, V.2 part 2: 963-80.

(1976) "Concrete technology. Vol. 3: properties and testing of aggregates". 3rd. Ed. Applied Science Publishers Ltd., London: $281 \mathrm{pp}$.

PARK, J.E. (1975) Paleomagnetism of the volcanic rocks at Red Rock Point, Wellington. Unpub. B.Sc. (Hons.) thesis, Geology Dept., Victoria University of Wellington: $31 \mathrm{pp}$.

PARKS, W.A. (1911) Report on the building and ornamental stones of Canada. Dept. of Mines, Canada, v. I: $376 \mathrm{pp}$.

PARRISH, W. (1960) Advances in X-ray diffractometry of clay minerals. Clay and clay Minerals; Proc. 7th Nat. Conf., Pergamon Press: 230-59.

PATERSON, M.S. (1978) "Experimental rock deformation - The brittle field". SpringerVerlag, New York: 254 pp.

PERRY, C.C. and IISSNER, H.R. (1962) "The strain gage primer". 2nd Ed., McGraw-Hill, New York: $332 \mathrm{pp}$.

PETTIJOHN, F.J. (1957) "Sedimentary rocks". 2nd Ed., Harper, New York: 718 pp.

(1963) Chemical composition of sandstones - excluding carbonate and volcanic sands. In Data of Geochemistry (6th Ed.). U.S. Geol. Survey Prof. Paper 440 S: $19 \mathrm{pp}$.

, POTTER, P.E. and SIEVER, R. (1972) "Sand and sandstone". SpringerVerlag, Berlin: $618 \mathrm{pp}$.

PIERSON, A.L. (1959) A photomultiplier photometer for studying quartz grain orientation. J2. Sed. Pet. V. 29(1): 98-103.

PRIEST, S.D. and HUDSON, J.A. (1976) Discontinuity spacings in rock. Int. Jl. Rock Mech. Min. Sci. and Geomech. Abstr., V. 13: 135-48. 
RAISBECK, D. (1973) Strength parameters for weathered sandstone. N.z. Engng. V. 28(9): $254-260$.

RAMSAY, D.M., DHIR, R.K. and SPENCE, I.M. (1974) The role of rock and clast fabric in the physical performance of crushed-rock aggregate. Engng. Geol., V. 8: 267-85.

RAU, R.C. (1963) Measurement of crystallite size by means of X-ray diffraction linebroadening. Norelco Reporter, V. 10: 114-8.

REED, J.J. (1957) Petrology of the Lower Mesozoic rocks of the Wellington district. N.Z. Geol. Survey Bulz. n.s. 57: 60 pp.

(1966) Geological and petrological investigations of wacke aggregates used in Auckland-Hamilton Motorway, Redoubt and Takanini sections. N.2. Geoz. Survey, Report No.20: $47 \mathrm{pp}$.

(1967) Application of recent petrological advances to selection of road aggregates. Proc. Roading Symp. 1967. Road Res, Unit, N.Z. Nat. Roads Board, V. 2: 716-42.

and GRANT-TAYLOR, T.L. (1966) Geological investigations of quarries and potential quarries for road metal production, Wellington area. N.Z. Geot. Survey, Report No. 5: $18 \mathrm{pp}$.

RHOADES, R. and MIELENZ, R.C. (1946) Petrography of concrete aggregate. Jl. Amer. Concrete Instit., V.42: 581-600.

RICHARDS, C.W. (1961) "Engineering materials science". Wadsworth Pub. Co., Belmont, california.

RIDDOLLS, B.W. and PERRIN, N.D. (1975) Engineering geological investigations: Wellington urban motorway - The Terrace tunnel. N.Z. Engng., V. 15: 221-4.

ROBERTS, A.F. (1977) "Geotechnology - An introductory text for students and engineers". Pergamon Press, Oxford: 347 pp.

ROPER, H. (1959) Study of shrinking aggregates in concrete. Nat. Bldg. Res. Instit., South African Council for Scientific and Industrial Res., Special Tech. Report No. 502: 136 pp.

' COX, J.E. and ERIIN, B. (1964) Petrographic studies on concrete containing shrinking aggregate. J2. PCA Res, and Develpment Lab., V. 6(3): 2-18.

ROWE, G.H. (1979) A method for assessing degradation in New Zealand greywackes. Proc. N.Z. Roading Symp. Road Res. Unit, Nat. Roads Board. Session A: A.2-I - A2-14.

SALTZMAN, U. (1975) Rock quality determination for large-size stone used in protective blankets. Unpub. Ph.D. thesis, Purdue University: 246 pp.

SAMESHIMA, T. (1977) Hydrothermal degradation of basecourse aggregate. Pavement Res. Project B.C. 21., Dept. of Geology, University of Auckland: $90 \mathrm{pp}$. and BLACK, P.M. (1979) Clay index - a simple method of assessing the quality and performance of roading aggregates. Froc. N.z. Roading Symp. Road Res. Unit, Nat. Roads Board, Session A: A3-1 - A3-10.

SCHAFFER, R.J. (1932) The weathering of natural building stones. Dept. Sci. Indust. Res., BLdg. Res. Spec. Report No. 18, HMSO, London: $149 \mathrm{pp}$. 
SCHOEN, R. (1962) Semi-quantitative analysis of chlorites by X-ray diffraction. Am. Min., V. 47: 1384-92.

SCHULZ, L.G. (1949a) A direct method of determining preferred orientation of a flat reflection sample using a Geiger Counter X-ray spectrometer. Tl. Applied Phys., V. 20: $1030-3$.

SHACKLOCK, B.W. (1974) "Concrete constituents and mix proportions". Cement and Concrete Ass., London: $102 \mathrm{pp}$.

SHAPIRO, I. and BRANNOCK, W.W. (1956) Rapid determination of carbon dioxide in silicate rocks. Analytical Chemistry, V. 27(11): 1796-7.

SHEPHERD, R. (1951) Physical properties and drillability of mine rock. Colziemy Engng, Jan. D. 28; Feb. p. 61; Mar. p. 121.

SHERGOLD, F.A. (1953) The percentage voids in compacted gravel as a measure of its angularity. Magazine of Conerete Res., V. 5(13): 3-10.

SIEVEP, R. (1962) Silica solubility $0^{\circ}-200^{\circ} \mathrm{C}$ and the diagenesis of siliceous sediments. JT. Geol., V. 70: 127-50.

SIPPEL, R.F. (1971) Quartz grain orientations - 1 (The photometric method). Jl. Sed. Pet., V. 41(1): $38-59$.

SMITH, J.V. (1974) "Feldspar minerals. Vol. 1. Crystal structure and physical properties". Springer-Verlag, New York: $627 \mathrm{pp}$.

SPARKS, B.W. (1960) "Geomorphology". Longmans: $371 \mathrm{pp}$.

SPEARS, D.A. (1976) The fissility of some carboniferous shales. Sed., V. 23(5): $721-5$.

SPEDEN, I.G. (1971) Geology of Papatowai Subdivision, south-east otago. N.z. Geol. Survey Buzz. n.s. 81: 166 pp.

(1976) Fossil localities in Torlesse rocks of the North Island, New Zealand. J2. Roy. Soc. N.z., V. 6(1): 73-91.

SPRY, A. (1968) "Metamorphic textures". Pergamon Press, New York: 350 pp.

STEVENS, G.R. (1974) "Rugged landscape". A.H. and A.W. Reed, Wellington: 286 pp.

(1976) Geology of the proposed Belmont regional hill park. Appendix 2 In Bagnall (Ed.) Survey of the proposed Belmont Regional Hill Park, part 1 , Recommendations on development and management, VUW Extension Pub. No. 14: 32-5.

STOCKER, P.T. (1972) Diffusion and diffuse cementation in lime and cement stabilised clayey soils. Aust. Road Res. Board, Special Report No. 8: 146 pp.

STOW, D.A.V. and LOVELL, J.P.B. (1979) Contourites: their recognition in modern and ancient sediments. Earth Sci. Rev., V. 14: 251-91.

SWENSON, E.G. and CHALY, V. (1956) Basis for classifying deleterious characteristics of concrete aggregate materials. Jl. Am. Concrete Instit. V.27(9): 937-1002.

Proc. V. 52, Titze No. 52-8. 
TANNER, C.B. and JACKSON, M.L. (1948) Nomoqraphs of sedimentation times for soil particles under gravity or centrifugal acceleration. Soir Sei. Soc. Amer. Froc. (1947), V. $12: 60-5$.

TATTERSFLL, G.H. (1976) "The workability of concrete". Cenent and Concrete Assn., Slovigh: $138 \mathrm{pp}$.

TAYLOR, J.M. (1950) Pore-space reduction in sandstones. Bull. Am. Ass. Pet. Geol., V. 34(4): 701-16.

TCHALENKO, J.S., BURNETT, A.D. and HUNG, J.J. (1971) The correspondence between optical and $\mathrm{X}$-ray measurements of particle orientation in clays. Clay Min., V. 9(1): 47-70.

TERZAGHI, R.D. (1965) Sources of error in joint surveys. Geotechnique, V. 15: $287-304$.

TEYCHENNE, D.C., FRANKIIN, R.E. and ERNTROY, H.C. (1976) Design of normal concrete mixes. Transport and Road Res. Lab. Dept. of Envirorment, London: 30 pp.

THOMSON, A. (1959) Pressure solution and porosity. In Ireland, H.A. (Ed.) Silica in sediments. Soc. Econ. Paleontologists and Mineralogists Special Pub. 7: 92-110.

TOBIN, D.G. and DONATH, F.A. (1971) Microscopic criteria for defining deformational modes in rock. Geol. Soc. Am. Bulz., V. 82: 1463-76.

TURNER, F.J. and WEISS, L.E. (1963) "Structural analysis of metamorphic tectonites". McGraw-Hill, San Francisco: 545 pp.

VAN DER PLAS, L. (1966) "The identification of detrital feldspars". Development in sedimentology 6; Elsevier Pub. Co., Amsterdam: 305 pp.

VUTUKURI, V.S., LAMA, R.D. and SALUJA, S.S. (1974) "Handbook on mechanical properties of rocks". Vol. 1. Trans. Tech. Pub.: $280 \mathrm{pp}$.

WALKER, R.G. (1967) Turbidite sedimentary structures and their relationship to proximal and distal depositional environments. Jl. Sed. Pet., V. 37(1): 25-43.

WARD, M. and GRANT, I.J. (1978) Planning for mineral resources in the Wellington region. Report 78.38. Undertaken for the Wellington Regional Planning Authority and Wellington Regional Water Board: $107 \mathrm{pp}$.

WATKINS, M.D. (1970) Terminology for describing the spacing of discontinuities of rock masses. Quat. Jl. Engng. Geor., V. 3(3): 193-5.

WATSON, J. (1911) "British and foreign building stones". Cambridge University Press: 483 pp.

WATTERS, W.A. (1969) Petrological examination of concrete aggregates. Proc. Nat. Conf. Concrete Aggregates, Hamilton, New Zealand: 48-54.

WEAST, R.C. (1975) "Handbook of chemistry and physics. A ready-reference book of chemical and physical data". 55th Ed., Chemical Rubber Co. Press, Ohio, U.S.A.

WEAVER, C.E. (1960) Possible uses of clay minerals in search for oil. Buzt. Am. Ass. Pet. Geol. V. 44(9): 1505-18. 
WEBBY, B.D. (1967) Tube fossils from the Triassic of south-west Wellington, New Zealand. Trans. Roy. Soc. N.Z., Geoz., V. 5(7): 181-91.

WELSH, W. (1967) The value of point-count model analysis of greywackes. Scot. Jl. Geol., V. $3(2): 318-28$.

WEST, T.R. and AUGHENBAUGH, N.B. (1964) The role of degradation in highway construction. 15th Annul Highway Geol. Symp., Rolla, Missoumi: 117-32.

WEYL, P.K. (1959) Pressure solution and the force of crystallisation - a phenomenological theory. Jt. Geophys. Res., V. 64: 2001-25.

WHITE, W.A. (1961) Colloidal phenomena in sedimentation of argillaceous rocks. Jl. Sed. Pet., V. 31: 560-70.

WILLIAMS, D.N. (1975) A bibliography of Wellington Geology, 1855-1970. N.2. Geol. Survey, Report No. $71: 54 \mathrm{pp}$.

WINKLER, E.M. (1973) "Stone: Properties, durability in man's environment". SpringerVerlag: $230 \mathrm{pp}$.

WOLF, K.H. (1971) Textural and compositional transitional stages between various lithic grain types (with a comment on "interpreting detrital modes on greywacke and arkose"). Jl. Sed. Pet., V. 41: 328-32.

WOOLF, D.O. (1966) Toughness, hardness, abrasion, strength and elastic properties. In Significance of tests and properties of concrete and concrete-making materials. ASTM STP 169-A: $462-75$.

YOUNG, J.F. (1974) An assessment of the influence of microstructure on time dependant deformations of hardened cement paste. 1st Australian Conf. on Engng. Materials, Sydney: $3-28$.

ZACHARIADIS, R.G.P. (1966) Near surface seismic velocities in the Wellington greywackes. Unpub. B.Sc. (Hons.) project, Geology Dept. Library, Victoria University of Wellington: $14 \mathrm{pp}$. 


\section{APPENDICES}

What one fool can do, another can. (Ancient Simian Proverb)

All Tables, Figures and Plates are numbered within each Appendix and bear the prefix ' $A$ ' to distinguish them from those in the thesis text. 
APPENDIX 1

Sample location sites

Index map for sample location maps of this Appendix. Numbers within the locality areas shown, correspond with those on the sample location maps. Map 7 is taken from Lands and Survey 1:15,840 Mosaic map series, all others are from the Lands and Survey $1: 10,000$ Wellington District map series. Working quarries are shown with a star symbol. Samples were taken along the traverse arrow shown, in chronological or other order shown.

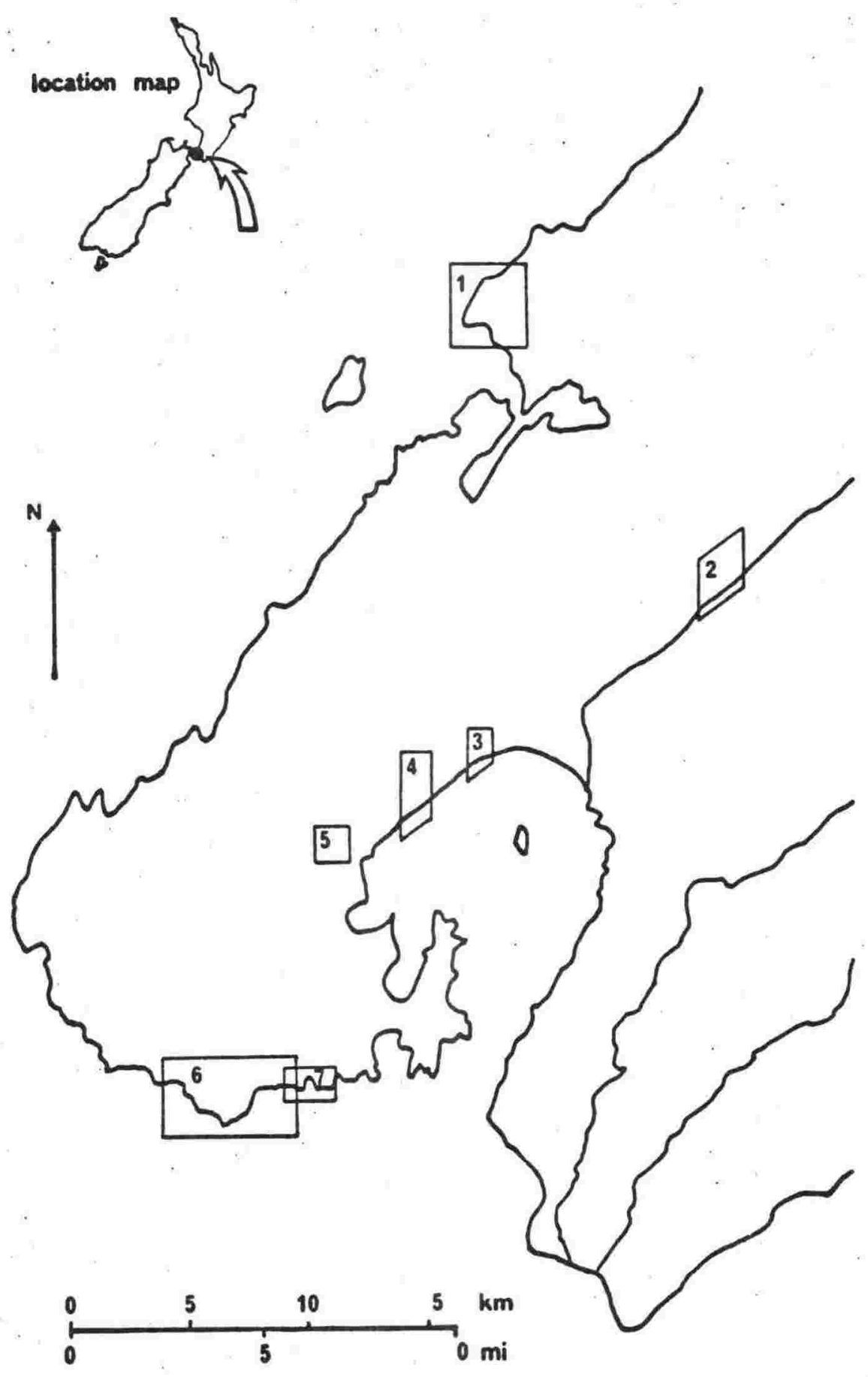




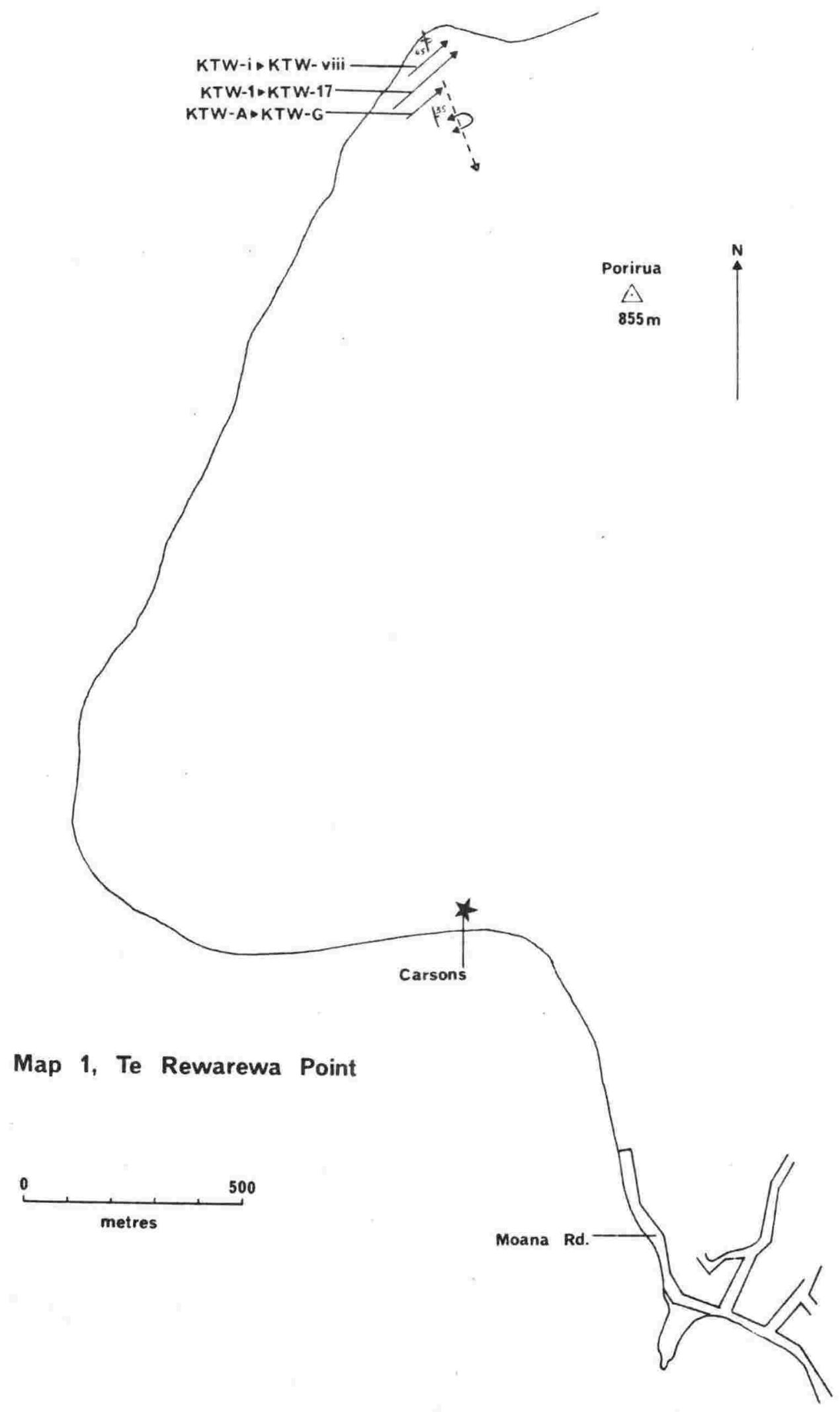




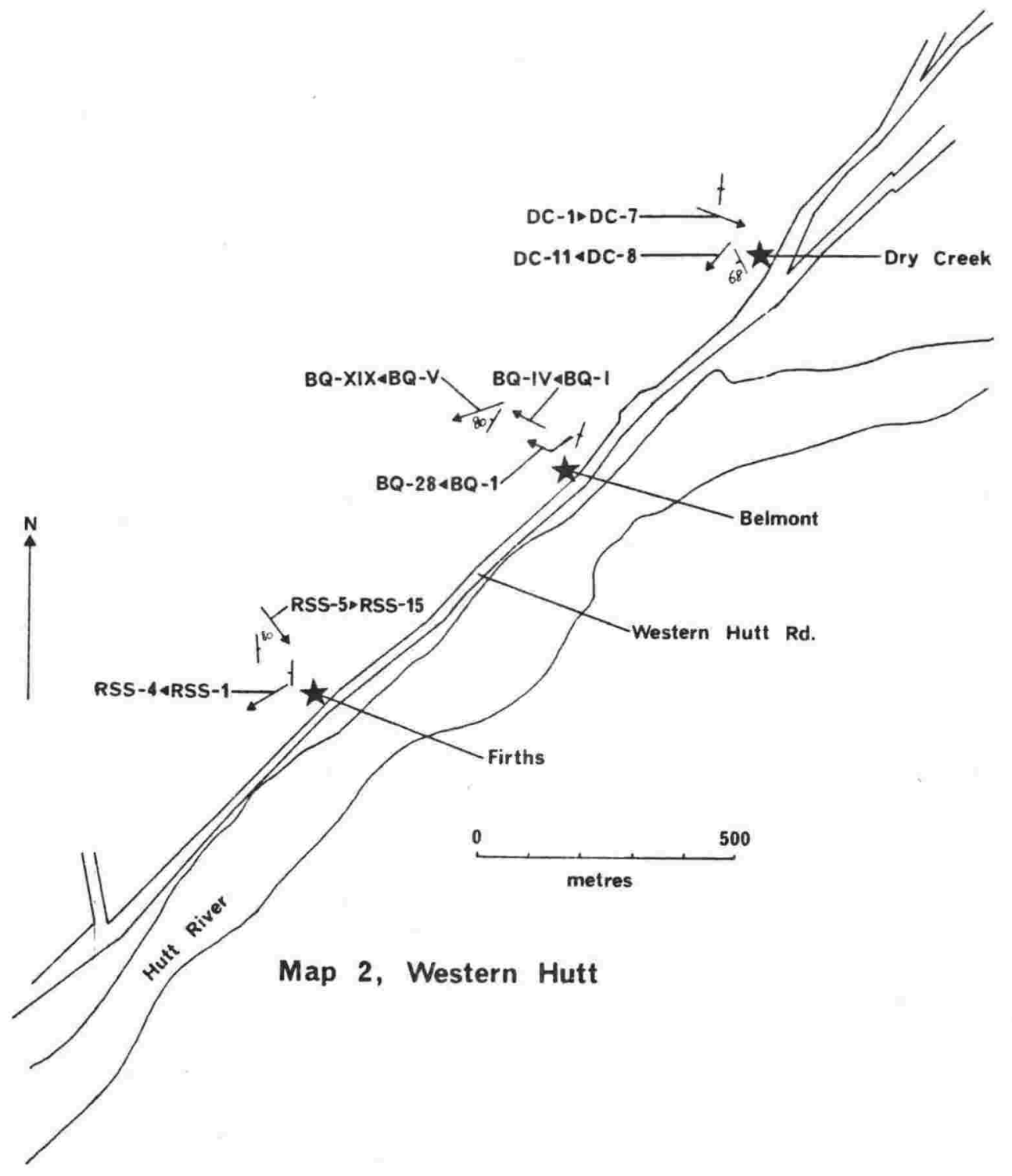




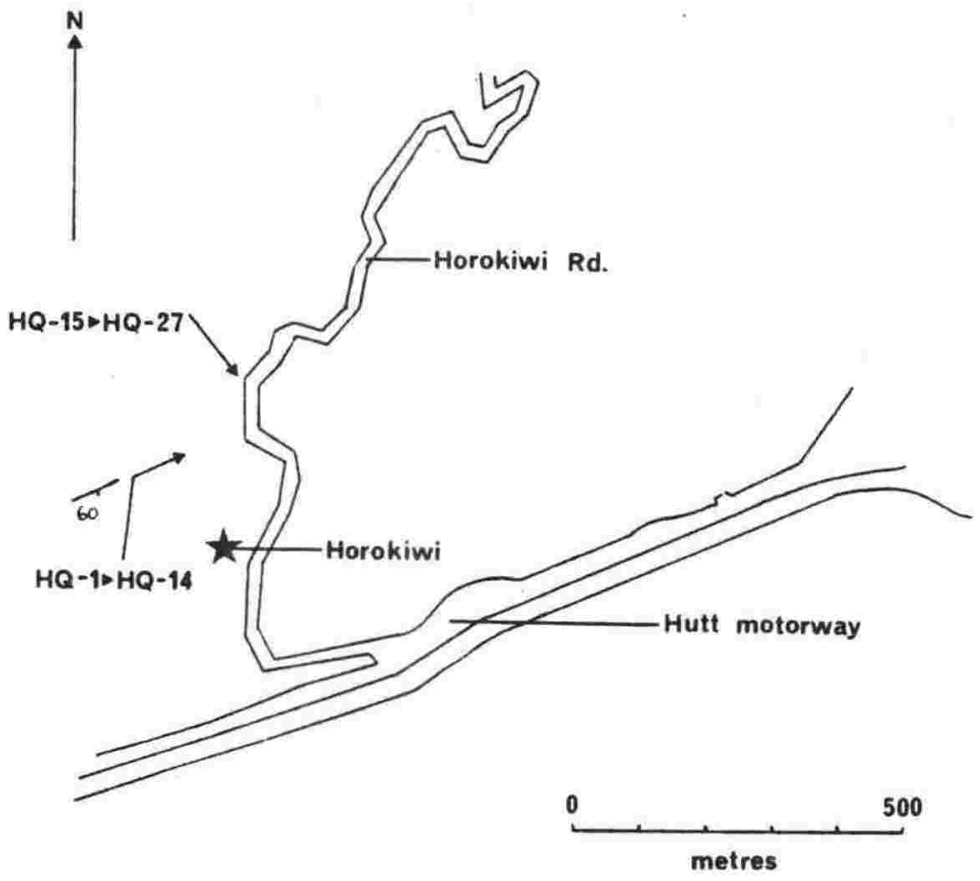

Map 3, Horokiwi 


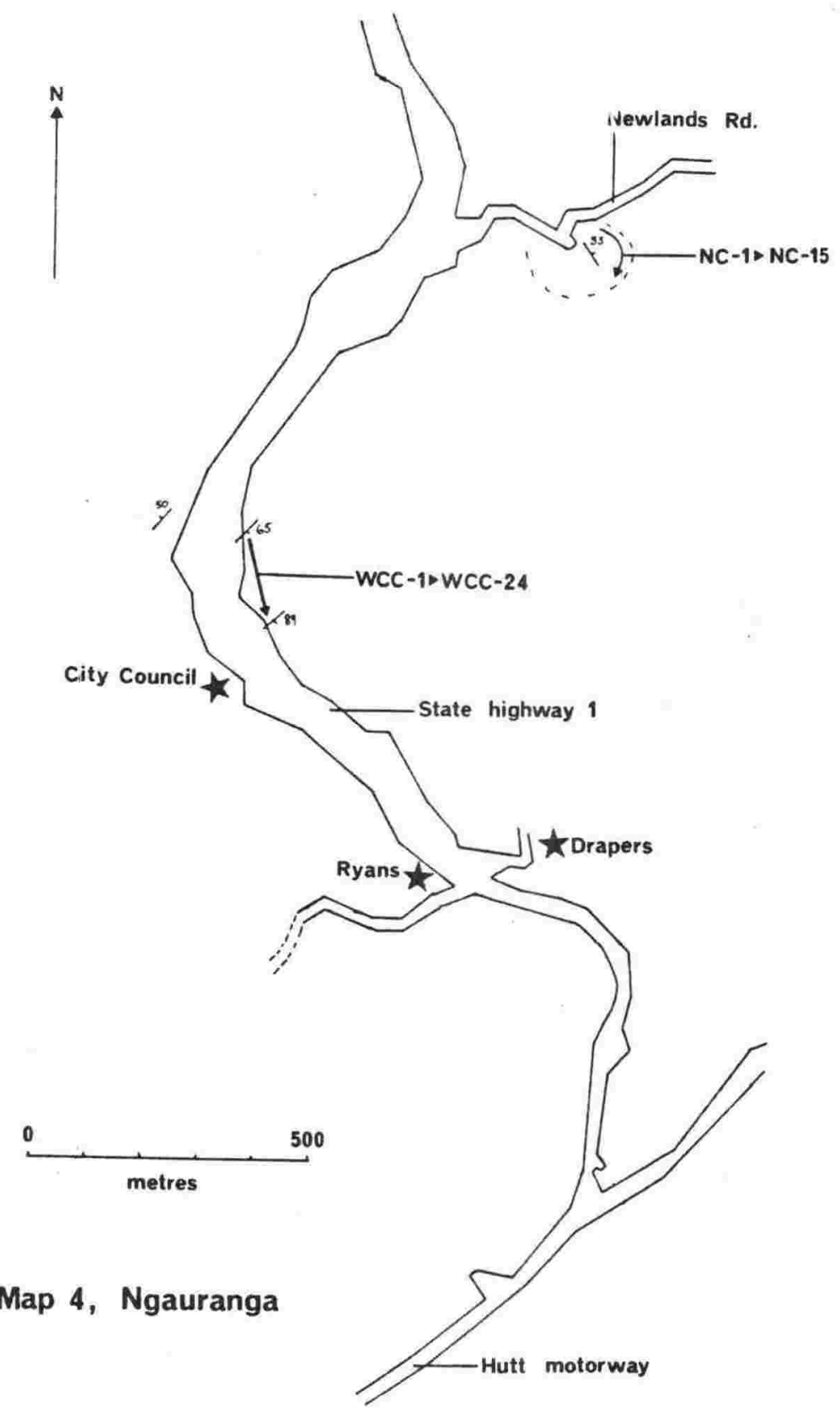



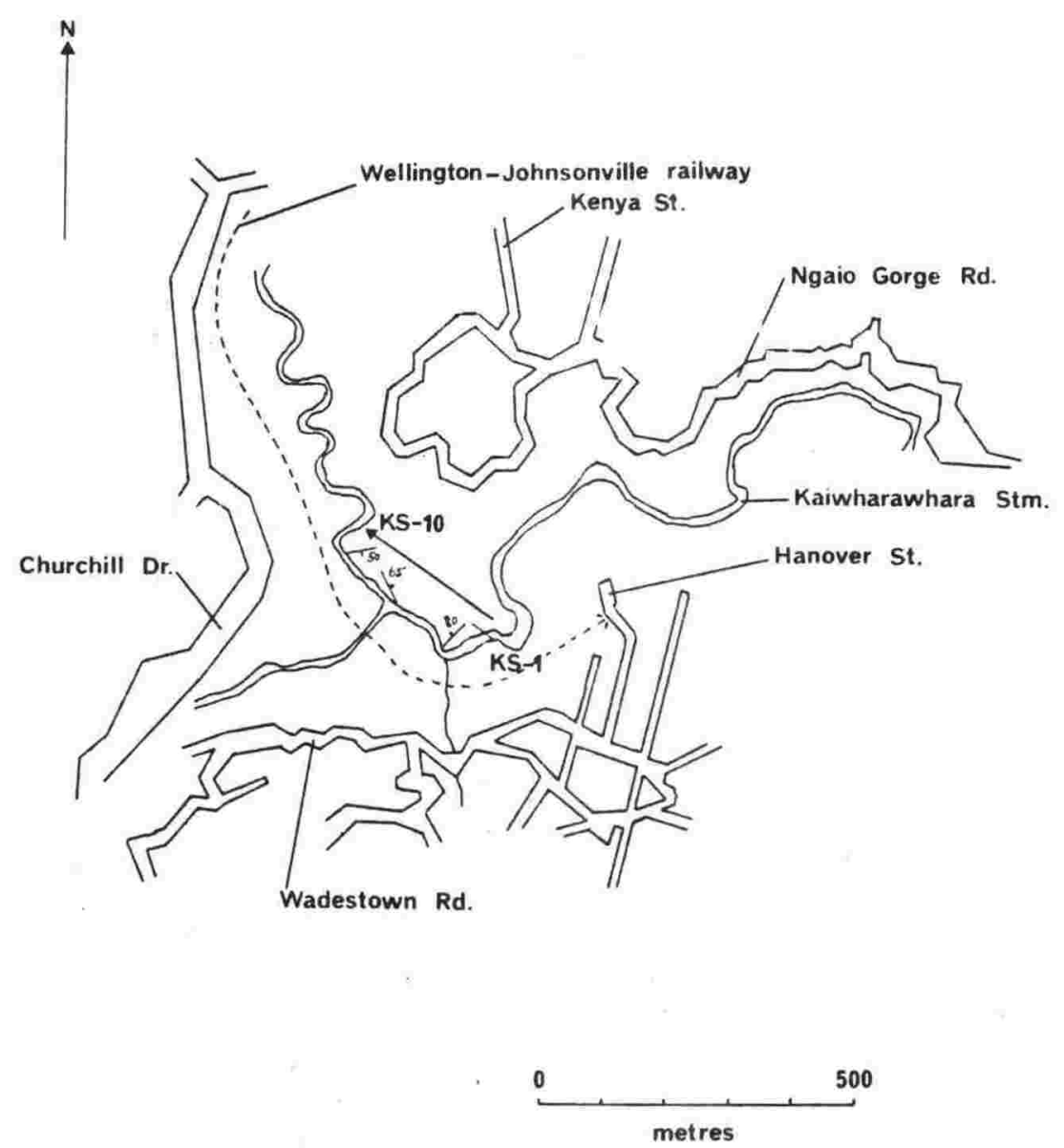

Map 5, Kaiwharawhara Stm.

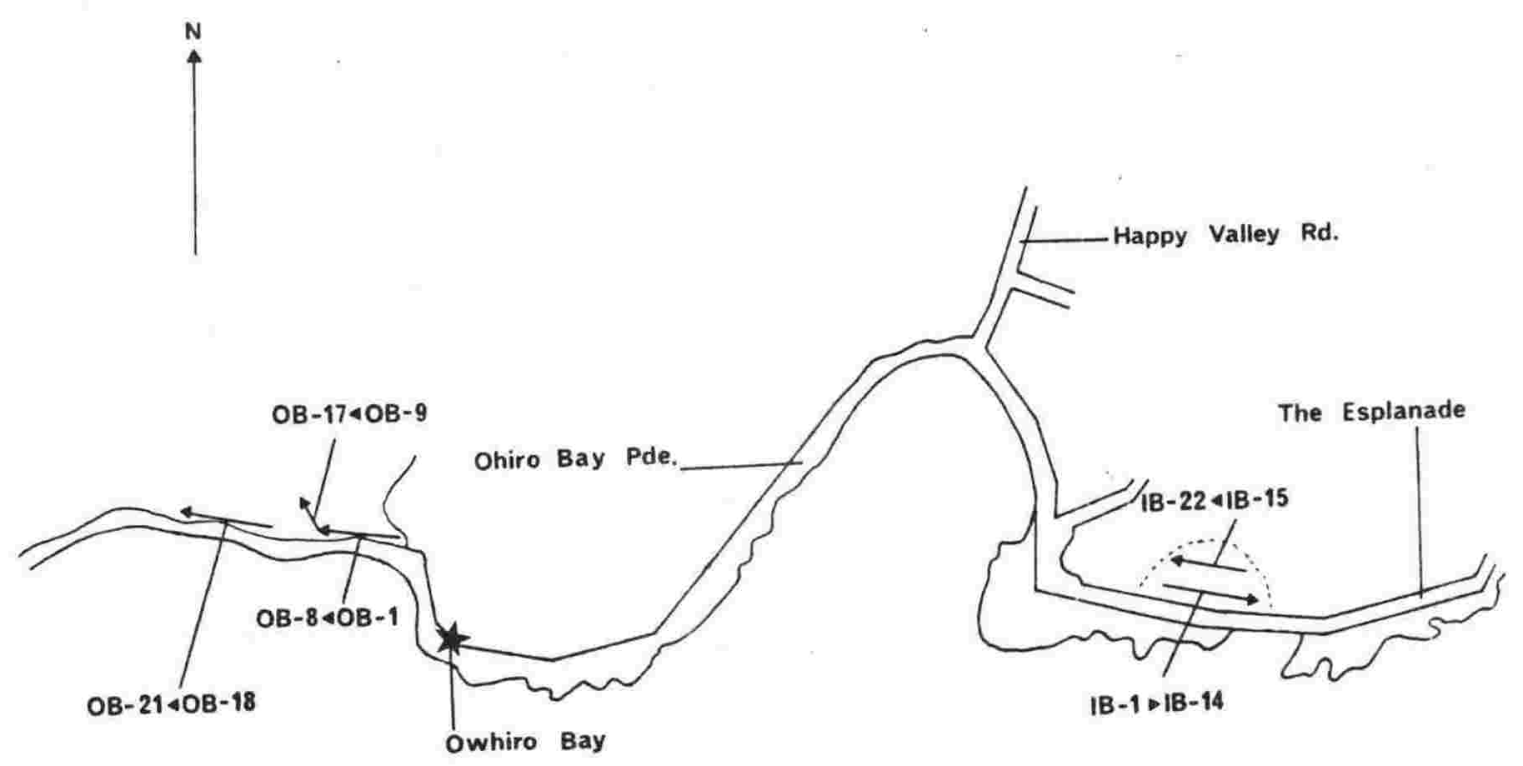

0

Map 6, Island Bay and Owhiro Bay 


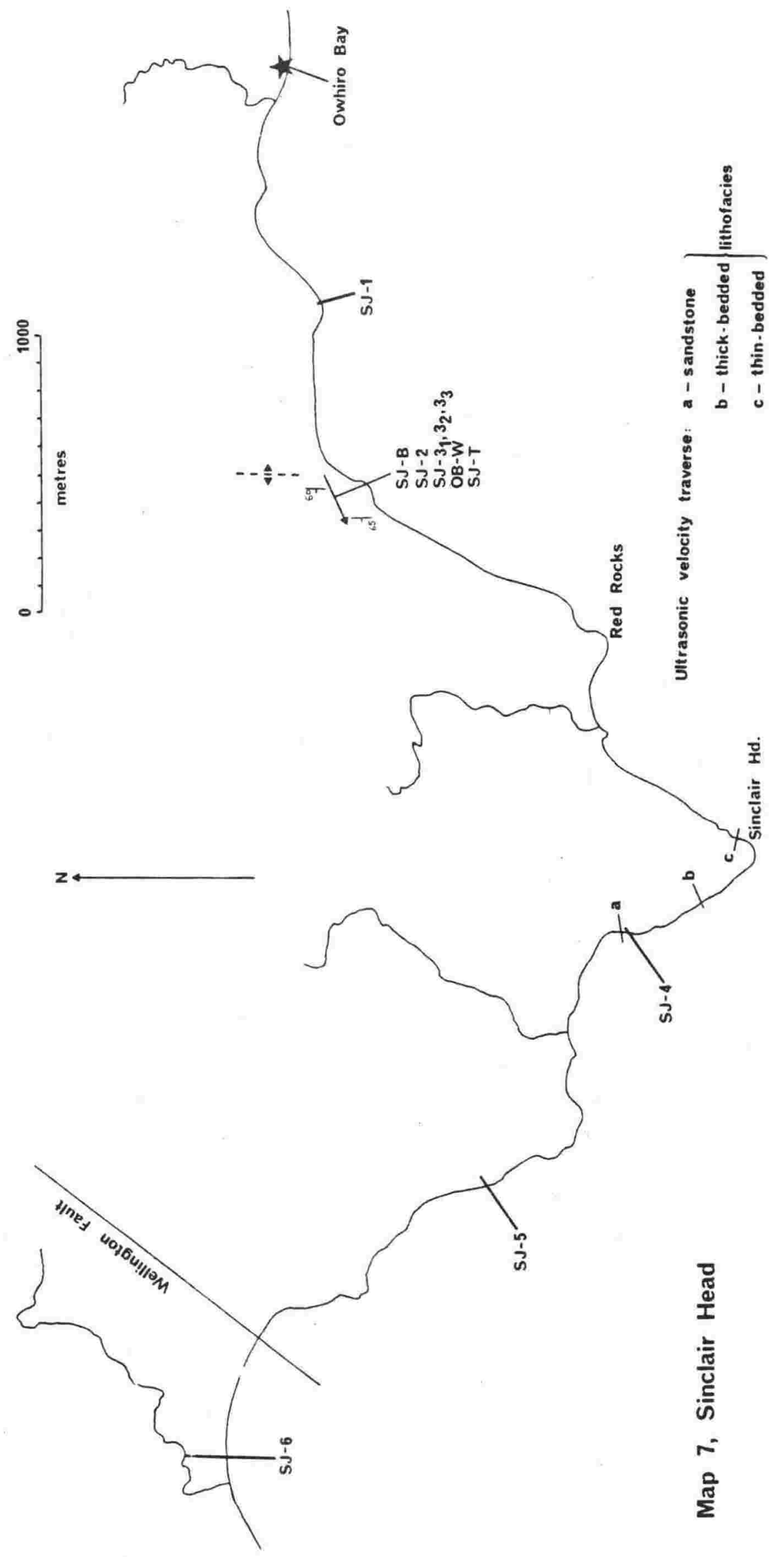


Staining of thin sections for identification of felsic minerals

Etching of thin sections to accomplish staining was carried out using hydrofluric acid fumes after the final grinding of the thin section. The most suitable etch was obtained by exposing thin sections to fumes for 90 seconds.

The method described by Bailey and Stevens (1960) was tried but as acid rhodizonate, a sodium salt, does not stain very sodic plagioclase, potassium chlorite was useã. When immersed in sodium cobaltinitrate, the plagioclase is stained yellow. All etched K-feldspar is also stained yellow in sodium cobaltinitrate. Thus all feldspar and potassium bearing minerals in the matrix were stained yellow, providing differentiation between feldspar and quartz but none between $\mathrm{K}$-feldspar and plagioclase.

A technique by Laniz et al. (1964) was also tried but the use of calcium chloride to stain highly sodic plagioclase proved unreliable so staining of $\mathrm{K}$-feldspar only was resorted to in most thin sections and then only when the rock was relatively "clean" as potassium bearing minerals had a masking effect.

Müller (1967) suggested a 5 percent barium chloride dip then sodium thiocyanate solution as a way of staining etched plagioclase with anorthite contents as low as 3 percent. This also proved unsatisfactory due primarily to authigenic albites.

If all feldspar is etched and stained, relatively accurate quartz to total feldspar ratios can be determined. From artificially prepared samples, Hayes and Klugman (1959) established relative errors of 3.2 percent for quartz, 5.3 percent for K-feldspar and 5.4 percent for plagioclase so by inference a total feldspar count should have a relative error of about 6 percent.

Although staining of plagioclase proved unsuccessful, etching gave it a whitish appearance providing a means by which unstained felsics could be differentiated. Etching is obvious under a microscope in plane polarised light and enhanced by the use of the substage iris. Hayes and Klugman (1959) had noted this effect and were using medium to fine sand sized grains ( 1 to $3 \mathrm{phi}, 0.5 \mathrm{~mm}$ to $0.125 \mathrm{~mm}$ ) with counts of 300 to 500 . Somewhat greater error may be expected in this study from reduced stained areas restricting grain counts to 200 , the use of a manual vernier stage instead of a mechanical click stage and the influence of potassium bearing matrix minerals. However, for rocks of mean grain size coarser than 3 phi $(0.125 \mathrm{~mm})$ maximum error will probably not exceed 8 percent. 


\section{APPENDIX 3}

Detailed petrography of greywacke samples

1. Quartz

(i) Cement

(ii) Healed fractures

2. K-feldspar

3. plagioclase feldspar

4. Rock fragments

4.1 Sedimentary rock fragments
(i) Very fine sandstones
(ii) Siltstones
(iii) Mudstones
(iv) Chert

4.2 Metamorphic and plutonic rock fragments
(i) Sericite schist
(ii) Quartz schist
(iii) Granitic fragments
(iv) Quartzite
(v) Gneissic fragments
(vi) Hornfels

4.3 Acid volcanic rock fragments

4.4 Basic volcanic rock fragments

(i) Chloritisation

(ii) Zeolitisation

(iii) Authigenic concentration of metallic opaque minerals

5. Muscovite

6. Biotite

7. Chlorite
(i) Chlorite after biotite
(ii) Detrital chlorite
(iii) Authigenic chlorite

8. Metamorphic accessories and cements

8.1 Zeolite

8.2 Prehnite

8.3 Calcite

8.4 Quartz

8.5 Epidote group minerals

8.6 Pumpellyite

8.7 Metallic opaques

8.8 Axinite

9. Detrital accessories 
The mean quartz content varies only slightly with lithofacies (Figure 2.3), the average for the greywackes studied being 29.7, 27.7 and 25.8 percent for the sandstone, thick-bedded and thin-bedded lithofacies respectively. No significant difference between these mean values is apparent ( $P$ is greater than 0.1 ).

The range of quartz content with lithofacies suggests a petrographic continuum. Quartz varies in its characteristics. Almost all quartz is monocrystalline, clear and strained. Some display boehm structure (Turner and weiss, 1963), e.g. SJ-6 and OB-2I, or induced twining (pseudotwins, DC-1) or an impression of laminations within the grains sometimes appearing wavy, an indication that these features have been induced in situ (DC-2). Strain may produce a $2 \mathrm{~V}$ of about $30^{\circ}$ to $50^{\circ}$ (HQ-17, HQ-25). Only competent rocks are able to withstand such strain and it is noteworthy that although strained quartz exists in the thinbedded lithofacies, pseudo-twinning is restricted to the more massive greywackes of the other lithofacies, usually near large faults, evidence which corroborates field interpretation well (section 3.3.1). Occasional grains of high sphericity (equant) occur in all grain sizes though small grains generally are more angular as they result predominantly from fracture of larger grains. The quartz population in greywackes of the sandstone lithofacies is angular to well rounded (KTW-17) with a few subrounded grains in the natural continuum. In larger grain sizes,i,e. those more often rounded, subequant grains attributed to breakage of equant rounded grains have a ragged outline. Extremes in grain shape (KTW-13) are more often associated with smaller grains. The thick-bedded lithofacies usually has a more poorly sorted population of angular to rounded quartz grains, the subrounded and rounded grains often showing "fresh" breakage - sometimes with long, broken, slivers adjacent to the host grain (HQ-17)

The average size of quartz varies with lithofacies from $0.2 \mathrm{~mm}$ in the sandstone lithofacies to $0.36 \mathrm{~mm}$ in the thick-bedded lithofacies and $0.073 \mathrm{~mm}$ in the thin-bedded lithofacies which also has a smaller maximum size $(0.36 \mathrm{~mm})$. A maximum size of $1.0 \mathrm{~mm}$ was obtained in the sandstone and thick-bedded lithofacies.

Quartz recrystallisation is apparent in greywackes of all Iithofacies in two forms:

(i) Cement: intimately packed adjacent quartz grains sometimes indicate overgrowths to be present ( $D C-1, D C-3)$. Some evidence in the form of sericite "entering" quartz may be misleading unless the quartz concerned is authigenic (HQ-25, HQ-16). Orientation of grain/grain boundary to the plane of the thin section is also important since where this is of low angle, a boundary contact is greatly exaggerated. With subtle undulose extinction in adjacent grains, optical continuity is sometimes difficult to confirm. Overgrowth evidence is seen most frequently in the thin-bedded lithofacies and is associated with veining where a quartz vein may include a detrital grain in its fabric.

(ii) Healed fractures: fractures in quartz are often oriented,e.g. parallel to extinction direction (HQ-17). Occasionally fractured grains retain their integrity by healing the fracture with quartz in optical continuity to produce a structure resembling an overgrowth $(K T W-14)$.

The differences between overgrowths and healed fractures may be observed by stopping down light and studying optical continuity over the overgrowth boundary; fractures show as a discontinuity over a distance of about $0.016 \mathrm{~mm}$ and the "dust" coating, common to overgrowths, may not be continuous. 
Although not common, included mineral grains (maximum size about $0.06 \mathrm{~mm}$ ), are found in quartz from greywackes of all lithofacies. The larger grains had included sericite, vacuoles, rutile (KTW-15), tourmaline (penetration twins, HQ-25), opaques e.g. magnetite, apatite, epidote group minerals and zircon. Epidote, tourmaline and rutile inclusions persist with decreased quartz grain size.

Most quartz grains show signs of erosion and/or suturing. Suturing occur especially in the more strongly oriented, laminated and finer greywackes (BQ-iv) and in close proximity to detrital grains (especially felsic grains). Erosion is seen in quartz grains which are highly strained or partly shattered and almost always adjacent to zones of sericite, muscovite (KTW-16), calcite, zeolite, pumpellyite or prehnite, which often form blebs or embayments in the grain,e.g. prehnite "enters" quartz (KTW-14) on occasion. A normal surface texture of erosion, or etch, gives up to $0,007 \mathrm{~mm}$ penetration in larger quartz grains, smaller grains (thin-bedded lithofacies) eroding to some $0.01 \mathrm{~mm}$ or $0.015 \mathrm{~mm}$.

\section{K-feldspar}

Identification of potassium feldspar depended strongly on staining for accuracy, and the inability to stain the finest greywackes successfully may have contributed to the trend of lowered $\mathrm{K}$-feldspar percentages through lithofacies; this is true also of quartz (Figure 2.4B).

The average potassium feldspar contents of greywackes is $4.1,3.7$ and 1.8 percent for the sandstone, thick and thin-bedded lithofacies respectively. The $\mathrm{K}$-feldspar mode did not exceed 9 percent for any greywacke studied and does not seem related to plagioclase contents.

$\mathrm{K}$-feldspar is most prolific in the thick-bedded lithofacies, grains average $0.45 \mathrm{~mm}$ in this lithofacies compared to $0.25 \mathrm{~mm}$ in the sandstone lithofacies and about $0.086 \mathrm{~mm}$ in the thinbedded lithofacies. The rock fragment population follows a similar trend.

The K-feldspar consists of microperthitic string and interpenetrant perthites and mesoperthites (composition nomenclature of Van der Plas, 1966; textural nomenclature after Spry, 1968), which may be strained (HQ-17) or strained microantiperthite (sodium phase may be compound, rod or banded). Chessboard texture (Smith, 1974) in one mesoperthite grain had patches averaging $0.045 \mathrm{~mm}(\mathrm{HQ}-25)$. Perthite is more common than microcline.

K-feldspars; microcline, orthoclase, perthite ( $\mathrm{QQ}-\mathrm{IXA}$ ), antiperthite and myrmekitic intergrowths with quartz often displayed good cleavage, carlsbad twinning (OB-21, KTw-13) and combined carlsbad - pericline twinning.

The varieties of $\mathrm{K}$-feldspar are reduced in finer grained greywackes, but are generally equant or elongate and angular or subrounded. Compared with plagioclase feldspars, they are more equant and tend to be of larger size, there being a transition between K-feldspar grains and metamorphic and plutonic rock fragments. Individual grains of K-feldspar may be $0.7 \mathrm{~mm}$ in size.

Inclusions are common, being tourmaline $(0.028 \mathrm{~mm}$ long), apatite (residing in fractures, approximately $0.34 \mathrm{~mm}$ long), and opaques - sometimes in bands (HQ-25). The minerals are pseudocubic, rectangular or hexagonal and predominantly pyrite.

$\mathrm{K} \sim$ feldspar grains, generally are less rounded than quartz, due to retrogressive rounding induced by calcite erosion (BQ-xviii), prehnite (DC-1), sericite or epidote group minerals. 
These minerals also occur within grains in blebs of 0.1 to $0.15 \mathrm{~mm}$. In greywackes of the sandstone lithofacies, approximately 60 percent of the K-feldspar population show some alteration (e.g. KTW-13).

K-feldspar grains are the second largest grains occurring in greywackes, subordinate to rock fragments and phyllosilicates in the coarsest and finest grained greywackes respectively.

\section{Plagioclase feldspar}

Greywackes of all lithofacies contain approximately subequal amounts of plagioclase, the least variation being apparent in the thick-bedded lithofacies (Figure 2.4A). When compared with the feldspar ratio figures (Figure 2.4C) this indicates either a more rapid breakdown of K-feldspar from the source sediment, a more prolific plagioclase provenance raw material, together with greater variation in grain size, or an effect of diagenesis to equilibrate plagioclase content by introducing authigenic plagioclase. There is an apparent trend for plagioclase to decrease in concentration from the sandstone to the thinbedded lithofacies.

Authigenic plagioclase, generally clear, unzoned and untwinned, was also counted in this mode. It was often exceedingly difficult to differentiate between this and detrital plagioclase, and some cements (zeolite and albite) possess undulose extinction making mineral and arain size identification difficult. The presence of authigenic plagioclase is important when engineering properties are considered.

Most detrital plagioclase, and especially that greater than $0.05 \mathrm{~mm}$ in size, was albite twinned (composition was obtained by the Michel-Lévy method) and ranged from $\mathrm{An}_{3-18}$. Grain sizes averaged 0.23 and $0.27 \mathrm{~mm}$ for the sandstone and thick-bedded lithofacies and $0.074 \mathrm{~mm}$ in the thin-bedded lithofacies. Grains are generally equant, elongate but rarely prismatic, angular to subrounded (rounded plagioclase is seen in HQ-23). Although having a less shattered appearance than quartz, deformation twins often kinked, bent (through $20^{\circ}$ ) and offset, and also combined carlsbad-albite, albite and pericline (KTW-16) twin lamellae are common especially in regions where grains are crushed. Plagioclase tends to fracture along a plane without the brecciation effects seen in quartz. Some grains show signs of healing. Undulose extinction, providing extinction over a $10^{\circ}$ angle of stage rotation, altered $2 \mathrm{~V}$ by up to about $40^{\circ}$ and indentation of grains by adjacent grains of quartz and feldspar, indicate this population to be less able to withstand tectonic stress. In spite of this, the mean size of the plagioclase population is exceeded by the quartz population only in greywackes of the thick-bedded lithofacies.

Generally, larger grains are less altered and more angular in the thin-bedded lithofacies. In the sandstone and thick-bedded lithofacies, however, the freshest looking grains are less than 20 percent of the population and are generally smaller than the mean size.

Alteration, erosion and replacement are well established, most alteration probably occurring whilst sediment was in the provenance region. The majority of grains in all lithofacies show some sericitisation, most grains showing at least 10 percent alteration, sometimes with complete destruction of the grain, by prehnite, sericite, calcite, zeolite and to lesser degree, by epidote minerals. Alteration takes place preferentially at the ends of elongate grains, along cleavage planes, along twin planes and about the grain periphery (the interior remaining unaffected). The material observed within and invading plagioclase achieves large grain sizes: calcite blebs 0.01 to $0.032 \mathrm{~mm}$; sericite may average $0.04 \mathrm{~mm}$; epidote group minerals $0.064 \mathrm{~mm}$, sometimes forming clumps $0.2 \mathrm{~mm}$ across. 
However, the average size of these alteration minerals is $0.006 \mathrm{~mm}$. This is significant when the minimum recognizable grain size of plagioclase is about $0.008 \mathrm{~mm}$.

Many grains are partly zeolited, up to 25 percent of the smaller grain being affected by anhedral crystallite clusters of sutured zeolite 0.005 to $0.019 \mathrm{~mm}$ in size. Zeolite invades plagioclase from the matrix and veins, often completely surrounding grains of highly undulose plagioclase in an undulose cement containing fine $(0.007 \mathrm{~mm})$ sericite which is oriented within the cement in two directions (HQ-17). Erosion of plagioclase may take place in some regions of a single slide with extensive authigenic deposition of plagioclase elsewhere.

Heavy sericitisation creates identification problems since some rock fragments, e.g. sericite schist, may resemble fully altered plagioclase, especially where sericite flakes are oriented. In these circumstances plagioclase may still be identified by observing twin lamellae (in grains larger than $0.05 \mathrm{~mm}$ ) under high power using the sensitive tint plate ( $\lambda$ plate). In untwinned varieties the problem remains unless graphic intergrowths with quartz are in evidence or refractive index can be checked. For zoned grains (SJ-6) the sensitive tint plate was again useful. Indistinct grain margins due to erosion were rationalised by medium to high magnification and stopped down light.

Non-authigenic inclusions in plagioclase are few but, when apparent, constituted zones $0.016 \mathrm{~mm}$ wide and parallel with prismatic grain outlines. The inclusions are about $0.003 \mathrm{~mm}$ long (HQ-19) and include quartz, zircon, chlorite, sericite and muscovite. The plagioclase concerned is generally untwinned. Zircon, in particular, was observed in well formed $0.02 \mathrm{~mm}$ rhombs (HQ-17).

Authigenic albite is difficult to identify, ultra-thin sections giving better indication of important suturing and random growth habits.

4. Rock fraqments

4.1 Sedimentary rock fragments

The thick-bedded lithofacies, in which the intraformational conglomerates (Grant-Taylor, 1976) or "chipwackes" are usually found, possesses the highest concentrations of sedimentary rock fragments (Figure 2.5A). The trend otherwise is for the concentrations of sedimentary rock fragments to diminish from the sandstone to the thin-bedded lithofacies.

Sedimentary rock fragments may be classified by lithology, based on textural parameters:

(i) Very fine sandstones: These have a mean grain size of $0.09 \mathrm{~mm}$ and are moderately sorted, often subrounded and rounded felsic detrital fragments "floating" in, and being replaced by, a fine sericite matrix. Quartz is strained and often polycrystalline. Fragments are moulded into interstices in the host rock fabric by up to 0.1 mm (pseudomatrix; Dickinson, 1970), the rock fragment matrix also eroding the host rock felsic grains. Small interstitial light brown-green chlorite flakes $(0.035 \mathrm{~mm})$ are also present. This rock fragment type is limited to coarser greywackes of the thick-bedded lithofacies.

(ii) Siltstones: Rock fragments with a mean grain size of between 16 and $40 \mathrm{~mm}$ and generally more mud rich than the very fine sandstones, they contain smaller equant, angular to rounded detrital quartz, and more rounded and slightly altering feldspar, floating in matrix. They constitute the most common sedimentary rock fragments and are ubiquitous in all greywackes except those of the thin-bedded lithofacies - only the finest textured varieties are found in that lithofacies. Some varieties have a carbonaceous matrix (DC-1) in fine, sinuous, ramifying bands up to $0.09 \mathrm{~mm}$, providing distinct anisotropy. Most are at 
least 30 to 70 percent matrix, composed of chlorite with lesser quantities of sericite, grey ?epidote (and other heavy minerals) and finely disseminated opaques (carbonaceous material). The latter, which in plane light imparts a grey-brown or brown-grey colour, assists readily in the formation of pseudomatrix (KTW-15). Phyllosilicates, subequal in size with felsic grains, are optically less clear than host rock phyllosilicates, oriented, and about 0.02 to $0.06 \mathrm{~mm}$ in size.

(iii) Mudstones: This variety of rock fragment is rarely found in other than the thin-ledded lithofacies greywackes. The fragments always form pseudomatrix and are invariably altered except where found in the thick-bedded and sandstone lithofacies (HQ-25). Fragments averaged about $0.19 \mathrm{~mm}$ and were the largest detrital grains in some thin-bedded lithofacies greywackes (RSS-i). They were almost totally of matrix sized material (exceeding 80 percent) and occurred only rarely in elongated, subrounded or rounded forms. Their mean grain size varied between 0.004 and $0.019 \mathrm{~mm}$ providing a well oriented structure mainly of brown chlorite material, supplimented by sericite, few felsics and heavy minerals. Bands of darker chloritic material indicated distortion of the fragments about more resistant host rock grains.

(iv) Chert: Found in all greywackes, this represents a small fraction of the total sedimentary rock fragment mode. Chert fragments are elongate, angular to rounded, averaging $0.32 \mathrm{~mm}$ in size but occurring in grains to $2 \mathrm{~mm}$. Larger grains tend to be subrounded to rounded. The fragments are of anhedral, sutured, equant quartz crystallites averaging $0.045 \mathrm{~mm}$.

\subsection{Metamorphic and plutonic rock fragments}

Rock fragments under this heading are physically strong felsic rocks. Pseudomatrix formation from, and replacement of, any lithologies in this mode was rarely observed. Variation in greywackes containing this mode is marked only by the thin-bedded lithofacies (Figure 2.58) which averages only 25 percent of the content of other lithofacies. With a slightly increased average, the sandstone lithofacies experiences a much wider range of modal values.

Rock types occurring in this mode include:

(i) Sericite schist: Found in greywacke of all lithofacies, it consists predominantly of quartz, muscovite and sericite. Small (averaging 0.016 to $0.09 \mathrm{~mm}$ ) strongly oriented, elongate, strained crystallites of quartz were intersutured with easily defined flakes of sericite/muscovite in strands averaging 0.013 to $0.08 \mathrm{~mm}$, but locally $0.5 \mathrm{~mm} 10 \mathrm{ng}$. The strongly oriented strands often possessed yellow, red or brown second order interference colours and formed foliated zones within the fragment locally, with brown or green chlorite which reached $0.09 \mathrm{~mm}$, and opaques $(0.015 \mathrm{~mm})$. The fragments averaged $0.28 \mathrm{~mm}$ in size, were subrounded and rounded, elongate - their long axes tending to he parallel to bedding (length to width ratios about 5.8 ). They occasionally formed pseudomatrix, penetrating the host rock fabric to $0.2 \mathrm{~mm}$.

Some fragments contained carbonaceous matter (?graphite, KTw-16), epidote group minerals and feldspar. Coarser varieties contained chlorite in flakes to $0.64 \mathrm{~mm}$, somewhat less quartz (about 5 percent) in grains averaging $0.16 \mathrm{~mm}$, and pyrite in rounded $0.005 \mathrm{~mm}$ grains. Sericite appears to be derived in part from degrading feldspar.

Sericite schist fragments are the most important variety of rock fragments in this mode for greywackes of the thin-bedded variety lithofacies, the only others being quartz schist and some granitic fragments. 
Differentiation between sericite "patches" from degrading plagioclase and sericite schist fragments proved difficult but the degree of distortion of the grain was helpful. Plagioclase, degraded sufficiently to be confusing, would probably not have endured the fluvial processes necessary for sediment accumulation if deposition had taken place after degradation. Therefore distorted "patches" of sericite were included as sericite schist fragments if they fulfilled the form and other characteristics indicative of that lithology.

(ii) Quartz schist: These elongate, subrounded and rounded fragments averaged $0.58 \mathrm{~mm}$ comprising quartz, feldspar, muscovite and chlorite grains averaging between $0.035 \mathrm{~mm}$ and $0.08 \mathrm{~mm}$ in intimate, sutured, strongly oriented association. Grains tended to pseudomatrix in the thin-bedded lithofacies where fragments were smaller, $0.26 \mathrm{~mm}$. Prehnite was sometimes a replacement mineral.

(iii) Granitic fragments: Generally coarse grained, these are seen to advantage only in the thick-bedded lithofacies. They are large $(0.85 \mathrm{~mm})$, subrounded, sutured, subhedral intergrowths of string antiperthite with a mineralogy of twinned and untwinned microcline and orthoclase, perthitic and myrmekitic intergrowths of sodic plagioclase $\left(\mathrm{An}_{10-14}\right)$ and quartz. Zoned feldspars, orthoclase, apatite, quartz, perthite, well crystallised muscovite and lesser amounts of green biotite with chlorite intergrowths were also present.

These are sometimes the largest rock fragments seen in thin section with elongate fragments rarely smaller than $0.25 \mathrm{~mm}(0.1 \mathrm{~mm}$ in thin-bedded lithofacies, DC-10) with individual component mineral grains equalling the fragment size. Most grains were not altered by more than 5 percent.

(iv) Quartzite: Angular to rounded fragments, averaging $0.5 \mathrm{~mm}$, these are mainly highly intersutured quartz, numerous non-opaque heavy interstitial minerals of $0.008 \mathrm{~mm}$, minor plagioclase and rare mica. Fragments sometimes possess a pronounced fabric orientation of crystallites. Crystallites average $0.065 \mathrm{~mm}$.

(v) Gneissic fragments: Subrounded or rounded, elongate, foliated, lepidoblastic, sometimes slightly deformed, these fragments comprise sutured quartz, highly pleochroic biotite and muscovite, averaging $0.09,0.25$ and 0.15 to $0.4 \mathrm{~mm}$ respectively. The included phyllosilicates were not as strained as the phyllosilicates of the host greywacke. The fragments were large (mean size $0.78 \mathrm{~mm}$ ), rare and sometimes eroded (KTW-13).

(vi) Hornfels: This occurred in one thin section (KTW-13) was subangular, fragment measuring $0.7 \mathrm{~mm}$, consisting mainly of biotite, muscovite and sutured quartz with minor plagioclase.

\subsection{Acid volcanic rock fragments}

Whilst difficulties exist in differentiating rock fragments bearing small grains of quartz (Boggs, 1968; Wolf, 1971), 10 greywackes of the thick-bedded lithofacies were observed to have a mode of acidic volcanic rock fragments consistently. These fragments are chemically unstable, mechanically weak and consequently are found consistently only in the coarsest greywackes with quantity diminishing rapidly from sandstone to thin-bedded lithofacies (Figure $2.5 \mathrm{C}$ ).

Fragments are mainly devitrifying, glassy, vesicular shards appearing as a brown-grey or dark grey-brown, drusy amorphous mass displaying flow texture in the glass and included microlites/phenocrysts. However a relatively fresh glassy example was observed from $\mathrm{BC}-\mathrm{xviii.}$ 
Mechanical weakness enables the fragments to assume a pseudomatrix (DC-2) role, especially at their margins, where host rock grains have penetrated fragments to $0.048 \mathrm{~mm}$ (HQ-25). Some, lacking microlites, are exclusively pseudomatrix; others, fresh fragments, may be entirely glass with remnant flow banding, the chipped outlines clearly showing conchoidal fracture (HQ-17). In these grains the glass may display slight anisotropy (very slight optically length fast orientation) due mainly to strain and/or very fine (minus $0.002 \mathrm{~mm}$ ) inclusions. The latter, with opaques (minus $0.002 \mathrm{~mm}$ ), impart optical drusiness.

Average fragment size is $0.45 \mathrm{~mm}$, varying with lithofacies from $0.032 \mathrm{~mm}$ ( $B Q-i$ ) in the thinbedded lithofacies and between $0.7 \mathrm{~mm}$ to $1.0 \mathrm{~mm}$ in the sandstone and thick-bedded lithofacies. Lithofacies association also tends to influence distortion, freshness and grain shape, e.g. fragments occurring in a greywacke with a zeolite or calcite cement dominance are fresher and less distorted than fragments in mainly prehnite cemented greywackes. Grain shapes are typically equant or elongate and subangular to rounded.

Mineralogy of the fragments exclusive of glass are well sorted microlite/phenocryst populations of rounded, granular, euhedral quartz with more common twinned or untwinned, euhedral laths of sodic plagioclase $\left(\mathbb{A}_{12}\right)$ which may be altering to sericite. Microlites average $0.1 \mathrm{~mm}$, with a length to width ratio about 3 . Accessories include iron oxides $(0.001$ to $0.012 \mathrm{~mm})$, the larger grains being euhedral. These opaques influence fragment colour and clarity, imparting a drusy or dusty appearance and increasing colour value as do the rounded, $0.004 \mathrm{~mm}$, heavy minerals.

Microlites or phenocrysts in the otherwise glassy groundmass "stand out"as relatively clear, colourless, elongate patches which assume an apparent pilotaxitic to trachytic texture. These textures aided identification of acid volcanic rock fragments by their patchy light grey or brown-grey appearance and darkness under crossed nicols. Although not as altered as some basic volcanic rock fragments, acid volcanic rock fragments of smaller sizes showed some alteration to chlorite, zeolite (HQ-17), or sericite and promoted vague fragment outlines making size identification impossible.

\subsection{Basic volcanic rock fragments}

This mode bears close relationship to metamorphic and plutonic rock fragments in that modal averages are relatively distributed between lithofacies, even though average modes and mode ranges from the sandstone and thick-bedded lithofacies are higher than those of volcanic rock fragments. There is no significant difference in mean or range for the thinbedded lithofacies, between the two mode classes (Figure 2.5D).

Fragments in this mode are chemically unstable but mechanically stronger than acid volcanic rock fragments, so alteration supercedes induration for optical identification.

Textures are mainly hyalopilitic but pilotaxitic and trachytic textures occur which, assuming a mobile basic lava, indicates the largest phenocrysts are not represented, fragments merely being groundmass residuals. Texture is well displayed by euhedral and subhedral microlites of plagioclase $\left(\mathrm{An}_{22}\right)$ measuring to a maximum of $0.23 \mathrm{~mm}$ (average $0.06 \mathrm{~mm}$ ) and appearing as almost acicular laths, sometimes ragged and eroded at the ends. Accessory groundmass minerals ( 5 percent) include mainly euhedral magnetite and ilmenite 0.016 to $0.02 \mathrm{~mm}$ in size (DC-10). Ilmenite, however, (light grey-brown colour in reflected light) may constitute 30 percent of the opaque accessories in skeletal crystals (HQ-25).

Glass in the groundmass is devitrified and most fragments have been altered somewhat to chlorite, yellow drusy elongate prehnite (DC-1), zeolite, calcite, metallic opaque minerals, albite (KIW-15), silica (giving a cherty appearance, HQ-27), sericite (in 0.006 mm flakes to 10 percent replacement), and epidote group minerals (0.006 mm). 
Less than 20 percent of the fragrents are completely altered.

The quantity of pseudomatrix formed from basic volcanic rock fragments is probably greater than that estimated since alteration (especially to zeolite) tends to round and "fill" the form of the fragments, replacing as necessary, adjacent host rock grains to do so. Deformation is apparent (HQ-25), however, where adjacent host rock grains have been "pushed" into the fabric by $0.06 \mathrm{~mm}$. Generally, the glassy grains are the most readily distored.

Fragment shape is elongate, subrounded and rounded, averaging $0.42 \mathrm{~mm}$ in size $(1.3 \mathrm{~mm}$ maximum), with smaller sizes grouped in the thin-bedded lithofacies (0.14 mm average).

The main alteration processes

(i) Chloritisation: Alteration begins in the groundmass of the fragment, generally as colourless, brown or yellow-green tinged euhedral grains and blebs which impart, by refractive index difference, a fibrous, felty appearance to the fragment. chlorite grain size appears to be governed by the size of fragment being replaced, i.e. $0.026 \mathrm{~mm}$ in a fragment measuring $0.19 \mathrm{~mm}$. Anomolous interference colours (Berlin blue) may accompany chlorite replacement. Phenocrysts generally remain unchanged.

(ii) Zeolitisation: Zeolite (laumontite) replaces as fibrous clumps, growing inwards from a locus - usually the rock fragment margin. Individual optically length slow fibrous crystals extend to $0.17 \mathrm{~mm}$ in clumps $0.22 \mathrm{~mm}$ wide. The "clumped" habit distinguishes completely zeolitised volcanic rock fragments (generally those less than $0.19 \mathrm{~mm}$ ) from authigenic zeolite cement, especially as most fragments show some zeolitisation e.g. up to 30 percent of the fragments in HQ-25 are totally zeolitised, and RSS-i has almost all the population zeolitised. In rock fragments the "clumps" formation is more complete and is observed as several small spherulites, in optical continuity to $0.026 \mathrm{~mm}$, displaying an "iron cross" extinction. This is quite distinctive and, together with contrasts in refractive index in the rock fragment, aids identification. Authigenic colourless chlorite is often associated with zeolitisation.

(iii) Authigenic concentration of metallic opaque minerals: Round, symetrical blebs of euhedral opaciue matter which often accompany early stages of zeolite alteration, may occupy the "interior" of basic volcanic rock fragments replacing between 5 and 50 percent of the fracment and leaving the plagioclase laths as residuals. Average size of the blebs is 0.007 to $0.001 \mathrm{~mm}$ (BQ-IXA). Under reflected light they have a bright yellow, speckled appearance with no bireflectance, so the material is considered to be pyrite. Calcite is not present.

\section{Muscovite}

From Figure 2.6, the relative importance of muscovite as a detrital phyllosilicate to greywackes of the thin-bedded lithofacies is apparent, but the coarsest greywackes bear no more than 2 percent.

Muscovite is always strained and kinked with wavy or incomplete extinction. In places, it may be physically ragged and threaded along the long sides of adjacent grains, in well developed (with included opaques) flakes of high birefringence, sometimes pinched or swollen or slightly anastomosing. Gaps in anastomosing flakes are filled with zeolite (HQ-25). 
Grains average about $0.14 \mathrm{~mm}$ in length often with large length to width ratios, e.g. 4 to 9.7, the higher value for the thin-bedded lithofacies greywackes. Maximum grain size exceeds $1.5 \mathrm{~mm}$. Muscovite is not as physically disrupted as some detrital phyllosilicates (biotite and chlorite) but may form an epimatrix locally.

Muscovite appears bimodal and grains smaller than about $0.072 \mathrm{~mm}$ may belong to a secondary population ranging to matrix size material, predominantly found adjacent to metamorphic and plutonic rock fragments, altering plagioclase or micaseous sedimentary rock fragments. A bimodal population was apparent also in the thin-bedded lithofacies where muscovite grains of reduced size, average $0.085 \mathrm{~mm}$, were in association with rock fragments and plagioclase.

Muscovite, including authigenic white mica, which exceeded matrix size $(0.02 \mathrm{~mm})$ was counted with the detrital population.

\section{Biotite}

Greywackes of the sandstone lithofacies and, to a lesser degree, the thick-bedded lithofacies contained biotite but it is scarce in the thin-bedded lithofacies greywackes. All biotite has pronounced pleochroism, very light yellow-brown, brown and dark red-brown with second order red, green and blue interference colours. Wavy extinction and kink bands are frequently observed.

Biotite is more disrupted than muscovite and may be squashed into unusual shapes to form epimatrix (KTW-16). Most biotite, especially smaller grains, shows some alteration to chlorite but its cleavage planes are more distinct. Biotite occurs in flakes to $0.9 \mathrm{~mm}$, averaging about $0.2 \mathrm{~mm}$. Biotite chemistry is given in Appendix 8 .

\section{Chlorite}

Chlorite content increases uniformly from the sandstone to the thin-bedded lithofacies (Figure 2.7 ) but its range is constant, except for a slight reduction in maxima and minima in the thick-bedded greywackes.

Both authigenic and detrital chlorite were included in this mode for practical reasons. Chlorite quantity does not effect the geological classification of the rock but it may well influence its engineering properties, and optical analyses may be correlated with other methods of assessing quantitative mineralogy, only if genesis is ignored.

Crystallite size of interstitial chlorite was determined by measurement of optical continuity limits, which accentuates smaller sizes in strained and wavy populations.

Chlorite was the most deformed of all phyllosilicate minerals and three types were present. (Chlorite chemistry is given and discussed in Appendix 8).

(i) Chlorite after biotite: Colour - light green, light brown, occasionally colourless. Some, mainly green, shows Berlin blue anomolous interference colour (KS-10). Pleochroic scheme - green variety: colourless or light yellow green, light yellow-brown, light brown. Brown variety: light brown-yellow, brown, red-brown. Optical properties - undulose extinction, $2 \mathrm{~V}$ about $20^{\circ}-60^{\circ}$ positive (sometimes negative) with length slow orientation. 
This is the most abundant ubiquitous variety of chlorite, easily confused with biotite but the latter has more distinct cleavage and stronger colouration.

Chlorite is flaky, often distorted and kinked (sometimes through $100^{\circ}$ ). Heavy minerals (epidote, euhedral magnetite and pyrite to $0.016 \mathrm{~mm}$ ) are associated with it, as are authigenic pyrite growths in cleavage traces in bigger grains $(1.0 \mathrm{~mm})$ and inclusions of zircon with pleochroic halos (DC-1).

Altered biotite was often in close association with seaimentary and sericite schist rock fragments $(D C-2)$. Biotite alters to chlorite at its periphery and along cleavage planes as seen in $\mathrm{BQ}-21$ which has chlorite as its largest mineral grains. Average grain size was $0.275 \mathrm{~mm}$ with a length to width ratio between 3 and 8 .

In the thin-bedded lithofacies, grain size was noticeably smaller, averaging $0.136 \mathrm{~mm}$ (maximum $0.56 \mathrm{~mm}$ ) with a length to width ratio of 7 and there were inclusions of up to $0.008 \mathrm{~mm}$, mainly pyrite and magnetite. Green biotite was rare in the lithofacies.

(ii) Detrital chlorite: Colour - as in (i) but brown variety interference colour, light yellow-brown, sometimes blotchy. Pleochroic scheme - green variety; colourless or light yellow-green, light green, green: brown variety; as (i) but lighter. Optical properties - as in (i) but harder to obtain from brown variety which also has a lower refractive index.

This is the least abundant variety of chlorite and is differentiated from authigenic chlorite by grain size and form. It is larger and more colourful than either chlorite after biotite or authigenic chlorite but was not usually as well formed being more crushed, strained and kinked. Cleavage planes were not well defined.

Grain sizes (maximum $0.5 \mathrm{~mm}$, average $0.2 \mathrm{~mm}$ green $0.24 \mathrm{~mm}$ brown) were smaller than in chlorite pseudomorphs after biotite and measurement is difficult because of indistinct outline and length to width ratios of 1 or 2 .

Detrital chlorite may appear in local concentration (BQ-IXA), often in association with smaller muscovite grains, and may contain elongate or equant pyrite in fine $(0.005$ to $0.021 \mathrm{~mm}$ ) layers along cleavage planes and between grains (DC-1).

Authigenic chlorite may grow from detrital chlorite grains.

Similar in character in all lithofacies, detrital chlorite mean grain size $(0.08 \mathrm{~mm})$ is smaller in the thin-bedded greywackes.

(iii) Authigenic chlorite: In all lithofacies, this chlorite variety is established in matrix size crystallites to grains in optical continuity over $0.048 \mathrm{~mm}$. The mergence of sizes is imperceptable, matrix material often being impossible to resolve into individual crystallites. The largest grains of authigenic chlorite may be associated with detrital chlorite grains and adding to them as a colourless to light green-yellow, equant growth with undulose extinction. Interference colours for such grains are light yellow, light green-brown or blue.

Optic properties include undulose or straight extinction and low $2 \mathrm{~V}$. Larger grain sizes are more easily defined and generally replace rock fragments. With decreasing size, authigenic chlorite merges with sedimentary rock fragment pseudomatrix as dark brown, poorly developed crystallites approximately $0.002 \mathrm{~mm}$ in size. In some rocks (HQ-17) authigenic chlorite may form interstitial fillings, $0.09 \mathrm{~mm}$ in size, $10.18 \mathrm{~mm}$ maximum, 
DC-3) of type (b) matrix of Dickinson (1970), where it exists often as oriented fibrous clusters of crystallites $0.02 \mathrm{~mm}$ long. In the same form it may be an intergrowth between flakes of non-metallic opaque material.

\section{Metamorphic accessories and cements}

From Figure 2.8, the occurrence of authigenic minerals show marked increase from the sandstone to the thin-bedded lithofacies.

Some authigenic minerals (quartz, albite, chlorite, pyrite), for reasons already discussed (section 2.6), were not included in this mode class since they were better counted in other mode classes for reasons of practicality, rock classification or engineering end use. Also, mainly adjacent to or part of veins (which were not included in optical modal analyses), they are relatively minor components compared with those detailed below, all of which may also be vein minerals.

\subsection{Zeolite:}

Laumontite and its anhydrous form leonhardite, are found commonly in greywackes of each lithofacies. Its concentration depends on rock mean grain size and field location. The radiating fibrous crystallites forming interstitial and replacement clumps, and their orientation, have already been mentioned (this Appendix 4.4(ii)). These clumps may extend interstitially 0.2 to $0.4 \mathrm{~mm}$ in crystalites, typically 0.03 to $0.06 \mathrm{~mm}$ long but ranging up to $0.3 \mathrm{~mm}$ long and $0.1 \mathrm{~mm}$ in diameter. Calcite is often associated at the base and sides of the clumps, generally in larger euhedral crystals which form after zeolite. The replacement of basic volcanic rock fragments in radial or quadrant crystal groups has been discussed (this Appendix 4.4(ii)).

Optical properties of laumontite (best observed in HQ-17) show it to be optically negative and length slow, with a $2 \mathrm{~V}$ of about $20^{\circ}$ and undulose extinction. It is colourless, homogenous and untwinned with interference colours of low first order, and low refractive index.

Adjacent to veins $(O B-21)$ zeolite achieves larger grain sizes $(0.48 \mathrm{~mm})$. Other associations are characteristic, e.g. with sericitising plagioclase, again in spherulite form, and as an extensive cement (HQ-17) it isolates grains, forming sutured boundaries with them, replacing plagioclase and quartz (HQ-25).

zeolite veins do not have sharply defined edges. They are well crystallised, with $1^{\circ}$ or $2^{\circ}$ extinction angles (interstitial material displays undulose extinction) indicating that the crystallites are hydrated (laumontite) as opposed to material exposed in quarry faces on joint planes which is leonhardite. Blebs of calcite as a late phase also occur in the veins.

The thin-bedded lithofacies has little zeolite cement which occurs mainly as a replacement mineral in basic volcanic rock fragments.

zeolite may modify rock colour induced by biotite, chlorite, altered feldspars and matrix (e.g. HQ-17), the white colour of the mineral lowering the rock colour value. 
Prehnite exists in a variety of forms:

(i) A yellow-grey fine drusy material, interstitially (DC-1) eroding plagioclase and basic volcanic rock fragments, which is ubiquitous in some greywackes (KTW-15) as a cement. In this form, prehnite may form a fine rim or discontinuous margin, 0.004 mm wide, about detrital untwinned felspar and quartz (DC-3) and rock fragments (DC-2). This cement, which may be intensified in areas adjacent to veining, is best seen in ultra-thin sections.

(ii) A well formed, non-uniformly distributed cement. In this form, prehnite occupies irregular patches, often as a fibrous, colourless mineral assemblage, with individual crystals varying from 0.016 to $0.7 \mathrm{~mm}(\mathrm{OB}-21)$ and averaging $0.24 \mathrm{~mm}$. Interference colours are distinct; yellow-grey, yellow and yellow-red. Prehnite replaces surrounding grains of cuartz plagioclase and rock fragments. Preferentially, it is associated with plagioclase with sericitising twin planes $(D C-6)$ and with basic volcanic rock fragments replaced by calcite $(B Q-21)$. Often replacement is observed as euhedral, well crystallised, twinned aggregates of prehnite in, and adjacent to, the grain being replaced.

(iii) Occurrance as a mineral in veins, which sometimes exceed $1.7 \mathrm{~mm}$ in width, displaying well formed crystals in optical continuity over $0.64 \mathrm{~mm}$. Often, these veins (KTw-15) host subangular detrital grains which "float" as individual grains of chlorite, quartz or opaques averaging $0.22 \mathrm{~mm}$ in size and often very etched. Generally, vein margins are not well developed and vein prehnite may coalesce locally with interstitial prehnite cement - this is particularly true of smaller veins. Larger veins usually digress little from a main path, but there is some erosion of adjacent sericitised feldspars and isolated quartz grains, indicative of local crushing which may lead to bifurcation of the vein. In such regions, crushing may rotate some minerals and sericite mixes with prehnite; limonite staining bordering the vein shows how such crushing facilitates water ingress. Epidote group minerals are often associated with prehnite veins (KTW-14). In greywackes of the thin-bedded lithofacies, prehnite occurs mainly in elongate patches $(0.128 \mathrm{~mm})$, rarely interstitially and then poorly crystallised.

\subsection{Calcite}

In some rocks, calcite is the most obvious and most abundant cement/replacement mineral (BQ-xviii), completely enveloping some acid and basic volcanic rock fragments and feldspar (especially along twin and cleavage planes), replacing zeolite (HQ-16) and actively eroding quartz. It is responsible in some cases for qualifying rock colouration (BQ-xviii). Calcite occurs in two forms:

(i) A discrete mineral, often in association with zeolite, prehnite, sericite and quartz. Veins are generally small and discontinuous, i.e. extending continuously only $0.6 \mathrm{~mm}$ in preformed fractures, which may also contain sericite and quartz. The veins may be up to $0.16 \mathrm{~mm}$ wide (HQ-23) with included minerals, other than calcite, of matrix size (BQ-IXA). Calcite often occurs in veins, as a late phase in the centre portion of veins of quartz, prehnite and/or zeolite.

(ii) Interstitial cement in patches or blebs from 0.01 to $0.3 \mathrm{~mm}$ (HQ-17, $1.5 \mathrm{~mm}$ ), averaging $0.08 \mathrm{~mm}$. In this form, calcite is often twinned, associated with zeolite, and replaces rock fragments. Extinction is generally undulose, and rhombohedral crystal outlines are clearly seen where cleavage is developed (HQ-25). The irregular edges of interstitial calcite patches are a more pronounced brown colour and blebs may be restricted to 
particular areas of the slide. Although less important than zeolite for replacement considerations, calcite replaces grains measuring $0.29 \mathrm{~mm}$. Calcite occurs more frequently than zeolite in intersitial habit, though individual zeolite patches are larger.

Calcite also replaces chlorite, sometimes forming a late phase infilling within authigenic chlorite. Calcite cement eliminates much matrix material in association with severe erosion of detrital grains. This is especially noticeable in the thin-bedded lithofacies; in $\mathrm{BQ}-\mathrm{i}$ all but the largest grains of chlorite in the matrix were replaced. Detrital grains "float" in calcite cement.

Etching of the surface of grains being eroded or replaced by calcite extends to $0.015 \mathrm{~mm}$. This is most obvious in the thin-bedded lithofacies, where the restriction of calcite to specific localities, is an indication of its ability to replace finer grained material within the rock. Areas with abundant calcite cement appear "well sorted" (BQ-iv).

\subsection{Quartz}

This mineral occurs, generally, in small $(0.2 \mathrm{~mm})$ interstitial patches and veins (DC-1, DC-2). Interstitial cementing by quartz (in patches to $0.2 \mathrm{~mm}$ ) is mostly in areas adjacent to veining $(O B-21)$ and occurs as a clear assemblage of sutured, strained, subhedral, $0.04 \mathrm{~mm}$ grains, almost always attending a detrital quartz grain and sutured to it. Sutures have an amplitude of $0.16 \mathrm{~mm}$.

The recrystallisation of quartz, especially (and plagioclase), is enhanced by recementation after comminution (RSS-i). Recrystallised grains are then difficult to distinguish from detrital grains. Authigenic quartz is more abundant in regions free of lutum, is associated with veins of various mineralogies, and has a larger size range than calcite.

Authigenic quartz is more obvious in greywackes of the thin-bedded lithofacies, the largest grains often associated with quartz veins where recrystallisation has taken place (DC-8).

\subsection{Epidote group minerals}

These minerals are well formed and are associated with altering grains or may occur in clumps of $0.3 \mathrm{~mm}$, made up of elongate or subequant, 0.015 to $0.026 \mathrm{~mm}$ grains associated with calcite and white mica and often with an orientation, possibly resulting from plagioclase or volcanic rock fragment alteration. They often occur adjacent to or within quartz or quartz-calcite veins, appearing as fractured grains.

Grains of this group may have been more common than was apparent, as matrix size material of prehnite, sericite and epidote have similar interference colours. They are most easily seen in ultra-thin sections with medium magnification and plane polarised light.

\subsection{Pumpellyite}

The mineral appears as equant, anhedral, blue-green or green coloured grains (averaging 0.005 to $0.008 \mathrm{~mm})$, occurring interstitally or adjacent to veins. Optic properties include undulose or incomplete extinction, length slow orientation and a biaxial positive $\left(2 \mathrm{~V}\right.$ about $\left.50^{\circ}\right)$ figure. The pleochroic scheme is: light green-yellow, light green, green. The mineral is rare and sometimes formed a "salt and pepper" aggregate (HQ-25) of very small $(0.005 \mathrm{~mm})$ crystals in parallel orientation. In one such clump measuring $0.11 \mathrm{~mm}$, crystals were $0.005 \mathrm{~mm}$ long, fibrous, distorted and showed undulose extinction. 
Pumpellyite is more intense, though generally lighter in colour, than green chlorite, is less pleochroic and under high power is seen to be authigenic. It was distinguishable, with difficulty, under plane polarised light with low magnification. Adjacent to veins of prehnite, pumpellyite may occur in larger grain sizes with long, indistinct boundaries and extinction angles of $24^{\circ}$, occasionally containing euhedral, square and hexagonal pyrite crystals $0.006 \mathrm{~mm}$ in diameter (DC-3).

\subsection{Metalic opaques}

These are principally pyrite, which may occur as thin $(0.01 \mathrm{~mm})$ flakes on joint faces and bedding planes in finer greywackes and argillites, and may grow to several millimeters. In thin section, the outline is irregular, drusy and eroded. Single grains may be euhedral, square or hexagonal shaped to $0.012 \mathrm{~mm}$. In reflected light, pyrite provides a speckled bright yellow colour and is isotropic. Pyrite (and opaque material generally) increases with increasing fineness of greywackes. It has affinities to carbonaceous material, basic volcanic rock fragments and chlorite.

\subsection{Axinite}

A single occurrance of ?axinate has been reported from Wellington greywackes by Bird (in prep.). ?Axinite may also occur in veins in RSS-ii(2).

From vein intersections, it appears that diagenetic/metamorphic paragenesis continued in the order of quartz - zeolite - prehnite - calcite. Veins are often polyminerallic, mineral associations being as follows: prehnite - calcite, zeolite - calcite, quartz - zeolite, quartz - zeolite (some prehnite), quartz - calcite (some zeolite), quartz - prehnite calcite, prehnite - quartz - calcite, albite - quartz - prehnite - zeolite - calcite, quartz - epidote, quartz - calcite - epidote, quartz - sericite.

9. Detrital accessories

The abundance of detrital accessories was directly related to lithofacies (Figure 2.9), the thin-bedded lithofacies greywackes having most - a mean of 3.5 percent. Ten accessories were identified.

(i) Epidote: Probably the most common accessory mineral, it occurred interstitially as elongate, subangular to subrounded grains of moderate relief, high $2 \mathrm{~V}$, optically negative and length fast. It usually displays incomplete, undulose or straight extinction, uneven fracture, and one well developed cleavage with a pleochroic scheme: colourless, yellow, yellow-green. It is ubiquitous in grains averaging $0.19 \mathrm{~mm}$ in the thick-bedded, 0.14 and $0.71 \mathrm{~mm}$ in the sandstone and the thin-bedded lithofacies. With mean size reduction, there was a change of dominance from epidote to zircon with increasing angularity of epidote grains. A similar trend was noted for other detrital accessories (Table A3.1).

(ii) Zircon: This occurs as colourless, or brownish, slightly birefringent, equant or elongate, cracked grains of high relief and wavy extinction which may be angular to rounded in form. Generally, the larger ( $0.46 \mathrm{~mm}$ ) grains are more angular, euhedral and twinned and show two cleavages. Optically, the grains are uniaxial positive, length slow and have parallel extinction. An euhedral square grain of zircon in biotite (HQ-25) displayed a pleochroic halo. zircon is the most common detrital accessory in fine greywackes. 
(iii) Sphene: This appears in grains of high sphericity, high interference colour, and high degrees of rounding (subangular to well rounded) which may be shattered, parallel twinned $(\mathrm{BQ}-\mathrm{V})$ and possess imcomplete extinction. It is optically positive with high $2 \mathrm{~V}$ (about $40^{\circ}$ ). Larger grains may be euhedral or subhedral, generally broken or chipped. In finer greywackes its mean size is reduced and the degree of rounding increases (DC-10).

(iv) Apatite: This is present in clear, colourless, angular to rounded, subequant grains up to $0.25 \mathrm{~mm}$ in size (KTW-16) with high relief. Larger grains are angular, smaller grains rounded. It was observed as euhedral angular crystals (0.001 to $0.005 \mathrm{~mm})$ in metamorphic and plutonic rock fragments, also as inclusions $(0.032 \mathrm{~mm})$ in plagioclase/ quartz myrmekitic intergrowths. Apatite has first order white interference colours and is near isotropic. Grains often show plucking due to thin section preparation.

(v) Tourmaline: Rare but distinctive, it occurs as euhedral broken and worn elongate grains with vivid second order interference colours. Optically the mineral is length slow, has strain induced extinction angles up to about $7^{\circ}$ and is colourless or grey. It may occur in grains down to $0.009 \mathrm{~mm}$. Optical properties showed that grains were sodic and the mineral variety elbaite was present. Tourmaline is often included in quartz and feldspar grains, elsewhere it is interstitial.

(vi) Hornblende: This has sporadic occurrence but is present in typical form in DC-3 and KS-2, green with good cleavage in broken, ragged, elongate prisms. Smaller grains can be confused with chlorite. Chemical data are given in Appendix 8 .

(vii) Allanite: This has an even brown colouration, slightly pleochroic (light brown, green-brown, brown). It occurs in subrounded grains displaying large $2 \mathrm{~V}$ and is optically negative.

(viii) Augite: Augite is very rare; it is green, subrounded, subequant with one cleavage displayed. It is biaxial positive with a pleochroic scheme; green-yellow, brown-green, green.

(ix) Metallic opaques: of this category, pyrite is by far the most important. Pyrite occurred as a detrital grain (though most pyrite present is authigenic) up to $0.24 \mathrm{~mm}$ in size and ranging to matrix size. Skeletal crystals were present in HQ-17, $0.049 \mathrm{~mm}$ in size.

Magnetite is also found interstitially, in conglomerates (KTW-16) of grains showing cubic forms or as rounded and elongate fragments averaging $0.06 \mathrm{~mm}$ in size.

Chromite also occurs as discrete subhedral crystal grains, often translucent and brown at the edge of grains (HQ-17).

Detrital metallic opaques in greywacke of the thin-bedded lithofacies are all of matrix size.

(x) Carbonaceous matter: Already mentioned (section 2.4), these are the leaf impressions manifest as carbon films impressed in greywacke and argillite. The material is ubiquitous but occurs in haphazard fashion in greywackes, being intensly concentrated in some (KTW-G, IB-13A), (Grant-Taylor, 1976). 
Carbonaceous matter occurs usually as discontinuous "strings" and patches, about $0.024 \mathrm{~mm}$ wide, often in association with authigenic pyrite and chlorite. Although strings of organic matter are irregularly oriented parallel to bedding, sublinear organic blebs, 0.01 to $0.02 \mathrm{~mm}$, amalgamate to extend $1.5 \mathrm{~mm}$, anastomosing through the rock parallel to bedding. Strings have "dusty", or finely (about $0.001 \mathrm{~mm}$ ) crenulate outlines, (probably induced by scatter of carbon during thin section preparation, and a flaky or platy form. Generally, the more elongate they are, the more wholly carbonaceous. In reflected light the material is black with light grey streaks (HQ-25). Pressure shadow effects are apparent where chlorite has grown between carbonaceous flakes separated perpendicular to bedding (RSS-i). Carbonaceous strings attain a reduced maximum length of $0.48 \mathrm{~mm}$ in the thin-bedded lithofacies.

Table A3.1 : Mean grain size of detrital accessory mineral grains by lithofacies.

\begin{tabular}{lccc}
\hline Detrital accessory mineral & Sandstone & Thick-bedded & Thin-bedded \\
\hline Epidote & $0.14 \mathrm{~mm}$ & $0.19 \mathrm{~mm}$ & $0.071 \mathrm{~mm}$ \\
Zircon & $0.15 \mathrm{~mm}$ & $0.24 \mathrm{~mm}$ & $0.049 \mathrm{~mm}$ \\
Sphene & $0.16 \mathrm{~mm}$ & $0.18 \mathrm{~mm}$ & $0.136 \mathrm{~mm})$ \\
Apatite & $0.11 \mathrm{~mm}$ & $0.156 \mathrm{~mm}$ & $0.03 \mathrm{~mm}$ \\
Tourmaline & - & $0.09 \mathrm{~mm}$ & $0.055 \mathrm{~mm}$ \\
Hornblende & $0.15 \mathrm{~mm}$ & - & $0.036 \mathrm{~mm}$ \\
Allanite & $0.24 \mathrm{~mm}$ & $0.06 \mathrm{~mm}$ & - \\
Augite & $0.1 \mathrm{~mm}$ & - & $0.088 \mathrm{~mm}$ \\
Metallic opaques & $0.06 \mathrm{~mm}$ & $0.096 \mathrm{~mm}$ & - \\
Carbonaceous matter & $0.015 \mathrm{~mm}$ & $0.029 \mathrm{~mm}$ & $0.024 \mathrm{~mm}$
\end{tabular}

10. Matrix

Matrix includes all interstitial detritus, whether recrystallised or not, smaller than the arbitary size of $0.02 \mathrm{~mm}$ and has been classified in part after Dickinson (1970). The range of matrix contents increases by lithofacies, from the sandstone to the thin-bedded lithofacies (Figure 2.10).

Dickinson recognises six varieties of interstitial constituents, viz:

(i) Cement, which may be of calcite, prehnite, zeolite, chalcedony or other easily recognisable minerals uncommon in the rock framework.

(ii) Homogenous, monominerallic phyllosilicate cement displaying textures indicative of pore filling.

(iii) Protomatrix, a term for unrecrystallised detrital lutum.

(iv) Orthomatrix, recrystallised detrital lutum which displays a relict clastic texture.

(v) Epimatrix, a murky, polymineralic, diagenetic, pore filling material lacking the homogenity and textural evidence required for classification as phyllosilicate cement. 
(vi) Pseudomatrix; this discontinuous interstitial paste is formed by the deformation of weak detrital grains. Argillaceous and altered volcanic rock fragments especially, fit this description, their boundaries conforming to the outlines of stronger grains and assuming irregular, attenuated shapes occupying volumes interstitial to the rigid grains.

For the greywackes studied, cements were counted in the mode of metamorphic accessories and cements. The homogenous phyllosilicate cements generally were of larger grain size than $0.02 \mathrm{~mm}$ and were counted in the appropriate mineral mode, usually chlorite. Pseudomatrix was almost entirely various distorted rock fragments, but white micas, biotite, some detrital chlorite and carbonaceous matter also assumed pseudomatrix roles. All these grains were counted in their different mineral modes if their grain size exceeded $0.02 \mathrm{~mm}$.

Most of the matrix discussed, therefore, and all counted in the matrix mode (less than $0.02 \mathrm{~mm}$ in size), is either protomatrix, orthomatrix or epimatrix. To better establish interstitial conditions for each lithofacies, however, all six interstitial categories are used to indicate order of importance in interstitial condition.

The three main varieties of matrix occurring in all rocks are epimatrix, pseudomatrix and cements, in their general order of importance, sometimes with local occurrances of homogeneous, monomineralic phyllosilicate cement and orthomatrix.

All detrital minerals occur in matrix size with the possible exception of biotite and some detrital accessories, e.g. hornblende. The predominant matrix mineral appears to be chlorite, often with strong orientation, and present as a dark grey-brown or brown but sometimes yellow or yellow-green mass. The latter colours are often masked by finely divided opaque minerals or cements, indeed, chlorite colouration may mask the true importance of sericite.

Average size for matrix material is about $0.009 \mathrm{~mm}$, for grains resembling fine filaments between larger fragments, commonly separating them be less than 0.001 to $0.01 \mathrm{~mm}$. However, thin section study often misleads by apparently increasing the distances between adjacent grains. Sericite, with yellow-white interference colours in flaky or tabular grains, may dominate matrix composition locally, adjacent to veins, rock fragments of schist, sedimentary rock fragments or altering plagioclase. Sericite flakes average $0.01 \mathrm{~mm}$. Both chlorite and sericite impart a fabric orientation to most greywackes. Locally, heavy detrital minerals, averaging $0.003 \mathrm{~mm}$, in close proximity may be important (OB-21) matrix components, with or without sericite, and impart a drusy dark appearance; chlorite is ubiquitous, however, and is of more restricted size range in matrix than sericite.

In the thin-bedded greywackes, slight differences are apparent in matrix constitution,e.g. notably more protomatrix is observed in the form of quartz and feldspar flakes (DC-LAM) augmenting the epimatrix, pseudomatrix and cements. Whereas sericite and chlorite may occur in subequal amounts in other greywackes, those of the thin-bedded facies have significantly less sericite. Effects of mineral colouration enhance this reduction, chlorite masking minerals without such colouration (sericite) but distinguishing features include greater widths of chlorite flake with respect to sericite flakes.

Increased matrix modes do not appear to repress authigenic albite formation.

Metallic opaque minerals of matrix size, are more abundant in the thin-bedded lithofacies, although, their parameters are consistent for all lithofacies. Most grains tend to be concentrated, with or without carbonaceous matter. Most of the opaque grains are pyrite (60 to 80 percent); other minerals include magnetite, chromite, ?ilmenite, some leucoxene 
(? from sphene) and carbonaceous matter. Nost of the pyrite is diagenetic as grains $0.008 \mathrm{~mm}$. Agglomerates of metallic opaques may extend for $0.16 \mathrm{~mm}$; carbonaceous matter for $0.2 \mathrm{~mm}$.

Non opaque heavy minerals, e.g. epidote, sphene, tourmaline, are concentrated into fine layers in the rocks of the thin-bedded lithofacies.

Variations of matrix mineral habit are apparent:

(i) Chlorite to $0.04 \mathrm{~mm}$ (in albite flakes), oriented with twin planes (HQ-25).

(ii) Euhedral calcite crystallising in a "void" in chlorite matrix (type b, Dickinson, 1970, type (ii) this section), between grains (HQ-17).

(iii) Sericite flakes, 0.009 to $0.04 \mathrm{~mm}$ in size, "entering" altering feldspar, and sometimes quartz, to depths of $0.048 \mathrm{~mm}$, and closely surrounding these minerals as a distinct border or layer (KTW-14, KTW-15) $0.006 \mathrm{~mm}$ thick - the rock being otherwise cemented by prehnite in the same region.

(iv) Chlorite, and especially sericite, of matrix size erodes grain boundaries of feldspar, quartz and rock fragments.

Tables $2.3,2.4,2.5$ present optic modes of greywackes by lithofacies association. 
APPENDIX 4

Basu plot: raw data.

These data were used to draft Figure 2.11.

\begin{tabular}{|c|c|c|c|c|c|c|c|}
\hline Sample & $\begin{array}{l}\text { Rock } \\
\text { mean } \\
\text { grain } \\
\text { size, } \\
\text { phi }\end{array}$ & $\begin{array}{l}\text { Polycrystalline } \\
\text { quartz, 2-3 } \\
\text { units, } \\
\text { percent }\end{array}$ & $\begin{array}{l}\text { Polycrystalline } \\
\text { quartz, >3 } \\
\text { units, } \\
\text { percent }\end{array}$ & $\begin{array}{l}\text { Total } \\
\text { polycrystalline } \\
\text { quartz, } \\
\text { percent }\end{array}$ & $\begin{array}{l}\text { Undulatory } \\
\text { quartz, } \\
\text { extinction } \\
\text { angle }>5^{\circ} \text {, } \\
\text { percent }\end{array}$ & $\begin{array}{l}\text { Non undulatory } \\
\text { quartz } \\
\text { extinction } \\
\text { angle } \leqslant 5^{\circ} \text {, } \\
\text { percent }\end{array}$ & $\begin{array}{l}\text { Metamorphic } \\
\text { rank } \\
\text { plotted }\end{array}$ \\
\hline HQ-17 & 1.3 & 13.6 & 22.0 & 35.6 & 35.6 & 28.8 & low rank \\
\hline$B Q-x v i i i$ & 2.6 & 3.9 & 9.8 & 13.7 & 15.7 & 70.6 & $\begin{array}{l}\text { middle and } \\
\text { upper rank }\end{array}$ \\
\hline $\mathrm{DC}-1$ & 2.7 & 10.4 & 5.2 & 15.6 & 43.0 & 41.4 & low rank \\
\hline $\mathrm{DC}-2$ & 2.7 & 9.4 & 3.8 & 13.2 & 67.9 & 18.9 & low rank \\
\hline$B Q-V$ & 2.7 & 11.6 & 17.4 & 29.0 & 20.3 & 50.7 & $\begin{array}{l}\text { middle and } \\
\text { upper rank }\end{array}$ \\
\hline HQ-16 & 2.8 & 17.4 & 21.7 & 39.1 & 30.4 & 30.4 & low rank \\
\hline KTW-16 & 2.8 & 11.1 & 22.2 & 33.3 & 27.8 & 38.9 & low rank \\
\hline$B Q-I X A$ & 2.9 & 24.1 & 14.8 & 38.9 & 25.9 & 35.2 & low rank \\
\hline
\end{tabular}

A minimum of 50 medium sand sized quartz grains were counted for each sample. 
APPENDIX 5

Greywacke and argillite grain size data.

Grain size raw data for greywackes and argillites of the bellington greywacke-suite rocks; tabulated in order of mean grain size by lithofacies association. Size classes are expressed in phi units.

\begin{tabular}{|c|c|c|c|c|c|c|c|c|c|c|c|c|c|c|c|c|c|c|c|c|}
\hline Sample & $\begin{array}{l}-2.0 \\
\text { to } \\
-1.5\end{array}$ & $\begin{array}{l}-1.5 \\
\text { to } \\
-1.0\end{array}$ & $\begin{array}{l}-1.0 \\
\text { to } \\
-0.5\end{array}$ & $\begin{array}{l}-0.5 \\
\text { to } \\
0\end{array}$ & $\begin{array}{l}0 \\
\text { to } \\
0.5\end{array}$ & $\begin{array}{l}0.5 \\
\text { to } \\
1.0\end{array}$ & $\begin{array}{l}1.0 \\
\text { to } \\
1.5\end{array}$ & $\begin{array}{l}1.5 \\
\text { to } \\
2.0 \\
\end{array}$ & $\begin{array}{l}\text { p h } \\
2.0 \\
\text { to } \\
2.5\end{array}$ & $\begin{array}{l}i \\
2.5 \\
\pm 0 \\
3.0\end{array}$ & $\begin{array}{l}\text { u n i } \\
3.0 \\
\text { to } \\
3.5\end{array}$ & $\begin{array}{l}t \mathbf{s} \\
3.5 \\
\text { tn } \\
4.0\end{array}$ & $\begin{array}{l}4.0 \\
\text { to } \\
4.5\end{array}$ & $\begin{array}{l}4.5 \\
\text { to } \\
5.0 \\
\end{array}$ & $\begin{array}{l}5.0 \\
\text { to } \\
5.5\end{array}$ & $\begin{array}{l}5.5 \\
\text { to } \\
6.0\end{array}$ & $\begin{array}{l}6.0 \\
\text { to } \\
6.5 \\
\end{array}$ & $\begin{array}{l}6.5 \\
\text { to } \\
7.0 \\
\end{array}$ & $>7$ & Totals \\
\hline KIW- 13 & & & & 0.8 & 0.4 & 8.2 & 12.9 & 16.9 & 16.9 & 14.9 & 11.4 & 6.7 & 2.0 & 1.6 & \multicolumn{2}{|c|}{1.6} & \multicolumn{2}{|c|}{0.4} & 5.5 & 100.2 \\
\hline $\begin{array}{l}\text { KTW-14 } \\
\text { RSS-12 }\end{array}$ & & & & & 0.4 & 3.0 & 13.4 & 16.0 & 17.5 & 17.5 & 12.3 & 4.5 & 5.2 & 1.9 & \multicolumn{2}{|c|}{5.6} & \multicolumn{2}{|c|}{2.2} & 0.7 & 100.2 \\
\hline $\begin{array}{l}\text { RSS-12 } \\
\text { BO-xviii }\end{array}$ & & & & & & 0.4 & 8.4 & 20.2 & 27.9 & 21.0 & 5.7 & 6.5 & 0.8 & 2.3 & \multicolumn{2}{|c|}{0.8} & \multicolumn{2}{|c|}{1.9} & 4.2 & 100.1 \\
\hline of $\begin{array}{l}\text { BQ-xvili } \\
D C-1\end{array}$ & & & & & 0.4 & 1.9 & 7.9 & 15.8 & 19.2 & 24.1 & 13.9 & 6.0 & 4.5 & 1.9 & \multicolumn{2}{|c|}{4.1} & \multicolumn{2}{|c|}{0.4} & - & 100.1 \\
\hline $\begin{array}{l}D C-1 \\
D C-2\end{array}$ & & & & & 0.8 & 1.2 & 8.8 & 18.3 & 19.5 & 19.9 & 13.2 & 5.6 & 4.8 & 3.6 & \multicolumn{2}{|c|}{2.0} & \multicolumn{2}{|c|}{2.0} & 1.0 & 100.1 \\
\hline $\begin{array}{l}\mathrm{DC}-2 \\
\mathrm{BQ}-\mathrm{V}\end{array}$ & & & & & & & 4.7 & 13.0 & 32.7 & 16.9 & 9.5 & 9.1 & 4.3 & 3.2 & \multicolumn{2}{|c|}{3.5} & & .2 & - & 100.1 \\
\hline $\begin{array}{l}\text { E } B Q-V \\
\text { क }\end{array}$ & & & & & & 2.4 & 8.8 & 16.6 & 18.0 & 15.9 & 13.6 & 11.2 & 4.8 & 3.1 & 3. & .7 & & 2.0 & - & 100.1 \\
\hline WCC-13A & & & & & & 0.4 & 5.8 & 18.2 & 23.6 & 19.3 & 9.7 & 7.3 & 6.6 & 2.7 & 2. & .3 & & .5 & 2.7 & 100.1 \\
\hline KTW-15 & & & & 0.4 & 0.8 & 3.9 & 11.8 & 13.7 & 20.8 & 14.9 & 7.1 & 7.8 & 3.5 & 3.9 & 5. & 1 & & 1.3 & 2.0 & 100.0 \\
\hline KTW-17 & & & & & 3.9 & 2.4 & 11.4 & 15.3 & 15.3 & 11.0 & 12.2 & 8.6 & 5.5 & 2.8 & 5. & .1 & & .1 & 3.5 & 100.1 \\
\hline $5 J-6$ & & & & & 0.4 & 3.9 & 9.5 & 14.6 & 18.1 & 18.9 & 8.7 & 7.5 & 7.1 & 3.2 & 3. & & & 3.2 & 1.2 & 100.2 \\
\hline हี KTW-16 & & & & & 0.4 & 3.8 & 8.6 & 14.5 & 16.9 & 19.0 & 10.7 & 9.7 & 3.8 & 4.8 & 5. & & & .1 & 1.0 & 100.1 \\
\hline BQ $\mathrm{BX}$ & & & & & & 0.4 & 8.2 & 18.9 & 15.6 & 18.9 & 11.1 & 9.1 & 4.5 & 4.9 & 4. & & & .3 & - & 99.8 \\
\hline$\sum O B-21$ & & & & & & 2.0 & 7.6 & 12.8 & 22.4 & 15.2 & 11.2 & 10.4 & 4.8 & 3.2 & 4. & & & .6 & 2.0 & $100: 0$ \\
\hline \& $D C-3$ & & & & & & & 0.8 & 3.4 & 20.5 & 30.0 & 19.0 & 10.7 & 5.7 & 3.4 & 3. & .8 & & .7 & - & 100.0 \\
\hline Но- 27 & & & & & 0.7 & 6.7 & 6.7 & 7.5 & 12.4 & 14.9 & 14.2 & 11.7 & 6.7 & 6.4 & 4. & .6 & & .6 & 3.9 & 100.0 \\
\hline SJ-2 & & & & & & & & 3.4 & 12.2 & 27.5 & 27.1 & 14.9 & 9.5 & 1.0 & 1. & .7 & &. .4 & 1.4 & 100.1 \\
\hline KS-2 & & & & & & 1.9 & 2.3 & 10.1 & 18.0 & 21.0 & 12.0 & 8.6 & 6.4 & 5.2 & 5. & .2 & & 1.5 & 4.9 & 100.1 \\
\hline NC-8 & & & & & & & 2.3 & 11.7 & 13.5 & 16.9 & 12.0 & 12.4 & 9.4 & 7.5 & 5. & .3 & & .0 & 6.0 & 100.0 \\
\hline $\mathrm{KS}-10$ & & & & & & 0.3 & 1.7 & .8 .8 & 13.5 & 15.8 & 10.8 & 15.2 & 11.8 & 6.7 & 8. & .4 & & .0 & 4.0 & 100.0 \\
\hline 器 & & & & & & & & & & & & & & & & & & & & \\
\hline$\underset{E}{U} D C-6$ & 3.3 & 6.3 & 6.6 & 2.2 & 1.5 & 4.0 & 16.5 & 28.7 & 14.3 & 5.2 & 4.8 & 1.8 & 1.1 & 1.1 & & .8 & & 0.7 & - & 99.9 \\
\hline $\mathrm{HQ}-17$ & & & & 2.01 & 11.01 & 18.5 & 32.5 & 19.0 & 7.0 & 2.0 & 0.5 & 2.5 & 2.5 & 1.5 & & .0 & & - & - & 100.0 \\
\hline E $5 \mathrm{SJ}^{-3}$ & & & 1.7 & 3.5 & 4.11 & 14.1 & 26.9 & 18.6 & 12.8 & 8.3 & 3.1 & 1.7 & 3.1 & 0.7 & & .0 & & 0.4 & - & 100.0 \\
\hline $\mathrm{HQ}-2 \frac{1}{1}$ & & & & 0.7 & 2.8 & 5.5 & 10.7 & 14.4 & 15.5 & 10.3 & 14.1 & 8.6 & 4.1 & 4.1 & & .8 & & 3.1 & 3.4 & 100.1 \\
\hline $\mathrm{HQ}-23$ & & & & & 0.4 & 1.8 & 9.9 & 17.5 & 19.3 & 16.8 & 9.9 & 9.9 & 7.3 & 2.9 & & .9 & & 1.5 & - & 100.1 \\
\hline $\mathrm{HO}-16$ & & & & & 1.8 & 6.7 & 8.5 & 13.4 & 13.4 & 16.5 & 11.3 & 10.7 & 5.5 & 3.7 & & .9 & & 2.7 & 0.9 & 100.0 \\
\hline нQ-25 & & & & & 1.5 & 4.2 & 10.4 & 17.2 & 11.9 & 15.3 & 14.2 & 7.7 & 3.1 & 4.2 & & .2 & & 2.3 & 3.8 & 100.0 \\
\hline $\mathrm{HQ}-19$ & & & & & 1.2 & 6.3 & 4.7 & 15.4 & 13.4 & 17.4 & 9.1 & 8.7 & 5.5 & 5.1 & & .5 & & 3.6 & 4.0 & 99.9 \\
\hline है KTW-G & & & & & 0.7 & 1.0 & 2.7 & 3.1 & 10.3 & 7.9 & 6.2 & 15.2 & 17.1 & 8.6 & 12. & .7 & & 5.2 & 8.6 & 100.2 \\
\hline $\mathrm{BQ}-21$ & & & & & 0.4 & 1.6 & 2.4 & 3.6 & 4.7 & 10.3 & 14.6 & 13.0 & 12.3 & 10.7 & 13. & .8 & & 7.1 & 5.5 & 100.0 \\
\hline of $B Q-i v$ & & & & & 0.4 & 1.1 & 3.9 & 12.6 & 11.2 & 16.5 & 12.3 & 12.3 & 9.5 & 6.7 & & 1.6 & & 3.5 & 5.6 & 100.2 \\
\hline$D C-10$ & & & & & & & & & 3.9 & 23.5 & 25.8 & 17.7 & 8.5 & 5.0 & & 1.6 & & 2.3 & 8.9 & 100.2 \\
\hline $\mathrm{BQ}-i i i$ & & & & & & & 0.4 & 1.5 & 5.5 & 14.7 & 22.4 & 24.6 & 7.7 & 9.6 & & .6 & & 2.9 & 4.0 & 99.9 \\
\hline RSS-i & & & & & & & 0.7 & 2.4 & 9.9 & 16.0 & 19.7 & 16.0 & 10.5 & 6.8 & & .8 & & 5.1 & 6.1 & 100.0 \\
\hline RSS-iii & & & & & & & 1.2 & 6.3 & 8.2 & 19.6 & 9.8 & 9.4 & 10.2 & 8.2 & 11. & .4 & & 8.6 & 7.1 & 100.0 \\
\hline$\exists \mathrm{KIW}-\mathrm{i}$ & & & & & & & & & 0.4 & 6.4 & 14.3 & 23.4 & 26.2 & 11.1 & 10 & .7 & & 6.0 & 1.6 & 100.1 \\
\hline$D C-8$ & & & & & & & & & 0.4 & 1.2 & 5.8 & 21.5 & 34.6 & 13.5 & 12 & 3 & & 3.9 & 6.9 & 100.1 \\
\hline 毛 $\mathrm{SJ}-\mathrm{T}$ & & & & & & & 0.4 & - & - & 1.5 & 5.1 & 17.6 & 23.8 & 19.8 & 9.5 & 9.9 & 2.9 & 4.8 & 4.8 & 100.1 \\
\hline DC-LAM & & & & & & & & 0.8 & 0.8 & 1.5 & 2.7 & 16.5 & 24.9 & 18.0 & 20 & .3 & & 7.7 & 6.9 & 100.1 \\
\hline $\mathrm{BQ}-i$ & & & & & & & & & & 0.8 & 3.8 & 8.6 & 24.0 & 23.2 & 29 & .6 & & 5.6 & 4.5 & 100.1 \\
\hline $\mathrm{KTW}-\mathrm{V}$ & & & & & & & & & & & 3.5 & 6.1 & 25.2 & 23.5 & 19.1 & 5.2 & 1.7 & 4.4 & 11.3 & 100.0 \\
\hline RSS- $i i$ & & & & & & & & 0.4 & - & 2.0 & 4.0 & 10.8 & 14.8 & 23.2 & 22 & .8 & & 7.6 & 14.4 & 100.0 \\
\hline но-26 & & & & & & & & & & 0.4 & 2.0 & 5.9 & 10.7 & 15.4 & 24.5 & 15.8 & 9.5 & 5.5 & 10.3 & 100.0 \\
\hline$N C-15$ & & & & & & & & & & & & 2.7 & 13.7 & 22.8 & 19.0 & 16.0 & 6.5 & 6.8 & 12.6 & 100.1 \\
\hline HQ- 24 & & & & & & & & & & & 1.1 & 2.5 & 8.7 & 13.7 & 21.7 & 21.7 & 13.4 & 8.3 & 9.0 & 100.1 \\
\hline $\mathrm{OB}-W$ & & & & & & & & & 0.4 & - & 0.8 & 3.1 & 11.5 & 14.5 & 19.9 & 17.9 & 10.3 & 9.5 & 12.2 & 100.1 \\
\hline $\mathrm{HQ}-2 \mathrm{O}$ & & & & & & & & & & & & 0.8 & 5.7 & 12.2 & 16.0 & 24.3 & 13.3 & 11.4 & 16.4 & 100.1 \\
\hline 언 WCC-8A & & & & & & & & & & & 0.4 & 4.7 & 4.3 & 16.7 & 12.0 & 23.6 & 9.7 & 13.2 & 15.5 & 100.1 \\
\hline WCC- $5 A$ & & & & & & & & & & & 1.1 & 2.2 & 8.6 & 10.8 & 14.6 & 20.2 & 11.6 & 11.2 & 19.8 & 100.1 \\
\hline $\mathrm{HQ}-18$ & & & & & & & & & 0.4 & - & 0.8 & 0.4 & 6.1 & 12.3 & 18.0 & 17.2 & 14.2 & 11.5 & 19.2 & 100.1 \\
\hline BQ-vil & & & & & & & & & & & 0.4 & 1.5 & 4.0 & 11.0 & 16.9 & 18.8 & 8.5 & 9.9 & 29.0 & 100.0 \\
\hline HQ -22 & & & & & & & & & & 0.4 & 0.4 & 1.6 & 3.5 & 6.7 & 15.7 & 19.6 & 13.3 & 10.2 & 28.6 & 100.0 \\
\hline OB-13 & & & & & & & & & & & & & 0.4 & 4.1 & 11.7 & 24.5 & 18.6 & 16.6 & 24.1 & 100.0 \\
\hline
\end{tabular}


Quantitative analysis by $\mathrm{X}$-ray diffraction.

Measurements of bulk mineralogy by X-ray diffraction. Samples and appendix prepared by W. Yardley.

1. Theory:

Klug and Alexander (1974) showed that:

$$
I_{j}=\frac{c_{j} x_{j}}{\rho_{j} \bar{\mu}}
$$

where $I_{j}=$ net diffracted intensity of $j^{\text {th }}$ component in an $n$-component system.

$c_{j}=$ constant of diffractometer geometry, and of component $j$.

$\rho_{j}=$ density of component $j$. $^{\prime}$

$\bar{\mu}=$ linear absorption coefficient of the sample.

Similarly for an internal standard, $s$, in the sample:

$$
\begin{aligned}
& I_{s}=\frac{C_{s} X_{s}}{{ }_{0} \bar{s}^{\bar{\mu}}} \\
& \text { where } \frac{I_{j}}{I_{s}}=\frac{x_{j} C_{j} \overline{\mu \rho} s}{x_{s} C_{s} \overline{\mu \rho}} \\
& c \text { and } D \text { are constants, so } \frac{x_{j}}{x_{s}}=k \frac{I_{j}}{I_{s}}
\end{aligned}
$$

Therefore, if the internal standard is added in a constant proportion, so that $\mathrm{x}_{\mathbf{s}}$ is constant for each sample analysed, then:

$$
x_{j}=k \frac{I_{j}}{I_{s}}
$$

regardless of absorption differences between samples.

\section{Preparation of standard samples:}

The following minerals, with respective d-spacings, were used to set up standard calibration curves.

$\begin{array}{llll}\text { Quartz } & \text { Albite } & \text { Muscovite } & \text { Chlorite } \\ 4.27 \AA & 3.19 \AA & 10.0 \AA & 7.14 \AA \\ & & \text { Calcite } & \text { Dolomite } \\ \text { Microcline } & 3.04 \AA & 2.89 \AA \\ 3.25 \AA & & \end{array}$

Lithium fluoride ( IiF) was chosen as an internal standard, as its peak at $2.33 \mathrm{~A}$ does not overlap any peaks of the above minerals.

Lif was added in the proportion $0.250 \mathrm{gm}$ per $1.000 \mathrm{gm}$ of sample, and the materials thoroughly mixed by grinding in an agate mortar for several minutes. The materials must be ground very fine to minimise scaling errors, which increase with particle size. 
Typical scaling errors (KIug and Alexander)
$<0.005 \mathrm{~mm}, 1$ percent;
0.005 to $0.015 \mathrm{~mm}, 2$ percent;
0.015 to $0.050 \mathrm{~mm}, 18$ percent

$I_{j} / I_{s}$ was measured from the diffractometer trace. Intensities were taken as peak height times peak width at half height (above background level). This takes into account broadening of peaks with size reduction of crystallites.

Calibration charts were drawn up for $I_{j} / I_{s}$ (s) versus $x_{j}$ for different concentrations of the pure minerals. Each point was the average of 3 determinations. The line of best fit, and the value of the constant $k$ for each mineral was determined.

XRD quantitative standards, percent by weight of mineral

\begin{tabular}{|c|c|c|c|c|c|c|c|}
\hline Sample & Quartz & Albite & Muscovite & Chlorite & Microcline & Calcite & Dolomite \\
\hline Q1 & 80 & 10 & 10 & & & & \\
\hline Q2 & 60 & 20 & 20 & & & & \\
\hline Q3 & 40 & & & 40 & & 20 & \\
\hline Q4 & & 80 & & 10 & & 10 & \\
\hline Q5 & 20 & & 60 & & & & 20 \\
\hline Q6 & & 40 & & 60 & & & \\
\hline Q7 & & & 40 & & 60 & & \\
\hline Q8 & 10 & & & & 10 & & 80 \\
\hline Q9 & & & & 80 & 20 & & \\
\hline Q10 & & 60 & & & 40 & & \\
\hline Q11 & & & & 20 & 80 & & \\
\hline Q12 & & & & & & 60 & 40 \\
\hline Q13 & & & & & & 40 & 60 \\
\hline Q14 & & 10 & & & & 80 & 10 \\
\hline
\end{tabular}

3. Results of calibration runs $I_{j} / I_{s}$ percent

$X_{i}=k I_{i} / I_{\ldots \ldots}=k=$ slone $n$ aranh

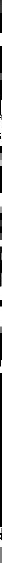


4 . Proportions from unknown samples:

LiF is mixed with the ground sample in an agate mortar in the proportion 0.250 gm per 1000 gm of sample.

Part of the mixed sample is mounted on a glass plate with acetone and left to dry. The sample is then run and the peak areas measured. The ratio $I_{j} / I_{s}$ is calculated for each mineral and the corresponding concentration, $x_{j}(\%)$, read off from the calibration charts, or calculated using the correct constant, $\mathrm{k}$.

At least 3 runs should be made for each sample to minimise errors.

\section{Errors:}

Automatic scanning produces errors of $>10$ percent (relative) for mineral concentrations of over 10 percent. (KIug and Alexander).

By summing all components, and correcting to 100 percent total components, errors can be reduced to probably \pm 5 percent relative for concentrations over 10 percent. It would be misleading to present results other than rounded off to the nearest percent.

Obviously, where amorphous material, or uncalibrated minerals are present, this correction cannot be applied.

A further error of unknown magnitude arises where the mineral in the sample has a different composition or has been strained, compared with the mineral standard used for calibration. This is probably most significant with the feldspars.

6 Results:

EN $24 / 64^{+}$

$\mathrm{XRD}$ Analysis

\begin{tabular}{|c|c|c|c|c|c|c|c|c|}
\hline Mineral & $\begin{array}{l}\text { Normative } \\
\text { modes from } \\
\text { chemical } \\
\text { analysis }\end{array}$ & ${ }_{\text {initial }}^{\text {Run }}$ & final & ${ }_{\text {initial }}^{\text {Run }}$ & $\begin{array}{l}2 \\
\text { final }\end{array}$ & ${ }_{\text {initial }}^{\text {Run }}$ & 3 final & $\begin{array}{l}\text { Average } \\
\text { corrected }\end{array}$ \\
\hline Quartz & 20 & 19 & 19 & 25 & 21 & 24 & 20 & 20 \\
\hline Calcite & 10 & 9 & 9 & 12 & 10 & 13 & 10 & 10 \\
\hline \multirow[t]{2}{*}{ Dolomite } & 70 & 71 & 72 & 80 & 68 & 85 & 70 & 70 \\
\hline & $100 \%$ & 998 & $100 \%$ & 1178 & $99 \%$ & $122 \%$ & $100 \%$ & $100 \%$ \\
\hline $\mathrm{HQ}-17$ & $\begin{array}{l}\text { Modal* } \\
\text { analysis }\end{array}$ & ${ }_{\text {initial }}^{\text {Run }}$ & final & ${ }_{\text {initial }}^{\text {Run }}$ & 2 final & initial $^{\text {Run }}$ & $\begin{array}{l}3 \\
\text { final }\end{array}$ & $\begin{array}{l}\text { Average } \\
\text { corrected }\end{array}$ \\
\hline Quartz & 43 & 55 & 51 & 50 & 47 & 50 & 44 & 48 \\
\hline $\begin{array}{l}\text { Total } \\
\text { feldspar }\end{array}$ & 48 & 44 & 41 & 48 & 45 & 56 & 49 & 45 \\
\hline Chlorite & 3.8 & 5 & 4 & 4 & 4 & 4 & 4 & 4 \\
\hline \multirow[t]{2}{*}{ Mica } & 4.6 & 4 & 4 & 5 & 5 & 4 & 4 & 4 \\
\hline & $99.4 \%$ & $108 \%$ & 1008 & $107 \%$ & $101 \%$ & 1148 & 1018 & 1018 \\
\hline
\end{tabular}

"initial" - "final" is recalculation procedure to 100 percent.

+ Sample from petrology collection, Geology Department, Victoria University of Wellington.

* Modal analysis of rock HQ-17 disregarding matrix or rock fragments as mode classes, alteration products within other minerals were counted in the mode of the alteration mineral. Cements and accessory minerals were disregarded. 
Fabric measurement of Wellington greywacke-suite rocks

The term rock fabric refers to the relationship of grains, to each other and to adjacent strata - a fundamental determinant in some engineering properties. The directional aspect of fabric (rock anisotropy) is of particular importance as this affects weathering, strength, elastic modulus and crushed particle shapes.

Two approaches were used in assessing fabric relationships, the natures of grain contacts and grain orientations.

1. Grain contacts (qualitative):

Four grain to grain contact types were considered, using the nomenclature of Taylor (1950).

(i) Sutured contact: stylolitic interpenetration of two or more grains, indicative of pressure solution.

(ii) convex-concave: a contact interface appearing as a curved line in the plane of the thin section.

(iii) Long: a contact appearing as a straight line in the plane of the thin section.

(iv) Tangential: a contact appearing as a point in the plane of the thin section.

The above classification is arranged in order of decreasing diagenesis/metamorphism. Rock fabrics are extremely variable, even within a single thin section, and various grain contact types may occur depending on textural considerations, sorting and mineral composition.

To provide a basis for qualitative assessment each grain contact type was allocated a number.

$\begin{array}{ll}\text { Sutured } & 1 \\ \text { Convex-concave } & 2 \\ \text { Long } & 3 \\ \text { Tangential } & 4\end{array}$

The order of abundance of each type was established by assessment at several locations, along a linear traverse of the thin section, using a mechanical stage, normal to any preferred orientation. The sum of the products of abundance order and quality order, gave a qualitative rating, from 20 for the lowest relative diagenetic effect to 30 for the highest, which can be expressed conveniently by histogram. Only greywackes from the sandstone and thick-bedded lithofacies were examined, grain size considerations prevented accurate resolution in the thin-bedded lithofacies (where sutured contacts "appeared" dominant). Argillites were not examined.

The results (Figure A7.1) indicate samples from the sandstone lithofacies to have been compacted and metamorphosed to a greater extent, than samples from the thick-bedded lithofacies. 


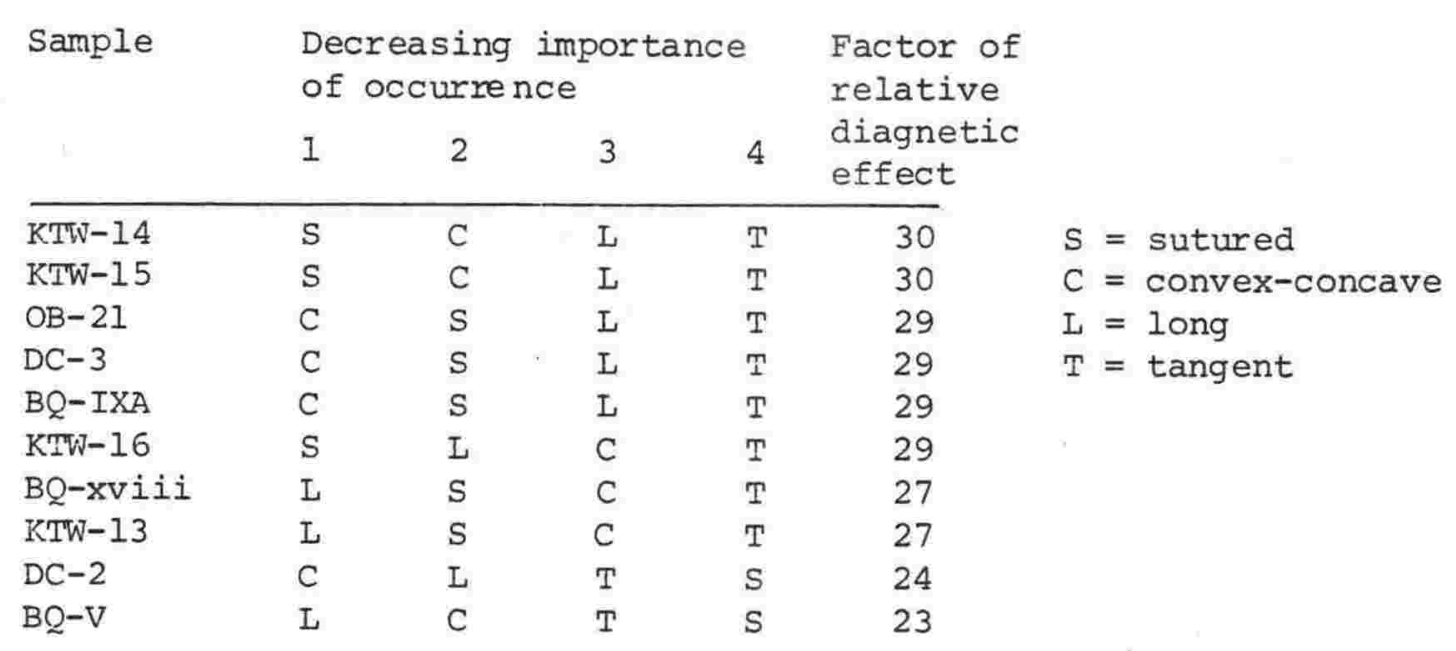

Sandstone lithofacies

Thick-bedded lithofacies

$\begin{array}{llllll}H Q-25 & \text { C } & \text { I } & \text { T } & \text { S } & 24 \\ H Q-17 & \text { C } & \text { L } & \text { T } & \text { S } & 24 \\ H Q-19 & \text { I } & \text { C } & \text { T } & \text { S } & 23 \\ H Q-2 I & \text { T } & \text { L } & \text { C } & \text { S } & 20\end{array}$

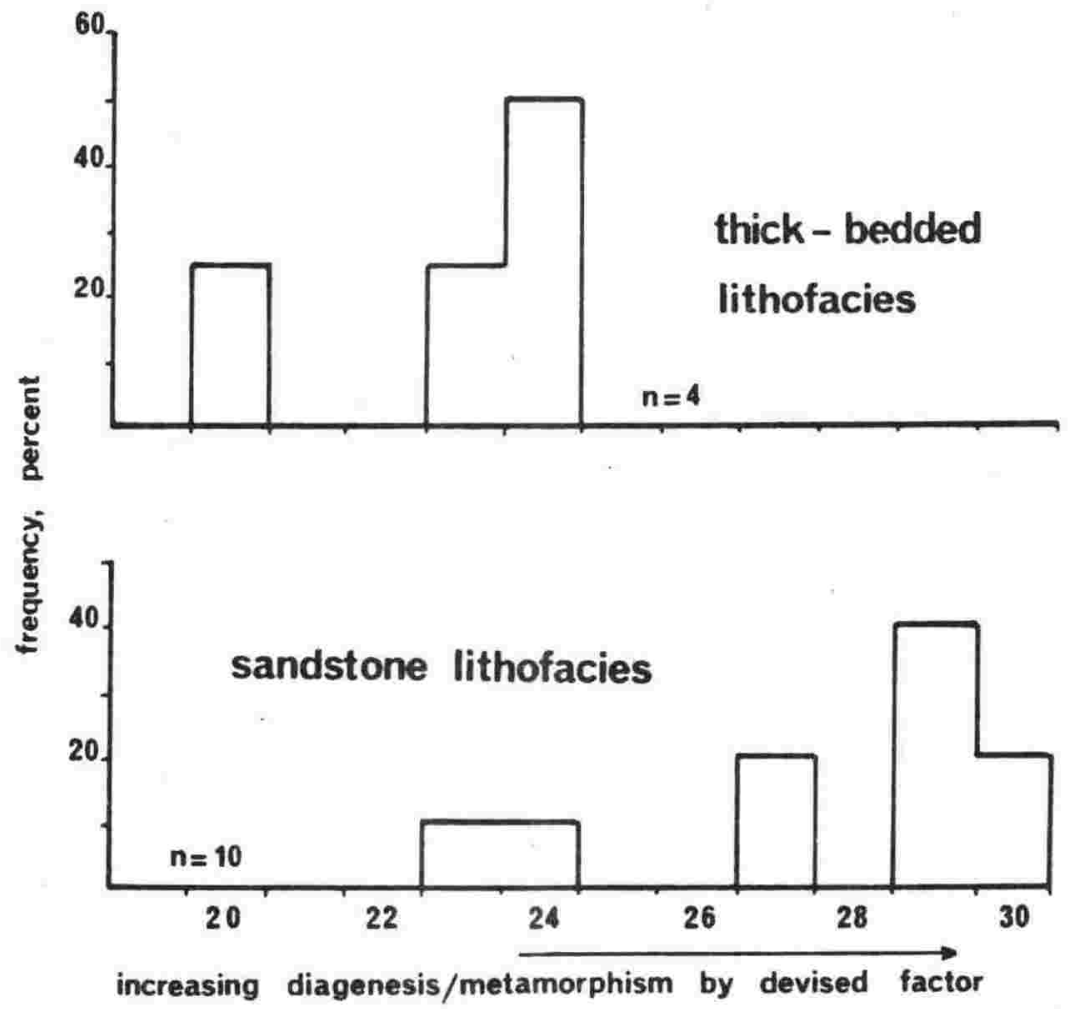

Figure A7.1 : Grain contact types in relative order of importance by lithofacies. By establishing a dimensionless factor (see text) the sandstone lithofacies displays grains in more intimate contact. 
Pressure solution of quartz grains (manifest as sutured grain contacts with or without overgrowths) and quartz veining, increases the competence of rocks (Thomson, 1959). This, with other diagenetic/metamorphic processes, reduced porosity to a minimum, limiting later movements of fluids to regions of induced porosity (joints, shears, fissures), often observed as a deposition of saw-tooth quartz or vein infillings. Where fluids are alkaline, pressure solution (with or without clay coatings), erosion and rounding or quartz may proceed as suggested by Thomson (1959) and Siever (1962) and indicated by the presence of calcite, prehnite and laumonite.

In the finer grained greywackes (i.e. the thin-bedded lithofacies) this process must have been particularly significant. Smaller quartz grains dissolved more readily than larger ones (Weyl, 1959) to produce some rounded grains, sutured grain contacts and provide competence in thinly bedded rocks, to enable fracturing and access of metamorphic minerals, and to provide an explanation of the equant felsic grains, high strength and high elastic modulus of thin-bedded greywackes (section 3.5.2).

2. Quantitative fabric assessment by Packing Proximity (Kahn, 1956).

Packing proximity was measured in conjunction with measurement of grain contact types; it is a measure of grain "closeness". The maximum value is 100 percent, when all grains are in contact with one another. Packing proximity is expressed by:

total number of grain/grain contacts encountered

total number of grains encountered

x 100 percent

Several results were averaged for one rock and traverses were made at $90^{\circ}$ to any preferred orientation, so that maximum values were recorded. Packing proximities may vary in any direction, and with composition and sorting. Coefficients of sorting should be taken into account when comparing packing proximities (Thomson, 1959), but was omitted in this study as all sediments measured are "poorly sorted" (Folk, 1968; see section 2.12).

Only the sandstone and the thick-bedded lithofacies were examined. Results are listed in Figure 8.7 .2 .

The use of packing proximity to assess greywackes is problematic, and results show the sandstone lithofacie to he packed similarly to the thick-bedded lithofacies. Minimum values are the same for both lithofacies but maximum values for the thick-bedded lithofacies are lower.

\section{Measurement of preferred orientation}

Settling of particles results in an orientation that tends to parallel the sedimentation surface. The more flaky, prismatic, tabular, elongate or rod-like the mineral shapes, the more pronounced the orientation. Subsequent load,increases the strength of orientation (decreases scatter) by increasing the area of contact between grains, deforming them as necessary and reducing pore space and moisture content. The process continues until lithification is achieved.

Rock deformation has further increased the strength of grain orientation (Clark, 1970), brought about by settling (Onions and Middleton, 1968) and lithostatic loading (diagenesis) so that, ultimately, recrystallisation has further developed preferred orientation 
Sandstone lithofacies

$\begin{array}{ll}\text { BQ-xviii } & 32 \\ \text { DC-1 } & 67 \\ \text { DC-2 } & 73 \\ \text { BQ-V } & 69 \\ \text { KTW-14 } & 64 \\ \text { BQ-IXA } & 54 \\ \text { OB-21 } & 75 \\ \text { DC-3 } & 81 \\ \text { KTW-16 } & 62 \\ \text { KTW-13 } & 48 \\ \text { mean } & 63 \text { percent } \\ \text { range } & 32-81 \text { percent }\end{array}$

sandstone lithofacies

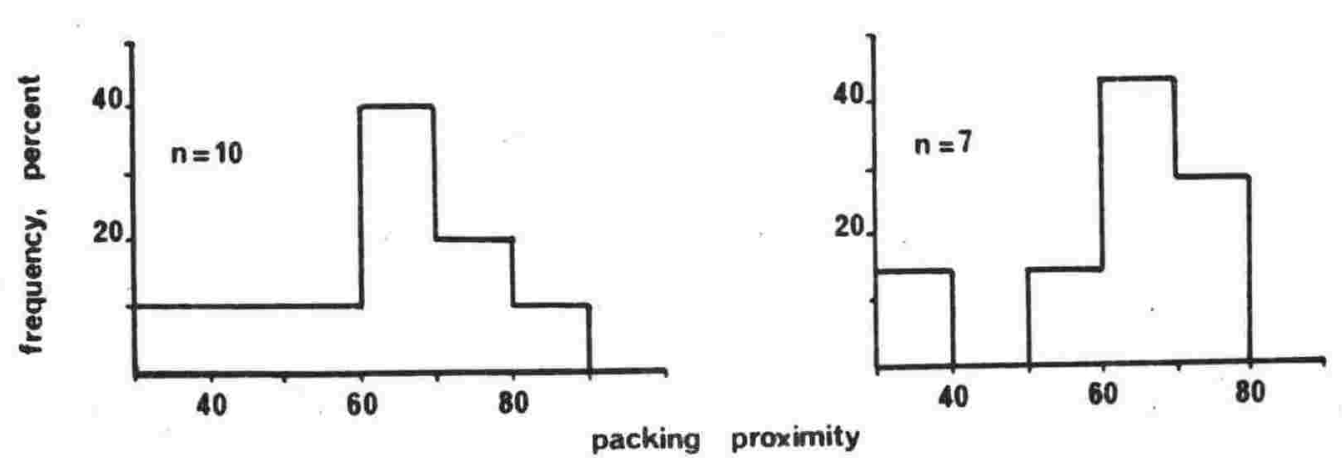

Figure A7.2 : Packing proximities for greywackes of the sandstone and thick-bedded lithofacies measured in directions perpendicular to bedding.

\section{Thick-bedded lithofacies}

$\begin{array}{ll}\text { HQ-25 } & 62 \\ \text { HQ-2I } & 50 \\ \text { HQ-19 } & 66 \\ \text { HQ-23 } & 30 \\ \text { HQ- } 17 & 73 \\ \text { DC-6 } & 61 \\ \text { SJ-3 } & 75\end{array}$

mean

60 percent range 30-75 percent thick - bedded

lithofacies 
Strong grain orientation results in clustering of optic axial directions. Quartz, for example, tends to recrystallise with its C-axis parallel to bedding, regardless of initial grain shape. Recrystallisation of quartz and phyllosilicates, results in mineral growth in the direction of minimum stress, the finer grained greywackes, because of their greater particle surface area, responding faster than coarser greywackes.

Argillites formed from sedimentation of fine muds in various states of flocculation and have achieved degrees of preferred orientation. Some display orientation textures indicative of shearing, due to large loading increments at lov water contents e.g. HQ-18 (Morgenstern and Tchalenko, 1967). Low water content tends to maintain random grain orientation (O'Brien, 1963) but most argillites display preferred orientation, therefore if original sediments were flocculated, sedimentation must have been rapid to entrap relatively large volumes of water (C'Brien, 1963; Blatt et al., 1972). Argillites show stronger preferred orientation than greywackes, their fabrics being unistrial similar to those shown by Brewer (1964; figures 115, 116, 117).

Quantification of preferred orientation is generally a time consuming,grain-by-grain measurement of long axes in thin section (Tobin and Donath, 1971). Due to the large amount of time involved in this type of investigation, a less precise method involving simple techniques, was sought so that patterns of preferred orientation would emerge.

Various methods, using X-rays (Schulz, 1949a; Tchalenko et ar., 1971; Kazi, 1975) and/ or elaborate specimen preparation (Jetter and Borrie, 1953; Barrett, pers. comm.) were examined but abandoned in favour of methods used by Martinez (1958), Fierson (1959) and Sippel (1971), based on the orientation of quartz grains, one of several minerals showing definite preferred orientations in greywacke-suite rocks.

Using crossed nicols and a $\lambda$ plate (older literature refers to a gypsum plate) with a phase difference of $550 \mathrm{~nm}$, producing interference colours of first order red, addition or subtraction of small phase differences, changes the interference colours towards blue or yellow respectively. The vibration directions of the $\lambda$ plate, with different mineral orientations and resultant colours, is shown in Figure A7.3.

As thin sections had been cut perpendicular to bedding, maximum preferred orientations (therefore optically slow orientations) and maximum interference colour changes could be observed. Different degrees of preferred orientation provide different distributions and intensities of yellow and blue colouration, when aligned with the $\lambda$ plate in the manner shown in Figure A7.3.

Colour intensity, therefore, becomes a measure of preferred grain orientation which can be evaluated readily, on a semi-quantitative basis, by photography.

Thin sections were photographed, using Ilford Pan F black and white film, exposed through a standard blue Leitz microscope filter and a Kodak gelatin photomechanical filter No. 23A which effectively "blocks" blue light. This allows only yellow and orange colours to be exposed to the film thus, when thin sections were arranged in format $\mathrm{A}$ of Figure A7.3, all grains displaying a preferred orientation would appear dark with other grains varying shades of grey.

Negatives were developed and printed on fine grained, hard, black and white paper to produce photographs of good contrast. Subjective measurement of relative black and white areas of each photograph,to assess degrees of orientation, was not possible as fine grain sizes and low magnifications used were not conducive to this. Low magnifications were necessary so that differences in preferred orientation were seen over large areas important in coarser rocks-and also to enable standardisation of exposure settings. Several pictures of each thin section were taken. 

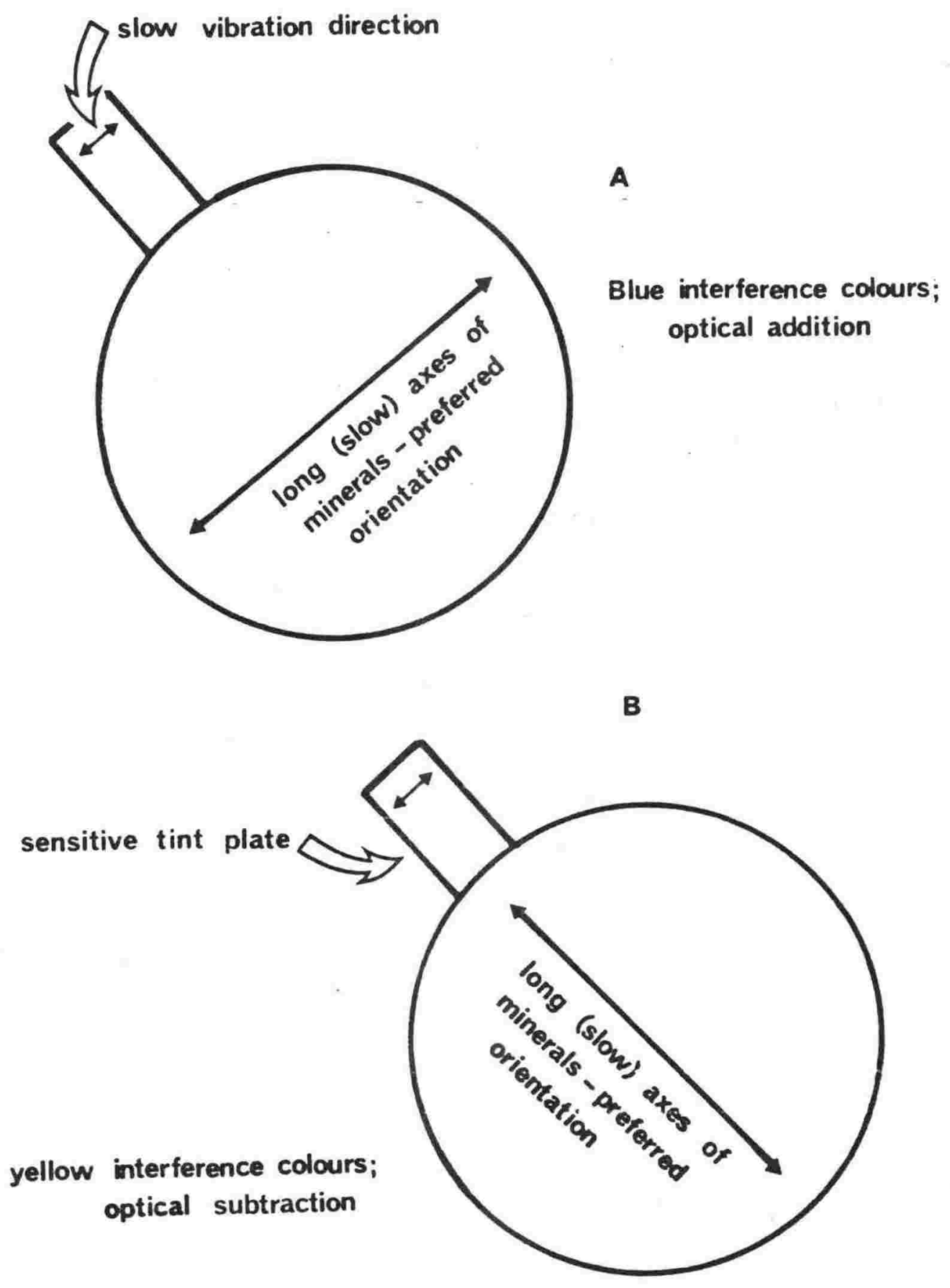

Figure A7.3 : Optical systems used with photomechanical filters to suppress or aid interference colours of optically length slow minerals. 
Assessment was undertaken in two ways: By inspection of shade, i.e. comparing relative areas of light and dark, and silicate minerals.

To ensure impartiality during test, photomicrographs vere not labelled and were shuffled face dow between tests, while to check consistency, several photomicrographs from different regions of the same rock were included. Results (Table A7.1) show the relative ranking of rock to be similar by both methods.

Mean grain size was ranked in addition to the fabric properties to check on the procedure ranking. The close comparison of ranked and measured mean grain size indicates the reliability of the procedure.

Results show relative preferred orientation to correlate well with relative mean grain size, that is, strength of grain orientation increases with decreasing mean grain size (Figure A7.4).

Whilst the technicues is relatively quick, repeatable and convenient, results are not absolute and therefore not directly comparable with other works or engineering parameters. mis severely restricts its usefulness.

Table A7.1 : Grain preferred orientation assessed from photomicrographs.

\begin{tabular}{|c|c|c|c|c|c|}
\hline $\begin{array}{l}\text { order by } \\
\text { rock mean } \\
\text { grain size }\end{array}$ & Sample & $\begin{array}{l}\text { Rock mean } \\
\text { grain size, } \\
\text { phi }\end{array}$ & $\begin{array}{l}\text { Assessed from } \\
\text { mechan } \\
\text { Order of dirinish- } \\
\text { ing mean grain } \\
\text { size }\end{array}$ & $\begin{array}{l}\text { hotomicrography usir } \\
\text { cal filters } \\
\text { Crder of increas- } \\
\text { ing opacity }\end{array}$ & $\begin{array}{l}\text { photo- } \\
\text { Order of increas- } \\
\text { ing mineral } \\
\text { orientation }\end{array}$ \\
\hline 1 & $D C-6$ & 1.25 & HQ-17 & HQ-17 & HQ-17 \\
\hline 2 & $\mathrm{HQ}-17$ & 1.317 & $5 J-3_{I}$ & $D C-6$ & $5 J-3_{I}$ \\
\hline 3 & $S J-3_{1}$ & 1.32 & $D C-6$ & $S J-3_{1}$ & $O B-21$ \\
\hline 4 & $\mathrm{KTW}-13$ & 2.4 & $\mathrm{KTW}-13$ & $O B-21$ & $B Q-I X A$ \\
\hline 5 & $\mathrm{HQ}-2 \mathrm{I}$ & 2.7 & $O B-21$ & $B \&-I X A$ & $D C-6$ \\
\hline 6 & $B Q-V$ & 2.73 & $\mathrm{HQ}-21$ & HO- 23 & HQ $-2 I$ \\
\hline 7 & $B Q-I X A$ & 2.9 & $B Q-I X A$ & $B Q-V$ & RSS-ii \\
\hline 8 & $O B-21$ & 2.93 & $B Q-V$ & $\mathrm{KS}-2$ & $O B-13$ \\
\hline 9 & $\mathrm{HQ}-19$ & 3.08 & HQ- 19 & $K T W-13$ & $B Q-V$ \\
\hline 10 & $\mathrm{KS}-2$ & 3.27 & RSS-iii & $\mathrm{HQ}-19$ & KS-2 \\
\hline 11 & $B Q-i i i$ & 3.78 & $\mathrm{KS}-2$ & $B Q-2 I$ & $\mathrm{HQ}-2 \mathrm{O}$ \\
\hline 12 & RSS-iii & 4.08 & $B Q-2 I$ & RSS-iii & $\mathrm{DC}-8$ \\
\hline 13 & $B Q-2 I$ & 4.13 & $B Q-2 I(R)$ & $B Q-i i i$ & нQ-19 \\
\hline $13 \mathrm{~A}$ & $B Q-2 I(R)$ & 4.13 & $B Q-i i i$ & $B Q-2 I(R)$ & $B Q-i$ \\
\hline 14 & $D C-8$ & 4.5 & RSS-ii & RSS-ii & RSS-iii \\
\hline 15 & $B 2-i$ & 4.87 & $D C-8$ & $O B-13$ & $K T W-13$ \\
\hline 16 & RSS-ii & 5.18 & $\mathrm{HQ}-20$ & НС- 20 & $B Q-i i i$ \\
\hline 17 & $E Q-26$ & 5.4 & $B Q-i$ & $D C-8$ & $B Q-21$ \\
\hline 18 & $O B-W$ & 5.6 & $B Q-v i i$ & $B Q-i$ & $B Q-2 I(R)$ \\
\hline 19 & $\mathrm{HQ}-20$ & 5.87 & $O B-13$ & $B Q-v i i$ & HQ-18 \\
\hline 20 & $\mathrm{H} Q-18$ & 5.95 & $\mathrm{HQ}-26$ & $\mathrm{HQ}-26$ & $B Q-v i i$ \\
\hline 21 & $\mathrm{~B} R-v i i$ & 6.18 & $\mathrm{HQ}-18$ & $\mathrm{HQ}-18$ & $\mathrm{HQ}-26$ \\
\hline 22 & $\mathrm{HQ}-22$ & 6.28 & но -22 & $O B-W$ & $\mathrm{OB}-\mathrm{W}$ \\
\hline 23 & $O B-13$ & 6.39 & $O B-W$ & HQ -22 & $\mathrm{HQ}-22$ \\
\hline
\end{tabular}




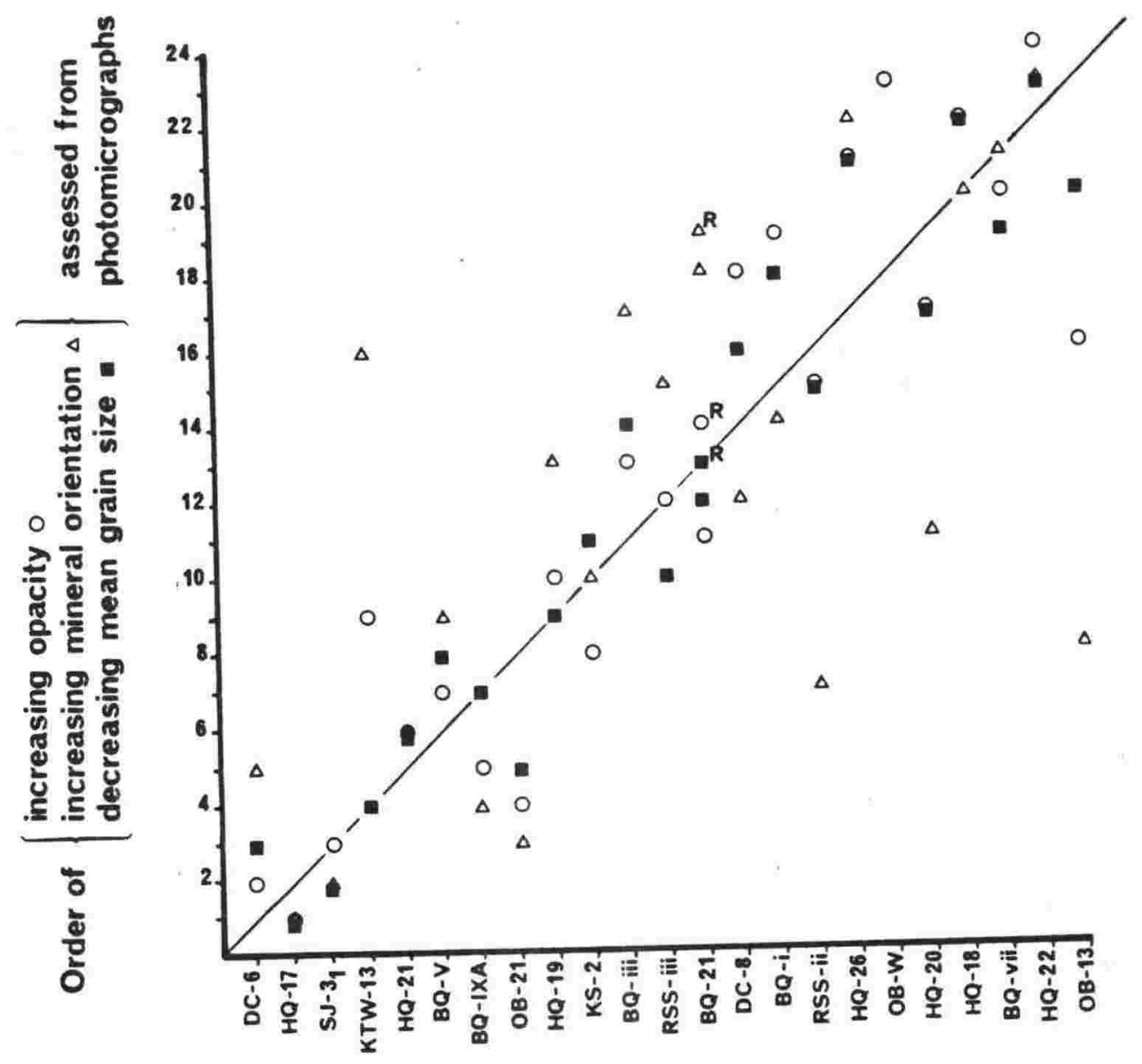

Order of decreasing mean grain size from point counting

Figure A7.4 : Study of preferred orientation by petrography indicates that relative mean grain size, degrees of opacity and preferred orientation are related and show a consistent trend with mean grain size measurements of Wellington greywacke-suite rocks. 


\section{APPENDIX 8}

Chlorite analysis by electron microprobe

Mr I. Pringle (Geology Department, Otago University) used an Electron Optics Laboratory electron microprobe, model JXA-5I., situated at that university, to ascertain the chemical affinities of green and brown detrital and authigenic phyllosilicate minerals, grouped as chlorite in modal analyses (section 2.6.6, Appendix 3). Some brown, broken accessory minerals were also probed for identification.

Test cores, $25 \mathrm{~mm}$ diameter, were taken from five greywacke lithologies known to contain adequate subject mineral and representing a wide textural range. Discs, $2.5 \mathrm{~mm}$ thick, were cut from the cores, arranged in textural order, stacked with epoxy adhesive to form a composite core, then cut longitudinally through a diameter. One of the half cylinders produced was epoxied to a glass slide and a polished thin section (probe mount), made by fine grinding and polishing to a thickness of 30 microns. A probing map of the grains to be examined was assembled.

\section{Analytical method}

Instrument settings were: $15 \mathrm{kV}$ accelerating potential, $0.03 \mu \mathrm{A}$ specimen current and 2-3 micron electron beam diameter. Each complete analysis was prepared by averaging 5 countings of 10 seconds integration time. Correction procedures for absorption, fluorescence and atomic number were those of Bence and Albee (1968) with correction factors given by Kushiro and Nakamura (1970).

Analyses were semi-automated using a FDP $8 F$ computer, controlling peak search at pre-set peak positions, X-ray intensity measurements for peaks and backgrounds, dead time, Bence and Albee corrections and cation calculations. Drift correction was made by measuring probe current (using the synthetic periclase standard) just before the $x$-ray intensity measurements of each standard and unknown.

Standard materials used were: natural albite from Amelia (Na), adularia from Gotthard (K), hematite from Sennin mine ( $F e$ ), maganosite from Nodatamagawa mine (Mn), chromite from Acoje mine (Cr), synthetic corundum (AI), rutile (Ti), quartz (Si), wollastonite (Ca), synthetic periclase $(M g)$.

Technical problems, associated with probing phyllosilicates, arise from relatively high water contents and varied iron oxidation states. All iron was calculated as Feo. Percentage totals and cation totals are variable and give no indication of analysis accuracy, however beam current stability, and analysis of standards as unknowns, are means by which probe error can be minimised.

2. Results

Analyses shown in Table A8.1 include analyses of grains undergoing a biotite - chlorite transition (Table A8.2). Tables A8.3 and A8.4 present data from hornblende and biotite. 
Table A8.1 : Electron microprobe analyses of chlorites and titano-chlorites (the latter five analyses) from Wellington greywacke-suite rocks. Total iron measured as $\mathrm{FeO}$ and $\mathrm{H}_{2} \mathrm{O}$ determined as difference of analysis total and 100 percent. Numbers in brackets denote different analyses from one lithology.

\begin{tabular}{|c|c|c|c|c|}
\hline & KIW-14(1) & $K T W-14(2)$ & $\mathrm{HQ}-17(1)$ & $D C-6(1)$ \\
\hline $\begin{array}{l}\mathrm{SiO}_{2} \\
\mathrm{Al}_{2} \mathrm{O}_{3} \\
\mathrm{TiO}_{2} \\
\mathrm{FeO} \\
\mathrm{MnO} \\
\mathrm{MgO} \\
\mathrm{CaO} \\
\mathrm{Na}_{2} \mathrm{O} \\
\mathrm{K}_{2} \mathrm{O}\end{array}$ & $\begin{array}{r}27.6860 \\
16.5720 \\
0.6919 \\
27.1851 \\
0.2173 \\
15.2250 \\
0.1447 \\
0.0299 \\
0.0378\end{array}$ & $\begin{array}{r}27.7479 \\
18.8719 \\
0.1356 \\
24.4961 \\
0.2821 \\
17.3959 \\
0.0798 \\
0.0256 \\
0.0113\end{array}$ & $\begin{array}{r}27.6466 \\
21.1213 \\
0.0216 \\
22.6487 \\
0.8091 \\
17.9222 \\
0.0441 \\
0.0135 \\
0.0270\end{array}$ & $\begin{array}{r}28.2941 \\
16.8992 \\
1.9436 \\
28.4723 \\
0.3609 \\
13.9729 \\
0.2720 \\
0.0000 \\
0.3439\end{array}$ \\
\hline Total & 87.7895 & 89.0462 & 90.2540 & 90.5588 \\
\hline $\mathrm{H}_{2} \mathrm{O}$ & 12.2105 & 10.9538 & 9.7460 & 9.4412 \\
\hline
\end{tabular}

Numbers of ions on the basis of 28 oxygen equivalents ignoring $\mathrm{H}_{2} \mathrm{O}$.

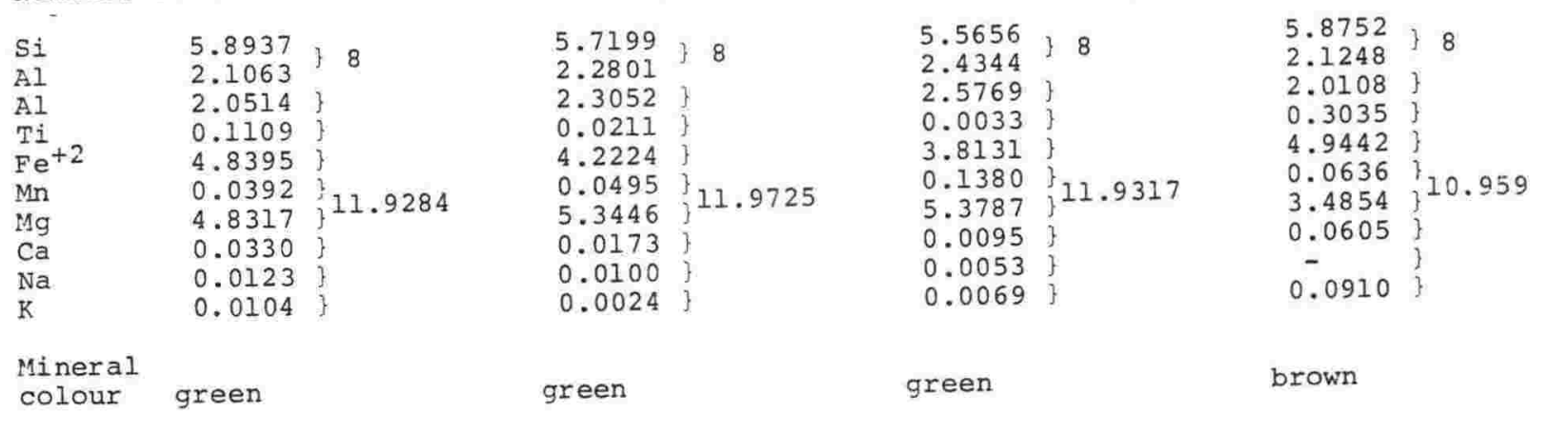

\begin{tabular}{|c|c|c|c|c|}
\hline & $D C-6(4)$ & KTW-14 (la) & KTW $-14(3)$ & $\mathrm{BQ}-\mathrm{IXA}(1)$ \\
\hline $\begin{array}{l}\mathrm{SiO}_{2} \\
\mathrm{Al}_{2} \mathrm{O}_{3} \\
\mathrm{TiO}_{2} \\
\mathrm{FeO} \\
\mathrm{MnO} \\
\mathrm{MgO} \\
\mathrm{CaO} \\
\mathrm{Na}_{2} \mathrm{O} \\
\mathrm{K}_{2} \mathrm{O}\end{array}$ & $\begin{array}{r}28.5256 \\
17.0053 \\
2.7756 \\
26.8845 \\
0.3229 \\
13.1658 \\
0.4049 \\
0.0504 \\
0.5404\end{array}$ & $\begin{array}{r}29.7806 \\
16.9933 \\
1.2751 \\
28.8337 \\
0.3004 \\
12.8572 \\
0.2188 \\
0.0562 \\
0.4429\end{array}$ & $\begin{array}{r}29.0941 \\
16.8990 \\
3.0373 \\
26.0171 \\
0.4545 \\
12.4588 \\
0.6966 \\
0.0393 \\
0.5683\end{array}$ & $\begin{array}{r}29.4984 \\
17.8545 \\
1.6157 \\
24.5462 \\
0.3678 \\
15.1307 \\
0.1154 \\
0.0433 \\
0.7240\end{array}$ \\
\hline Total & 89.6753 & 90.7580 & 89.2650 & 89.8959 \\
\hline $\mathrm{H}_{2} \mathrm{O}$ & 10.3247 & 9.2420 & 10.7350 & 10.1041 \\
\hline
\end{tabular}

Numbers of ions on the basis of 28 oxygen equivalents ignoring $\mathrm{H}_{2} \mathrm{O}$

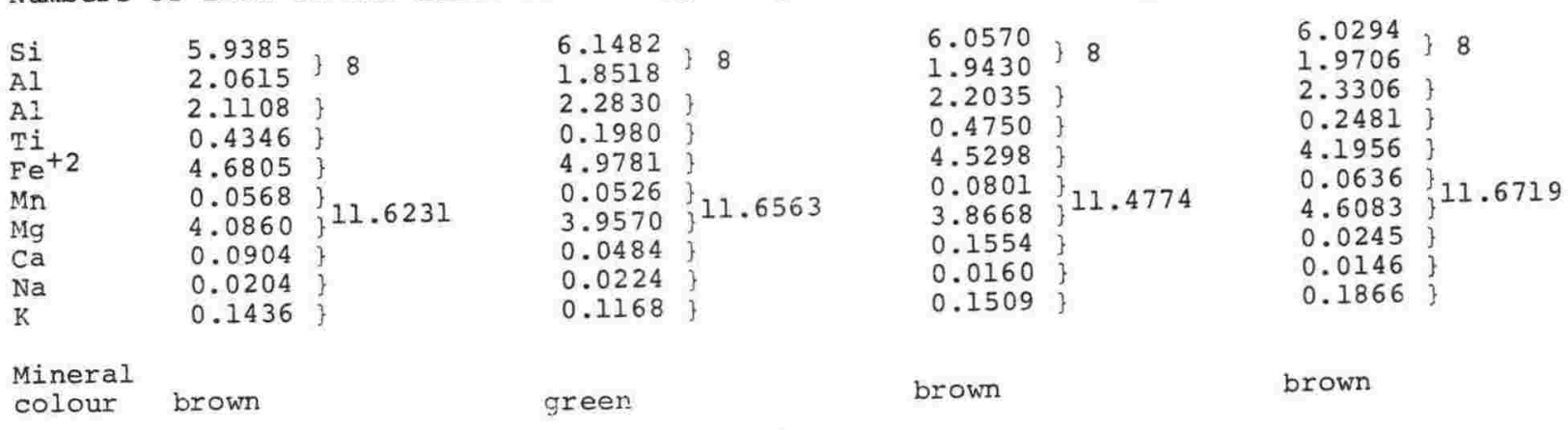


Table A8.2 : Electron microprobe analyses of altering biotite-chlorite minerals. Total iron measured as $\mathrm{FeO}$ and $\mathrm{H}_{2} \mathrm{O}$ determined as difference of analysis total and 100 percent. Numbers in brackets denote different analyses from one lithology.

\begin{tabular}{|c|c|c|c|c|}
\hline & $D C-6(1 a)$ & $D C-6(4 a)$ & HQ-17 ( la) & $K T W-14(2 a)$ \\
\hline $\mathrm{SiO}_{2}$ & 32.4090 & 32.6519 & 32.7546 & 32.2828 \\
\hline $\mathrm{Al}_{2} \mathrm{O}_{3}$ & 17.2386 & 16.7103 & 15.8706 & 21.2784 \\
\hline $\mathrm{TiO}_{2}$ & 1.5724 & 3.7986 & 3.0384 & 2.6269 \\
\hline $\mathrm{FeO}$ & 23.9776 & 22.1925 & 21.5722 & 21.2544 \\
\hline Mno & 0.3044 & 0.3976 & 0.5168 & 0.3283 \\
\hline MgO & 13.8341 & 13.6615 & 13.8703 & 10.9791 \\
\hline $\mathrm{CaO}$ & 0.3876 & 0.2445 & 0.1488 & 0.1055 \\
\hline $\mathrm{Na}_{2} \mathrm{O}$ & 0.0430 & 0.0392 & 0.0363 & 0.1689 \\
\hline $\mathrm{K}_{2} \mathrm{O}$ & 2.0625 & 4.0039 & 3.2288 & 4.5422 \\
\hline Total: & 91.8289 & 93.6998 & 91.0366 & 93.5662 \\
\hline $\mathrm{H}_{2} \mathrm{O}$ & 8.1711 & 6.3002 & 8.9634 & 6.4338 \\
\hline Mineral colour & brown & brown & brown/green & brown \\
\hline
\end{tabular}

Table A8.3 : Electron microprobe analyses of hornblende from Wellington greywacke-suite rocks. Total iron measured as $\mathrm{FeO}$ and $\mathrm{H}_{2} \mathrm{O}$ determined as difference of analysis total and 100 percent. Numbers in brackets denote different analyses from one lithology.

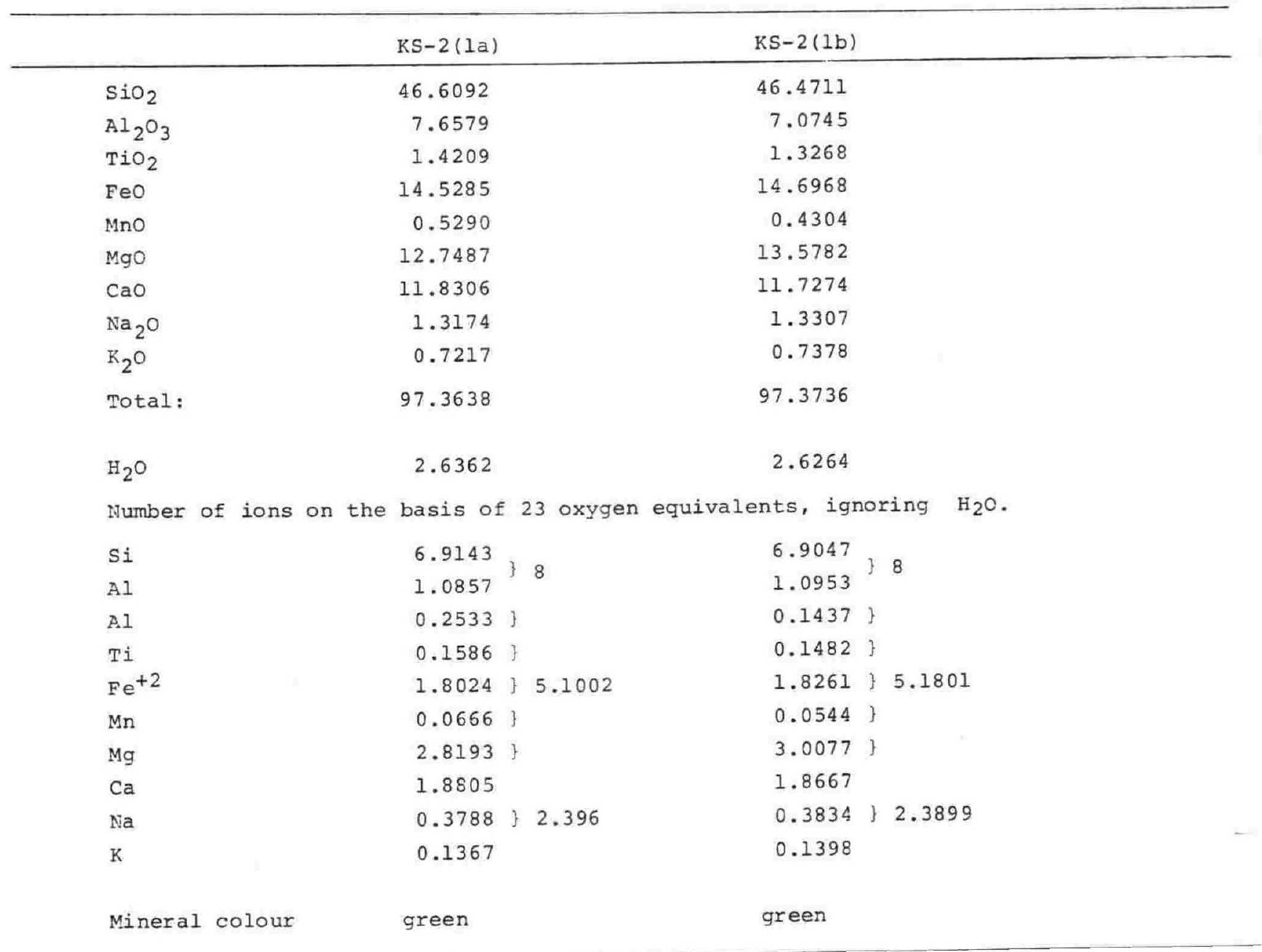


Table A8.4 : Electron microprobe analyses of biotites from Wellington greywacke-suite rocks. Total iron measured as $\mathrm{FeO}$ and $\mathrm{H}_{2} \mathrm{O}$ determined as difference of analysis total and 100 percent. Numbers in brackets denote different analyses from one lithology.

\begin{tabular}{|c|c|c|c|c|c|}
\hline & $\mathrm{HQ}-17(2)$ & $\mathrm{HQ}-17(3)$ & $\mathrm{HQ}-17(4)$ & HQ $-17(4 a)$ & $B Q-I X A(2)$ \\
\hline $\begin{array}{l}\mathrm{SiO}_{2} \\
\mathrm{Al}_{2} \mathrm{O}_{3} \\
\mathrm{TiO}_{2} \\
\mathrm{FeO} \\
\mathrm{MnO} \\
\mathrm{MgO} \\
\mathrm{CaO} \\
\mathrm{Na}_{2} \mathrm{O} \\
\mathrm{K}_{2} \mathrm{O}\end{array}$ & $\begin{array}{r}35.1198 \\
19.7249 \\
2.9991 \\
19.4696 \\
0.2476 \\
9.3728 \\
0.0470 \\
0.1200 \\
8.9975\end{array}$ & $\begin{array}{r}34.6475 \\
18.0907 \\
6.3035 \\
18.0759 \\
0.4365 \\
11.1126 \\
0.2270 \\
0.0753 \\
5.2318\end{array}$ & $\begin{array}{r}32.2040 \\
17.1396 \\
3.2928 \\
17.5434 \\
0.5366 \\
13.3219 \\
0.1472 \\
0.1111 \\
9.1615\end{array}$ & $\begin{array}{r}34.4313 \\
17.2256 \\
2.8135 \\
18.6475 \\
0.5237 \\
14.2282 \\
0.0496 \\
0.0474 \\
5.1553\end{array}$ & $\begin{array}{r}36.6752 \\
22.2174 \\
1.8269 \\
16.5015 \\
0.2174 \\
9.7464 \\
0.0762 \\
0.1275 \\
5.6785\end{array}$ \\
\hline Total: & 96.0981 & 94.2005 & 93.4580 & 93.1220 & 93.0668 \\
\hline $\mathrm{H}_{2} \mathrm{O}$ & 3.9019 & 5.7995 & 6.5420 & 6.8780 & 6.9332 \\
\hline
\end{tabular}

Numbers of ions on the basis of 22 oxygen equivalents, ignoring $\mathrm{H}_{2} \mathrm{O}$

\begin{tabular}{|c|c|c|c|c|c|c|c|c|c|c|}
\hline $\begin{array}{l}\mathrm{Si} \\
\mathrm{Al} \\
\mathrm{Al} \\
\mathrm{Ti} \\
\mathrm{Fe}+2 \\
\mathrm{Mn} \\
\mathrm{Mg} \\
\mathrm{Ca} \\
\mathrm{Na} \\
\mathrm{K}\end{array}$ & $\left.\begin{array}{l}5.2923 \\
2.7077 \\
0.7956 \\
0.3399 \\
2.4537 \\
0.0317 \\
2.1056 \\
0.0077 \\
0.0350 \\
1.7300\end{array}\right\}$ & 1.7727 & $\begin{array}{l}\left.\begin{array}{l}5.2043 \\
2.7957 \\
0.4068 \\
0.7121 \\
2.2706 \\
0.0554 \\
2.4884 \\
0.0365 \\
0.0220 \\
1.0024\end{array}\right\} \\
\}\end{array}$ & 1.0609 & $\left.\begin{array}{l}5.0335 \\
2.9665 \\
0.1908 \\
0.3870 \\
2.2931 \\
0.0710 \\
3.1041 \\
0.0247 \\
0.0337 \\
1.8268\end{array}\right\}$ & $\begin{array}{l}6.0460 \\
1.8852\end{array}$ & $\begin{array}{l}\left.\begin{array}{l}5.2536 \\
2.7464 \\
0.3514 \\
0.3227 \\
2.3795 \\
0.0678 \\
3.2364 \\
0.0081 \\
0.0141 \\
1.0036\end{array}\right\} \\
\}\end{array}$ & $\begin{array}{l}6.3578 \\
1.0258\end{array}$ & $\begin{array}{l}5.4622 \\
2.5378 \\
1.3619 \\
0.2046 \\
2.0552 \\
0.0275 \\
2.1639 \\
0.0121 \\
0.0367 \\
1.0789\end{array}$ & 5.8131 \\
\hline colour & brown & & brown & & brown & & brown & & brown & \\
\hline
\end{tabular}

\begin{tabular}{|c|c|c|c|c|c|}
\hline & $B Q-I X A(3)$ & $\mathrm{KS}-2(1)$ & $\mathrm{KS}-2(2)$ & $\mathrm{KS}-2(3)$ & KS $-2(4)$ \\
\hline $\begin{array}{l}\mathrm{SiO}_{2} \\
\mathrm{Al}_{2} \mathrm{O}_{3} \\
\mathrm{TiO}_{2} \\
\mathrm{FeO} \\
\mathrm{MnO} \\
\mathrm{MgO} \\
\mathrm{CaO} \\
\mathrm{Na}_{2} \mathrm{O} \\
\mathrm{K}_{2} \mathrm{O}\end{array}$ & $\begin{array}{r}33.2146 \\
20.3431 \\
2.8557 \\
18.2542 \\
0.3945 \\
11.2819 \\
0.0397 \\
0.1032 \\
5.7176\end{array}$ & $\begin{array}{r}35.2481 \\
20.1806 \\
3.3771 \\
19.8506 \\
0.2223 \\
8.7515 \\
0.0018 \\
0.1242 \\
8.8649\end{array}$ & $\begin{array}{r}36.0030 \\
16.1670 \\
3.0105 \\
16.3583 \\
0.4440 \\
11.8618 \\
0.0765 \\
0.1124 \\
8.5768\end{array}$ & $\begin{array}{r}35.7041 \\
18.1081 \\
2.0805 \\
19.4379 \\
0.1958 \\
10.9959 \\
0.1405 \\
0.0939 \\
6.1793\end{array}$ & $\begin{array}{r}35.0274 \\
14.8645 \\
3.6369 \\
17.5051 \\
0.2272 \\
13.6015 \\
0.4853 \\
0.0967 \\
5.3351\end{array}$ \\
\hline Total: & 92.2043 & 96.6208 & 92.6102 & 92.9359 & 90.7795 \\
\hline $\mathrm{H}_{2} \mathrm{O}$ & 7.7957 & 3.3792 & 7.3898 & 7.0641 & 9.2205 \\
\hline
\end{tabular}

Numbers of ions on the basis of 22 oxygen equivalents, ignoring $\mathrm{H}_{2} \mathrm{O}$

\begin{tabular}{|c|c|c|c|c|c|c|c|c|c|c|}
\hline $\mathrm{Si}$ & $\begin{array}{r}5.1137 \\
3\end{array}$ & 8 & $\begin{array}{l}5.2800 \\
2.7200\end{array}$ & 8 & $5.5579\}$ & 8 & $\left.\begin{array}{l}5.4721 \\
2.5279\end{array}\right\}$ & 8 & $\begin{array}{l}5.4681 \\
2.5319\end{array}$ & 8 \\
\hline Al & $2.88 \in 3$ & 0 & 2.7200 & & 2.4421 & & $\begin{array}{l}2.524 \\
0.7428\end{array}$ & & 0.2029 & \\
\hline A1 & $0.8051\}$ & & $0.8429\}$ & & $\begin{array}{l}0.4993 \\
0.3496\end{array}$ & & 0.2398 & & 0.4270 & \\
\hline $\mathrm{Fi}^{+}+2$ & $\left.\begin{array}{l}0.3307 \\
2.3503\end{array}\right\}$ & & $\begin{array}{l}\left.\begin{array}{l}0.3806 \\
2.4867\end{array}\right\} \\
3\end{array}$ & 5.6927 & $\begin{array}{l}0.3496 \\
2.1118\end{array}$ & 5.7488 & 2.4913 & 6.0118 & 2.2854 & 6.1108 \\
\hline $\begin{array}{l}\mathrm{Fe} \\
\mathrm{Mn}\end{array}$ & 0.0515 & 6.1270 & $0.0282\}$ & & $0.0581\}$ & & 0.0255 & & $0.0301\}$ & \\
\hline Mg & 2.5894 & & $1.9543\}$ & & 2.7300 & & 2.5124 & & $3.1654\}$ & \\
\hline $\mathrm{Ca}$ & 0.0066 & & 0.0004 & & 0.0128 & & 0.0231 & & 0.0369 & 17288 \\
\hline $\mathrm{Na}$ & $\begin{array}{l}0.0308 \\
1.1231\end{array}$ & 1.1605 & $\begin{array}{l}0.0363 \\
6940\end{array}$ & 1.7307 & $\begin{array}{l}0.0337 \\
1.6892\end{array}$ & 1.7357 & $\begin{array}{l}0.0279 \\
1.2082\end{array}$ & 1.2592 & $\left.\begin{array}{l}0.0293 \\
1.0626\end{array}\right\}$ & 1.1288 \\
\hline & & & & & & & & & & \\
\hline colour & brown & & brown & & brown & & brown & & brown & \\
\hline
\end{tabular}


Chlorite minerals are discussed in section 2.6.6 and Appendix 3 but salient points are restated for convenience. Most of the chlorite in the Wellington greywacke - suite rocks, not resident in the matrix, is of detrital origin and may be considered as two populations:

$$
\text { Chlorite from alteration of titanium rich biotite }
$$

Detrital chlorite.

Titanium rich chlorite constitutes the first population, as microscopic examination shows detrital biotite altering to chlorite along cleavage planes - this was confirmed by microprobe analysis (Table A8.2).

Both populations are considered to have common provenance, indicated as being of mainly metamorphic affinity by biotite chemistry (Deer, et a.., 1971) also amphibole chemistry (Table A8,3).

Authigenic chlorites display berlin blue anomalous interference colours more often, perhaps indicating these to be less oxidised. These chlorites are finer grained than their detrital counterparts, display "pinch and swell" forms (Sameshima, 1977) and grade in grain size to form orthomatrix, pseudomatrix, and epimatrix components (Dickinson, 1970).

The majority of grains analysed are (or altering to) chlorites. Confusion in identification of biotite and chlorite is due to similarity in colour, habit and optical properties of some grains. These problems were also noted by NcKean (1976) and Sameshima (1977).

The latter studied Auckland greywacke-suite rocks and showed the chlorite to be oxidised (Table A8.5). Optical properties of chlorite were presented in Appendix 3 . Although microprobe analysis was undertaken to confirm differences in phyllosilicate grains with otherwise similar appearance, an interesting occurrence of titanium-rich chlorite was noted (Table A8.1). This is a probable product of chemical transition from titanium rich biotites and would explain their red-brown colour. Such occurrences were noted by Sameshima (1977) and by Inomata and Tareyama (1974), who describe titano-penninite from altering phlogopites in ultramafic rocks of south-west Japan.

If the analysed chlorites are oxidised $\left(\mathrm{Fe}_{2} \mathrm{O}_{3}>4\right.$ percent) then the chlorites may be classified as chamosite (Figure A8.1). The chlorite in wellington greywacke-suite rocks is not oxidised, however. Oxidisation of chlorites may be determined by two means. In some, a high $\mathrm{Fe}_{2} \mathrm{O}_{3}$ content is associated with a low value for $\mathrm{H}_{2} \mathrm{O}$ ( $\mathrm{Table} \mathrm{A} 8.5$ ), and when a structural formula is calculated on the basis of 28 oxygen equivalents, the total of the octahedral ions falls somewhat short of the ideal twelve (compare Table A8.1 with Table A8.5). These are often reported as chlorites which have been oxidised (Deer, et al., 1971).

The oxidising reaction, where $\mathrm{Fe}^{+2} \rightarrow \mathrm{Fe}^{+3}$ with a loss of hydrogen, indicates that the water content should be low for an internally oxidised chlorite, and thus the elemental oxide total relatively high, say greater than 90 percent. For these reasons the Nellington greywacke-suite rocks examined are believed to contain ortho-chlorite, specially pynochlorite (Figure A8.1). Although not apparent from microprobe analyses, optical investigation indicated penninite to be present. The chlorites plot in a relatively narrow field, variation in iron content being characteristic and high ( 20 to 30 percent total iron oxide).

Five of the analyses showed that the $\mathrm{TiO}_{2}$ content, normally not more than 0.8 percent, was unusually high, all in excess of 1.0 percent with a 2.13 percent average. 
Table A8.5 : Electron microprobe analyses of oxychlorites, extracted from Sameshima (1977). Structural formulae have been added. Where $\mathrm{Fe}_{2} \mathrm{O}_{3}$ is absent, total iron is measured as FeO. $\mathrm{H}_{2} \mathrm{O}$ determined as difference of analysis total and 100 percent.

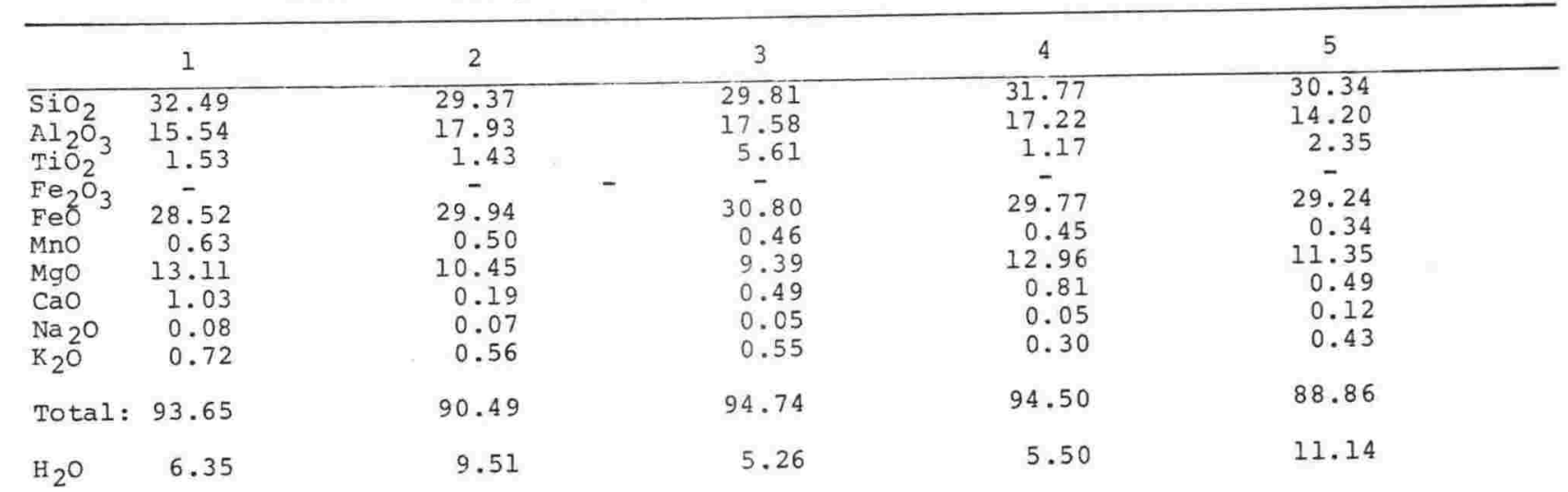

Numbers of ions on the basis of 28 oxygen equivalents, ignoring $\mathrm{H}_{2} \mathrm{O}$.

\begin{tabular}{|c|c|c|c|c|c|c|c|c|c|c|}
\hline $\mathrm{Si}$ & 6.483 & & 6.122 & & 5.953 & ) 8 & 6.289 & \} 8 & $\begin{array}{l}6.441 \\
1.559\end{array}$ & ] 8 \\
\hline Al & 1.517 & +8 & 1.878 & 18 & 2.047 & 10 & 1.711 & & & 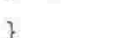 \\
\hline Al & 2.139 & \} & 2.528 & \} & 2.092 & \} & 2.308 & \} & $\begin{array}{l}1.995 \\
0.375\end{array}$ & 3 \\
\hline $\mathrm{Ti}$ & 0.230 & \} & 0.232 & \} & 0.843 & \} & 0.174 & \} & 0.375 & f \\
\hline $\mathrm{Fe}^{+3}$ & 0.000 & \} & 0.000 & \} & 0.000 & ? & 0.000 & \} & 0.000 & ? \\
\hline $\mathrm{Fe}^{+2}$ & 4.759 & ] & 5.219 & \} & 5.144 & \} & 4.928 & \} & 5.191 & \} \\
\hline $\mathrm{Mn}$ & 0.106 & 311.567 & 0.088 & \} 11.532 & 0.078 & 11.216 & 0.075 & 11.575 & 0.061 & 11.489 \\
\hline Mg & 3.899 & \} & 3.246 & \} & 2.795 & \} & 3.823 & \} & 3.591 & \} \\
\hline $\mathrm{Ca}$ & 0.220 & \} & 0.042 & j & 0.105 & \} & 0.172 & \} & 0.111 & \} \\
\hline $\mathrm{Na}$ & 0.031 & \} & 0.028 & \} & 0.019 & \} & 0.019 & j & 0.049 & \} \\
\hline $\mathrm{K}$ & 0.183 & \} & 0.149 & j & 0.140 & \} & 0.076 & \} & 0.116 & \} \\
\hline
\end{tabular}

\begin{tabular}{|c|c|c|c|c|}
\hline & 6 & 7 & 8 & 9 \\
\hline $\begin{array}{l}\mathrm{SiO}_{2} \\
\mathrm{Al}_{2} \mathrm{O}_{3} \\
\mathrm{TiO}_{2} \\
\mathrm{Fe}_{2} \mathrm{O}_{3} \\
\mathrm{FeO} \\
\mathrm{MnO} \\
\mathrm{MgO} \\
\mathrm{CaO} \\
\mathrm{Na}_{2} \mathrm{O} \\
\mathrm{K}_{2} \mathrm{O}\end{array}$ & $\begin{array}{c}28.93 \\
15.51 \\
3.17 \\
- \\
28.98 \\
0.35 \\
9.83 \\
0.65 \\
0.08 \\
0.32\end{array}$ & $\begin{array}{c}29.75 \\
15.22 \\
1.93 \\
- \\
30.05 \\
0.35 \\
11.37 \\
0.75 \\
0.00 \\
0.13\end{array}$ & $\begin{array}{c}26.78 \\
15.66 \\
1.66 \\
- \\
30.22 \\
0.29 \\
11.49 \\
0.85 \\
0.05 \\
0.00\end{array}$ & $\begin{array}{r}27.11 \\
17.42 \\
0.35 \\
30.98 \\
2.91 \\
0.00 \\
9.75 \\
0.21 \\
0.00 \\
0.00\end{array}$ \\
\hline Total: & 87.82 & 89.55 & 87.00 & 88.73 \\
\hline $\mathrm{H}_{2} \mathrm{O}$ & 12.18 & 10.45 & 13.00 & $\begin{array}{rr}\mathrm{H}_{2} \mathrm{O}^{-} & 0.51 \\
\mathrm{H}_{2} \mathrm{O}^{+} & 11.07\end{array}$ \\
\hline
\end{tabular}

Numbers of ions on the basis of 28 oxygen equivalents, ignoring $\mathrm{H}_{2} \mathrm{O}$

\begin{tabular}{|c|c|c|c|c|c|c|c|c|c|}
\hline $\mathrm{Si}$ & 6.221 & 10 & 6.283 & & 5.888 & 38 & 5.512 & \} & 8 \\
\hline AI & 1.779 & 1 8 & 1.717 & \} 8 & 2.112 & $\neq 8$ & 2.488 & , & \\
\hline AI & 2.153 & \} & 2.073 & \} & 1.947 & \} & 1.688 & \} & \\
\hline $\mathrm{Ti}$ & 0.513 & \} & 0.307 & \} & 0.274 & \} & 0.054 & \} & \\
\hline $\mathrm{Fe}^{+3}$ & 0.000 & \} & 0.000 & \} & 0.000 & f & 4.740 & \} & \\
\hline $\mathrm{Fe}^{+2}$ & 5.212 & & 5.308 & \} & 5.557 & j & 0.495 & \} & \\
\hline $\mathrm{Mn}$ & 0.064 & 11.363 & 0.063 & 11.535 & 0.054 & 11.818 & 0.000 & j & 9.977 \\
\hline $\mathrm{Mg}$ & 3.150 & \} & 3.579 & \} & 3.765 & $\hat{j}$ & 2.954 & \} & \\
\hline $\mathrm{Ca}$ & 0.150 & \} & 0.170 & \} & 0.200 & \} & 0.046 & \} & \\
\hline $\mathrm{Na}$ & 0.033 & \} & 0.000 & j & 0.021 & \} & 0.000 & \} & \\
\hline $\mathrm{K}$ & 0.088 & \} & 0.035 & 3 & 0.000 & \} & 0.000 & \} & \\
\hline
\end{tabular}

1. Stevenson and Sons Quarry, Drury, bottom cut typical argillite, D-5.

2. Winstones Russel Road Quarry, Whangarei, greywacke.

3. Winstones Russel Road Quarry, Qhangarei, greywacke.

4. Brynderwyn Quarry, Brynderwyn, argillite.

5. Moutohora Quarry, greywacke.

6. Moutohora Quarry, greywacke.

7. Moutohora Quarry, greywacke.

8. Titahi Bay, North Wellington, greywacke.

9. Chlorite, intersertal in spilite, Great Island, Three Kings Group, New Zealand, Battey (1956). 


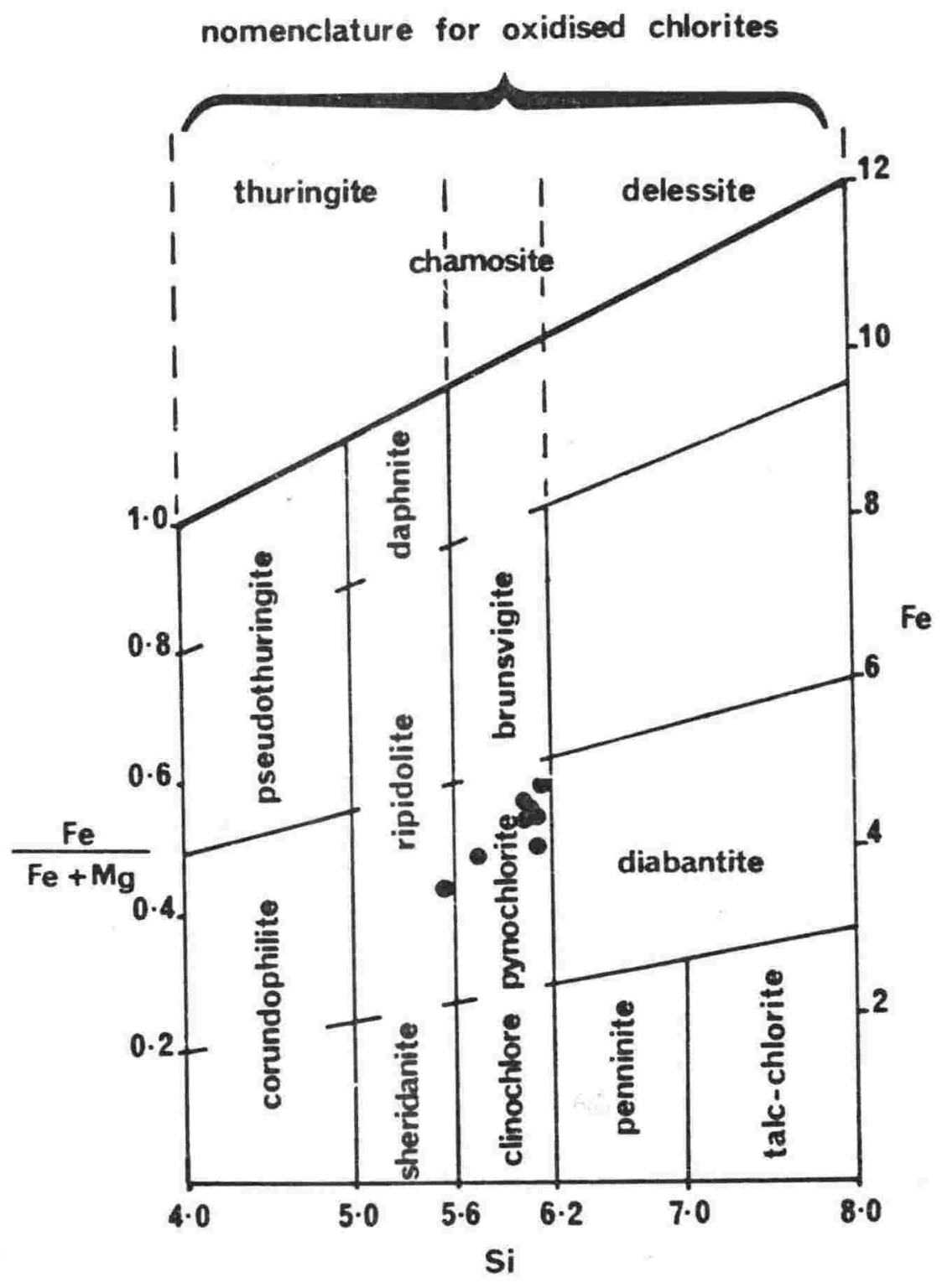

Figure A3.1 : Nomenclature of ortho-chlorites and oxidised chlorites (after Hey, 1954). Specimens for which analyses are given in Table A8.1 are plotted. 
APPENDIX 9

Scratch hardness test to ASTM C235-68

This test was used to divide the Wellington greywacke-suite rocks into hard and soft lithologies.

A standard Vicat apparatus (reference ASTM test C191-77 'Standard method of test for time of setting of hyaraulic cement by Vicat needle') was adapted to give a brass point, to ASTM C235-68, the required loading of $8.9 \pm 0.4 \mathrm{~N}$ ( $2 \pm 0.1 \mathrm{lb}$ ) by adding weights to the stem (Plate A9.1). Rocks to be tested were positioned under the point and then drawn sideways. Tests were carried out on both natural and prepared planar surfaces.

The equipment is validated by the 1978 Annual Book of ASTM standards which features a specifically designed instrument of similar type, now commercially available (part 14, pages 512-4).

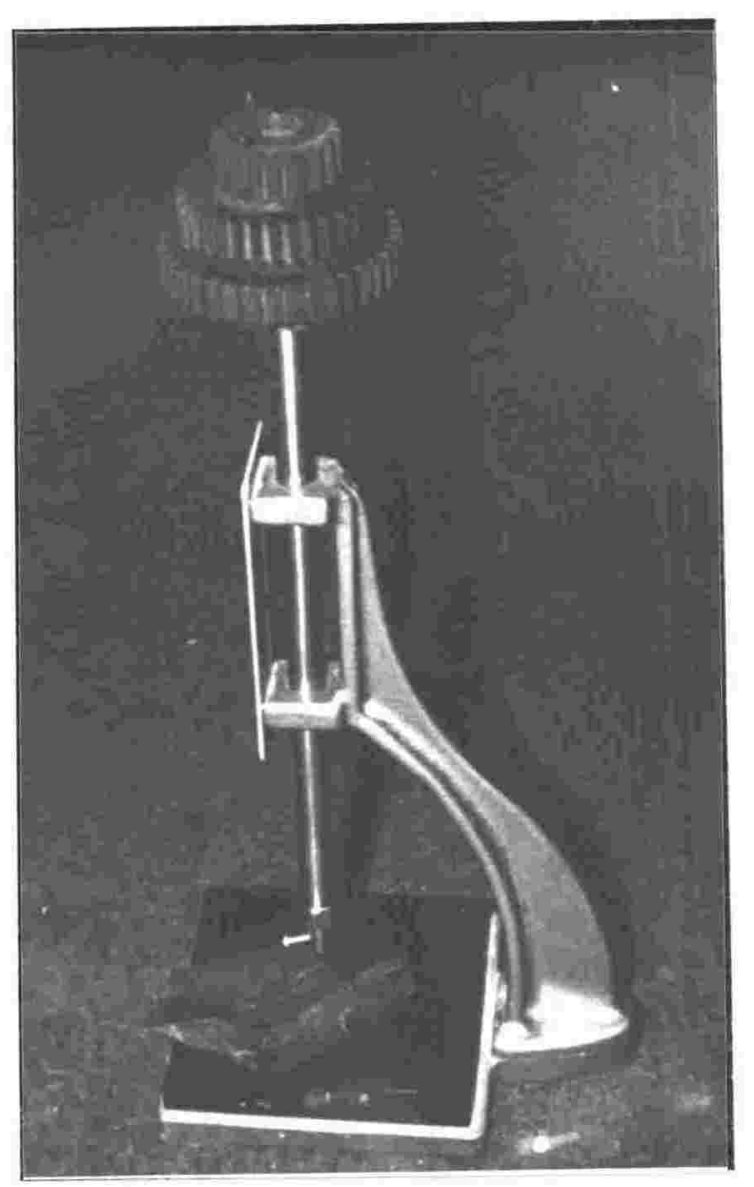

Plate A9.1 : Vicat apparatus (ASTM C191-77, 'Time of setting of hydraulic cement by Vicat needle'), adapted to perform the ASTM C235-68 'Scratch hardness of coarse aggregate particles'. Shown, are the weights added to the top of the spindle to meet weight specifications for the brass rod stylus, seen here easily scratching argillite $(\mathrm{OB}-\mathrm{W})$. 
Density, effective porosity and ultrasonic velocity of rock cores and handspecimens

The ultrasonic velocity apparatus requires that sample least lateral dimension - the dimension measured perpendicular to the path travelled by the fulse - be not less than the pulse wave length. Handspecimen samples were cut with up to three pairs of parallel faces for authogonal velocity studies to assess the degree of anisotropism. Handspecimen samples were tested saturated and oven dry and results are given in Table Al0.1. Figure Al0.1 is a graphic summary of handspecimen density data.

Table Al0.2 lists density, effective porosity and ultrasonic velocity of rock cores, which were tested saturated and air dried (50 percent R.H.). Both moisture conditions were maintained at $20 \pm 1^{\circ} \mathrm{C}$.

Table Al0.1 : Densities, effective porosities and ultrasonic velocities of greywacke and argillite handspecimens.

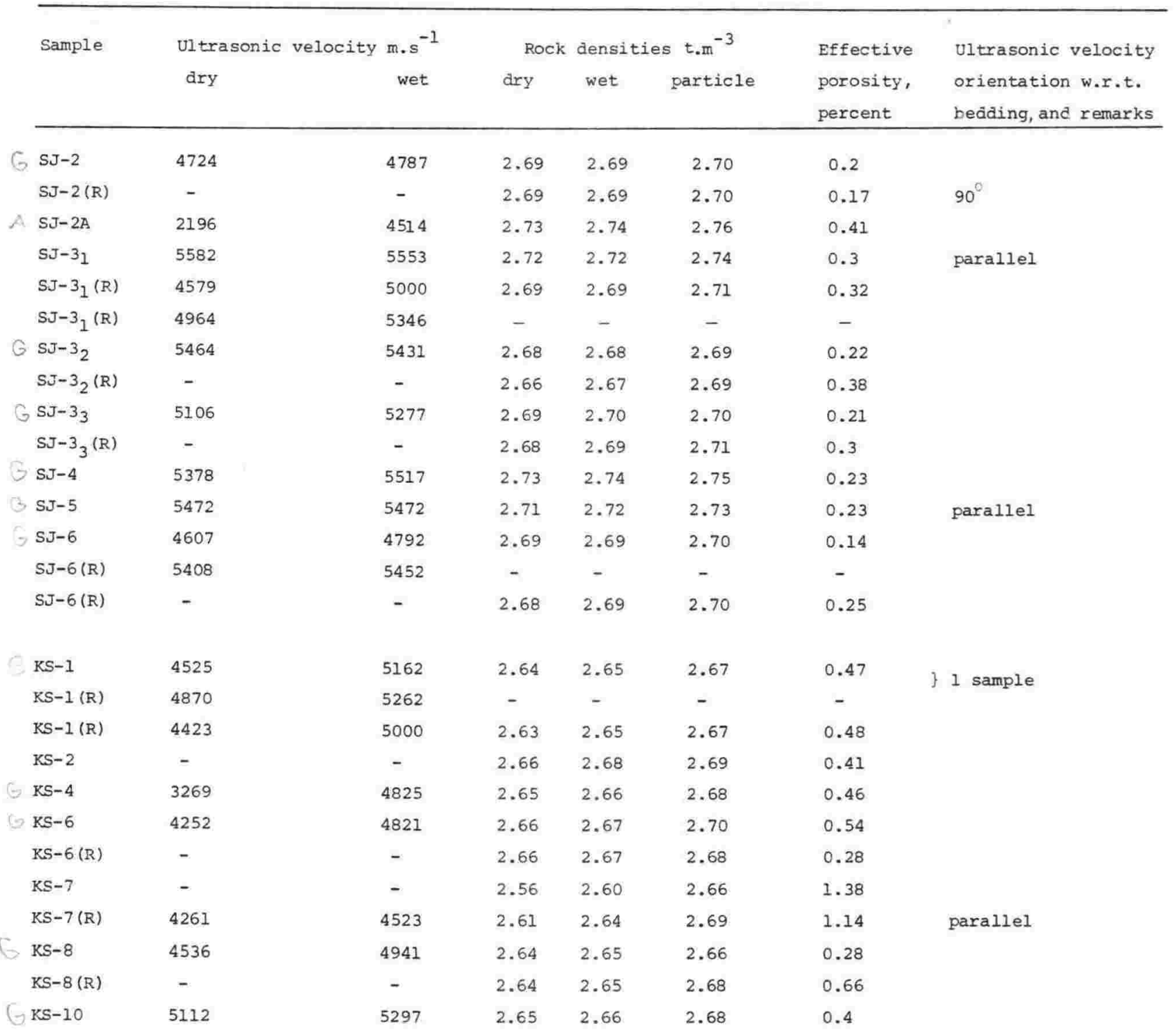


Table Alo.1 : continued

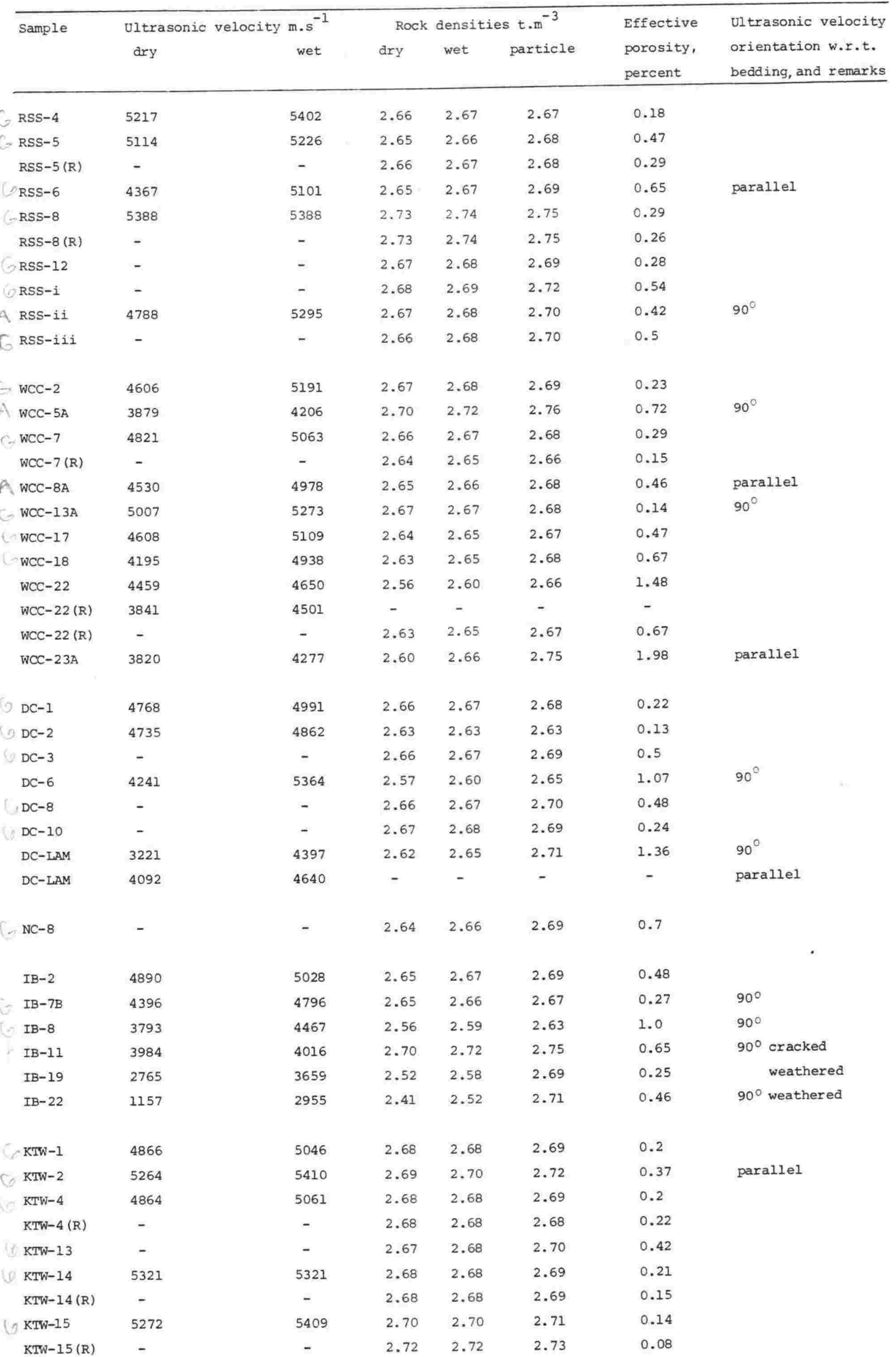


Table Al0.1 : continued

Sample Ultrasonic velocity $\mathrm{m}^{-1}$
dry

Effective Ultrasonic velocity

porosity, orientation w.r.t.

percent

bedđing, and remarks

\begin{tabular}{|c|c|c|c|c|c|c|c|c|c|}
\hline$\theta$ & KTW-16 & - & - & 2.67 & 2.68 & 2.69 & 0.26 & & \\
\hline 6 & KTW-17 & 4155 & 4873 & 2.68 & 2.68 & 2.69 & 0.28 & & \\
\hline & $\mathrm{KTW}-17$ (R) & - & - & 2.67 & 2.68 & 2.69 & 0.25 & & \\
\hline & KTW-i & 5110 & 5251 & 2.69 & 2.69 & 2.70 & 0.14 & & \\
\hline & $K I W-i(R)$ & - & - & 2.69 & 2.69 & 2.70 & 0.22 & & \\
\hline & KTW-ii & 5172 & 5138 & 2.68 & 2.69 & 2.70 & 0.36 & & parallel \\
\hline & KTW-ii (R) & - & - & 2.69 & 2.70 & 2.72 & 0.44 & & \\
\hline A & KTW-iii & 4915 & 5188 & 2.70 & 2.72 & 2.76 & 0.87 & & parallel \\
\hline A & KTW-v & - & - & 2.70 & 2.71 & 2.73 & 0.34 & & \\
\hline & $K T W-G$ & 4203 & 4750 & 2.66 & 2.67 & 2.70 & 0.66 & & parallel \\
\hline 6 & $O B-1$ & 5103 & 5342 & 2.65 & 2.66 & 2.68 & 0.47 & & \\
\hline & $O B-1(R)$ & - & - & 2.65 & 2.67 & 2.69 & 0.6 & & \\
\hline & $O B-1(R)$ & - & - & 2.64 & 2.65 & 2.68 & 0.65 & & \\
\hline f & $\mathrm{OB}-11$ & 2283 & 4375 & 2.71 & 2.73 & 2.76 & 0.6 & & $90^{\circ}$ \\
\hline 6 & $\mathrm{OB}-12$ & 4991 & 6172 & 2.68 & 2.69 & 2.69 & 0.2 & & $90^{\circ}$ \\
\hline 4 & $O B-13$ & 4667 & 4471 & 2.72 & 2.74 & 2.77 & 0.64 & & parallel \\
\hline & $\mathrm{OB}-13(\mathrm{R})$ & - & - & 2.70 & 2.74 & 2.81 & 1.4 & & \\
\hline 6 & $\mathrm{OB}-14$ & 4407 & 4491 & 2.68 & 2.69 & 2.69 & 0.07 & & $90^{\circ}$ \\
\hline 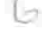 & $\mathrm{OB}-21$ & - & - & 2.65 & 2.66 & 2.68 & 0.44 & & \\
\hline$A$ & $O B-W$ & - & - & 2.73 & 2.75 & 2.78 & 0.72 & & \\
\hline & $\mathrm{HO}-13$ & 1636 & 3798 & 2.56 & 2.60 & 2.67 & 1.65 & & zeolitised \\
\hline & $\mathrm{HQ}-14$ & 3609 & 4400 & 2.61 & 2.63 & 2.67 & 0.81 & & zeolitised \\
\hline A & $\mathrm{HQ}-14(\mathrm{R})$ & 3407 & 4299 & 2.61 & 2.63 & 2.67 & 0.92 & & zeolitised \\
\hline A & $\mathrm{HQ}-15$ & - & - & 2.68 & 2.69 & 2.72 & 0.57 & & \\
\hline 6 & HQ- 16 & 4527 & 4867 & 2.66 & 2,67 & 2.68 & 0.28 & & \\
\hline & $\mathrm{HQ}-17$ & 3364 & 4440 & 2.57 & 2.59 & 2.62 & 0.85 & & $\begin{array}{l}\text { parallel, zeolite } \\
\text { bearing }\end{array}$ \\
\hline & $\mathrm{HQ}-17(\mathrm{R})$ & 2895 & 3929 & 2.55 & 2.58 & 2.63 & 1.28 & & \\
\hline & $\mathrm{HQ}-17(\mathrm{R})$ & 2422 & 3426 & 2.53 & 2.55 & 2.58 & 0.68 & \} & \\
\hline & $\mathrm{HQ}-17(\mathrm{R})$ & 2996 & 3439 & - & - & - & - & \} & I sample \\
\hline & HO-17 (R) & 2355 & 3686 & - & - & - & - & \} & \\
\hline & $\mathrm{HQ}-17(\mathrm{R})$ & 2336 & 3344 & 2.54 & 2.55 & 2.58 & 0.65 & \} & \\
\hline & HO- $17(R)$ & 2278 & 3576 & - & - & - & - & j & I sample \\
\hline & HQ-17(R) & 1725 & 3113 & - & - & - & - & \} & \\
\hline & HQ-17 (R) & 4175 & 5000 & 2.57 & 2.60 & 2.65 & 1.46 & & $90^{\circ}$ \\
\hline 海 & $\mathrm{HO}-18$ & 3842 & 4450 & 2.49 & 2.49 & 2.50 & 0.29 & & \\
\hline A & но-18 (R) & 4732 & - & 2.70 & 2.72 & 2.75 & 0.59 & & \\
\hline & $\mathrm{HQ}-19$ & 5030 & 5147 & 2.67 & 2.67 & 2.68 & 0.25 & & \\
\hline A & HQ-2O & 3361 & 4075 & 2.70 & 2.72 & 2.76 & 0.8 & & \\
\hline C & $\mathrm{HQ}-21$ & 4882 & 5108 & 2.64 & 2.66 & 2.68 & 0.52 & & \\
\hline f & $\mathrm{HQ}-22$ & 5278 & 4978 & 2.70 & 2.72 & 2.75 & 0.67 & & parallel \} \\
\hline & $\mathrm{HO}-22(\mathrm{R})$ & 4677 & 4915 & - & - & - & 0.75 & & \} I sample \\
\hline & $\mathrm{HQ}-22(\mathrm{R})$ & 4711 & 4872 & - & - & - & - & & $90^{\circ}$ \\
\hline & $\mathrm{HQ}-22(\mathrm{R})$ & - & 4909 & 2.70 & 2.72 & 2.76 & 0.75 & & \\
\hline & HQ -23 & 4910 & 5031 & 2.62 & 2.63 & 2.64 & 0.26 & & \\
\hline A & $\mathrm{HQ}-24$ & 3915 & 4529 & 2.69 & 2.70 & 2.73 & 0.56 & & $90^{\circ}$ \\
\hline C & HQ-25 & 4549 & 5198 & 2.66 & 2.67 & 2.69 & 0.46 & & $90^{\circ}$ \\
\hline & $\mathrm{HQ}-26$ & - & - & 2.67 & 2.68 & 2.71 & 0.62 & & \\
\hline & $\mathrm{HQ}-27$ & 4279 & 5045 & 2.61 & 2.64 & 2.67 & 0.88 & & $90^{\circ}$ \\
\hline
\end{tabular}


Tarle 8.10 .1 : continued

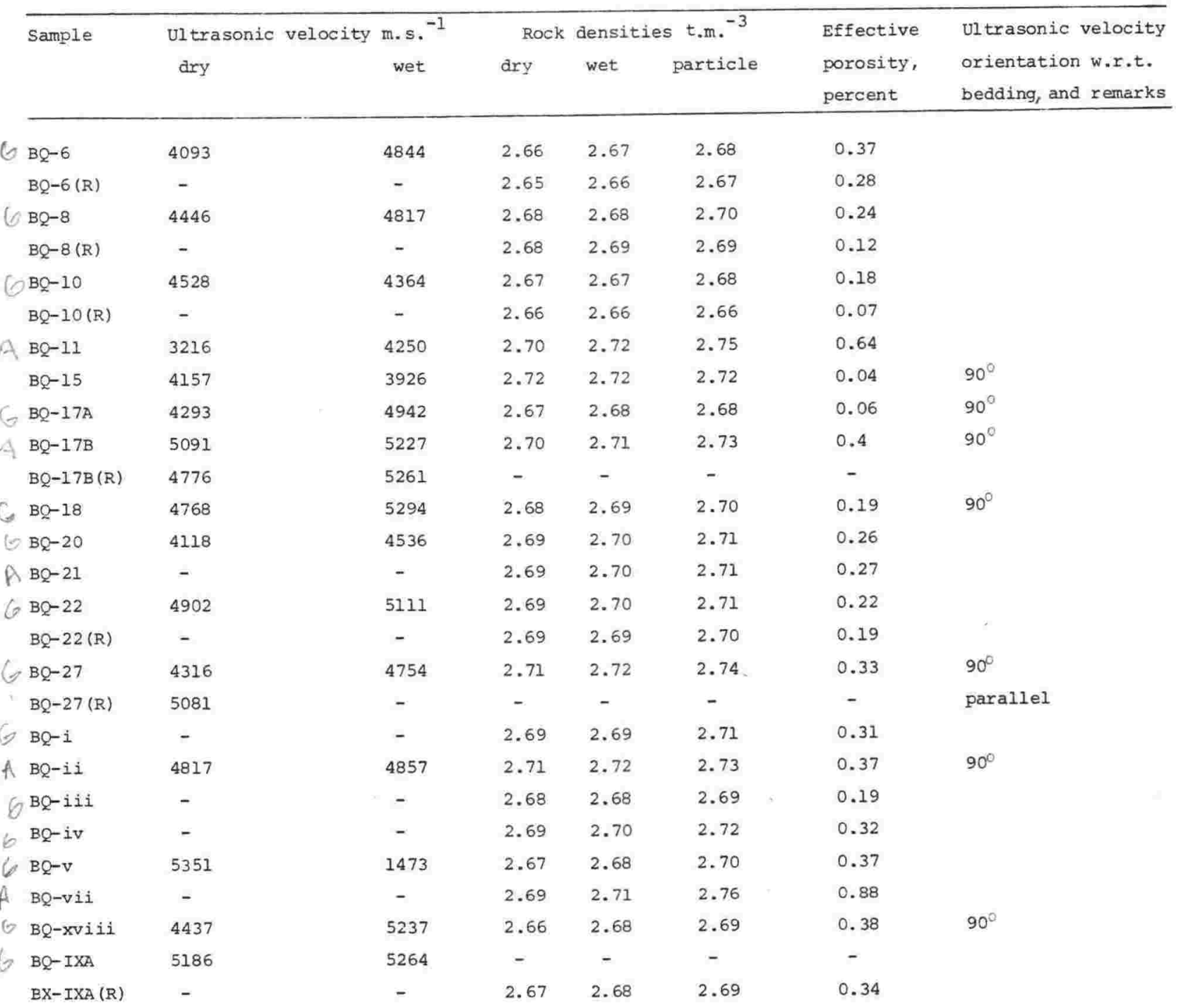




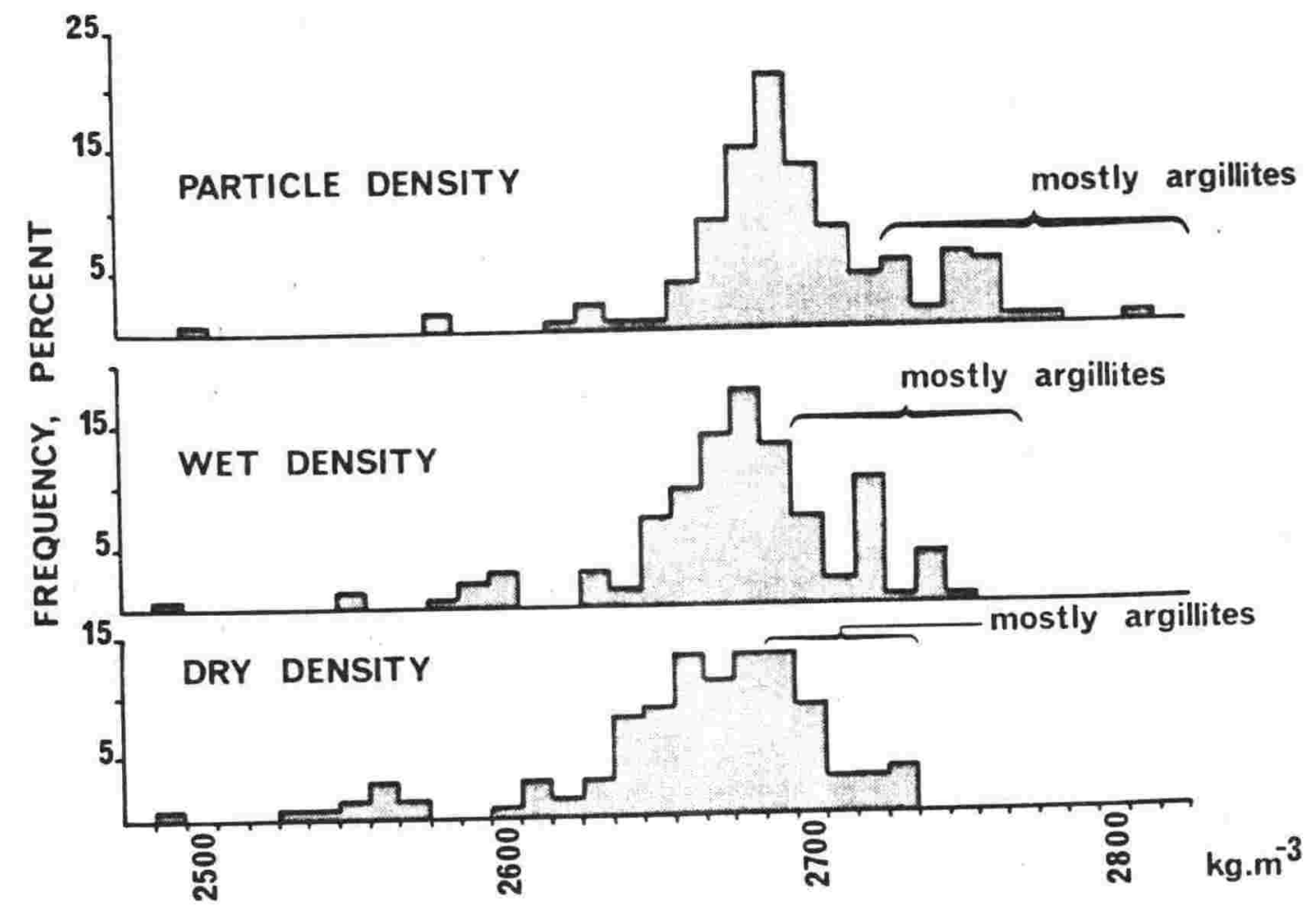

Figure AlO.1 : Densities of handspecimen samples, all lithologies; $\mathrm{n}=136$. 
Table A.10.2 : Densities, effective porosities and ultrasonic velocities of greyracke and argillite rock cores.

\begin{tabular}{|c|c|c|c|c|c|c|c|c|c|c|c|c|c|}
\hline \multirow{2}{*}{$\begin{array}{l}\text { Rock } \\
\text { mean } \\
\text { grain } \\
\text { size, } \\
\text { phi } \\
\end{array}$} & \multirow[t]{2}{*}{ Sample } & \multirow[t]{2}{*}{$\begin{array}{l}\text { Core } \\
\text { No. }\end{array}$} & \multicolumn{2}{|c|}{ Weight, gm. } & \multicolumn{2}{|c|}{$\begin{array}{l}\text { PUNDIT time } \\
\text { secs } \times 10^{-3}\end{array}$} & \multirow{2}{*}{$\begin{array}{l}\text { Core } \\
\text { length } \\
\text { h } \\
\text { inches }\end{array}$} & \multirow{2}{*}{$\begin{array}{l}\text { Core } \\
\text { volume } \\
\mathrm{cm}^{3} \\
\frac{\pi \mathrm{d}^{2}}{4} \times \mathrm{h}\end{array}$} & \multicolumn{2}{|c|}{$\begin{array}{l}\text { Density } \\
\mathrm{kg} \cdot \mathrm{m}^{-3}\end{array}$} & \multicolumn{2}{|c|}{$\begin{array}{l}\text { Ultrasonic } \\
\text { velocity m.s }\end{array}$} & \multirow{2}{*}{$\begin{array}{l}\text { Apparent } \\
\text { porosity, } \\
\text { percent }\end{array}$} \\
\hline & & & $d r y$ & wet & dry & wet & & & dry & wet & dry & wet & \\
\hline \multirow[t]{2}{*}{1.25} & $D C-6$ & 1 & 56.42 & & & & 1.708 & 21.300 & 2649 & & & & \\
\hline & & 2 & 54.22 & & & & 1.650 & 20.573 & 2636 & & & & \\
\hline \multirow{6}{*}{2.73} & $B O-V$ & & & & & & & & 2643 & mean & & & \\
\hline & $B Q-V$ & 1 & 66.17 & & & & 1.995 & 24.873 & 2660 & & & & \\
\hline & & 2 & 66.17 & & & & 1.998 & 24.912 & 2656 & & & & \\
\hline & & 3 & 66.34 & & & & 2.000 & 24.936 & $\begin{array}{l}2660 \\
2659\end{array}$ & mean & & & \\
\hline & & 1 & 49.20 & & & & 1.497 & 18.665 & 2636 & & & & \\
\hline & & 2 & 49.04 & & & & 1.494 & 18.628 & 2633 & & & & \\
\hline \multirow[t]{8}{*}{4.23} & $\mathrm{KTW}-\mathrm{i}$ & 1 & 66.50 & 66.71 & 9.4 & 9.3 & 1.998 & 24.912 & 2669 & 2678 & 5399 & 5457 & 0.316 \\
\hline & & 2 & 66.54 & & & & 1.997 & 24.897 & 2673 & & & & \\
\hline & & 3 & 66.72 & 66.92 & 9.4 & 9.4 & 2.002 & 24.961 & 2673 & 2681 & 5410 & 5410 & 0.300 \\
\hline & & 4 & 66.44 & & & & 1.993 & 24.848 & 2674 & & & & \\
\hline & & $\begin{array}{l}5 \\
6\end{array}$ & 66.72 & & & & 2.002 & 24.961 & 2673 & & & & \\
\hline & & $\begin{array}{l}6 \\
7\end{array}$ & $\begin{array}{l}66.47 \\
66.42\end{array}$ & 66.59 & 9.4 & & 1.994 & 24.863 & 2674 & & & & \\
\hline & & & & & 9.4 & 9.3 & 1.994 & 24.863 & 2672 & 2678 & $\begin{array}{l}5388 \\
5399\end{array}$ & $\begin{array}{l}5446 \\
5438\end{array}$ & 0.256 \\
\hline & & & & & & & & & $\begin{array}{r}2673 \\
2\end{array}$ & $\begin{array}{c}2679 \\
-\end{array}$ & $\begin{array}{r}5399 \\
11.0\end{array}$ & $\begin{array}{r}5438 \\
24.6\end{array}$ & $\begin{array}{l}0.291 \text { mean } \\
0.031 \text { s.d. }\end{array}$ \\
\hline 1.317 & $\mathrm{H} S-17$ & 1 & 66.54 & & & & 2.002 & 24.961 & 2666 & & & & \\
\hline & & 2 & 66.40 & 66.58 & 9.7 & 9.4 & 2.002 & 24.961 & 2660 & 2667 & 5242 & 5410 & 0.271 \\
\hline & & 3 & 66.58 & & & & 2.002 & 24.961 & 2667 & & & & \\
\hline & & 4 & 66.47 & 66.66 & 9.7 & 9.6 & 1.999 & 24.927 & 2667 & 2674 & 5235 & 5290 & 0.286 \\
\hline & & 5 & 66.53 & & & & 2.002 & 24.961 & 2665 & & & & \\
\hline & & 6 & 66.49 & 66.66 & 9.7 & 9.3 & 2.000 & 24.936 & 2666 & 2673 & 5237 & 5462 & 0.256 \\
\hline & & $\begin{array}{l}7 \\
8\end{array}$ & 66.04 & & & & 1.997 & 24.897 & 2653 & & & & \\
\hline & & $\begin{array}{l}8 \\
9\end{array}$ & 65.21 & 65.41 & 9.7 & 9.4 & 2.000 & 24.936 & 2615 & 2623 & 5237 & 5404 & 0.307 \\
\hline & & $\begin{array}{r}9 \\
10\end{array}$ & 66.14 & & & & $\begin{array}{l}2.001 \\
1.996\end{array}$ & 24.951 & 2651 & & & & \\
\hline & & $\begin{array}{l}10 \\
11\end{array}$ & $\begin{array}{l}66.29 \\
66.40\end{array}$ & 66.50 & 9.7 & 9.3 & $\begin{array}{l}1.996 \\
1.997\end{array}$ & 24.887 & 2664 & 2672 & 5227 & 5452 & 0.317 \\
\hline & & 12 & 66.45 & 66.62 & 9.8 & 9.5 & $\begin{array}{l}1.997 \\
2.000\end{array}$ & $\begin{array}{r}24.897 \\
24.936\end{array}$ & 2667 & & & 5347 & \\
\hline & & 13 & 66.58 & & & & $\begin{array}{l}2.000 \\
2.002\end{array}$ & $\begin{array}{l}24.936 \\
24.961\end{array}$ & 2665 & 2672 & 5184 & & 0.256 \\
\hline & & 14 & 66.60 & - & 9.7 & 9.3 & 2.003 & & 2667 & - & 5245 & 5471 & - \\
\hline & & 15 & 66.53 & & & & 2.001 & $\begin{array}{l}24.976 \\
24.951\end{array}$ & 2667 & - & & & - \\
\hline & & 16 & 62.27 & & & & 1.972 & $\begin{array}{l}24.951 \\
24.587\end{array}$ & & & & & \\
\hline & & 17 & 66.43 & 66.61 & 9.7 & 9.3 & 1.999 & $\begin{array}{l}24.587 \\
24.927\end{array}$ & $\begin{array}{l}2533 \\
2665\end{array}$ & 2672 & 5235 & 5460 & 0.271 \\
\hline & & & & & & & & & $\begin{array}{l}2665 \\
2653\end{array}$ & 2665 & 5230 & 5412 & 0.281 mean \\
\hline & & & & & & & & & 33 & 185 & 19.4 & 64.4 & 0.024 s.d. \\
\hline 4.72 & $S J-T$ & 1 & 67.17 & & & & 1.994 & 24.863 & 2702 & & & & \\
\hline & & 2 & 67.27 & & & & 2.001 & 24.951 & 2696 & & & & \\
\hline & & 3. & 67.07 & 67.26 & 9.2 & 9.3 & 1.995 & 24.873 & 2697 & 2704 & 5508 & 5448 & 0.283 \\
\hline & & 4 & 67.55 & 67.76 & 9.2 & 9.3 & 2.005 & 24.999 & 2702 & 2711 & 5536 & 5476 & 0.311 \\
\hline & & 5 & 67.06 & & & & 2.000 & 24.936 & 2689 & & & & \\
\hline & & $\begin{array}{l}6 \\
7\end{array}$ & 66.92 & & & & 1.996 & 24.887 & 2689 & & & & \\
\hline & & $\begin{array}{l}7 \\
8\end{array}$ & 67.30 & 67.51 & 9.2 & 9.3 & 2.002 & 24.961 & 2696 & 2705 & 5527 & 5468 & 0.312 \\
\hline & & & 67.12 & & & & 1.994 & 24.863 & $\begin{array}{l}2700 \\
2696\end{array}$ & 2707 & 5524 & 5464 & 0.302 mean \\
\hline & & & & & & & & & 5 & - & 14.3 & 14.4 & 0.017 s.d. \\
\hline 1.32 & $S J-31$ & $\begin{array}{l}1 \\
2\end{array}$ & $\begin{array}{l}66.09 \\
66.04\end{array}$ & & & & $\begin{array}{l}1.996 \\
2.000\end{array}$ & $\begin{array}{l}24.887 \\
24.936\end{array}$ & $\begin{array}{l}2656 \\
2648\end{array}$ & - & 5292 & 5462 & - \\
\hline & & 3 & 65.80 & - & 9.6 & 9.3 & $\begin{array}{l}2.000 \\
1.999\end{array}$ & 24.927 & 2640 & & 5292 & & \\
\hline & & 4 & 66.11 & - & 9.5 & 9.0 & 1.999 & 24.927 & 2652 & - & 5345 & 5642 & - \\
\hline & & 5 & 65.97 & & & & 1.995 & 24.873 & 2652 & & & & \\
\hline & & 6 & 66.23 & 66.38 & 9.6 & 9.1 & 2.000 & 24.936 & 2656 & 2662 & 5292 & 5582 & 0.227 \\
\hline & & 7 & 66.12 & & & & 1.998 & 24.912 & 2654 & & & & \\
\hline & & 8 & 67.00 & & & & 1.995 & 24.873 & 2694 & , & & & \\
\hline & & 9 & 67.36 & 67.56 & 9.5 & 9.2 & 1.995 & 24.873 & 2708 & 2716 & 5334 & 5508 & 0.297 \\
\hline & & 10 & 66.96 & & & & 1.996 & 24.887 & 2691 & & & & \\
\hline & & 11 & 67.41 & - & 10.5 & 9.8 & 2.003 & 24.976 & 2699 & - & 4846 & 5192 & - \\
\hline & & 12 & 67.05 & 67.24 & 9.4 & 9.2 & 1.998 & 24.912 & 2692 & 2699 & 5399 & 5516 & 0.283 \\
\hline & & & & & & & & & 2670 & 2692 & 5251 & 5484 & 0.269 mean \\
\hline & & & & & & & & & 24 & - & 202.5 & 156.2 & 0.037 s.d. \\
\hline
\end{tabular}


Table Al0.2 : continued.

\begin{tabular}{|c|c|c|c|c|c|c|c|c|c|c|c|c|c|}
\hline \multirow{2}{*}{$\begin{array}{l}\text { Rock } \\
\text { mean } \\
\text { grain } \\
\text { size, } \\
\text { phi } \\
\end{array}$} & \multirow[t]{2}{*}{ Sample } & \multirow[t]{2}{*}{$\begin{array}{l}\text { Core } \\
\text { No. }\end{array}$} & \multicolumn{2}{|c|}{ Weight gm. } & \multicolumn{2}{|c|}{$\begin{array}{l}\text { PUNDIT time } \\
\text { secs } \times 10^{-3}\end{array}$} & \multirow{2}{*}{$\begin{array}{l}\text { Core } \\
\text { length } \\
\text { h } \\
\text { inches }\end{array}$} & \multirow{2}{*}{$\begin{array}{l}\text { Core } \\
\text { volume } \\
\mathrm{cm}^{3} \\
\frac{\pi \mathrm{d}^{2}}{4} \times \mathrm{h}\end{array}$} & \multicolumn{2}{|c|}{$\begin{array}{l}\text { Density } \\
\mathrm{kg} \cdot \mathrm{m}^{-3}\end{array}$} & \multicolumn{2}{|c|}{$\begin{array}{l}\text { Ultrasonic } \\
\text { velocity m.s }\end{array}$} & \multirow{2}{*}{$\begin{array}{l}\text { Apparent } \\
\text { porosity, } \\
\text { percent }\end{array}$} \\
\hline & & & $d r y$ & wet & dry & wet & & & dry & wet & dry & wet & \\
\hline \multirow{15}{*}{2.6} & \multirow{15}{*}{$\mathrm{KTW}-14$} & $\begin{array}{l}2 \\
3\end{array}$ & $\begin{array}{l}66.71 \\
66.90\end{array}$ & 67.10 & 9.5 & 9.2 & $\begin{array}{l}2.001 \\
2.005\end{array}$ & $\begin{array}{l}24.951 \\
25.000\end{array}$ & $\begin{array}{l}2674 \\
2676\end{array}$ & & & & \\
\hline & & 4 & 66.66 & & & & $\begin{array}{l}2.000 \\
2.003\end{array}$ & $\begin{array}{l}25.000 \\
24.976\end{array}$ & $\begin{array}{l}2676 \\
2669\end{array}$ & 2684 & 5361 & 5536 & 0.299 \\
\hline & & 5 & 66.87 & 67.07 & 9,4 & 9.1 & 2.004 & 24.986 & 2676 & 2684 & 5415 & 5593 & 0.299 \\
\hline & & 6 & 66.95 & & & & 2.007 & 25.024 & 2675 & & 5415 & 5593 & 0.299 \\
\hline & & 7 & 66.52 & & & & 1.999 & 24.927 & 2669 & & & & \\
\hline & & 8 & 66.54 & & & & 1.996 & 24.887 & 2674 & & & & \\
\hline & & 9 & 66.19 & 66.39 & 9.3 & 9.1 & 2.005 & 25.000 & 2648 & 2656 & 5476 & 5597 & 0.302 \\
\hline & & 10 & 66.75 & 66.93 & 9.4 & 9.2 & 2.002 & 24.961 & 2674 & 2681 & 5410 & 5527 & 0.270 \\
\hline & & $\begin{array}{l}11 \\
12\end{array}$ & $\begin{array}{l}66.70 \\
66.62\end{array}$ & & & & $\begin{array}{l}1.998 \\
1.999\end{array}$ & $\begin{array}{l}24.912 \\
24.927\end{array}$ & 2677 & & & & \\
\hline & & $\begin{array}{l}12 \\
13\end{array}$ & $\begin{array}{l}66.62 \\
66.65\end{array}$ & 66.80 & 9.5 & 9.2 & $\begin{array}{l}1.999 \\
1.997\end{array}$ & $\begin{array}{l}24.927 \\
24.897\end{array}$ & $\begin{array}{l}2673 \\
2677\end{array}$ & 2680 & 5345 & 5520 & 0.270 \\
\hline & & 14 & 66.73 & 66.92 & 9.5 & 9.2 & 2.002 & $\begin{array}{l}24.897 \\
24.961\end{array}$ & 2673 & 2681 & 5353 & & \\
\hline & & 15 & 66.55 & 66.73 & 9.7 & 9.4 & 1.995 & 24.873 & 2676 & 2683 & $\begin{array}{l}5353 \\
5224\end{array}$ & $\begin{array}{l}5527 \\
5390\end{array}$ & $\begin{array}{l}0.285 \\
0.271\end{array}$ \\
\hline & & 16 & 66.65 & & & & 1.997 & 24.897 & 2677 & & 5224 & & \\
\hline & & & & & & & & & 2673 & 2679 & 5368 & 5528 & 0.289 mean \\
\hline & & & & & & & & & 7 & 9 & 73.0 & 63.5 & 0.017 s.d. \\
\hline & & $\begin{array}{l}2 \\
3\end{array}$ & $\begin{array}{l}66.82 \\
66.45\end{array}$ & 67.06 & 9.4 & 9.2 & $\begin{array}{l}2.004 \\
2.003\end{array}$ & $\begin{array}{l}24.986 \\
24.976\end{array}$ & $\begin{array}{l}2674 \\
2661\end{array}$ & 2684 & 5415 & 5533 & 0.359 \\
\hline & & 4 & 66.60 & - & 9.3 & 9.2 & 2.003 & 24.976 & 2667 & - & 5471 & 5530 & - \\
\hline & & 5 & 66.23 & & & & 1.996 & 24.887 & 2661 & & & & \\
\hline & & $\begin{array}{l}6 \\
7\end{array}$ & $\begin{array}{l}66.30 \\
66.55\end{array}$ & 66.56 & 9.4 & 9.2 & 1.998 & 24.912 & 2661 & 2672 & 5399 & 5516 & 0.392 \\
\hline & & $\begin{array}{l}7 \\
8\end{array}$ & $\begin{array}{l}66.55 \\
66.55\end{array}$ & 66.77 & 9.3 & & 1.998 & 24.912 & $\begin{array}{l}2671 \\
2670\end{array}$ & & & & \\
\hline & & 9 & 66.59 & & 1.3 & 9.1 & $\begin{array}{l}1.999 \\
2.000\end{array}$ & $\begin{array}{l}24.927 \\
24.936\end{array}$ & $\begin{array}{l}2670 \\
2670\end{array}$ & 2679 & 5460 & 5580 & 0.331 \\
\hline & & 10 & 66.47 & 66.67 & 9.5 & 9.3 & $\begin{array}{l}2.000 \\
2.003\end{array}$ & 24.976 & 2661 & 2669 & 5356 & 5471 & 0.301 \\
\hline & & 11 & 67.01 & & & & 2.011 & 25.074 & 2673 & & & & 0.301 \\
\hline & & 12 & 66.49 & - & 9.3 & 9.2 & 2.005 & 25.000 & 2680 & - & 5476 & 5536 & - \\
\hline & & $\begin{array}{l}13 \\
14\end{array}$ & $\begin{array}{l}66.46 \\
66.18\end{array}$ & 66.67 & 9.4 & 9.2 & 1.995 & 24.873 & 2672 & 2680 & 5390 & 5508 & $0 . \overline{316}$ \\
\hline & & 15 & 66.33 & & & & $\begin{array}{l}1.997 \\
1.997\end{array}$ & $\begin{array}{l}24.897 \\
24.897\end{array}$ & 2658 & & & & \\
\hline & & 16 & 66.06 & - & 9.3 & 9.1 & $\begin{array}{l}1.997 \\
1.996\end{array}$ & $\begin{array}{l}24.897 \\
24.887\end{array}$ & $\begin{array}{l}2664 \\
2654\end{array}$ & - & & 5571 & - \\
\hline & & 17 & 66.53 & & & & 2.001 & 24.951 & $\begin{array}{l}2654 \\
2666\end{array}$ & - & 5452 & 5571 & - \\
\hline & & 18 & 66.48 & 66.70 & 9.3 & 9.2 & 1.995 & 24.873 & 2673 & 2682 & 5448 & 5508 & 0.331 \\
\hline & & 19 & 66.58 & 66.81 & 9.4 & 9.2 & 1.999 & 24.927 & 2671 & 2680 & 5402 & 5520 & $\begin{array}{l}0.331 \\
0.346\end{array}$ \\
\hline & & 20 & 66.12 & & & & 1.984 & 24.737 & 2673 & & & & \\
\hline & & 21 & 66.58 & & & & 1.999 & 24.927 & 2671 & & & & \\
\hline & & $\begin{array}{l}22 \\
23\end{array}$ & $\begin{array}{l}66.34 \\
66.43\end{array}$ & - & 9.4 & 9.2 & 1.998 & 24.912 & & - & 5399 & 5516 & - \\
\hline & & & & & & & 2.000 & 24.936 & $\begin{array}{l}2664 \\
2667\end{array}$ & 2678 & & & \\
\hline & & & & & & & & & 7 & 5 & $\begin{array}{r}5424 \\
38.9\end{array}$ & $\begin{array}{l}5526 \\
30.0\end{array}$ & $\begin{array}{l}0.339 \text { mean } \\
0.03 \text { s.d. }\end{array}$ \\
\hline & & $\begin{array}{l}2 \\
3\end{array}$ & $\begin{array}{l}66.05 \\
65.87\end{array}$ & 66.40 & 11.1 & 10.0 & $\begin{array}{l}2.001 \\
1.996\end{array}$ & $\begin{array}{l}24.951 \\
24.887\end{array}$ & $\begin{array}{l}2647 \\
2647\end{array}$ & 2661 & & & \\
\hline & & 4 & 65.06 & 65.37 & 10.6 & 9.9 & 2.000 & 24.936 & 2609 & 2622 & 4793 & 5131 & 0.477 \\
\hline & & 5 & 64.24 & 64.53 & 10.0 & 9.6 & 1.997 & 24.897 & 2580 & 2592 & 5072 & 5283 & 0.451 \\
\hline & & 6 & 65.60 & & & & 1.995 & 24.873 & 2637 & & & & \\
\hline & & 7 & 64.49 & & & & 2.000 & 24.936 & 2586 & & & & \\
\hline & & 8 & 64.89 & 65.15 & 10.0 & 9.5 & 2.005 & 25.000 & 2596 & 2606 & 5093 & 5305 & 0.401 \\
\hline & & 9 & 66.28 & & & & 2.000 & 24.936 & 2658 & & & & \\
\hline & & $\begin{array}{l}10 \\
11\end{array}$ & $\begin{array}{l}66.24 \\
64.71\end{array}$ & & & & 2.002 & 24.961 & 2654 & & & & \\
\hline & & $\begin{array}{l}11 \\
12\end{array}$ & $\begin{array}{l}64.71 \\
66.04\end{array}$ & - & 10.1 & 9.6 & $\begin{array}{l}1.996 \\
1.997\end{array}$ & $\begin{array}{l}24.887 \\
24.897\end{array}$ & $\begin{array}{l}2600 \\
2653\end{array}$ & - & 5020 & 5281 & - \\
\hline & & 13 & 65.44 & 65.70 & 10.0 & 9.5 & $\begin{array}{l}1.997 \\
2.001\end{array}$ & 24.951 & 2623 & 2633 & 5083 & 5351 & 0.397 \\
\hline & & 14 & 6575 & & & & 2.000 & 24.936 & 2637 & 2033 & 5083 & & \\
\hline & & 15 & 65.82 & 66.11 & 10.1 & 9.6 & 2.002 & 24.961 & 2637 & 2649 & 5035 & 5297 & 0.441 \\
\hline & & 16 & 65.96 & 66.35 & 11.1 & 10.0 & 1.999 & 24.927 & 2646 & 2662 & 4575 & 5078 & 0.591 \\
\hline & & 17 & 65.46 & & & & 1.996 & 24.887 & 2630 & & & & \\
\hline & & 18 & 65.60 & & & & 1.996 & 24.887 & 2636 & & & & \\
\hline & & 19 & 65.87 & 66.23 & 10.9 & 9.8 & 1.995 & 24.873 & 2648 & 2663 & 4649 & 5170 & 0.547 \\
\hline & & & & & & & & & 2627 & 2636 & 4878 & 5220 & 0.479 \\
\hline
\end{tabular}


Table Al0.2 : continued.

\begin{tabular}{|c|c|c|c|c|c|c|c|c|c|c|c|c|c|}
\hline \multirow{2}{*}{$\begin{array}{l}\text { Rock } \\
\text { mean } \\
\text { grain } \\
\text { size, } \\
\text { phi }\end{array}$} & \multirow[t]{2}{*}{ Sample } & \multirow[t]{2}{*}{$\begin{array}{l}\text { Core } \\
\text { No. }\end{array}$} & \multicolumn{2}{|c|}{ Weight gm. } & \multicolumn{2}{|c|}{$\begin{array}{l}\text { PUNDIT time } \\
\text { secs } \times 10^{-3}\end{array}$} & \multirow{2}{*}{$\begin{array}{l}\text { Core } \\
\text { length } \\
\text { h } \\
\text { inches }\end{array}$} & \multirow{2}{*}{$\begin{array}{l}\text { Core } \\
\text { volume } \\
\mathrm{cm}^{3} \\
\frac{\pi \mathrm{d}^{2}}{4} \times \mathrm{h}\end{array}$} & \multicolumn{2}{|c|}{ 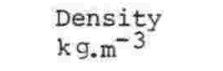 } & \multicolumn{2}{|c|}{$\begin{array}{l}\text { Ultrasonic } \\
\text { velocity } \mathrm{m} \cdot \mathrm{s}^{-1}\end{array}$} & \multirow{2}{*}{$\begin{array}{l}\text { Apparent } \\
\text { porosity, } \\
\text { percent }\end{array}$} \\
\hline & & & dry & wet & dry & wet & & & dry & wet & dry & wet & \\
\hline \multirow[t]{22}{*}{5.6} & $O B-W$ & 1 & 67.39 & 67.64 & 10.0 & 10.5 & 1.997 & 24.897 & 2707 & 2717 & 5072 & 4831 & 0.371 \\
\hline & & $\begin{array}{l}2 \\
3\end{array}$ & $\begin{array}{l}67.39 \\
67.31\end{array}$ & & & & 2.000 & 24.936 & $\begin{array}{l}2703 \\
2702\end{array}$ & & & & \\
\hline & & 4 & 67.42 & 67.66 & 10.0 & 10.3 & $\begin{array}{l}1.998 \\
2.000\end{array}$ & $\begin{array}{l}24.912 \\
24.936\end{array}$ & $\begin{array}{l}2702 \\
2704\end{array}$ & 2713 & 5080 & 4932 & 0.356 \\
\hline & & 5 & 67.42 & & & & 1.999 & 24.927 & 2705 & & & & \\
\hline & & 6 & 67.31 & & & & 1.995 & 24.873 & 2706 & & & & \\
\hline & & 7 & 67.19 & & & & 1.995 & 24.873 & 2701 & & & & \\
\hline & & 8 & 67.59 & & & & 1.993 & 24.848 & 2720 & & & & \\
\hline & & 9 & 67.23 & 67.48 & 10.1 & 10.4 & 2.000 & 24.936 & 2696 & 2703 & 5030 & 4885 & 0.372 \\
\hline & & 10 & 67.54 & 67.78 & 9.9 & 10.2 & 1.991 & 24.824 & 2721 & 2730 & 5108 & 4958 & 0.355 \\
\hline & & 11 & 67.14 & 67.37 & 9.9 & 10.0 & 1.997 & 24.897 & 2697 & 2706 & 5123 & 5072 & 0.343 \\
\hline & & 12 & 67.78 & 68.05 & 9.9 & 10.2 & 1.994 & 24.863 & 2726 & 2737 & 5116 & 4966 & 0.398 \\
\hline & & 13 & 67.97 & & & & 1.997 & 24.897 & 2730 & & & & \\
\hline & & 14 & 67.90 & 68.17 & 10.0 & 10.2 & 1.997 & 24.897 & 2727 & 2738 & 5072 & 4973 & 0.398 \\
\hline & & 15 & 67.25 & 67.51 & 10.0 & 10.3 & 1.992 & 24.838 & 2708 & 2718 & 5060 & 4913 & 0.387 \\
\hline & & 16 & 68.06 & & & & 1.998 & 24.912 & 2732 & & & & \\
\hline & & 17 & 67.95 & 68.22 & 10.0 & 10.3 & 1.999 & 24.927 & 2726 & 2737 & 5078 & 4930 & 0.397 \\
\hline & & 18 & 67.90 & & & & 1.999 & 24.927 & 2724 & & & & \\
\hline & & 19 & 67.19 & 67.44 & 9.9 & 10.1 & 1.994 & 24.863 & 2702 & 2713 & 5116 & 5015 & 0.372 \\
\hline & & 20 & 67.91 & & & & 2.000 & 24.936 & 2723 & & & & \\
\hline & & 21 & 67.96 & 68.23 & 10.0 & 10.3 & 1.997 & 24.897 & 2730 & 2741 & 5072 & 4924 & 0.397 \\
\hline & & & & & & & & & 2714 & 2723 & 5084 & 4945 & 0.377 mean \\
\hline & & & & & & & & & 124 & 139 & 28.5 & 63.9 & 0.019 s.d. \\
\hline \multirow[t]{19}{*}{6.28} & $\mathrm{HQ}-22$ & 1 & 66.57 & & & & 1.995 & 24.873 & 2676 & & & & \\
\hline & & 2 & 66.81 & & & & 1.994 & 24.863 & 2687 & & & & \\
\hline & & 3 & 66.59 & & & & 1.995 & 24.873 & 2677 & & & & \\
\hline & & 4 & 66.77 & 67.12 & 10.1 & 10.3 & 1.994 & 24.863 & 2686 & 2700 & 5015 & 4918 & 0.524 \\
\hline & & 5 & 66.89 & 67.24 & 9.9 & 10.2 & 1.995 & 24.873 & 2689 & 2703 & 5118 & 4968 & 0.523 \\
\hline & & 6 & 66.77 & & & & 1.995 & 24.873 & 2684 & & & & \\
\hline & & 7 & 66.97 & 67.30 & 9.8 & 10.1 & 1.996 & 24.887 & 2691 & 2704 & 5174 & 5020 & 0.493 \\
\hline & & 8 & 66.65 & & & & 1.994 & 24.863 & 2681 & & & & \\
\hline & & 9 & 66.67 & - & 9.9 & 10.2 & 1.996 & 24.887 & 2679 & - & 5121 & 4971 & - \\
\hline & & & & & & & & & 2685 & 2702 & 5107 & 4969 & 0.513 mean \\
\hline & & & & & & & & & 5 & - & 66.5 & 41.7 & 0.018 s.a. \\
\hline & & 1 & 50.12 & & & & 1.495 & 18.640 & 2689 & & & & \\
\hline & & 2 & 50.04 & & & & 1.492 & 18.603 & 2690 & & & & \\
\hline & & 3 & 49.80 & & & & 1.486 & 18.528 & 2688 & & & & \\
\hline & & 4 & 49.71 & & & & 1.490 & 18.578 & 2676 & & & & \\
\hline & & 5 & 49.78 & & & & 1.486 & 18.528 & 2687 & & & & \\
\hline & & 6 & 49.78 & & & & 1.486 & 18.528 & 2687 & & & & \\
\hline & & 7 & 49.87 & & & & 1.491 & 18.590 & 2683 & & & & \\
\hline & & 8 & 49.76 & & & & 1.484 & 18.503 & 2689 & & & & \\
\hline
\end{tabular}


APPENDIX 11

Discontinuity spacing : table of raw data.

This table is the basis of Figures 3.1 and 3.2.

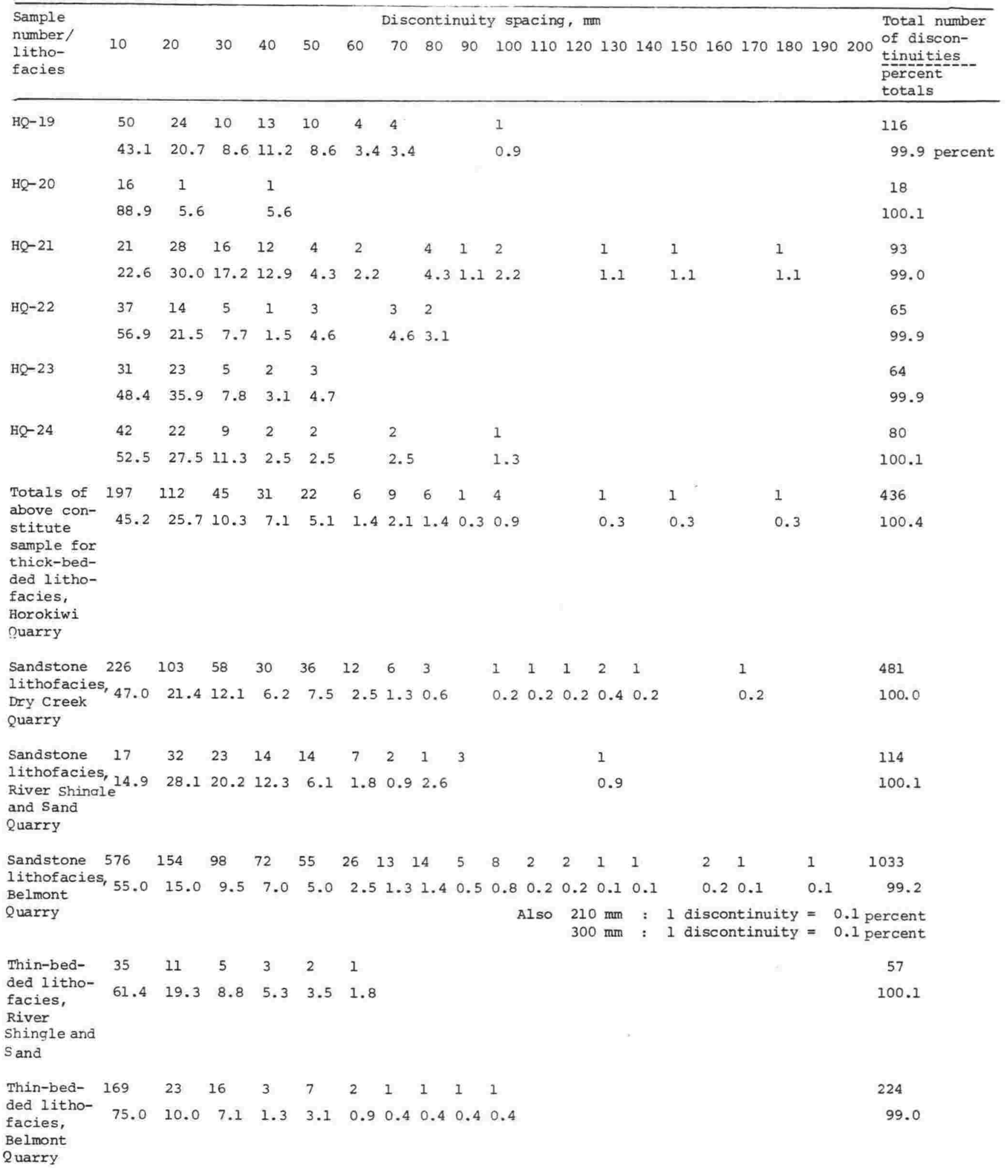


APPENDIX 12

Rock core preparation for uniaxial compression testing

Blocks from individual beds, representative of geologic parameters, were hand quarried to enable flaw-free core samples to be cut from them. Blocks from a few kilogrammes to over $50 \mathrm{~kg}$ were identified and worked according to bedding plane attitude.

A 24 inch slabbing saw was used to cut blocks into 3 inch slabs parallel to bedding. More than 30 linear feet of rock was cut to provide the number of cores tested. Cores $25 \mathrm{~mm}$ in diameter were then taken, perpendicular to bedding, with a continuous rim core bit in a precision drill press with the slabs firmly clamped to prevent "wander". A specially made holding arm was fitted to a Hilquist thin section machine to facilitate cutting and surface grinding of end faces perpendicular to core axis. Other than water coolants, lubricants or solvents were not used at any stage. These precautions were necessary for specimen uniformity and the following criteria were achieved:

Diameter $\pm 0.0015^{\prime \prime}$ (micrometer checked).

(ii) Sides smooth, free from irregularities and straight to within $0.3 \mathrm{~mm}$ over length, checked with straight edge and feeler gauge.

Ends flat to within $0.02 \mathrm{~mm}$ (microscope inspection).

(iv) Core sides parallel with end plane vertical to axis. This proved difficult to check with precision but tolerance of the former was of the order of $0.025 \mathrm{~mm}$ and the 1 atter four to five minutes.

(v) Minimum surface contamination.

Hawkes and Mellor (1970) and Vutukuri et al. (1974) provided guidance for core geometry, and a length to diameter ratio of 1.5 was chosen to establish a "feel" for the rock types being tested.

Finished cores were thoroughly washed and from that stage not touched by bare hand.

After air drying, they were packed in cotton wool in a constant environment $\left(20 \pm 1^{\circ} \mathrm{C}\right.$, 50 percent R.H.) for one month, when a representative set of cores was removed and immersed in distilled water at $20 \pm 1^{\circ} \mathrm{C}$ for one month.

Individual cores or rock types were not tested in any particular order but, generally, stressstrain measurements were done last in both wet and dry core testing programmes and dry testing was carried out before wet testing.

The air dried and saturated cores were tested in the third month after preparation. At the same time cores for two rock types ( $B Q-I X A$ and HQ-22) taken 18 months previously were tested air dried for comparison (Appendix 13).

Compression testing was carried out in constant temperature conditions $\left(20^{\circ} \pm 5^{\circ} \mathrm{C}\right)$ on an Avery universal testing machine with a three range capability of 400,000 lbs graded A to NZS 1021:1965 on all three ranges. The low range up to $80,000 \mathrm{lbs}$ in $50 \mathrm{lb}$ divisions was used. The machine had one spherical platen seat (the upper platen), lightly oiled and held 
horizontal by four adjustable coil springs. Cores were accurately placed between test platens with the aid of templates. False platens were used above and below core specimens (Plate Al2.1) with no lubricant between platen and sample.

The spherical platen seating conforms to criteria for uniformity assessed by the New Zealand Concrete Research Associations', Foote proving device (Boult, pers. comm.).

A loading rate of $127 \mathrm{lbf} . \mathrm{in}^{-2} \cdot \mathrm{s}^{-1}\left(0.87 \mathrm{MPa} . \mathrm{s}^{-1}\right)$ was used throughout, i.e. 6,000 1b $10 a d$ per minute on the cores tested. 


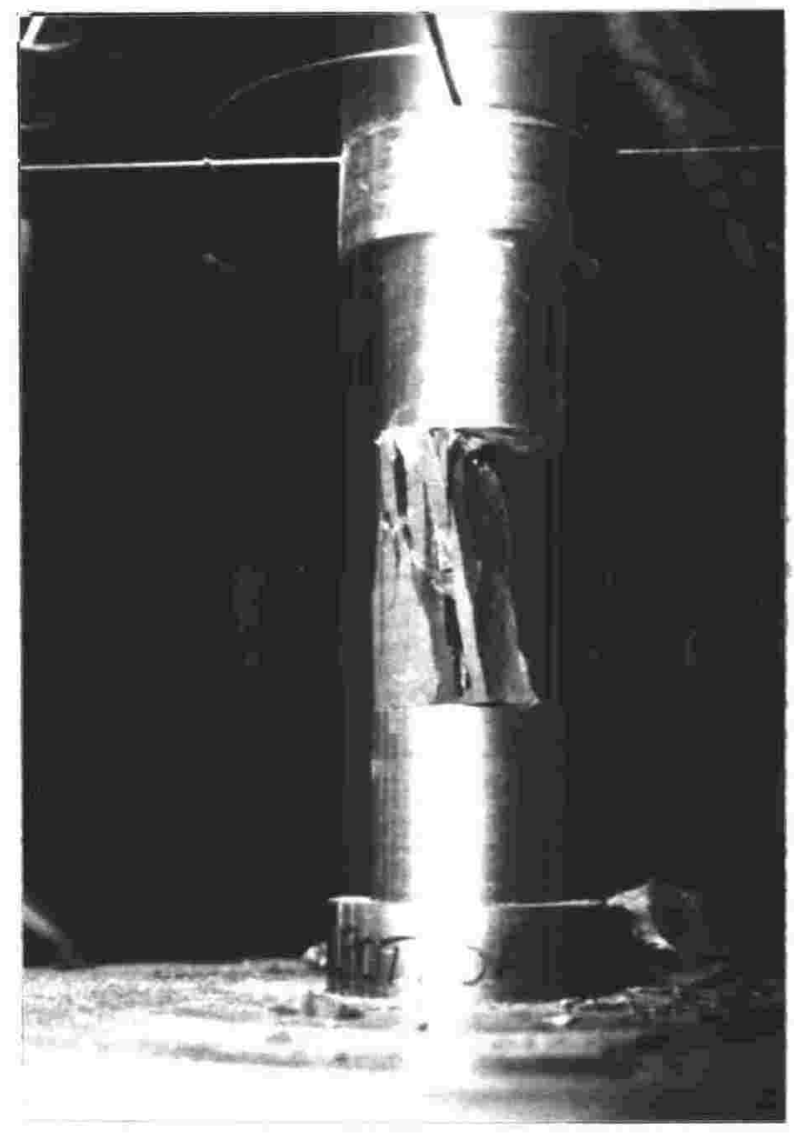

Plate Al2.1 : After recommendations of Vutukuri et al. (1974), uniaxial compression testing of rock cores involved placing hard false-platens either end of the sample. The false platens had a $\mathrm{h}$ :d ratio of 1 and matched core sample diameter exactly.

The larger platens, between false-platens and testing machine platens, are of mild steel and protect testing machine platen surfaces.

A sample of argillite $(O B-W)$ is shown (h:d ratio of 1.5 ) failed from axial cleavage during equipment trials. 
APPENDIX 13

Uniaxial compressive strengths of Wellington greywacke-suite rocks : tables

Stress-strain curves were derived from cores marked *. Cores marked + were prepared for testing 18 months in advance of others, and, without exception their strengths are higher for any given lithology; accordingly, where numbers justify, their mean strengths are calculated separately. Failure load marked \# indicate premature failure not included in results.

Included are results from Bryant (1977); he tested samples which were $47.6 \mathrm{~mm}, 50.8 \mathrm{~mm}$, $146.0 \mathrm{~mm}$ and $152.4 \mathrm{~mm}$ in diameter with a length:diameter ratio of 2, loaded at approximately $14 \mathrm{MPa}$ per minute.

\begin{tabular}{|c|c|c|c|c|c|c|c|c|c|c|c|}
\hline \multirow[t]{2}{*}{ Sample } & \multirow{2}{*}{$\begin{array}{l}\text { Core } \\
\text { No. }\end{array}$} & \multirow{2}{*}{$\begin{array}{l}\frac{\mathrm{h}}{\mathrm{D}} \\
\text { ratio }\end{array}$} & \multirow{2}{*}{$\begin{array}{l}\text { Core } \\
\text { diameter } \\
\text { D, inches }\end{array}$} & \multirow{2}{*}{$\begin{array}{l}\text { Bearing } \\
\text { area } \\
\text { inches }\end{array}$} & \multirow{2}{*}{$\begin{array}{l}\text { Failure } \\
\text { load, } \\
\text { lb }\end{array}$} & \multicolumn{3}{|c|}{ Strength } & \multirow[t]{2}{*}{ s.d. } & \multirow[t]{2}{*}{ Variance } & \multirow{2}{*}{$\begin{array}{l}\text { Coefficient } \\
\text { of } \\
\text { variation, }\end{array}$} \\
\hline & & & & & & Ibf. in ${ }^{-2}$ & $\mathrm{MPa}$ & Mean & & & \\
\hline $\mathrm{HQ}-17$ & 1 & 2 & 0.985 & 0.762 & 25,400 & 33,333 & 230 & 221 & 25.6 & 581 & 11.6 \\
\hline \multirow{8}{*}{ dry } & $3 *$ & & & & 24,700 & 32,415 & 224 & $n=9$ & & & \\
\hline & 5 & & & & 23,500 & 30,840 & 213 & & & & \\
\hline & 7 & & & & 20,900 & 27,428 & 189 & & & & \\
\hline & $9 *$ & & & & 28,900 & 37,927 & 262 & & & & \\
\hline & 11 & & & & 25,800 & 33,858 & 233 & & & & \\
\hline & 13 & & & & 20,400 & 26,772 & 185 & & & & \\
\hline & $\begin{array}{l}15^{*} \\
16\end{array}$ & & & & 22,700 & 29,790 & 205 & & & & \\
\hline & 1 & 1.5 & & & 27,300 & 35,827 & 247 & & & & \\
\hline \multirow[t]{9}{*}{ wet } & 2 & 2 & & & 28,300 & 37,139 & 256 & 256 & - & 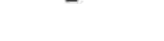 & - \\
\hline & $4 *$ & & & & 23,300 & 30,577 & 211 & 194 & 32.1 & 902 & 16.6 \\
\hline & $6 *$ & & & & 25,900 & 33,990 & 234 & $n=8$ & & & \\
\hline & 8 & & & & 23,500 & 30,840 & 213 & & & & \\
\hline & 10 & & & & 18,000 & 23,622 & 163 & & & & \\
\hline & 12 & & & & $\begin{array}{l}19,500 \\
15,300\end{array}$ & 25,591 & 176 & & & & \\
\hline & 14 & & & & $\begin{array}{l}15,300 \\
24,000\end{array}$ & 20,079 & 138 & & & & \\
\hline & $17 *$ & & & & $\begin{array}{l}24,000 \\
21,900\end{array}$ & 31,496 & 217 & & & & \\
\hline & & & & & 21,900 & 28,740 & 198 & & & & \\
\hline \multirow{7}{*}{$\begin{array}{l}\mathrm{SJ}-31 \\
\mathrm{dry}\end{array}$} & $\begin{array}{l}1 \\
3 *\end{array}$ & 2 & 0.985 & 0.762 & 26,100 & 34,252 & 236 & 234 & 22.2 & 412 & 9.5 \\
\hline & $\begin{array}{l}3^{*} \\
5\end{array}$ & & & & 27,500 & 36,089 & 249 & $n=6$ & & & \\
\hline & 7 & & & & 26,500 & 34,777 & 240 & & & & \\
\hline & $8 *$ & & & & 23,600 & 30,971 & 214 & & & & \\
\hline & $10 *$ & & & & 22,300 & 29,265 & 202 & & & & \\
\hline & 1 & 1.5 & & & 29,000 & 38,058 & $\begin{array}{l}262 \\
205\end{array}$ & & & & \\
\hline & 2 & & & & $\begin{array}{r}\# 22,700 \\
31,800\end{array}$ & $\begin{array}{l}29,790 \\
41,732\end{array}$ & $\begin{array}{l}205 \\
288\end{array}$ & 288 & - & - & - \\
\hline \multirow[t]{6}{*}{ wet } & 2 & 2 & & & 15,000 & & 136 & 149 & 41.7 & 1452 & 28.0 \\
\hline & 4 & & & & 22,800 & $\begin{array}{l}19,685 \\
29,921\end{array}$ & $\begin{array}{l}136 \\
206\end{array}$ & $n=6$ & 31.1 & 1402 & \\
\hline & $6 *$ & & & & 19,400 & $\begin{array}{l}29,921 \\
25,459\end{array}$ & $\begin{array}{l}206 \\
176\end{array}$ & & & & \\
\hline & $9 *$ & & & & 11,200 & $\begin{array}{l}25,459 \\
14,698\end{array}$ & $101\}$ & & & & \\
\hline & 11 & & & & 18,400 & 24,147 & $167\}$ & \multirow{2}{*}{\multicolumn{2}{|c|}{ relatively c }} & oarse grair & ned \\
\hline & $12 *$ & & & & 11,600 & 15,223 & $105\}$ & & & & \\
\hline & & & & & & & & & & & \\
\hline \multirow{7}{*}{ dry } & $\begin{array}{l}4 \\
6 *\end{array}$ & & & & $\# 19,400$ & 25,459 & 176 & $n=7$ & & & \\
\hline & $\begin{array}{l}6 * \\
7\end{array}$ & & & & 25,600 & 33,596 & 232 & & & & \\
\hline & 8 & & & & 30,500 & 40,026 & 276 & & & & \\
\hline & 11 & & & & 29,500 & 38,714 & 267 & & & & \\
\hline & $13 *$ & & & & 27,200 & 35,696 & 246 & & & & \\
\hline & 16 & & & & 25,900 & 33,990 & 234 & & & & \\
\hline & 1 & 1.5 & & & 29,900 & 39,239 & 271 & & & & \\
\hline \multirow{9}{*}{ wet } & & & & & 31,200 & 40,945 & 282 & 282 & - & - & - \\
\hline & $3 *$ & & & & 30,500 & 40,026 & 276 & 239 & 40.4 & 1401 & 16.9 \\
\hline & $5 *$ & & & & 28,000 & 36,745 & 253 & $n=7$ & & & \\
\hline & 9 & & & & 29,600 & 38,845 & 268 & & & & \\
\hline & $10 *$ & & & & 20,800 & 27,297 & 188 & & & & \\
\hline & 12 & & & & 23,200 & 30,446 & 210 & & & & \\
\hline & 14 & & & & 21,400 & 28,084 & 194 & & & & \\
\hline & 15 & & & & 31,300 & 41,076 & 283 & & & & \\
\hline & & & & & $\# 9,300$ & 12,205 & 84 & & & & \\
\hline
\end{tabular}




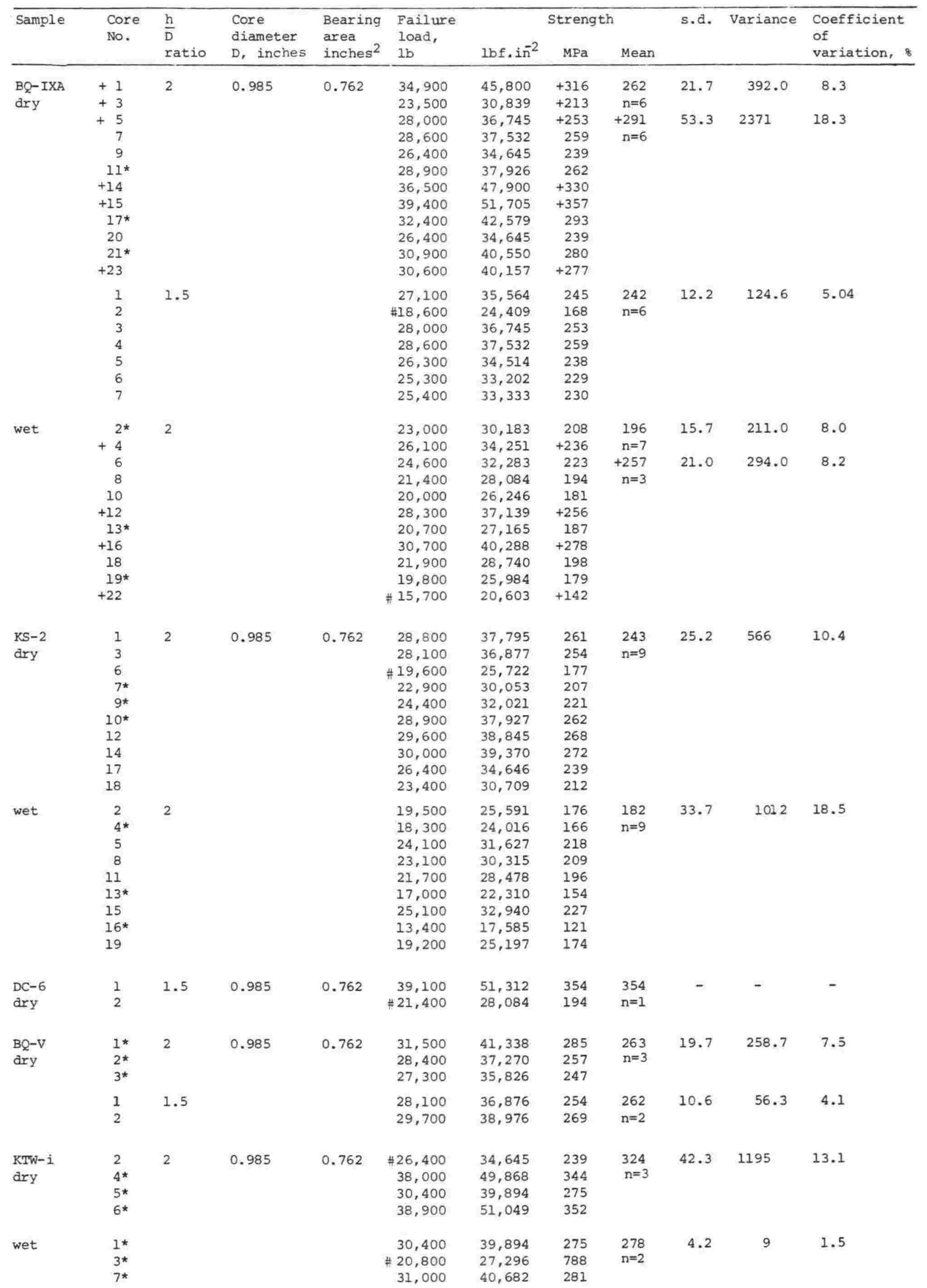




\begin{tabular}{|c|c|c|c|c|c|c|c|c|c|c|c|}
\hline Sample & $\begin{array}{l}\text { Core } \\
\text { No. }\end{array}$ & $\begin{array}{l}\frac{h}{D} \\
\text { ratio }\end{array}$ & $\begin{array}{l}\text { Core } \\
\text { diameter } \\
\text { D, inches }\end{array}$ & $\begin{array}{l}\text { Bearing } \\
\text { area } \\
\text { inches }{ }^{2}\end{array}$ & $\begin{array}{l}\text { Failure } \\
\text { load, } \\
\text { lb }\end{array}$ & lbf. in $^{-2}$ & $\begin{array}{l}\text { treng th } \\
\mathrm{MPa}\end{array}$ & Mean & s.d. & Variance & $\begin{array}{l}\text { Coefficient } \\
\text { of } \\
\text { variation, } \frac{8}{8}\end{array}$ \\
\hline $\begin{array}{l}\mathrm{SJ}-\mathrm{T} \\
\mathrm{dry}\end{array}$ & $\begin{array}{l}1^{*} \\
2 \\
5^{*} \\
6 \\
8^{*}\end{array}$ & 2 & 0.985 & 0.762 & $\begin{array}{r}24,000 \\
28,200 \\
32,100 \\
\# 21,000 \\
\$ 21,600\end{array}$ & $\begin{array}{l}31,496 \\
37,007 \\
42,125 \\
27,558 \\
28,346\end{array}$ & $\begin{array}{l}217 \\
255 \\
290 \\
190 \\
195\end{array}$ & $\begin{array}{l}254 \\
n=3\end{array}$ & 36.5 & 888.7 & 14.4 \\
\hline & $\begin{array}{l}1 \\
2\end{array}$ & 1.5 & & & $\begin{array}{l}39,400 \\
31,400\end{array}$ & $\begin{array}{l}51,705 \\
41,207\end{array}$ & $\begin{array}{l}357 \\
284\end{array}$ & $\begin{array}{l}321 \\
n=2\end{array}$ & 51.6 & 1332 & 16.1 \\
\hline wet & $\begin{array}{l}3 * \\
4^{*} \\
7 *\end{array}$ & & & & $\begin{array}{r}30,500 \\
\# 17,700 \\
26,700\end{array}$ & $\begin{array}{l}40,026 \\
23,228 \\
35,039\end{array}$ & $\begin{array}{l}276 \\
160 \\
242\end{array}$ & $\begin{array}{l}259 \\
n=2\end{array}$ & 24.0 & 289 & 9.3 \\
\hline $\begin{array}{l}\text { OB-W } \\
\text { ary }\end{array}$ & $\begin{array}{l}2 \\
3^{*} \\
5 \\
6 \\
7 \\
8^{*} \\
13 \\
16^{*} \\
18 \\
20\end{array}$ & 2 & 0.985 & 0.762 & $\begin{array}{r}29,700 \\
26,400 \\
26,000 \\
21,900 \\
\# 17,800 \\
23,100 \\
32,600 \\
30,600 \\
23,600 \\
30,100\end{array}$ & $\begin{array}{l}38,976 \\
34,646 \\
34,121 \\
28,740 \\
23,360 \\
30,315 \\
42,782 \\
40,158 \\
30,971 \\
39,501\end{array}$ & $\begin{array}{l}269 \\
239 \\
235 \\
198 \\
161 \\
209 \\
295 \\
277 \\
214 \\
272\end{array}$ & $\begin{array}{l}245 \\
n=9\end{array}$ & 34.3 & 1048.0 & 14.0 \\
\hline & $\begin{array}{l}1 \\
2 \\
3\end{array}$ & 1.5 & & & $\begin{array}{l}24,900 \\
31,600 \\
22,000\end{array}$ & $\begin{array}{l}32,677 \\
41,470 \\
28,871\end{array}$ & $\begin{array}{l}225 \\
286 \\
199\end{array}$ & $\begin{array}{l}237 \\
n=3\end{array}$ & 44.7 & 1330 & 18.9 \\
\hline wet & $\begin{array}{l}1 \\
4 * \\
9 \\
10 \\
11 \\
12 * \\
14 \\
15 \\
17 \\
19 \\
21 *\end{array}$ & 2 & & & $\begin{array}{l}21,800 \\
16,700 \\
21,400 \\
21,700 \\
21,000 \\
19,300 \\
23,300 \\
25,400 \\
18,600 \\
24,200 \\
23,800\end{array}$ & $\begin{array}{l}28,609 \\
21,916 \\
28,084 \\
28,478 \\
27,559 \\
25,328 \\
30,577 \\
33,333 \\
24,409 \\
31,759 \\
31,234\end{array}$ & $\begin{array}{l}197 \\
151 \\
194 \\
196 \\
190 \\
175 \\
211 \\
230 \\
168 \\
219 \\
215\end{array}$ & $\begin{array}{l}195 \\
n=11\end{array}$ & 23.6 & 505 & 12.1 \\
\hline $\begin{array}{l}\text { HQ-22 } \\
\text { dry }\end{array}$ & $\begin{array}{l}1^{*} \\
2 \\
3^{*} \\
6^{*} \\
8 \\
+1\end{array}$ & 2 & 0.985 & 0.762 & $\begin{array}{r}17,500 \\
14,000 \\
20,400 \\
13,000 \\
\# 8,900\end{array}$ & $\begin{array}{l}22,966 \\
18,373 \\
26,772 \\
17,060 \\
11,680\end{array}$ & $\begin{array}{r}158 \\
127 \\
185 \\
118 \\
81\end{array}$ & $\begin{array}{l}147 \\
n=4\end{array}$ & 30.6 & 702 & 20.8 \\
\hline & $\begin{array}{r}+1 \\
+2 \\
3 \\
4 \\
5 \\
6\end{array}$ & 1.5 & & & $\begin{array}{l}23,000 \\
22,100 \\
85.1 \mathrm{kN} \\
65.8 \mathrm{kN} \\
66.9 \mathrm{kN} \\
83.2 \mathrm{kN}\end{array}$ & $\begin{array}{l}30,184 \\
29,003 \\
25,128 \\
19,429 \\
19,754 \\
24,567\end{array}$ & $\begin{array}{r}+208 \\
+200 \\
173 \\
134 \\
136 \\
169\end{array}$ & $\begin{array}{r}+204 \\
n=2 \\
153 \\
n=4\end{array}$ & $\begin{array}{r}5.7 \\
20.9\end{array}$ & $\begin{array}{r}16 \\
327\end{array}$ & $\begin{array}{r}2.8 \\
13.7\end{array}$ \\
\hline wet & $\begin{array}{l}4^{\star} \\
5^{*} \\
7 * \\
9\end{array}$ & 2 & & & $\begin{array}{r}\# \quad 450 \\
\# \quad 100 \\
13,300 \\
5,700\end{array}$ & $\begin{array}{r}591 \\
131 \\
17,454 \\
7,480\end{array}$ & $\begin{array}{c}4 \\
0.9 \\
120 \\
52\end{array}$ & $\begin{array}{r}86 \\
n=2\end{array}$ & 48.1 & 1156 & 55.9 \\
\hline
\end{tabular}


Uniaxial compressive strengths and elastic properties (after Bryant, 1977)

\begin{tabular}{|c|c|c|c|c|c|c|c|}
\hline \multicolumn{2}{|c|}{$\begin{array}{l}\text { Sample } \\
\text { No. }\end{array}$} & $\begin{array}{l}\text { Brief lithological } \\
\text { description }\end{array}$ & \multicolumn{2}{|c|}{$\begin{array}{c}\text { Uniaxial compressive } \\
\text { strength }\end{array}$} & \multicolumn{2}{|c|}{$\begin{array}{l}\text { Youngs modulus (Tangent } \\
\text { mod. at } 50 \% \text { ultimate) } \\
\text { GPa } \\
\text { psi } \times 10^{6}\end{array}$} & $\begin{array}{l}\text { Poissons } \\
\text { ratio, }\end{array}$ \\
\hline 1 & 1 & $\begin{array}{l}\text { Sandstone with some thin } \\
\text { argillite beds }\end{array}$ & 99.2 & 14,386 & - & - & - \\
\hline 1 & 2 & $\begin{array}{l}\text { Sandstone with some thin } \\
\text { argillite beds }\end{array}$ & 128.7 & 18,664 & - & - & - \\
\hline 1 & 3 & Sandstone & 49.3 & 7,153 & - & - & - \\
\hline 1 & 4 & Autoclastic breccia & 99.2 & 14,386 & - & - & - \\
\hline 1 & 5 & Autoclastic breccia & 98.5 & 14,285 & 64.4 & 9.34 & 0.36 \\
\hline \multirow{2}{*}{$\begin{array}{l}1 \\
1\end{array}$} & \multirow{2}{*}{$\begin{array}{l}6 \\
7\end{array}$} & Autoclastic breccia & 83.5 & 12,109 & 68.7 & 9.97 & 0.24 \\
\hline & & $\begin{array}{l}\text { Sandstone with very faint } \\
\text { argillaceous bedding }\end{array}$ & 102.9 & 14,930 & - & - & - \\
\hline 1 & 8 & $\begin{array}{l}\text { Sandstone with some thin } \\
\text { argillite beds }\end{array}$ & 97.5 & 14,145 & 69.9 & 10.14 & 0.20 \\
\hline 1 & 9 & $\begin{array}{l}\text { Sandstone with faint } \\
\text { argillaceous bedding }\end{array}$ & 20.8 & 3,022 & 84.0 & 12.18 & 0.13 \\
\hline 1 & 10 & $\begin{array}{l}\text { Sandstone with faint } \\
\text { argillaceous bedding }\end{array}$ & 80.2 & 11,625 & 71.6 & 10.38 & 0.20 \\
\hline s & 1 & $\begin{array}{l}\text { Sandstone with intersecting } \\
\text { quartz veins }\end{array}$ & 129.4 & 18,780 & 78.7 & 11.42 & 0.26 \\
\hline s & 2 & $\begin{array}{l}\text { Siltstone with intersecting } \\
\text { quartz veins }\end{array}$ & 197.5 & 28,648 & 87.1 & 12.64 & 0.24 \\
\hline s & 3 & $\begin{array}{l}\text { Sandstone and argillite } \\
\text { interbedded }\end{array}$ & 131.2 & 19,035 & 65.9 & 9.56 & 0.20 \\
\hline s & 4 & $\begin{array}{l}\text { Sandstone quartz veins } \\
\text { and argillite laminations }\end{array}$ & 166.8 & 24,192 & 75.8 & 11.00 & 0.24 \\
\hline s & 5 & $\begin{array}{l}\text { Argillite with some quartz } \\
\text { veins }\end{array}$ & 89.1 & 12,923 & 56.0 & 8.12 & 0.26 \\
\hline s & 6 & Argillite, massive & 59.3 & 8,594 & - & - & - \\
\hline s & 7 & $\begin{array}{l}\text { Argillite with interbedded } \\
\text { sandstone }\end{array}$ & 195.8 & 28,393 & 63.7 & 9.24 & 0.32 \\
\hline s & 8 & $\begin{array}{l}\text { Sandstone with some quartz } \\
\text { veins }\end{array}$ & 148.8 & 21,581 & 72.2 & 10.47 & 0.25 \\
\hline s & 9 & $\begin{array}{l}\text { Argillite with interbedded } \\
\text { siltstone }\end{array}$ & 122.5 & 17,762 & 56.3 & 8.16 & 0.20 \\
\hline s & 10 & $\begin{array}{l}\text { Sandstone with some quartz } \\
\text { veins }\end{array}$ & 206.3 & 29,921 & 68.8 & 9.98 & 0.28 \\
\hline s & 11 & $\begin{array}{l}\text { Sandstone with some quartz } \\
\text { veins }\end{array}$ & 197.1 & 28,584 & 60.9 & 8.83 & 0.22 \\
\hline s & 12 & $\begin{array}{l}\text { Sandstone with some quartz } \\
\text { veins }\end{array}$ & 33.4 & 4,838 & - & - & - \\
\hline & ean va & alues & 121.1 & 17,593 & 69.6 & 10.1 & 0.24 \\
\hline
\end{tabular}


APPENDIX 14

Stress-strain curves: methods and instrumentation

There is a wealth of data on the many dynamic and static strain measuring devices available but choice for this study was limited by finance and availability.

study of basic principles and equipment characteristics and discussion by authors viz. Perry and Lissner (1962) Neubert (1967) Hawkes and Mellor (1970) Lama and Vutukuri (1978) led to the method adopted.

Strain measurement of rock cores and concrete cylinders was undertaken using TML series "P" polyester strain gauges, manufactured by Tokyo Sokki Kenkyujo Co. Ltd., Japan, the characteristics of which are given in Table Al4.1. Type PL-20 were used for rock cores and the PL-60 for concrete.

Strain gauge cement - Kyowa CC-15A (cyanoacrylate) - was used to attach the gauges which were positioned by template to preclude finger contact with the core surface.

Gauges were centred on the mid-point and parallel with the vertical axis of the sample, two diametrically opposed on rock cores and one on concrete cylinders.

To promote gauge adhesion, the attachment area surface dryness was ensured and concrete lightly dressed with medium grit emery paper to remove surface debris and laita nce. Connector strips to facilitate soldered contacts between cables and gauges were cemented to the specimens at the same time as the gauges. Shielded cable was used for electrical connection, coaxial for rock samples, twin for concrete. Cables were all cut to the same length and the adequacy of shielding checked. Joints not soldered were made with high quality proprietary brand connectors.

Rock core gauges were connected in a full bridge configuration (Figure Al4.1) with two "dumm" gauges mounted on a concrete specimen providing a reference and temperature compensation. Outputs were fed to a digital strain bridge (BLH Electronics, model 1200) connected to the X-axis of an X-Y plotter (Rikadenki - Kogyo model BW-133 serial number 59588). A load cell (safe working load $300 \mathrm{kN}$, gauge factor 2) used to detect rock core stress movement fed the $\mathrm{Y}$-axis of the plotter via a strain bridge amplifier (San-ei, 6M51). Concrete specimens were connected in a half bridge configuration (Figure Al4.1) using one "dummy" gauge. In these tests, the load cell was not used and $Y$-axis input was triggered manually from a. low voltage source at load intervals of 10,000 lbs read from the compression test machine dial (Plate Al4.1). 
Table Al4.1 : The series ' $P$ ' polyester strain gauge used for this study is a wire strain gauge utilising a transparent plastic backing impregnated with a polyester resin. It may be used on metals, concrete, wood and synthetic resins.

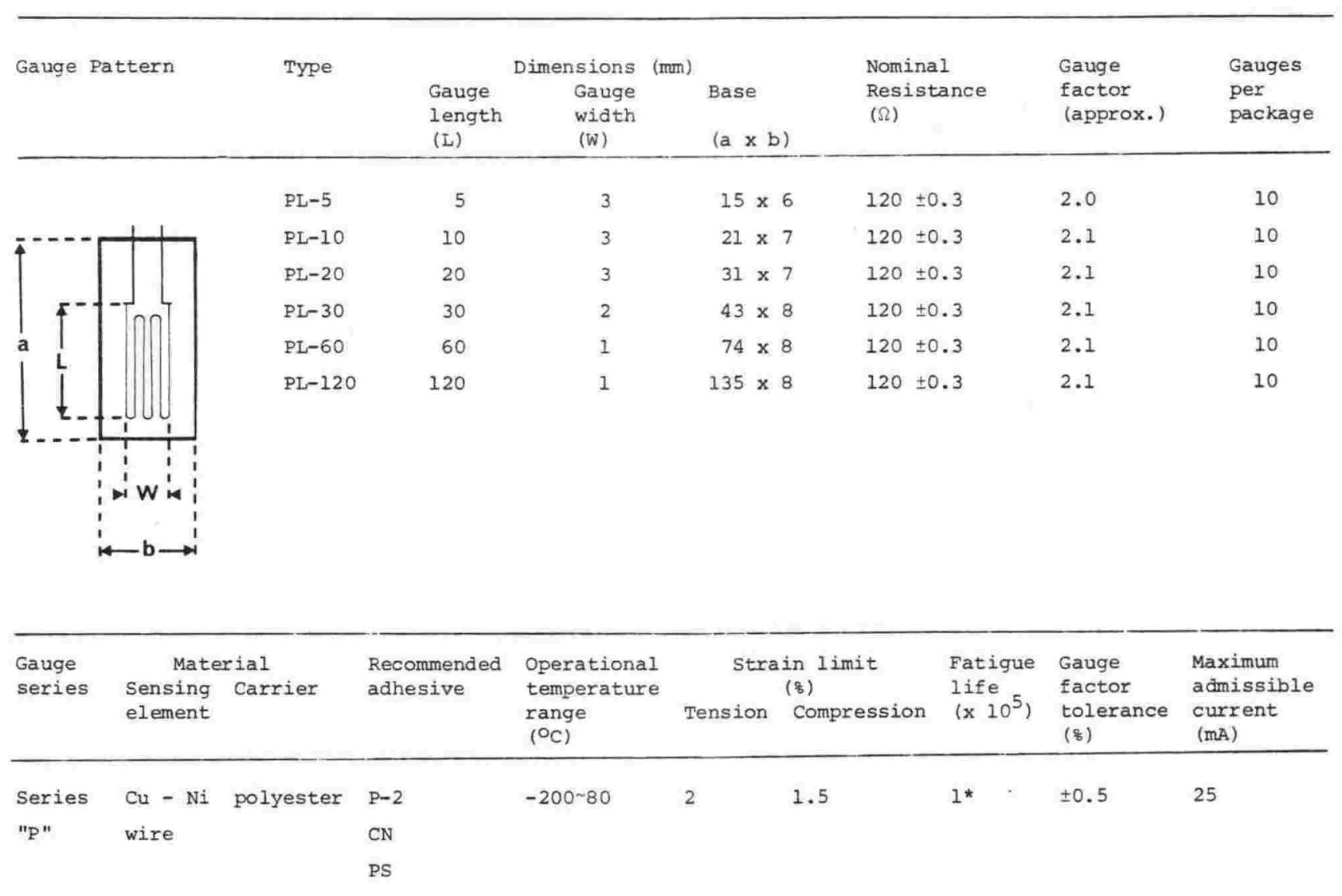

*Strain level $1500 \times 10^{-6}$ vibratory frequency $40 \mathrm{~Hz}$. 


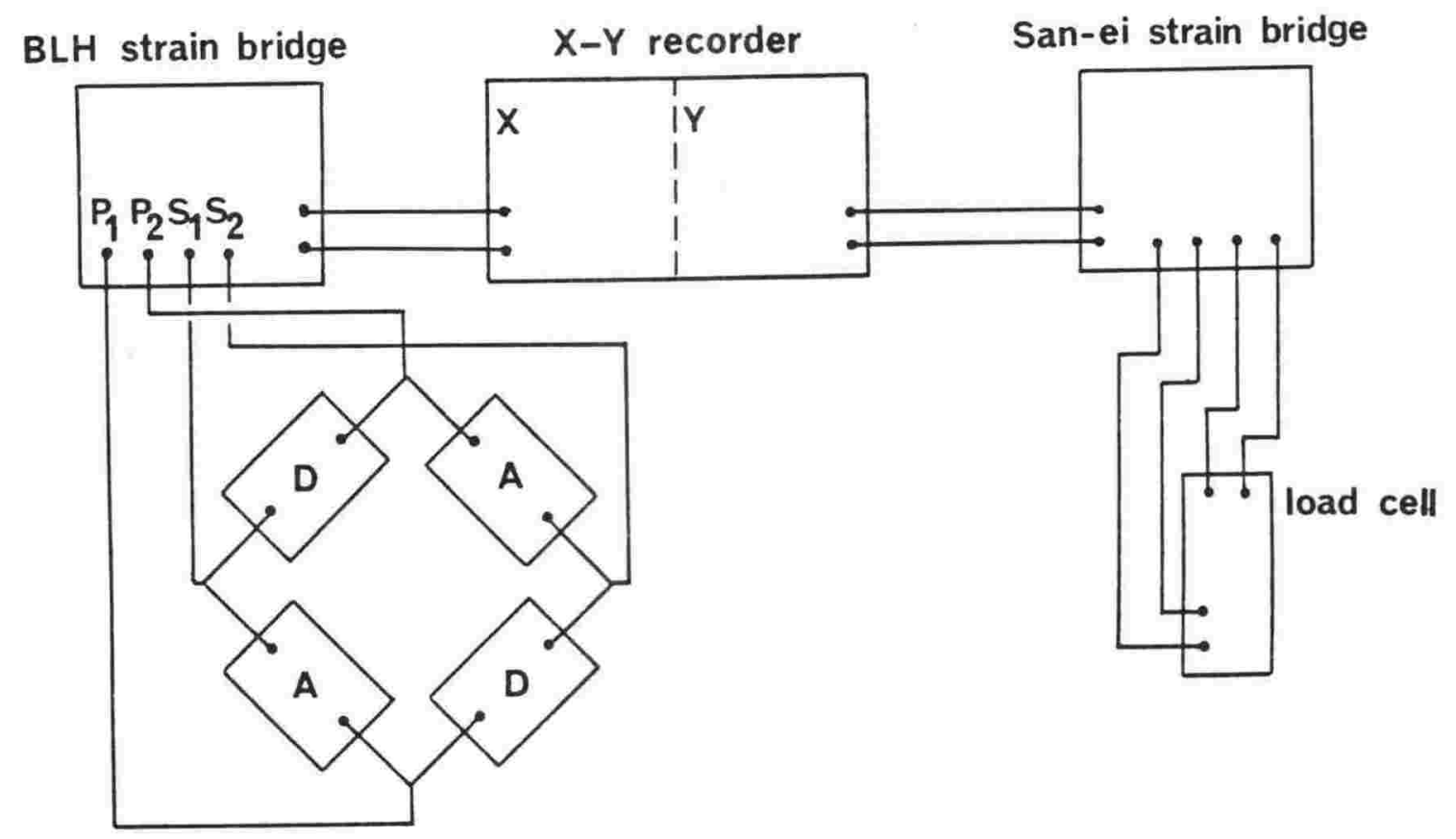

FULL-BRIDGE CIRCUITRY FOR ROCK CORE TESTING, ACTIVE GAUGES (A) ARE ON CORES, DUMMY GAUGES (D) ON A CONCRETE REFERENCE

\section{BLH strain bridge} $X-Y$ recorder

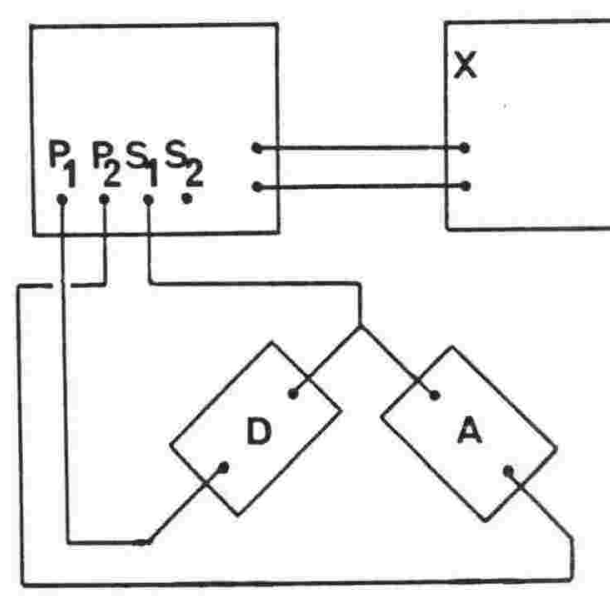

HALF-BRIDGE CIRCUITRY FOR CONCRETE CYLINDER TESTING

Figure Al4.1 : Circuit arrangements for stress-strain recording of rock cores and concrete cylinders. Full-bridge layouts provide twice the strain signal of half-bridge layouts, important when calibrating strain axes. 

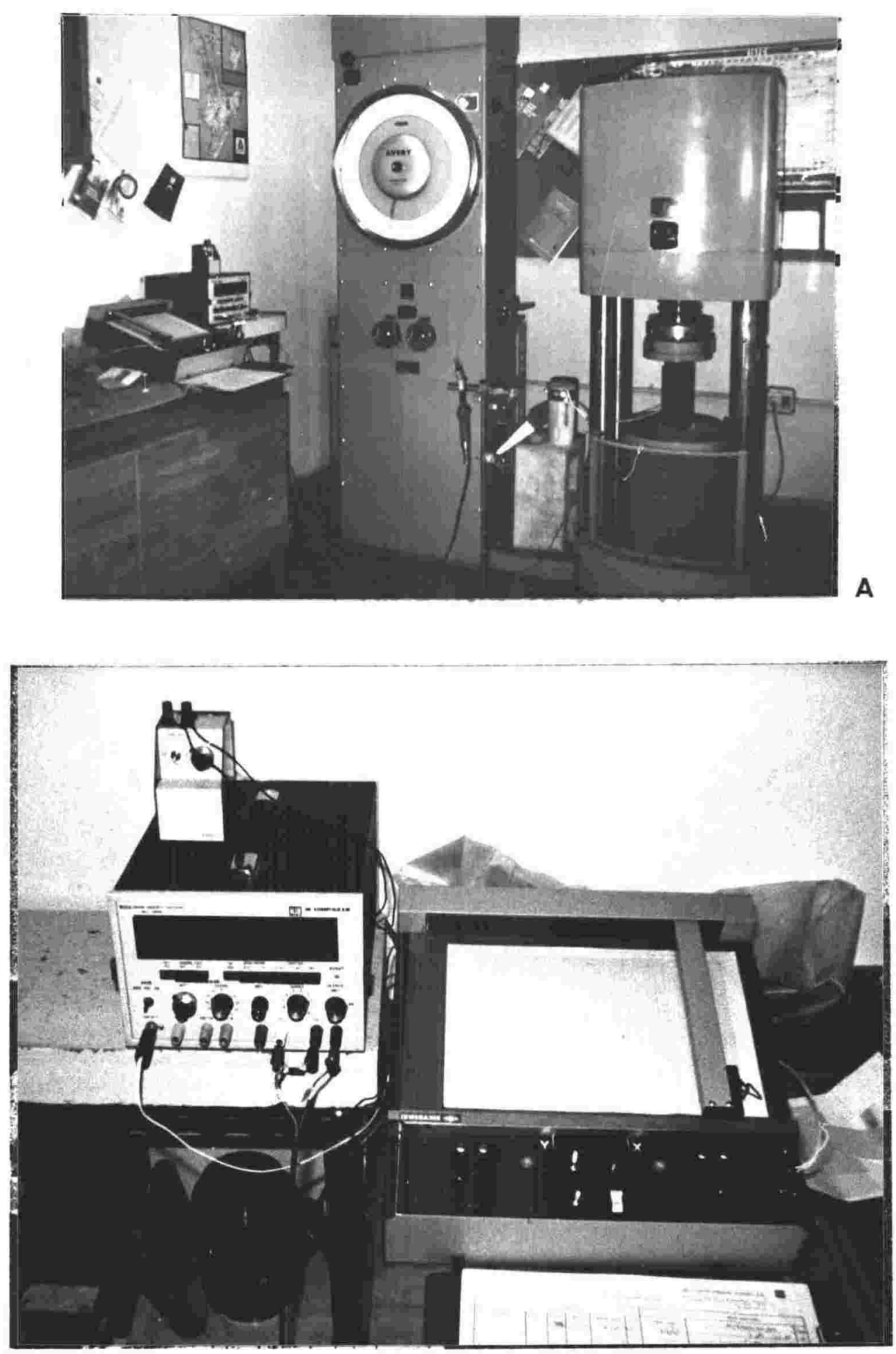

B

Plate Al4.1 : (A) The Avery universal testing machine used for rock core and concrete cylinder uniaxial compression tests, and the arrangements of electronic apparatus.

(B) Photograph showing the strain bridge, $\mathrm{X}-\mathrm{Y}$ plotter and low voltage source, used for 28 day concrete stress-strain measurements using a half strain bridge circuit. 


\section{APPENDIX 15}

Static elastic moduli determination and failure mode analysis of rock cores

\section{Static elastic modulus}

The static elastic modulus, Young's modulus, compression modulus, modulus of elasticity or modulus of deformation is the ratio of stress to strain in a given material. If a stressstrain curve is plotted for a perfectly elastic solid, the result will be a straight line and its slope which represents the elastic modulus (E) will be the same for all stress levels. This is not the case with rocks where the stress-strain curve is not linear but a shape determined by constituent material (Figure Al5.1). Thus the slope of the curve, $E$, varies at different stress levels.

E can be represented at any point on the curve in two ways, firstly as a tangent at that point - this is tangental modulus $E_{t}$ and secondly by a secant from the origin through the point - the secant modulus $E_{S}$. The stress at that point is given by the $Y$ intercept.

At any point on the near linear portion of the curve, tangental modulus will be more truly representative of $\mathrm{E}$.

As the stress in rocks increases, elasticity becomes apparent and the curve nears linearity, generally in the vicinity of 50 percent of ultimate stress (C in Figure Al5.1). It is customary therefore to determine $\mathrm{E}$ at one or more of three discrete levels of stress initial stress, 50 percent ultimate stress and ultimate stress; the intial modulus $E_{i}$ and the 50 percent modulus $E_{t}$ both measured tangentally and the ultimate $E_{S}$ as a secant modulus. As the slope at the origin of the curve is difficult to ascertain, $E_{i}$ tends to be the least accurate, particularly in curves where it would be of greatest use, i.e. types iii, iv, v and vi of Deere and Miller (1966) (Figure Al5.2).

In this study all stress-strain curves were plotted on the first loading of specimens which continued to failure. $E_{i}$ provides information on initial rock stress and the phenomenon of microcrack or pore closure, $E_{t}$ was representative of the elastic portion of the stressstrain curve and reduced errors inherent in early portions of the strain history and $E_{S}$ included the plastic or ductile portion of the curve from the yield point. Moduli from this study are presented in Table Al5.1.

The complete stress-strain curve for rock (Figure Al5.1) illustrates the behaviour of rock in uniaxial compression. The portion $O C$ of the curve is a facsimile of those obtained from rocks of this study. From 0 , the slope of the curve decreases to zero, with increasing stress - a situation observed at c. Here, induced irreversable changes take place in the rock which passes to a brittle state and its ability to resist load decreases with increasing deformation. The $C D$ portion of the curve - the brittle field, is not observed from stress-strain curves presented in Figures A15.3 to A.15.12 due to the characteristic of the machine used for tests in this study.

Energy stored in the machine during test is released when the sample reaches the stage of internal plastic deformation (Deere and Miller, 1966; Jaeger 1972), i.e. when the material becomes ductile after yield.point (Jaeger and Cook, 1976) and the sample sustains permanent deformation without loss of load bearing ability. Rapid volume changes now occur marking transition to the brittle field and specimen failure, which can be violent and catastrophic. Speed and violence of failure are related to test machine "stiffness" 


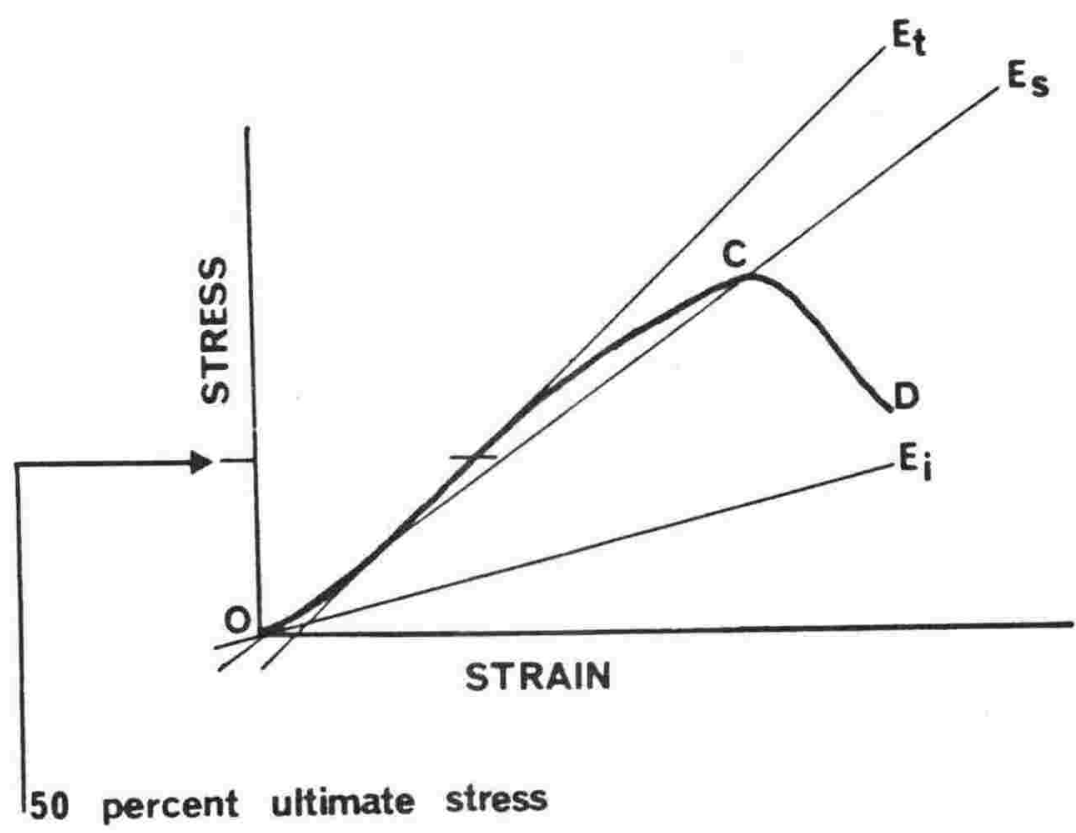

Figure Al5.1 : A complete stress-strain curve for rock (from Jaeger and Cook, 1969).

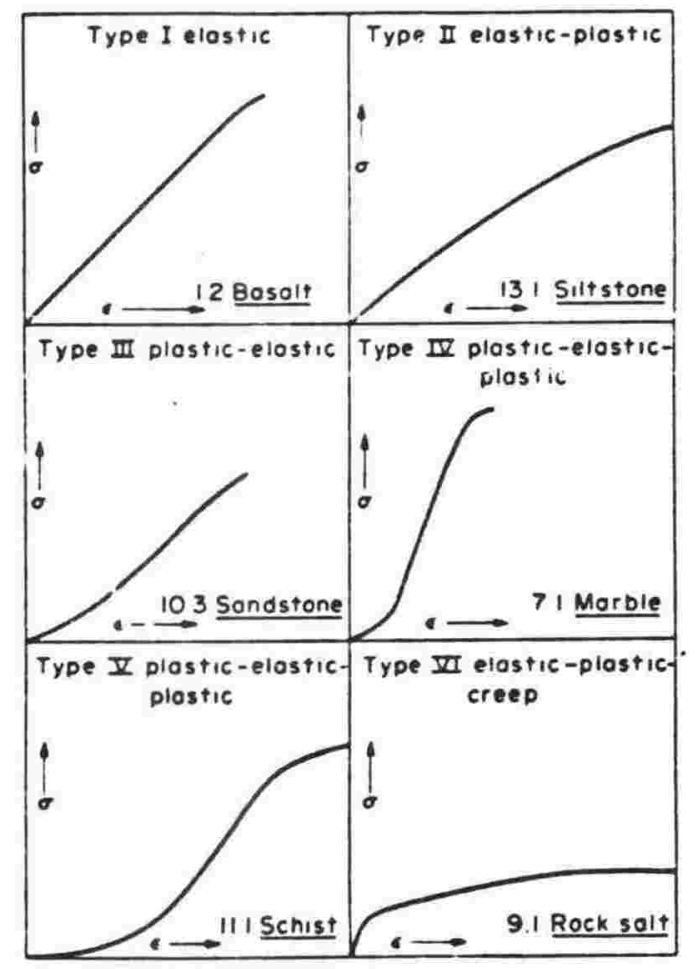

Figure A15.2 : Typical stress-strain curves for rock in uniaxial compression. After Deere and Miller (1966). 


\begin{tabular}{|c|c|c|c|c|c|c|c|c|c|c|c|c|c|}
\hline \multirow[t]{2}{*}{ Sample } & & \multicolumn{4}{|c|}{ Initial tangent modulus } & \multicolumn{4}{|c|}{$\begin{array}{l}\text { CORES TESTED DRY } \\
\text { Tangent modulus at } 50 \% \\
\text { ultimate stress }\end{array}$} & \multicolumn{4}{|c|}{$\begin{array}{r}\text { Secant modulus to } \\
\text { stress }\end{array}$} \\
\hline & & $\begin{array}{l}\text { Stress } \\
\text { MPa }\end{array}$ & $\begin{array}{l}\text { Strain } \\
\text { g }\end{array}$ & $\begin{array}{l}\mathrm{E}_{i} \\
\mathrm{GPa}\end{array}$ & $\begin{array}{l}\text { Mean } E_{i} \\
G P a\end{array}$ & $\begin{array}{l}\text { Stress } \\
\mathrm{MPa}\end{array}$ & $\begin{array}{l}\text { Strain } \\
{ }_{5}\end{array}$ & $\begin{array}{l}E_{t} \\
G P a\end{array}$ & $\begin{array}{l}\text { Mean } E_{t} \\
\text { GPa }\end{array}$ & $\begin{array}{l}\text { Stress } \\
\mathrm{MPa}\end{array}$ & $\begin{array}{l}\text { Strain } \\
{ }_{\xi}\end{array}$ & $\begin{array}{l}\mathrm{E}_{\mathrm{S}} \\
\mathrm{GPa}\end{array}$ & $\begin{array}{l}\text { Mean } E_{S} \\
\text { GPa }\end{array}$ \\
\hline $\mathrm{HO}-17$ & $\begin{array}{l}3 \\
5 \\
9\end{array}$ & $\begin{array}{l}325 \\
155 \\
175\end{array}$ & $\begin{array}{l}4991 \\
2304 \\
2304\end{array}$ & $\begin{array}{l}65.1 \\
67.3 \\
76.0\end{array}$ & $\begin{array}{l}69.5 \\
n=3\end{array}$ & $\begin{array}{l}230 \\
219\end{array}$ & $\begin{array}{l}3427 \\
3318\end{array}$ & $\begin{array}{l}67.1 \\
66.0\end{array}$ & $\begin{array}{l}66.6 \\
n=2\end{array}$ & 224 & 3335 & 67.2 & $\begin{array}{l}67.2 \\
n=1\end{array}$ \\
\hline sJ-31 & $\begin{array}{r}8 \\
3 \\
10\end{array}$ & $\begin{array}{l}391 \\
320 \\
391\end{array}$ & $\begin{array}{l}5000 \\
5000 \\
5000\end{array}$ & $\begin{array}{l}78.2 \\
64.0 \\
78.2\end{array}$ & $\begin{array}{l}73.5 \\
n=3\end{array}$ & $\begin{array}{l}112 \\
185 \\
197\end{array}$ & $\begin{array}{l}1495 \\
2604 \\
2627\end{array}$ & $\begin{array}{l}74.9 \\
71.1 \\
75.0\end{array}$ & $\begin{array}{l}73.7 \\
n=3\end{array}$ & $\begin{array}{l}202 \\
262\end{array}$ & $\begin{array}{l}2829 \\
3479\end{array}$ & $\begin{array}{l}71.4 \\
75.3\end{array}$ & $\begin{array}{l}73.4 \\
n=2\end{array}$ \\
\hline $\mathrm{KIW}-14$ & $\begin{array}{r}2 \\
6 \\
13\end{array}$ & $\begin{array}{l}480 \\
398 \\
340\end{array}$ & $\begin{array}{l}5600 \\
5000 \\
5000\end{array}$ & $\begin{array}{l}85.7 \\
79.6 \\
68.0\end{array}$ & $\begin{array}{l}77.8 \\
n=3\end{array}$ & $\begin{array}{l}300 \\
303 \\
295\end{array}$ & $\begin{array}{l}3798 \\
3630 \\
3462\end{array}$ & $\begin{array}{l}79.0 \\
83.5 \\
85.2\end{array}$ & $\begin{array}{l}82.6 \\
n=3\end{array}$ & $\begin{array}{l}295 \\
232 \\
234\end{array}$ & $\begin{array}{l}3651 \\
2861 \\
2933\end{array}$ & $\begin{array}{l}80.8 \\
81.1 \\
79.8\end{array}$ & $\begin{array}{l}80.6 \\
n=3\end{array}$ \\
\hline$B \cap-V$ & $\begin{array}{l}2 \\
1 \\
3\end{array}$ & $\begin{array}{l}190 \\
335 \\
335\end{array}$ & $\begin{array}{l}2825 \\
5000 \\
5000\end{array}$ & $\begin{array}{l}67.3 \\
67.0 \\
67.0\end{array}$ & $\begin{array}{l}67 \cdot 1 \\
n=3\end{array}$ & $\begin{array}{l}315 \\
315 \\
315\end{array}$ & $\begin{array}{l}5000 \\
5000 \\
5000\end{array}$ & $\begin{array}{l}63.0 \\
63.0 \\
63.0\end{array}$ & $\begin{array}{l}63.0 \\
n=3\end{array}$ & 257 & 4000 & 64.3 & $\begin{array}{l}64.3 \\
n=1\end{array}$ \\
\hline$B Q-I X A$ & $\begin{array}{l}17 \\
21 \\
11\end{array}$ & $\begin{array}{l}153 \\
187 \\
220\end{array}$ & $\begin{array}{l}2500 \\
2500 \\
2500\end{array}$ & $\begin{array}{l}61.4 \\
74.8 \\
88.0\end{array}$ & $\begin{array}{l}74.7 \\
n=3\end{array}$ & $\begin{array}{l}153 \\
218 \\
276\end{array}$ & $\begin{array}{l}2725 \\
3225 \\
3400\end{array}$ & $\begin{array}{l}56.0 \\
67.6 \\
81.2\end{array}$ & $\begin{array}{l}68.3 \\
n=3\end{array}$ & 293 & 4550 & 64.4 & $\begin{array}{l}64 \cdot 4 \\
n=1\end{array}$ \\
\hline $\mathrm{KS}-2$ & $\begin{array}{r}10 \\
9 \\
7\end{array}$ & $\begin{array}{l}251 \\
226 \\
250\end{array}$ & $\begin{array}{l}5000 \\
5000 \\
5000\end{array}$ & $\begin{array}{l}50.1 \\
45.2 \\
50.0\end{array}$ & $\begin{array}{l}48.4 \\
n=3\end{array}$ & $\begin{array}{l}150 \\
136 \\
182\end{array}$ & $\begin{array}{l}2625 \\
2475 \\
3200\end{array}$ & $\begin{array}{l}57.1 \\
55.0 \\
56.9\end{array}$ & $\begin{array}{l}56.3 \\
n=3\end{array}$ & $\begin{array}{l}262 \\
221\end{array}$ & $\begin{array}{l}4800 \\
4525\end{array}$ & $\begin{array}{l}54.6 \\
48.8\end{array}$ & $\begin{array}{l}51.7 \\
n=2\end{array}$ \\
\hline$K T W-i$ & $\begin{array}{l}6 \\
5 \\
4\end{array}$ & $\begin{array}{l}290 \\
366 \\
366\end{array}$ & $\begin{array}{l}3600 \\
4600 \\
4600\end{array}$ & $\begin{array}{l}80.6 \\
79.6 \\
73.0\end{array}$ & $\begin{array}{l}77.7 \\
n=3\end{array}$ & $\begin{array}{l}220 \\
304 \\
219\end{array}$ & $\begin{array}{l}3600 \\
4600 \\
3335\end{array}$ & $\begin{array}{l}61.1 \\
66.1 \\
65.7\end{array}$ & $\begin{array}{l}64 \cdot 3 \\
n=3\end{array}$ & $\begin{array}{l}352 \\
344\end{array}$ & $\begin{array}{l}5612 \\
5382\end{array}$ & $\begin{array}{l}62.7 \\
63.9\end{array}$ & $\begin{array}{l}63.3 \\
n=2\end{array}$ \\
\hline$S J-T$ & $\begin{array}{l}5 \\
1 \\
8\end{array}$ & $\begin{array}{l}235 \\
235 \\
235\end{array}$ & $\begin{array}{l}2500 \\
2500 \\
2500\end{array}$ & $\begin{array}{l}94.0 \\
94.0 \\
94.0\end{array}$ & $\begin{array}{l}94.0 \\
n=3\end{array}$ & $\begin{array}{l}200 \\
200 \\
200\end{array}$ & $\begin{array}{l}2750 \\
2750 \\
2750\end{array}$ & $\begin{array}{l}72.7 \\
72.7 \\
72.7\end{array}$ & $\begin{array}{l}72.7 \\
n=3\end{array}$ & 251 & 3575 & 70.2 & $\begin{array}{l}70.2 \\
n=1\end{array}$ \\
\hline$O B-W$ & $\begin{array}{r}8 \\
16 \\
3\end{array}$ & $\begin{array}{l}319 \\
290 \\
349\end{array}$ & $\begin{array}{l}5000 \\
5000 \\
5000\end{array}$ & $\begin{array}{l}63.8 \\
58.0 \\
69.8\end{array}$ & $\begin{array}{l}63.9 \\
n=3\end{array}$ & $\begin{array}{l}165 \\
130 \\
185\end{array}$ & $\begin{array}{l}3125 \\
2725 \\
3400\end{array}$ & $\begin{array}{l}52.8 \\
47.7 \\
54.4\end{array}$ & $\begin{array}{l}51.6 \\
n=3\end{array}$ & $\begin{array}{l}209 \\
277 \\
239\end{array}$ & $\begin{array}{l}4100 \\
6325 \\
4825\end{array}$ & $\begin{array}{l}51.0 \\
43.8 \\
49.5\end{array}$ & $\begin{array}{l}48.1 \\
n=3\end{array}$ \\
\hline $\mathrm{BO}-22$ & $\begin{array}{l}6 \\
3 \\
1 \\
\end{array}$ & $\begin{array}{l}347 \\
347 \\
330\end{array}$ & $\begin{array}{l}5000 \\
5000 \\
5000\end{array}$ & $\begin{array}{l}69.4 \\
69.4 \\
66.0\end{array}$ & $\begin{array}{l}68.3 \\
n=3\end{array}$ & $\begin{array}{l}160 \\
300\end{array}$ & 2500 & 64.0 & $\begin{array}{l}68.4 \\
n=2\end{array}$ & $\begin{array}{l}118 \\
309 \\
158\end{array}$ & $\begin{array}{l}2325 \\
5000 \\
2250\end{array}$ & $\begin{array}{l}50.8 \\
61.8 \\
70.2\end{array}$ & $\begin{array}{l}60.9 \\
n=3\end{array}$ \\
\hline
\end{tabular}

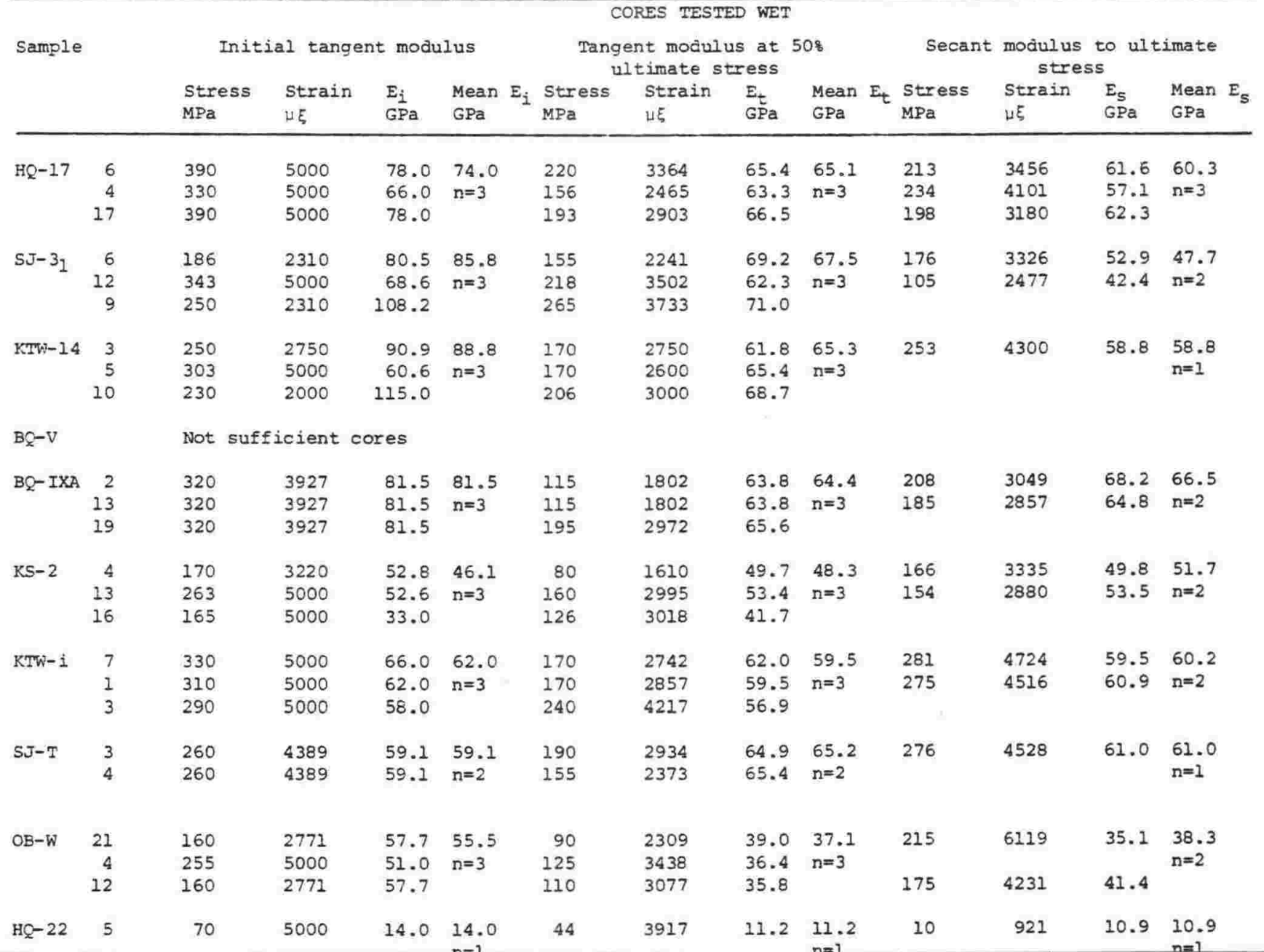



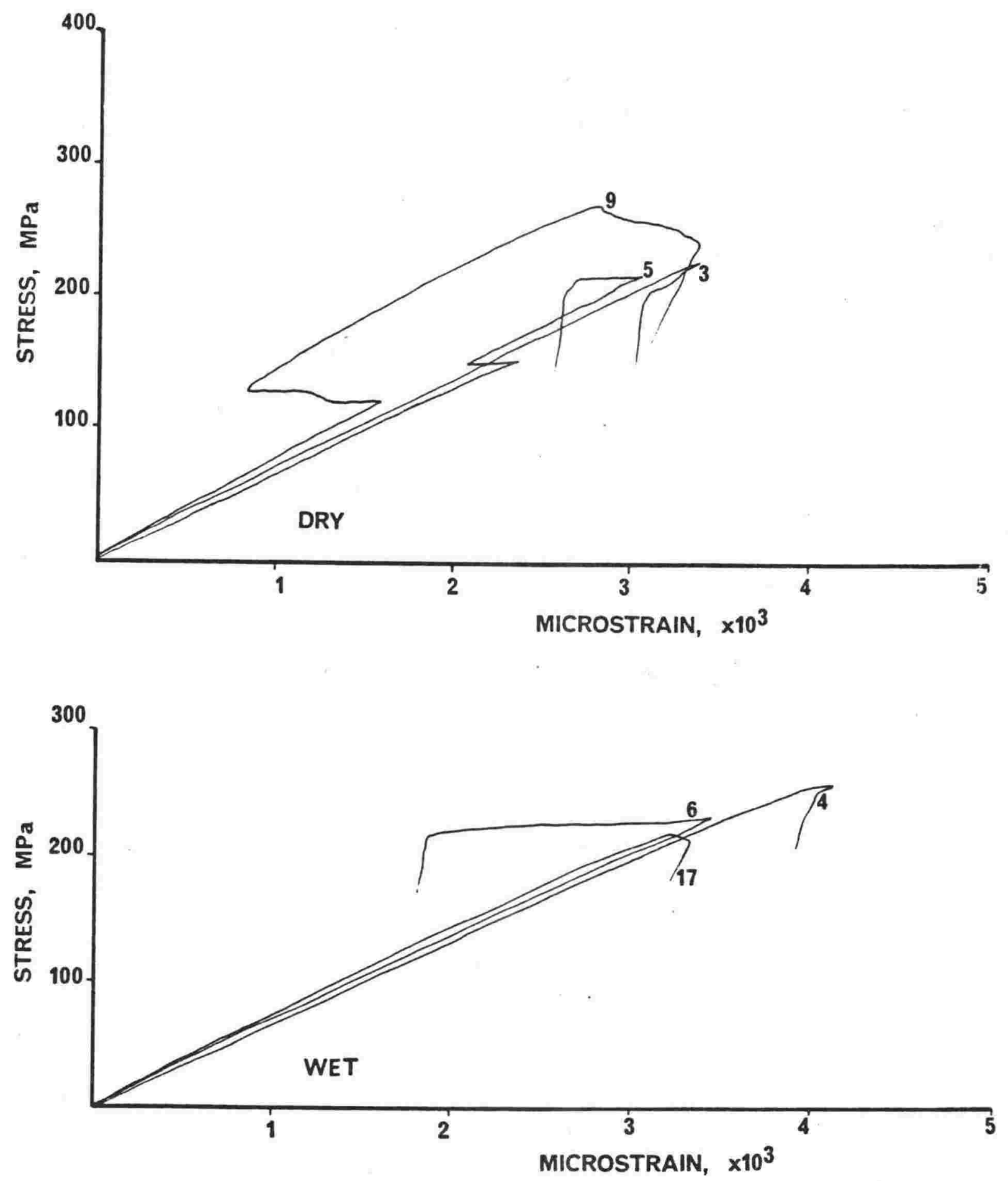

Figure A15.3 : Stress-strain curves of HQ-17 greywacke ( 1.3 phi, mean grain size). Curve numbers indicate core

sample numbers.

Static elastic modulus figures are:

\begin{tabular}{|c|c|c|c|c|}
\hline \multicolumn{3}{|c|}{ dry } & \multicolumn{2}{|c|}{ wet } \\
\hline$E_{\text {i }}$ & 69.5 & $\mathrm{GPa}$ & 74.0 & $\mathrm{GPa}$ \\
\hline$E_{t}$ & 66.6 & $\mathrm{GPa}$ & 65.1 & $\mathrm{GPa}$ \\
\hline$E_{S}$ & 67.2 & $\mathrm{GPa}$ & 60.3 & $\mathrm{GPa}$ \\
\hline
\end{tabular}

$\mathrm{N} \cdot \mathrm{B}$. 1000 microstrain $=1 \mathrm{~mm} \cdot \mathrm{m}^{-1}$ 

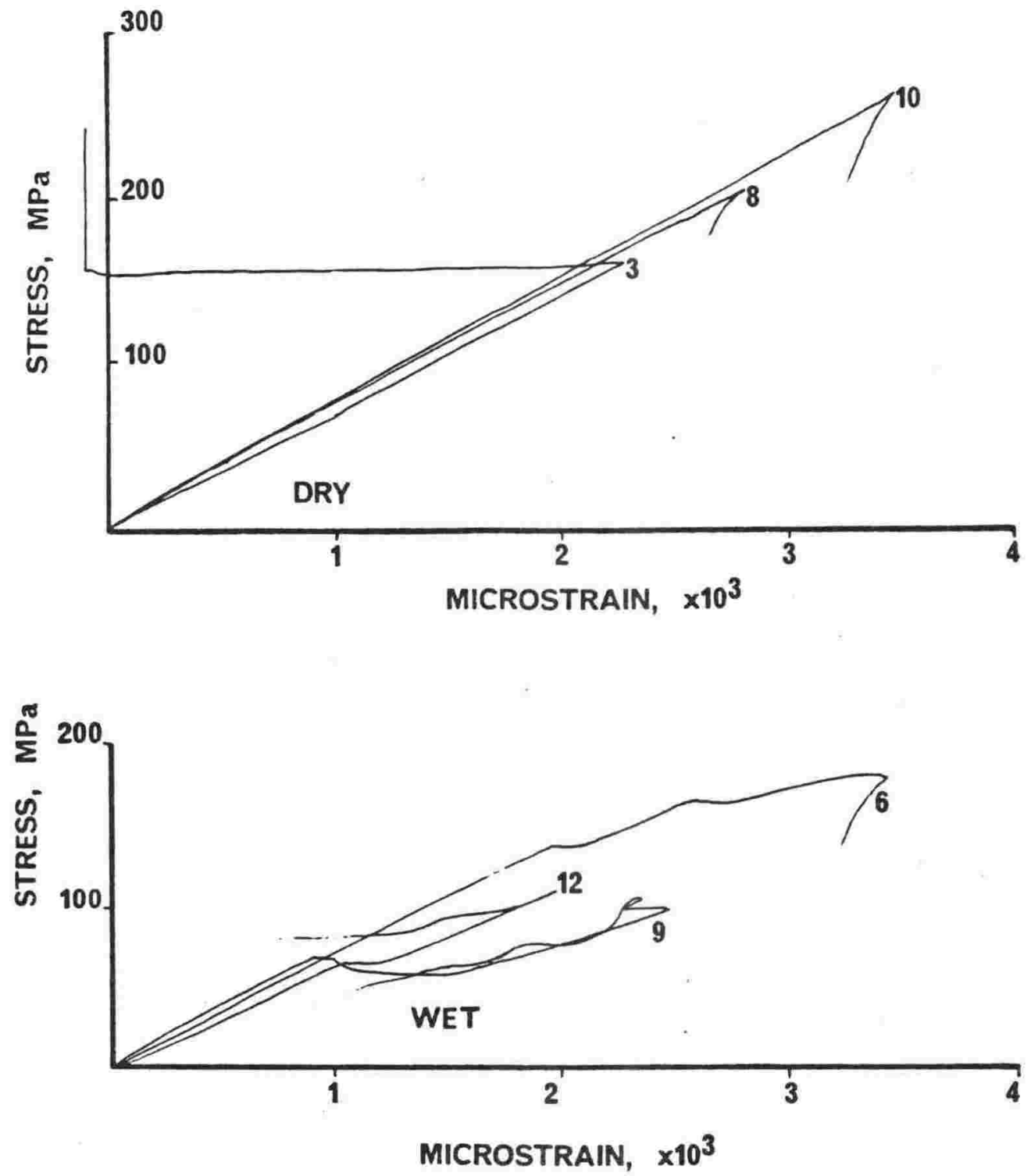

Figure Al5.4 : Stress-strain curves of SJ-3 1 greywacke (1.3 phi, mean grain size). Curve numbers indicate core sample numbers.

Static elastic modulus figures are:

\begin{tabular}{|c|c|c|c|c|}
\hline \multirow[b]{2}{*}{$E_{i}$} & \multicolumn{2}{|c|}{ dry } & \multicolumn{2}{|c|}{ wet } \\
\hline & 73.5 & $\mathrm{GPa}$ & 85.8 & $\mathrm{GPa}$ \\
\hline$E_{t}$ & 73.7 & GPa & 67.5 & $\mathrm{GPa}$ \\
\hline$E_{n}$ & 73.4 & $\mathrm{GPa}$ & 47.7 & $\mathrm{GPa}$ \\
\hline
\end{tabular}

N.B. 100 microstrain $=1 \mathrm{~mm} \cdot \mathrm{m}^{-1}$ 

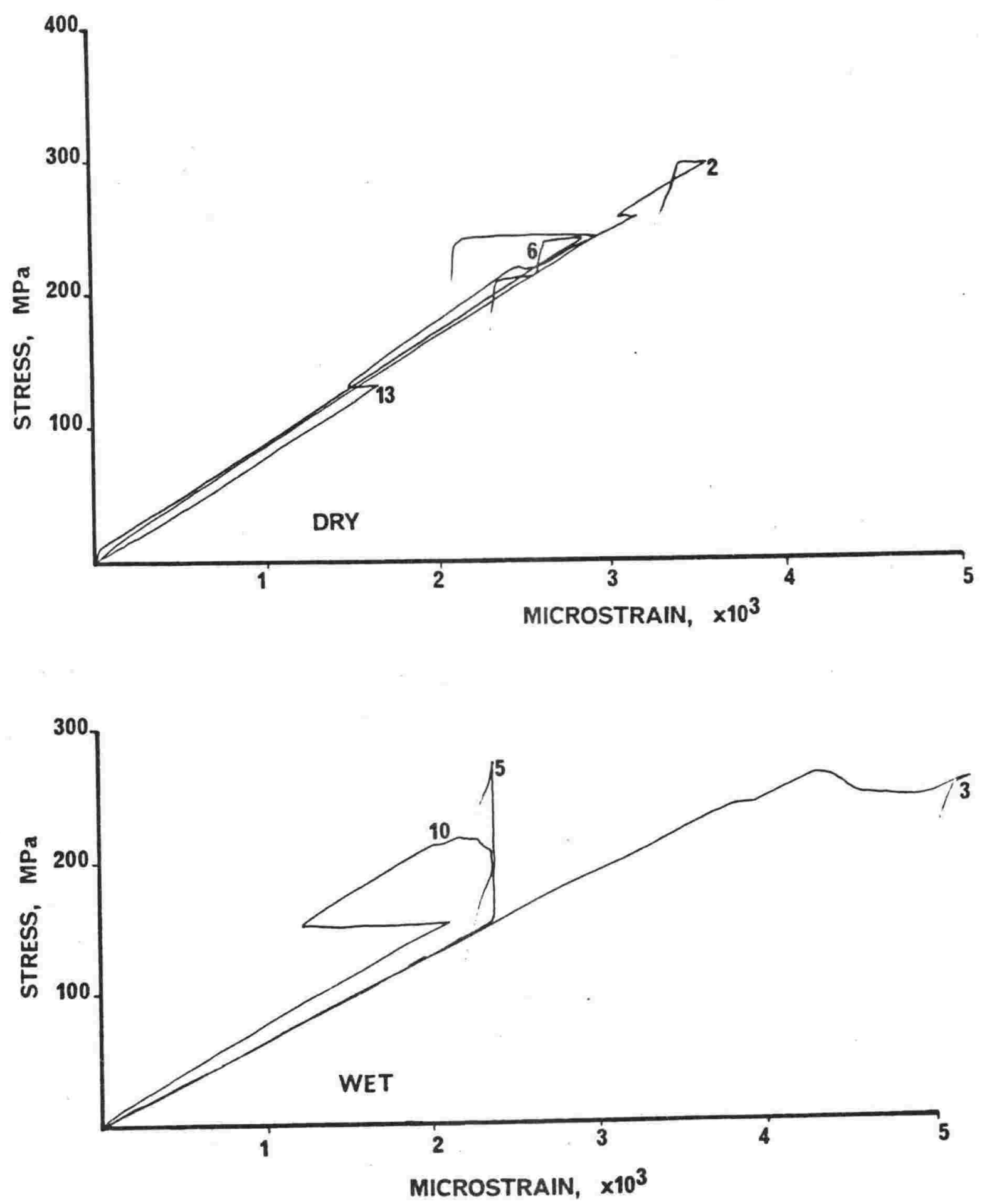

Figure A15.5 : Stress-strain curves of KTW-14 greywacke (2.6 phi, mean grain size). Curve numbers indicate core

sample numbers.

Static elastic modulus figures are:

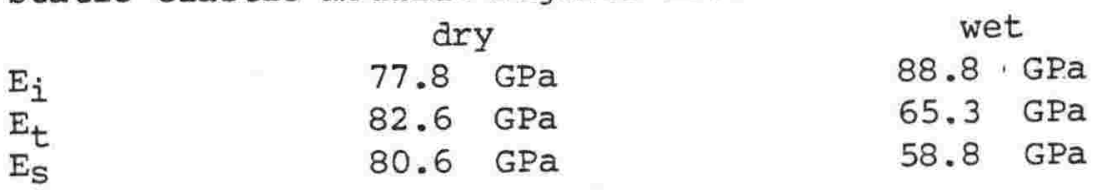

N.B. 1000 microstrain $=1 \mathrm{~mm} \cdot \mathrm{m}^{-1}$ 


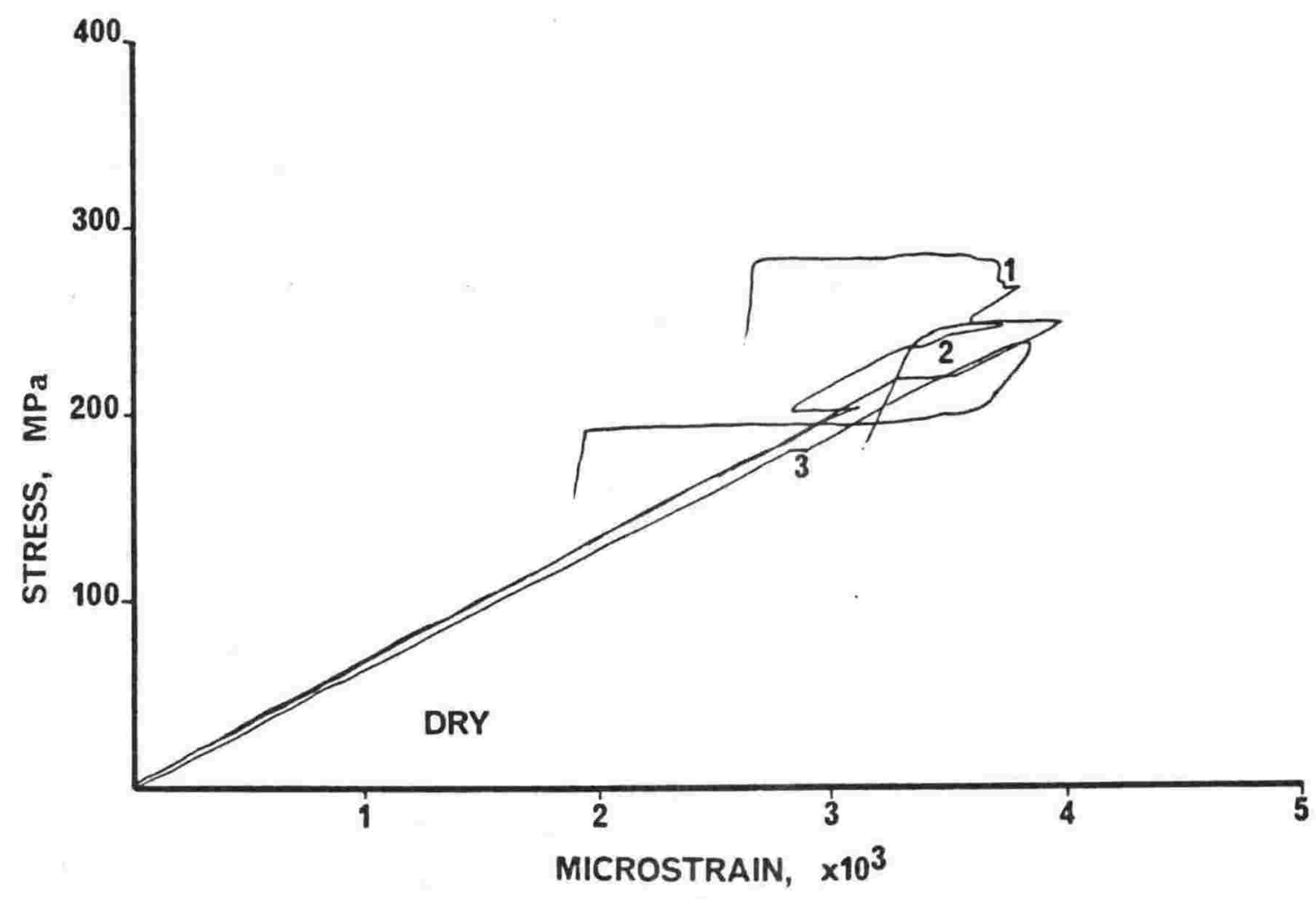

Figure Al5.6 : Stress-strain curve of BQ-V greywacke (2.7 phi, mean grain size). Curve numbers indicate core sample

numbers.

Static elastic modulus figures are:

\begin{tabular}{lll} 
& \multicolumn{2}{c}{ dry } \\
$E_{i}$ & 67.1 & $\mathrm{GPa}$ \\
$\mathrm{E}_{\mathrm{t}}$ & $63.0 \mathrm{GPa}$ \\
$\mathrm{E}_{\mathrm{S}}$ & $64.3 \mathrm{GPa}$
\end{tabular}

N.B. 1000 microstrain $=1 \mathrm{~mm} \cdot \mathrm{m}^{-1}$ 

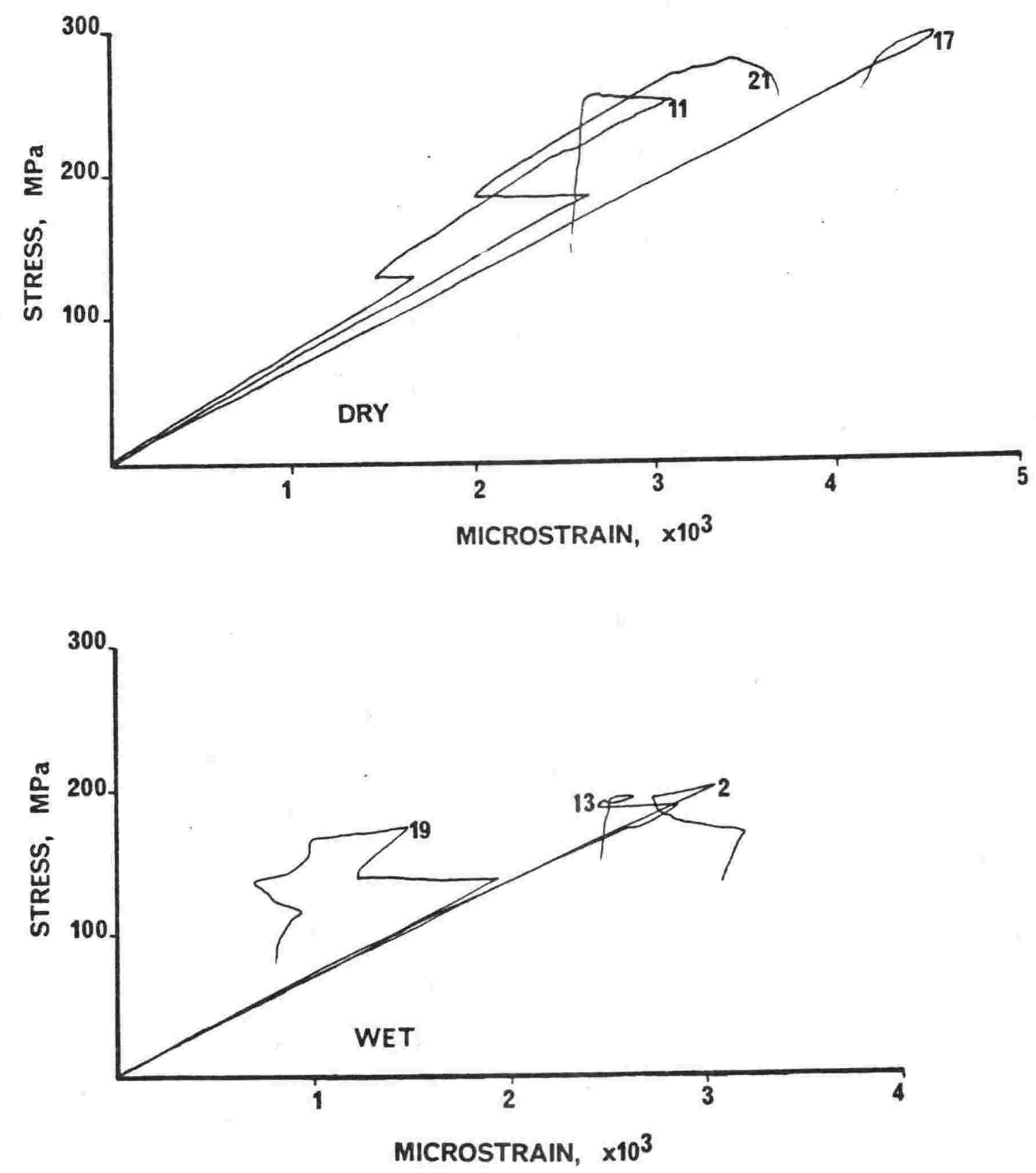

Figure Al5.7 : Stress-strain curves of BQ-IXA greywacke (2.9 phi, mean grain size). Curve numbers indicate core

sample numbers. Note, strain axes not identical scales.

Static elastic modulus figures are:

\begin{tabular}{lllll} 
& \multicolumn{2}{c}{ dry } & \multicolumn{2}{c}{ wet } \\
$\mathrm{E}_{\mathrm{i}}$ & 74.7 & $\mathrm{GPa}$ & 81.5 & $\mathrm{GPa}$ \\
$\mathrm{E}_{\mathrm{t}}$ & $68.3 \mathrm{GPa}$ & 64.4 & $\mathrm{GPa}$ \\
$\mathrm{E}_{\mathrm{S}}$ & $64.4 \mathrm{GPa}$ & 66.5 & $\mathrm{GPa}$
\end{tabular}

N.B. 1000 microstrain $=1 \mathrm{~mm} \cdot \mathrm{m}^{-1}$ 

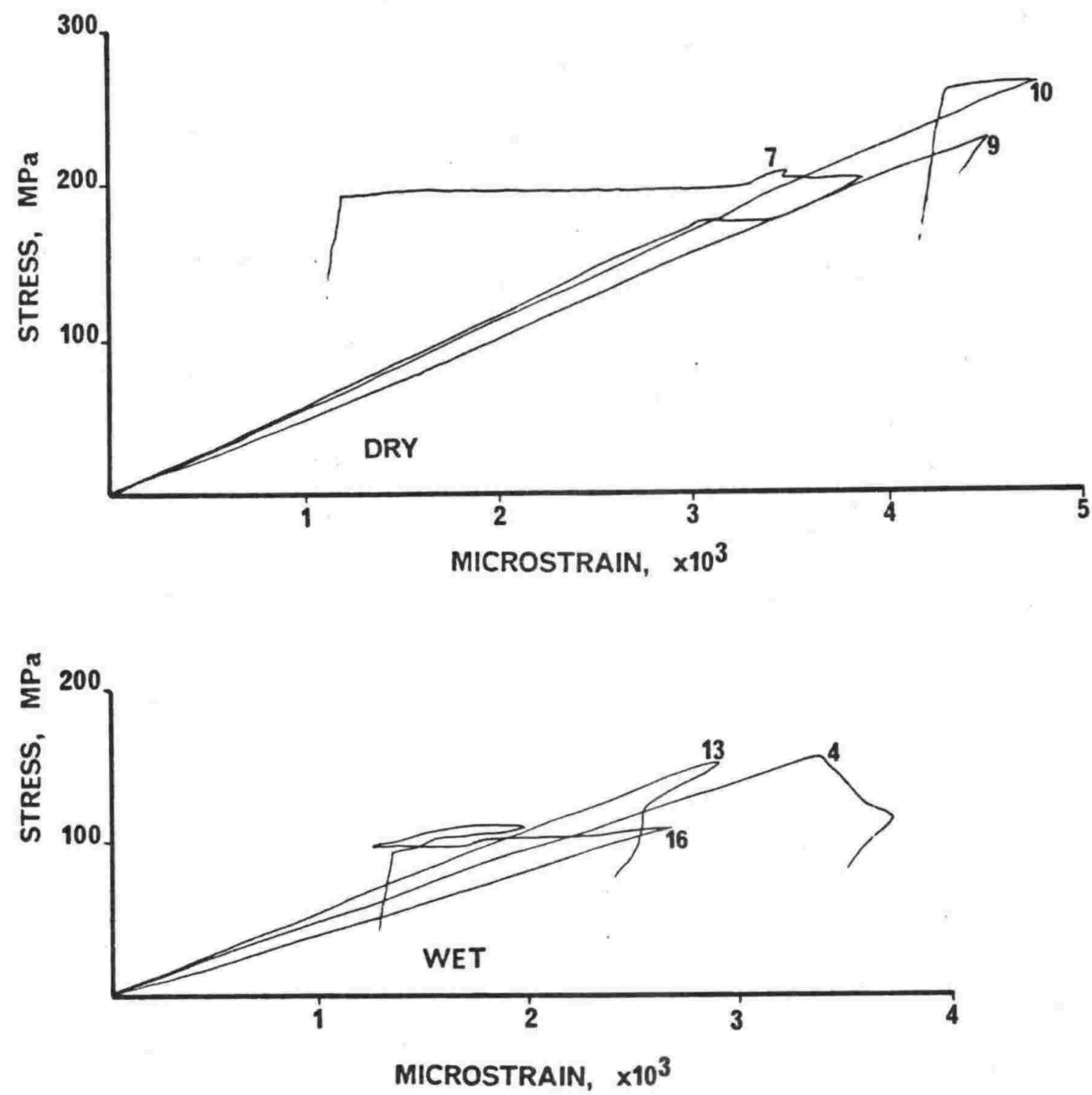

Figure Al5.8 : Stress-strain curves of KS-2 greywacke (3.3 phi, mean grain size). Curve numbers indicate core sample numbers. Note, strain axes not identical scales. Static elastic modulus figures are:

\begin{tabular}{lrrr} 
& \multicolumn{2}{c}{ dry } & \multicolumn{2}{c}{ wet } \\
$\mathrm{E}_{i}$ & $48.4 \mathrm{GPa}$ & 46.1 & $\mathrm{GPa}$ \\
$\mathrm{E}_{t}$ & $56.3 \mathrm{GPa}$ & $48.3 \mathrm{GPa}$ \\
$\mathrm{E}_{\mathrm{S}}$ & $51.7 \mathrm{GPa}$ & $51.7 \mathrm{GPa}$ \\
$\mathrm{N} . \mathrm{B}$. & & & \\
& & &
\end{tabular}



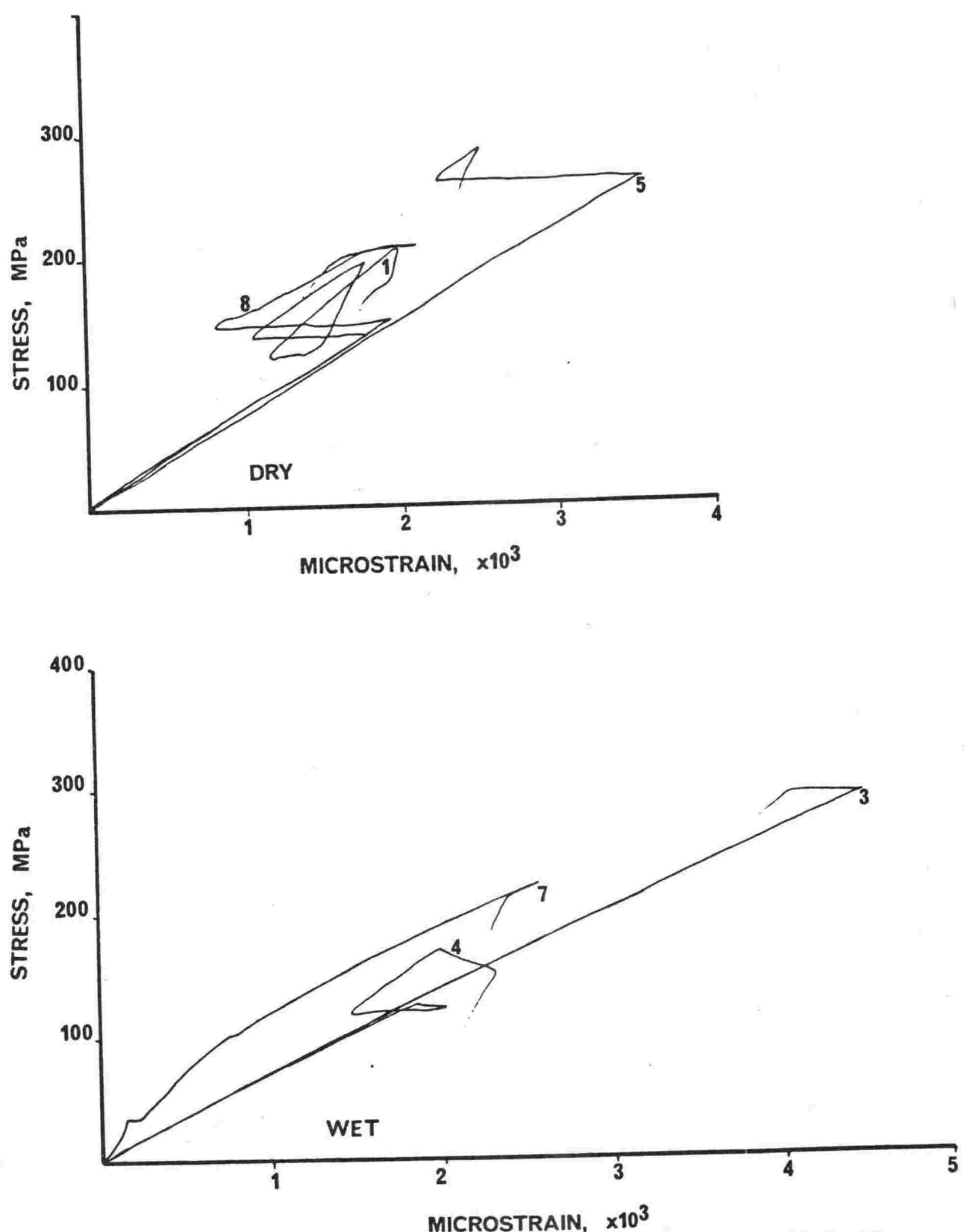

Figure Al5.10 : Stress-strain curves of SJ-T greywacke (4.7 phi, mean grain size). Curve numbers indicate core sample numbers. Note, strain axes not identical scales. Static elastic modulus figures are:

\begin{tabular}{lrrr} 
& \multicolumn{2}{c}{ dry } & wet \\
$\mathrm{E}_{\mathrm{i}}$ & $94.0 \mathrm{GPa}$ & 59.1 & $\mathrm{GPa}$ \\
$\mathrm{E}_{\mathrm{t}}$ & $72.7 \mathrm{GPa}$ & $65.2 \mathrm{GPa}$ \\
$\mathrm{E}_{\mathrm{S}}$ & $70.2 \mathrm{GPa}$ & $61.0 \mathrm{GPa}$ \\
$\mathrm{N} . \mathrm{B}$. & 1000 microstrain $=1 \mathrm{~mm} \cdot \mathrm{m}^{-1}$ & &
\end{tabular}



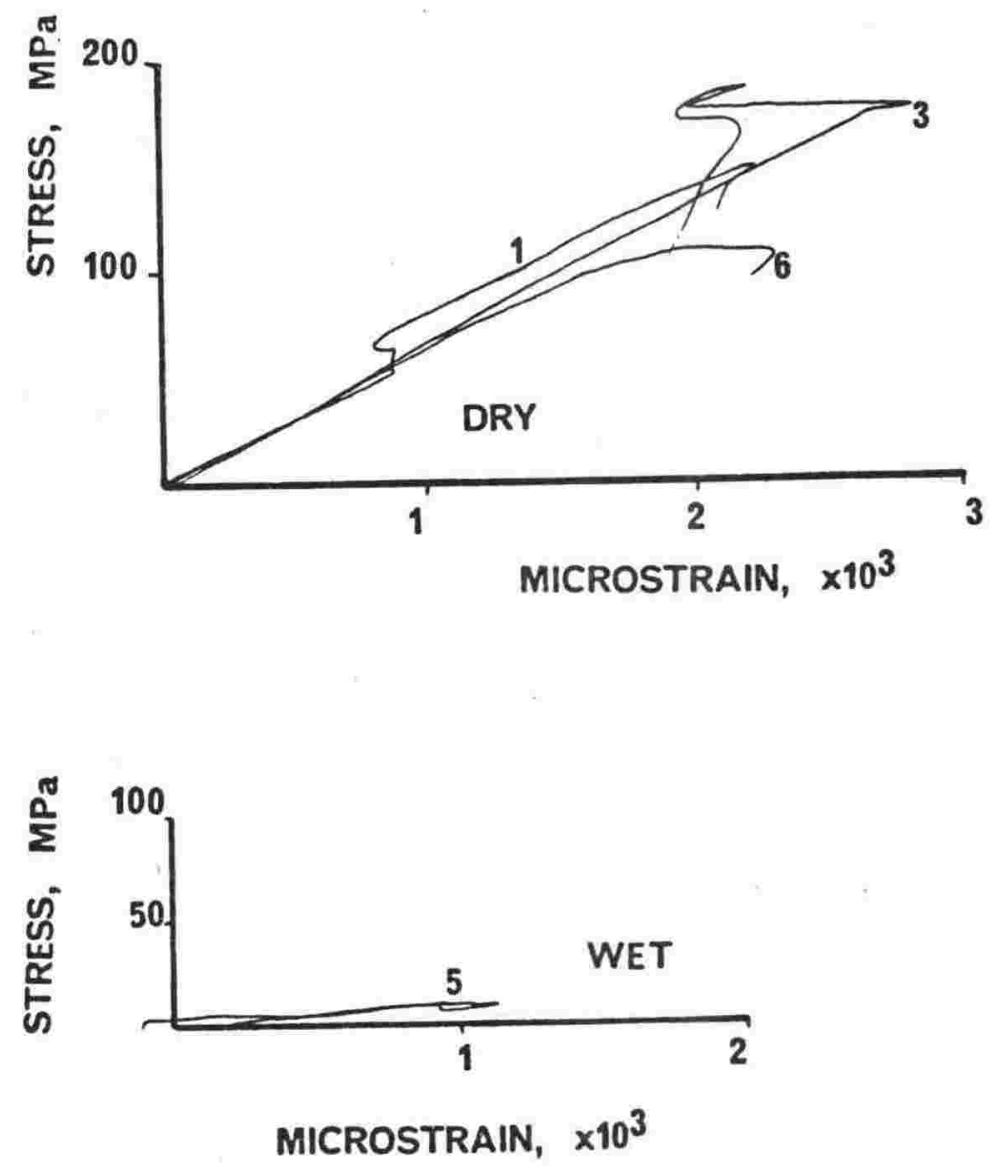

Figure Al5.12 : Stress-strain curves of HQ-22 argillite $(6.3$ phi, mean grain size). Curve numbers indicate core sample numbers. Note, strain ares not identicat-scales.

Static elastic modulus figures are:

\begin{tabular}{|c|c|c|c|c|}
\hline & $d r$ & & \multicolumn{2}{|c|}{ wet } \\
\hline$E_{i}$ & 68.3 & GPa & 14.0 & GPa \\
\hline$E_{+}$ & 68.4 & $\mathrm{GPa}$ & 11.2 & GPa \\
\hline & 60.9 & $\mathrm{GPa}$ & 10.9 & $\mathrm{GPa}$ \\
\hline
\end{tabular}


and test load respectively, the former inversely, the latter directly. Sudden failure, the usual result from all but the highest quality test equipment, masks the CD portion of the curve and may jeopardise the accuracy of ultimate stress deternination.

Deere and Miller (1966) characterised six types of stress-strain curves (Figure A.15.2), three of which apply to this study. In general, greywackes display type i elastic behaviour when dry but type ii elastic-plastic when wet. Some of the finer greywackes and all the argillites appear elastic - plastic wet or ary. In one case only was type iii plastic elastic affinity noted, KS-2 greywacke, tested dry. The difference between wet and dry greywacke and argillites suggests moisture related promotion of plastic deformation at least in coarser examples.

An initial "plastic" closing of pores and/or fissures is generally thought to be the reason for the concave shape from the origin of the type iii curve - the elimination of this effect in KS-2 on saturation, indicates a pressure role by pore water in straightening this part of the stress-strain curve, though not enough to raise the mean initial tangent modulus $\left(E_{j}\right)$ above that of the ary samples. All coarser grained greywackes have an increased $E_{i}$, probably due to an initial expulsion of water, requiring stress but not straining the sample. Strain fluctuations were apparent in both positive and negative senses, e.g. SJ-3l, and $\mathrm{KIW}-\mathrm{i}$ (dry) respectively, and it is suggested that these resulted from differences in failure mode.

\section{Core failure modes}

Failure could be categorised in three groups, two main and one subordinate.

2.1 The first form of fracture mode (Plate A15.1A) is well reported in the literature under various names; extension failure (Griggs and Handin, 1960), axial cleavage fracture (Gramberg, 1965; Hawkes and Mellor, 1970), indirect tensile fracture or induced tensile fracture (Duncan, 1969), brittle fracture (Jaeger, 1972), typical "brittle" cataclasis type failure (Attewell and Farmer, 1976), longitudinal splitting (Jaeger and Cook, 1976), cataclastic failure (Bryant, 1977). This mode is the most common in rocks under uniaxial compression (Duncan, 1969) and is the type of failure experienced in rocks displaying the stress-strain curves of Figure A15.2, type $i$ and $i$ (Griggs and Handin, 1960). During dry testing, failure would be so explosively violent as to completely eject all but small fragments of the sample from between the test platens; lower rates of loading, used in trials gave less violent results. Samples tested wet gave fewer, longer and therefore larger pieces, probably due to lower loads at failure.

The early formation of this type of fracture involves parting in tension across a surface, parallel to the direction of applied load. This occurs without relative displacement normal to the applied load. Extention fracturing in this way is characteristic of brittle materials (Handin, 1966). In the samples tested, this cracking which occurred at above 50 percent ultimate stress, although audible was invisible and rarely resulted in strain relief, appearing on the stress-strain curve as an $\mathrm{X}$-axis displacement (Figure A15.7). This form of strain relief must be localised to interior zones and external ends of the specimen as the sample rarely lost its ability to bear load. The process occurred as frequently in wet tests as in dry and there appears to be no gradient change between displaced portions of the stress-strain curve. This is consistent with the analysis of stress distribution by Hawkes and Mellor (1970). Ultimate failure often resulted from cracking in this manner so that the sample, with increasing deformation, had decreasing ability to resist load - a brittle failure (KTW-i, wet). The effects described may have 

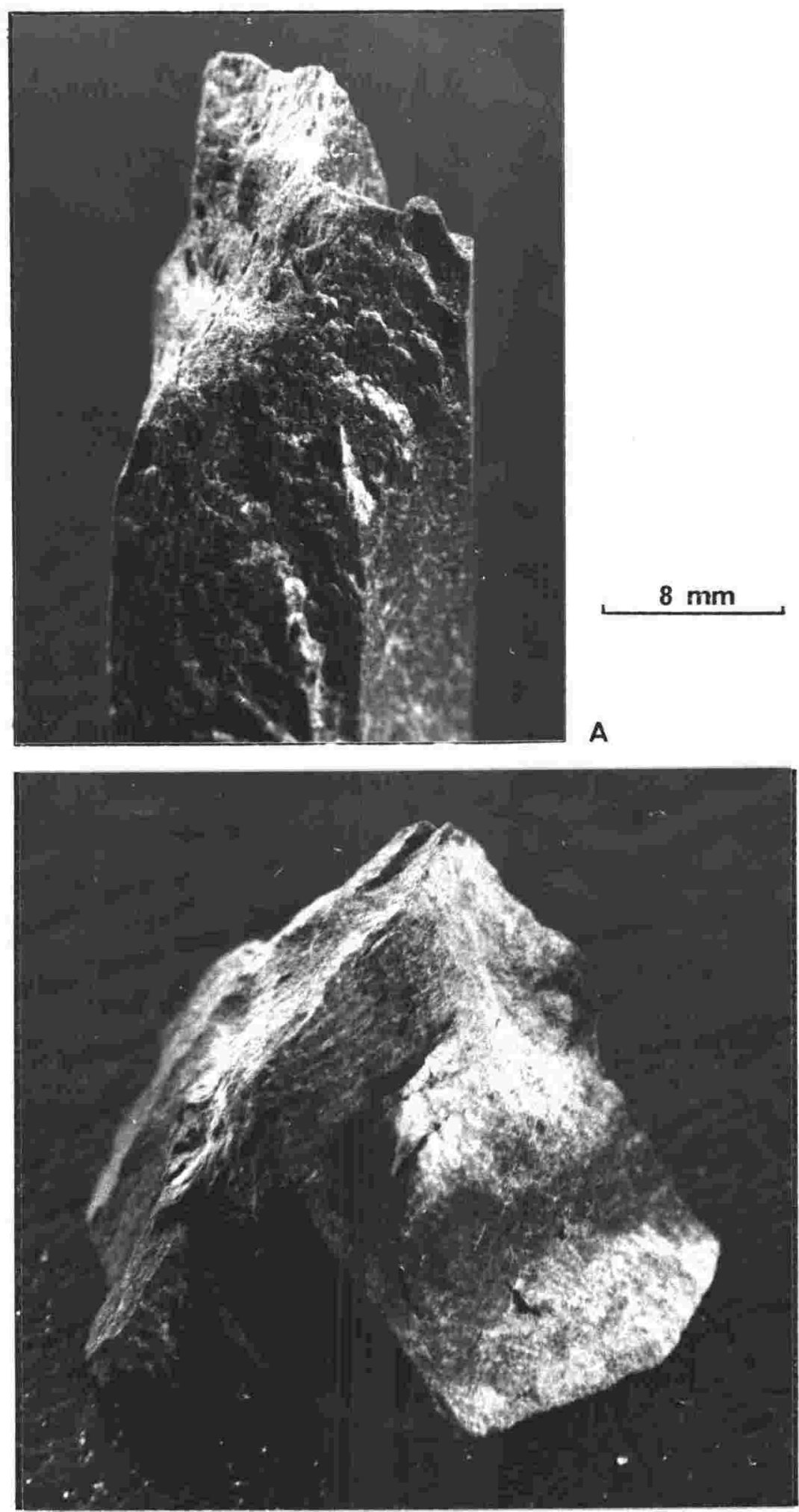

B

\section{$5 \mathrm{~mm}$}

Plate Al5.1

(A) Axial cleavage failure mode in $\mathrm{KTW}-\mathrm{i}$ with intense apical comminution and surface flaking.

(B) Bottom cone from a double cone failure of $O B-W$. Intense comminution and en echelon flaking are

apparent. 
been attributable to small sample size, end effects due to platen placement or end constraint, or uneven distribution of load on the end bearing surfaces, i.e. point loading. The effect merely indicates an unbalancing of one strain gauge in the testing system as it is momentarily relieved.

2.2 The second form of failure known variously as faulting (Handin, 1966), shear failure (Jaeger, 1972) or double cone failure (Vutukuri et al., 1974) occurred more often in argillites. It is more common in the testing of larger specimens or in concrete, developing from end constraint (Vutukuri et al., 1972; Jaeger and cook, 1976). The distribution of stress in cylindrical specimens under uniaxial compression between metal surfaces is discussed by Hawkes and Mellor (1970) and Vutukuri et al. (1974). The latter describe this type of failure as a "development of multiple cracks parallel to the direction of applied force at mid-height of the specimen near the surface and its extention to the ends and into the centre of the specimen". On failure and collapse, conical end fragments remain along with large longitudinal slivers from around the periphery (Plate Al5.1B, A15.2). It is a predominance of this failure mode that imparts sudden strain increase to the stress-strain curves approaching failure stress; examples seemingly of greater magnitude, if not prevalence appears to be greater in samples tested wet and it is suggested that the effect is due to distortion of the strain gauge by sudden brittle failure, audible but invisible, occurring under the strain gauge attachment area "at the mid-height of the specimen near the surface" vutukuri et al. (1974).

2.3 The third form of failure is shear fracture along a single oblique plane (Jaeger and cook, 1976; Paterson, 1978). Occurring rarely but more prevalent in wet tests, it resulted usually from an invisible flaw at a stress much lower than the true uniaxial strength of the rock. In these cases results were not considered further. Some failures may have been induced by machine geometry (Hawkes and Mellor, 1970) although efforts had been made to eliminate this cause.

Vutukuri et al. (1972) states all three of these failure modes may appear in a single specimen. Bryant (1977), in a study of Kaimanawa greywackes, noted a range of failures involving all three failure modes.

Generally, dry samples in this study failed in a longitudinal splitting mode. This is not unexpected since end constraint was reduced by using dummy platens of identical diameter to the cores tested (Plate Al2.1). Wet samples displayed a failure mode which. encompassed both longitudinal splitting and cone formation. Griggs and Handin (1960, plate 1) illustrate this well, though specimens in this study usually broke into fewer pieces, one end usually having a better formed end cone fragment.

3. Surface features of failed rock cores

A study of broken surfaces proved interesting and is relevant to surface texture and dust generation considerations in bonding of rock aggregate in concrete (section 4.2 .7 ). Three main types of surface were produced by compression failure.

3.1 Cataclastic surfaces: Curved or planer faces on which intense comminution of surface grains was apparent. These faces formed at angles of up to $40^{\circ}$ from the longitudinal axis of the core. Intense differential movement took place along the more planer surfaces in apical regions of wedge and cone shaped portions of fragments. This surface, generally confined to the greywackes, sometimes displayed poorly developed slickensides in 

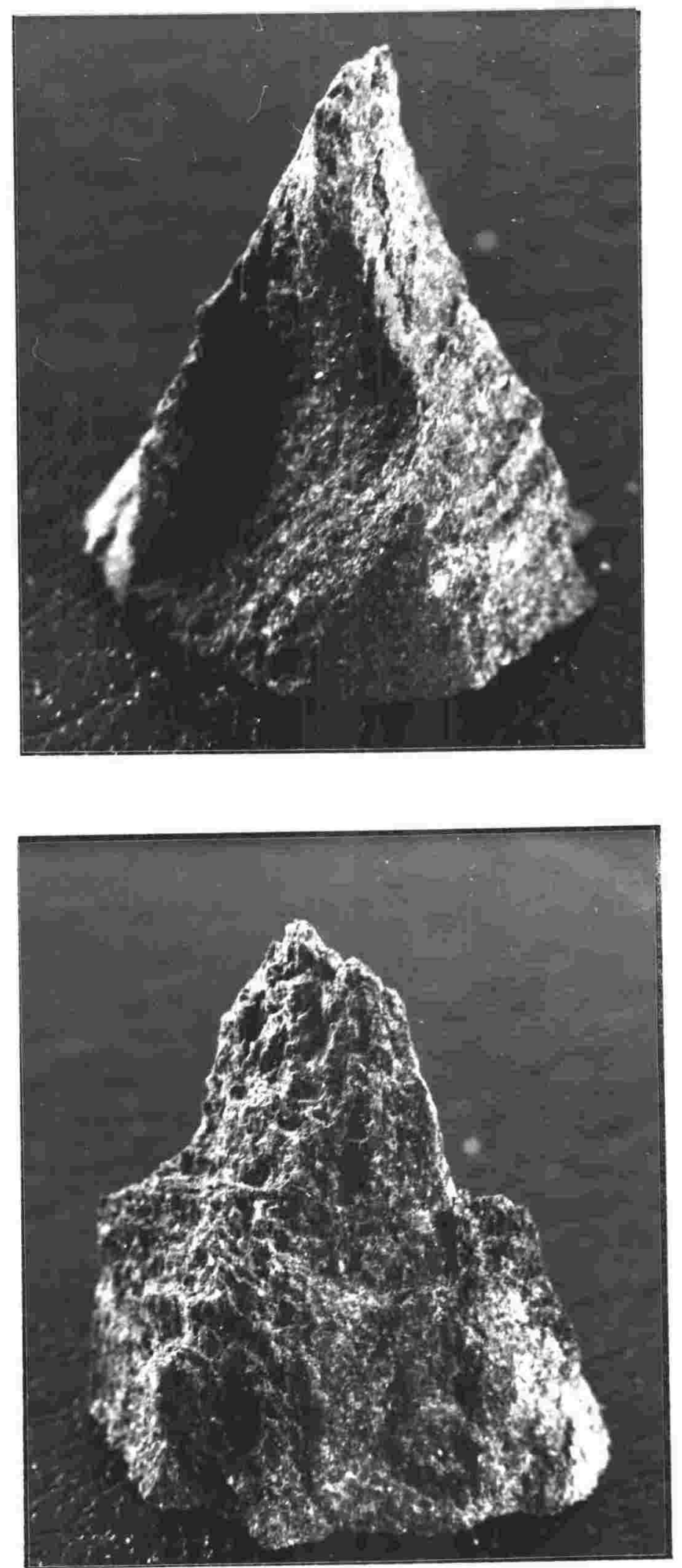

Plate Al5.2 : Two views of HQ-17 (core 4) are shown, both are bottom cones from double cone failures showing surface flaking and en echelon flaking. Both fragments are $25 \mathrm{~mm}$ high. 
intensely cominuted surface rock material. The fineness of comminution appeared directly related to the mean grain size of the parent rock and was a white powder in greywackes, grey in argillites. In all cases it was quite strongly bound to the rock surface (Plate Al5.1A). Cataclastic surfaces are formed in association with all three failure modes but more strongly developed in longitudinal splitting and double cone failure modes. They developed regardless of rock moisture content.

3.2 Irregular planar surfaces: Surfaces were most commonly formed at angles between $0-15^{\circ}$ to the longitudinal axis but smaller surfaces had orientations up to $90^{\circ}$ (Plate A15.IA). These are the most comonly formed surfaces-a tensile splitting such that corresponding portions of the surface across the fracture do not come into frictional contact during or after core failure. These surfaces formed in all rock types in wet and dry test conditions; rather larger in wet. Surface colour is lighter (lower value) than that of the rock itself due to the presence of many very thin flakes of rock material which are partially detached from the surface. They remain as a non-comminuted flake, flat against the surface with perhaps one, two or three edges. Their surface extent is about two to three times the mean grain size of the rock in which they formed and they may have an irregular outline. Irregular planar surfaces, while not having any loose detritus was densely covered in a veneer of partly divorced thin (about $0.15 \mathrm{~mm}$ ) flakes which would reduce bond strengths of aggregate in concrete (Alexander, 1963).

Irregular planar surfaces were most commonly formed in association with the logitudinal splitting failure mode.

3.3 Transition features: These formed in all rock types and were commonly associated with double cone failure modes. They represented a transition from the irregular planar surface to the cataclastic surface. They existed as a series of sharply en echelon, partly comminuted "ridges outlining a relatively broad zone of shear movement within the core (Plate A.15.1B, Al5.2). Their areal extent varied, but the fineness of the ridge structure was again a direct function of rock mean grain size - better developed in finer grained rocks. Core failure followed no obvious lithogical feature. Recemented shears $(O B-W$, see section 2.16 .3$)$ were traversed by failure planes. Because cores were cut perpendicular to bedding, no influence was apparent from the strength of grain orientation and hence fissility. Occasional fine veins (approximately $0.02 \mathrm{~mm}$ wide) in $O B-W$ and HQ-22 were seen to "guide" some cracking but did not appear to reduce the boad at failure compared with vein free cores. Larger veins (approximately $0.06 \mathrm{~mm}$ wide) promoted shear failure when orientated obliquely to applied load if they were of zeolite or calcite. veins of quartz and prehnite showed no tendancy to become portions of fracture planes. 
APRENDIX 16

Classification of intact rock by deformation characteristics, applied to Vellington greywacke-suite rocks

The significance of establishing uniaxial compressive strengths of rocks is explained elsewhere (section 3.5). Results aid the choice of equipment required for winning and processing rock products and provides comon ground between engineer and geologist.

Increasingly, engineering rock classification is finding favour as a means of cuantitatively assessing in situ rock masses but systems derived to date fall well short of universal satisfaction and experience still outveighs calculated evaluation.

Lama and Vutukuri (1978) have sumarised the development of intact rock classifications (i.e. the classification of rock "material removea from its environment and devoid of discontinuites") and show the importance of compressive strength and the stress-strain curve to these classifications.

The classification scale of Deere and Miller (1966) is now the most widely used (Figure 2.16.1) for describing and comparing intact rock characteristics. Deformation characteristics of rock which are used for classification are related to compressive strength in a "modulus ratio" expressed either graphically or descriptively. 


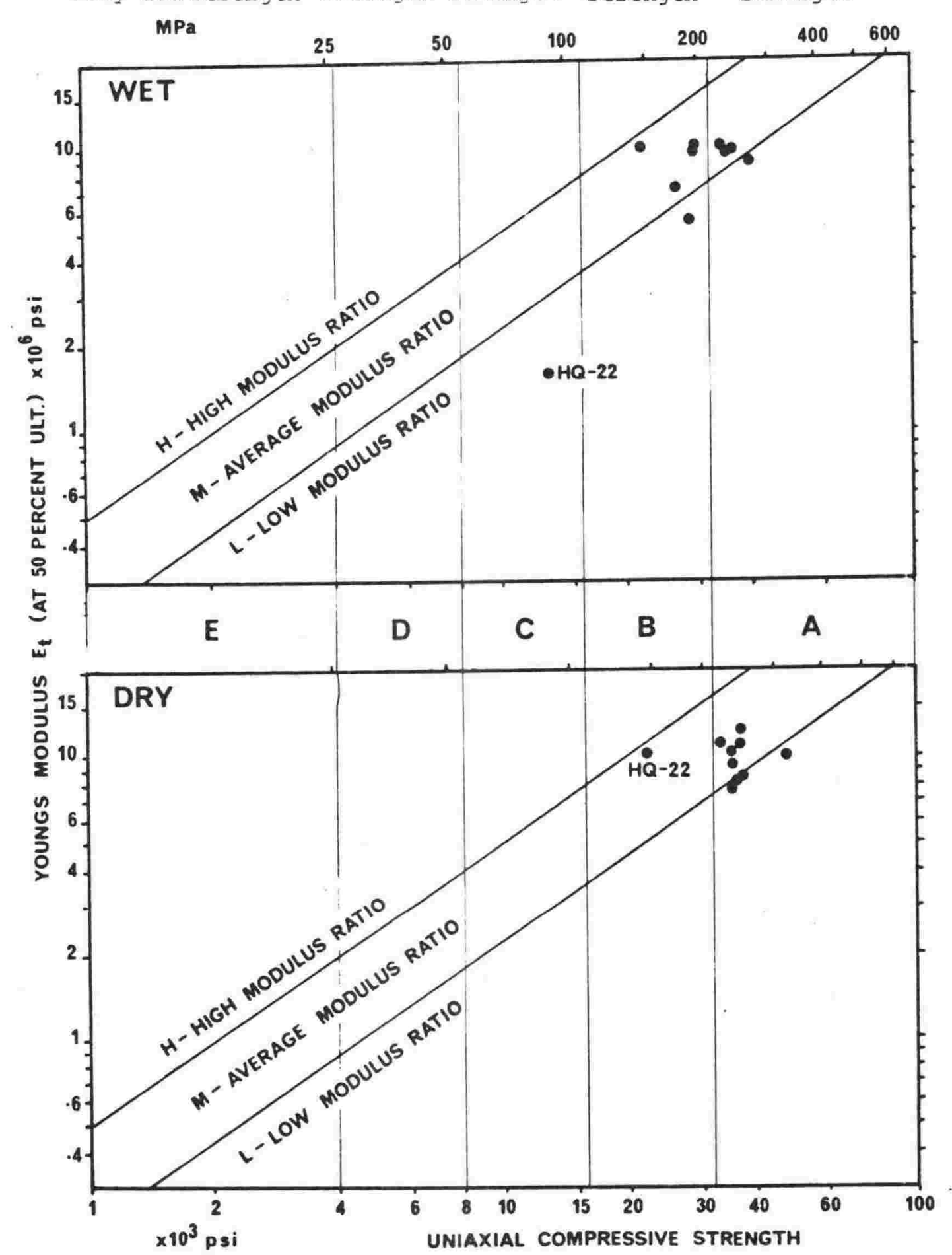

Figure Al6.1 : Rock classification chart used by Deere and lfiller (1966) originally for igneous rocks. Black dots show the classification of Wellington greywacke-suite rocks according to this scheme. Strength is subdivided into classes $A, B, C, D$ and $E$ for very high, medium, low and very low strengths respectively. Rocks are classified by both strength and modulus ratio e.g. wet samples would be classified AL, AM, BI, BM, CL; dry: $A L, F M$ and $B M$. 
Argularity of rock particles: raw data

Included are photocopies of sectioned concrete cyinders from which particle angularity was measured using a method of Lees (1964); Plate Al7.1 to 12 . Figure Al7.1 is the grid used to select particles which were counted. Raw data arrears in mable P.17.1. Figures Al7.2, $A 17.3, A 17.4$ show relative frecuency of particle angularity $\left(A_{2 D}\right)$ for each aggregate.

The concrete cylinders were randomly selected from each of the groups of three tested in uniaxial compression at three days. 


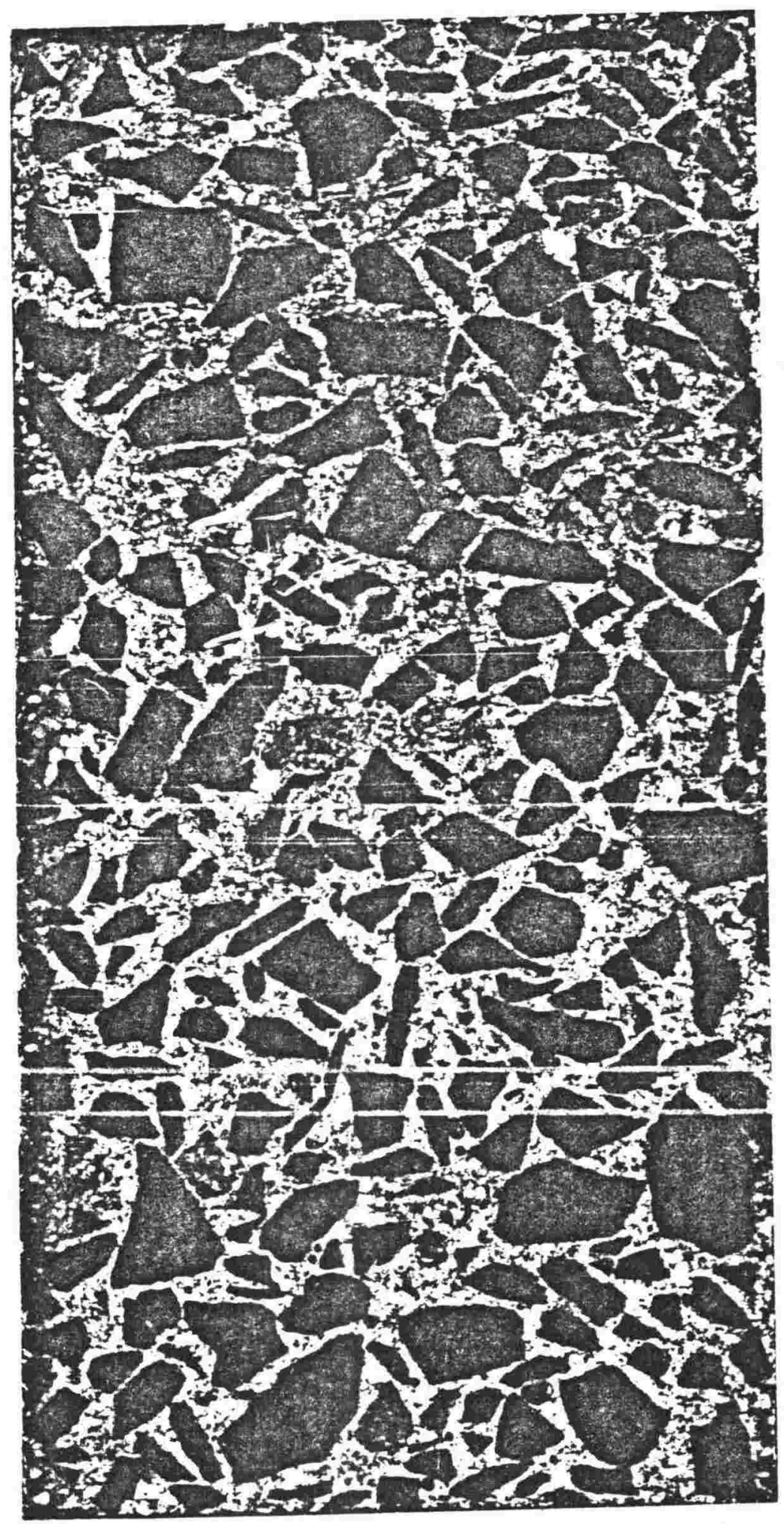

HQ-17 mix 9 (4)

Figure Al7.1 to 12 : Photocopy images of sectioned concrete specimens from which angularity measurements were taken.

The top of the cylinder as cast, is to the top of the page. The number in brackets indicates the specimens place in the order angularity measurements were taken. 


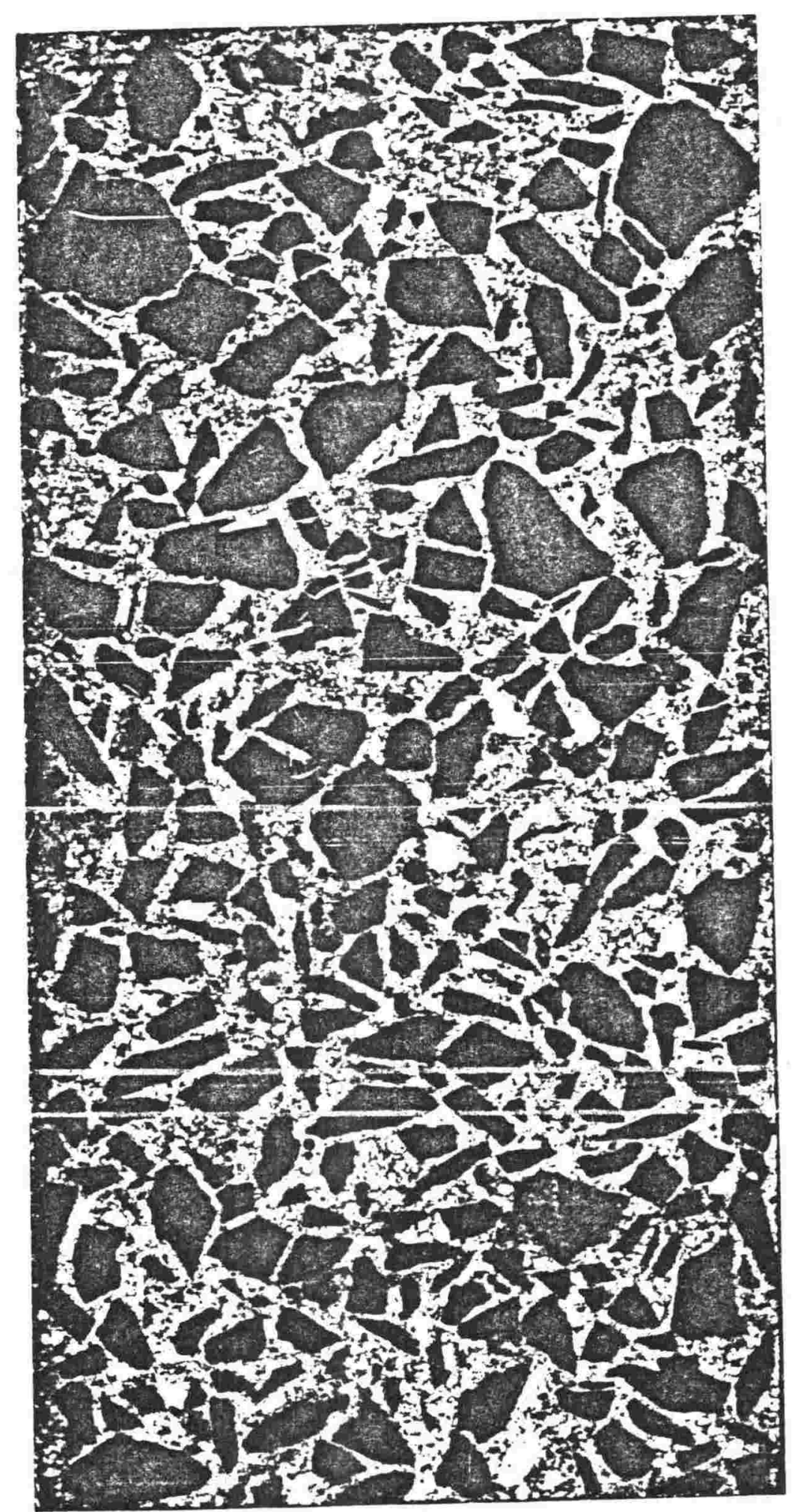

HQ-17 $\operatorname{mix} 2(10)$ 


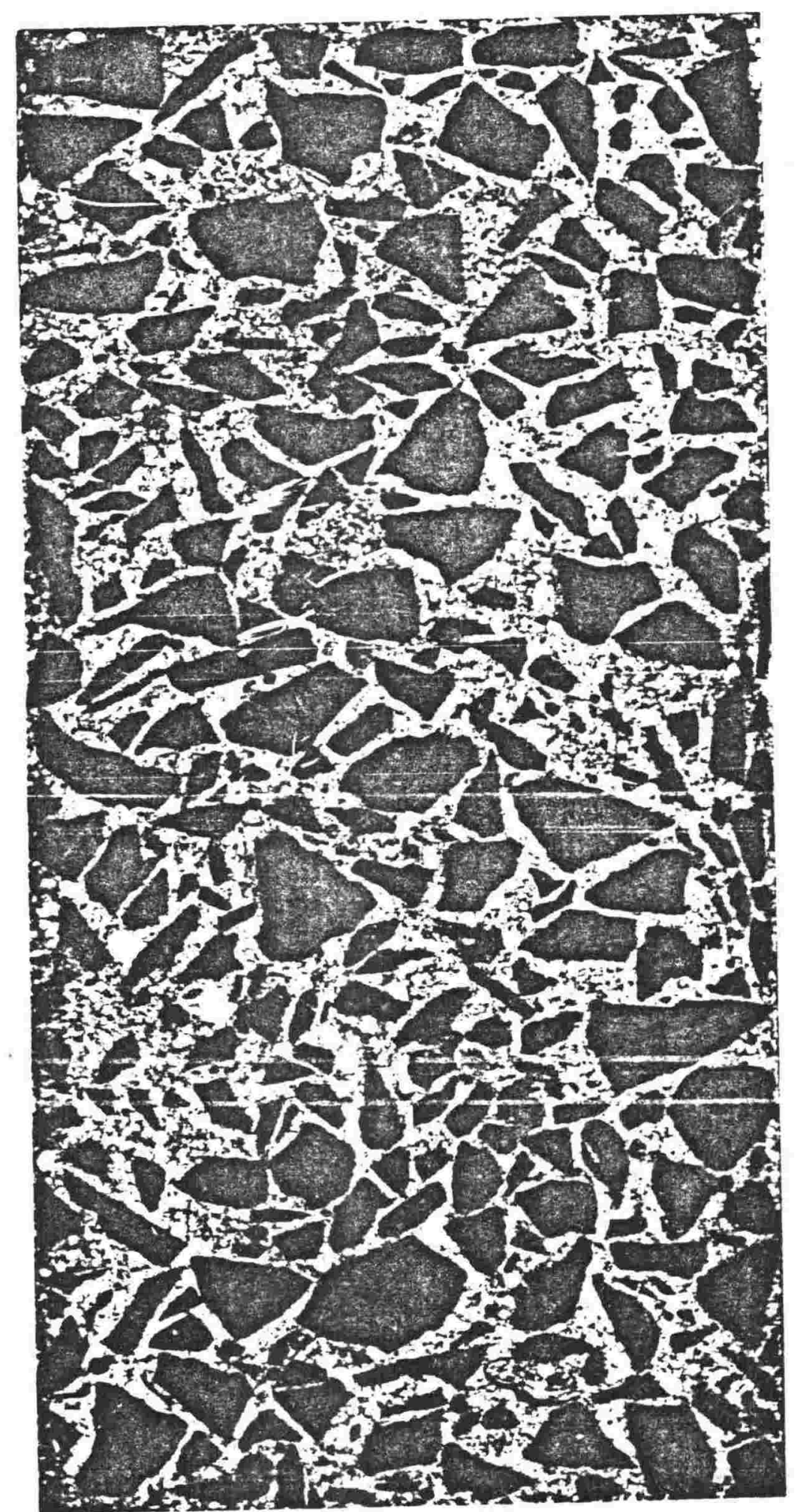

KTW-14 $\operatorname{mix} 1$ (2) 


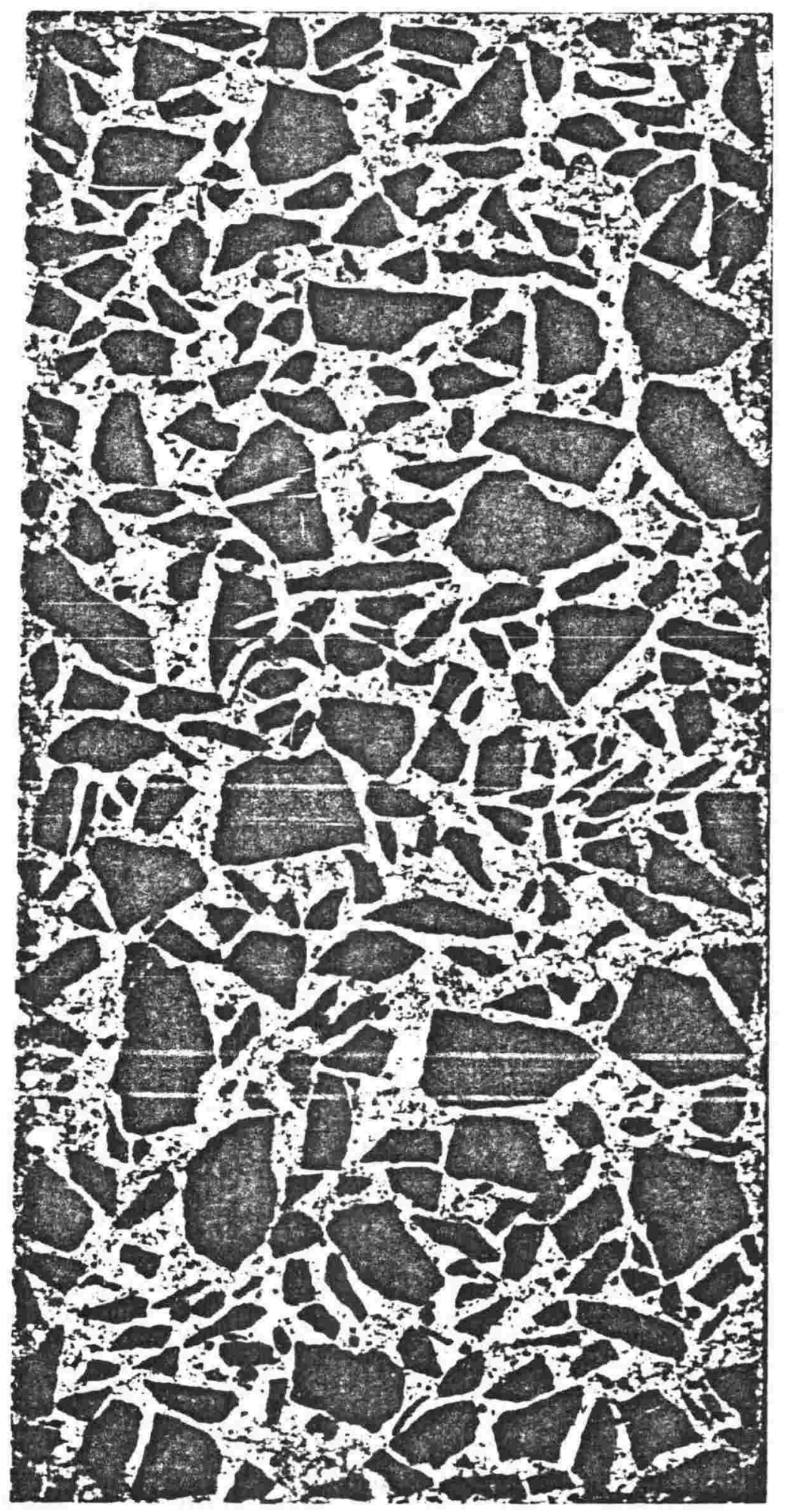

KTW-14 $\operatorname{mix} 2(6)$ 


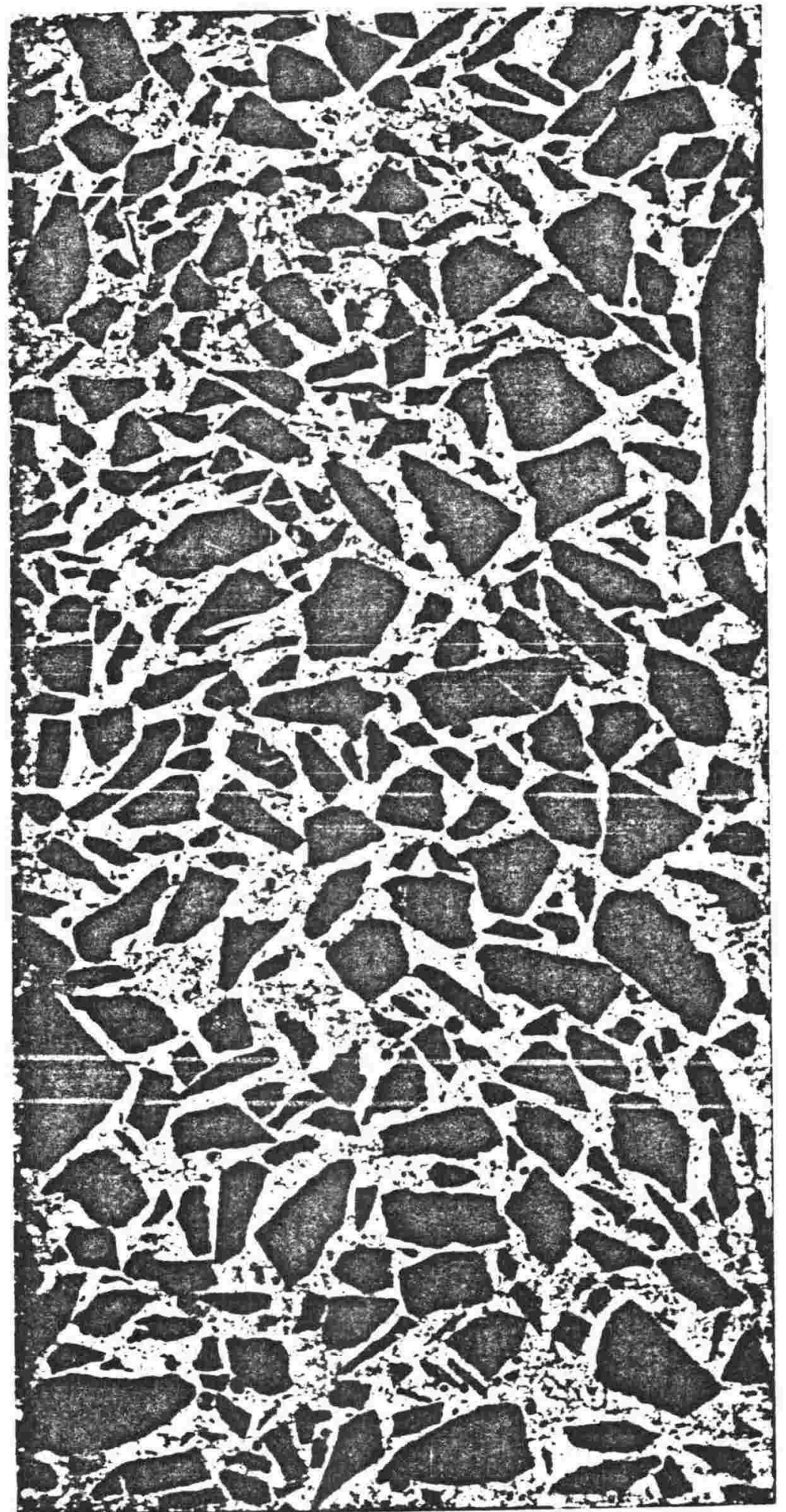

$B Q-I X A \operatorname{mix} 1$ (1) 


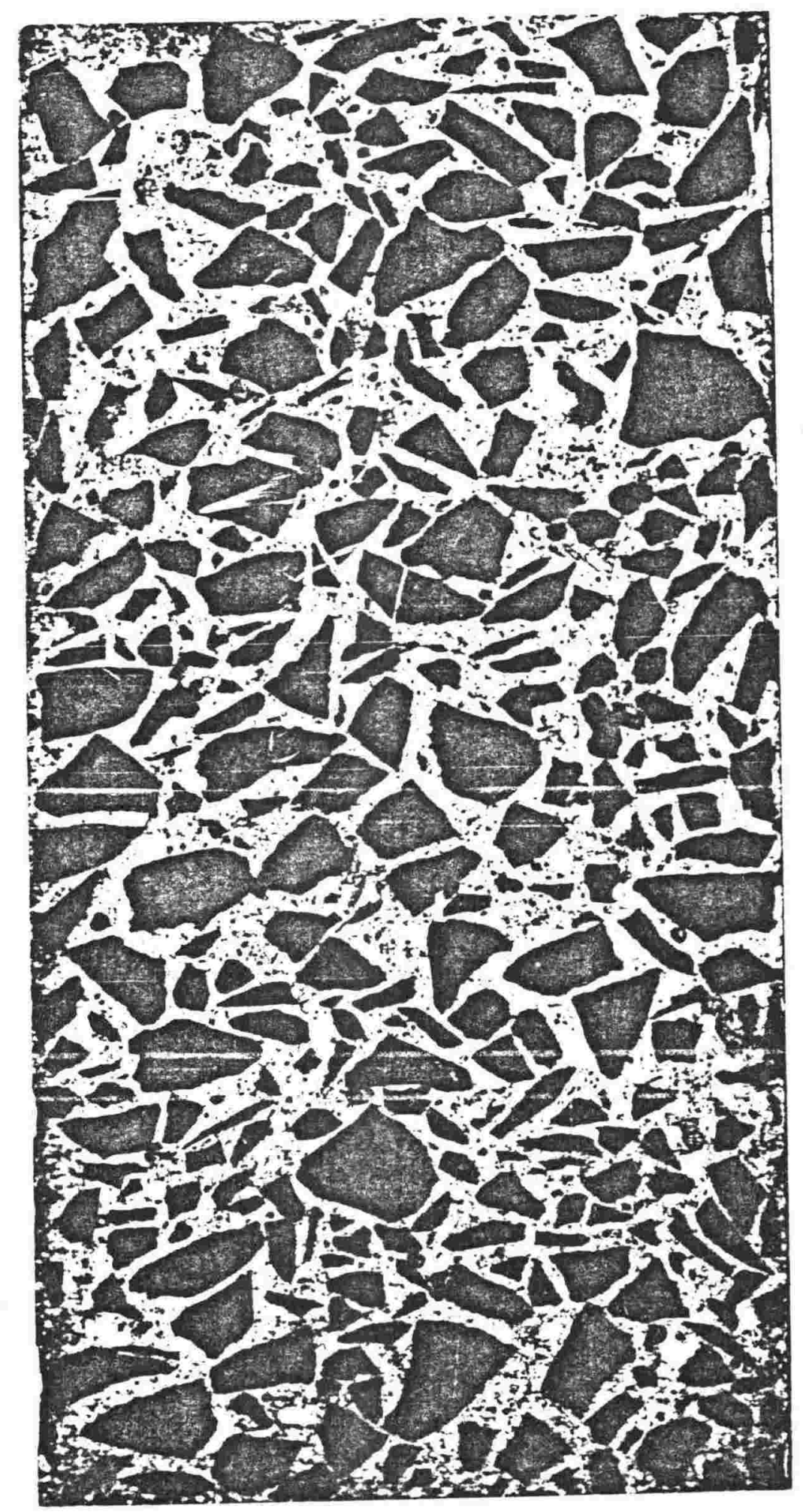

$B Q-I X A \operatorname{mix} 2(9)$ 


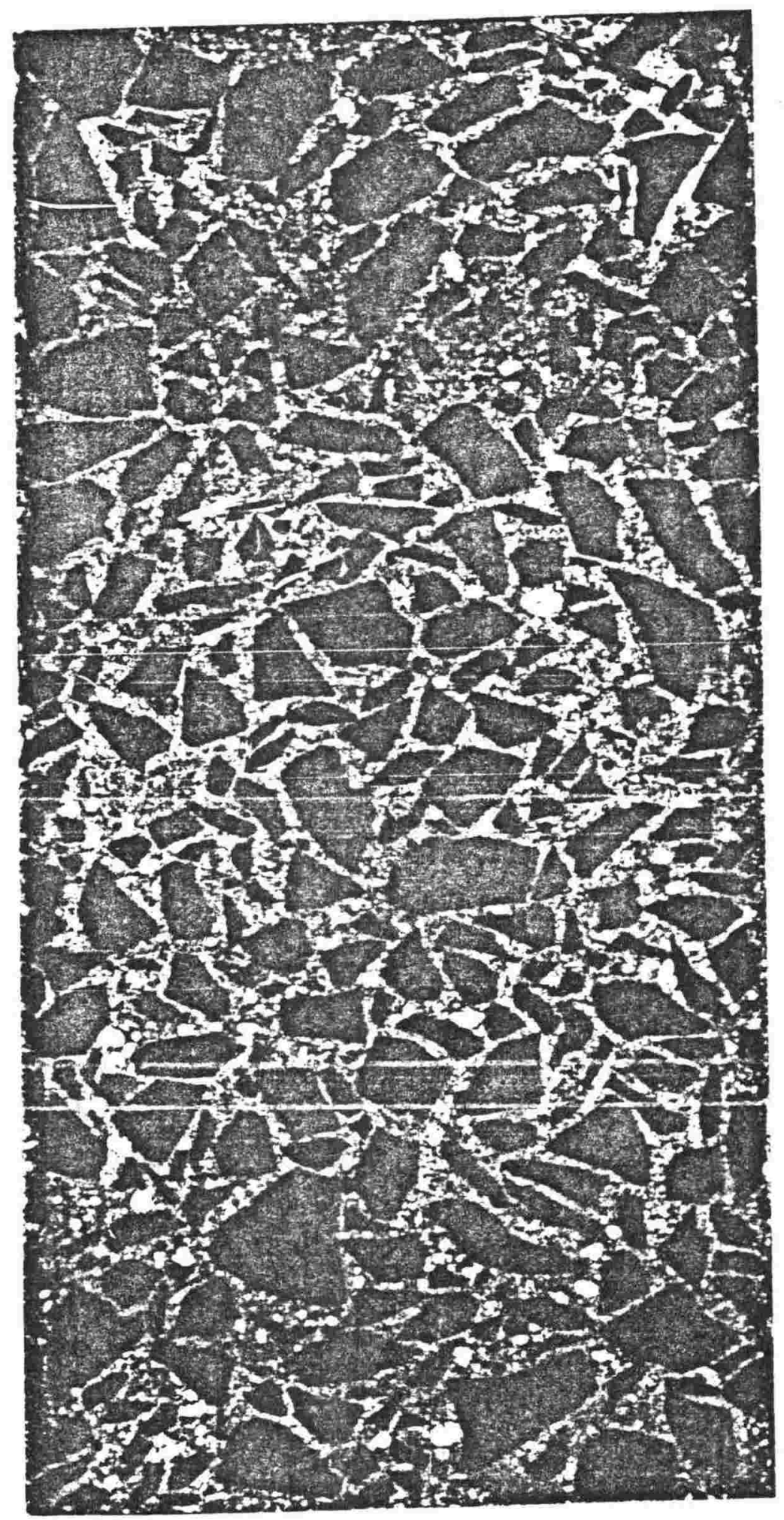

SJ-T mix 1 (7) 


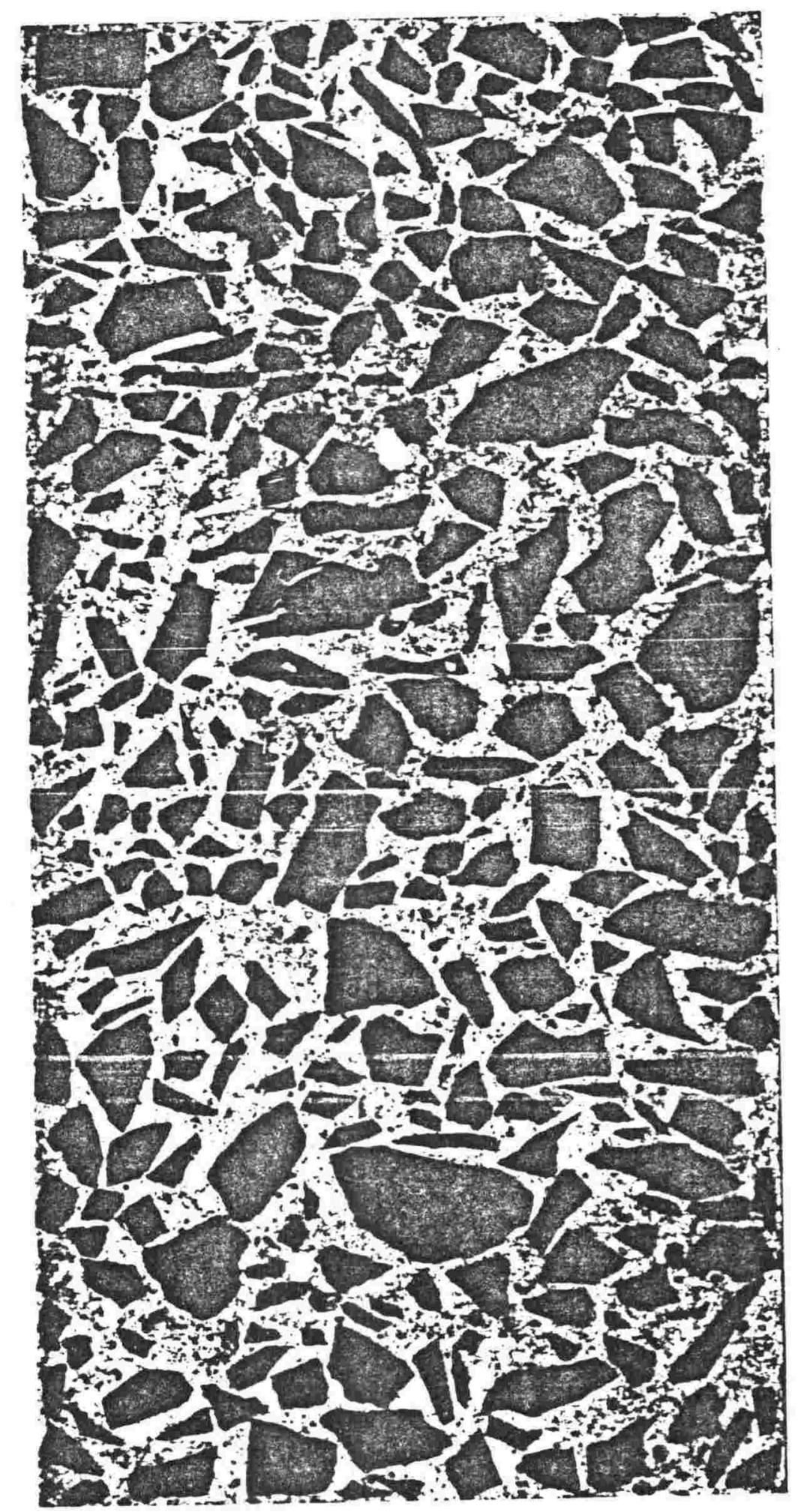

SJ-T $\operatorname{mix} 2(8)$ 


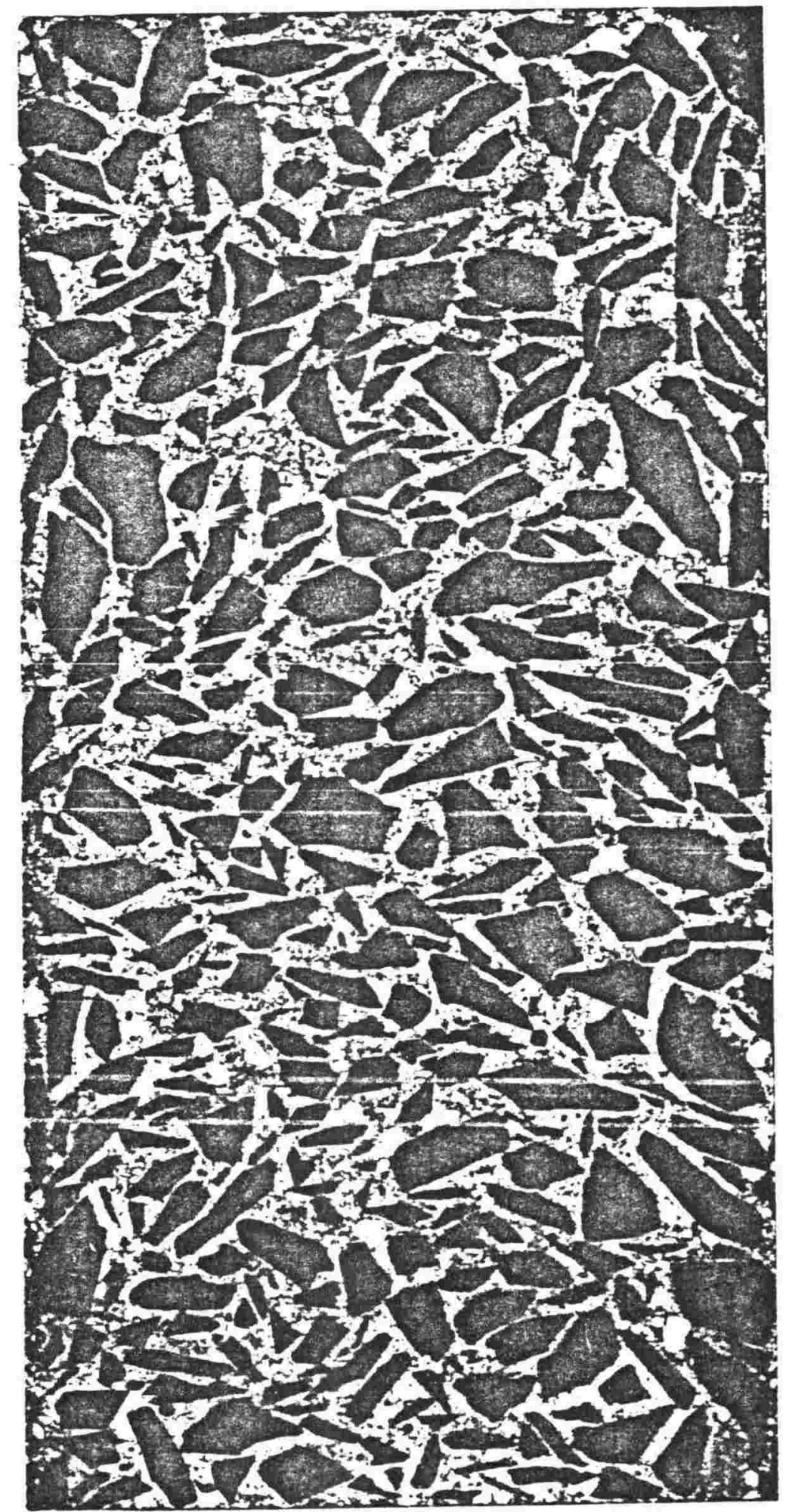

$O B-W$ mix 1 (12) 


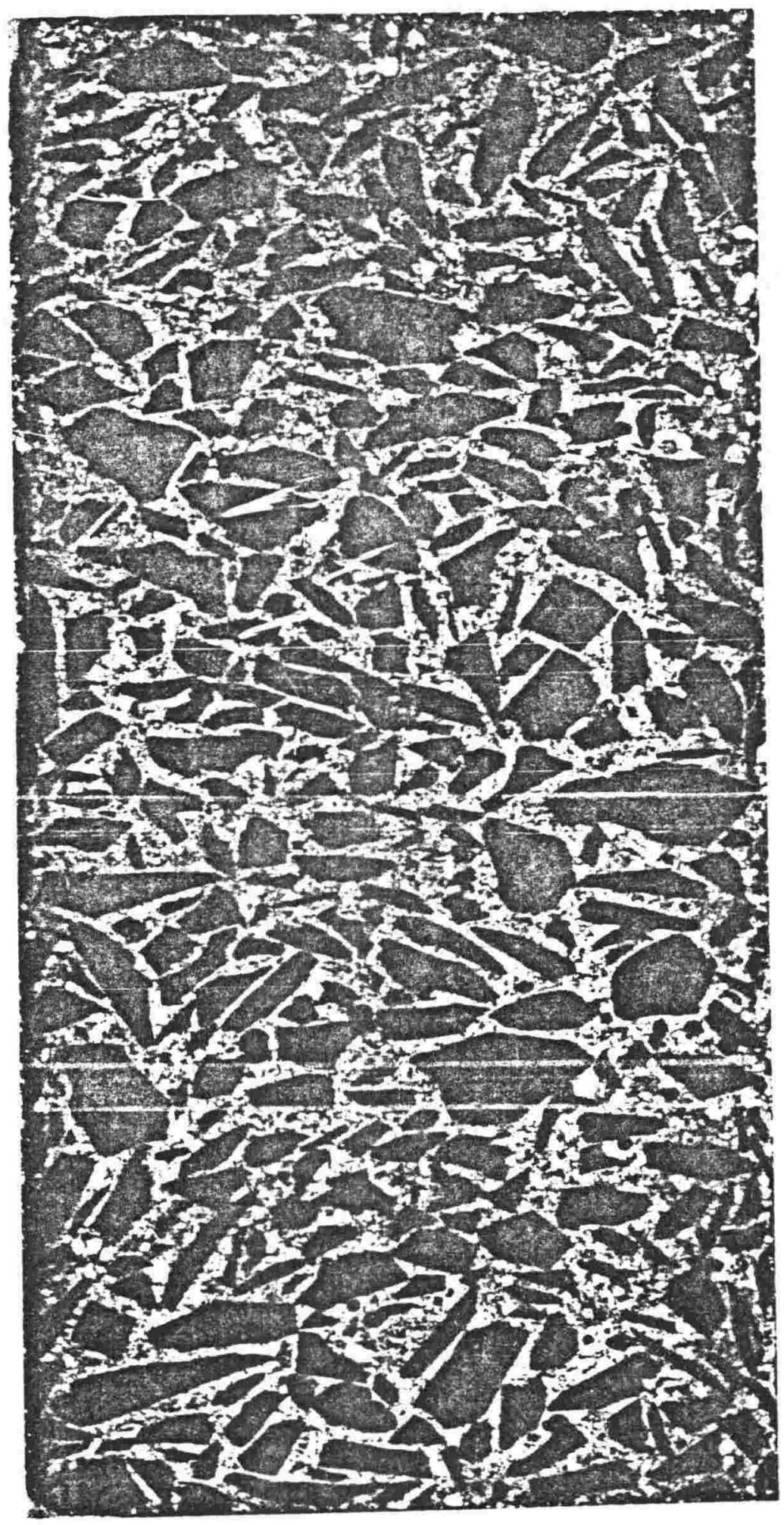

$O B-W \quad \operatorname{mix} 2$ (11) 


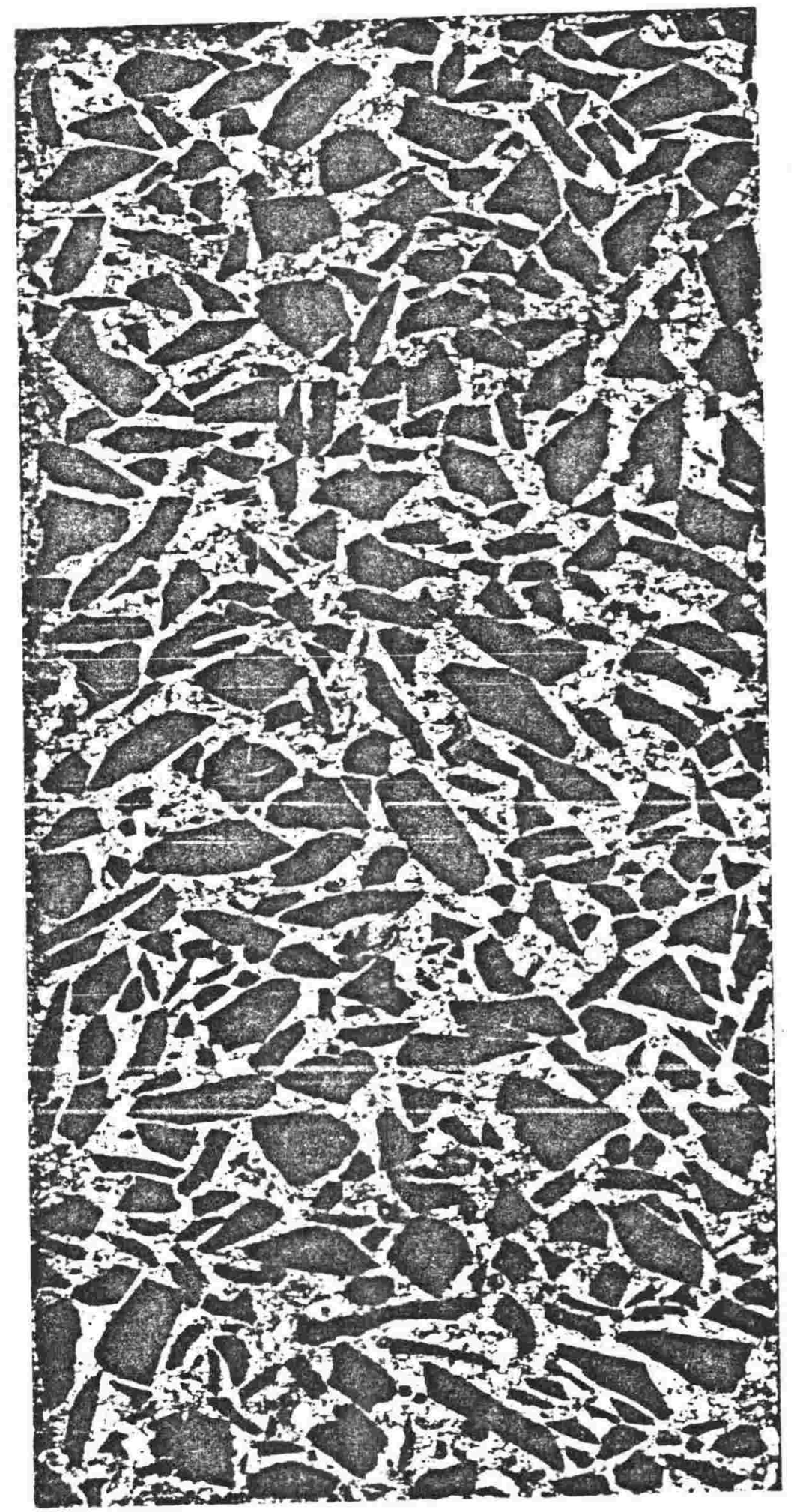

$H Q-22 \operatorname{mix} 1$ (3) 


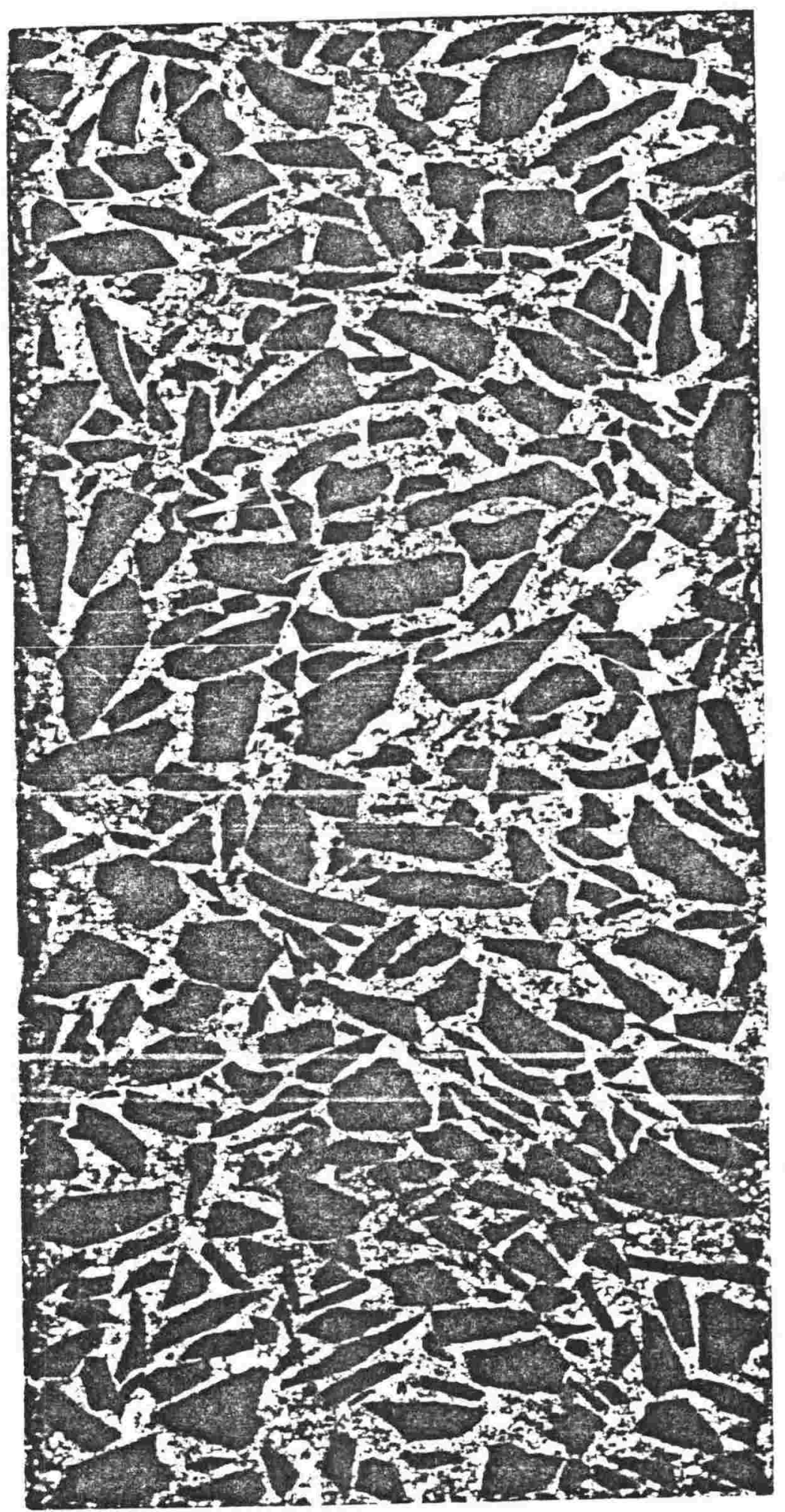

$H Q-22 \operatorname{mix} 2(5)$ 


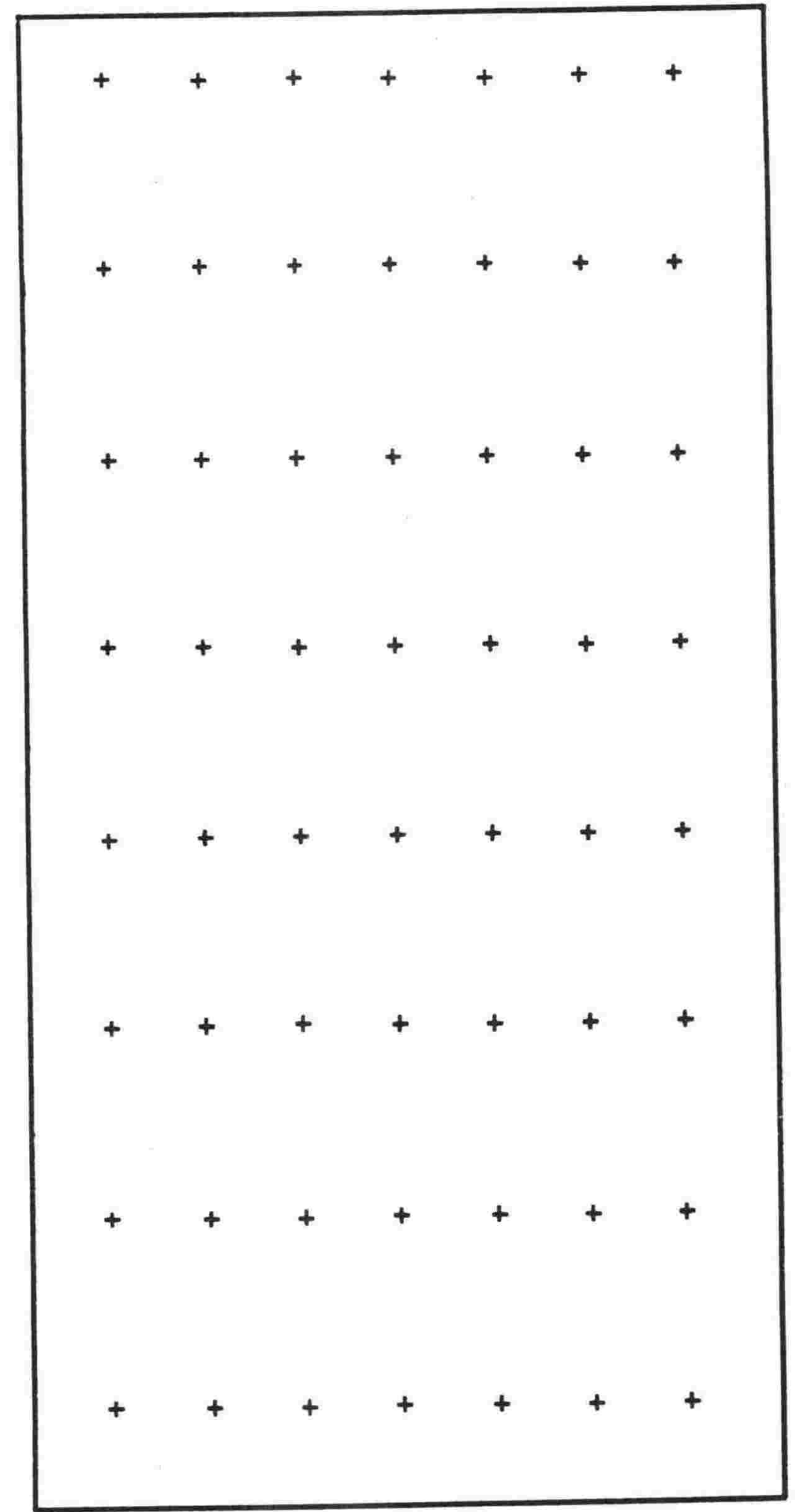

Figure Al7.1 : Grid template used in particle selection for angularity measurements. Crosses mark points from which samples were taken. The border indicates the edge of the photocopy image of the sectioned cylinder. 
Table A.17.1 : Angularity raw data for aggregate samples determined from sectioned concrete cylinders. At the base of each column in respective order are the total mean, stancard deviation and coefficient of variation for angularity of the acdregate narticles of the cylinder examined. The final value, $n$, is the number of aggregate particles.

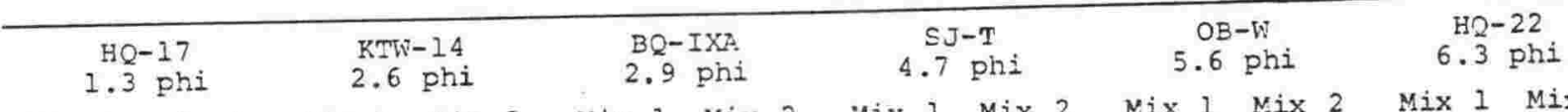

$\operatorname{Mix} 1 \operatorname{Mix} 2 \operatorname{Mix} 1 \operatorname{Mix} 2 \operatorname{Mix} 1 \operatorname{Mix} 2 \operatorname{Mix} 1 \operatorname{Mix} 2 \operatorname{Mix} 1 \mathrm{Mix} 2 \mathrm{Mix} 1 \mathrm{Mix} 2$

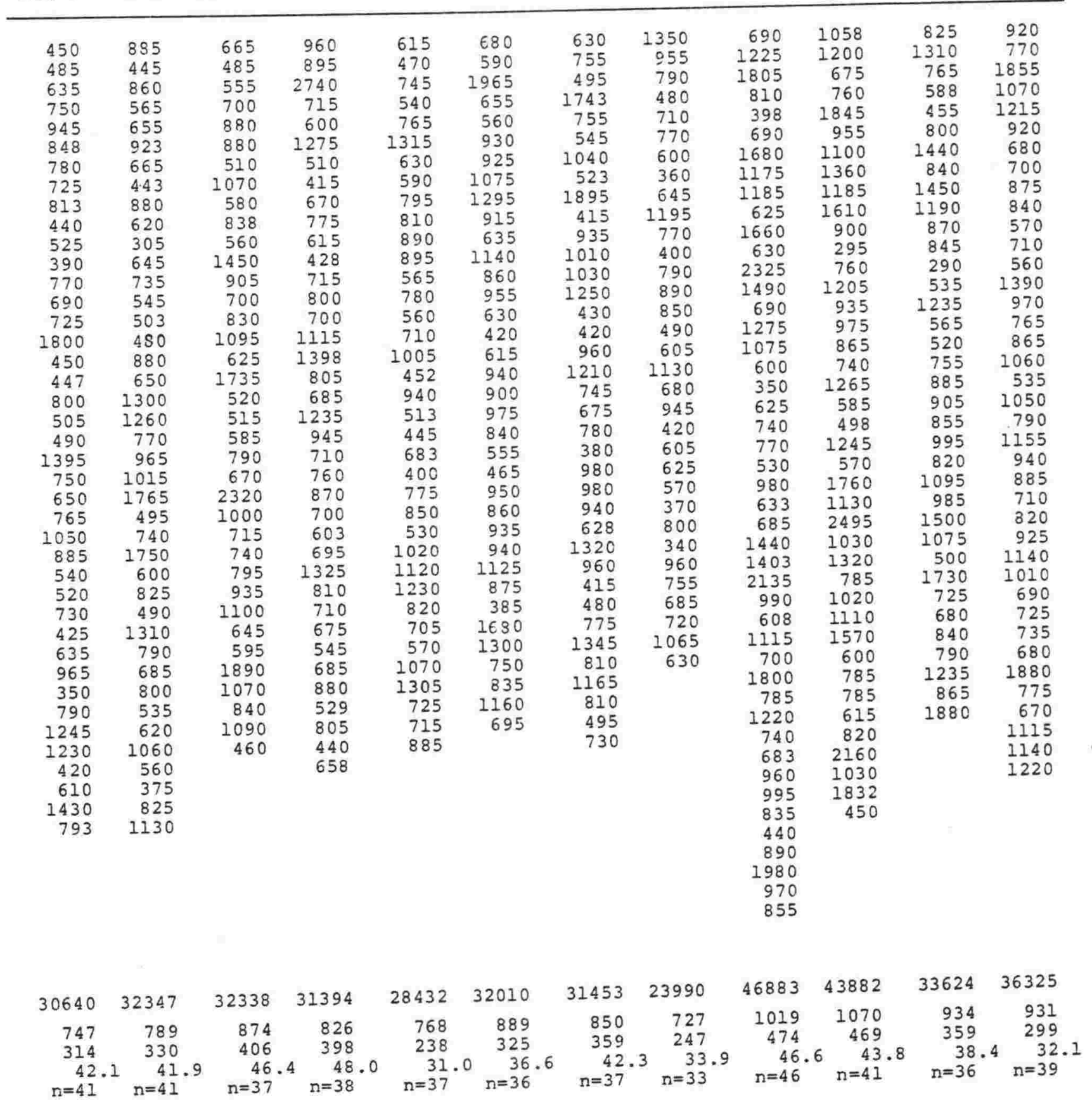



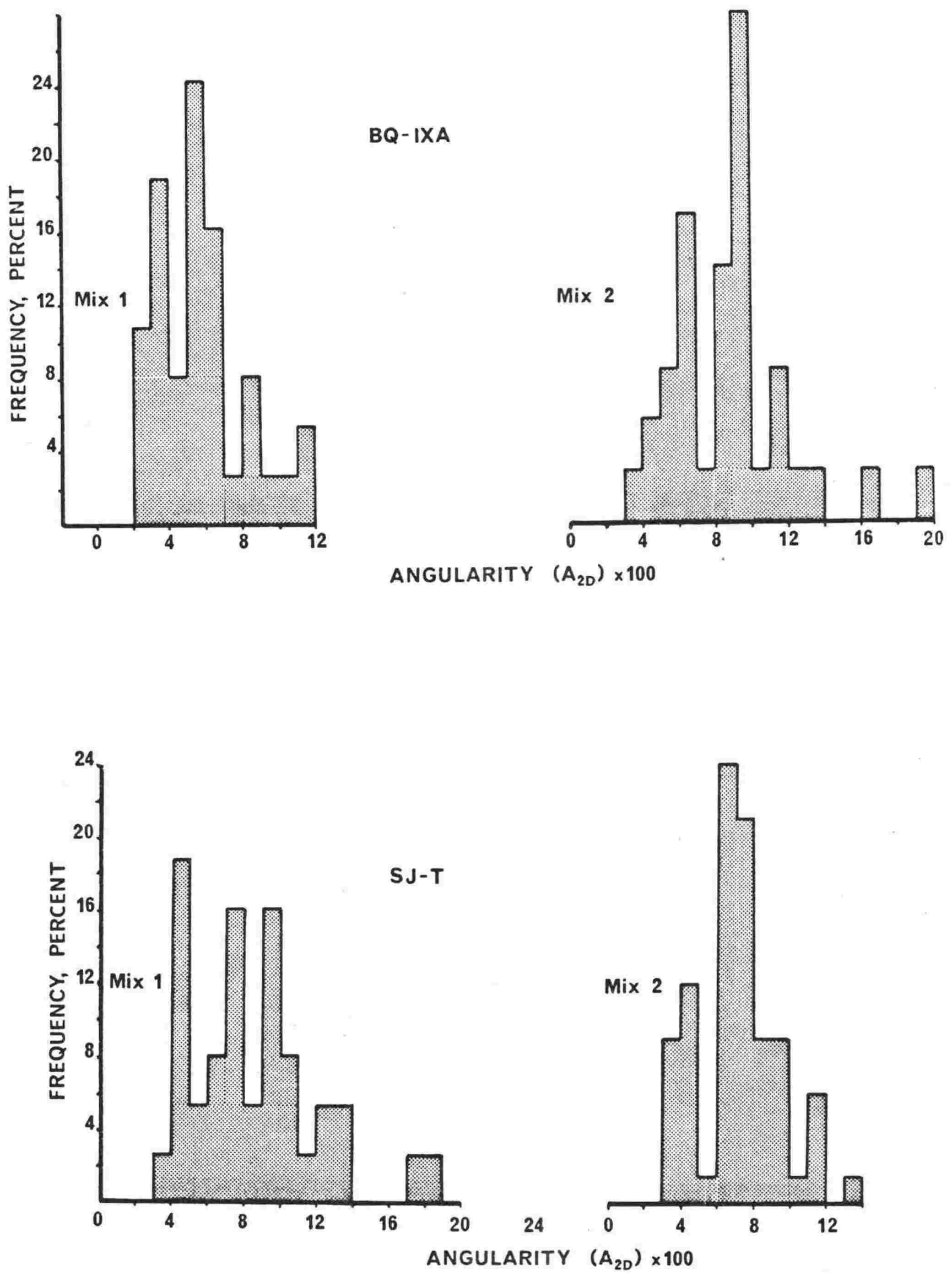

Figure Al7.3 : Angularity freqency histogram of aggregate particles $B Q-I X A$ and SJ-T. 

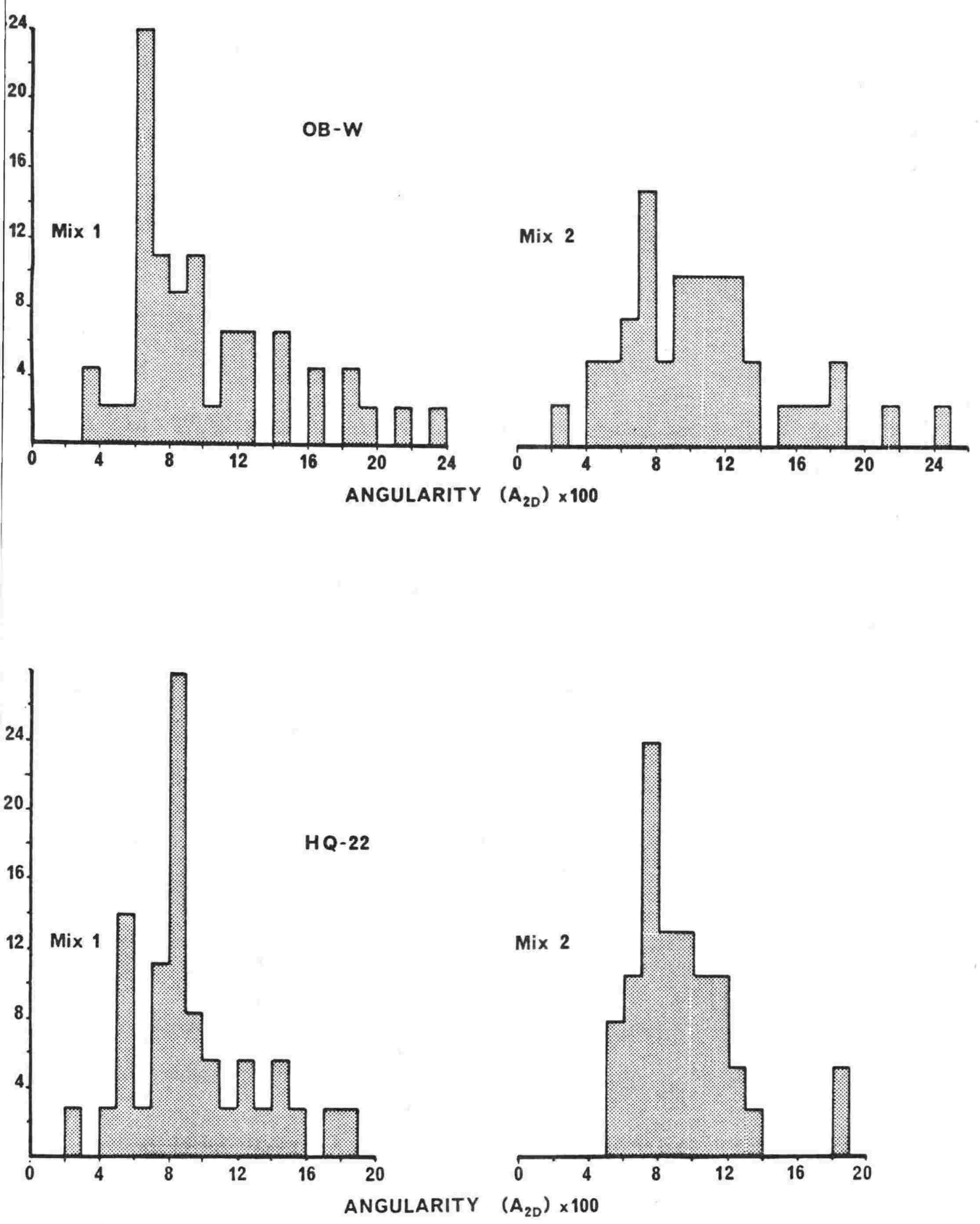

Figure A17.4 : Angularity frequency histogram of aggregate particles, $\mathrm{OB}-\mathrm{W}$ and $\mathrm{HQ}-22$. 
Comparison of the Los Angeles abrasion test with uniaxial compression test as a measure of rock strength

Recently a paper by Kazi and Al-Mansour (1980) presented data on igneous rock from Jeddah, Saudi Arabia, indicating that its use for engineering purposes could be assessed by its average unit mass and results of the schmidt hammer test. Indeed Los Angeles results may be predicted from schmidt hammer test results, or uniaxial compressive strength.

Figure Al8.1 is reproduced from Kazi and Al-Mansour (1980) and shows the relationship between Los Angeles abrasion test results and uniaxial compression strength. Superimposed data from this study extends the graph from $170 \mathrm{MPa}$ to $263 \mathrm{MPa}$. The result for $\mathrm{OB}-\mathrm{W}$ is attributable entirely to its high particle angularity (section 4.2.6, Figure 4.8). It appears from this, that for rounded and strong aggregates, the Los Angeles test is ineffectual and that it is best utilised on rocks of strength ranging between $20 \mathrm{MPa}$ and $100 \mathrm{MPa}$. Rocks stronger than this are delineated by particle shape rather than on resistance to abrasion and particle shape is better assessed by other means.

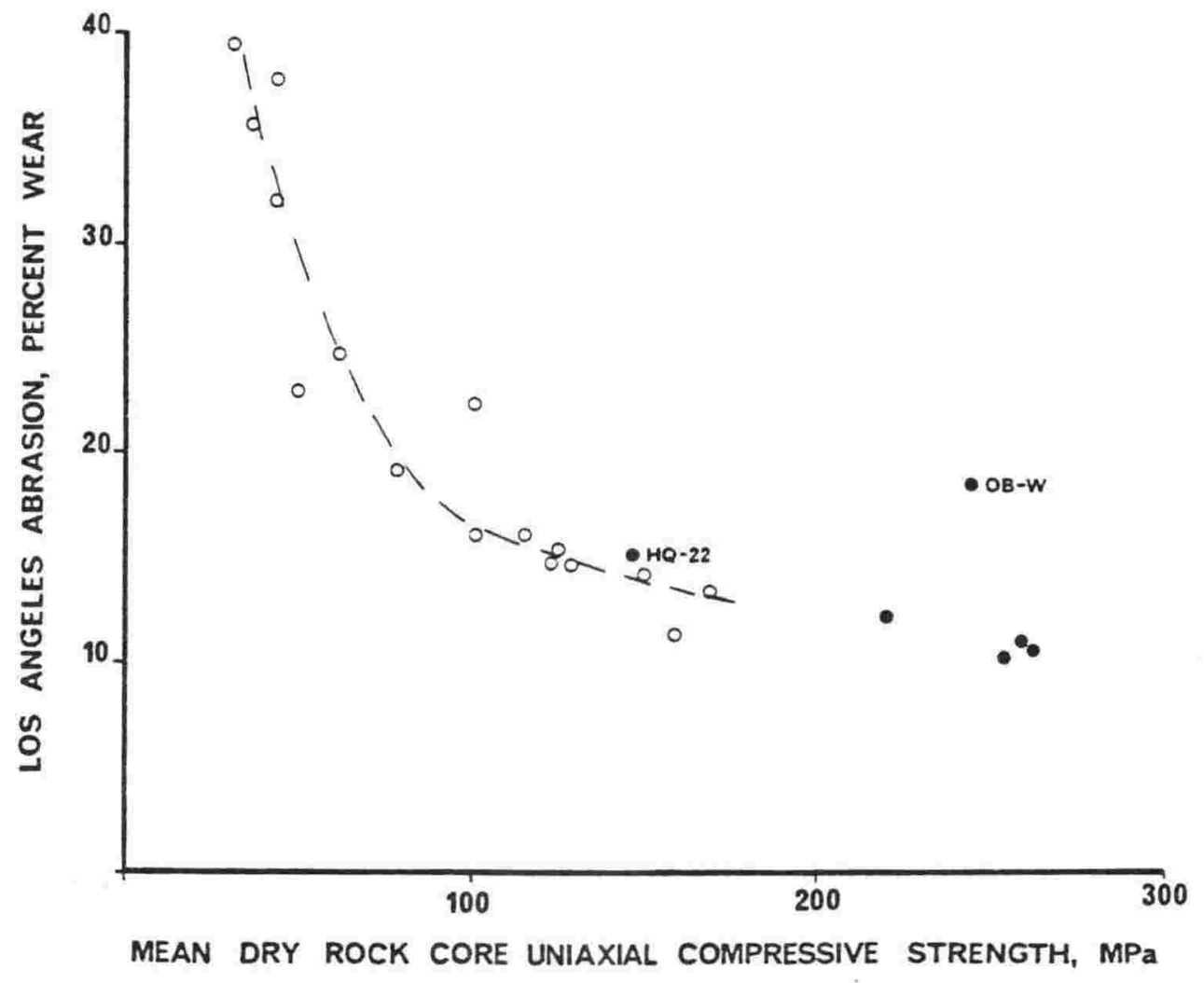

Figure A18.1 : The relationship of Los Angeles abrasion results and uniaxial compressive strength of rocks. Data shown by open symbols are from Kazi and Al-Mansour (1980). Solid symbols are from this study. 
Effect of moisture content on ultrasonic velocity of rock

A homogeneous, flaw free, right prism was prepared from a fine grained greywacke (KTw-i), grading at one end over approximately $50 \mathrm{~mm}$ into an argillite. The prism measured $209 \times 50 \times 50 \mathrm{~mm}$, its long axis perpendicular to bedding. The sample was allowed to ecuilibrate at room temperature after cutting and was then immersed in tap water for 38 days. After a further 12 days drying at room temperature, the sample was placed in an oven at $105 \pm 5^{\circ} \mathrm{C}$ for one day, then left at room temperature a further eight days. During this time the effects of water was educed from daily tests with the ptNDIT apparatus, along the long axis of the prism.

Ultrasonic velocity in a solid depends on the density and elastic properties of the material. In porous materials the ultrasonic velocity may be enhanced by saturation with water, the water enabling a more complete acoustic path to be formed. This effect is shown by greywackes, so the state of saturation of the prism could be assessed by measuring the relative "completeness" of the acoustic path. Acoustic contact for trasducers was made using a paste of glycerin and talcum powder. Results are shown in Figure Al9.1.

Within six days, the prism had reached saturation, and fluctuations in ultrasonic velocity over the next 32 days were within the 2 percent error of the apparatus. Release of water is a slower process than water uptake, considering the gradient of the line (Figure Alg.1) showing acoustic change between day 38 and day 46 , whilst the prism was drying at room temperature. After oven drying, a marked reduction in ultrasonic velocity was apparent. Moisture uptake from the atmosphere at room temperature appeared to take place at a rate, reflected in ultrasonic velocity change, similar to that of water immersion. A short-fall of $69 \mathrm{~m} \cdot \mathrm{s}^{-1}$ was noticed after the experiment, compared with the initial ultrasonic velocity. This may be due to permanent moisture loss from the prism and/or cracking of the prism. Sparce microcracking had occurred in the argillaceous end of the prism before the end of the experiment. 


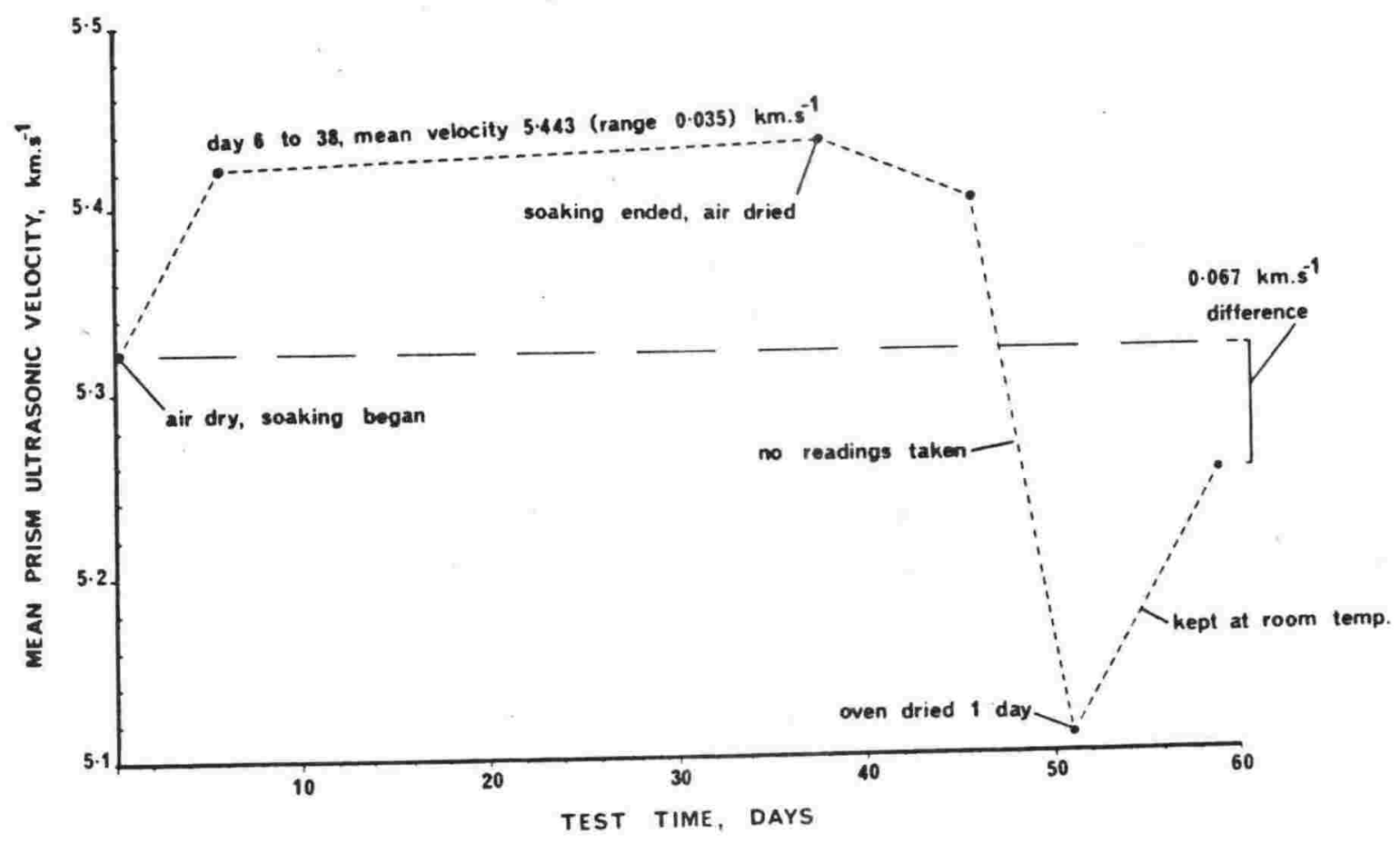

Figure Al9.1 : The response of a prism of KTW-i greywacke ( 4.2 phi, $0.054 \mathrm{~mm}$ rock mean grain size) to various degrees of saturation measured by ultrasonic velocity variations. A permanent loss of moisture seems apparent after oven drying of rock. 
Measurement of unrestrained moisture movement in rock

The apparatus was made from a heavy retort stand with a heavy sliding collar fitted to its upright. The collar had $3 / 16$ inch $w^{2} H I$. grub screws inserted in threaded holes at $90^{\circ}$ so that it could be adjusted for height (Figure A20.1). F. lug welded to the collar enabled mounting of a dial gauge reading to 0.0001 inches. A locating shoe with a conical recess, $5.5 \mathrm{~mm}$ diameter and $90^{\circ}$ apical angle, centered in its lower face was fitted to the gauge spindle. Apparatus using similar principles may be seen in Duncan (1969).

Samples were prepared from $25 \mathrm{~mm}$ diameter cores, cut perpendicular to bedding, one end ground plane and at right angles to the vertical axis; the other end, coarse ground $\left( \pm 20^{\circ}\right)$, had a ball bearing ( $4.8 \mathrm{~mm}$ diameter) cemented (black, two part epoxy "plastic Steel" was best) at its centre.

After drying for 24 hours at $50^{\circ} \mathrm{C}$, samples were placed free standing in a vessel with a plane, flat base (inside and out) and of convenient size to completely accommodate the sample. The vessel, filled with distilled water to the level of the ball bearing, was placed on the retort stand with the ball bearing centred under the dial gauge shoe. only the ball bearing was above the water level.

After ensuring the system was aligned correctly the dial guage was read and the time noted. Dial gauge readings were taken at intervals until no significant change was noted between readings or until the sample failed from internal air pressures.

Throughout all tests the apparatus was placed on a vibration free pad on a piece of firm carpet in a constant temperature room. Vibration free conditions for each test period were further ensured by restricting access to the room. 


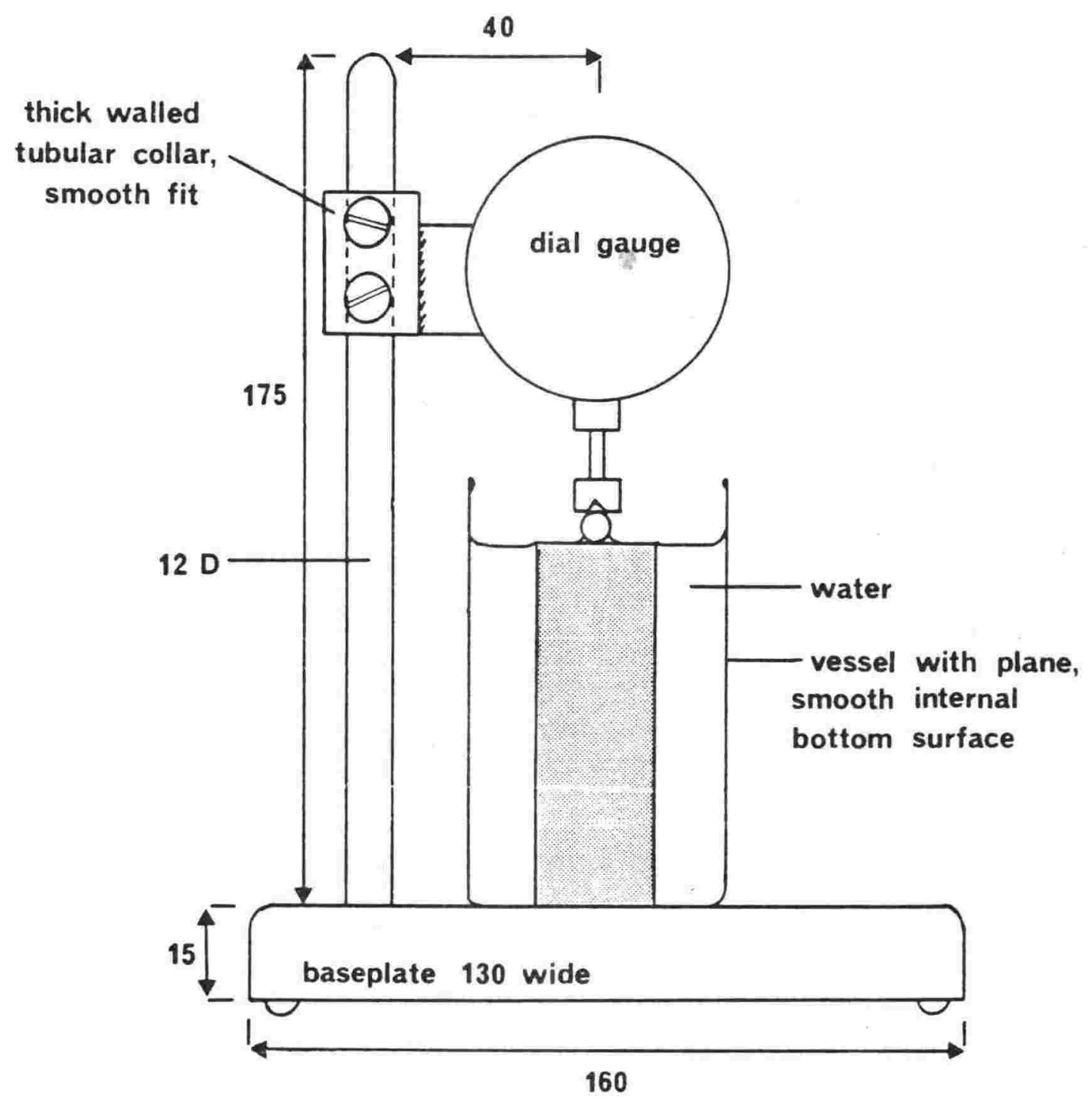

Figure A20.1 : Apparatus used for rock core unrestrained moisture movement determinations. A rock core (shaded) with ball bearing reference point afixed, is shown in position. Adjusting feet keep baseplate level. All parts are mild steel except baseplate and locating shoe which are cast iron and stainless respectively. Dial gauge is adjusted to suit sample length.

Figure not to scale, dimensions in millimetres. 
Measurement of cyclic moisture movement in rock

Apparatus for this test series was identical with that shown by Duncan (1969, plate 18, p 97, and also Figure A21.1). It is also described in N2S 3112:1974, Method Cl "Determination of the drying shrinkage and wetting expansion of concrete". The method involves the use of a comparitor bar.

Samples with planar ends were cut from cores perpendicular to bedding. Ball bearings $4.8 \mathrm{~mm}$ diameter were cemented in the centre of each end. After intial drying to constant mass in a constant environment room $\left(20 \pm 1^{\circ} \mathrm{C}, 50\right.$ percent R.H.), samples were tested in a similar manner of Roper (1959), i.e. the comparitor bars and cores vere measured and compared using a dial gauge mounted in the apparatus. Samples were then placed in distilled water at $20^{\circ} \mathrm{C}$ for four days \pm 4 hours, measured, oven dried $\left(50^{\circ} \mathrm{C}\right)$ for three days \pm 4 hours then remeasured. The process was continued for several cycles.

The dial gauge provided reasings to 0.0001 inches and comparitor rods were made of invar and stainless steel for the rock prism (KTW-i) and rock cores tested respectively. A.ll measurements were taken, and comparitor bars stored, in the constant environment room. Comparitor bars were used as a length standard against which correction could be made for changes in the dimension of apparatus.

Results were expressed as percentages, i.e. movement increments with respect to sample length before testing. The sample cross-section is irrelevant to the test and any convenient cross-section may be used. 


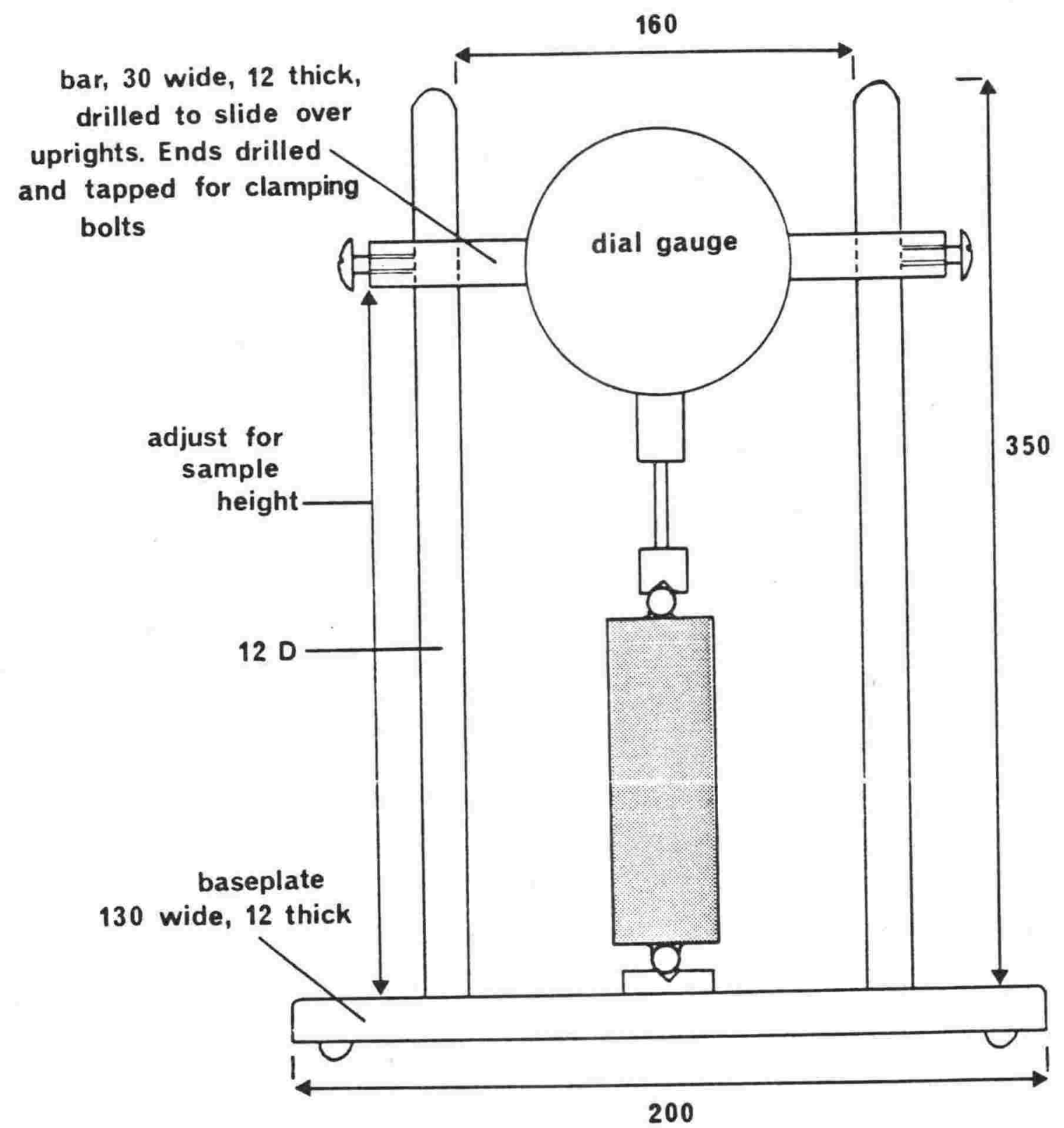

Figure A21.1 : Apparatus used for rock core cyclic moisture movement determinations. A rock core (shaded) with ball

bearing reference points afixed, is shown in position for measurement. Bottom locating shoe is vertically beneath dial gauge locating shoe. Adjusting feet keep baseplate level. All parts are mild steel except locating shoes which are stainless.

Figure not to scale, dimensions in millimetres. 
APPENDIX 22

Measurement of rock permeability

1. Sample preparation

Sample preparation was similar to that of Jaeger (1972).

Rock core, $25 \mathrm{~mm}$ diameter, was air dried for approximately one week, cut to a convenient length with one end finished as a plane surface perpendicular to the vertical axis and encapsulated with epoxy resin in a wax paper mould (drinking cup) in the following manner:

$$
\text { Epoxy was mixed in the following proportions }
$$

100 parts Araldite GY252 resin

100 parts Araldite CY208 resin

30 parts Araldite HY956 hardener

CY208 resin was added to retard the exothermic reaction, allowing the soft walled mould to retain its shape during setting and to enable trapped air bubbles to surface.

Each rock sample was coated in a thin layer of the mixed epoxy to ensure air bubbles would not be trapped at the epoxy/rock interface, promoting a local increase in permeability at that point.

(ii) Each sample was placed centrally in a waxed drinking cup (base 45 mm diameter, top $70 \mathrm{~mm}$ diameter, height $100 \mathrm{~mm}$ ) and epoxy gently poured round the sample. The cup was filled until the sample was just encapsulated.

(iii) Encapsulation was timed to provide overnight setting.

(iv) After 12 hours the paper cup was carefully peeled off and the quality of casting inspected. Care was needed at this stage as the epoxy could still be deformed slightly under heavy finger pressure due to the retardant action of CY208 resin. If successfully cast, samples were placed in an oven at $40^{\circ} \mathrm{C}$ for 24 hours to cure.

(v) Top and bottom surfaces of the epoxy were ground away until rock core ends were exposed. Both surfaces were fine ground parallel.

(vi) The upper face of the epoxy surround was drilled $(3.7 \mathrm{~mm})$ using a template to the pattern shown in Figure A22.1 and tapped ( $3 / 16$ inch WHIT) to accept $3 / 16$ inch wHIT gutter bolts.

\section{Apparatus}

The apparatus used was of the falling head type illustrated by curtis (1971), particularly applicable to materials of low permeability. To simulate the natural movement of water, the most important media to move through rock, it was nesessary to ensure that there was no soluable or insoluable matter introduced which could "seal" the sample, so distilled water was used throughout the test. 


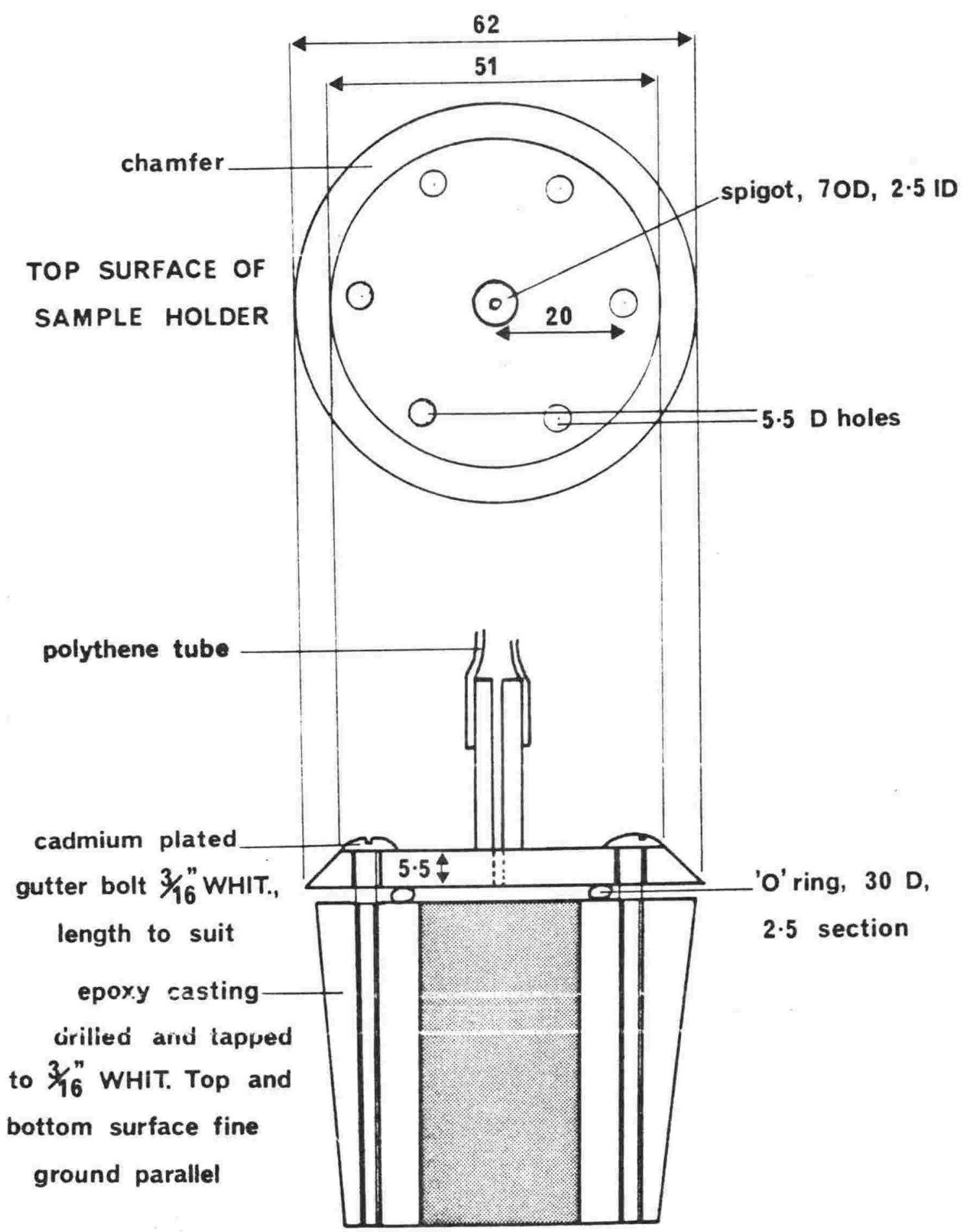

\section{LONGITUDINAL SECTION ASSEMBLED SAMPLE AND HOLDER}

Figure A22.1 : Permeability apparatus sample holder detail. Figure not to scale, all dimensions in milli-

metres. Sample holder made from brass. 
The apparatus (Figure A22.2, Plate A22.1) consisted of a thick-walled precision calibration tube $(2.27 \mathrm{~mm}$ internal diameter, measured with an optical micrometer) $600 \mathrm{~mm}$ long, fastened by a rubber bung in a 5 litre aspirator reservoir. A heavy walled polythene tube (2.5 mm internal diameter, $5.0 \mathrm{~mm}$ external diameter) was connected, at the outlet tap, and $16 \mathrm{~m}$ of this, taped to $5 \mathrm{~mm}$ polypropylene braided line at approximately $300 \mathrm{~mm}$ intervals, was connected to the brass sample holder (Figure A22.1).

\section{Permeameter operation}

Samples were fixed to the sample holder using six gutter bolts and an "O" ring soaked in distilled water for at least one month. To ensure that no air bubbles were trapped in the system, the reservoir was filled and the feeder tube to the sample holder bled by opening the reservoir tap before the sample was finally fixed in place. Great care was taken to exclude all air from between sample and sample holder. The sample and sample holder as a unit were then lowered down a $1 \mathrm{~m}$ diameter concrete lined hole $15 \mathrm{~m}$ deep and made fast at the top of the hole by the $5 \mathrm{~mm}$ line. A maximum and minimum thermometer was lowered to the same depth as the sample.

Finally the calibration tube was extracted, the reservoir topped-up and the calibration tube replaced, allowing water displaced from the reservoir to rise in the tube.

\section{Minimising errors}

Potential sources of error included:

(i) Temperature change over the test duration.

(ii) The tube between reservoir and sample holder changing dimension with time.

(iii) Leakage.

(iv) Elastic "relief" of the rubber bung holding the calibration tube in position.

(v) The length of the calibration tube.

To check their probability, monitor their effects and minimise these where practicable, the following precautionary steps were taken:

(i) Temperature change was monitored by a maximum and minimum thermometer reading to $0.1^{\circ} \mathrm{C}$. The hole down which testing took place was drilled in weathered rock beneath the building and air circulation was limited. Temperature change at the bottom of the hole was negligible over the duration of each test. Temperatures at the reservoir were higher but still stable over the duration of a test. The room in which the equipment was housed had no windows and was ventilated by an air condition/heating system. Access to the room by personnel was restricted.

The temperature gradient from reservoir to sample on test was continuous and water velocities in the tube so low as to ensure water in the tube was at equilibrium with the environment immediately surrounding it. In this way the viscosity of the water at the sample was maintained constant, for the temperature at that point. After change of sample, adequate time was allowed for the system to equilibrate with temperature before readings were taken. 


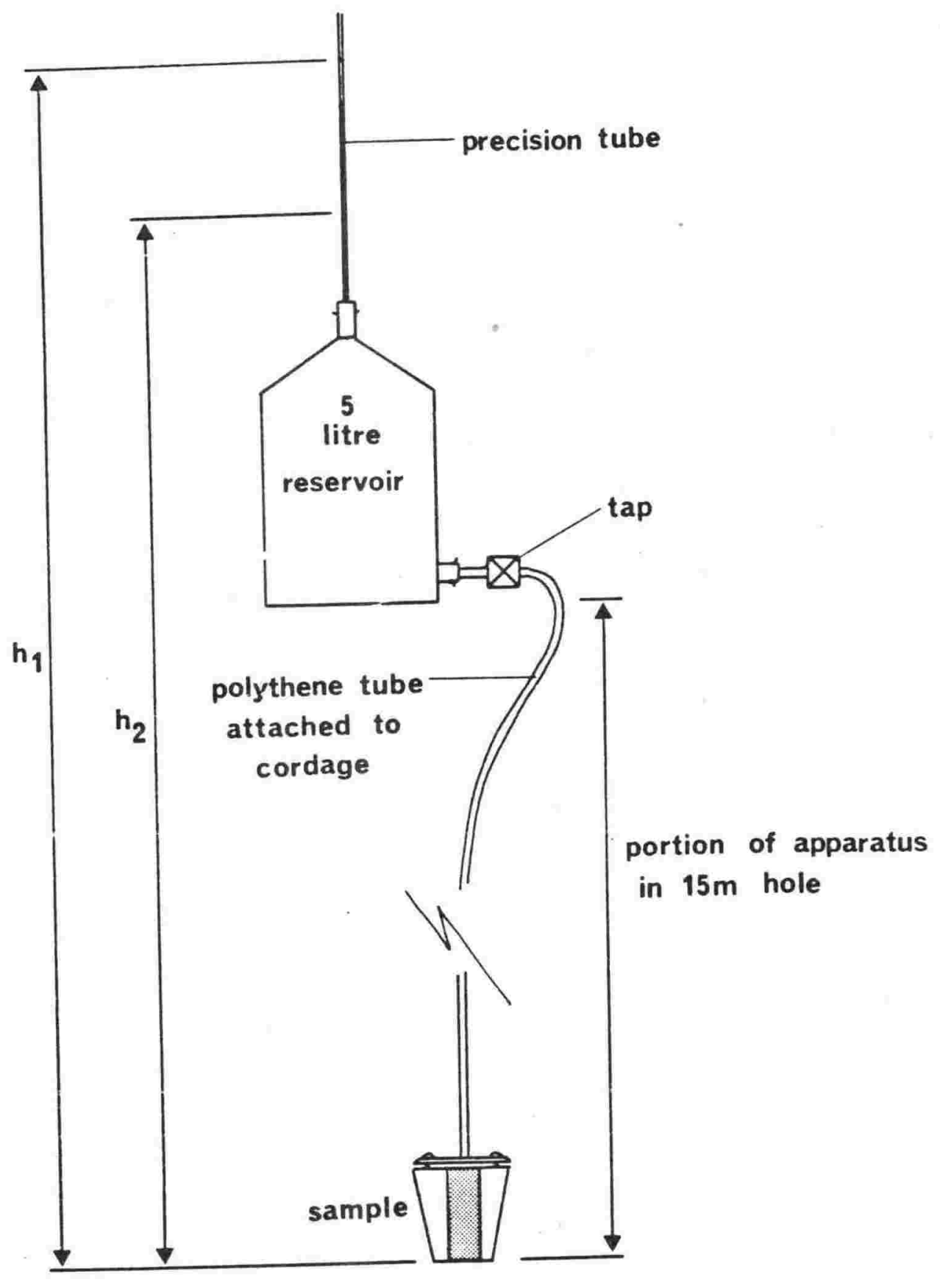

Figure A22.2 : Schematic diagram of the permeability apparatus. 


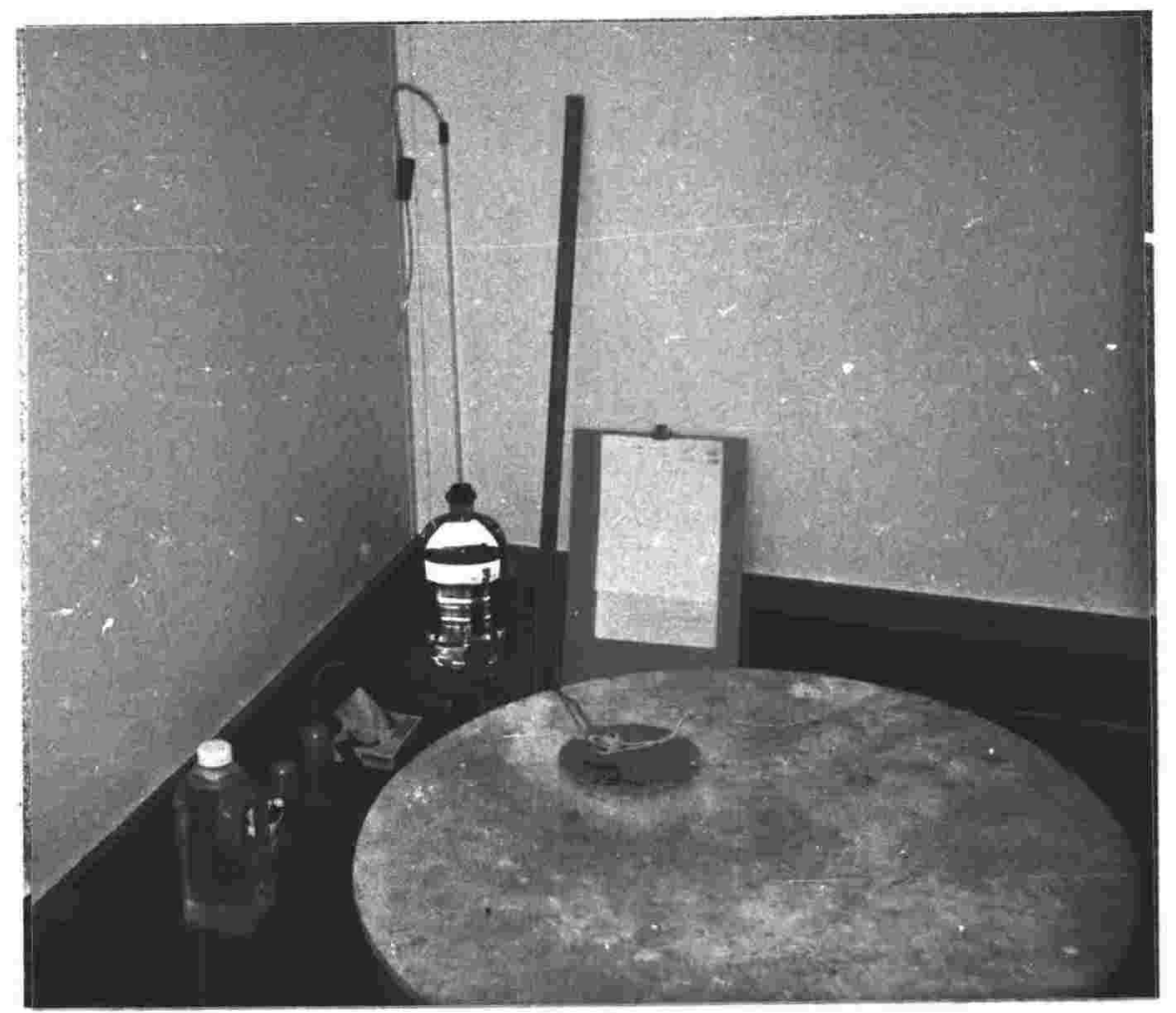

Plate A22.1 : The falling head permeameter showing calibration tube protruding from the 5 litre reservoir vessel. The sample was connected to this by polythene tube, seen entering the $15 \times 1 \mathrm{~m}$ diameter hole via the small circular plate in the large circular cover over the hole. 
(ii) It was assumed that the polythene tube from reservoir to sample holder would stretch both under the combined weight of sample assembly and its own weight and would also dilate, especially near the bottom of the hole - the two effects tending to negate any increase in the volume of water recorded as a loss of head in the calibration tube.

As a result of these assumptions:

(i) A test was carried out over one week on an impermeable sample (a 7 m thick Araldite disc, prepared in the same manner as the rock samples) prestretched the tube and allowed its behaviour to be observed. There was no discernible reduction in head in the calibration tube.

This also confirmed the apparatus was free of leaks.

(ii) Time was allowed after each sample change to offset the effects of tube stretch recovery, which occurred with the release of pressure. This time was coincidental with temperature equilibrium time.

Because a rubber bung was used to hold the calikration tube in place some elastic recovery was observable after it was placed in the neck of the reservoir. This recovery generally ceased after about 20 minutes. It caused a significant drop in head level in the calibration tube.

Unfortunately the calibration tube was short, but was all that was available and the reduction of head in the fine bore tube over the period of one test required multiple fillings, each necessitating the removable of the bung and subsequent equilibration. A calibration tube of small bore size was necessary as the sensitivity of a falling head permeameter is dependant on the ratio of the bore internal diameter to rock sample diameter, particularly important in rocks of low permeability.

After being placed on test at a noted date and time, a sample was critically observed over a period of generally one to two hours to check for possible leaks and ensure equilibrium of the system. Subsequently, readings were taken of the head height above

the reservoir (the difference in height between the neck of the reservoir and sample base was also known) and the time of each recording noted.

\section{Calculations}

The following formula was used for the determination of permeability: in c.g.s. units).

$$
k=2.3 \frac{d^{2} \mu L}{D^{2}(g \Delta t} \cdot \log \frac{h_{1}}{h_{2}}
$$

where: $d$ is internal diameter of the calibration tube $(2.27 \mathrm{~mm})$

$D$ is the sample diameter $(25.0 \mathrm{~mm})$

$\mu$ is the viscosity of water

$i$ is the length of the specimen along the flow path

$\Delta t$ the number of seconds between observation of head heights $h_{1}$ and $h_{2}$ above the base of the sample

$f$ is the density of the water

$g$ is gravitational acceleration 
To convert permeabilities expressed in square centimetres to Darcys, the following formula was used:

$$
\mathrm{k}_{\mathrm{Cm}} ?=9.869 \times 10^{-9} \mathrm{k}_{\text {Darcys }}
$$

Values for $\mu$ and $\rho$ were obtained from tables in Weast (1975).

\section{Comparison of apparatus performance}

J. Hogan (Petroleum Corporation of New Zealand (Exploration) Ltd.,) kindly donated $25 \mathrm{~mm}$ core samples taken from core samples from the Kapuni-3 Well. These were measured (parallel to bedding) by air permeability at the laboratories of KSEPL (Konoklijke Shell Exploratie Petroleum Laboratoria; Royal Shell Exploration Petroleum Laboratories) Hague, The Netherlands. Measurements of the material by apparatus described provided correlations shown in Table A22.1 and Figure A22.3.

Repetitive tests confirmed that pore pressure took approximately the same time to equilibrate in new samples as in samples already thoroughly saturated by one cycle of permeability testing. Variations in permeability generally occur extremely quickly stratigraphically and even within one sample. Porosity influences permeability even if no constant relationship exists. An average of a 10 fold increase in permeability results from a 3 percent increase in porosity (Archie, 1950). Grain size, grading, grain shape and stratification also influence permeability.

Permeabilities also vary due to rock anistropy. Vertical permeability, i.e. that permeability measured normal to bedding, is commonly considered lower than that parallel to bedding although there may be substantial directional variation within bedding planes.

In clayey (argillaceous) samples, water freed of air and salts has been found to give permeability values lower than, by as much as two orders of magnitude, those obtained using saline water. This reflects an increase in structural water on clay particle surfaces when ion concentration is low. Because finding compatable fluids can be impracticable, a non-polar fluid of low viscosity and high boiling point, e.g. kerosene, is often used. Determination of permeability using gas was not undertaken because values are higher than those given by any polar liquid and because water is the fluid usually encountered by aggregate. Gas permeabilities however, may be of value in studying weathering greywackesuite rocks.

Although Curtis (1971, figure 4) shows the bottom surface of permeability samples immersed in water, the apparatus made for this project had no such provision. All samples were soaked for one month before testing and were wet at the exposed base of the sample after testing. 
Table A22.1 : A comparison of distilled water permeabilities determined on Kapuni 3 rock cores also air permeability tested by the KSEPL, Hague, The Netherlands. (see Hogan, 1979 for additional sample data).

\begin{tabular}{|c|c|c|c|c|}
\hline Sample & $\begin{array}{l}\text { Sample depth below } \\
\text { rotary table }\end{array}$ & $\begin{array}{l}\text { Method of permea- } \\
\text { bility test }\end{array}$ & $\begin{array}{l}\text { This study } \\
\text { MD }\end{array}$ & $\begin{array}{l}\text { KSEPL } \\
\mathrm{MD}\end{array}$ \\
\hline $\mathrm{KA}-8$ & $\begin{array}{l}12,054 \mathrm{ft} \\
(3674.5 \mathrm{~m})\end{array}$ & $\begin{array}{l}\text { air } \\
\text { water }\end{array}$ & 0.039 & 0.02 \\
\hline $\mathrm{KA}-2$ & $\begin{array}{l}11,950 \mathrm{ft} \\
(3642.6 \mathrm{~m})\end{array}$ & $\begin{array}{l}\text { air } \\
\text { water }\end{array}$ & 0.845 & 0.23 \\
\hline $\mathrm{KA}-12$ & $\begin{array}{l}12,172 \mathrm{ft} \\
(3690.8 \mathrm{~m})\end{array}$ & $\begin{array}{l}\text { air } \\
\text { water }\end{array}$ & 23.44 & 84.0 \\
\hline
\end{tabular}

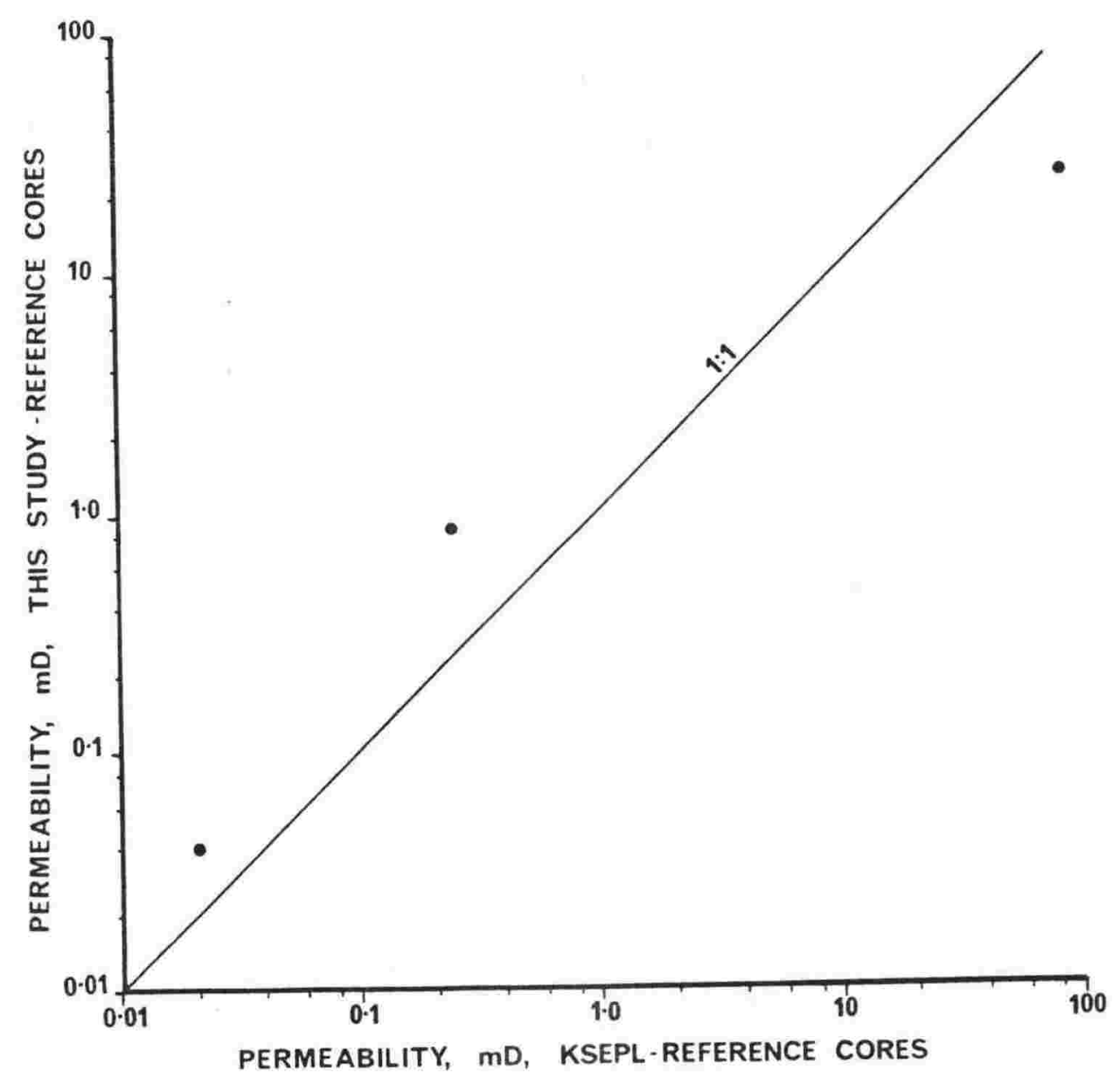

Figure A22.3 : A comparison of distilled water permeabilities (this study) determined on rock cores from Kapuni 3 drill hole, with air permeabilities of the same material determined by KSEPL, The Netherlands. see Hogan (1979) for additional sample data. 
Aggregate degradation assessment of grevwacke-suite rocks

1. Introduction

Failure of basecourse aggregate used in the Auckland-Hamilton Motorway in 1964 prompted several investigations of the aggregate used (Cornwell, 1966; Reed, 1966; Buckland, 1967). The aggregation was quarried from greywacke-suite rocks, found extensively in New Zealand, and had passed the standard tests for strength and stability.

Sameshima (1977) after simulating in the laboratory the temperature/pressure environment of basecourse aggregate beneath a road surface, suggested that hydrothermal alteration increases the proportion of clay and the extent of hydration resulting in degradation of the aggregate and failure of the road. He attributed this mainly to the increase in accessible montmorillonite and other swelling clays and devised a method for determining their abundance, in terms of "clay index" (Sameshima, 1977, p 56).

This Appendix examines the clay index, and its relationship to montmorillonite percentage, and reviews the clay index as an indicator of potential degradation of Wellington greywackesuite rocks.

2. The "clay index"

The clay index is found using methylene blue, which provides a means of estimating the amount of montmorillonite and other swelling clays by utilising the high cation-enchange capacity, surface area and state of dispersion of these clays (Jones, 1964). He also gives figures that indicate an accuracy of about 0.33 volume percent if titration is taken to the nearest millilitre, or 0.1 volume percent by appraoching the end point a fraction of a millilitre at a time.

The "clay index" is defined as "the amount of dye, in ml., (4.5 gm/litre distilled water) 'consumed' by $1 \mathrm{gm}$ of the sample", i.e. a basecourse or powdered rock sample finer than a BS 200 sieve (Sameshima, 1977; Sameshima and Black, 1979). The Clay Index Grade is a classification of fines of an aggregate based on the "clay index", and a relationship between the clay index grade of aggregate fines and qualities of the basecourse is proposed (after Sameshima and Black, 1979):

$\begin{array}{llllll}\text { Clay index } & 0-1 & 1.1-2 & 2.1-3 & 3.1-4 & 4.1-5 n \\ \text { clay index grade } & 1 & 2 & 3 & 4 & 5 n \\ \text { quality } & \text { sound } & \text { good } & \text { poor } & \text { unsound } & \text { unsound }\end{array}$

3. The methyline blue test as an indicator of montmorillonite:

It has been claimed that the methylene blue test can be used to estimate the percentage of montmorillonite (Sameshima, 1977). However, the test has been widely used in a non specific way for "an estimation of cation exchange capacity of clays" (Baroid Drilling Mud Data Book, 1954; Fairbairn and Robertson, 1957); applicable particularly to drilling muds but also applied to aqueous dispersions of powdered clay, cores, drilled cuttings and foundry moulding sands. However, minerals other than swelling clays can respond to the test especially if they have a large surface area. Even albite shows some response, and 
a standard ilite sample yielded a value that is equivalent to a "montmorillonite percentage of 18 (Table A23.1). The Baroid Drilling Mud Data Book (1954) gives many other examples. Therefore the test results cannot be used to estimate, positively, abundance of montmorillonite or even of swelling clays with much reliability where other phyllosilicates are also abundant.

In assessing the reliability of methylene blue for estimating montmorillonite percentage, Sameshima has relied solely on X-ray diffractometry (XRD), and quotes values as low as 1 percent (Sameshima, 1977; Table A23.2). However, Carroll (1970), this study (Table 2.10 ) and Claridge, pers. comm. (1980) all suggest that standard XRD procedures are insensitive to montmorillonite abundances of less than 10 percent even for clay size material.

\section{Response of Wellington greywacke-suite rocks to the methylene blue test:}

The methylene blue test was carried out on 26 Wellington greywacke-suite rocks using the method according to Sameshima (1977), but with methylene blue being added in $0.1 \mathrm{ml}$, rather then $0.5 \mathrm{ml}$, increments. An additional three tests were carried out on quarry sludges, ultra-fine material settled out of quarry wash waters. Finally, four international standard minerals (albite, dickite, illite and montmorillonite) were tested along with vUW standard chlorite, 196/1/1(b). Results are shown in Tables A23.1, A23.3 and Figure A23.1. Repeated analyses indicate good precision of the method.

The data show that those greywacke-suite rocks witha mean grain size coarser than 5.5 phi $(0.022 \mathrm{~mm})$ have clay indices less than one (exceptions being KTW-G and DC- 6 mentioned below). These are rocks that to not degrade (Rowe, 1979). However, rocks finer than 5.5 phi and which do degrade, have clay indices greater than one. These data suggest that the transition in clay index grade from "good" to "poor" would be better placed at the clay index value of 1 instead of 2 for Wellington greywacke-suite rocks.

An interpretation of the methylene blue test in terms of montmorillonite percentage indicates values ranging up to 3 percent in the fresh rock samples, but no montmorillonite was positively identified despite careful XRD study. However, montmorillonite was positively identified, by XRD, in quarry sludge, which certainly includes weathered material. Montmorillonite is present in soils in the wellington area (New zealand Soil Bureau Bulletin No. 26, Soils of New Zealand, 1968).

Occasional departures from the trend (KTW-G, DC-6) are in response to carbon and non-typical argillaceous rock fragment concentrations respectively, even though organic matter, such as lignites, polyacrylates and lignosulfonates, is removed by hydrogen peroxide. The relatively high metamorphic rank of rocks suggests that surface area effects of amorphous carbon (Bird, pers. comm.) are responsible. 
Table A23.1 : A sumary of some common minerals responding to the methylene blue test. Note the "Bentonite" sample contains 76 percent montmorillonite.

$\begin{array}{llll}\text { Mineral standard } & \begin{array}{l}\text { Sample } \\ \text { wt. } \\ \text { (gm.) }\end{array} & \begin{array}{l}\text { Methylene } \\ \text { blue } \\ \text { solution } \\ \text { titrated (ml) }\end{array} & \begin{array}{l}\text { Percent "montmorillonite" } \\ \text { content }\end{array} \\ & & & \\ & & \end{array}$

Sodium feldspar (albite)

No. 99, T.S. Dept. of Commerce,

Bureau of Standards

0.7

0.6

0.4

VUW standard chlorite,

$196 / 1 / 1$ (b)

1.3358

0.4

0.5

0.3

*Dickite, No. 15A,

San Juanito, Chihuahua,

Mexico

1.0

0.9

0.5

*Illite, No. 35, Fithian, Illinois

$2.0000 \quad 20.5 \quad 17.5$

10.3

*Montmorillonite, No. 20,

Husband Mine (Bentonite),

polkville, Mississippi

1.0038

45.0

76.7

44.8

* Samples used in "American Petroleum Institute Clay Mineral Standards Project No. 49".

Table A23.2 : After Sameshima (1977) X-Ray modal analyses and methylene blue titration results for greywackes from the Whitehall Quarry, Waotu Quarry, Moutohora Quarry, Wellington area and Minors Road Quarry, Canterbury. Sample 8 is from Wellington.

\begin{tabular}{|c|c|c|c|c|c|c|c|c|c|c|c|}
\hline & 1 . & 2. & 3. & 4. & 5. & 6. & 7. & 8 . & 9. & 10. & 11. \\
\hline Quartz & 25 & 20 & 20 & 20 & 25 & 25 & 20 & 30 & 30 & 30 & 30 \\
\hline Plagioclase & 40 & 20 & 30 & 30 & 25 & 30 & 30 & 30 & 35 & 35 & 35 \\
\hline Potash-feldspar & 10 & 5 & 10 & 10 & 10 & 10 & 10 & 5 & 10 & 10 & 10 \\
\hline Hornblende & 3 & 1 & 2 & 3 & 3 & 3 & 3 & 2 & 0 & 0 & 0 \\
\hline Prehnite & 2 & 5 & 3 & 3 & 3 & 0 & 5 & 1 & 0 & 0 & 0 \\
\hline Calcite & 1 & 0 & 1 & 0 & 1 & 0 & 0 & 1 & 0 & 0 & 0 \\
\hline Chlorite & 10 & 10 & 20 & 15 & 15 & 10 & 10 & 15 & 10 & 10 & 10 \\
\hline Illite & 5 & 2 & 3 & 3 & 3 & 5 & 2 & 10 & 5 & 10 & 7 \\
\hline Laumontite & 1 & 10 & 1 & 2 & 2 & 10 & 15 & 0 & 0 & 0 & 2 \\
\hline Heulandite & 0 & 10 & 2 & $i$ & 2 & 0 & 0 & 0 & 0 & 0 & 0 \\
\hline Kaolin & 0 & 10 & 3 & 5 & 3 & 3 & 5 & 5 & 5 & 5 & 3 \\
\hline Montmorillonite & 1 & 10 & 1 & 5 & 2 & 1 & 3 & 1 & 3 & 1 & 2 \\
\hline $\begin{array}{l}\text { Montmorillonite } \\
\text { by titration }\end{array}$ & 0.8 & 11.1 & 0.8 & 3.2 & 1.4 & 0.6 & 2.4 & 1.1 & 3.1 & 1.1 & 1.9 \\
\hline $\mathrm{Cl}$ ay index & 0.5 & 6.5 & 0.5 & 1.9 & 0.8 & 0.4 & 1.4 & 0.6 & 1.8 & 0.6 & 1.1 \\
\hline
\end{tabular}

1. Whitehall Quarry, argillite. 2. Whitehall Quarry, stockpile aggregate fines. Heulandite include 5\% stilbite. 3. Waotu Quarry, greywacke. 4. Ex Waotu Quarry aggregate fines from the State Highway No. I, Ngutuwera-Pokaiwhenua Section. 5 . Same as 4, separate sample. 6. Moutohora Quarry, greywacke. 7. Moutohora Quarry aggregate fines. 8. Titahi Bay, north of Wellington, greywacke. 9. West end Wainuiomataorongorongo tunnel greywacke, Reed (1957) sample No.7328. Chemical composition in Appendix 4. 10. Ex Minors Road shingle Quarry aggregate fines from Cant. Univ. Test Track, $10^{2}$ EDA. il. Same as $10,10^{5}$ EDA. 
Table A23.3 : Fresh greywacke-suite rock samples representing a textural range from Wellington. X-ray diffractometry showed montmorillite to be present only in sludge samples RSS-NS and RSS-F.

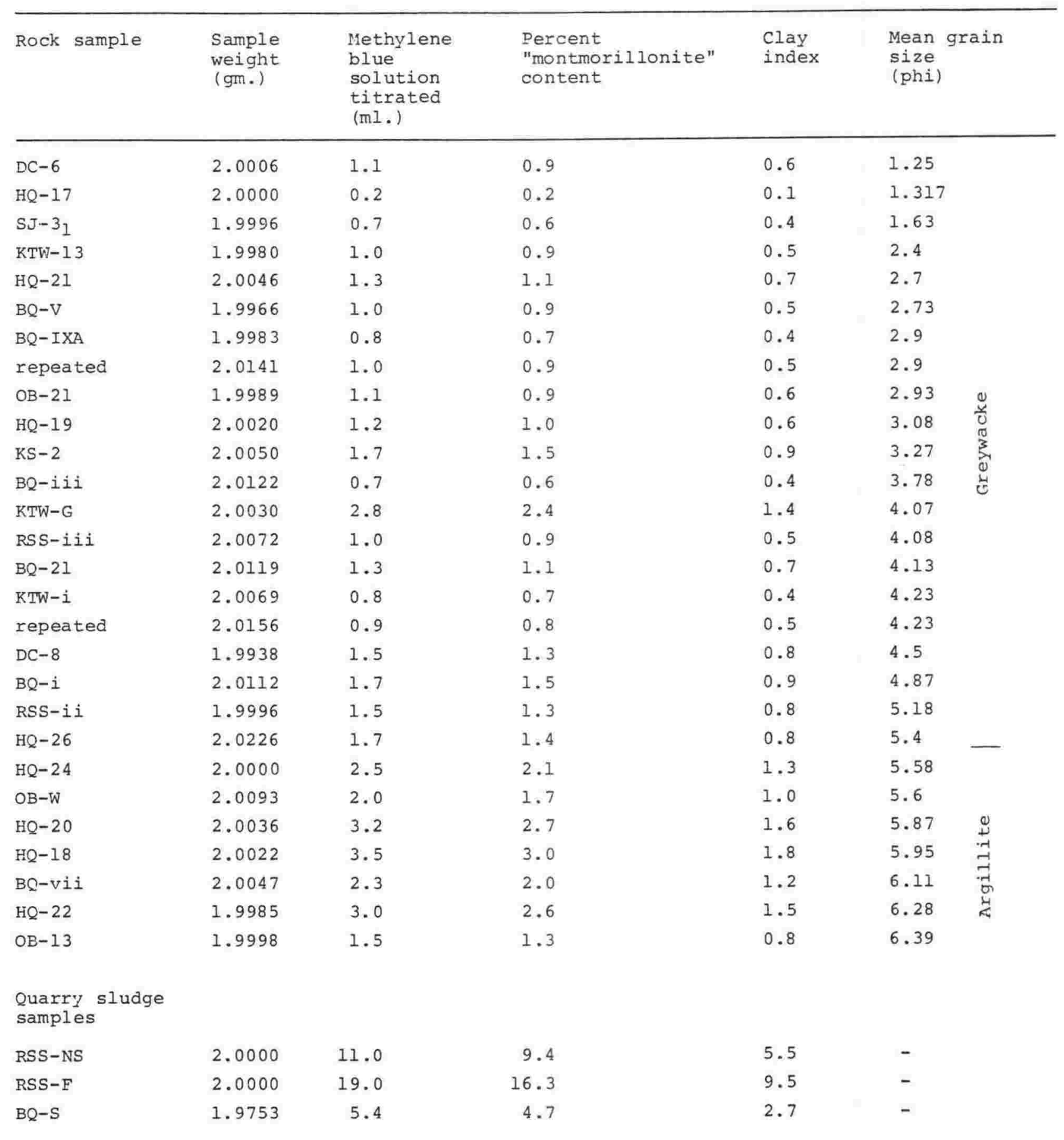




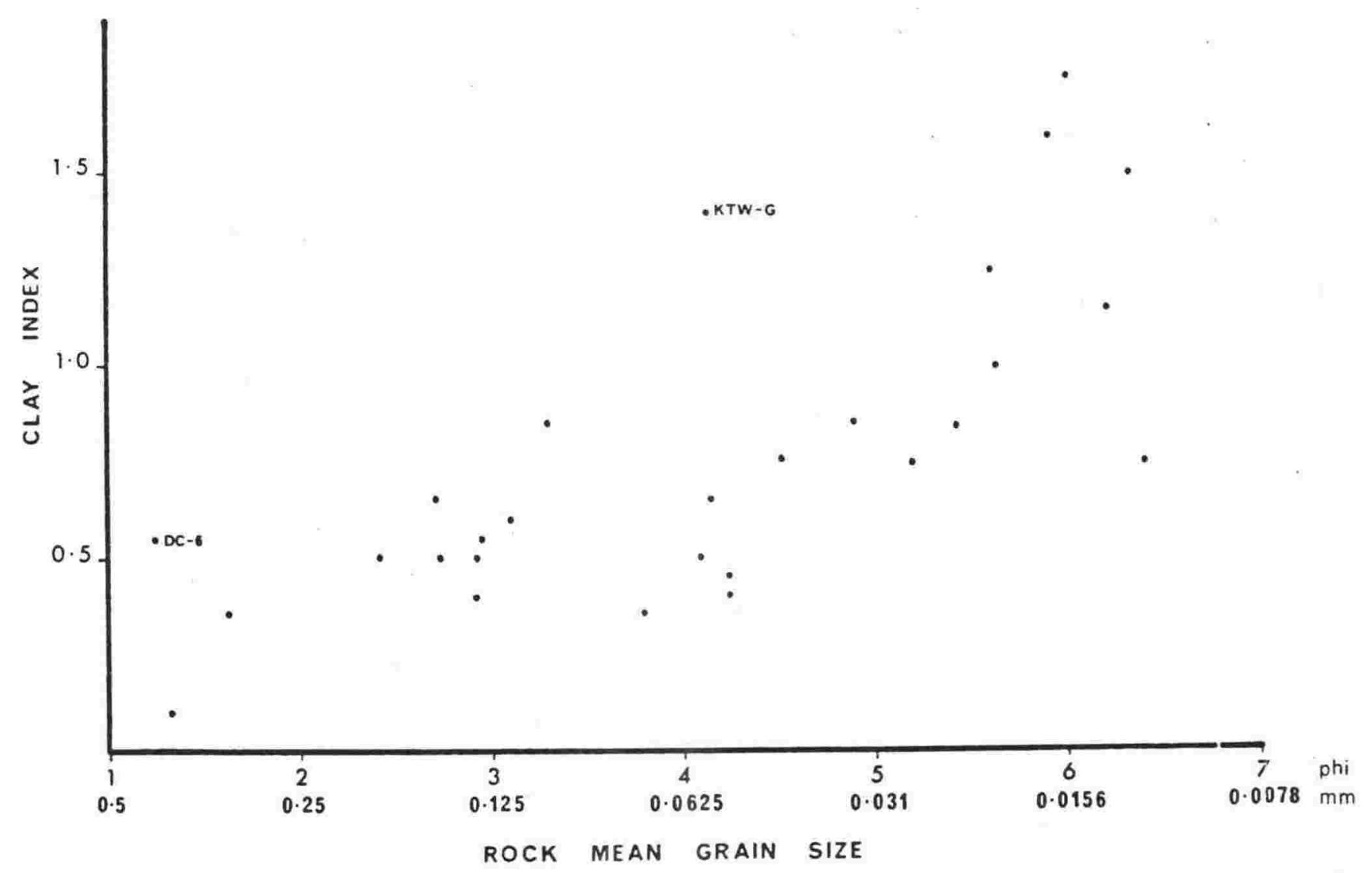

Figure A23.1 : Clay index increases directly with reduced mean grain sizes of Wellington greywacke-suite rocks. The rise is steady from 1 to $5 \mathrm{phi}(0.5$ to $0.031 \mathrm{~mm})$ and rises more steeply in rocks finer than $5 \mathrm{phi}$. KTW-G contains much organic matter and mica; DC- 6 contains many argillaceous clasts. 
APPENDIX 24

Aggregate degradation: Washington degradation test and current research

1. Introduction

The New Zealand National Roads Board Road Research Unit Newsletter 58 No. 6, 1978, described preliminary results (Road Research Project BC/12-2) from an investigation assessing durability of basecourse and sub-base aggregate, with an accelerated attrition mill which utilizes the basic principles of a large gem polisher. The mill operates at cascading speed causing breakdown of the aggregate by attrition.

Tests on argillite and basalt indicated, among other things, that "the moist attrition mill appeared to offer a method of assessing aggregate durability". The test method and apparatus used is similar to those developed by Melville (1948), Ekse and Morris (1959) and Minor (1959), as the traditional Los Angeles and Deval machine tests did not satisfactorily identify poor aggregate. Improved resolution of potential degradation was achieved using the Los Angeles machine, without the use of steel spheres, as an abrasive surcharge and by determining Atterberg limits on the produced fines (Ekse and Morris, 1959). Further refinement was added by including a "degradation factor", ranging from 0 - 100 (superior materials having high values), based on the cleanness value of fines, produced by abrading saturated aggregate in a 1 gallon polythene jar for one hour (Minor, 1959). Melville, 11 years before, also used a ball mill method of assessing aggregates. Each author concluded that conventional testing may not detect potential degradation in some aggregates.

\section{The Washington degradation test}

The degradation factor established by Minor (1959) has been refined, testing technique and calculations have been simplified, and the method is now known as the Washington degradation test (Marshall, 1967). Marshall has also shown good correlation between results of the new and old methods.

To illustrate the discrepancies between different test methods, nine different commercially produced basecourse aggregates from the Wellington region were tested by the washington method. The samples were supplied by Mr T. Grant-Taylor (NZ Geological survey) after test by conventional means to provide data for a publication (Grant-Taylor, 1976). They were subjected to the Washington test carried out in strict adherence to the method of Marshall (1967) except for one detail; the required 1.75" (44.45 mm) throw on the sieve shaker cam could not be matched. The "ro-tap" machine used, had a throw of 1 " (25.4 mm). Results should therefore reflect maximum degradation factors for any particular sample, i.e. a "best" result.

Table A24.1 lists the Washington test results along with results from Grant-Taylor (1976).

The methylene blue test was performed on aggregate fines (less than BS 100 sieve; finer than $0.075 \mathrm{~mm})$ and on fines generated by the Washington test. 
Table A24.1 : Comparative data of nine greywacke-suite basecourse aggregates assessed using clay index, Washington test and X-ray diffractometry (this study) and by crushing resistance and Los Angeles tests (Grant-Taylor, 1976).

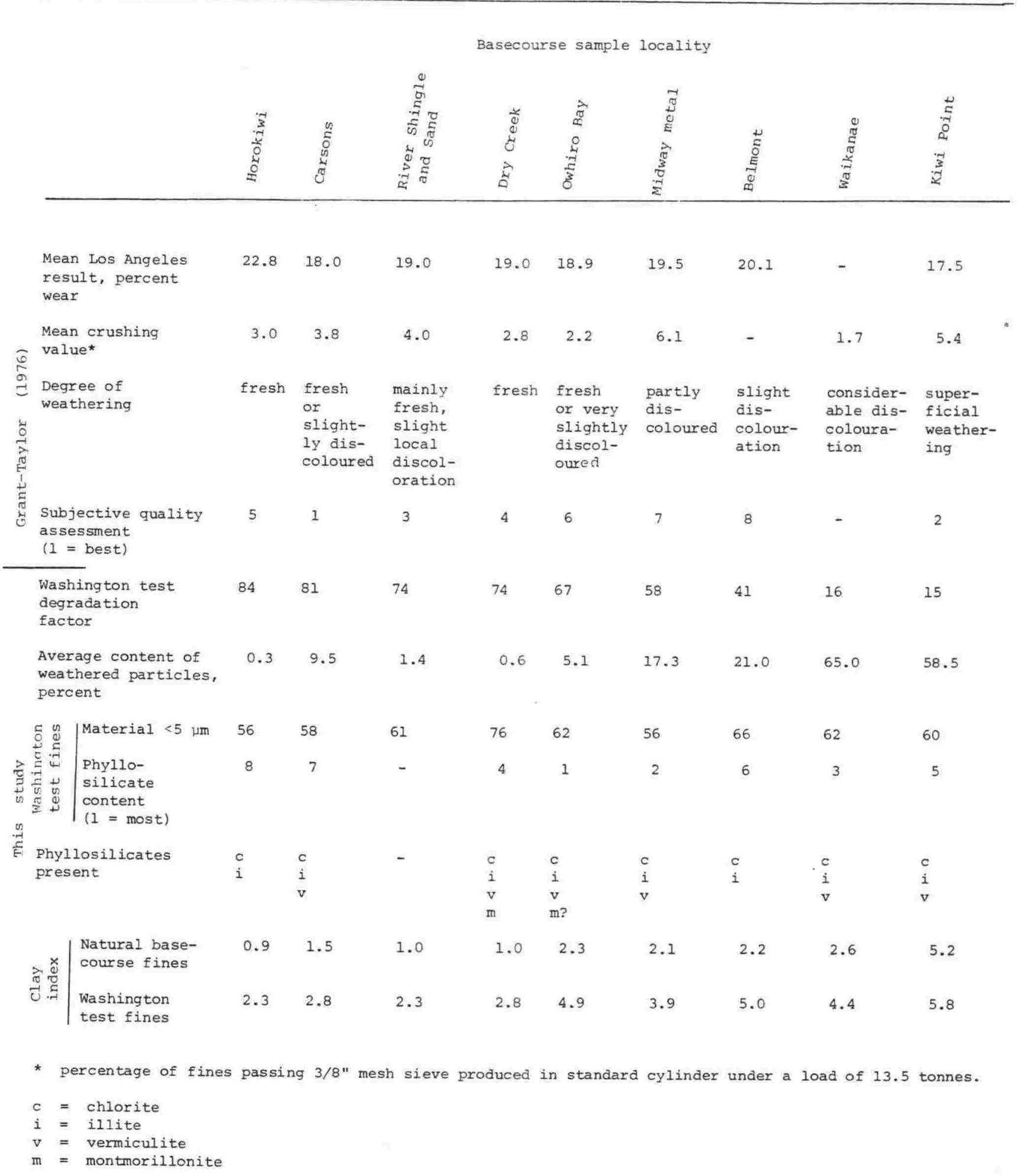


Subjective assessment is highly unreliable for recognising aggregates likely to degrade. Semi-quantitative assessment of clay mineral content and grain size analysis of fines from basecourse samples were undertaken (Table A24.1, Figure A24.1). Neither relate to the methylene blue test or the washington test. X-ray diffractometry of the fines from the Washington test indicates that approximately half of the less than 10 to 15 micron fraction (about 80 percent of the fines sample) is of phyllosilicate mineral composition. The grain size distributions of fines produced by the Washington test are similar (Figure A24.1).

The amount of weathered rock material in a basecourse also directly influences the methylene blue test for that basecourse, but the correlation is not as good as that from the Washington test (Figures A24.2, A24.3).

Recent work by Goonewardane (1977) on the Washington test has shown:

(i) That comminution of aggregate particles does not occur.

(ii) Fines are created by "leaching of hydrophilic minerals".

(iii) Autodenous grinding occurs, its influence depending on size, type and weathered nature of the sample.

All the basecourse aggregates tested were of similar type and particle size distributions were similar.

4. Conclusions

(i) Ball mill based tests are inconclusive unless augmented by other evidence.

(ii) To date, no single test or subjective visual inspection of rock is sufficient to predict its engineering performance.

(iii) The inclusion of heavily weathered rock in road base layers involves high risk of degradation problems unless adequate stabilisation is utilised. 


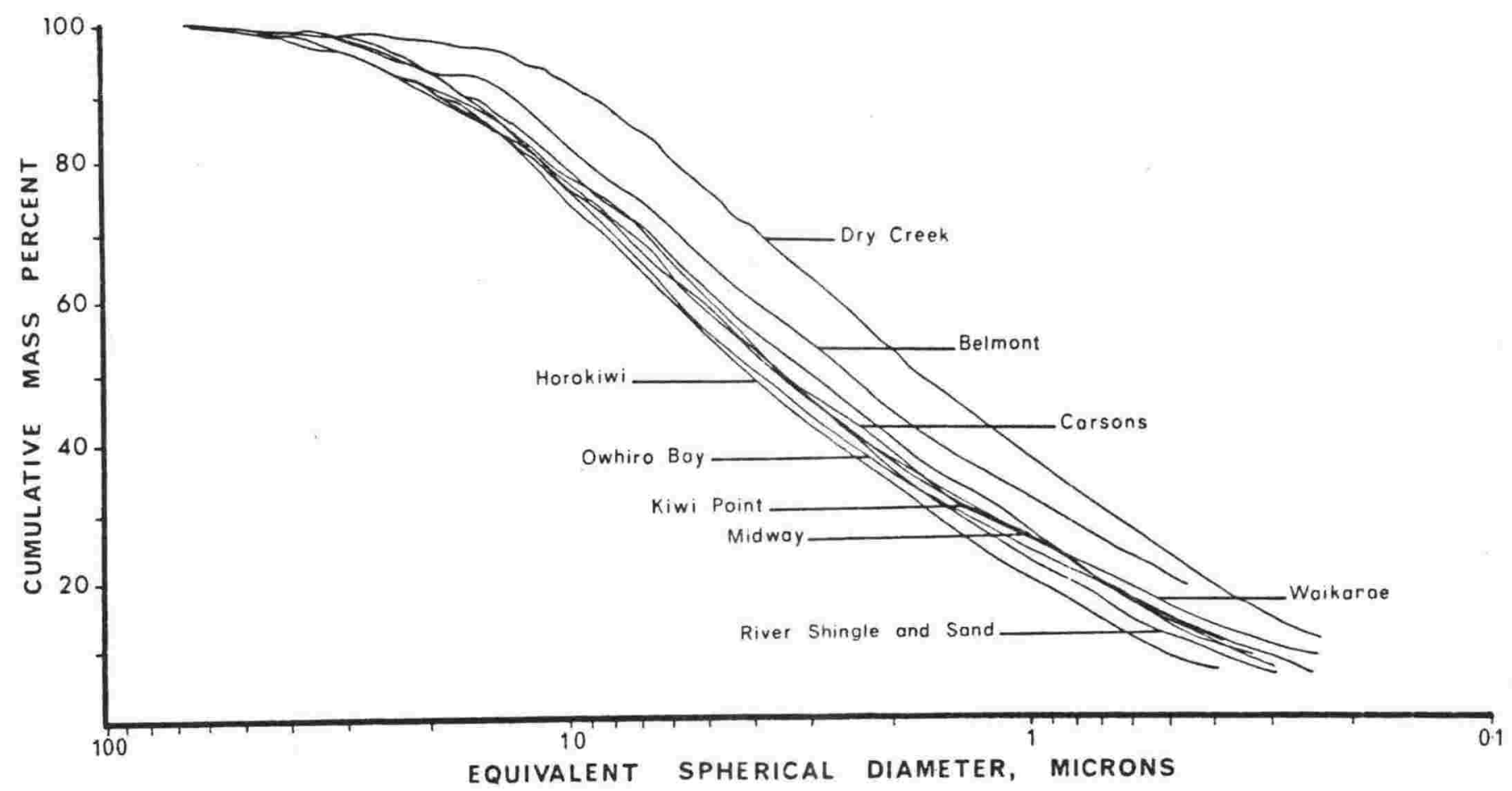

Figure A24.1 : Comparison of gradings of fine material generated by the Washington test, from nine basecourse aggregates. 


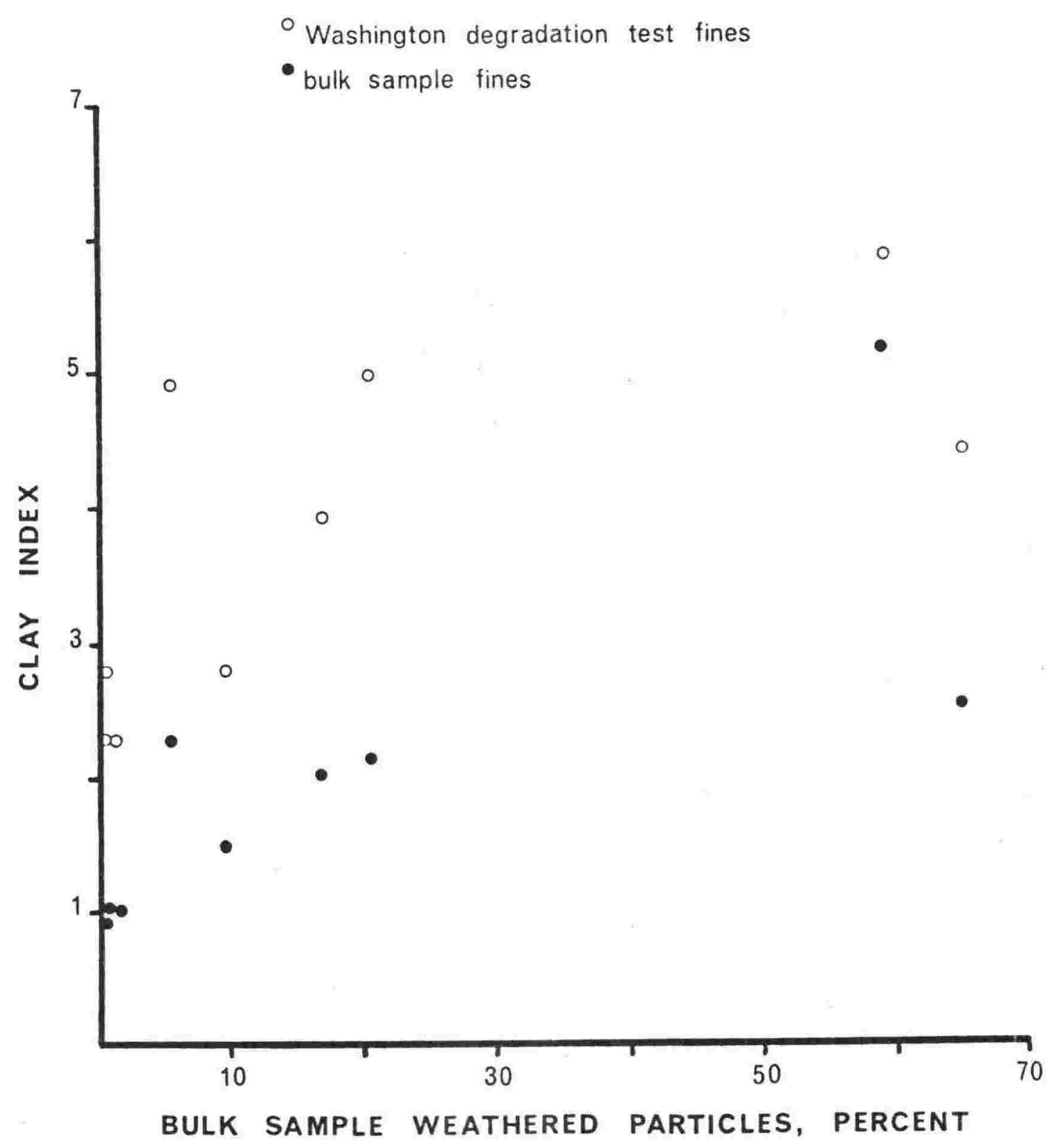

Figure A24.2 : Clay index is directly influenced by the percentage of weathered particles in the aggregate tested.

Similar findings have been reported by Orchard (1976). Generally, fines generated by the washington test give a clay index reading double that of bulk sample fines, C.f. Figure A24.3. 


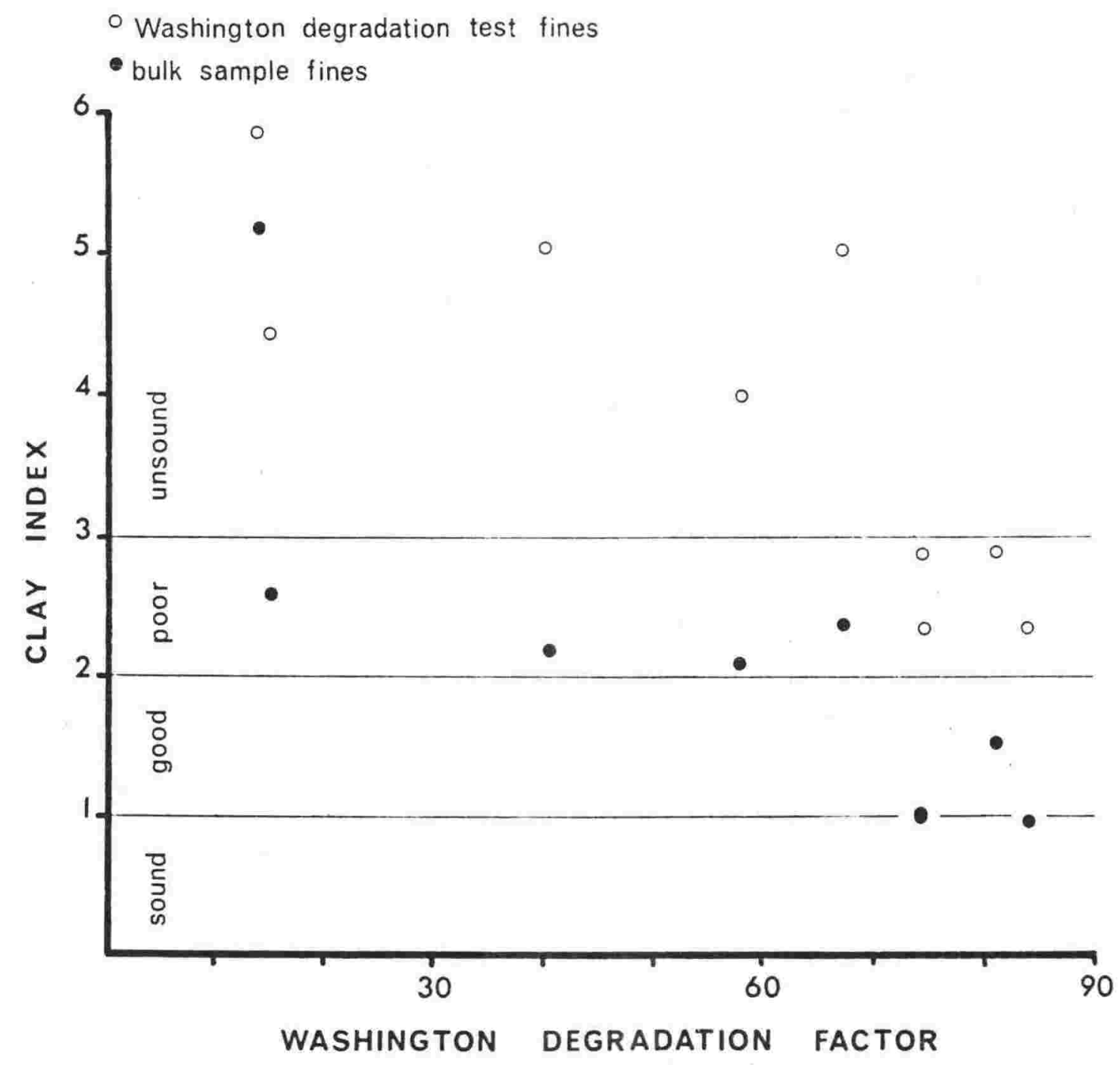

Figure A24.3 : Clay index and Washington test results are inversely related. Note, only four samples comply with "sound" and "good" categories of Sameshima (1977). According to Orchard (1976) the relationship may differ between rock types but this Figure (and Figure A24.2) indicate the desirability of conducting both tests as, at a high values of the Washington test, the clay index is relatively insensitive. 
Storage of greywacke-suite aggregates

1. Introduction

Elsewhere in this study (section 3.6; Appendices 23, 24), reference has been made to aggregate degradation. The rate and process of this phenomenon has received little research attention. It is the object of this Appendix to provide a better understanding of the natural agencies promoting degradation, the rate at which the process takes place, the sequence of the events which ultimately manifest themselves in degraded rocks and to provide an indication of how degradation losses in stockpiled aggregates may be minimised.

Generally, fresh argillite and fresh intensely zeolitised greywackes, are rock types most susceptible to degradation and can be expected to induce excess undersize materials in graded aggregate stockpiles.

2. Outdoor observations on degradation

Lack of published material on quantification of degradation effects in the field, has prompted an attempt in this study to quantity degradation effects from a pebble garden and from two quarries.

The pebble garden studied consisted of nominal $38 \mathrm{~mm}$ Horokiwi aggregate placed over black plastic sheeting. The aggregate was fresh and laid within a week of being processed. Exposure conditions approximated those of a stockpile surface, i.e., the surface was even and sloped at about $15^{\circ}$ (with a northerly aspect), was shaded about half the daylight hours and experienced occasional frost. The entire surface received rain and was well drained. The surface was exposed over a period of four years and received only very light pedestrian traffic.

Assessment of degradation was made using a $0.25 \mathrm{~m}^{2}$ frame divided into 100 mm squares by string lines to form a grid. Aggregate particles were contained within squares and categorised according to a simple scheme (Table A25.1). Over 2600 aggregate particles were assessed from about 8 percent of the garden's surface.

Particles which degraded had their requisite pieces adjacent, although detached (Plate A25.1). Up to eight pieces, formerly one particle, could be seen juxtaposed in this way. Smaller $(<10 \mathrm{~mm})$ products of degradation were lost - removed to the base of the aggregate cover to lie on the plastic substrate.

Weathered particles did not degrade in the same manner as fresh rock. Weathered material was reduced in size by removal of surface mineral grains, a quantity of mineral fines being obscured beneath the particles affected.

"Fresh zeolitised greywacke particles" were aggregate particles won from areas of the quarry where zeolite veining occurred on a millimetre interval scale, e.g., HQ-13 and HQ-14.

Results indicate that argillite and fresh zeolitised greywacke particles (the zeolite concerned being laumontite) required no mechanical stress to degrade. Size reduction of graded aggregate is mostly influenced by zeolitised particles. On average, a fresh 
Table A25.1 : Results of observations on 2600 particles from a pebble garden. The aggregate had been crushed, washed and had a nominal $38 \mathrm{~mm}$ size.

\begin{tabular}{lcc}
\hline Particle categories & As laid & $\begin{array}{c}\text { After } \\
\text { four years } \\
\text { exposure }\end{array}$ \\
\hline Whole fresh greywacke pieces & 86.4 \\
Whole fresh argillite pieces & 5.3 & 4.2 \\
Whole fresh zeolitised greywacke pieces & 7.0 & 5.6 \\
Whole weathered pieces & - & 1.3 \\
Degraded fresh zeolitised greywacke pieces & - & 1.4 \\
Degraded fresh argilite pieces & $100.0 \%$ & $100.0 \%$ \\
& & $18: 1$
\end{tabular}

Table A25.2 : Rock stability values of pebble garden aggregates and lithologies approximating them, show that laboratory prediction of degradation for the fresh zeolitised greywacke and fresh argillite categories is possible.

Representative particles of each aggregate category

Rock stability value

\section{7}

14.7

10.9

6.5

Average weight percent

loss per day
0.275
0.85
0.438
0.263

Fresh greywacke
Fresh argillite
Fresh zeolitised greywacke
Weathered greywacke

Prepared rock specimens from Horokiwi Quarry

approximating lithologies of the above aggregate particles

HQ-17 fresh greywacke

HQ-22 fresh argillite

HQ-14 fresh zeolitised greywacke

$\begin{array}{rl}6.1 & 0.267 \\ 11.9 & 0.641 \\ 8.1 & 0.289\end{array}$



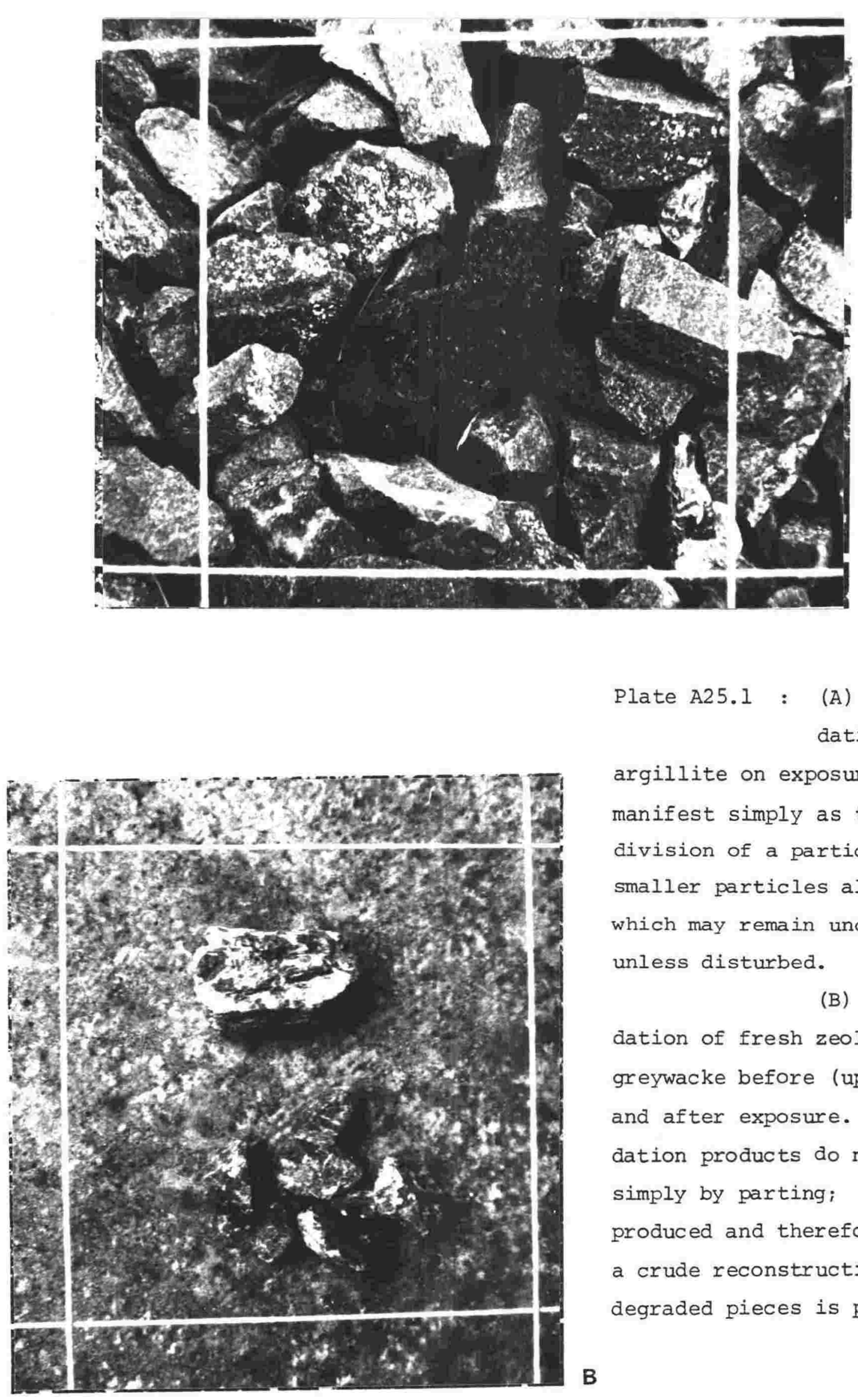

Plate A25.1 : (A) Degradation of argillite on exposure is manifest simply as the division of a particle into smaller particles along planes which may remain undetected unless disturbed.

(B) Degra-

dation of fresh zeolitised greywacke before (upper) and after exposure. Degradation products do not form simply by parting; fines are produced and therefore only a crude reconstruction of degraded pieces is possible.

The grid is $100 \mathrm{~mm}$ square. 
zeolitised greywacke particle degraded into 3.4 pieces (range 2 - 8 pieces), the degree of size reduction being dependent on the degree of veining displayed. A 20 percent reduction of whole fresh zeolitised greywacke particles occurred in four years of exposure (Table A25.1). In terms of volume, the degradation of argillite appears more significant. Fresh argillite particles degraded into an average of 2.9 pieces (range 2 - 5 pieces), a 21 percent reduction in argillite particles in four years. Table A25.2 shows that Rock stability values (Rowe, 1979) of particles corresponds well with the observations of degradation. Degradation of argillite may be seen where quarrying has temporarily ceased. Blocks $0.01 \mathrm{~m}^{3}$ to $0.25 \mathrm{~m}^{3}$ in size at Owhiro Bay and Horokiwi quarries, were observed after eight years and four years of exposure respectively. The blocks become surrounded by debris in which microcracks propagated along planes, parallel and sub-parallel to bedding and subperpendicular to bedding. Original shape of blocks was often preserved but integrity so destroyed that attempts to move blocks resulted in their disintegration to slabby clasts of sub-equal size. Occasionally disaggregation of the surface portion only was apparent, giving a superficially cracked but otherwise intact interior bounded by curved surfaces, suggesting a volume change of the exterior (degrading) material, to provide tensile stresses exceeding the tensile strength of the rock at the curved interface. No fine material (sand or silt) is produced by this degradation process - pieces may be reassembled as a "jig-saw puzzle". Degradation pieces are usually a minimum size of 25 mm with relatively large surface area to volume ratios.

\section{Exposure of argillite to water}

To observe the effects of water loss (section 3.5.1) a large (about $50 \mathrm{~kg}$ ) sample of argillite $(O B-W)$ from Owhiro Bay Quarry was cut parallel to bedaing and three $25 \mathrm{~mm}$ diameter cores taken, perpendicular to bedding, from the centre portion of the block. Cores were approximately $75 \mathrm{~mm}$ long and were kept wet until the experiment began.

Cores were weighed in a saturated surface dry (SSD) condition before one was placed in each of three localities; a window ledge with a north-west aspect, a toilet cistern to ensure permanent fresh water wetness and after drying for 24 hours at room temperature in a thermostatically controlled oven $\left(105 \pm 5^{\circ} \mathrm{C}\right)$. Cores remained in their respective locations for 14 months.

At the start of the experiemnt all cores were completely sound, with no microcracking apparent. Observations from each core with time were as follows:

Sample Saturated surface dry (SSD) core
$\begin{aligned} & \text { examined, } \mathrm{gm} . \\ & 6.2 .78\end{aligned} 28.2 .78 \quad \begin{aligned} & 18.5 .78\end{aligned}$ 6.2 .78
start we

A Window ledge 100.00 B Permanently $\quad 104.20$ wet

C Permanently dry

95.3 95.17
100.30

100.26

$-$

95.33
Ultrasonic velocity on completion of experiment, $\left(\mathrm{m}_{\mathrm{s}}{ }^{-1}\right)$ 
The core from the window ledge was microcracked, at $25 \mathrm{~mm}$ intervals, within approximately eight weeks. After fourteen months the microcracks were only a few millimetres apart. one large, open diagonal crack $0.3 \mathrm{~mm}$ wide, developed after about 10 months of exposure. Edges of the crack developed yellow-brown weathering colouration within a further two months. The crack did not extend through the core, being limited to a depth of $10 \mathrm{~mm}$. Its width was reduced when finger pressure was applied.

The permanently wet core showed no rircrocracking; no flaw whatever was found and its weight was constant throughout the test.

The oven dried core was microcracked at $10 \mathrm{~mm}$ spacings. Cracking was first noticed after 10 months. The core possibly lost weight, the technique of establishing SSD reference conditions for rock is subjective and weight variability may be the result of increasing amounts of water being held as microcracking increases.

Microcracks were, in all cases, approximately linear or gently curving, sub-parallel to bedding. They were invisible to the naked eye when the rock surface was dry. On wetting, water absorbed quickly into the microcracks, enlarging them and creating relatively dry crack margins. On drying, they retained water. They could be seen with the naked eye in both cases. They ranged to $0.004 \mathrm{~mm}$ in width.

The integrity of cores was established quantitatively by measuring their ultrasonic velocities parallel to their long axes. Cracks in the rock attenuate the signal pulse and lower the transmission time (New, 1976). Sound cores of OB-W had an average SSD ultrasonic velocity of $4945 \mathrm{~m} . \mathrm{s}^{-1}$ (range $4831-5072, \mathrm{n}=11$ ). The velocity $\left(5000 \mathrm{~m} . \mathrm{s}^{-1}\right.$ ) for the core kept permanently wet is near the mean of velocities from sound cores and so this core may be considered unaffected by its experimental treatment. The core kept permanently dry gave a significantly lower ultrasonic velocity $\left(4704 \mathrm{~m} . \mathrm{s}^{-1}\right)$ from that of the lowest reading of sound cores, i.e., a difference in excess of the 2 percent accuracy of the PUNDIT apparatus used for the measurements. The core from the window ledge was unavailable for test.

The core experiments indicate that degradation may take place quickly (within two months) and requires wet and dry cycling to bring it about.

\section{The effects of wetting and drying on rock durability}

To examine the role wetting and drying plays in degradation, two further experiments were completed to establish the volume change inherent in different rock types when wetted and to study the cyclic effects of wetting the drying, i.e., cycling these volurne changes.

Eleven greywacke-suite rocks were tested for unrestrained moisture movement using an apparatus similar to that shown by Duncan (1969, vol. 1, plate 18), see also Appendix 20. Movement values are maxima as samples were $25 \mathrm{~mm}$ diameter rock cores cut perpendicular to bedding. Samples were measured over several days after initial drying $\left(50^{\circ} \mathrm{C}\right.$ for 24 hours). Three lithologies were retested, one of these (HQ-22) three times due to fractures forming during testing.

Results (Table A25.3, Figure A25.1) show unrestrained moisture movement in argillites to be an order of magnitude greater than that in greywackes.

Cyclic moisture movements were determined using a technique described by Roper (1959), see also Appendix 21. The cores used for unrestrained moisture movements were used for this experiment. In addition a prism of KTW-i greywacke (see Appendix 19 and Table A25.4) 
Table A25.3 : Data from unrestrained moisture movement tests. Dial gauge used was calibrated in inches, therefore $\Delta I$ is in inches. $M_{S}$ is the unrestrained moisture movement, percent. I is sample length, $\mathrm{M}_{\mathrm{z}}$ is rock mean grain size and RSV the Rock stability value.

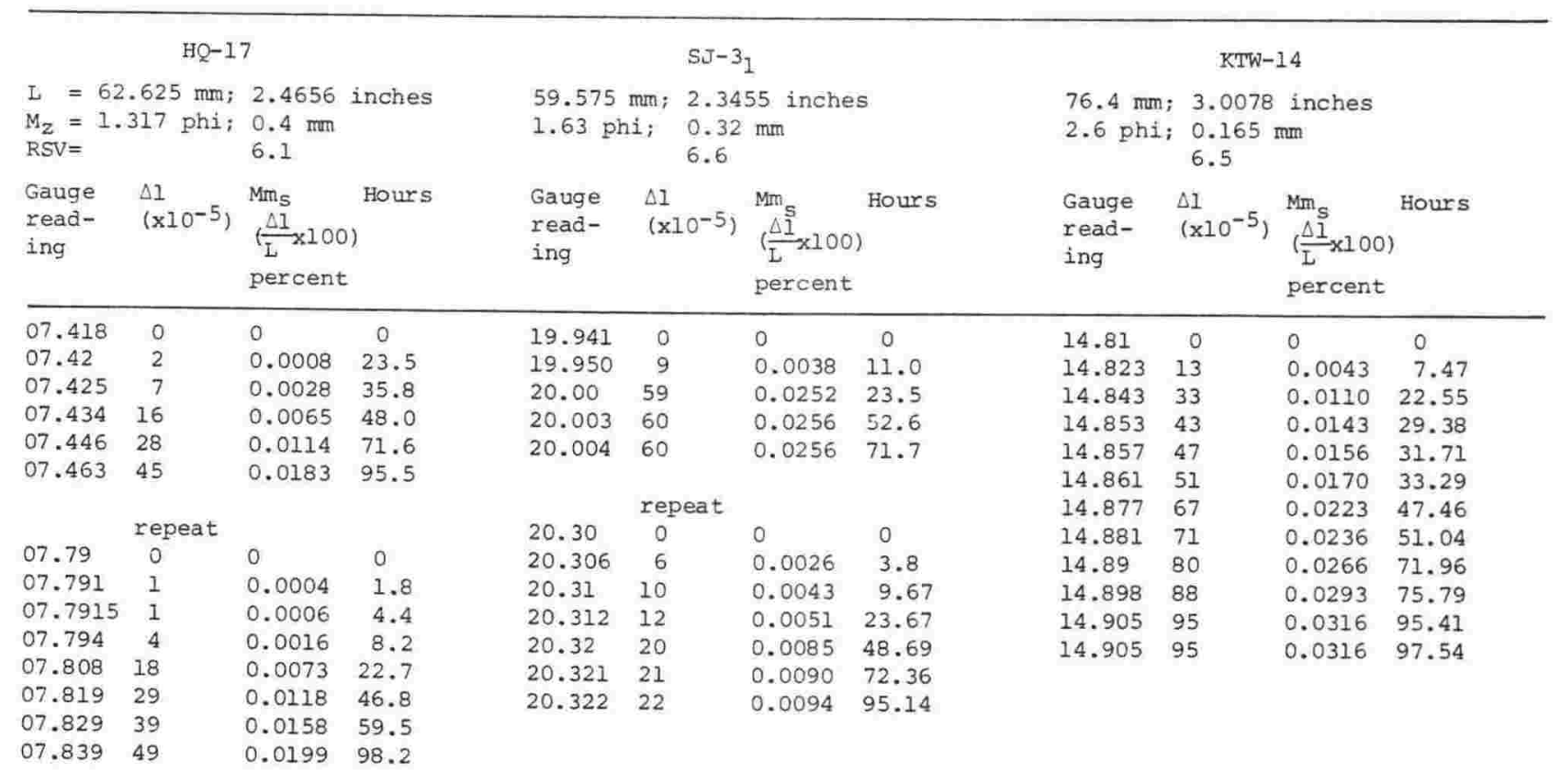

\begin{tabular}{|c|c|c|c|c|c|c|c|c|c|c|c|}
\hline \multicolumn{4}{|c|}{$B Q-V$} & \multicolumn{4}{|c|}{$B Q-I X A$} & \multicolumn{4}{|c|}{$\mathrm{KS}-2$} \\
\hline \multicolumn{4}{|c|}{$\begin{array}{l}\mathrm{L}=68.0 \mathrm{~mm} ; 2.6772 \text { inches } \\
\mathrm{M}_{\mathrm{z}}=2.73 \mathrm{phi} ; 0.15 \mathrm{~mm} \\
\mathrm{RSV}= \\
7.1\end{array}$} & \multicolumn{4}{|c|}{$\begin{aligned} 78.4 \mathrm{~mm} ; & 3.0866 \text { inches } \\
2.9 \mathrm{phi} ; & 0.134 \mathrm{~mm} \\
& 5.4\end{aligned}$} & \multicolumn{4}{|c|}{$\begin{array}{ll}70.7 \mathrm{~mm} ; & 2.7835 \text { inches } \\
3.27 \mathrm{phi} ; & 0.104 \mathrm{~mm} \\
& 7.15\end{array}$} \\
\hline $\begin{array}{l}\text { Gauge } \\
\text { read- } \\
\text { ing }\end{array}$ & $\frac{\Delta 1}{\left(x \perp 0^{-5}\right)}$ & $\begin{array}{l}\mathrm{Mm}_{\mathrm{S}} \\
\left(\frac{\Delta \mathrm{I}}{\mathrm{L}} \times 100\right. \\
\text { percent }\end{array}$ & Hours & $\begin{array}{l}\text { Gauge } \\
\text { read- } \\
\text { ing }\end{array}$ & $\begin{array}{l}\Delta 1 \\
\left(x \perp 0^{-5}\right)\end{array}$ & $\begin{array}{l}\mathrm{Mm} \\
\left(\frac{\Delta \bar{I}}{\mathrm{~L}} \times 100\right. \\
\text { percent }\end{array}$ & Hours & $\begin{array}{l}\text { Gauge } \\
\text { read- } \\
\text { ing }\end{array}$ & $\frac{\Delta 1}{\left(x 10^{-5}\right)}$ & $\begin{array}{l}\mathrm{Mm}_{\mathrm{S}} \\
\left(\frac{\Delta I}{\mathrm{~L}} \times 100\right) \\
\text { percent }\end{array}$ & Hours \\
\hline 01.591 & 0 & 0 & 0 & 22.35 & 0 & 0 & 0 & 11.695 & 0 & 0 & 0 \\
\hline 01.591 & 0 & 0 & 0.95 & 22.355 & 5 & 0.0016 & 5.62 & 11.733 & 38 & 0.0137 & 1.83 \\
\hline 01.592 & 1 & 0.0004 & 2.60 & 22.37 & 20 & 0.0065 & 11.62 & 11.813 & 118 & 0.0424 & 5.50 \\
\hline 01.599 & 8 & 0.0029 & 4.77 & 22.385 & 35 & 0.0113 & 23.92 & 11.878 & 183 & 0.0657 & 21.75 \\
\hline 01.60 & 9 & 0.0034 & 9.47 & 22.39 & 40 & 0.0129 & 31.84 & 11.883 & 188 & 0.0675 & 48.17 \\
\hline 01.608 & 17 & 0.0064 & 14.10 & 22.407 & 57 & 0.0185 & 47.54 & 11.884 & 189 & 0.0679 & 69.12 \\
\hline 01.617 & 26 & 0.0097 & 24.07 & 22.415 & 65 & 0.0211 & 57.37 & 11.885 & 190 & 0.0683 & 71.67 \\
\hline 01.626 & 35 & 0.0131 & 29.52 & 22.422 & 72 & 0.0283 & 71.67 & 11.885 & 190 & 0.0683 & 76.05 \\
\hline 01.630 & 39 & 0.0146 & 33.22 & 22.427 & 77 & 0.0249 & 100.17 & 11.885 & 190 & 0.0683 & 77.58 \\
\hline 01.655 & 64 & 0.0239 & 48.30 & 22.43 & 80 & 0.0259 & 110.59 & 11.885 & 190 & 0.0683 & 93.33 \\
\hline 01.665 & 74 & 0.0276 & 55.70 & & & & & & & & \\
\hline 01.686 & 95 & 0.0355 & 71.68 & & & & & & & & \\
\hline 01.7011 & 110 & 0.0411 & 80.51 & & & & & & & & \\
\hline 01.7081 & 170 & 0.0437 & 96.01 & & & & & & & & \\
\hline
\end{tabular}


Table A25.3 : continued

\begin{tabular}{|c|c|c|c|c|c|c|c|c|c|c|c|}
\hline \multicolumn{4}{|c|}{ KTW-i } & \multicolumn{4}{|c|}{ SJ-T } & \multicolumn{4}{|c|}{$\mathrm{OB}-\bar{W}$} \\
\hline \multicolumn{2}{|c|}{$\begin{array}{l}\mathrm{L}=75.0 \mathrm{~mm} \\
M_{z}=4.23 \mathrm{phi}\end{array}$} & \multicolumn{2}{|c|}{$\begin{array}{l}2.9528 \text { inches } \\
0.053 \mathrm{~mm} \\
3.9\end{array}$} & \multicolumn{4}{|c|}{$\begin{aligned} 64.5 \mathrm{~mm} ; & 2.5394 \text { inches } \\
4.72 \mathrm{phi} ; & 0.038 \mathrm{~mm} \\
& 8.8\end{aligned}$} & \multicolumn{4}{|c|}{$\begin{array}{c}73.84 \mathrm{~mm} ; 2.9071 \text { inches } \\
5.6 \mathrm{phi} ; 0.021 \mathrm{~mm} \\
11.3\end{array}$} \\
\hline $\begin{array}{l}\text { Gauge } \\
\text { read- } \\
\text { ing }\end{array}$ & $\begin{array}{l}\Delta I \\
\left(x 10^{-5}\right)\end{array}$ & $\begin{array}{l}\mathrm{Mm}_{\mathrm{S}} \\
\left(\frac{\Delta \mathrm{I}}{\mathrm{I}} \times 100\right) \\
\text { percent }\end{array}$ & Hours & $\begin{array}{l}\text { Gauge } \\
\text { read- } \\
\text { ing }\end{array}$ & $\begin{array}{l}\Delta 1 \\
\left(x 10^{-5}\right)\end{array}$ & $\begin{array}{l}{ }_{\left(\frac{\Delta I}{\mathrm{~L}}\right.}^{\mathrm{Mm}} \mathrm{S} \\
\text { percent }\end{array}$ & Hours & $\begin{array}{l}\text { Gauge } \\
\text { read- } \\
\text { ing }\end{array}$ & $\underset{\left(x \perp 0^{-5}\right)}{\Delta 1}$ & $\begin{array}{l}\mathrm{Mm}_{\mathrm{S}} \\
\left(\frac{\Delta 1}{\mathrm{~L}} \times 100\right) \\
\text { percent }\end{array}$ & Hours \\
\hline 09.318 & 0 & 0 & 0 & 11.728 & 0 & 0 & 0 & 05.05 & 0 & 0 & 0 \\
\hline 09.32 & 2 & 0.0007 & 1.72 & 11.732 & 4 & 0.0016 & 3.50 & 05.086 & 36 & 0.0124 & 2.6 \\
\hline 09.329 & 11 & 0.0037 & 4.34 & 11.738 & 10 & 0.0039 & 5.47 & 05.11 & 60 & 0.0206 & 4.52 \\
\hline 09.338 & 20 & 0.0068 & 7.27 & 11.740 & 12 & 0.0047 & 6.47 & 05.148 & 98 & 0.0337 & 7.63 \\
\hline 09.367 & 49 & 0.0166 & 22.05 & 11.752 & 24 & 0.0095 & 13.59 & 05.213 & 163 & 0.0561 & 10.46 \\
\hline 09.379 & 61 & 0.0207 & 30.62 & 11.77 & 42 & 0.0165 & 24.00 & 05.38 & 330 & 0.1135 & 21.79 \\
\hline 09.409 & 91 & 0.0308 & 46.92 & 11.789 & 61 & 0.0240 & 34.13 & 05.41 & 360 & 0.1238 & 25.46 \\
\hline 09.42 & 102 & 0.0345 & 54.72 & 11.808 & 80 & 0.0315 & 48.08 & 05.438 & 388 & 0.1335 & 29.16 \\
\hline 09.44 & 122 & 0.0413 & 73.97 & 11.820 & 92 & 0.0362 & 59.08 & 05.444 & 394 & 0.1355 & 30.88 \\
\hline 09.45 & 132 & 0.0447 & 93.97 & 11.836 & 108 & 0.0425 & 71.80 & 05.523 & 473 & 0.1627 & 45.96 \\
\hline & & & & 11.848 & 120 & 0.0473 & 85.42 & 05.535 & 485 & 0.1668 & 49.39 \\
\hline & & & & 11.869 & 141 & 0.0555 & 121.04 & 05.581 & 531 & 0.1827 & 70.38 \\
\hline & & & & 11.871 & 143 & 0.0563 & 146.42 & 05.59 & 540 & 0.1858 & 77.76 \\
\hline & & & & 11.872 & 144 & 0.0567 & 169.35 & 05.599 & 549 & 0.1889 & 93.79 \\
\hline & & & & & & & & 05.60 & 550 & 0.1892 & 96.96 \\
\hline
\end{tabular}

HQ- 22

$L=67.9 \mathrm{~mm} ; 2.6732$ inches

$M_{z}=6.28$ phi; $0.013 \mathrm{~mm}$

$$
11.9
$$

\begin{tabular}{lll}
$\begin{array}{l}\text { Gauge } \\
\text { read- } \\
\text { ing }\end{array}$ & $\begin{array}{l}\Delta 1 \\
\left(\times 10^{-5}\right)\end{array}$ & $\begin{array}{l}M_{5} \\
\left(\frac{\left.\Delta l_{x} \times 100\right)}{\mathrm{L}}\right. \\
\text { percent }\end{array}$ \\
& & Hours \\
\hline
\end{tabular}

$\begin{array}{llll}07.791 & 0 & 0 & 0\end{array}$

$\begin{array}{llll}07.997 & 206 & 0.0771 & 2.2\end{array}$

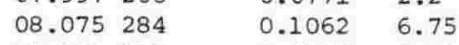

$\begin{array}{llll}08.123 & 332 & 0.1242 & 8.58\end{array}$

$\begin{array}{llll}08.229 & 438 & 0.1639 & 13.18\end{array}$

$\begin{array}{lll}08.367576 & 0.2155 & 23.75\end{array}$

$\begin{array}{llll}08.383 & 592 & 0.2215 & 28.42\end{array}$

$\begin{array}{llll}08.411 & 620 & 0.2319 & 36.09\end{array}$

sample cracked?

$\begin{array}{llll}08.415 & 624 & 0.2334 & 48.12\end{array}$

$\begin{array}{llll}08.415 & 624 & 0.2334 & 73.42\end{array}$

$\begin{array}{lll}08.416 \quad 625 & 0.2338 \quad 95.59\end{array}$

repeat

$\begin{array}{llll}0.45 & 0 & 0 & 0\end{array}$

$\begin{array}{llll}01.526 & 76 & 0.0284 & 0.70\end{array}$

$\begin{array}{llll}01.705 & 255 & 0.0954 & 3.77\end{array}$

$\begin{array}{llll}01.797 & 347 & 0.1298 & 6.15\end{array}$

$\begin{array}{llll}01.863 & 413 & 0.1550 & 9.75\end{array}$

$\begin{array}{llll}01.882 & 432 & 0.1616 & 13.62\end{array}$

sample cracked

$\begin{array}{llll}01.90 & 450 & 0.1683 & 24.22\end{array}$

$\begin{array}{llll}01.918 & 468 & 0.1751 & 26.87\end{array}$

$\begin{array}{llll}01.919 & 469 & 0.1755 & 47.87\end{array}$ 


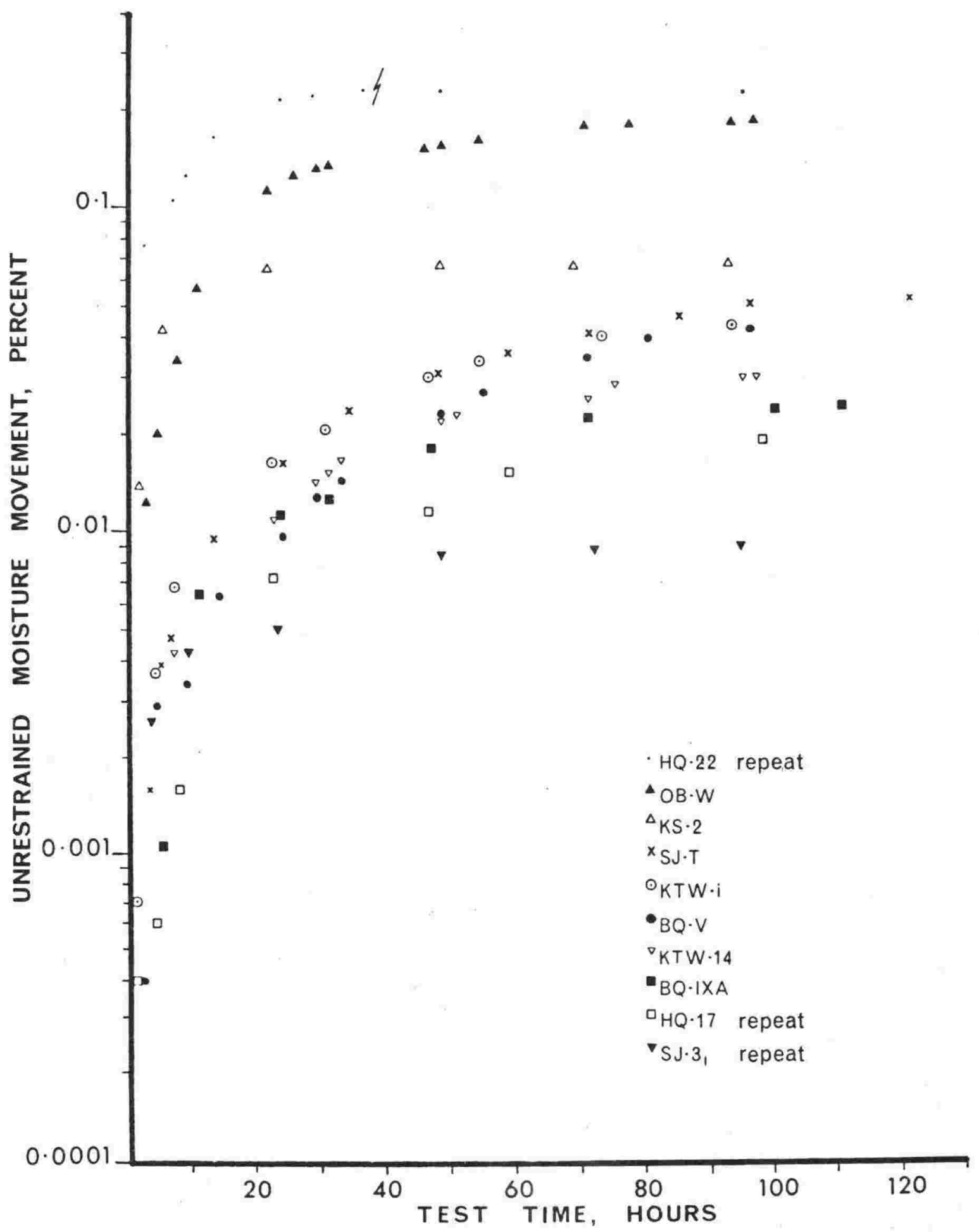

Figure A25.1 : Unrestrained moisture movement of greywacke-suite rocks takes place rapidly within the first 20 hours of testing, gradually attaining equilibrium after approximately 90 hours (4 days). Note the $\log$ scale of the y-axis. Argillite movements are an order of magnitude greater than greywackes. 
Table A25.4 : Cyclic moisture movement values for prism KTW-i. A25.2.

Length $(L)=20.9 \mathrm{~cm}$

\begin{tabular}{|c|c|c|c|c|}
\hline $\begin{array}{l}\text { Cycle } \\
\text { number }\end{array}$ & $\begin{array}{l}\text { Comparitor } \\
\text { measurement }\end{array}$ & $\begin{array}{l}\text { Sample } \\
\text { measurement }\end{array}$ & $\begin{array}{l}\Delta 1 \\
\mathrm{x} \quad 0.001 \mathrm{~cm}\end{array}$ & $\frac{M m_{\mathrm{d}}}{\frac{\Delta 1}{\mathrm{~d}} \times 100}$ \\
\hline $\begin{array}{l}1 \\
1\end{array}$ & $\begin{array}{l}0 \\
0\end{array}$ & $\begin{array}{l}05.677 \\
05.428\end{array}$ & $\begin{array}{l}0 \\
-0.0249\end{array}$ & $\begin{array}{c}0 \\
-0.12\end{array}$ \\
\hline $\begin{array}{l}2 \\
2\end{array}$ & $\begin{aligned} & 0 \\
+ & 0.0001\end{aligned}$ & $\begin{array}{l}05.77 \\
05.43\end{array}$ & $\begin{array}{l}+0.0093 \\
-0.0247\end{array}$ & $\begin{array}{l}+0.05 \\
-0.12\end{array}$ \\
\hline $\begin{array}{l}3 \\
3\end{array}$ & $\begin{array}{l}0 \\
0\end{array}$ & $\begin{array}{l}05.79 \\
05.45\end{array}$ & $\begin{array}{l}+0.0113 \\
-0.0227\end{array}$ & $\begin{array}{l}+0.05 \\
-0.11\end{array}$ \\
\hline $\begin{array}{l}4 \\
4\end{array}$ & $\begin{array}{l}0 \\
0\end{array}$ & $\begin{array}{l}05.79 \\
05.45\end{array}$ & $\begin{array}{l}+0.0113 \\
-0.0227\end{array}$ & $\begin{array}{l}+0.05 \\
-0.11\end{array}$ \\
\hline $\begin{array}{l}5 \\
5\end{array}$ & $\begin{array}{l}0 \\
0\end{array}$ & $\begin{array}{l}05.79 \\
05.47\end{array}$ & $\begin{array}{l}+0.0113 \\
-0.0207\end{array}$ & $\begin{array}{l}+0.05 \\
-0.10\end{array}$ \\
\hline 5 & -0.0002 & 05.83 & +0.0153 & +0.07 \\
\hline
\end{tabular}

was included. Measurements were recorded with reference to an invar rod (for the prism) and a stainless steel rod (for the cores).

Results (Table A25.5,Figure A25.2) show the argillite cores and the nrism to have cumulative expansions. Roper (1959) attributed this to crack formation and propagation. Indeed, during the experiment, argillite cores developed microcracks and a small argillaceous portion of the prism further microcracked. Comparison between KTW-i core and prism results show similar percentages of expansion, indicating the greywacke to be cracking also (KTW-i core was free of any argillite).

Roper (1959) concluded that volume changes were related to internal surface area. Applied to Figure A25.2, this suggests argillites to have larger internal surface areas than greywackes, some of which indicated shrinkage tendancies.

\section{Permeability as an indicator of rock durability}

Permeabilities of Wellington greywackes and argillites were studied to better understand the role of internal surface area and rock degradation, and establish the effects water has as it passes through a rock.

Factors influencing rock permeability include; anisotropy, porosity, texture and mineralogy.

Permeability measurements were made on $25 \mathrm{~mm}$ diameter cores of maximum integrity, with axis orientation perpendicular to bedding and therefore the permeabilities measured are a minimum. This is the only orientation for which results could be confidently related between samples, as permeability parallel to bedding varies due to fabric anisotropy. Sample preparation is outlined in Appendix 22. Calculations were based on a formula from 
Curtis (1971) which determines $k$ and may be related to pore geometry and internal surface characteristics of rocks. Absolute or specific permeability, $k$, is dimensioned as an area which may be considered as "average pore area" determining the rate of flow. It may be considered a characteristic of the rock provided the transmitted fluid does not alter the volume or internal surface of voids or solids.

Values of $\mathrm{k}$, established for 10 different greywacke-suite rocks (Table A25.6), diminish with time (Figure A.25.3) and appeared to stabilise after a minimum of 90 hours on test - an equilibrium time consistent with that of other tests (section 3.6; Appendix 19). However, all permeabilities were low, after 90 hours the mean value of $\mathrm{k}$ being $1.63 \times 10^{-19} \mathrm{mD}$ (standard deviation $0.87 \times 10^{-19} \mathrm{mD}$ ) and values are masked by spurious change.

The reduction of $\mathrm{k}$ values with time is probably a response to pressure differences within the sample. As the rock becomes saturated, water is absorbed on internal surfaces. This water has a high viscosity, but is mobile and takes part in the flow (Neville, 1975), and surface tension within pores is increased. This process takes place regardless of the length of soaking period before testing (at least one month) and takes place even when a sample is retested.

Because of this $k$ reduction (Figure A25.3), argillite permeability reduction rates tend to be faster and $k$, after 90 hours on test, is low.

It is probable that rates at which greywacke-suite rock come to equilibrium reflect their relative susceptability to degradation (see Mayer, 1963 and Farran and Thenot, in Mayer, $1963)$.

The equilibrated state of permeability after four days is mainly dependant on pore geometry, the chemical status of moisture within the rock, and the properties of organic and accessory minerals (Krynine and Judd, 1957). Initial permeabilities therefore may be hetter for comparative studies since these values are most likely to reflect mineralogy, textural and porosity differences.

The relationship of $\mathrm{k}$ with rock mean grain size is uncertain due to $\mathrm{k}$ changing with time; however a linear relationship does result after 75 hours of testing $(r=-0.62$, Figure A25.4). The initial, or three hour values of $\mathrm{k}$ show a relationship with rock mean grain size analogous to that shown by Rock stability value (RSV) and by $\Sigma$ chlorite content (Rowe, 1979) but the trends for RSV and $\Sigma$ chlorite are not linearly related to $k$ at any test time.

Relationships of three hour permeability, chlorite content and RSV indicate that increasing phyllosilicate contents generally effect increases in k. The lower volumes of matrix (phyllosilicates) in coarser grained greywackes do not produce lower $\mathrm{k}$ values in these rocks since phyllosilicates are abundant in the sedimentary rock fragments the rocks contain and because zeolite, a permeable mineral, is often present also.

6.

Discussion: a sequence of degradation by natural agencies

From data presented, degradation appears strongly influenced by:

(i) Water; both that influencing the rock from climatic conditions and that as an inherent component of the rock. 
Table A25.5 : Data from cyclic moisture movement tests. Dial gauge used was calibrated in inches therefore $\Delta \rho$ is in inches. Mma is the cyclic moisture movement, percent and $L$ is the sample length

\begin{tabular}{|c|c|c|c|c|c|c|c|c|c|c|}
\hline \multirow{2}{*}{$\begin{array}{l}\text { Sample } \\
\text { length } \\
\text { Cycle } \\
\text { number }\end{array}$} & \multirow{2}{*}{$\begin{array}{l}\text { number } \\
\text { (L) } \\
\text { Comparitor } \\
\text { measurement }\end{array}$} & \multicolumn{3}{|c|}{2.4115 inches } & \multicolumn{3}{|c|}{2.3115 inches } & \multicolumn{3}{|c|}{$\begin{array}{l}\text { KTW-14 } \\
\text { nches }\end{array}$} \\
\hline & & $\begin{array}{l}\text { Sample } \\
\text { measure- } \\
\text { ment }\end{array}$ & $\frac{\Delta 1}{\left(x 10^{-4}\right)}$ & $\begin{array}{l}M m_{d} \\
\left(\frac{\Delta I}{L} \times 100\right) \\
\text { percent }\end{array}$ & $\begin{array}{l}\text { Sample } \\
\text { measure- } \\
\text { ment }\end{array}$ & $\frac{\Delta 1}{\left(\times 10^{-4}\right)}$ & $\begin{array}{l}\mathrm{Mm}_{\mathrm{d}} \\
\left(\frac{\Delta I}{\mathrm{I}} \times 100\right) \\
\text { percent }\end{array}$ & $\begin{array}{l}\text { Sample } \\
\text { measure- } \\
\text { ment }\end{array}$ & $\stackrel{\Delta 1}{\left(x 10^{-4}\right)}$ & $\begin{array}{l}\mathrm{Mm}_{\mathrm{d}} \\
\left(\frac{\Delta \mathrm{I}}{\mathrm{L}} \mathrm{xl00}\right) \\
\text { percent }\end{array}$ \\
\hline 1 & 900 & 1067 & 0 & 0 & 2061 & 0 & 0 & 1691 & 0 & 0 \\
\hline 1 & & 1049 & +18 & +0.075 & 2036 & +25 & +0.108 & 1668 & +23 & +0.098 \\
\hline $\begin{array}{l}2 \\
2\end{array}$ & & $\begin{array}{l}1061 \\
1046\end{array}$ & $\begin{array}{r}+6 \\
+2 I\end{array}$ & $\begin{array}{l}+0.025 \\
+0.087\end{array}$ & $\begin{array}{l}2054 \\
2039\end{array}$ & $\begin{array}{r}+7 \\
+22\end{array}$ & $\begin{array}{l}+0.030 \\
+0.095\end{array}$ & $\begin{array}{l}1685 \\
1673\end{array}$ & +6 & +0.026 \\
\hline 3 & & 1064 & +3 & +0.012 & 2054 & +7 & +0.030 & 1685 & $\begin{array}{r}+18 \\
+6\end{array}$ & $\begin{array}{l}+0.077 \\
+0.026\end{array}$ \\
\hline 3 & & 1049 & +18 & +0.075 & ball bear & ng regis & ter failed & 1671 & +20 & +0.085 \\
\hline 4 & & 1062 & +5 & +0.021 & 2014 & 0 & 0 & 1683 & +8 & +0.034 \\
\hline 4 & & 1048 & +19 & +0.079 & 2012 & +2 & +0.008 & 1674 & +17 & +0.072 \\
\hline 5 & & 1063 & +4 & +0.017 & 2018 & -4 & -0.017 & 1682 & +9 & +0.038 \\
\hline 5 & & 1049 & +18 & +0.075 & 2010 & +4 & +0.017 & 1668 & +23 & +0.098 \\
\hline $\begin{array}{l}6 \\
6\end{array}$ & & $\begin{array}{l}1061 \\
1047\end{array}$ & $\begin{array}{r}+6 \\
+20\end{array}$ & +0.025 & 2016 & -2 & -0.008 & 1680 & +11 & +0.047 \\
\hline 7 & & 1063 & +4 & $\begin{array}{l}+0.083 \\
+0.017\end{array}$ & 2010 & +4 & +0.017 & 1673 & +18 & +0.077 \\
\hline 7 & & 1048 & $\begin{array}{r}+4 \\
+19\end{array}$ & $\begin{array}{l}+0.017 \\
+0.079\end{array}$ & $\begin{array}{l}2018 \\
2012\end{array}$ & $\begin{array}{l}-4 \\
+2\end{array}$ & $\begin{array}{l}-0.017 \\
+0.008\end{array}$ & $\begin{array}{l}1685 \\
1677\end{array}$ & $\begin{array}{r}+6 \\
+14\end{array}$ & $\begin{array}{l}+0.026 \\
+0.060\end{array}$ \\
\hline 8 & & 1063 & +4 & +0.017 & 2020 & -6 & -0.026 & 1689 & +2 & +0.009 \\
\hline 8 & & 1049 & +18 & +0.075 & 2014 & 0 & - & 1677 & +14 & +0.060 \\
\hline 9 & & 1058 & +9 & +0.037 & 2017 & -3 & -0.013 & 1683 & +8 & +0.034 \\
\hline 9* & & 1032 & +35 & +0.145 & 2011 & +3 & -0.013 & 1660 & +31 & +0.132 \\
\hline
\end{tabular}

* Water soak period prolonged three days i.e. was seven day soak.

\begin{tabular}{|c|c|c|c|c|c|c|c|c|c|c|}
\hline \multirow{2}{*}{$\begin{array}{l}\text { Sample } \\
\text { length } \\
\text { Cycle } \\
\text { number }\end{array}$} & \multirow{2}{*}{$\begin{array}{l}\text { number } \\
\text { (L) } \\
\text { Comparitor } \\
\text { measurement }\end{array}$} & \multicolumn{3}{|c|}{2.4027 inches } & \multicolumn{3}{|c|}{$\begin{array}{c}\text { BQ-IXA } \\
2.3865 \text { inches }\end{array}$} & \multicolumn{3}{|c|}{$\begin{array}{r}\text { KS-2 } \\
2.3433 \text { inches }\end{array}$} \\
\hline & & $\begin{array}{l}\text { Sample } \\
\text { measure- } \\
\text { ment }\end{array}$ & $\begin{array}{l}\Delta 1 \\
\left(x 10^{-4}\right)\end{array}$ & $\begin{array}{l}\mathrm{Mm}_{\mathrm{d}} \\
\left(\frac{\Delta \mathrm{I}}{\mathrm{L}} \times 100\right) \\
\text { percent }\end{array}$ & $\begin{array}{l}\text { Sample } \\
\text { measure- } \\
\text { ment }\end{array}$ & $\frac{\Delta 1}{\left(x 10^{-4}\right)}$ & $\begin{array}{l}\mathrm{Mm}_{\mathrm{d}} \\
\left(\frac{\Delta \mathrm{I}}{\mathrm{L}} \times 100\right) \\
\text { percent }\end{array}$ & $\begin{array}{l}\text { Sample } \\
\text { measure- } \\
\text { ment }\end{array}$ & $\begin{array}{l}\Delta I \\
\left(\times 10^{-4}\right)\end{array}$ & $\begin{array}{l}{ }^{M m_{\mathrm{a}}} \\
\left(\frac{\Delta I}{\mathrm{I}} \times 100\right) \\
\text { percent }\end{array}$ \\
\hline $\begin{array}{l}1 \\
1\end{array}$ & 900 & $\begin{array}{l}1159 \\
1135\end{array}$ & $\begin{array}{r}0 \\
+24\end{array}$ & $\begin{array}{c}0 \\
+0.1\end{array}$ & $\begin{array}{l}1312 \\
1284\end{array}$ & $\begin{array}{r}0 \\
+28\end{array}$ & $\begin{array}{l}0 \\
+0.117\end{array}$ & $\begin{array}{l}751 \\
\text { ball bear }\end{array}$ & $\stackrel{0}{\text { ring reg }}$ & $\begin{array}{c}0 \\
\text { ter }\end{array}$ \\
\hline $\begin{array}{l}2 \\
2\end{array}$ & & $\begin{array}{l}1154 \\
1144\end{array}$ & $\begin{array}{r}+5 \\
+15\end{array}$ & $\begin{array}{l}+0.021 \\
+0.062\end{array}$ & $\begin{array}{l}1307 \\
1290\end{array}$ & $\begin{array}{r}+5 \\
+22\end{array}$ & $\begin{array}{l}+0.021 \\
+0.092\end{array}$ & & & \\
\hline $\begin{array}{l}3 \\
3\end{array}$ & & $\begin{array}{l}1155 \\
1138\end{array}$ & $\begin{array}{r}+4 \\
+21\end{array}$ & $\begin{array}{l}+0.017 \\
+0.087\end{array}$ & $\begin{array}{l}1309 \\
1289\end{array}$ & $\begin{array}{r}+3 \\
+23\end{array}$ & $\begin{array}{l}+0.013 \\
+0.096\end{array}$ & $\begin{array}{l}737 \\
721\end{array}$ & $\begin{array}{r}0 \\
+16\end{array}$ & $\begin{array}{l}0 \\
+0.068\end{array}$ \\
\hline $\begin{array}{l}4 \\
4\end{array}$ & & $\begin{array}{l}1156 \\
1140\end{array}$ & $\begin{array}{r}+3 \\
+19\end{array}$ & $\begin{array}{l}+0.013 \\
+0.08\end{array}$ & $\begin{array}{l}1307 \\
1293\end{array}$ & $\begin{array}{r}+5 \\
+19\end{array}$ & $\begin{array}{l}+0.021 \\
+0.08\end{array}$ & $\begin{array}{l}734 \\
719\end{array}$ & $\begin{array}{r}+3 \\
+18\end{array}$ & $\begin{array}{l}+0.013 \\
+0.077\end{array}$ \\
\hline $\begin{array}{l}5 \\
5\end{array}$ & & $\begin{array}{l}1157 \\
1140\end{array}$ & $\begin{array}{r}+2 \\
+19\end{array}$ & $\begin{array}{l}+0.008 \\
+0.08\end{array}$ & $\begin{array}{l}1308 \\
1286\end{array}$ & $\begin{array}{r}+4 \\
+26\end{array}$ & $\begin{array}{l}+0.017 \\
+0.109\end{array}$ & $\begin{array}{l}733 \\
717\end{array}$ & $\begin{array}{r}+4 \\
+20\end{array}$ & $\begin{array}{l}+0.017 \\
+0.085\end{array}$ \\
\hline $\begin{array}{l}6 \\
6\end{array}$ & & $\begin{array}{l}1155 \\
1141\end{array}$ & $\begin{array}{r}+4 \\
+18\end{array}$ & $\begin{array}{l}+0.017 \\
+0.075\end{array}$ & $\begin{array}{l}1302 \\
1285\end{array}$ & $\begin{array}{l}+10 \\
+27\end{array}$ & $\begin{array}{l}+0.042 \\
+0.113\end{array}$ & $\begin{array}{l}731 \\
716\end{array}$ & $\begin{array}{r}+6 \\
+21\end{array}$ & $\begin{array}{l}+0.026 \\
+0.09\end{array}$ \\
\hline $\begin{array}{l}7 \\
7\end{array}$ & & $\begin{array}{l}1156 \\
1142\end{array}$ & $\begin{array}{r}+3 \\
+17\end{array}$ & $\begin{array}{l}+0.013 \\
+0.071\end{array}$ & $\begin{array}{l}1302 \\
1285\end{array}$ & $\begin{array}{l}+10 \\
+27\end{array}$ & $\begin{array}{l}+0.042 \\
+0.113\end{array}$ & $\begin{array}{l}732 \\
716\end{array}$ & $\begin{array}{r}+5 \\
+21\end{array}$ & $\begin{array}{l}+0.021 \\
+0.09\end{array}$ \\
\hline $\begin{array}{l}8 \\
8\end{array}$ & & $\begin{array}{l}1158 \\
1141\end{array}$ & $\begin{array}{r}+1 \\
+18\end{array}$ & $\begin{array}{l}+0.004 \\
+0.075\end{array}$ & $\begin{array}{l}1304 \\
1291\end{array}$ & $\begin{array}{r}+8 \\
+21\end{array}$ & $\begin{array}{l}+0.034 \\
+0.088\end{array}$ & $\begin{array}{l}732 \\
717\end{array}$ & $\begin{array}{r}+5 \\
+20\end{array}$ & $\begin{array}{l}+0.021 \\
+0.085\end{array}$ \\
\hline $\begin{array}{l}9 \\
9 *\end{array}$ & & $\begin{array}{l}1154 \\
1130\end{array}$ & $\begin{array}{r}+5 \\
+29\end{array}$ & $\begin{array}{l}+0.021 \\
+0.121\end{array}$ & $\begin{array}{l}1302 \\
\text { ball bear }\end{array}$ & $\begin{array}{l}+10 \\
\text { ing regis }\end{array}$ & $\begin{array}{l}+0.042 \\
\text { ter failed }\end{array}$ & $\begin{array}{l}730 \\
717\end{array}$ & $\begin{array}{r}+7 \\
+20\end{array}$ & $\begin{array}{l}+0.03 \\
+0.085\end{array}$ \\
\hline
\end{tabular}

* Water soak period prolonged three days i.e. was seven day soak. 
Table A25.5: continued.

\begin{tabular}{|c|c|c|c|c|c|c|c|c|c|c|}
\hline \multirow{2}{*}{$\begin{array}{l}\text { Sample } \\
\text { length } \\
\text { cycle } \\
\text { number }\end{array}$} & \multirow{2}{*}{$\begin{array}{l}\text { number } \\
\text { (L) } \\
\text { comparitor } \\
\text { measurement }\end{array}$} & \multicolumn{3}{|c|}{2.4233 inches } & \multicolumn{3}{|c|}{2.398 inches } & \multicolumn{3}{|c|}{$\begin{array}{r}\mathrm{OB}-\mathrm{W} \\
\text { inches }\end{array}$} \\
\hline & & $\begin{array}{l}\text { Sample } \\
\text { measure- } \\
\text { ment }\end{array}$ & $\begin{array}{l}\Delta 1 \\
\left(x 10^{-4}\right)\end{array}$ & $\begin{array}{l}\mathrm{Mm}_{\mathrm{a}} \\
\left(\frac{\Delta I}{\mathrm{I}} \times 100\right) \\
\text { percent }\end{array}$ & $\begin{array}{l}\text { Sample } \\
\text { measure- } \\
\text { ment }\end{array}$ & $\begin{array}{l}\Delta 1 \\
\left(x 10^{-4}\right)\end{array}$ & $\begin{array}{l}\mathrm{Mm}_{\mathrm{d}} \\
\left(\frac{\Delta 1}{\mathrm{~L}} \times 100\right) \\
\text { percent }\end{array}$ & $\begin{array}{l}\text { Sample } \\
\text { measure- } \\
\text { ment }\end{array}$ & $\left(x 10^{-4}\right)$ & $\begin{array}{l}\mathrm{Mm}_{\mathrm{d}} \\
\left(\frac{\Delta \mathrm{I}}{\mathrm{L}} \times 100\right) \\
\text { percent }\end{array}$ \\
\hline $\begin{array}{l}1 \\
1\end{array}$ & 900 & $\begin{array}{l}951 \\
933\end{array}$ & $\begin{array}{r}0 \\
+18\end{array}$ & $\begin{array}{l}0 \\
+0.074\end{array}$ & $\begin{array}{l}1198 \\
1182\end{array}$ & $\begin{array}{r}0 \\
+16\end{array}$ & $\begin{array}{l}0 \\
+0.067\end{array}$ & $\begin{array}{l}1701 \\
1664\end{array}$ & $\begin{array}{r}00 \\
+57\end{array}$ & $\begin{array}{l}0 \\
+0.243\end{array}$ \\
\hline $\begin{array}{l}2 \\
2\end{array}$ & & $\begin{array}{l}946 \\
924\end{array}$ & $\begin{array}{r}+5 \\
+27\end{array}$ & $\begin{array}{l}+0.021 \\
+0.111\end{array}$ & $\begin{array}{l}1194 \\
1178\end{array}$ & $\begin{array}{r}+4 \\
+20\end{array}$ & $\begin{array}{l}+0.017 \\
+0.083\end{array}$ & $\begin{array}{l}1699 \\
1642\end{array}$ & $\begin{array}{r}+2 \\
+59\end{array}$ & $\begin{array}{l}+0.009 \\
+0.251\end{array}$ \\
\hline $\begin{array}{l}3 \\
3\end{array}$ & & $\begin{array}{l}945 \\
929\end{array}$ & $\begin{array}{r}+6 \\
+22\end{array}$ & $\begin{array}{l}+0.025 \\
+0.091\end{array}$ & $\begin{array}{l}1196 \\
1179\end{array}$ & $\begin{array}{r}+2 \\
+19\end{array}$ & $\begin{array}{l}+0.008 \\
+0.079\end{array}$ & $\begin{array}{l}1699 \\
1642\end{array}$ & $\begin{array}{r}+2 \\
+59\end{array}$ & $\begin{array}{l}+0.009 \\
+0.251\end{array}$ \\
\hline $\begin{array}{l}4 \\
4\end{array}$ & & $\begin{array}{l}943 \\
929\end{array}$ & $\begin{array}{r}+8 \\
+22\end{array}$ & $\begin{array}{l}+0.033 \\
+0.091\end{array}$ & $\begin{array}{l}1195 \\
1179\end{array}$ & $\begin{array}{r}+3 \\
+19\end{array}$ & $\begin{array}{l}+0.013 \\
+0.079\end{array}$ & $\begin{array}{l}1692 \\
1644\end{array}$ & $\begin{array}{r}+9 \\
+57\end{array}$ & $\begin{array}{l}+0.038 \\
+0.243\end{array}$ \\
\hline $\begin{array}{l}5 \\
5\end{array}$ & & $\begin{array}{l}942 \\
921\end{array}$ & $\begin{array}{r}+9 \\
+30\end{array}$ & $\begin{array}{l}+0.037 \\
+0.124\end{array}$ & $\begin{array}{l}1193 \\
1172\end{array}$ & $\begin{array}{r}+5 \\
+26\end{array}$ & $\begin{array}{l}+0.021 \\
+0.108\end{array}$ & $\begin{array}{l}1696 \\
1642\end{array}$ & $\begin{array}{r}+5 \\
+59\end{array}$ & $\begin{array}{l}+0.021 \\
+0.251\end{array}$ \\
\hline $\begin{array}{l}6 \\
6\end{array}$ & & $\begin{array}{l}938 \\
925\end{array}$ & $\begin{array}{l}+13 \\
+26\end{array}$ & $\begin{array}{l}+0.054 \\
+0.107\end{array}$ & $\begin{array}{l}1188 \\
1176\end{array}$ & $\begin{array}{l}+10 \\
+22\end{array}$ & $\begin{array}{l}+0.042 \\
+0.092\end{array}$ & $\begin{array}{l}1695 \\
1643 \\
\text { visible c }\end{array}$ & $\begin{array}{l}+6 \\
+58 \\
\text { cracking }\end{array}$ & $\begin{array}{l}+0.026 \\
+0.247\end{array}$ \\
\hline $\begin{array}{l}7 \\
7\end{array}$ & & $\begin{array}{l}941 \\
925\end{array}$ & $\begin{array}{l}+10 \\
+26\end{array}$ & $\begin{array}{l}+0.041 \\
+0.107\end{array}$ & $\begin{array}{l}1190 \\
1175\end{array}$ & $\begin{array}{r}+8 \\
+23\end{array}$ & $\begin{array}{l}+0.033 \\
+0.096\end{array}$ & $\begin{array}{l}1697 \\
1643\end{array}$ & $\begin{array}{r}+4 \\
+58\end{array}$ & $\begin{array}{l}+0.017 \\
+0.247\end{array}$ \\
\hline $\begin{array}{l}8 \\
8\end{array}$ & & $\begin{array}{l}940 \\
924\end{array}$ & $\begin{array}{l}+11 \\
+27\end{array}$ & $\begin{array}{l}+0.045 \\
+0.111\end{array}$ & $\begin{array}{l}1189 \\
1177\end{array}$ & $\begin{array}{r}+9 \\
+21\end{array}$ & $\begin{array}{l}+0.038 \\
+0.088\end{array}$ & $\begin{array}{l}1697 \\
1642\end{array}$ & $\begin{array}{r}+4 \\
+59\end{array}$ & $\begin{array}{l}+0.017 \\
+0.251\end{array}$ \\
\hline $\begin{array}{l}9 \\
9 *\end{array}$ & & $\begin{array}{l}935 \\
909\end{array}$ & $\begin{array}{l}+16 \\
+42\end{array}$ & $\begin{array}{l}+0.066 \\
+0.173\end{array}$ & $\begin{array}{l}1185 \\
1155\end{array}$ & $\begin{array}{l}+13 \\
+43\end{array}$ & $\begin{array}{l}+0.054 \\
+0.179\end{array}$ & $\begin{array}{l}1696 \\
1620\end{array}$ & $\begin{array}{r}+5 \\
+81\end{array}$ & $\begin{array}{l}+0.021 \\
+0.345\end{array}$ \\
\hline
\end{tabular}

* Water soak period prolonged three days i.e. was seven day soak.

\begin{tabular}{|c|c|c|c|c|c|c|c|}
\hline \multirow{2}{*}{$\begin{array}{l}\text { Sample } \\
\text { length } \\
\text { Cycle } \\
\text { number }\end{array}$} & \multirow{2}{*}{$\begin{array}{l}\text { number } \\
\text { (L) } \\
\text { Comparitor } \\
\text { measurement }\end{array}$} & \multicolumn{3}{|c|}{$\begin{array}{c}\text { He-22 (1) } \\
3.123 \text { inches }\end{array}$} & \multicolumn{3}{|c|}{$\begin{array}{c}\text { HQ-22 (2) } \\
2.963 \text { inches }\end{array}$} \\
\hline & & $\begin{array}{l}\text { Sample } \\
\text { measure- } \\
\text { ment }\end{array}$ & $\begin{array}{l}\Delta 1 \\
\left(x 10^{-4}\right)\end{array}$ & $\begin{array}{l}\mathrm{Mm}_{\mathrm{d}} \\
\left(\frac{\Delta 1}{\mathrm{~L}} \times 100\right) \\
\text { percent }\end{array}$ & $\begin{array}{l}\text { Sample } \\
\text { measure- } \\
\text { ment }\end{array}$ & $\begin{array}{l}\Delta 1 \\
\left(x 10^{-4}\right)\end{array}$ & $\begin{array}{l}\mathrm{Mm}_{\mathrm{d}} \\
\left(\frac{\Delta I}{\mathrm{~L}} \times 100\right) \\
\text { percent }\end{array}$ \\
\hline $\begin{array}{l}1 \\
1\end{array}$ & \multirow[t]{9}{*}{900} & \multicolumn{3}{|c|}{ ball bearing register failed } & \multirow{2}{*}{\multicolumn{3}{|c|}{ ball bearing register failed }} \\
\hline $\begin{array}{l}2 \\
2\end{array}$ & & $\begin{array}{l}115 \\
069\end{array}$ & $\begin{array}{r}0 \\
+46\end{array}$ & $\begin{array}{l}0 \\
+0.147\end{array}$ & & & \\
\hline $\begin{array}{l}3 \\
3\end{array}$ & & $\begin{array}{l}113 \\
073\end{array}$ & $\begin{array}{r}+2 \\
+42\end{array}$ & $\begin{array}{l}+0.006 \\
+0.135\end{array}$ & $\begin{array}{l}1713 \\
1673\end{array}$ & $\begin{array}{r}0 \\
+40\end{array}$ & $\begin{array}{l}0 \\
+0.135\end{array}$ \\
\hline $\begin{array}{l}4 \\
4\end{array}$ & & $\begin{array}{l}112 \\
068\end{array}$ & $\begin{array}{r}+3 \\
+47\end{array}$ & $\begin{array}{l}+0.009 \\
+0.151\end{array}$ & $\begin{array}{l}1710 \\
1672\end{array}$ & $\begin{array}{r}+3 \\
+41\end{array}$ & $\begin{array}{l}+0.01 \\
+0.138\end{array}$ \\
\hline $\begin{array}{l}5 \\
5\end{array}$ & & $\begin{array}{l}112 \\
072\end{array}$ & $\begin{array}{r}+3 \\
+43\end{array}$ & $\begin{array}{l}+0.009 \\
+0.138\end{array}$ & $\begin{array}{l}1709 \\
1669\end{array}$ & $\begin{array}{r}+4 \\
+44\end{array}$ & $\begin{array}{l}+0.014 \\
+0.149\end{array}$ \\
\hline $\begin{array}{l}6 \\
6 \\
7\end{array}$ & & $\begin{array}{l}110 \\
061 \\
\text { visible c: }\end{array}$ & $\begin{array}{l}+5 \\
+54 \\
\text { racking }\end{array}$ & $\begin{array}{l}+0.016 \\
+0.173\end{array}$ & $\begin{array}{l}1709 \\
1668\end{array}$ & $\begin{array}{r}+4 \\
+45\end{array}$ & $\begin{array}{l}+0.014 \\
+0.152\end{array}$ \\
\hline $\begin{array}{l}7 \\
7\end{array}$ & & $\begin{array}{l}108 \\
067\end{array}$ & $\begin{array}{l}+7 \\
+48\end{array}$ & $\begin{array}{l}+0.022 \\
+0.154\end{array}$ & \multirow{2}{*}{$\begin{array}{l}1708 \\
1664 \\
\text { visible } \\
1706 \\
1663\end{array}$} & \multirow{2}{*}{$\begin{array}{c}+5 \\
+49 \\
\text { longitudina } \\
+7 \\
+50\end{array}$} & \multirow{2}{*}{$\begin{array}{l}+0.017 \\
+0.165 \\
\text { al crack } \\
+0.024 \\
+0.169\end{array}$} \\
\hline $\begin{array}{l}8 \\
8 .\end{array}$ & & $\begin{array}{l}110 \\
066\end{array}$ & $\begin{array}{r}+5 \\
+49\end{array}$ & $\begin{array}{l}+0.016 \\
+0.157\end{array}$ & & & \\
\hline $\begin{array}{l}9 \\
9 *\end{array}$ & & $\begin{array}{l}105 \\
062\end{array}$ & $\begin{array}{l}+10 \\
+53\end{array}$ & $\begin{array}{l}+0.032 \\
+0.17\end{array}$ & $\begin{array}{l}1705 \\
1658\end{array}$ & $\begin{array}{r}+8 \\
+55\end{array}$ & $\begin{array}{l}+0.027 \\
+0.186\end{array}$ \\
\hline
\end{tabular}

* Water soak period prolonged three days i.e. was seven day soak. 

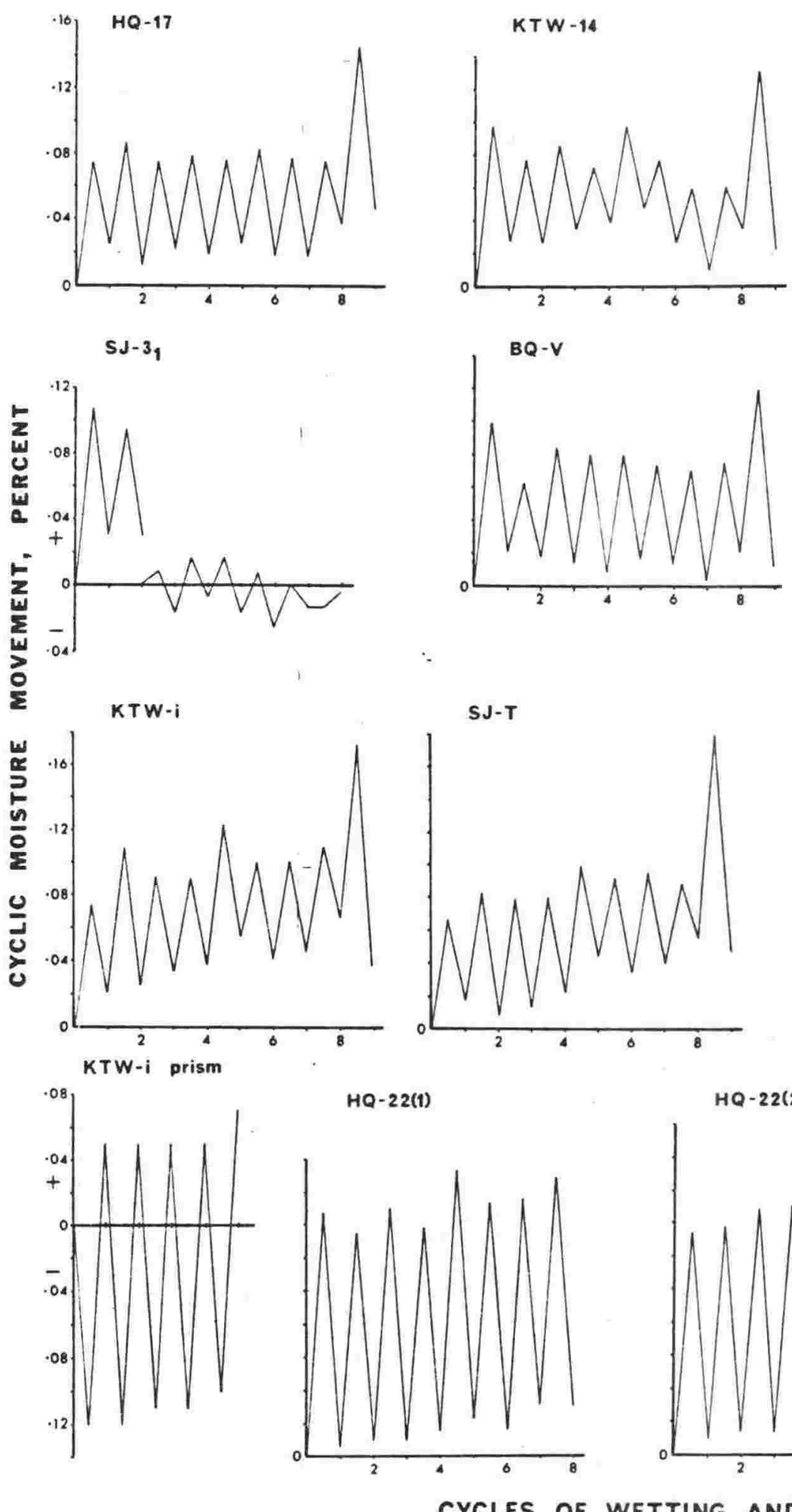

CYCLES OF WETTING AND DRYING

Figure A25.2 : From cyclic moisture movement measurements, greywackes SJ-3 1 and BQ-V appear to shrink. Greywackes KTW-i and 'SJ-T as well as all argillites tested, appear to expand. 
Table A25.6 : Specific permeability, $k$, at nominal time intervals for all samples tested. The nearest recorded times, corresponding to the permeabilities calculated in millidarcies $\left(x 10^{-19}\right)$, are shown in brackets.

\begin{tabular}{|c|c|c|c|c|c|c|c|}
\hline Sample & $\begin{array}{l}\text { Rock mean } \\
\text { grain size, } \\
\text { phi }\end{array}$ & 3 & Nom & $\begin{array}{l}1 \text { time i } \\
48\end{array}$ & $\begin{array}{c}\text { intervals, } \\
75\end{array}$ & $\begin{array}{l}\text { hours } \\
\qquad 100\end{array}$ & 130 \\
\hline $\mathrm{HQ}-17$ & 1.317 & $\begin{array}{l}19.6 \\
(4)\end{array}$ & $\begin{array}{l}11.6 \\
(22)\end{array}$ & $\begin{array}{l}88.34 \\
(47)\end{array}$ & $\begin{array}{l}3.02 \\
(74)\end{array}$ & $\begin{array}{l}0.71 \\
(119)\end{array}$ & $\begin{array}{l}1.25 \\
(143)\end{array}$ \\
\hline $\mathrm{SJ}-3_{\mathrm{I}}$ & 1.32 & $\begin{array}{l}18.37 \\
(6)\end{array}$ & $\begin{array}{l}11.24 \\
(22)\end{array}$ & $\begin{array}{l}3.34 \\
(45)\end{array}$ & $\begin{array}{l}1.09 \\
(75)\end{array}$ & - & - \\
\hline$K T W-14$ & 2.6 & $\begin{array}{l}14.6 \\
(4.6)\end{array}$ & $\begin{array}{l}10.7 \\
(20)\end{array}$ & $\begin{array}{l}2.47 \\
(44)\end{array}$ & $\begin{array}{l}3.19 \\
(68)\end{array}$ & $\begin{array}{l}0.8 \\
(115)\end{array}$ & $\begin{array}{l}1.34 \\
(140)\end{array}$ \\
\hline$B Q-V$ & 2.73 & $\begin{array}{l}7.34 \\
(2)\end{array}$ & $\begin{array}{l}5.11 \\
(20)\end{array}$ & $\begin{array}{l}3.22 \\
(55)\end{array}$ & $\begin{array}{l}2.88 \\
(68)\end{array}$ & $\begin{array}{l}2.65 \\
(92)\end{array}$ & $\begin{array}{l}2.62 \\
(141)\end{array}$ \\
\hline$B Q-I X A$ & 2.9 & $\begin{array}{l}3.79 \\
(5)\end{array}$ & $\begin{array}{l}4.09 \\
(19)\end{array}$ & $\begin{array}{l}3.74 \\
(43)\end{array}$ & $\begin{array}{l}3.06 \\
(68)\end{array}$ & $\begin{array}{l}2.95 \\
(91)\end{array}$ & - \\
\hline $\mathrm{KS}-2$ & 3.27 & $\begin{array}{l}8.41 \\
(3)\end{array}$ & $\begin{array}{l}8.52 \\
(22)\end{array}$ & $\begin{array}{l}6.71 \\
(42)\end{array}$ & - & $\begin{array}{l}0.48 \\
(103)\end{array}$ & $\begin{array}{l}0.48 \\
(138)\end{array}$ \\
\hline KTW-i & 4.23 & $\begin{array}{l}15.2 \\
(4)\end{array}$ & $\begin{array}{l}7.73 \\
(23)\end{array}$ & $\begin{array}{l}6.34 \\
(47)\end{array}$ & $\begin{array}{l}0.52 \\
(79)\end{array}$ & $\begin{array}{l}1.23 \\
(96)\end{array}$ & $\begin{array}{l}2.49 \\
(131)\end{array}$ \\
\hline$S J-T$ & 4.72 & $\begin{array}{l}11.3 \\
(4)\end{array}$ & $\begin{array}{l}8.09 \\
(22)\end{array}$ & $\begin{array}{l}6.86 \\
(51)\end{array}$ & $\begin{array}{c}1.43 \\
(70)\end{array}$ & $\begin{array}{l}2.52 \\
(117)\end{array}$ & $\begin{array}{l}2.88 \\
(143)\end{array}$ \\
\hline$O B-W$ & 5.6 & $\begin{array}{l}23.61 \\
(2)\end{array}$ & - & $\begin{array}{l}4.1 \\
(47)\end{array}$ & $\begin{array}{l}1.24 \\
(76)\end{array}$ & $\begin{array}{l}1.45 \\
(98)\end{array}$ & $\begin{array}{l}1.76 \\
(140)\end{array}$ \\
\hline $\mathrm{HQ}-22$ & 6.28 & $\begin{array}{r}9.28 \\
(12.6)\end{array}$ & $\begin{array}{l}7.29 \\
(23)\end{array}$ & $\begin{array}{l}6.42 \\
(47)\end{array}$ & $\begin{array}{l}0.57 \\
(81)\end{array}$ & $\begin{array}{l}0.91 \\
(106)\end{array}$ & $\begin{array}{l}1.14 \\
(129)\end{array}$ \\
\hline
\end{tabular}

Average $k_{\mathrm{mD}}$ after 90 hours $=1.63 \times 10^{-19}$

$$
\text { s.d. }=0.87
$$




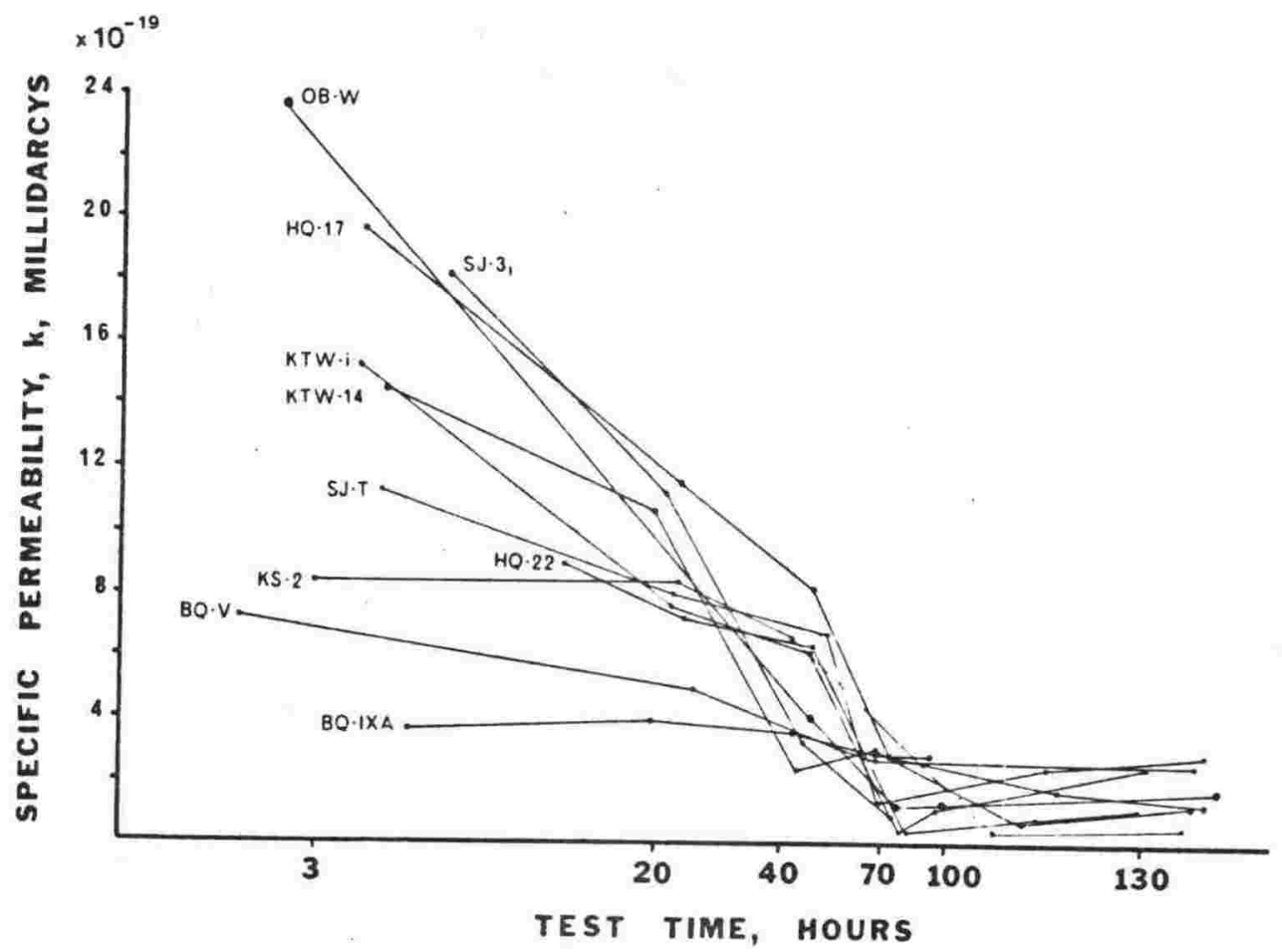

Figure A25.3 : Dermeability is reduced with test time for all rocks tested. Equilibrium is achieved after approximately 90 hours on test at a value less than $4 \times 10^{-19} \mathrm{mD}$. 


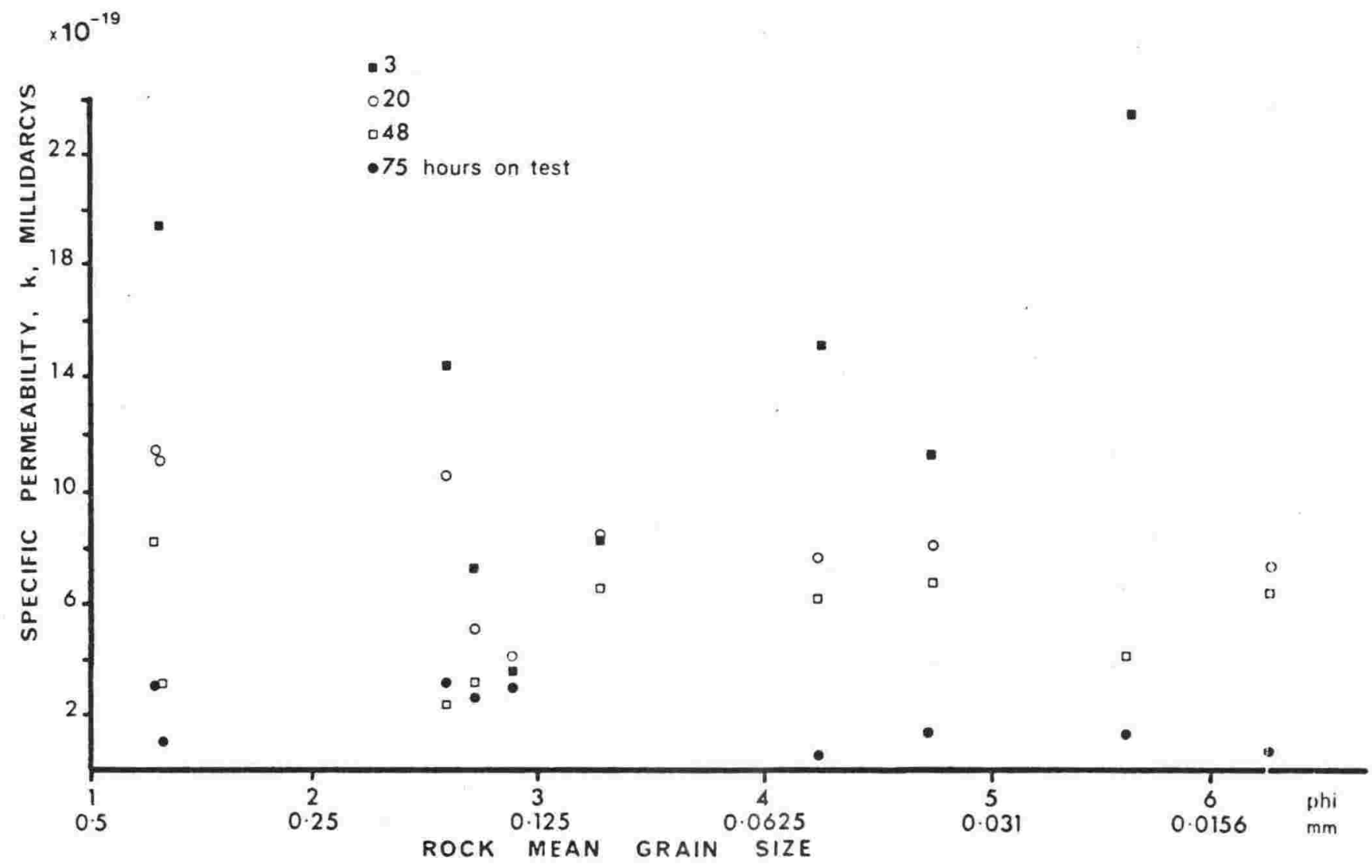

Figure A25.4 : Permeability shows an inverse relationship with finer rock mean grain sizes for times exceeding 20 hours on test. Initial permeabilities (three hours on test), show that greywackes around 3 phi ( $0.125 \mathrm{~mm})$ mean grain size, have permeabilities 25 to 30 percent of those of the very coarse and very fine rocks in the suite, with a gradation between minimum and maximum values. 
(ii) Mineralogy (which is related to rock mean grain size) and the presence of zeolite veining.

Internal surface area of the rock.

The degradation process appears to commence at the moment of release from the quarry face and to be initiated by rock expansion. Perhaps this is best shown where ripping is used to loosen in situ material. The alternating greywacke and argillite, dipping nearly vertically, are confined - the greywacke less so than the argillite which because of its plasticity has developed recemented shears referred to by clelland (1971) as "discontinuities effectively healed by later recrystallisation". Ripping of greywacke presents little difficultly but argillite presents a massive unyielding obstable; even when ripper depth is reduced the ripper will merely glide over the bed, often completely lifting the rear portion of very large machines. When the argillite finally yields, it breaks out as very large blocks. Ripper teeth have a life measured in minutes, rather than hours, in such conditions and a single ripper is generally used.

Rock expansion in response to pressure release, although not easily quantified, is a well documented phenomenon (Ollier, 1969; Winkler, 1973). Pressure release probably continues as dessication starts, i.e. dessication of both capillary and ordered water or quarry "sap" (Howie, 1910; Parks, 1911; Watson, 1911; Winkler, 1973). Accompanying pressure release and dessication, are thermal expansion effects (heating and cooling), as yet unresearched, and the effects of wetting and drying. From the ultrasonic velocity measurement of $\mathrm{KTW}-\mathrm{i}$ prism (Appendix 19) and measurement of unrestrained moisture movement and permeability, equilibrium within an aqueous environment is achieved in approximately four days. The observation of Schaffer (1932) that a stress gradient is produced by rain, because rock is only soaked to a slight depth, may be significant for blocks of rock with relatively low surface area to volume ratios.

If some constraint is placed on rocks undergoing cyclic moisture movement they must experience an elastic deformation. In dessicated rocks, water penetrating into capillaries builds high vapour pressure in adjacent dry air spaces, due to the small meniscus radii (Mayer, 1963), which induces deformation - even complete disintegration. Indeed a measure of the ability of some shales to disintegrate in water is given by air-dried moisture content (Badger et al., 1956), indicative of potential vapour pressures. Cyclic stress brings about the slabby degradation seen in cores cut perpendicular to beding, the flaking effect along foliation planes and, in larger pieces of rock (reduced surface area to volume ratios), the concentric spalling observed (P1ate A.25.2, A.25.3) - similar to that noted by Heidecker (1968). These observations are consistent with permeability effects or the ingress of water. Internal surface areas must be greater in rocks rich in phyllosilicates due to the presence of interlamellar spaces. Murray and Lyons (1960) have shown, for kaolinite, a relationship of surface area to base exchange capacity; total iron and titanium increasing with decreasing degrees of crystallinity. Chlorite is recognised as a mineral which decays early where weathering processes are active (Goldich, 1938; Loughnan, 1969), and has been shown by Marshall (1974) to be the first common mineral to be destroyed in the weathering of greywackes. Chlorite components occur in significant quantities in Wellington greywacke-suite rocks and have been shown to decrease in crystallinity with finer mean grain size of these rocks (section 2.14.3). The chlorites are rich in titanium and iron (Sameshima, 1977; Appendix 8) and the surface area and base exchange capacity is probably enhanced with reduced crystallinity. 


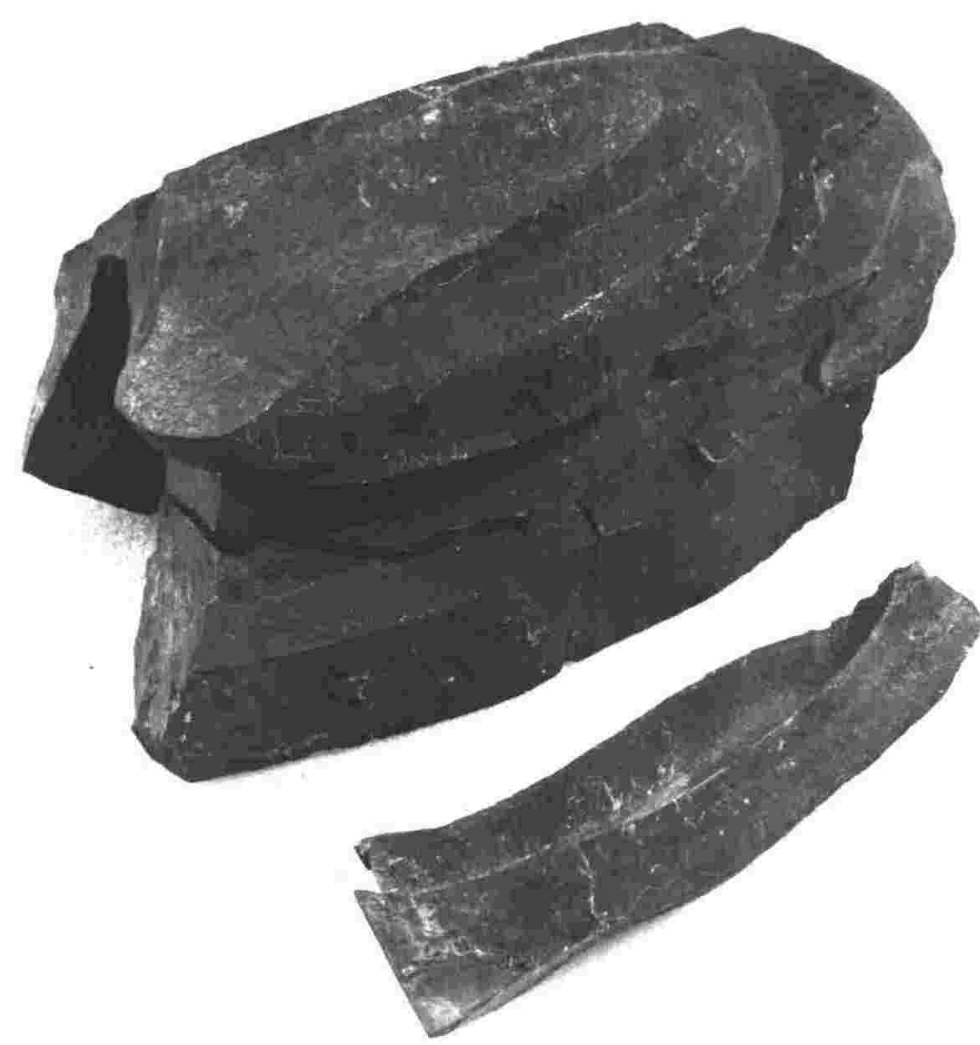

$42 \mathrm{~mm}$

A

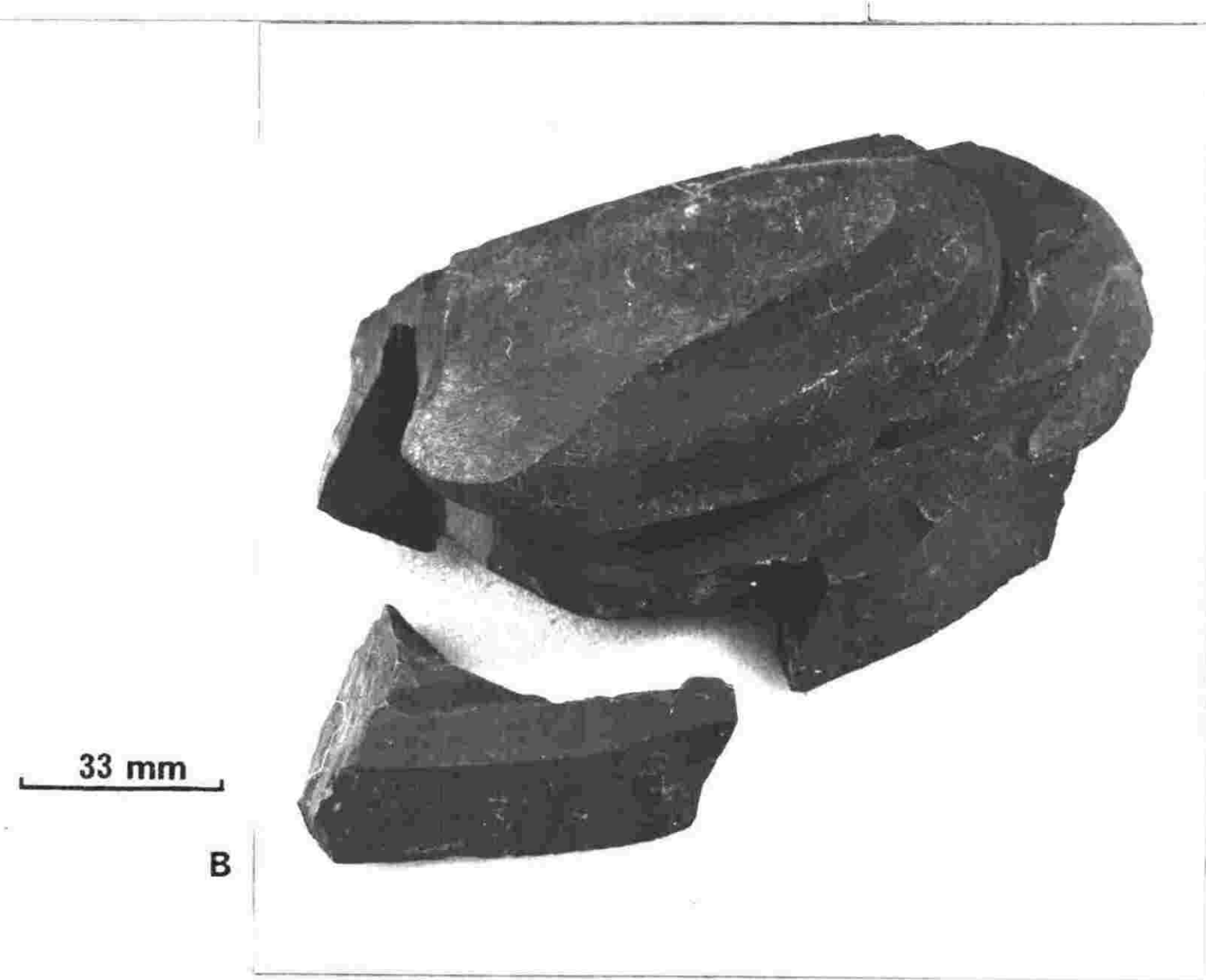

Plate A25.2 : Degradation of argillite (OB-W shown) displays portions displaced from a central core along curvilinear planes; (A), (B) and (C) show the phenomena, which is probably dependant on surface area to volume ratios. In (D) the control of degradation by curved planes perpendicular to bedding and bedding plane fissility is shown. 


$$
80
$$




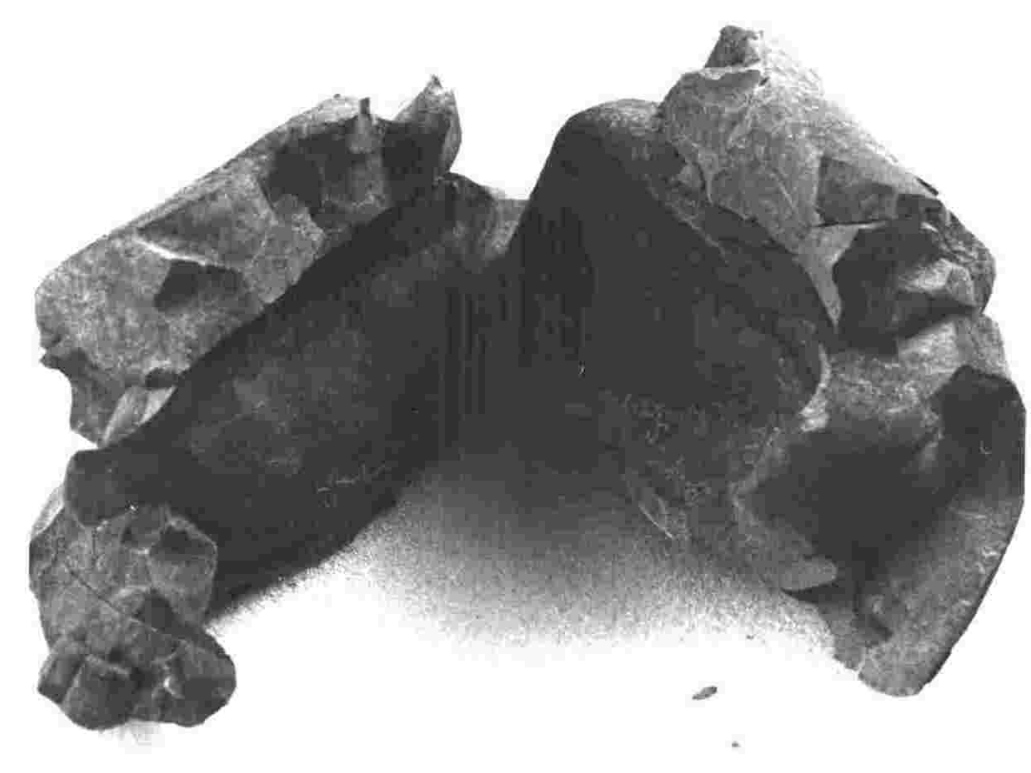

A

$40 \mathrm{~mm}$

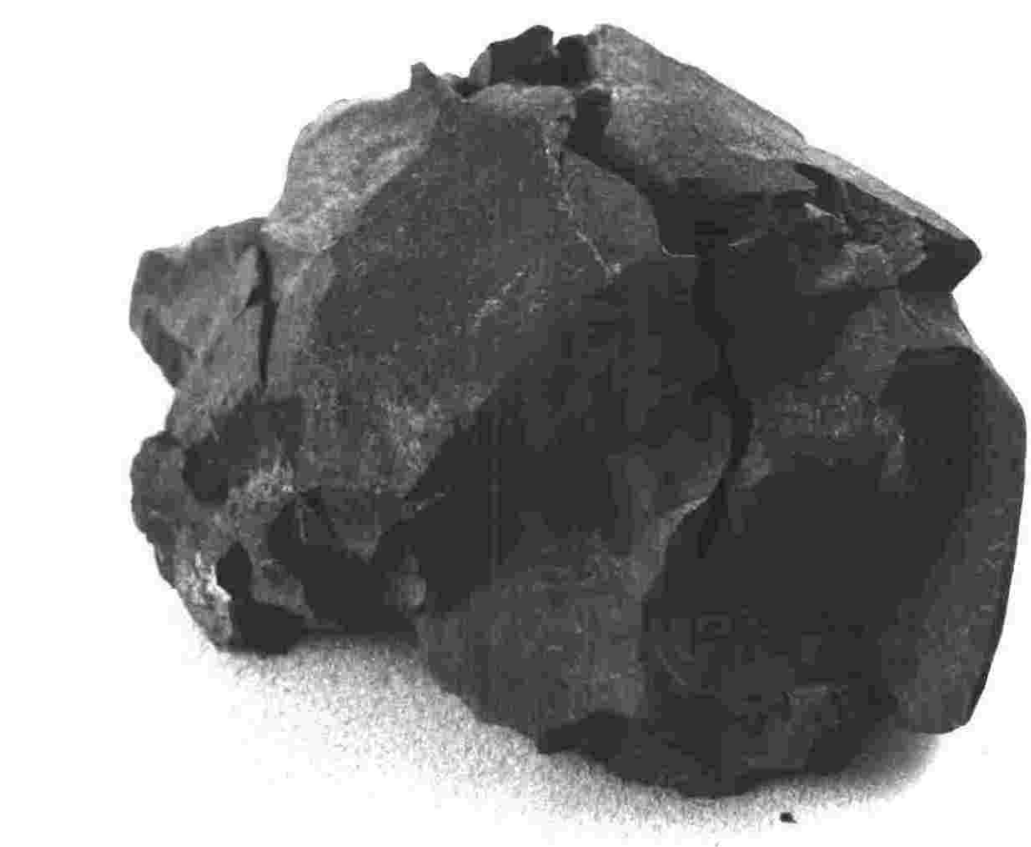

B

\section{$38 \mathrm{~mm}$}

Plate A25.3 : Kawhia siltstone (KW-1) shows curved fracture surfaces about a core after exposure to wetting and drying

cycles. Both $(A)$ and $(B)$ are of the same sample. 
When microcracks develop due to cyclic wetting and drying, chemical weathering of a more obvious nature occurs at their edges and corners.

The dilation of crack openings and propagation of the crack with wetting of the rocks no doubt facilitates this development. The rock alters its colouration as yellow-brown, brown or red-brown oxides of iron are leached from chlorite and pyrite although this staining may be obvious only in thin section. The colouration is transmitted through the matrix material which both propagates and provides the iron oxides. The rock may now be considered to be incipiently weathered, to an extent that could certainly be detected by the Washington degradation test and probably by the clay index test (Appendix 23, 24).

Degradation, although decreasing physical size of rock particles, increases their surface area to volume ratios without reducing their strength. Only their physical integrity is destroyed. Indeed, on dessication most rocks gain strength, although pore pressure and weakened bond strength result in earlier compressive failure when rocks are tested wet (Michalopoulos and Triandafilidis, 1976; section 3.5.1; Appendix 13). Such a hardening/strengthening procedure is well known to stone masons, who speak of "seasoning" building stone prior to its use (Howie, 1910; Parks, 1911; Watson, 1911). Sir Christopher Wren insisted that the Portland stone chosen for the construction of St Pauls Cathedral, London, be seasoned for at least three years before use. (Schaffer 1932).

From the stage where physical strength is adversely affected by degradation,i.e. the stage at which iron oxides form, the rock and its associated engineering properties are most complicated and, as yet, little has been done to research geological aspects of these rocks, let alone marry geological properties to end use as engineering material.

Many engineering problems encountered, particularly with aggregates, have been attributable, at least in part, to excessive weathering; particles experiencing a loss of strength due to the formation of various chemical oxides. This variety of weathered (degraded) rock probably influenced failure of the Auckland-Hamilton motorway (Cornwell, 1966) and was certainly a factor in degradation mentioned by Dekker and Scott (1969).

Inconsistencies between petrographic prediction and performance tests (Clelland, 1971) have not helped in the establishment of limits for deleterious substances and physical property requirements for the end use of various aggregates for New zealand (similar to ASTM C33-74a, table 3).

7. Conclusions

(i) The rate of degradation can be suprisingly rapid with cracks developing in argillites within two months of exposure.

(ii) The measurement of internal rock surface area may lead to a better understanding of the degradation process.

(iii) Chlorite content (and zeolite in veins) and degradation are directly related. 
Test results for sand (Walton Park) used in concrete mixes

The sand used in concrete mixes for this study was a natural rounded silica sand supplied by Walton Park Sand Co. Ltd., Green Island, Dunedin. The sand has impurities of iron oxide (less than 5 percent) imparting a yellow-orange-light brown stain to surface irregularities and cracks in the sand particles. The average diameter of the grains is 700 microns and all pass a $4.8 \mathrm{~mm}$ sieve. Two clean 200 litre (44 gallon) drums of the sand was homogenised by thorough mixing before being split to obtain representative samples for use in concrete.

The sand has been tested frequently by the New Zealand Concrete Research Association, over the last decade, and has been used as a standard repeatedly over this period. Results of tests conforming to NZS 1051:1953 and NZS 3111:1974, obtained in 1969 and 1978 respectively, are presented below (Table A26.1). Additional tests were carried out specifically for this study and are included with the 1978 test results.

Table A26.1 : Two sets of results of Walton Park sand tested ten years apart. Tests conformed to NZS 1051:1953 and NZS 3111:1974 for work done in 1969 and 1978 respectively. Sand represented by the sample tested in 1978 was used in concrete made for this study.

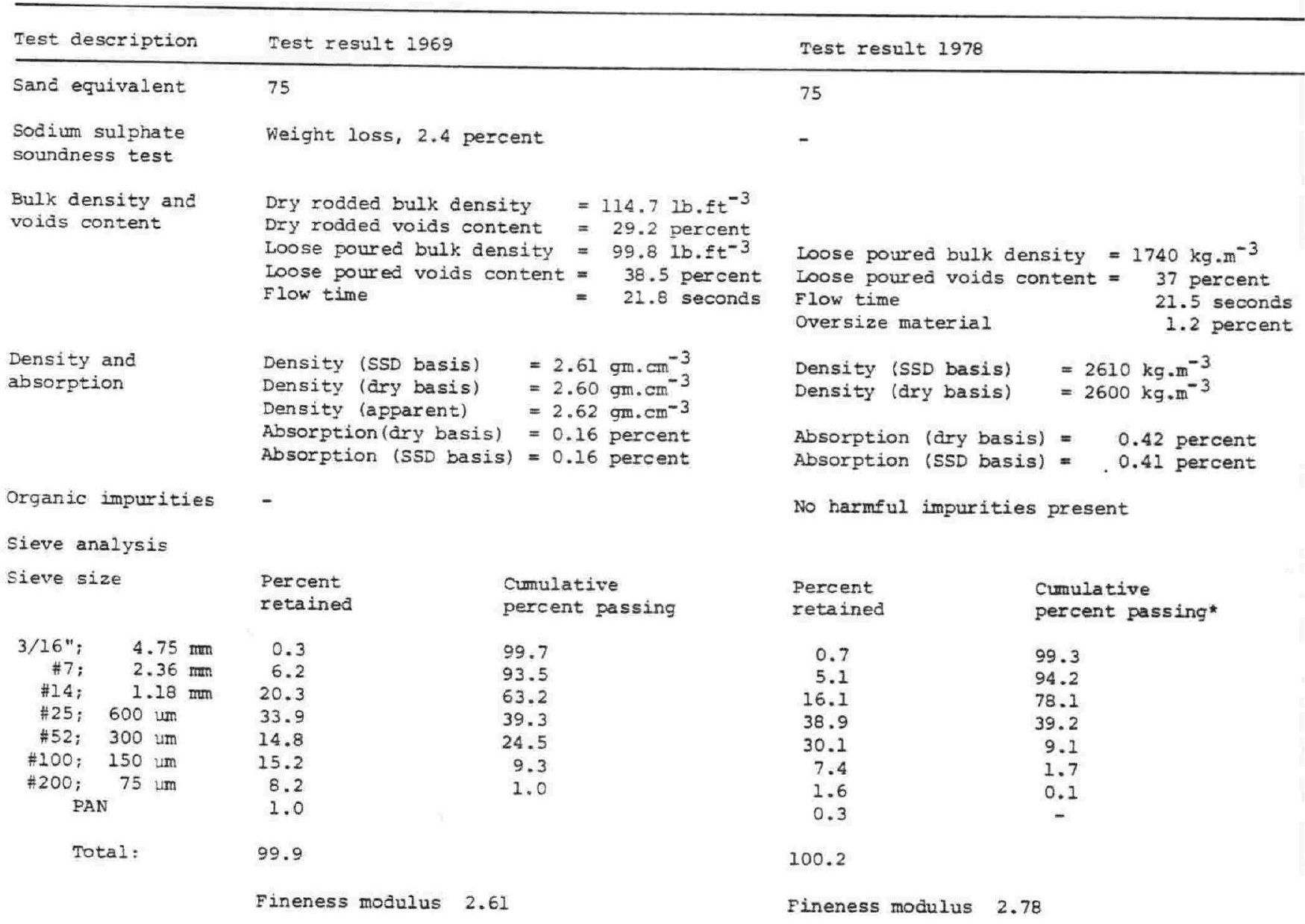




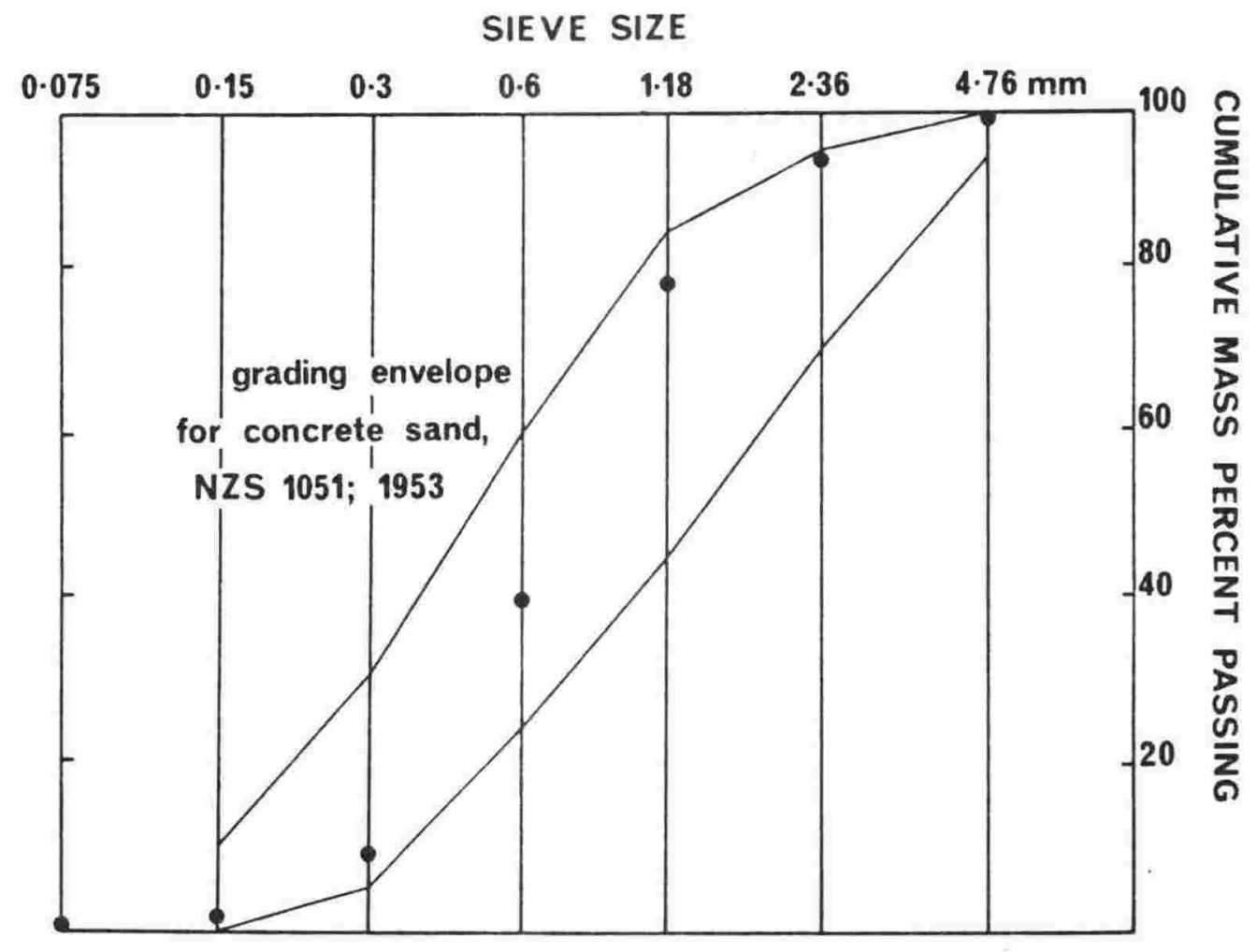

Figure A26.1 : Grading of Walton Park sand used for this study. 
APPENDIX 27

Concrete mix designs

The concrete mix designs used in this study were based on work by lic Intosh (1966), Shacklock (1974), Neville (1975) and Teychenne et al. (1976), consistent with achieving two easily comparable mixes, of high strength, low water content, very low workability and high aggregate to cement ratio with coarse aggregate, particularly $19 \mathrm{~mm}$ aggregate, constituting 66 percent of the coarse aggregate blend.

Initial trials included water cement ratios of 0.4 and 0.5 , but the contrast between such drastically different water to cement ratios, masked subtle workability affects imparted by aggregate and did not provide concrete of sufficient strength.

These mixes, designed specifically to attain high strength with high aggregate to cement ratios, would not normally be commercially viable because workability and cohesion are low due to lack of sand.

Mix 1 and 2 design calculations, for each aggregate, are given in Tables A27.1, A27.2.

Table A27.1 : Mix 1 concrete was designed on the basis of a $1 \mathrm{~m}^{3}$ volume; values marked with an asterisk (*) indicate weights of components for a $1 \mathrm{~m}^{3}$ volume of concrete.

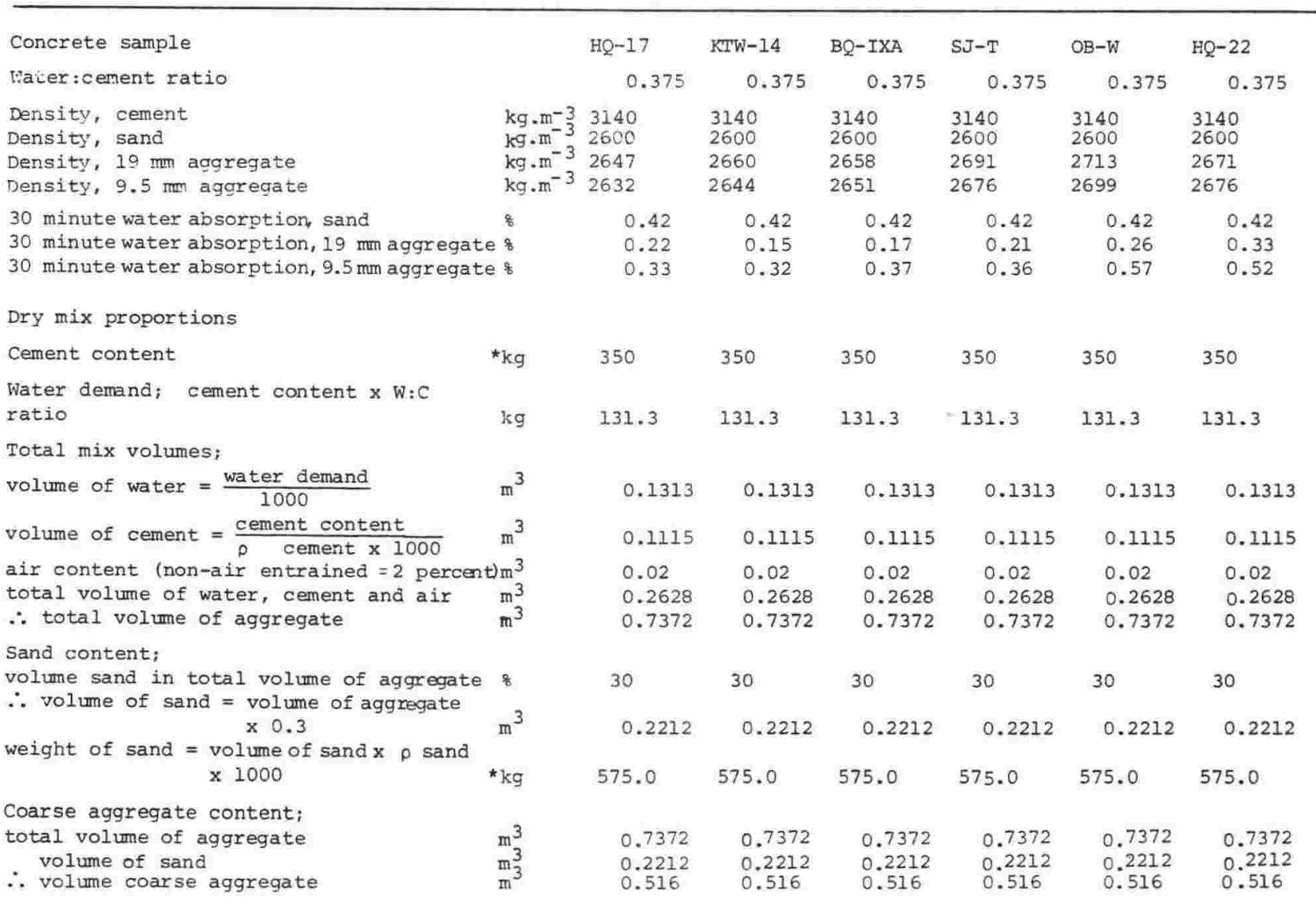


Concrete sample

$19 \mathrm{~mm}$ aggregate content

volume $19 \mathrm{~mm}$ aggregate in coarse aggregate blend

volume $19 \mathrm{~mm}$ aggregate = total volume aggregate $\mathrm{x} 0.66 \mathrm{~m}^{3}$

weight of $19 \mathrm{~mm}$ aggregate = volume $19 \mathrm{~mm}$

aggregate

p. $19 \mathrm{~mm}$

aggregate $x$

1000

$\star \mathrm{kg}$

$9.5 \mathrm{~mm}$ aggregate content;

volume $9.5 \mathrm{~mm}$ aggregate in coarse aggre-

gate blend

volume $9.5 \mathrm{~mm}$ aggregate = total volume

aggregate $x$

$0.33 \quad \mathrm{~m}^{3}$

weight of $9.5 \mathrm{~mm}$ aggregate $=$ volume $9.5 \mathrm{~mm}$

aggregate $x$

p $9.5 \mathrm{~mm}$

aggregate $\mathrm{x}$

$$
1000
$$

* $\mathrm{kg}$

Corrections for aggregate absorptions

Sand: weight of water required to bring sand to SSD condition

$=\frac{\text { weight sand }}{100} \times(30 \mathrm{~min}$. water

absorption - moisture content)

$\mathrm{kg}$

$19 \mathrm{~mm}$ aggregate: weight of water required

to bring $19 \mathrm{~mm}$ aggregate

to SSD condition

$=\frac{\text { weight } 19 \mathrm{~mm} \text { aggregate }}{100}$

x (30 minute water absorp-

tion-moisture content) $\mathrm{kg}$

$9.5 \mathrm{~mm}$ aggregate: weight of water required

to bring $9.5 \mathrm{~mm}$ aggre-

gate to SSD condition

$=\frac{\text { weight } 9.5 \mathrm{~mm} \text { aggregate }}{100}$

$x$ (30 min. water absorp

tion-moisture content) $\mathrm{kg}$

Calculated water demand

corrected water demand

$\mathrm{kg}$

1.48

1.44

1.67

1.64

2.62

2.37

131.3

131.3

131.3

131.3

131.3

131. 3

137.2

136.5

136.9

137.3

138.7

139.1

Batch weights for $0.03 \mathrm{~m}^{3}$ concrete (i.e. twelve, $200 \times 100 \mathrm{~mm}$ cylinder moulds)

\section{water}

cement

sand

$19 \mathrm{~mm}$ aggregate

$9.5 \mathrm{~mm}$ aggregate

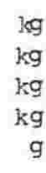

4.1

10.5

17.3

27.1

4.1

4.1

10.5

4.1

10.5

42

10.5

17.3

27.2

17.3

17.3

17.3

27.7

$\begin{array}{ll}13.7 & 13.8\end{array}$

13.6

27.3

13.7
909.6

0.3406 
Table A27.2 : Mix 2 concrete was designed on the basis of a $1 \mathrm{~m}^{3}$ volume; values marked with an asterisk (*) indicate weights of components for a $1 \mathrm{~m}^{3}$ volume of concrete.

\begin{tabular}{|c|c|c|c|c|c|c|c|}
\hline Concrete sample & & $\mathrm{HQ}-17$ & KTVI-14 & $B Q-I X A$ & $S J-T$ & $\mathrm{OB}-\mathrm{W}$ & $\mathrm{HQ}-22$ \\
\hline Water:concrete ratio & & 0.4 & 0.4 & 0.4 & 0.4 & 0.4 & 0.4 \\
\hline $\begin{array}{l}\text { Density, cement } \\
\text { Density, sand } \\
\text { Density, } 19 \mathrm{~mm} \text { aggregate } \\
\text { Density, } 9.5 \mathrm{~mm} \text { aggregate }\end{array}$ & $\begin{array}{l}\mathrm{kg} \cdot \mathrm{m}^{-3} \\
\mathrm{~kg} \cdot \mathrm{m}^{-3} \\
\mathrm{~kg} \cdot \mathrm{m}^{-3} \\
\mathrm{~kg} \cdot \mathrm{m}^{-3}\end{array}$ & $\begin{array}{l}3140 \\
2600 \\
2647 \\
2632\end{array}$ & $\begin{array}{l}3140 \\
2600 \\
2660 \\
2644\end{array}$ & $\begin{array}{l}3140 \\
2600 \\
2658 \\
2651\end{array}$ & $\begin{array}{l}3140 \\
2600 \\
2691 \\
2676\end{array}$ & $\begin{array}{l}3140 \\
2600 \\
2713 \\
2699\end{array}$ & $\begin{array}{l}3140 \\
2600 \\
2671 \\
2676\end{array}$ \\
\hline $\begin{array}{l}30 \text { minute water absorption, sand } \\
30 \text { minute water absorption, } 19 \mathrm{~mm} \text { aggregate } \\
30 \text { minute water absorption, } 9.5 \mathrm{~mm} \text { aggregate }\end{array}$ & $\begin{array}{l}\% \\
8\end{array}$ & $\begin{array}{l}0.42 \\
0.22 \\
0.33\end{array}$ & $\begin{array}{l}0.42 \\
0.15 \\
0.32\end{array}$ & $\begin{array}{l}0.42 \\
0.17 \\
0.37\end{array}$ & $\begin{array}{l}0.42 \\
0.21 \\
0.36\end{array}$ & $\begin{array}{l}0.42 \\
0.26 \\
0.57\end{array}$ & $\begin{array}{l}0.42 \\
0.33 \\
0.52\end{array}$ \\
\hline Dry mix proportions & & & & & & & \\
\hline Cement content & $\star \mathrm{kg}$ & 350 & 350 & 350 & 350 & 350 & 350 \\
\hline $\begin{array}{l}\text { Water demand; cement content } \mathrm{x} \text { W: C ratio } \\
\text { Total mix volumes; }\end{array}$ & $\mathrm{kg}_{\mathrm{g}}$ & 140 & 140 & 140 & 140 & 140 & 140 \\
\hline volume of water $=\frac{\text { water demand }}{1000}$ & $\mathrm{~m}^{3}$ & 0.1400 & 0.1400 & 0.1400 & 0.1400 & 0.1400 & 0.1400 \\
\hline volume of cement $=\frac{\text { cement content }}{\text { cement } \times 1000}$ & $\mathrm{~m}^{3}$ & 0.1115 & 0.1115 & 0.1115 & 0.1115 & 0.1115 & 0.1115 \\
\hline $\begin{array}{l}\text { air content (non-air entrained }=2 \text { percent } \\
\text { total volume of water, cement and air } \\
\therefore \text { total volume of aggregate }\end{array}$ & $\begin{array}{r}t m^{3} \\
m^{3} \\
m^{3}\end{array}$ & $\begin{array}{l}0.02 \\
0.2715 \\
0.7285\end{array}$ & $\begin{array}{l}0.02 \\
0.2715 \\
0.7285\end{array}$ & $\begin{array}{l}0.02 \\
0.2715 \\
0.7285\end{array}$ & $\begin{array}{l}0.02 \\
0.2715 \\
0.7285\end{array}$ & $\begin{array}{l}0.02 \\
0.2715 \\
0.7285\end{array}$ & $\begin{array}{l}0.02 \\
0.2715 \\
0.7285\end{array}$ \\
\hline $\begin{array}{l}\text { Sand content; } \\
\text { volume sand in total volume of aggregate } \\
\begin{aligned} \therefore \text { volume of sand }= & \text { volume of aggregate } \\
& \times 0.3\end{aligned} \\
\begin{aligned} \text { weight of sand }= & \text { volume of sand } \times \text {. } \\
& \text { sand } \times 1000\end{aligned}\end{array}$ & $\mathrm{~m}^{3}$ & $\begin{array}{l}0.2186 \\
568.2\end{array}$ & $\begin{array}{l}0.2186 \\
568.2\end{array}$ & $\begin{array}{l}0.2186 \\
568.2\end{array}$ & $\begin{array}{l}0.2186 \\
568.2\end{array}$ & $\begin{array}{l}0.2186 \\
568.2\end{array}$ & $\begin{array}{l}0.2186 \\
568.2\end{array}$ \\
\hline $\begin{array}{l}\text { Coarse aggregate content; } \\
\text { total volume of aggregate } \\
\quad \text { volume of sand } \\
\therefore \text { volume coarse aggregate }\end{array}$ & $\begin{array}{l}\mathrm{m}^{3} \\
\mathrm{~m}^{3} \\
\mathrm{~m}^{3}\end{array}$ & $\begin{array}{l}0.7285 \\
0.2186 \\
0.5099\end{array}$ & $\begin{array}{l}0.7285 \\
0.2186 \\
0.5099\end{array}$ & $\begin{array}{l}0.7285 \\
0.2186 \\
0.5099\end{array}$ & $\begin{array}{l}0.7285 \\
0.2186 \\
0.5099\end{array}$ & $\begin{array}{l}0.7285 \\
0.2186 \\
0.5099\end{array}$ & $\begin{array}{l}0.7285 \\
0.2186 \\
0.5099\end{array}$ \\
\hline $\begin{array}{l}19 \mathrm{~mm} \text { aggregate content; } \\
\text { volume } 19 \mathrm{~mm} \text { aggregate in coarse aggregate } \\
\text { blend } \\
\text { volume } 19 \mathrm{~mm} \text { aggregate = total volume aggre- } \\
\text { gate } \times 0.66 \\
\text { weight of } 19 \mathrm{~mm} \text { aggregate }= \\
\begin{aligned} & \text { volume } 19 \mathrm{~mm} \\
& 19 \mathrm{~mm} \text { aggregate } \mathrm{x} \\
& \times 1000\end{aligned}\end{array}$ & $-\mathrm{m}^{3}$ & $\begin{array}{l}66 \\
0.3365\end{array}$ & $\begin{array}{l}66 \\
0.3365\end{array}$ & $\begin{array}{l}66 \\
0.3365\end{array}$ & $\begin{array}{l}66 \\
0.3365\end{array}$ & $\begin{array}{l}66 \\
0.3365\end{array}$ & $\begin{array}{l}66 \\
0.3365\end{array}$ \\
\hline 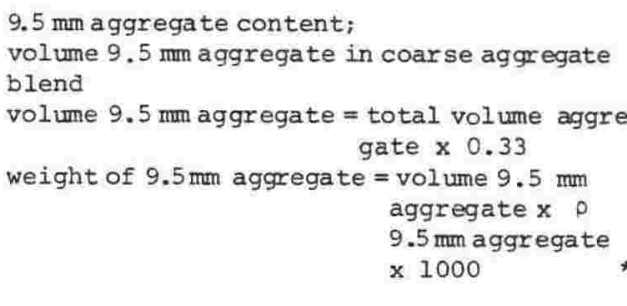 & $\mathrm{e}^{\mathrm{8}}$ & 0.1683 & 0.1683 & 0.1683 & $\begin{array}{l}33 \\
0.1683\end{array}$ & $\begin{array}{l}33 \\
0.1683\end{array}$ & $\begin{array}{l}33 \\
0.1683\end{array}$ \\
\hline $\begin{array}{l}\text { Corrections for aggregate absorptions } \\
\text { Sand: weight of water required to bring } \\
\text { sand to SSD condition } \\
=\frac{\text { weight sand }}{100} \times \text { ( } 30 \text { min. water } \\
\text { absorption - moisture content) }\end{array}$ & $\mathrm{kg}$ & 2.39 & 2.39 & 2.39 & 2.39 & 2.39 & 2.39 \\
\hline $\begin{array}{l}19 \mathrm{~mm} \text { aggregate: weight of water required to } \\
\text { bring } 19 \mathrm{~mm} \text { aggregate to } \\
\text { SSD condition } \\
=\frac{\text { weight } 19 \mathrm{~mm} \text { aggregate }}{100} \\
\\
\times \text { tion - moisture content }\end{array}$ & $\mathrm{kg}$ & 1.96 & 1.34 & 1.52 & 1.90 & 2.37 & 2.97 \\
\hline
\end{tabular}


Table A27.2 : continued

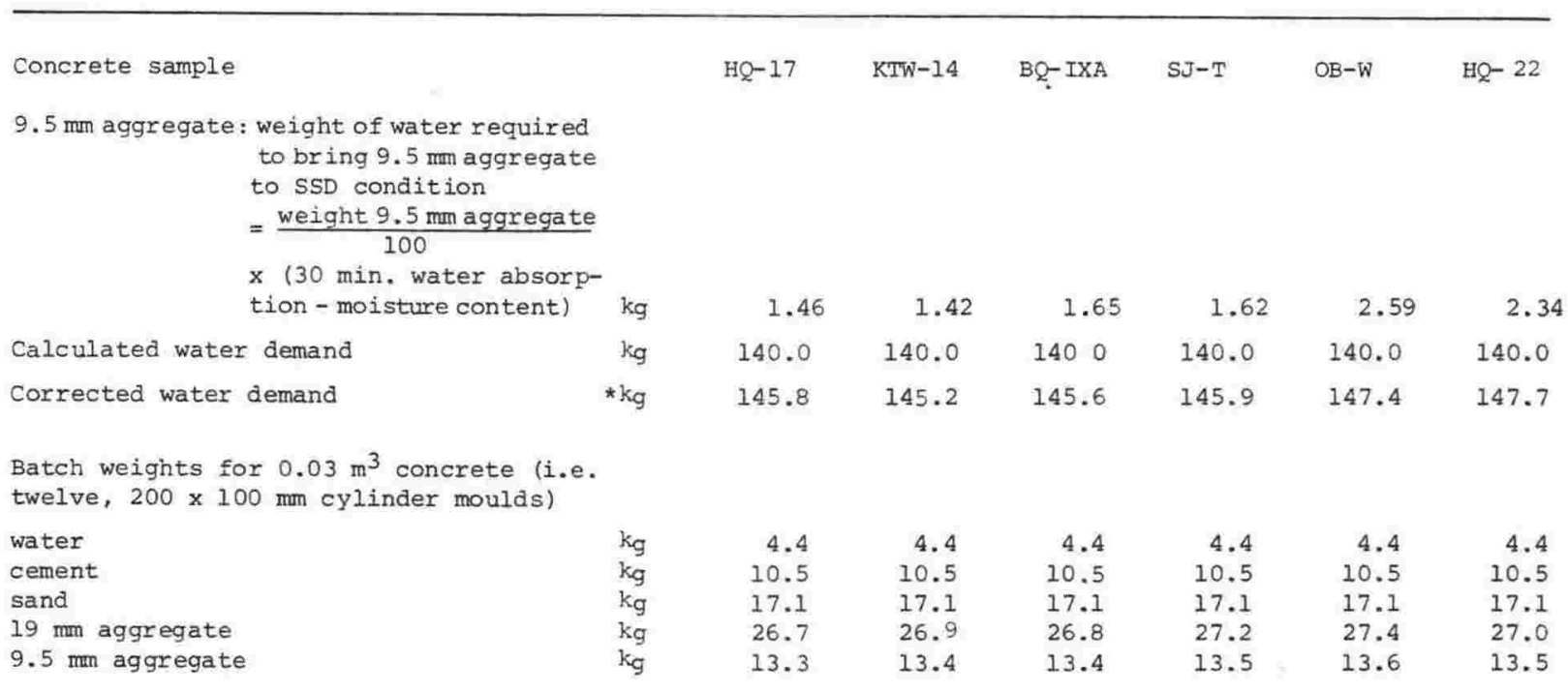


APPENDIX 28

Concrete cylinders: Materials preparation, mixing, moulding, curing and test

1. Preparation

Raw materials were prepared in the following manner:

(i) Coarse aggregate preparation:

After crushing, the six test aggregates were graded (section 4.2.1), thoroughly hand washed, drained and slowly oven dried to constant mass at $105 \pm 3^{\circ} \mathrm{C}$. Washing was necessary to remove adhering surface coatings(section 4.2.7) enabling closer adherance to mix design and hence more accurate assessment of the aggregate as a rock type in concrete. Oven drying obviates measurements of water content, an important mix parameter which must be determined for each size grading of aggregate but which is difficult to control, promotes aggregate storage problems and is both tedious and time consuming to obtain. If aggregates are oven dried, the 30 minute absorption test supplies all the information necessary for design criteria.

(ii) Sand:

The well rounded quartz sand from Walton Park, Dunedin, conforms fully to NzS 3111:1974 and has been used for several years by the NZ Concrete Research Association as a standard in many research and development programmes. The Association test results are compared with those obtained in this study in Appendix 27. This sand has the advantage of being monomineralic and light in colour - aiding studies of crushed and sawn concrete made from it. (section 5.4.1 and Appendix 17). For use in this study, two 200 litre (44 gallon) drums of sand was homogenised and a representative sample oven dried for each concrete mix. No further pretreatment was necessary.

\section{(iii) Cement:}

Cement used was a fresh shipment of bagged wilsons ordinary Portland cement, from one batch. One $40 \mathrm{~kg}$ bag made two to three mixes and six bags were used in all. No bag remained open longer than two days. Storage was indoors. Pending use, each bag was stored in two plastic bags with their open ends reversed and tightly tied closed. In use, the open bag was kept in a waterproof metal container with a tightly fitting lid.

The cement was not tested, but assumed to be of good quality meeting NZS 3122:1974 "Portland cement (ordinary and rapid hardening)".

2. Fresh concrete tests

Mix design is given in Appendix 27. Two $0.03 \mathrm{~m}^{3}$ mixes were made from each aggregate, utilising water to cement ratios of 0.375 ( $\operatorname{mix~} 1$ ) and 0.4 ( $\operatorname{mix} 2$ ). Each mix made sufficient concrete for 12 cylinders, $100 \mathrm{~m}$ diameter and $200 \mathrm{~mm}$ long, conforming to NzS 3112:1974, clause 201 .

Tests were carried out to NZS 3112:1974 and results are given in Table 5.1. A compaction factor test was also carried out to BS 1881:Part 2:1970, alternative number 1; results also being listed in Table 5.1 . 
3. Moulding and curing of concrete test cylinders

To optimise compaction of fresh concrete in the moulds, a vibrating table was used with visual monitoring of segregation and laitance.

Moulds were filled in three equal layers, marked for identification and placed in a curing chamber in an environment of 100 percent R.H. (atomised water spray) at $21 \pm 1^{\circ} \mathrm{C}$. Initially the cylinders were stacked horizontally with the seam uppermost but after removal from the moulds, placed vertically on galvanised expanded metal shelving.

\section{Testing of cylinders}

The twelve cylinders from each batch were tested, in randomly selected groups of three, at $3,7,28$ and 90 day ageing. Cylinders were taken singly from the curing chamber and weighed immediately in air then in water. Their long axis ultrasonic velocity was determined using the PUNDIT apparatus and they were measured lengthwise and across two diameters at mid-height, $22.5^{\circ}$ either side of the mould seam. They were then uniaxially compression tested. Complete results are given in Appendix 29. At 28 days, the static elastic modulus was determined using temperature compensated half bridge strain instrumentation, a single PL-60 strain gauge $(60 \mathrm{~mm}$ gauge length) being attached parallel to the longitudinal axis of the cylinder centred on mid-height (Appendix 14). 
Concrete cylinders: tabulated test results.

Results presented in this Appendix are those obtained from tests outlined in Appendix 28.

Over the whole test programme the coefficient of variation did not exceed 6.8 percent and was generally considerably lower, averaging 2.8 percent for $\mathrm{mix} 1$ and 2.5 percent for $\operatorname{mix} 2$.

HQ-17 Mix $1 \quad(0.375 \mathrm{w}: \mathrm{c})$

\begin{tabular}{|c|c|c|c|c|c|c|c|c|c|c|c|c|c|c|c|c|}
\hline $\begin{array}{l}\text { PUNDIT } \\
\text { time }\end{array}$ & $\begin{array}{l}\text { Age } \\
\text { at } \\
\text { test } \\
\text { days }\end{array}$ & $\begin{array}{l}\text { Type } \\
\text { of } \\
\text { test }\end{array}$ & $\begin{array}{l}\text { Wt. } \\
\text { in } \\
\text { air } \\
\text { gms }\end{array}$ & $\begin{array}{l}\text { wt. } \\
\text { in } \\
\text { water } \\
\text { gms }\end{array}$ & Density & $\begin{array}{l}\text { Diam } \\
1 \\
\text { units } \\
\text { in }\end{array}$ & $\begin{array}{l}\text { Diam } \\
2 \\
\text { units } \\
\text { in }\end{array}$ & $\begin{array}{l}\text { Mean } \\
\text { diam } \\
\text { units } \\
\text { in }\end{array}$ & $\begin{array}{l}\text { Length } \\
\text { units } \\
\text { in }\end{array}$ & $\begin{array}{l}\text { Load } \\
\text { at } \\
\text { failure } \\
\text { units } \\
\text { lbf }\end{array}$ & Strength & $\begin{array}{l}\text { Mean } \\
\text { strength }\end{array}$ & Range & $\begin{array}{l}\text { Std } \\
\text { dev }\end{array}$ & $\begin{array}{l}C \\
\text { of } \\
V \\
8\end{array}$ & $\begin{array}{l}\text { Ultra- } \\
\text { sonic } \\
\text { pulse } \\
\text { velocity } \\
\text { m.s }\end{array}$ \\
\hline 43.9 & & & 3880 & 2314 & 2478 & 3.932 & 3.928 & 3.930 & 7.878 & 52,800 & 30.0 & & & & & 4558 \\
\hline 43.9 & 3 & comp & 3882 & 2310 & 2470 & 3.942 & 3.932 & 3.937 & 7.881 & 53,300 & 30.0 & 30.1 & 0.2 & 0.12 & 0.4 & 4560 \\
\hline 43.6 & & & 3897 & 2324 & 2477 & 3.948 & 3.928 & 3.938 & 7.882 & 53,300 & 30.2 & & & & & 4592 \\
\hline 42.2 & & & 3892 & 2321 & 2477 & 3.935 & 3.936 & 3.935 & 7.876 & 85,300 & 48.4 & & & & & 4741 \\
\hline 42.5 & 7 & comp & 3891 & 2321 & 2478 & 3.949 & 3.920 & 3.934 & 7.880 & 87,200 & 49.5 & 49.3 & 1.7 & 1.00 & 2.0 & 4710 \\
\hline 42.3 & & & 3885 & 2317 & 2478 & 3.934 & 3.928 & 3.931 & 7.878 & 88,200 & 50.1 & & & & & 4731 \\
\hline 41.0 & & & 3876 & 2311 & 2477 & 3.929 & 3.928 & 3.928 & 7.884 & 131,000 & 74.5 & & & & & 4884 \\
\hline 41.0 & 28 & comp & 3900 & 2329 & 2483 & 3.930 & 3.940 & 3.935 & 7.878 & 130,600 & 74.0 & 74.4 & 0.8 & 0.47 & 0.6 & 4881 \\
\hline 40.7 & & & 3915 & 2340 & 2486 & 3.937 & 3.934 & 3.935 & 7.890 & 132,000 & 74.8 & & & & & 4924 \\
\hline 40.3 & & & 3899 & 2326 & 2479 & 3.936 & 3.940 & 3.938 & 7.878 & 156,300 & 88.5 & & & & & 4965 \\
\hline 40.4 & 90 & comp & 3889 & 2321 & 2480 & 3.927 & 3.935 & 3.931 & 7.876 & 151,500 & 86.1 & 88.0 & 3.3 & 1.95 & 2.2 & 4952 \\
\hline 40.4 & & & 3886 & 2322 & 2485 & 3.928 & 3.931 & 3.930 & 7.876 & 157,300 & 89.4 & & & & & 4952 \\
\hline mean de & & y $\mathrm{kg} \cdot \mathrm{m}$ & $n^{-3}$ & & & & : & 3 day: & 2475 & 7 day: & 2478 & 28 day: & 2482 & 90 & day & 2481 \\
\hline $\begin{array}{l}\text { reporte } \\
\text { mean ul }\end{array}$ & $\begin{array}{l}\text { ed in } \\
\text { ltraso }\end{array}$ & $\begin{array}{l}\text { compl } \\
\text { onic p }\end{array}$ & $\begin{array}{l}\text { liance } \\
\text { pulse }\end{array}$ & $\begin{array}{l}\text { e with } \\
\text { veloci }\end{array}$ & $\begin{array}{l}\text { NZS } 31 \\
\text { ity } \mathrm{m} \cdot \mathrm{s}\end{array}$ & $1: 1974$ & $\begin{array}{l}: \\
:\end{array}$ & & $\begin{array}{l}2480 \\
4570\end{array}$ & & $\begin{array}{l}2480 \\
4727\end{array}$ & & $\begin{array}{l}2480 \\
4896\end{array}$ & & & $\begin{array}{l}2480 \\
4956\end{array}$ \\
\hline
\end{tabular}

KTW-14 Mix $1 \quad(0.375 \mathrm{~W}: \mathrm{c})$

\begin{tabular}{|c|c|c|c|c|c|c|c|c|c|c|c|c|c|c|c|c|}
\hline 42.5 & & & 3899 & 2330 & 2485 & 3.940 & 3.928 & 3.934 & 7.886 & 55,400 & 31.4 & & & & & 4713 \\
\hline 43.1 & 3 & comp & 3890 & 2321 & 2479 & 3.937 & 3.937 & 3.937 & 7.879 & 52,600 & 29.8 & 30.3 & 1.8 & 1.06 & 3.5 & 4643 \\
\hline 42.6 & & & 3900 & 2329 & 2483 & 3.936 & 3.946 & 3.941 & 7.881 & 52,400 & 29.6 & & & & & 4699 \\
\hline 41.5 & & & 3907 & 2337 & 2489 & 3.937 & 3.939 & 3.938 & 7.876 & 87,000 & 49.3 & & & & & 4821 \\
\hline 42.1 & 7 & comp & 3895 & 2322 & 2476 & 3.942 & 3.935 & 3.938 & 7.876 & 89,200 & 50.5 & 49.8 & 1.2 & 0.71 & 1.4 & 4752 \\
\hline 41.8 & & & 3890 & 2318 & 2475 & 3.936 & 3.941 & 3.938 & 7.876 & 87,400 & 49.5 & & & & & 4786 \\
\hline 40.1 & & & 3879 & 2316 & 2482 & 3.929 & 3.930 & 3.929 & 7.875 & 131,400 & 74.7 & & & & & 4988 \\
\hline 40.3 & 28 & comp & 3908 & 2336 & 2486 & 3.929 & 3.937 & 3.933 & 7.889 & 129,500 & 73.5 & 73.9 & 1.2 & 0.71 & 0.96 & 4972 \\
\hline 40.2 & & & 3899 & 2329 & 2483 & 3.932 & 3.933 & 3.932 & 7.877 & 129,700 & 73.6 & & & & & 4977 \\
\hline 40.4 & & & 3901 & 2330 & 2483 & 3.934 & 3.938 & 3.936 & 7.874 & 153,400 & 86.9 & & & & & 4951 \\
\hline 40.3 & 90 & comp & 3906 & 2333 & 2483 & 3.938 & 3.942 & 3.940 & 7.874 & 144,800 & 81.9 & 85.5 & 5.7 & 3.4 & 3.9 & 4963 \\
\hline 0.2 & & & 3902 & 2330 & 2482 & 3.913 & 3.944 & 3.929 & 7.876 & 154,000 & 87.6 & & & & & 4976 \\
\hline
\end{tabular}

mean density $\mathrm{kg} \cdot \mathrm{m}^{-3}: \quad 3$ day: 24827 day: 248028 day: 248490 day: 2483

reported in compliance with NZS 3111:1974: $\quad 2480 \quad 2480$

$\begin{array}{lllll}\text { mean ultrasonic pulse velocity m.s } & -1 & \text { : } & 4685 & 4786\end{array}$ 
BQ-IXA Mix I (0.375 w:C)

\begin{tabular}{|c|c|c|c|c|c|c|c|c|c|c|c|c|c|c|c|c|}
\hline $\begin{array}{l}\text { PUNDIT } \\
\text { time }\end{array}$ & $\begin{array}{l}\text { Age } \\
\text { at } \\
\text { test } \\
\text { days }\end{array}$ & $\begin{array}{l}\text { Type } \\
\text { of } \\
\text { test }\end{array}$ & $\begin{array}{l}\text { Wt. } \\
\text { in } \\
\text { air } \\
\text { gms }\end{array}$ & $\begin{array}{l}\text { Wt. } \\
\text { in } \\
\text { water } \\
\text { gms }\end{array}$ & Density & $\begin{array}{l}\text { Diam } \\
1 \\
\text { units } \\
\text { in }\end{array}$ & $\begin{array}{l}\text { Diam } \\
2 \\
\text { units } \\
\text { in }\end{array}$ & $\begin{array}{l}\text { Mean } \\
\text { diam } \\
\text { units } \\
\text { in }\end{array}$ & $\begin{array}{l}\text { Length } \\
\text { units } \\
\text { in }\end{array}$ & $\begin{array}{l}\text { Load } \\
\text { at } \\
\text { failure } \\
\text { units } \\
\text { lbf }\end{array}$ & Strength & $\begin{array}{l}\text { Mean } \\
\text { strength }\end{array}$ & Range & $\begin{array}{l}\text { Std } \\
\text { dev }\end{array}$ & $\begin{array}{l}C \\
\text { of } \\
V \\
8\end{array}$ & $\begin{array}{l}\text { Ultra- } \\
\text { sonic } \\
\text { pulse } \\
\text { velocity } \\
\text { m.s }\end{array}$ \\
\hline 43.7 & & & 3899 & 2326 & 2479 & 3.948 & 3.926 & 3.937 & 7.881 & 50,600 & 28.7 & & & & & 4581 \\
\hline 43.5 & 3 & comp & 3932 & 2350 & 2486 & 3.933 & 3.942 & 3.937 & 7.937 & 56,600 & 32.1 & 29.8 & 3.4 & 2.01 & 6.7 & 4635 \\
\hline 43.6 & & & 3902 & 2329 & 2481 & 3.937 & 3.937 & 3.937 & 7.889 & 50,700 & 28.7 & & & & & 4596 \\
\hline 42.6 & & & 3896 & 2324 & 2478 & 3.938 & 3.940 & 3.939 & 7.883 & 87,300 & 49.4 & & & & & 4700 \\
\hline 42.1 & 7 & comp & 3891 & 2324 & 2483 & 3.929 & 3.931 & 3.930 & 7.879 & 83,100 & 47.2 & 48.0 & 2.2 & 1.30 & 2.7 & 4754 \\
\hline 42.2 & & & 3905 & 2330 & 2479 & 3.942 & 3.935 & 3.938 & 7.889 & 84,000 & 47.5 & & & & & 4748 \\
\hline 40.4 & & & 3899 & 2331 & 2487 & 3.934 & 3.930 & 3.932 & 7.881 & 126,400 & 71.8 & & & & & 4955 \\
\hline 40.5 & 28 & comp & 3909 & 2337 & 2487 & 3.934 & 3.935 & 3.934 & 7.876 & 130,000 & 73.7 & 74.0 & 4.7 & 2.77 & 3.8 & 4940 \\
\hline 40.5 & & & 3891 & 2322 & 2480 & 3.932 & 3.933 & 3.932 & 7.881 & 134,800 & 76.5 & & & & & 4943 \\
\hline 39.9 & & & 3904 & 2332 & 2484 & 3.935 & 3.943 & 3.939 & 7.876 & 154,600 & 87.5 & & & & & 5014 \\
\hline 39.9 & 90 & comp & 3910 & 2338 & 2487 & 3.937 & 3.929 & 3.933 & 7.884 & 154,000 & 87.4 & 87.2 & 0.9 & 0.53 & 0.61 & 5019 \\
\hline 40.0 & & & 3904 & 2333 & 2485 & 3.939 & 3.932 & 3.936 & 7.876 & 152,700 & 86.6 & & & & & 5001 \\
\hline $\begin{array}{l}\text { mean a } \\
\text { report } \\
\text { mean u }\end{array}$ & $\begin{array}{l}\text { ensity } \\
\text { ed in } \\
\text { traso }\end{array}$ & $\begin{array}{l}\mathrm{kg} \cdot \mathrm{m} \\
\text { compl } \\
\text { nic p }\end{array}$ & $\begin{array}{l}\mathrm{n}^{-3} \\
\text { liance } \\
\text { oulse }\end{array}$ & $\begin{array}{l}\text { with } \\
\text { veloci }\end{array}$ & NZS 3111 & $1: 1974$ & $\begin{array}{l}: \\
:\end{array}$ & 3 day: & $\begin{array}{l}2482 \\
2480\end{array}$ & 7 day: & $\begin{array}{r}2480 \\
2480\end{array}$ & 28 day: & $\begin{array}{l}2491 \\
2490 \\
4946\end{array}$ & 90 & day: & $\begin{array}{l}2485 \\
2490\end{array}$ \\
\hline
\end{tabular}

SJ-T Mix 1 (0.375 w:c)

\begin{tabular}{|c|c|c|c|c|c|c|c|c|c|c|c|c|c|c|c|c|}
\hline 44.0 & & & 3932 & 2360 & 2501 & 3.938 & 3.932 & 3.935 & 7.882 & 49,600 & 28.1 & & & & & 4550 \\
\hline 43.7 & 3 & comp & 3920 & 2350 & 2497 & 3.927 & 3.933 & 3.930 & 7.881 & 49,500 & 28.1 & 28.4 & 0.8 & 0.47 & 1.7 & 4581 \\
\hline 4.2 & & & 3922 & 2354 & 2501 & 3.926 & 3.934 & 3.930 & 7.878 & 50,800 & 28.9 & & & & & 4527 \\
\hline 2.4 & & & 3936 & 2359 & 2496 & 3.945 & 3.934 & 3.939 & 7.880 & 89,400 & 50.6 & & & & & 4721 \\
\hline 2.6 & 7 & comp & 3941 & 2364 & 2499 & 3.944 & 3.943 & 3.943 & 7.884 & 85,500 & 48.3 & 49.9 & 2.4 & 1.42 & 2.8 & 4701 \\
\hline 42.6 & & & 3915 & 2344 & 2492 & 3.940 & 3.937 & 3.938 & 7.884 & 89,600 & 50.7 & & & & & 4701 \\
\hline 1.0 & & & 3929 & 2362 & 2507 & 3.936 & 3.940 & 3.938 & 7.874 & 129,000 & 73.0 & & & & & 4878 \\
\hline 0.9 & 28 & comp & 3940 & 2365 & 2502 & 3.934 & 3.936 & 3.935 & 7.887 & 128,100 & 72.6 & 73.8 & 3.1 & 1.83 & 2.5 & 4898 \\
\hline 1.1 & & & 3927 & 2354 & 2497 & 3.933 & 3.939 & 3.936 & 7.887 & 133,600 & 75.7 & & & & & 4874 \\
\hline 0.3 & & & 3940 & 2369 & 2508 & 3.947 & 3.921 & 3.934 & 7.882 & 147,000 & 83.4 & & & & & 4968 \\
\hline 40.5 & 90 & comp & 3931 & 2360 & 2502 & 3.932 & 3.936 & 3.934 & 7.882 & 152,500 & 86.5 & 83.4 & 6.3 & 3.7 & 4.5 & 4943 \\
\hline 40.4 & & & 3946 & 2371 & 2505 & 3.936 & 3.941 & 3.939 & 7.879 & 141,700 & 80.2 & & & & & 4954 \\
\hline ean & $\begin{array}{l}\text { a in } \\
\text { traso }\end{array}$ & oni & & 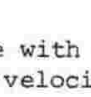 & ity $\mathrm{m}$ & 4 & $\begin{array}{l}\text { : } \\
: \\
:\end{array}$ & 3 day: & $\begin{array}{l}2500 \\
2500 \\
4553\end{array}$ & 7 day: & $\begin{array}{l}2496 \\
2500 \\
4708\end{array}$ & 28 day: & $\begin{array}{l}2502 \\
2500 \\
4883\end{array}$ & 90 & day: & $\begin{array}{l}2505 \\
2510 \\
4955\end{array}$ \\
\hline
\end{tabular}

$\mathrm{OB}-\mathrm{W} \operatorname{Mix} I \quad(0.375 \mathrm{w}: \mathrm{c})$

$\begin{array}{crrrr}- & & 3939 & 2372 & 2514 \\ 45.9 & 3 & \text { comp } 3964 & 2387 & 2514 \\ 46.0 & & 3941 & 2376 & 2518 \\ 44.4 & & 3965 & 2391 & 2519 \\ 44.7 & 7 & \text { comp } 3963 & 2392 & 2523 \\ 44.5 & & 3964 & 2390 & 2518 \\ 43.2 & & 3961 & 2390 & 2521 \\ 43.1 & 28 & \text { comp } 3954 & 2380 & 2512 \\ 43.1 & & 3966 & 2392 & 2520 \\ 42.5 & & 3953 & 2386 & 2523 \\ 42.5 & 90 & \text { comp } 3970 & 2398 & 2526 \\ 42.7 & & 3966 & 2393 & 2521\end{array}$

\begin{tabular}{|c|c|c|}
\hline $\begin{array}{l}\text { Diam } \\
1\end{array}$ & $\begin{array}{l}\text { Diam } \\
2\end{array}$ & $\begin{array}{l}\text { Mean } \\
\text { diam }\end{array}$ \\
\hline $\begin{array}{l}\text { units } \\
\text { in }\end{array}$ & $\begin{array}{l}\text { units } \\
\text { in }\end{array}$ & $\begin{array}{l}\text { units } \\
\text { in }\end{array}$ \\
\hline 3.948 & 3.926 & 3.93 \\
\hline 3.933 & 3.942 & 3.937 \\
\hline 3.937 & 3.937 & 3.937 \\
\hline 3.938 & 3.940 & 3.93 \\
\hline 3.929 & 3.931 & 3.930 \\
\hline 3.942 & 3.935 & 3.93 \\
\hline 3.934 & 3.930 & 3.932 \\
\hline 3.934 & 3.935 & 3.934 \\
\hline 3.932 & 3.933 & 3.932 \\
\hline 3.935 & 3.943 & 3.939 \\
\hline 3.937 & 3.929 & 3.933 \\
\hline 3.939 & 3.932 & 3.936 \\
\hline$: 1974$ & $\begin{array}{l}: \\
\vdots \\
:\end{array}$ & 3 day \\
\hline 3.938 & 3.932 & 3.935 \\
\hline 3.927 & 3.933 & 3.930 \\
\hline 3.926 & 3.934 & 3.930 \\
\hline 3.945 & 3.934 & 3.939 \\
\hline 3.944 & 3.943 & 3.943 \\
\hline 3.940 & 3.937 & 3.938 \\
\hline 3.936 & 3.940 & 3.938 \\
\hline 3.934 & 3.936 & 3.935 \\
\hline 3.933 & 3.939 & 3.936 \\
\hline 3.947 & 3.921 & 3.934 \\
\hline 3.932 & 3.936 & 3.934 \\
\hline 3.936 & 3.941 & 3.939 \\
\hline 974 & $\begin{array}{l}: \\
:\end{array}$ & 3 day \\
\hline - & - & $3.94 \mathrm{C}$ \\
\hline
\end{tabular}

- $\quad$ - 3.9407 .887

$\begin{array}{llll}3.943 & 3.940 & 3.941 \quad 7.886\end{array}$

- $\quad$ - $\quad 3.9407 .887$

$\begin{array}{llll}3.936 & 3.943 & 3.939 & 7.894\end{array}$

$\begin{array}{llll}3.934 & 3.941 & 3.937 & 7.888\end{array}$

$\begin{array}{llll}3.942 & 3.944 & 3.943 \quad 7.880\end{array}$

$\begin{array}{lllll}3.933 & 3.939 & 3.936 & 7.889\end{array}$

$\begin{array}{lllll}3.943 & 3.939 & 3.941 & 7.876\end{array}$

$\begin{array}{llll}3.939 & 3.944 \quad 3.941 & 7.877\end{array}$

$\begin{array}{lllll}3.929 & 3.926 & 3.928 & 7.875\end{array}$

$\begin{array}{llll}3.934 & 3.935 & 3.935 & 7.880\end{array}$

$\begin{array}{llll}3.935 & 3.928 & 3.932 & 7.881\end{array}$
$53,60030.3$

$56,30031.8$

$56,800 \quad 32.1$

$85,50048.4$

$85,100 \quad 48.2$

$87,000 \quad 49.1$

$112,70063.9$

$113,10063.9$

$106,90060.4$

$111,800 \quad 63.6$

$125,90071.4$

$121,20068.8$

mean density $\mathrm{kg} \cdot \mathrm{m}^{-3}$

: 3 day: 25157 day: 2520

reported in compliance with NZS 3111:1974: $\quad \begin{array}{ll}2515 & 2520\end{array}$

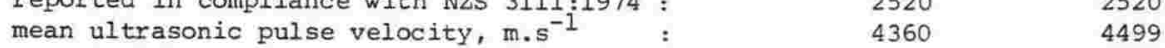

$\begin{array}{lllll}31.4 & 1.8 & 1.06 & 3.4 & 4364\end{array}$

4355

4516

$\begin{array}{llllll}48.6 & 0.9 & 0.53 & 1.1 & 4482\end{array}$

4498

4638

$\begin{array}{lllll}62.7 & 3.5 & 2.07 & 3.3 & 4642\end{array}$

4642

4707

$\begin{array}{lllll}67.9 & 7.8 & 4.6 & 6.8 & 4710\end{array}$

4688

28 day: 2518 90 day: 2523

$2520 \quad 2520$


HQ-22 Mix $1 \quad(0.375 \mathrm{w}: \mathrm{c})$

\begin{tabular}{|c|c|c|c|c|c|c|c|c|c|c|c|c|c|c|c|c|}
\hline $\begin{array}{l}\text { PUNDIT } \\
\text { time }\end{array}$ & $\begin{array}{l}\text { Age } \\
\text { at } \\
\text { test } \\
\text { days }\end{array}$ & $\begin{array}{l}\text { Type } \\
\text { of } \\
\text { test }\end{array}$ & $\begin{array}{l}\text { Wt. } \\
\text { in } \\
\text { air } \\
\text { gms }\end{array}$ & $\begin{array}{l}\text { Wt. } \\
\text { in } \\
\text { water } \\
\text { gms }\end{array}$ & $\begin{array}{l}\text { Density } \\
\mathrm{kg} \cdot \mathrm{m}^{-3}\end{array}$ & $\begin{array}{l}\text { Diam } \\
1 \\
\text { units } \\
\text { in }\end{array}$ & $\begin{array}{l}\text { Diam } \\
2 \\
\text { units } \\
\text { in }\end{array}$ & $\begin{array}{l}\text { Mean } \\
\text { diam } \\
\text { units } \\
\text { in }\end{array}$ & $\begin{array}{l}\text { Length } \\
\text { units } \\
\text { in }\end{array}$ & $\begin{array}{l}\text { Load } \\
\text { at } \\
\text { failure } \\
\text { units } \\
\text { lbf }\end{array}$ & Streng th & $\begin{array}{l}\text { th Mean } \\
\text { strength }\end{array}$ & Range & $\begin{array}{l}\text { Std } \\
\text { dev }\end{array}$ & $\begin{array}{l}\mathrm{C} \\
\text { of } \\
\mathrm{V} \\
\\
8\end{array}$ & $\begin{array}{l}\text { Ultra- } \\
\text { sonic } \\
\text { pulse } \\
\text { velocity } \\
\text { m.s } \text { s }^{-1}\end{array}$ \\
\hline 45.1 & & & 3917 & 2344 & 2490 & 3.940 & 3.946 & 3.943 & 7.884 & 51,500 & 29.1 & & & & & 4440 \\
\hline 45.2 & 3 & comp & 3903 & 2332 & 2484 & 3.938 & 3.941 & 3.939 & 7.879 & 52,000 & 29.4 & 29.9 & 2.0 & 1.18 & 4.0 & 4428 \\
\hline 44.8 & & & 3910 & 2341 & 2492 & 3.934 & 3.931 & 3.932 & 7.885 & 54,800 & 31.1 & & & & & 4471 \\
\hline 43.5 & & & 3920 & 2348 & 2494 & 3.932 & 3.944 & 3.938 & 7.879 & 84,400 & 47.8 & & & & & 4601 \\
\hline 43.6 & 7 & comp & 3915 & 2346 & 2495 & 3.928 & 3.932 & 3.930 & 7.881 & 85,400 & 48.5 & 48.5 & 1.5 & 0.89 & 1.8 & 4591 \\
\hline 43.7 & & & 3917 & 2345 & 2492 & 3.930 & 3.938 & 3.934 & 7.881 & 86,900 & 49.3 & & & & & 4581 \\
\hline 42.0 & & & 3916 & 2349 & 2499 & 3.934 & 3.931 & 3.932 & 7.878 & 127,900 & 72.6 & & & & & 4764 \\
\hline 41.8 & 28 & comp & 3926 & 2355 & 2499 & 3.943 & 3.928 & 3.935 & 7.876 & 126,100 & 71.5 & 71.3 & 2.9 & 1.7 & 2.44 & 4786 \\
\hline 42.0 & & & 3918 & 2349 & 2497 & 3.932 & 3.931 & 3.931 & 7.874 & 122,700 & 69.7 & & & & & 4762 \\
\hline 4.1 .6 & & & 3915 & 2347 & 2497 & 3.907 & 3.914 & 3.911 & 7.852 & 142,700 & 81.9 & & & & & 4794 \\
\hline 41.7 & 90 & comp & 3928 & 2356 & 2499 & 3.940 & 3.936 & 3.938 & 7.879 & 150,500 & 85.2 & 82.4 & 5.1 & 3.0 & 3.74 & 4799 \\
\hline 41.9 & & & 3920 & 2349 & 2495 & 3.932 & 3.933 & 3.933 & 7.875 & 141,100 & 80.1 & & & & & 4774 \\
\hline $\begin{array}{l}\text { mean ds } \\
\text { reporte } \\
\text { mean ul }\end{array}$ & $\begin{array}{l}\text { ensity } \\
\text { ed in } \\
\text { ltraso }\end{array}$ & $\begin{array}{l}y \text { kg.m } \\
\text { compl } \\
\text { onic p }\end{array}$ & $\begin{array}{l}m^{-3} \\
\text { liance } \\
\text { pulse }\end{array}$ & veloci & $\begin{array}{c}\text { NZS } 3 \\
\text { ity } \mathrm{m} .\end{array}$ & 974 & $\begin{array}{l}: \\
: \\
:\end{array}$ & 3 day: & $\begin{array}{l}2489 \\
2490 \\
4446\end{array}$ & $\begin{array}{l}9 \\
0 \\
6\end{array}$ & $\begin{array}{l}2494 \\
2490 \\
4591\end{array}$ & $28 \mathrm{day}$ & $y: \begin{array}{l}249 \\
250 \\
477\end{array}$ & & 90 day: & $: \quad \begin{array}{l}2497 \\
2500 \\
4789\end{array}$ \\
\hline
\end{tabular}

HQ-17 Mix 2 (0.4 w:c)

\begin{tabular}{|c|c|c|c|c|c|c|c|c|c|c|c|c|c|c|c|c|}
\hline 4.6 & & & 3857 & 2289 & 2460 & 3.932 & 3.930 & 3.931 & 7.874 & 39,800 & 22.6 & & & & & 4484 \\
\hline 44.5 & 3 & comp & 3869 & 2298 & 2463 & 3.934 & 3.933 & 3.933 & 7.880 & 38,400 & 21.8 & 22.1 & 0.8 & 0.472 & 2.1 & 4498 \\
\hline 14.2 & & & 3872 & 2302 & 2466 & 3.928 & 3.939 & 3.933 & 7.883 & 38,700 & 22.0 & & & & & 4530 \\
\hline 2.5 & & & 3870 & 2298 & 2462 & 3.937 & 3.934 & 3.935 & 7.895 & 74,900 & 42.5 & & & & & 4718 \\
\hline 2.3 & 7 & comp & 3861 & 2296 & 2468 & 3.932 & 3.926 & 3.929 & 7.874 & 68,000 & 38.7 & 41.4 & 4.2 & 2.486 & 6.0 & 4728 \\
\hline 42.6 & & & 3870 & 2298 & 2462 & 3.929 & 3.947 & 3.938 & 7.881 & 75,700 & 42.9 & & & & & 4699 \\
\hline 11.1 & & & 3890 & 2314 & 2468 & 3.937 & 3.936 & 3.936 & 7.879 & 121,800 & 69.0 & & & & & 4869 \\
\hline 11.1 & 28 & comp & 3879 & 2306 & 2466 & 3.933 & 3.939 & 3.936 & 7.875 & 115,800 & 65.6 & 66.9 & 3.4 & 2.0 & 3.0 & 4867 \\
\hline 1.0 & & & 3890 & 2313 & 2467 & 3.938 & 3.941 & 3.939 & 7.877 & 117,000 & 66.2 & & & & & 4880 \\
\hline 10.5 & & & 3888 & 2314 & 2470 & 3.933 & 3.940 & 3.937 & 7.877 & 141,500 & 80.2 & & & & & 4940 \\
\hline 40.6 & 90 & comp & 3886 & 2312 & 2469 & 3.935 & 3.938 & 3.937 & 7.875 & 140,800 & 79.8 & 79.6 & 1.3 & 0.77 & 0.96 & 4927 \\
\hline 40.5 & & & 3888 & 2316 & 2473 & 3.931 & 3.935 & 3.933 & 7.881 & 139,0007 & 78.9 & & & & & 4943 \\
\hline & & & & & $s^{-1}$ & 1974 & $\begin{array}{l}: \\
:\end{array}$ & $\mathrm{d} a$ & $\begin{array}{l}2463 \\
2460 \\
4504\end{array}$ & day & $\begin{array}{l}2464 \\
2460 \\
4715\end{array}$ & 28 & $\begin{array}{l}2467 \\
2470 \\
4872\end{array}$ & 90 & day: & $\begin{array}{l}2471 \\
2470 \\
4937\end{array}$ \\
\hline
\end{tabular}

KTW-14 Mix $2 \quad(0.4 \mathrm{~W}: \mathrm{C})$

\begin{tabular}{|c|c|c|c|c|c|c|c|c|c|c|c|c|c|c|c|c|}
\hline 44.3 & & & 3869 & 2305 & 2474 & 3.924 & 3.931 & 3.927 & 7.879 & 43,700 & 24.9 & & & & & 4518 \\
\hline 44.4 & 3 & comp & 3882 & 2312 & 2473 & 3.928 & 3.935 & 3.931 & 7.883 & 45,800 & 26.0 & 25.4 & 1.1 & 0.65 & 2.6 & 4551 \\
\hline 44.3 & & & 3888 & 2316 & 2473 & 3.940 & 3.937 & 3.938 & 7.875 & 44,800 & 25.4 & & & & & 4515 \\
\hline 42.3 & & & 3874 & 2307 & 2472 & 3.933 & 3.928 & 3.930 & 7.875 & 75,200 & 42.7 & & & & & 4729 \\
\hline 42.0 & 7 & comp & 3900 & 2328 & 2481 & 3.938 & 3.938 & 3.938 & 7.877 & 73,000 & 41.3 & 42.1 & 1.4 & 0.83 & 2.0 & 4764 \\
\hline 42.3 & & & 3865 & 2302 & 2473 & 3.926 & 3.925 & 3.925 & 7.875 & 74,400 & 42.4 & & & & & 4729 \\
\hline 40.9 & & & 3890 & 2318 & 2475 & 3.937 & 3.935 & 3.936 & 7.878 & 119,000 & 67.4 & & & & & 4893 \\
\hline 40.7 & 28 & comp & 3894 & 2324 & 2480 & 3.937 & 3.933 & 3.935 & 7.878 & 119,200 & 67.6 & 68.8 & 4.1 & 2.42 & 3.5 & 4917 \\
\hline 40.6 & & & 3912 & 2336 & 2482 & 3.938 & 3.945 & 3.941 & 7.876 & 126,600 & 71.5 & & & & & 4927 \\
\hline 40.3 & & & 3894 & 2324 & 2480 & 3.932 & 3.933 & 3.933 & 7.876 & 136,300 & 77.4 & & & & & 4964 \\
\hline 40.2 & 90 & comp & 3882 & 2316 & 2479 & 3.931 & 3.931 & 3.931 & 7.871 & 142,600 & 81.0 & 80.0 & 4.1 & 2.42 & 3.02 & 4973 \\
\hline 40.3 & & & 3897 & 2325 & 2479 & 3.935 & 3.938 & 3.937 & 7.875 & 143,900 & 81.5 & & & & & 4963 \\
\hline $\begin{array}{l}\text { mean } \\
\text { repor } \\
\text { mean }\end{array}$ & a & 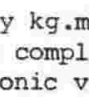 & & ity $n$ & is 3 & $1: 1974$ & $\begin{array}{l}: \\
\vdots \\
:\end{array}$ & 3 day: & $\begin{array}{l}2473 \\
2470 \\
4528\end{array}$ & 7 day: & $\begin{array}{l}2475 \\
2480 \\
4741\end{array}$ & 28 day: & $\begin{array}{l}2479 \\
2480 \\
4912\end{array}$ & 90 & day: & $\begin{array}{l}2479 \\
2480 \\
4967\end{array}$ \\
\hline
\end{tabular}


BQ-IXA Mix $2 \quad(0.4 \mathrm{w}: \mathrm{c})$

\begin{tabular}{|c|c|c|c|c|c|c|c|c|c|c|c|c|c|c|c|c|}
\hline $\begin{array}{l}\text { PUNDIT } \\
\text { time } \\
\text { H secs }\end{array}$ & $\begin{array}{l}\text { Age } \\
\text { at } \\
\text { test } \\
\text { days }\end{array}$ & $\begin{array}{l}\text { Type } \\
\text { of } \\
\text { test }\end{array}$ & $\begin{array}{l}\text { Wt. } \\
\text { in } \\
\text { air } \\
\text { gms }\end{array}$ & $\begin{array}{l}\text { Wt. } \\
\text { in } \\
\text { water } \\
\text { gms }\end{array}$ & Density & $\begin{array}{l}\text { Diam } \\
1 \\
\text { units } \\
\text { in }\end{array}$ & $\begin{array}{l}\text { Diam } \\
2 \\
\text { units } \\
\text { in }\end{array}$ & $\begin{array}{l}\text { Mean } \\
\text { diam } \\
\text { units } \\
\text { in }\end{array}$ & $\begin{array}{l}\text { units } \\
\text { in }\end{array}$ & $\begin{array}{l}\text { Load } \\
\text { at } \\
\text { failure } \\
\text { units } \\
\text { lbf }\end{array}$ & Strength & $\begin{array}{l}\text { Mean } \\
\text { strength }\end{array}$ & Range & $\begin{array}{l}\text { Std } \\
\text { dev }\end{array}$ & $\begin{array}{l}\mathrm{C} \\
\text { of } \\
\mathrm{V} \\
8\end{array}$ & $\begin{array}{l}\text { Ultra- } \\
\text { sonic } \\
\text { pulse } \\
\text { velocity } \\
\mathrm{m} \cdot \mathrm{s}^{-1}\end{array}$ \\
\hline 44.4 & & & 3880 & 2307 & 2467 & 3.936 & 3.936 & 3.936 & 7.880 & 38,600 & 21.9 & & & & & 4508 \\
\hline 44.8 & 3 & comp & 3868 & 2298 & 2464 & 3.932 & 3.932 & 3.932 & 7.879 & 38,400 & 21.8 & 21.7 & 0.5 & 0.30 & 1.4 & 4467 \\
\hline 44.1 & & & 3881 & 2313 & 2475 & 3.935 & 3.932 & 3.934 & 7.873 & 37,700 & 21.4 & & & & & 4535 \\
\hline 42.8 & & & 3880 & 2308 & 2468 & 3.936 & 3.934 & 3.935 & 7.877 & 68,000 & 38.6 & & & & & 4675 \\
\hline 42.7 & 7 & comp & 3874 & 2304 & 2468 & 3.945 & 3.925 & 3.935 & 7.878 & 67,700 & 38.4 & 38.2 & 1.1 & 0.65 & 1.7 & 4686 \\
\hline 43.0 & & & 3878 & 2306 & 2467 & 3.938 & 3.935 & 3.936 & 7,875 & 66,100 & 37.5 & & & & & 4652 \\
\hline 41.2 & & & 3889 & 2318 & 2476 & 3.932 & 3.938 & 3.935 & 7.876 & 113,000 & 64.1 & & & & & 4856 \\
\hline 41.4 & 28 & comp & 3880 & 2307 & 2467 & 3.938 & 3.931 & 3.934 & 7.876 & 119,500 & 67.8 & 65.9 & 3.7 & 2.18 & 3.3 & 4832 \\
\hline 41.4 & & & 3870 & 2303 & 2470 & 3.931 & 3.931 & 3.931 & 7.879 & 116,000 & 65.9 & & & & & 4834 \\
\hline 40.8 & & & 3882 & 2315 & 2477 & 3.934 & 3.930 & 3.932 & 7.877 & 134,500 & 76.4 & & & & & 4904 \\
\hline 40.7 & 90 & comp & 3897 & 2324 & 2477 & 3.933 & 3.939 & 3.936 & 7.880 & 136,300 & 77.2 & 75.6 & 4.1 & 2.42 & 3.2 & 4918 \\
\hline 40.8 & & & 3902 & 2326 & 2476 & 3.942 & 3.935 & 3.939 & 7.881 & 129,200 & 73.1 & & & & & 4906 \\
\hline $\begin{array}{l}\text { mean de } \\
\text { reporte } \\
\text { mean ul }\end{array}$ & $\begin{array}{l}\text { ensity } \\
\text { ed in } \\
\text { ltraso }\end{array}$ & onic & pulse & velocit & ty & 974 & $\begin{array}{l}: \\
:\end{array}$ & day: & $\begin{array}{l}2469 \\
2470 \\
4503\end{array}$ & 7 day: & $\begin{array}{l}2468 \\
2470 \\
4671\end{array}$ & $28 \mathrm{~d}$ & $\begin{array}{l}2471 \\
2470 \\
4841\end{array}$ & 90 & day: & $=\begin{array}{l}2477 \\
2480 \\
4909\end{array}$ \\
\hline
\end{tabular}

SJ-T Mix 2 (0.4 w: c)

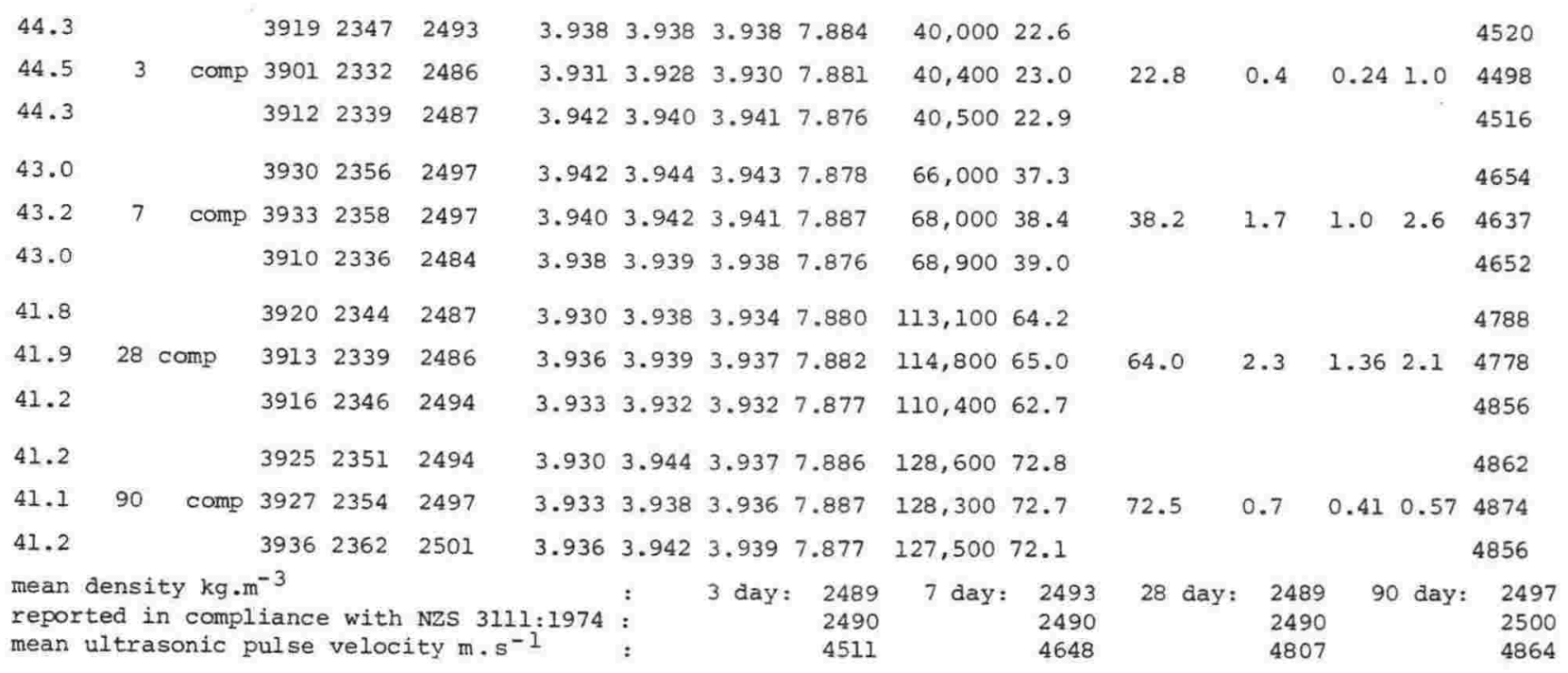

$\mathrm{OB}-\mathrm{W} \operatorname{Mix} 2 \quad(0.4 \mathrm{~W}: \mathrm{C})$

\begin{tabular}{|c|c|c|c|c|c|c|c|c|c|c|c|c|c|c|c|}
\hline 47.5 & & & 3936 & 2362 & 2501 & 3.923 & 3.948 & 3.935 & 7.882 & 42,500 & 24.1 & & & & 4215 \\
\hline 47.0 & 3 & comp & 3933 & 2365 & 2508 & 3.937 & 3.929 & 3.933 & 7.876 & 40,400 & 22.9 & 23.6 & 1.2 & 0.713 .0 & 4256 \\
\hline 47.0 & & & 3925 & 2358 & 2505 & 3.930 & 3.930 & 3.930 & 7.876 & 42,100 & 23.9 & & & & 4256 \\
\hline 44.7 & & & 3952 & 2379 & 2512 & 3.939 & 3.935 & 3.937 & 7.892 & 75,800 & 42.9 & & & & 4485 \\
\hline 45.2 & 7 & comp & 3950 & 2375 & 2508 & 3.937 & 3.940 & 3.938 & 7.880 & 73,700 & 41.7 & 42.4 & 1.2 & 0.711 .7 & 4428 \\
\hline 44.8 & & & 3951 & 2380 & 2515 & 3.930 & 3.937 & 3.933 & 7.900 & 75,000 & 42.6 & & & & 4479 \\
\hline 43.2 & & & 3956 & 2382 & 2513 & 3.936 & 3.938 & 3.937 & 7.875 & 108,200 & 61.3 & & & & 4630 \\
\hline 43.2 & 28 & comp & 3946 & 2374 & 2510 & 3.935 & 3.934 & 3.934 & 7.879 & 106,000 & 60.1 & 60.5 & 1.2 & 0.711 .2 & 4633 \\
\hline 43.3 & & & 3945 & 2377 & 2516 & 3.931 & 3.927 & 3.929 & 7.882 & 105,600 & 60.1 & & & & 4624 \\
\hline 42.7 & & & 3963 & 2389 & 2518 & 3.940 & 3.928 & 3.934 & 7.884 & 111,800 & 63,4 & & & & 4690 \\
\hline 42.6 & 90 & comp & 3957 & 2382 & 2512 & 3.929 & 3.941 & 3.935 & 7.880 & 116,200 & 65.9 & 65.4 & 3.6 & $2.1 \quad 3.3$ & 4698 \\
\hline 42.9 & & & 3942 & 2370 & 2508 & 3.932 & 3.934 & 3.933 & 7.877 & 118,000 & 67.0 & & & & 4664 \\
\hline $\begin{array}{l}\text { mean } \\
\text { repor } \\
\text { mean }\end{array}$ & 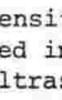 & $x+$ & pulse & ve & $\begin{array}{l}\text { NZS } \\
\text { ity m }\end{array}$ & 74 & $\begin{array}{l}: \\
: \\
:\end{array}$ & 3 day: & $\begin{array}{l}2505 \\
2510 \\
4242\end{array}$ & 7 day: & $\begin{array}{l}2512 \\
2510 \\
4464\end{array}$ & 28 day: & $\begin{array}{l}2513 \\
2510 \\
4629\end{array}$ & 90 day: & $\begin{array}{l}2513 \\
2510 \\
4684\end{array}$ \\
\hline
\end{tabular}


HQ-22 Mix 2 (0.4 w: C)

\begin{tabular}{|c|c|c|c|c|c|c|c|c|c|c|c|c|c|c|c|c|}
\hline $\begin{array}{l}\text { PUNDIT } \\
\text { time }\end{array}$ & $\begin{array}{l}\text { Age } \\
\text { at } \\
\text { test } \\
\text { days }\end{array}$ & $\begin{array}{l}\text { Type } \\
\text { of } \\
\text { test }\end{array}$ & $\begin{array}{l}\text { Wt. } \\
\text { in } \\
\text { air } \\
\text { gms }\end{array}$ & $\begin{array}{l}\text { wt. } \\
\text { in } \\
\text { water } \\
\text { gms }\end{array}$ & Density & $\begin{array}{l}\text { Diam } \\
1 \\
\text { units } \\
\text { in }\end{array}$ & $\begin{array}{l}\text { Diam } \\
2 \\
\text { units } \\
\text { in }\end{array}$ & $\begin{array}{l}\text { Mean } \\
\text { diam } \\
\text { units } \\
\text { in }\end{array}$ & $\begin{array}{l}\text { Length } \\
\text { units } \\
\text { in }\end{array}$ & $\begin{array}{l}\text { Load } \\
\text { at } \\
\text { failure } \\
\text { units } \\
\text { lbf }\end{array}$ & Strength & $\begin{array}{l}\text { Mean } \\
\text { strength }\end{array}$ & Range & $\begin{array}{l}\text { Std } \\
\text { dev } \\
\mathrm{MPa}\end{array}$ & $\begin{array}{l}C \\
\text { of } \\
V \\
\text { \& }\end{array}$ & $\begin{array}{l}\text { Ultra- } \\
\text { sonic } \\
\text { pulse } \\
\text { velocity } \\
\mathrm{m} \cdot \mathrm{s}^{-1}\end{array}$ \\
\hline 46.0 & & & 3899 & 2327 & 2480 & 3.931 & 3.937 & 3.934 & 7.881 & 42,400 & 24.1 & & & & & 4352 \\
\hline 46.2 & 3 & comp & 3906 & 2334 & 2485 & 3.939 & 3.938 & 3.938 & 7.874 & 42,900 & 24.3 & 23.6 & 1.9 & 1.12 & 4.8 & 4329 \\
\hline 46.2 & & & 3908 & 2334 & 2483 & 3.945 & 3.928 & 3.036 & 7.886 & 39,600 & 22.4 & & & & & 4336 \\
\hline 44.4 & & & 3890 & 2319 & 2476 & 3.939 & 3.937 & 3.938 & 7.884 & 72,600 & 41.1 & & & & & 4510 \\
\hline 44.5 & 7 & comp & 3910 & 2335 & 2483 & 3.942 & 3.937 & 3.939 & 7.889 & 74,500 & 42.2 & 41.1 & 2.3 & 1.363 & 3.3 & 4503 \\
\hline 44.4 & & & 3910 & 2334 & 2481 & 3.949 & 3.939 & 3.944 & 7.881 & 70,700 & 39.9 & & & & & 4509 \\
\hline 42.5 & & & 3919 & 2343 & 2487 & 3.942 & 3.943 & 3.942 & 7.881 & 121,100 & 68.4 & & & & & 4710 \\
\hline 42.6 & 28 & comp & 3919 & 2343 & 2487 & 3.940 & 3.936 & 3.938 & 7.879 & 120,000 & 67.9 & 68.0 & 0.6 & 0.35 & 0.5 & 4698 \\
\hline 42.5 & & & 3893 & 2325 & 2483 & 3.933 & 3.926 & 3.929 & 7.872 & 119,200 & 67.8 & & & & & 4705 \\
\hline 42.2 & & & 3897 & 2329 & 2485 & 3.926 & 3.932 & 3.929 & 7.879 & 129,000 & 73.4 & & & & & 4742 \\
\hline 42.1 & 90 & comp & 3918 & 2345 & 2491 & 3.939 & 3.931 & 3.935 & 7.883 & 125,300 & 71.0 & 72.8 & 2.9 & 1.7 & 2.4 & 4756 \\
\hline 42.2 & & & 3894 & 2326 & 2483 & 3.933 & 3.935 & 3.935 & 7.875 & 130,300 & 73.9 & & & & & 4740 \\
\hline $\begin{array}{l}\text { mean de } \\
\text { reporte } \\
\text { mean ul }\end{array}$ & $\begin{array}{l}\text { ensity } \\
\text { ed in } \\
\text { Itraso }\end{array}$ & $\begin{array}{l}\mathrm{kg} \cdot \mathrm{m} \\
\text { compl } \\
\text { onic p }\end{array}$ & $\begin{array}{l}\mathrm{n}^{-3} \\
\text { Liance } \\
\text { pulse }\end{array}$ & $\begin{array}{l}\text { with } \\
\text { veloci }\end{array}$ & $\begin{array}{l}\text { NZS } 311] \\
\text { ity } \mathrm{m} \cdot \mathrm{s}^{-1}\end{array}$ & : 1974 & $\begin{array}{l}: \\
: \\
:\end{array}$ & 3 day: & $\begin{array}{l}2483 \\
2480 \\
4339\end{array}$ & 7 day : & $\begin{array}{l}2480 \\
2480 \\
4507\end{array}$ & 28 day: & $\begin{array}{l}2486 \\
2490 \\
4704\end{array}$ & 90 & day: & $\begin{array}{l}2486 \\
2490 \\
4746\end{array}$ \\
\hline
\end{tabular}


APPENDIX 30

Measurement of rock specific heat

Specific heat tests by Mr G.R. Clark (New Zealand Concrete Research Association) and calculations by Mr A. Aldrige (Applied Maths Division, DSIR), were carried out in accordance with ASTM C351-61 "Standard test method for mean specific heat of thermal insulation" but with two minor changes in technique related to the physical properties of the sample.

As rock is a dense homogenious mass which can readily be brought to thermal equilibrium in water, a sample holder was not necessary and pre-immersion temperature $\left(C_{i}\right)$ was obtained as a surface reading by thermometer, instead of by thermocouple at the geometric centre. This obviated mutilation of the sample and simplified calculation.

The method involves monitoring, in relation to time, temperature ofawater bath into which a heated sample is dropped. The water temperature rises abruptly then decreases towards ambient. Specific heat is calculated from the formula:

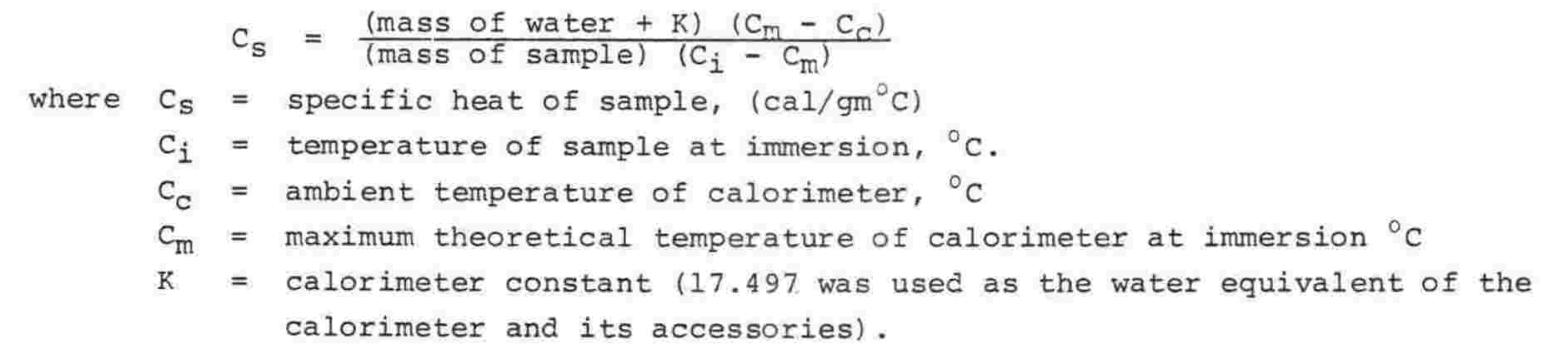

$C_{m}$ is a theoretical temperature which would result from perfect thermal conductivity (between sample and water): it was obtained from a plot of temperature against time by extrapolation using least squares regression from maximum measured temperature. Equipment calibration and the use of Lagrangian interpolation gave a temperature plot accuracy of $0.01{ }^{\circ} \mathrm{C}$. Results are presented in Table $\mathrm{A} 30.1$. 
Table A30.1 : Raw data and calculated specific heat values for Wellington greywackesuite rocks. Two samples of two argillites were tested. Samples were off-cuts from $25 \mathrm{~mm}$ diameter cores.

\begin{tabular}{|c|c|c|c|c|c|c|c|c|c|c|c|}
\hline \multirow[t]{2}{*}{ Sample } & \multirow[t]{2}{*}{ Lithology } & \multirow{2}{*}{$\begin{array}{l}\text { Rock } \\
\text { mean } \\
\text { grain } \\
\text { size, } \\
\text { phi }\end{array}$} & \multicolumn{2}{|c|}{ Sample } & \multirow{2}{*}{$\begin{array}{l}\text { Duration } \\
\text { of } \\
\text { test } \\
\text { seconds }\end{array}$} & \multirow{2}{*}{$\begin{array}{l}\text { Time } \\
\text { sample } \\
\text { added to } \\
\text { water bath } \\
\text { seconds }\end{array}$} & \multirow{2}{*}{$\begin{array}{l}\text { Tempera- } \\
\text { ture } \\
\text { recording } \\
\text { intervals, } \\
\text { seconds }\end{array}$} & \multirow{2}{*}{$\begin{array}{l}\text { Water } \\
\text { mass, } \\
\text { gm. }\end{array}$} & \multirow{2}{*}{\multicolumn{2}{|c|}{$\begin{array}{l}\text { Temperature } \\
\text { Calori- Mixture } \\
\text { meter } \\
\text { ambient, } \\
\mathrm{C}_{\mathrm{c}},{ }^{\circ} \mathrm{C} \mathrm{C}_{\mathrm{m}},{ }^{\circ} \mathrm{C}\end{array}$}} & \multirow{2}{*}{$\begin{array}{l}\text { Specific } \\
\text { heat, } \\
\mathrm{c}_{\mathrm{s}} \text { ' } \\
\mathrm{cal} / \mathrm{gm} \cdot{ }^{\circ} \mathrm{c}\end{array}$} \\
\hline & & & $\begin{array}{l}\text { Mass, } \\
\text { gm. }\end{array}$ & $\begin{array}{l}\text { Temp.. } \\
\mathrm{C}_{1,} \\
{ }^{\circ} \mathrm{C}\end{array}$ & & & & & & & \\
\hline $\mathrm{DC}-6$ & greywacke & & 18.0517 & 103.7 & 520 & 240 & 20 & 301.22 & 13.033 & 13.978 & 0.1860 \\
\hline $\mathrm{HQ}-17$ & greywacke & 1.317 & 23.2358 & 100.4 & 750 & 360 & 30 & 301.13 & 14.260 & 15.327 & 0.1720 \\
\hline $5 J-3_{1}$ & greywacke & 1.32 & 14.1193 & 102.6 & 390 & 240 & 15 & 303.75 & 14.220 & 15.046 & 0.2146 \\
\hline KIW-14 & greywacke & 2.6 & 14.7592 & 103.9 & 390 & 255 & 15 & 303.69 & 15.270 & 16.000 & 0.1805 \\
\hline$B Q-V$ & greywacke & 2.73 & 19.0108 & 101.7 & 520 & 240 & 20 & 302.5 & 12.913 & 13.889 & 0.1871 \\
\hline $\mathrm{KS}-2$ & greywacke & 3.27 & 12.1689 & 101.9 & 390 & 180 & 15 & 300.76 & 15.426 & 15.987 & 0.1708 \\
\hline$K T W-i$ & greywacke & 4.23 & 17.2061 & 103.2 & 520 & 240 & 20 & 301.55 & 13.435 & 14.310 & 0.1825 \\
\hline$S J-T$ & greywacke & 4.72 & 19.3121 & 105.3 & 520 & 260 & 20 & 304.98 & 14.781 & 15.814 & 0.1927 \\
\hline$O B-W$ & argillite & 5.6 & 12.7120 & 100.8 & 390 & 180 & 15 & 302.13 & 15.740 & 16.314 & 0.1708 \\
\hline$O B-W(R)$ & argillite & 5.6 & 11.8990 & 100.1 & 390 & 180 & 15 & 302.27 & 13.082 & 13.615 & 0.1656 \\
\hline HO-22 & argillite & 6.28 & 6.4678 & 100.1 & 210 & 90 & 10 & 302.64 & 13.164 & 13.498 & 0.1909 \\
\hline \multirow{2}{*}{\multicolumn{2}{|c|}{ HQ-22 (R) argillite }} & 6.28 & 4.1534 & 101.3 & 120 & 60 & 5 & 302.82 & 13.164 & 13.382 & 0.1912 \\
\hline & & & & & & & & & & mean & 0.1837 \\
\hline
\end{tabular}

Based on determinations of $25 \mathrm{~mm}$ cores of concrete tested similarly, a standard deviation of $0.008 \mathrm{cal} . / \mathrm{gm} .{ }^{\circ} \mathrm{C}$ applied to the above samples, which, at the 95 percent confidence interval, indicates values to be within $0.02 \mathrm{cal} . / \mathrm{gm} .{ }^{\circ} \mathrm{C}$ of the true value.

Specific heat in SI units (joules/kilogram.K) is obtained* from either the f.p.s. or c.g.s, values by multiplying by $4.1868 \times 10^{3}$.

* Rhodes, J.A. (1978) "Significance of tests and properties of concrete and concrete making materials". chapter 17 - Thermal properties; ASTM STP 169B: 242-61. 
Measurement of rock durability by ultrasonic cavitation test

This test was devised by the U.S. Bureau of Reclamation* to measure the resistance of rock to cavitation (de Puy 1965). A small disc of rock sample was attached by epoxy cement to the horn of a commercially available ultrasonic probe which was run in water for one minute at $20 \mathrm{kH}_{\mathrm{z}}$ with a power output of 150 watts.

The possibility of flaking of the cement precluded evaluation by weight loss, so results were assessed by microscopic examination of the specimen surface in terms of a scale based on cavitation:

$\begin{array}{cl}\text { Durability rating } & \text { Amount of cavitation damage } \\ 0 & \text { Sample completely broken up before one minute } \\ 1 & \text { Sample broken up by end of one minute test } \\ 2 & \text { Severe deterioration } \\ 3 & \text { Severe general erosion } \\ 4 & \text { Severe pitting } \\ 5 & \text { Moderately severe pitting } \\ 6 & \text { Moderate pitting } \\ 7 & \text { Minor pitting or some intergranular erosion } \\ 8 & \text { Some minor intergranular erosion } \\ 9 & \text { Very slight pitting } \\ 10 & \text { No visual damage }\end{array}$

More recently, Saltzman (1975) gave a full account of ultrasonic techniques in estimating rock quality for protective blankets (rip-rap). This author elaborated on some important imperfections in the original test.

Saltzmans' test was carried out on some representative greywacke-suite rocks with a Branson Sonifer ultrasonic cell disrupter, model B-30, producing up to 300 watts at $20 \mathrm{kH}_{\mathrm{z}}$.

The horn tip measured 0.5 inch $(12 \mathrm{~mm})$. Samples were prepared from discs of varying thickness trimmed from rock cores prepared for use else here in this study. They measured $25 \mathrm{~mm}$ in diameter, were fine surface ground, oven dried to constant mass at $110^{\circ} \mathrm{C}$, and cooled in a desiccator to room temperature.

Samples were placed in a heavy brass holder beneath the transducer horn, in a water bath measuring $220 \mathrm{~mm}$ in diameter at the top, tapering to $210 \mathrm{~mm}$ at its base and contained $60 \mathrm{~mm}$ of water (maintained at $50^{\circ} \mathrm{C}$ ) which covered the sample.

The distance between sample and transducer could be adjusted without alteration to vertical axis alignment and was set to procure maximum transducer output (measured by wattmeter) Samples were tested for 10 minutes with the following results:

* U.S. Bureau of Reclamation (1965) Progress report: rip-rap testing research, comparison of an ultrasonic cavitation test with petrographic and physical tests to evaluate rock durability. Laboratory report ChE-23, Denver, Colorado. 


\begin{tabular}{|c|c|c|c|c|c|c|}
\hline Sample & $\begin{array}{l}\text { Rock mean } \\
\text { grain size, } \\
\text { phi }\end{array}$ & $\begin{array}{l}\text { Transducer } \\
\text { wattage }\end{array}$ & $\begin{array}{l}\text { Weight before } \\
\text { testing, } \\
\text { gm }\end{array}$ & $\begin{array}{l}\text { Weight after } \\
\text { testing, } \\
\text { gm }\end{array}$ & $\begin{array}{l}\text { Weight } \\
\text { percent } \\
\text { loss }\end{array}$ & $\begin{array}{l}\text { Numerical } \\
\text { durability } \\
\text { rating }\end{array}$ \\
\hline$D C-6$ & 1.25 & $125-130$ & 18.0536 & 18.0335 & 0.1 & 5 \\
\hline $\mathrm{HQ}-17$ & 1.317 & $125-130$ & 23.2173 & 23.2094 & 0.03 & 9 \\
\hline $\mathrm{SJ}-3_{1}$ & 1.32 & $125-130$ & 14.1458 & 14.1039 & 0.3 & 6 \\
\hline KTW-14 & 2.6 & 150 & 14.7576 & 14.7412 & 0.1 & 7 \\
\hline$B Q-V$ & 2.73 & 150 & 19.0108 & 18.9773 & 0.2 & 6 \\
\hline$B Q-I X A$ & 2.9 & 150 & 4.9621 & 4.9364 & 0.5 & 7 \\
\hline $\mathrm{KS}-2$ & 3.27 & 150 & 12.1779 & 12.1343 & 0.4 & 5 \\
\hline$K T W-i$ & 4.23 & - & 17.2081 & 17.1716 & 0.2 & 6 \\
\hline$S J-T$ & 4.72 & - & 19.3369 & 19.2833 & 0.3 & 7 \\
\hline$O B-W$ & 5.6 & $125-130$ & 11.8905 & 11.8572 & $0.3\}$ & 5 \\
\hline$O B-W(R)$ & 5.6 & $125-130$ & 12.6866 & 12.6672 & $0.2\}^{0.25}$ & 7 \\
\hline $\mathrm{HQ}-22$ & 6.28 & $125-130$ & 4.1537 & 4.1272 & $0.6\}$ & 6 \\
\hline \multirow[t]{3}{*}{$\mathrm{HQ}-22(\mathrm{R})$} & 6.28 & $125-130$ & 6.4548 & 6.4305 & $0.4\}^{0.5}$ & 7 \\
\hline & & & & $\bar{x}$ & 0.26 & \\
\hline & & & & s.d & 0.16 & \\
\hline
\end{tabular}

Although some difficulty was experienced in maintaining power output, there is correlation between percentage weight loss and mean grain size - slightly positive

$$
\mathrm{Y}=0.048 x+0.104, \mathrm{r}=0.53
$$

As samples had been prepared with preferred orientation perpendicular to the probe axis, the damage to argillites was probably rather less than may otherwise be expected, so only the greywacke results are considered representative. Some greywackes (SJ-3I and kS-2) showed relatively high loss.

Indications are that the test could provide valuable information on the suitability of various greywacke-suite rocks for rip-rap applications particularly rocks in the mean grain size range, 2.5 to $3.5 \mathrm{phi}$ : ( 0.18 to $0.09 \mathrm{~mm}$ ), a possibility reinforced by findings of this study. 
Quarry sludge properties

During quarrying operation, a significant portion of the rock is washed out as sludge. This poses three related problems for the industry, i.e. product wastage, disposal and environmental.

The most attractive solution is commercial use, so sludge from two quarries was sampled to determine its properties. Results are tabulated below:

\begin{tabular}{|c|c|c|c|c|c|c|c|}
\hline Sample & $\begin{array}{l}\mathrm{pH} \text { on } \\
\text { sampling }\end{array}$ & $\begin{array}{l}\text { Moisture } \\
\text { content } \\
\text { on samp- } \\
\text { ling o }\end{array}$ & $\begin{array}{l}\text { Liquid } \\
\text { limit }\end{array}$ & $\begin{array}{l}\text { Plastic } \\
\text { limit }\end{array}$ & $\begin{array}{l}\text { Plasticity } \\
\text { index }\end{array}$ & $\begin{array}{l}\text { Drying } \\
\text { shrinkage }\end{array}$ & Remarks \\
\hline $\begin{array}{l}\text { Belmont Quarry } \\
\text { settling pond } \\
\text { BQ-S }\end{array}$ & 8 & 30 & 37 & 25 & 12 & $\begin{array}{l}4.3 \text { at } \\
\text { plastic } \\
\text { limit }\end{array}$ & $\begin{array}{l}\text { sand size fraction } \\
\text { up to } 20 \text { percent } \\
\text { of sample }\end{array}$ \\
\hline $\begin{array}{l}\text { River Shingle } \\
\text { and Sand Ltd., } \\
\text { settling pond } \\
\text { RSS-NS }\end{array}$ & 7.6 & 54 & - & - & - & - & \\
\hline $\begin{array}{l}\text { River Shingle } \\
\text { and Sand Ltd., } \\
\text { settling pond } \\
\text { RSS-F }\end{array}$ & 8.1 & 92 & - & - & - & - & \\
\hline \multicolumn{8}{|l|}{ Chemical data } \\
\hline & & RSS-F & \multicolumn{3}{|c|}{ RSS-NS } & & $B Q-S$ \\
\hline $\mathrm{SiO}_{2}$ & & 60.47 & \multicolumn{3}{|c|}{57.82} & & 59.58 \\
\hline $\mathrm{Al}_{2} \mathrm{O}_{3}$ & & 16.31 & \multicolumn{3}{|c|}{16.99} & & 16.46 \\
\hline $\mathrm{TiO}_{2}$ & & 0.53 & \multicolumn{3}{|r|}{0.62} & & 0.67 \\
\hline$\star \mathrm{Fe}_{2} \mathrm{O}_{3}$ & & 5.76 & \multicolumn{3}{|r|}{6.82} & & 5.78 \\
\hline $\mathrm{FeO}$ & & - & \multicolumn{3}{|r|}{ - } & & - \\
\hline Mno & & 0.12 & \multicolumn{3}{|r|}{0.16} & & 0.10 \\
\hline Mgo & & 2.09 & \multicolumn{3}{|r|}{2.06} & & 2.02 \\
\hline $\mathrm{CaO}$ & & 2.73 & \multicolumn{3}{|r|}{2.37} & & 3.28 \\
\hline $\mathrm{Na}_{2} \mathrm{O}$ & & 1.68 & \multicolumn{3}{|r|}{1.88} & & 2.07 \\
\hline $\mathrm{K}_{2} \mathrm{O}$ & & 2.51 & \multicolumn{3}{|r|}{2.55} & & 3.36 \\
\hline $\mathrm{P}_{2} \mathrm{O}_{5}$ & & 0.13 & \multicolumn{3}{|r|}{0.16} & & 0.18 \\
\hline LOI & & 7.71 & \multicolumn{3}{|r|}{8.06} & & 5.84 \\
\hline Total & & 100.04 & \multicolumn{3}{|c|}{99.49} & & 99.35 \\
\hline
\end{tabular}

* All $\mathrm{Fe}$ represented as $\mathrm{Fe}_{2} \mathrm{O}_{3}$

Belmont Quarry also provided results of tests made by the New Zealand Geological Survey for the Wellington Regional water Board. These infra-red spectrophotometric modal analyses (weight percent) of sludge samples from the settling pond showed:

\section{Quartz}

Sample A

Sample B
$37 \pm 3$

$31 \pm 3$
Feldspar

$18 \pm 3$

$16 \pm 3$
Illite

$29 \pm 5$

$35 \pm 5$
Kaolinitic clay mineral (halloysite) 
In addition, up to 10 percent chlorite and rare calcite were detected. Mineralogy was confirmed by $\mathrm{x}$-ray diffractometry.

To assess possible ceramic use, several firing tests were made, all thwarted by the very low green and dry strengths of the material, due to the $\mathrm{pH}$ and relatively high content of sand sized material. Most heavy ceramic clay bodies have:

(i) Minimal sand-size material; less than 15 percent.

(ii) Between 40 and 50 percent of particles finer than $0.005 \mathrm{~mm}$.

(iii) A mean grain size of about $0.015 \mathrm{~mm}$ (Figure A32.1).

Beneficiation of the sludge by sand removal may not be economic but the addition of $\mathrm{NaCO}_{3}$ would ameliorate $\mathrm{pH}$ and improve knitting properties by deflocculation.

Suggested uses for the sludge materials, subject to research, may include fertilizer base, filter material, inert filler, or abrasive. With the addition of lime and/or cement it may be possible to use the material as a solid base material, low strength castable, or insulant. Higher strengths may be attainable from autoclaving. 


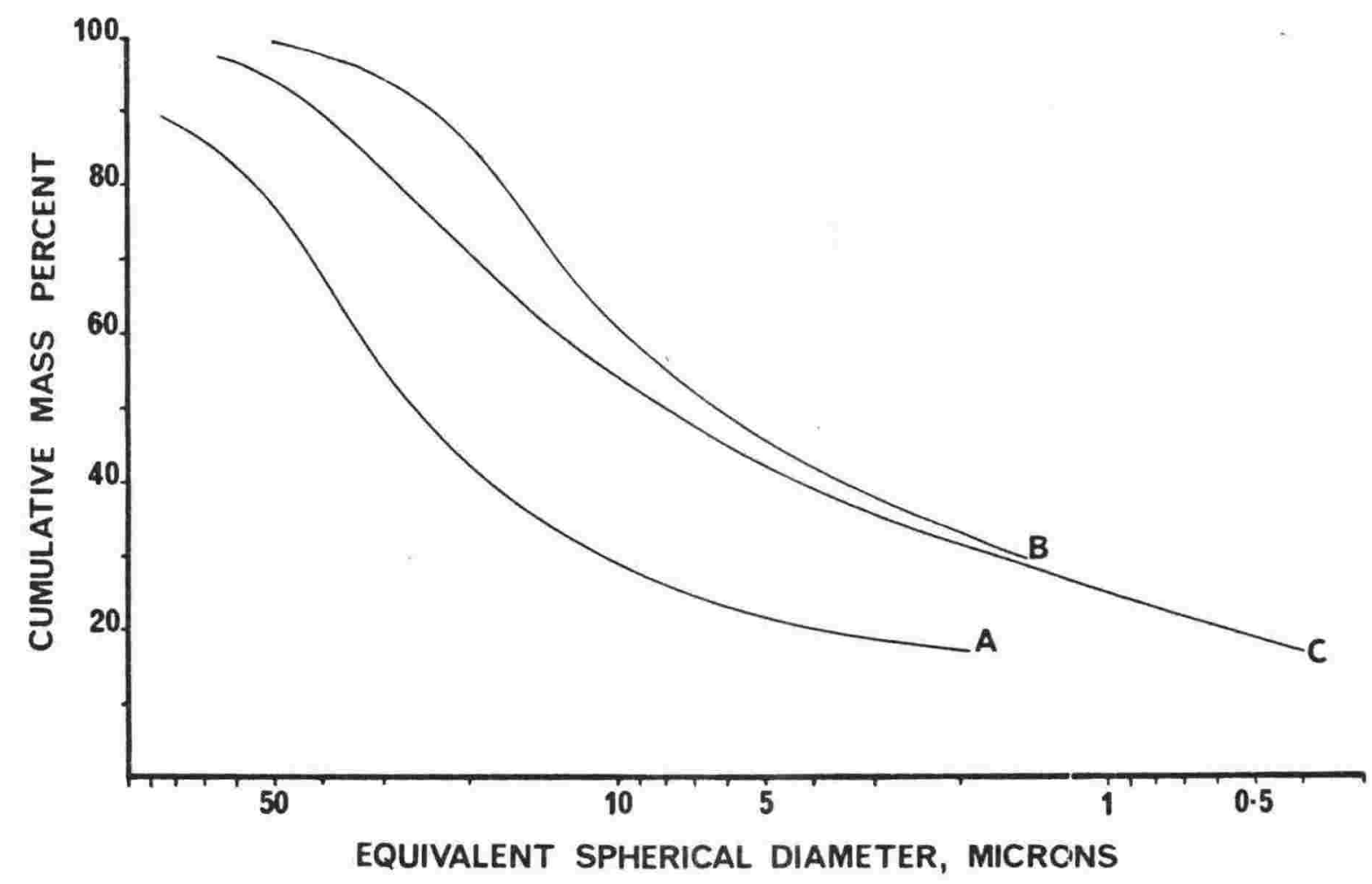

Figure A32.1 : Particle size gradings of two quarry sludges (curves $A$ and $B$ ) examined by the New Zealand Geological Survey. Curve $C$ is the particle size grading of a typical earthware pipe clay. 
Sample number correlation with the petrology collection, Geology Department, Victoria University of Wellington.

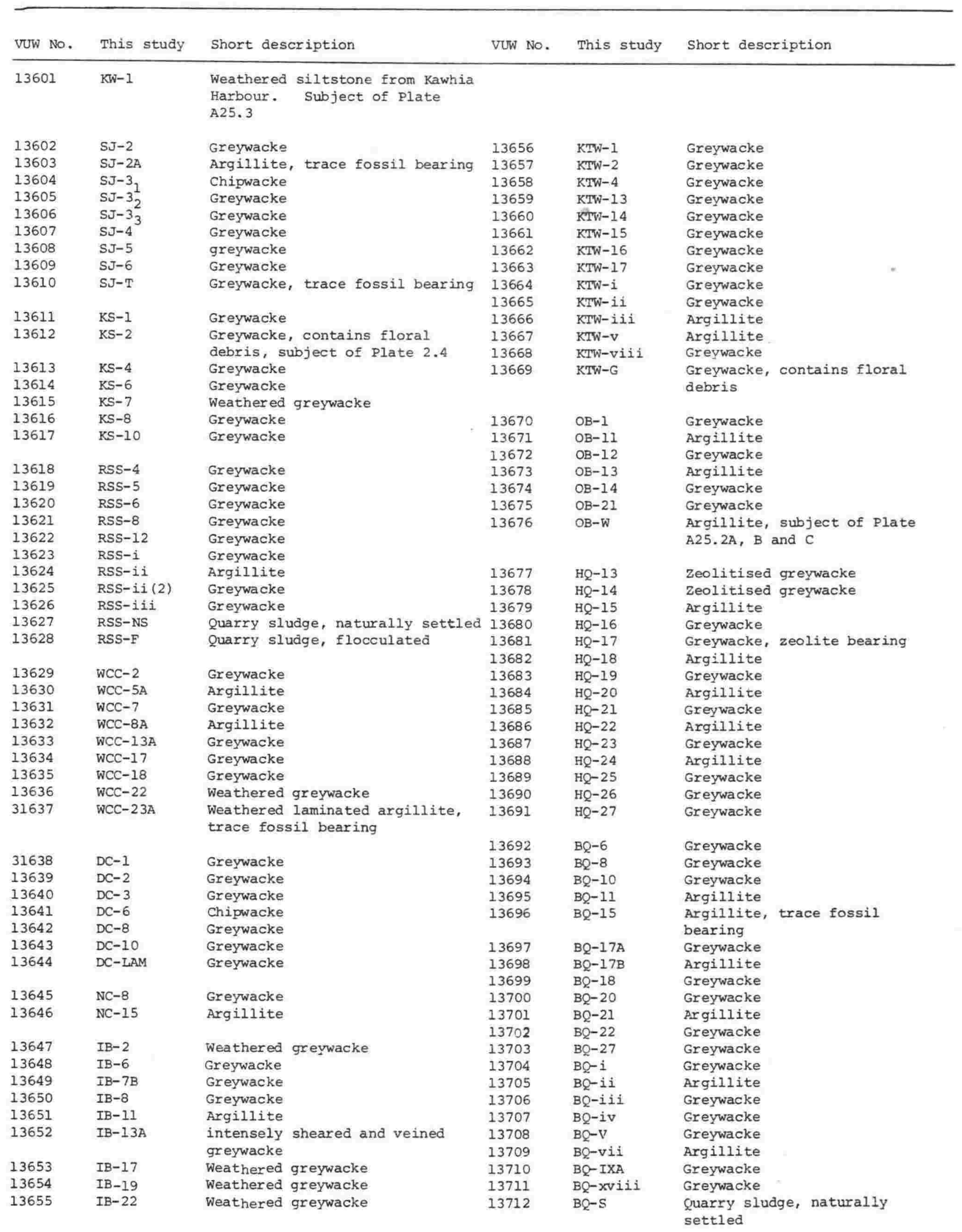


vUW No. This study short description

vuW No. This study

Short description

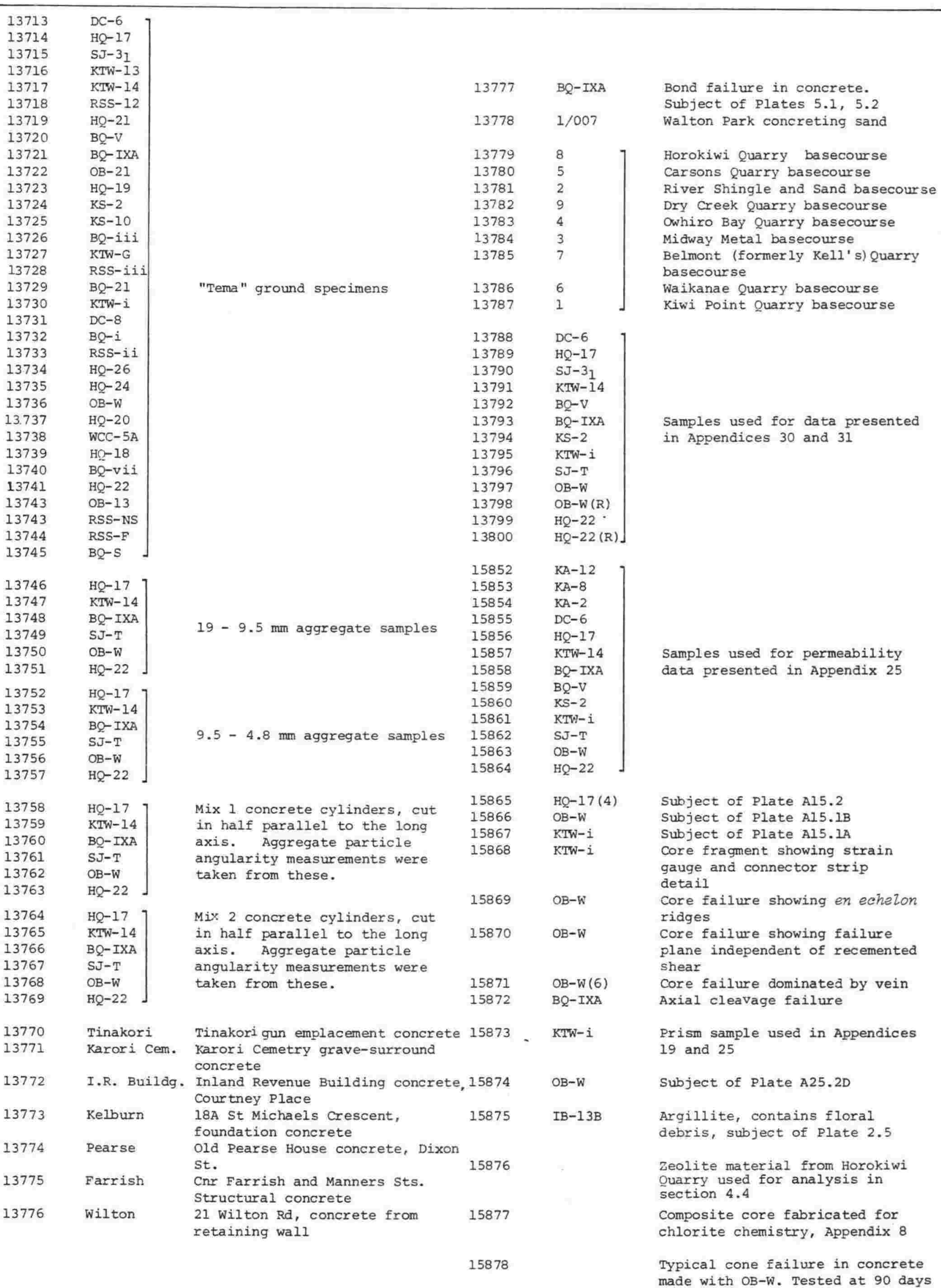

